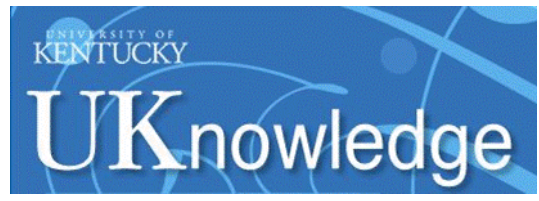

University of Kentucky

UKnowledge

Anthropology Faculty Book Gallery

Anthropology

2017

\title{
Ancient Maya Commerce: Multidisciplinary Research at Chunchucmil
}

Scott R. Hutson

University of Kentucky, scotthutson@uky.edu

Follow this and additional works at: https://uknowledge.uky.edu/anthro_book

Part of the Archaeological Anthropology Commons, and the Social and Cultural Anthropology Commons 
Ancient Maya Commerce 



\section{Ancient Maya Commerce}

Multidisciplinary

RESEARCH AT

Chunchucmil

Edited by

SCOTT R. HUTSON

UNIVERSITY PRESS OF COLORADO

Boulder 
(C) 2017 by University Press of Colorado

Published by University Press of Colorado

5589 Arapahoe Avenue, Suite 206C

Boulder, Colorado 80303

All rights reserved

Printed in the United States of America

The University Press of Colorado is a proud member of
The Association of American University Presses.

The University Press of Colorado is a cooperative publishing enterprise supported, in part, by Adams State University, Colorado State University, Fort Lewis College, Metropolitan State University of Denver, Regis University, University of Colorado, University of Northern Colorado, Utah State University, and Western State Colorado University.

$\infty$ This paper meets the requirements of the ANSI/NISO Z39.48-1992 (Permanence of Paper).

ISBN: 978-1-60732-539-0 (cloth)

ISBN: 978-1-60732-555-o (ebook)

Library of Congress Cataloging-in-Publication Data

Names: Hutson, Scott, editor.

Title: Ancient Maya commerce : multidisciplinary research at Chunchucmil / edited by Scott Hutson. Description: Boulder : University Press of Colorado, [2017] | Includes bibliographical references and index.

Identifiers: LCCN 2016038253 | ISBN 9781607325390 (cloth) | ISBN 9781607325550 (ebook)

Subjects: LCSH: Mayas-Commerce. | Mayas_Economic conditions. | Mayas-Antiquities. | Excavations (Archaeology)-Mexico-Chunchucmil Site. | Mexico-Antiquities. | Chunchucmil Site (Mexico)

Classification: LCC Fi 435.3.C6 A523 2016 | DDC 972/.6-dc23

LC record available at https://lccn.loc.gov/2017038253

An electronic version of this book is freely available, thanks to the support of libraries working with Knowledge Unlatched. KU is a collaborative initiative designed to make high-quality books open access for the public good. The open access ISBN for the PDF version of this book is $978-\mathrm{I}-60732-697-7$; for the ePUB version the open access ISBN is 978-I60732-723-3. More information about the initiative and links to the open-access version can be found at www.knowledgeunlatched.org.

COVER PHOTOGRAPH: villagers from Kochol, Yucatan, Mexico, participating in a ceremony at the ancient Copo quadrangle, Group SIEI-F. Photograph by Jamie Forde. 


\section{Contents}

List of Figures vii

List of Tables $\quad \mathrm{xi}$

Foreword

Anthony P. Andrews xiii

Acknowledgments $\quad$ xvii

Chapter i. Introduction: The Long Road to Maya Markets Scott R. Hutson and Bruce H. Dablin 3

Chapter 2. The Map of Chunchucmil

Scott R. Hutson and Aline Magnoni 27

Chapter 3. Architectural Group Typology and Excavation Sampling Within Chunchucmil

Scott R. Hutson, Aline Magnoni, and Bruce H. Dablin

Chapter 4. Chunchucmil Chronology and Site Dynamics

Socorro Jiménez, Aline Magnoni, Eugenia Mansell, and

Tara Bond-Freeman 73

Chapter 5. Chunchucmil's Urban Population

Scott R. Hutson, Aline Magnoni, Traci Ardren,

Chelsea Blackmore, and Travis W. Stanton 107 
Chapter 6. Environmental Heterogeneity in the

Chunchucmil Economic Region

David R. Hixson, Timothy Beach, Sheryl Luzzadder-Beach, and Bruce H. Dablin $\quad 139$

Chapter 7. Hydrology on the Edge of the Chicxulub Crater:

Chunchucmil and UCí-Cansahcab

Groundwater Resources

Sheryl Luzzadder-Beach and Timothy Beach $\quad$ I57

Chapter 8. Hinterland Settlement Patterns within the

Chunchucmil Economic Region

David R. Hixson and Daniel E. Mazeau $\quad 169$

Chapter 9. Soils and Agricultural Carrying Capacity

Timothy Beach, Sheryl Luzzadder-Beach, Ryan V. Sweetwood,

Patrice Farrell, Daniel E. Mazeau, and Richard E. Terry

197

Chapter io. Perishable Resources Produced for Exchange

in the Chunchucmil Economic Region

Bruce H. Dablin, Traci Ardren, David R. Hixson, and

Anthony P. Andrews 22I

Chapter ii. Marketing Within Chunchucmil

Scott R. Hutson, Richard E. Terry, and Bruce H. Dablin 24I

Chapter i2. Connections beyond Chunchucmil

Traci Ardren, Scott R. Hutson, David R. Hixson, and Justin Lowry 273

Chapter i3. Conclusions

Scott R. Hutson 299

References $\quad 315$

List of Contributors $\quad 363$

Index $\quad 367$ 


\section{Figures}

I.I. Map: locations mentioned in the text 6

I.2. Map: the region immediately around Chunchucmil 22

2.I. Map: the extent of Ioo\% coverage mapping at Chunchucmil and subdivisions 31

2.2. Key to the detailed Chunchucmil site map and a sample group 33

2.3. Photo: paired albarradas that make up a callejuela 40

2.4. Map: houselots in Chunchucmil, quad $S_{2} E_{1}$, residential core

2.5. Map: sacbes at Chunchucmil, quadrangles, and other monumental groups 42

3.I. Examples of group types at Chunchucmil: Types I, 3, 6, and io 55

3.2. Examples of group types at Chunchucmil: Types 5, I2, I4a, I5, and I6 56

3.3. Map: all excavation operations within the $9.3-\mathrm{km}^{2}$ map of Chunchucmil 63

4.I. Common ceramics types from Chunchucmil I 79

4.2. Map: groups with significant quantities of Middle Preclassic pottery 80

4.3. Map: groups with significant quantities of Late Preclassic pottery 83

4.4. Common ceramics types from Chunchucmil II 90

4.5. Common ceramics types from Chunchucmil III 9I 
4.6. Common ceramics types from Chunchucmil IV 92

4.7. Technological development of unslipped wares of Chunchucmil 95

4.8. Map: groups with Late/Terminal Classic pottery 98

4.9. Map: groups with Postclassic pottery 104

5.I. Map: Chunchucmil site center and the surrounding residential core Io9

5.2. Map: Group $\mathrm{N}_{\mathrm{IE}} \mathrm{I}-\mathrm{C} / \mathrm{Pich}$, an example of a type 2 group II3

5.3. Map: architecture, the residential core and periphery

5.4. Map: Group $S_{2} E_{I}-G / K a a b$ ', a type 9 group $\quad 122$

5.5. Placement of cached Chencoh bowl under front step, Structure $S_{2} E_{I}-34$ I2 4

5.6. Exterior profiles of excavated portion of Structure $S_{2} E_{I}-33 \quad$ I25

5.7. Map: Group $\mathrm{S}_{4} \mathrm{~W} 8-\mathrm{F} /$ Balam, a type ro group $\quad$ I30

6.I. The Chunchucmil Economic Region I4I

6.2. Salt pans, or charcas, of the Celestún Peninsula I43

6.3. Aerial photo: coastline west of Chunchucmil, with Punta Canbalam I45

6.4. Canal near Punta Canbalam $\quad 147$

6.5. Idealized landscape: karst features, shallow/buried soils, ancient stone $\begin{array}{ll}\text { platforms } & 152\end{array}$

7.I. Typical ancient Maya wells $\quad$ I59

7.2. Chunchucmil groundwater sample sites, 1994 and 1997 I6I

7.3. 20Ir Hydrologic study area: Ucí-Cansahcab well sites and Digital Elevation Model

8.I. Map: sites found by Pakbeh regional surveys and the Archaeological Atlas of Yucatán

8.2. Map: sites between Chunchucmil and the Gulf Coast, overlaid on a LANDSAT image $\quad 175$

8.3. Map: Pochol Ch'en, west of Chunchucmil $\quad 177$

8.4. Map: Pochol Ch'en's eastern wall, with detail of the central gate $\quad$ I79

8.5. Map: Poc Che Manuel Juárez, west of Chunchucmil I8I

8.6. Map: Yokop/Atlas 39, located to the southwest of Chunchucmil I83

8.7. Map: Kum/Atlas 66, southwest of Chunchucmil on the edge of the savanna

$\begin{array}{ll}\text { 8.8. Map: Chun Ch'en, southwest of Chunchucmil } & \text { I87 }\end{array}$ 
8.9. Map: Ya'ab K'i'ix, an isolated household, east of Chunchucmil

8.ı. Map: Kanan, a non-stratified community, northeast of Chunchucmil

8.II. Map: Puut, a stratified community, east of Chunchucmil

8.I2. Map: Yaxkakap, a stratified community, regional node, east of Chunchucmil

9.I. Landscape elevation model and vegetation zones, Gulf Coast to the Sierrita de Ticul

II.I. Shell ornaments recovered from Chunchucmil

II.2. Map: Chunchucmil site center, areas tested geochemically

II.3. Area D, spatial distribution of phosphorus concentrations

II.4. Area D, spatial distribution of iron concentrations

II.5. Area D, spatial distribution of zinc concentrations

II.6. Map: Chunchucmil, distribution of high and low quantities of obsidian 265

I2.I. Map: Maya area, land- and sea-based trade routes

12.2. Photo: andador

12.3. Map: andadores near Chen Huech, west of Chunchucmil

I2.4. Map: Chunchucmil hub-and-spoke pattern connecting residential zones to the site center

I2.5. Temple Patio Adoratorio complexes, Oaxaca, juxtaposed with type I quadrangle, Chunchucmil

12.6. Structure $\mathrm{N}_{2} \mathrm{E}_{2}-75$, showing talud-tablero façade

I2.7. Map: Group $S_{2} E_{2}-F / A a k$ 



\section{Tables}

3.I. Classification of architectural groups at Chunchucmil

3.2. Total architectural groups, per group type and $\mathrm{I}-\mathrm{km}^{2}$ block, within the $9.3-\mathrm{km}^{2}$ polygon

3.3. Total architectural groups per group type within the $9.3-\mathrm{km}^{2}$ polygon 59

3.4. Total architectural groups per $\mathrm{I}-\mathrm{km}^{2}$ block within the $9.3-\mathrm{km}^{2}$ polygon $\quad 64$

3.5. Operation numbers for all 167 excavations, by group type and $\mathrm{r}-\mathrm{km}^{2}$ block

3.6. Group labels for each operation number 66

4.I. Ceramic groups at Chunchucmil, listed by time period and quantity $\quad 74$

4.2. Operations in which $5 \%$ of classifiable ceramics date to the Middle Preclassic

4.3. Operations that have at least $4 \%$ Late Preclassic sherds

4.4. Platforms built in the Late and Terminal Classic periods

4.5. Operations with Early/Late Classic architecture and Late/Terminal Classic ceramics

4.6. Operations that uncovered Postclassic pottery

5.I. Mapped features and their distribution across the three major zones, Chunchucmil 
5.2 Population estimates, Chunchucmil, sixth and seventh centuries CE

7.I. Field measurement summary: depth, electrical conductivity, and salinity

7.2. Laboratory groundwater results: Chunchucmil and Ucí-Cansahcab

7.3. Laboratory groundwater results: Chunchucmil, Ucí-Cansahcab, and other Yucatán sites

II.I. Quantities of shell artifacts identified to genus and/or species level

II.2. Excavation contexts, Chunchucmil, with the most shells per cubic meter of excavation

II.3. Extractable phosphorus data, Chunchucmil, Yucatán

II.4. Correlation matrix, selected extractable and total element concentrations

II.5. Fine pottery and obsidian, four architectural groups, Chunchucmil

II.6. Excavation contexts, Chunchucmil, where green obsidian was recovered 


\section{Foreword}

Anthony P. Andrews

It seems that research at Chunchucmil began only yesterday, but it actually goes back more than forty years. The first anthropologist to visit the ruins of Chunchucmil was Salvador Rodríguez Losa, in the early to mid-1970s. At the time he was the director of the Escuela de Ciencias Antropológicas of the University of Yucatán, and he showed his sketch map of the site to Silvia Garza Tarazona de González, Edward Kurjack, and David Vlcek (Vlcek, Garza Tarazona de González, and Kurjack 1978:223). Garza Tarazona de González and Kurjack were then directing the project "Atlas Arqueológico del Estado de Yucatán," and Vlcek was conducting surveys for the project. This was a state-wide archaeological survey conducted from 1974 until 1980, when Garza Tarazona de González and Kurjack published a compilation of the survey data in two volumes of text and maps. Several airphotos and a preliminary airphoto-based map of Chunchucmil were included in volume I (Garza Tarazona de González and Kurjack 1980:31-35, figures 7-10). As an urban center, Chunchucmil was considered one of the most important "finds" of the Atlas project, and is discussed in several sections of volume $\mathrm{I}$.

After examining air photos of the site, Vlcek and Kurjack visited Chunchucmil in 1975 , and quickly realized its importance as a dense urban settlement. They asked Norberto González, then director of the Centro Regional del Sureste of the Instituto Nacional de Antropología e Historia, if he would support a mapping project, which he did. The purpose of the project was to obtain a detailed map of a residential sector of the city, which included the foundations of houses and other 
domestic structures, patio walls, winding streets, sacbes, and other features. I visited Vlcek with Kurjack shortly after he began work in June of 1976 , and was impressed by the progress of his mapping, which continued until 1977. The final map-a residential area northeast of the site center-covered an area of 500-by-250 m, approximately io ha (or 25 acres). At the time Vlcek and his colleagues estimated the site covered an area of $6 \mathrm{~km}^{2}$, with a population of approximately 12,000 people. From surface materials, it was clear that the city dated to the Classic period (Vlcek 1978; Vlcek, Garza Tarazona de González, and Kurjack 1978).

The ruins of Chunchucmil have long been known to residents of the region. A cattle ranch was established there in the late eighteenth century, and it evolved into a henequen hacienda in the nineteenth century. Stones from the prehispanic ruins were used to build the hacienda of Chunchucmil, and to provide a bed for the many tranvia (Decauville) rail tracks that crisscrossed the property. Today, the hacienda has become a village, and the core of the prehispanic city lies on the northeastern outskirts of the community.

The first published archaeological notice of Chunchucmil appeared in an article by Kurjack and E. Wyllys Andrews V on "Early Boundary Maintenance in Northwest Yucatan, Mexico," published in American Antiquity in 1976. Subsequent reports include the above-cited reports of Vlcek (1978), Vlcek, Garza Tarazona de González, and Kurjack (1978), the Atlas Arqueológico del Estado de Yucatán (Garza Tarazona de González and Kurjack 1980), and an article on settlement patterns in the northern lowlands by Kurjack and Garza Tarazona de González (198I).

After a hiatus of 16 years, a second phase of research, directed by Bruce Dahlin (194I-20II), began in 1993. This project was known as the Pakbeh Regional Economy Program (PREP), and involved all the authors in this book, as well as a host of students from Mexico, the United States, Europe, and Japan, and hundreds of fieldworkers from Chunchucmil and other surrounding villages. The project lasted 12 seasons, until 2006. Bruce had a long history of research in the Maya area, had experience investigating urban settlements (Tikal, El Mirador), and had particularly strong interests in settlement patterns and environmental adaptations. In an earlier draft of chapter 9 of this book, Timothy Beach and Sheryll LuzzadderBeach offered a perceptive take on Bruce's key interests:

Bruce Dahlin was interested in dirt. Based on many conversations with Dahlin, this interest arose from his deep past experience on settlement archaeology projects and his acquaintance with many of the soil scientists and other geoscientists working in the Maya world, from Gerald Olsen to John Foss, Kevin Pope, and Gene Perry. His work at Tikal, El Mirador, northern Belize, and northern Yucatán all had soil components, and Bruce was keenly aware of soil and geology in the field. At Chunchucmil and 
Canbalam, the driving questions from the start were environmental and geographical: how did the Maya here subsist in a clearly marginal environment? What happened to the coastal site of Canbalam? What were their resources and how did they use them? How were these sites connected? Did the historical canals that penetrate the coast and lead eastward have Maya precedents? All of these questions attempt to explain the "colossus of Chunchucmil," to imitate a title he had used for El Mirador (Dahlin 1984). Chunchucmil's growth posed some of the same questions raised by other huge Maya sites: how did a large city thrive in an environment-the tropics— that some have considered inimical to advanced cultures? (personal communication 2015)

The contents of this book celebrate Bruce's multidisciplinary approach to archaeological investigation, and he would have been proud of the results. Half of the chapters deal with issues of demography, settlement patterns, natural resources, and various aspects of the environment of Chunchucmil and its periphery. And they accomplish the main objective of the research: explaining how a city of 30,000 inhabitants - one of the largest in the Classic Maya world-could have prospered in an environmentally marginal region, one that has poor soils, and the most arid climate in the Maya lowlands. Careful analysis of the soils led Timothy Beach and his colleagues to conclude, in chapter 9 , that

the many lines of evidence to assess the agricultural resources surrounding Chunchucmil make us question its agricultural self-sufficiency. It is reasonable to conclude that poor building materials, shallow rocky soils, low fertility, variable rains, seasonal inundation, and water repellent soils would deter any sustained large and dense population as it does today. Historic agricultural yields using traditional methods could not have supported the ancient population during Chunchucmil's major period of occupation.

While low-yield farming, house gardening, and regional resources would have supported part of the population, only access to additional resources would have allowed the city to exist. At the outset of the project, we discussed the possible role of craft production and exports of such items, but the evidence suggests that not many people specialized in the production of non-perishable goods. However, since many household-produced goods are perishable (such as cotton cloth and clothing, wooden objects, string and rope, palm-woven petates, and other goods), or go off to market, there is scant evidence of such activities at the household level. Still, if we look at historic and ethnographic evidence from other parts of Yucatán, household industries were widespread (and still are in some places-witness the production of hammocks, huipiles, ceramics, and wooden objects in many towns today). I personally suspect that a community as large and complex as Chunchucmil had a sizeable set of cottage industries. In fact, once the Project members had developed 
a consensus that Chunchucmil was not a "regal-ritual" city (Fox 1977), we jokingly referred to it as the "Pittsburgh" of the Maya area.

As Scott Hutson and Dahlin note in the Introduction, this book presents irrefutable evidence for the existence of a market economy in a Classic-period urban context. At Chunchucmil, this economy was integrated into long-distance trade networks from the Early Classic period onwards. While Maya scholars have emphasized the role of trade and markets for the Postclassic Maya, many have suspected that complex economies and long-distance trade emerged in Preclassic times, and played a major role in the rise of Maya civilization. The research presented here clearly supports this. Chunchucmil's resources included a bounty of maritime resources, and one of the richest salt-production areas of the Mesoamerica. As Traci Ardren and her coauthors propose in chapter I2, Kenneth Hirth's "gateway" concept (1978) offers an excellent model to explain the role of trade at Chunchucmil. With its rich forest and maritime resources, craft goods, and salt, Chunchucmil had much to offer its neighbors in northwestern Yucatán. Its geographical position, and that of its port at Canbalam at the mouth of the Celestún estuary, was strategically located for trade. The salt, and perhaps some of the other resources, would have also been traded down the Gulf Coast, perhaps as far as Tabasco or even Veracruz, a trade route that dates back to Middle Preclassic times (i.e., Yucatec Nabanché ceramics reached as far as La Venta). In return, obsidian and other goods from the west would have entered northern Yucatán through the gateway of Chunchucmil's markets.

This book stands out as a cutting-edge model of multidisciplinary research, and future projects would do well to emulate its overall approach, which includes a meticulous investigation of the larger regional environment, coupled with a thorough examination of the settlement patterns. In the end we have a sophisticated view of interactions between the city and the hinterland, and an excellent example of the role of long-distance trade in the emergence of urbanism in the Maya lowlands. 


\section{Acknowledgments}

An enormous variety of people and institutions helped the Pakbeh Regional Economy Program (PREP) conduct the research discussed in this book. The authors of the chapters extend sincere thanks to all. In Yucatán, the research took place on lands that pertain to five ejidos-Kochol, Chunchucmil, San Mateo, Santo Domingo, and Coahuila — and to a landowner from the town of Halacho. The people from these ejidos who gave us the most help are Maestro Gualberto Tzuc Mena (Chunchucmil), Rosalino Camal (Chunchucmil), Esteban Uh (Chunchucmil), Roberto Pérez Cam (Chunchucmil), Filiberto May (Chunchucmil), Alonso Pool May (Kochol), Marcos Pool May (Kochol), Ramón Canul Cahuich (Kochol), Galdino Canul Cauich (Kochol), Martín Canul Canul (San Mateo), Cesar Yam Yah (San Mateo), Hervasio Dzib Hu (Santo Domingo), and Martín Puch Tzuc (Santo Domingo). While in the field, we lived in Celestún until 2000, and we thank Eneida Pech Wicab, Doña Carmen, and Don Saul for kindnesses of all sorts. We lived in the village of Chunchucmil beginning in 2000, and we thank Alejandro Patrón, Gualberto Tzuc Mena, Juventino Tzuc Dzul, Aida Cahuich Canul, and Guadalupe Canul Chim for making this possible.

The Consejo de Arqueología of the Instituto Nacional de Antropología e Historia provided permission to conduct research in Mexico. We thank the presidents of the consejo-Ing. Joaquin García Bárcena, Arqlgo. Roberto García Moll, and Arqlga. Mari Carmen Serra Puche—as well as the directors of the Centro INAH YucatánLuis Millet Cámara and Alfredo Barrera Rubio-for their efforts on our behalf. 
Major funding for PREP came from the National Science Foundation (one grant to Dahlin, one to Dahlin and Ardren, BCS 0303322 to Hutson, and BCS 0440640 to Magnoni), the National Geographic Society, and Howard University. The following institutions also supported PREP in various ways: the Anne U. White Foundation of the Association of American Geographers, Brigham Young University, Pre-Columbian Studies at Dumbarton Oaks, Florida State University, Fundación Haciendas del Mundo Maya, Georgetown University, George Mason University, Grupo Plan, the Stennis Space Center at NASA, the Middle American Research Institute at Tulane University, UNAVCO, the University of California, Berkeley, and the University of Miami. Other support came from Alejandro Patrón Peón and Roberto and Claudia Hernández.

A number of individuals boosted PREP with their expertise and help. We thank E. Wyllys Andrews V, Joann Andrews, Ronald Bishop, Clifford Brown, Ramon Celis, Nick Dunning, Paul Hixson, Phillip Hofstetter, John Jones, Edward Kurjack, Rosemary Joyce, Marilyn Masson, Eugene Perry, Kevin Pope, and David Vlcek. Dozens of others have provided welcome ideas, comments, and criticisms on methods, manuscripts, and other project-related items over more than a k'atun.

Through the course of PREP, over 200 people from the villages of Chunchucmil, Kochol, San Mateo, Coahuila, Santo Domingo, and Maxcanú helped us cut brechas, find sites, chop brush, dig pits, wash sherds, preserve structures, and more. We thank each of them warmly. We also thank the students and professionals from beyond the local villages who worked with us in the field and/or lab. They are David Anderson, Iliana Ancona Aragón, Kevin Anchukaitis, Noemie Arazi, Daniel Bair, Dehmian Barrales Rodríguez, Marjukke Bastamow, Eric Becker, Franca Berti, Clara Bezanilla, Marcel Bradtmoller, Judith Buchino, Rich Burnett, Michelle Butler, Donald Cantu, Julieta Carmona, Ramón Carrillo, Mary Elizabeth Chambers, Dylan Clark, Jessica Conroy, Duncan Cook, Justin Dahlin, Markus Eberl, Max Farrar, Mollie Fletcher-Klocek, Jamie Forde, Vince Goldston, Adolfo González, Shannon Iverson, Chris Jensen, Alexandra Jones, Clarissa Jones, Cynthia Jones, Uta Karrer, Frauke Kenkel, Lauren Kohut, Olga Krasnov, Sean Kriletich, Peter Kritzinger, Valarie McCormack, Pierre Meyrat, David Moulton, Ardlisse Monasterios, Brett Moore, Lee Moore, Shanti Morell-Hart, Claire Novotny, Virginia Ochoa, Lea Pickard, Stephanie Powell, Jason Ramsey, Chris Rayle, Georgina Reyes, James Richard, Vanessa Rodens, Timoteo Rodríguez, Rhianna Rogers, Stanley Serafin, Stephanie Simms, Jobita Smith, Rodrigo Solinis Casparius, Mareike Steffen, Rosemary Steffy, Sharita Towne, Tyler Tuttle, José Manuel Vallines Vásquez, Dave Vlcek, Emily Walsh, Denise Warner, Isabel Warner, Takeshi Watanabe, William Werner, Crystal West, Mary West, Anthony White, Raphael "Zack" Wood, and Marion Woynar. 
Finally, we thank everyone who has helped produce this book. Darrin Pratt, Jessica d'Arbonne, and Laura Furney have been extraordinarily supportive. Eleanor King and Marilyn Masson both went beyond the call of duty by sending extremely detailed and thoughtful comments on the entire manuscript. Their close readings have made this a much better book. As editor, Hutson received unending encouragement from James Hutson, Kathryn Hutson, and Shannon Plank. 

Ancient Maya Commerce 



\section{Introduction \\ The Long Road to Maya Markets}

Scott R. Hutson and Bruce H. Dahlin

The occupation to which [the Maya] had the greatest inclination was trade.

(Landa in Tozzer 1941:94; see also Roys 1943:51-53)

All but a small minority of the Maya, before or after the conquest, were simply outside a market economy with little to sell and little need to buy.

(Farriss 1984:156; see also Restall 1997:185).

This book argues that market exchange was a significant aspect of the Classic Maya world. The essays that follow draw on broad-ranging, interdisciplinary datasets from the ancient Maya city of Chunchucmil to illuminate some of the thorny questions about ancient economies signaled by the tensions between the two quotations above (see also Hirth 2010; Hirth and Pillsbury 2013a; Masson and Freidel 2012; Shaw 20I2). Were Classic Maya households mostly self-sufficient in the sense that each acquired the raw materials and produced the finished goods necessary for daily life? Or was exchange a critical factor in provisioning Maya society? If exchange was essential, what was the relative importance of the various forms that exchange can take, such as reciprocity, redistribution, and marketing? If markets were important, how often did they take place? What was their geographic reach? Who controlled and/or benefited from them? The significance of these questions cannot be underestimated. The ancient Maya spent many of their waking hours provisioning themselves, and human beings have devised a spectacular array of strategies for doing this, from farming to multicrafting to alienating their labor in capitalist economies. If 
we do not know how the Maya approached production, we will not know, in a very basic sense, what most people were doing with so much of their time. Furthermore, if we do not know how goods moved from producer to consumer, we miss out on basic links between different segments of society as well as a knowledge of what segments remain unlinked (Hirth and Pillsbury 2013a:4; Shaw 2012:118). If we do not look closely at exchange, we miss out on a chance to learn about the power and decisions of a broad variety of actors.

One reason why we know so little about production and exchange among the ancient Maya is that they worked with many biodegradable materials. Preservation conditions have erased wood, textiles, hides, fuel, fruits, seeds, nuts, vegetables, spices, dyes, gourds, cordage, bags, bundles, baskets, and, often, bone-materials that formed the core of Maya lives and livelihoods (Dahlin et al. 2007; Foias 2002; King 2015:53). The two quotations at the beginning of this chapter highlight deep differences in scholarly opinion about the degree of commercialization in ancient Maya society. Usually when such different views coexist within a discipline, it is because gaps in knowledge are so fundamental that they prevent falsification of any stance whatsoever. In this case, the biggest gap comes from the archaeological invisibility of most traces of what the Maya spent so much of their time doing. The preservation issue points at the deeper epistemological question that lurks under the surface of scholarly disagreements: if poor preservation has erased the best data on ancient Maya lives, how can we study ancient economies? More specifically, how can we determine the degree of commercialization at a particular Maya site? In this book we approach the challenge of missing data by turning to a variety of other lines of evidence that, with the right questions and bridging arguments, can be made to speak to the issues.

Not long ago, general accounts of the Maya (e.g., Henderson 1981:152) saw commerce as an important component of Maya economies in the centuries immediately prior to contact with the Spanish-the Postclassic period-but not in the Classic period, from 250 to $900 \mathrm{CE}$. Several well-known historical sources from the contact period underscore the prominence of long-distance exchange. For example, members of Christopher Columbus's fourth voyage to the New World met up with a Maya canoe full of trade goods off the coast of Honduras (Colón 1959:231). Also around the time of contact, a member of one of Yucatán's ruling families, the Cocom, escaped certain death because he was away on a coastal trading mission when the rest of his kin were ambushed and assassinated by members of the rival Xiu family (Roys 1962:48). Furthermore, Ralph Roys (1943:51) cited Spanish historical documents that speak of the existence of large markets near the coast in northeastern Yucatán and others in the interior. Ethnohistorical material for the Maya highlands suggests that a majority of households depended on marketplaces for everyday 
needs (King 2015:38). The importance of trade indicated in these historical sources receives support from the archaeology of the Postclassic period, which has documented a rise in obsidian exchange, the appearance of bustling centers on coastal trade routes, and changes in ceramic production geared toward exports (Masson 2001; Masson and Chaya 2000; Masson and Peraza Lope 2014:26; McKillop 1996; Rathje 1975; Sabloff and Rathje 1975; West 2002).

In contrast, scholars have characterized the economy of the preceding Classic period as relatively uncommercialized. About 25 years ago, many archaeologists wrote about the exchange of prestige goods among nobles in the upper crust of Maya society, but few (Fry 1979, 1980) explored the exchange of non-prestige goods across the rest of Maya society (Shaw 2012). In her synthesis of Late Classic-period Maya economies, Rice (1987:77) detailed some of the problems in reconstructing non-elite exchange, including a lack of evidence for architecture that could be clearly identified as storehouses or marketplaces, a lacuna in the hieroglyphic record with regard to economic affairs, and little evidence that producers located their activities near areas where consumers might congregate. Some earlier work did in fact highlight the importance of long-distance exchange of non-prestige goods: William Rathje (197I) assigned it the chief role in the development of complex Maya societies. In his view, people in the southern lowlands developed temples, hieroglyphic writing, and astronomical knowledge in exchange for salt, obsidian, and grinding stones. Though some lines of data did not align with Rathje's argument (serviceable grinding stones, for example, were very often made with locally available stone), his early arguments still provide valuable insights (Freidel 2002; Freidel et al. 2002; Hutson et al. 2010:81; Masson 2002a:I4). In any event, redistribution, as opposed to marketing, was thought to dominate exchange across the Maya area in the Classic period.

Nevertheless, markets have not been invisible in earlier writing about Classicperiod Maya economies. For example, expanding on a very brief passage written by J. Eric S. Thompson (1966:22), David Freidel (198I) argued that when massive ceremonies and rituals drew rural settlers to religious centers, marketplaces most likely accompanied these events. To support this position, Freidel referred to the conjunction of markets and religious events in medieval Europe and historic and contemporary Guatemala. Though Freidel's argument did not refer to any particular archaeological site, other authors writing at about the same time as Freidel proposed that specific plazas at specific sites, such as Tikal (Jones 199I), Sayil (Wurtzburg 1991; cf. Terry et al. 2015), Cobá (Folan et al. 1983), and Seibal (Tourtellot 1988) served as marketplaces (figure I.I).

For reasons discussed later in this chapter, those who argued that marketplaces played an important role in Maya economies faced an uphill battle. Everyone 


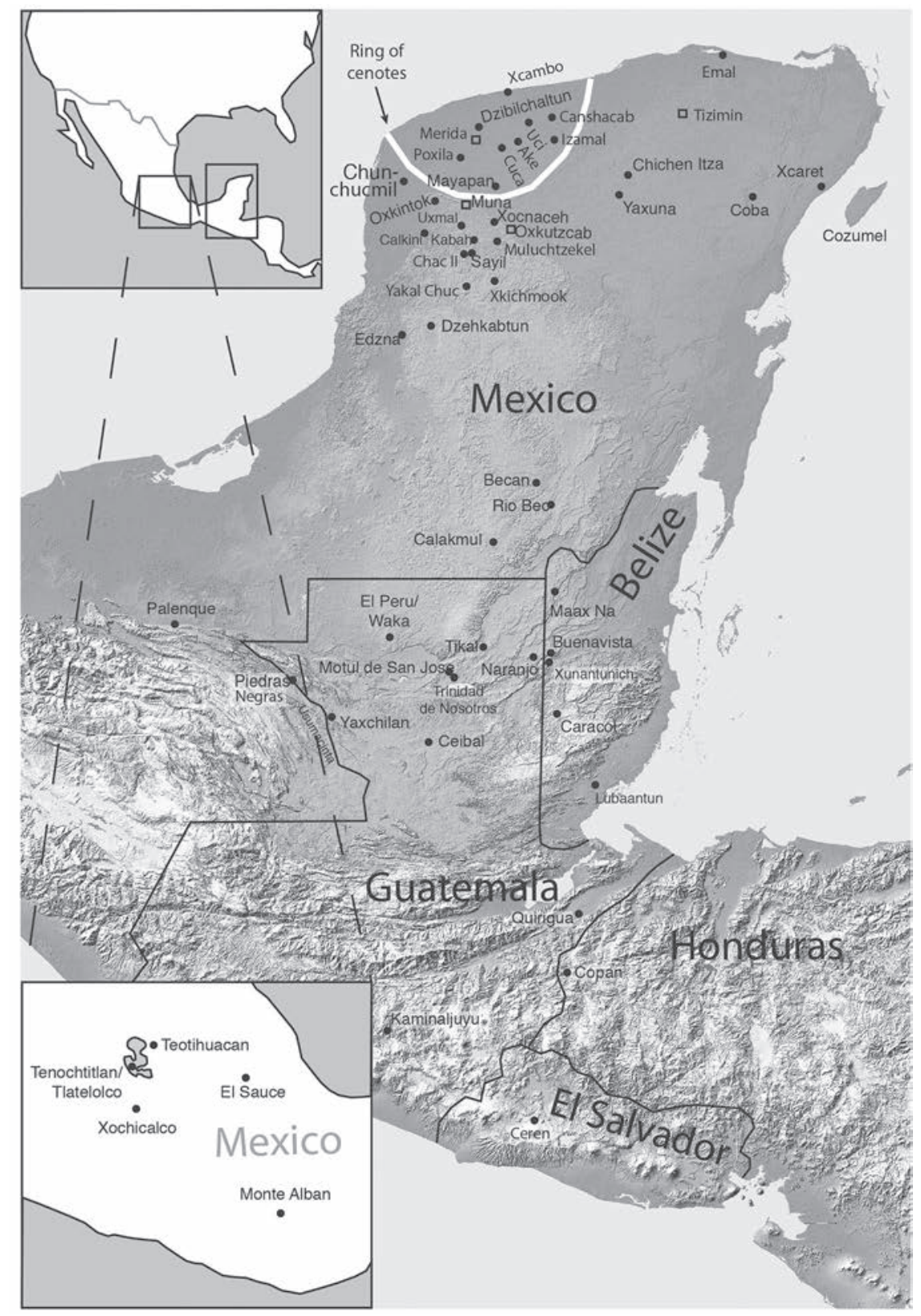

FIGURE I.I. Maps showing many locations mentioned in the text. Figures I.2, 8.I, and I2.I present other locations mentioned in the text. 
agreed that some degree of economic exchange took place at various levels of society-interregional trade among nobles for exotic goods (Hammond 1972a), intraregional trade among the hoi polloi for utilitarian pottery (Rands and Bishop 1980), and redistribution between these two social strata - but few argued that commerce was central to subsistence. Yet neither of the positions from a quarter century agolittle commerce versus lots of commerce-could make headway because of a shortage of research specifically designed to tackle this question. As Patricia McAnany wrote in 1993 , "we have only very rudimentary notions about the economic organization of the [Classic] Maya household and polity. This state of the art, in part, is due to the fact that we simply haven't been aggressively asking questions or structuring focused programs of inquiry regarding the Classic Maya economic system."

In the same year that McAnany published her call for research designs closely focused on economic systems, Bruce Dahlin (194I-20II) began working at the ruins of Chunchucmil. Dahlin's project came to be known as the Pakbeh Regional Economy Program (PREP). ${ }^{1}$ Located $70 \mathrm{~km}$ southwest of the modern city of Mérida, the ruins got their name from a twentieth-century henequen plantation (now a village of $\mathrm{I}, 200$ people) located $2 \mathrm{~km}$ to the west of the ancient site center. Chunchucmil interested Dahlin and colleagues because of preliminary research undertaken by Ed Kurjack and Dave Vlcek in the ro7os (see the foreword, this volume). After mapping to ha of the site, surveying other portions, and scrutinizing aerial photos, Vlcek and colleagues (1978) produced a population estimate of I2,000. This relatively high estimate came as a surprise, given that Chunchucmil occupied one of the least agriculturally productive areas of the entire Maya world. According to Kurjack (1974:x), this paradox also applied to Dzibilchaltún, whose estimated population was too large to be fed entirely by swidden agriculture on the rocky soils nearby. Vlcek and Kurjack's findings spurred Dahlin to take a closer look at Chunchucmil and initiate the PREP, which now estimates Chunchucmil's population at more than 30,000 (see chapter 5 , this volume). Given such estimates, Chunchucmil challenges orthodox views of Maya subsistence and settlement patterns. Amidst poor soils and scarce precipitation, traditional forms of agriculture such as slash and burn could not feed such a large population (see chapter 9) and no clear evidence of the kinds of intensive agriculture that were beginning to be documented in the southern lowlands (drained fields, terraces) could be found.

How, then, did the people of Chunchucmil support themselves? Vlcek et al. suggested that they traded salt (see below and chapter io). Mesoamerica's secondlargest salt works are located only $30 \mathrm{~km}$ to the northwest of Chunchucmil and scholars have long been aware of extensive contact-era trade in salt (A. P. Andrews 1983; Roys 1943:52-53). Taking the position, recently and succinctly expressed by Ken Hirth (2010:227), that "market exchange and marketplaces are fundamental 
social and economic institutions that have been largely overlooked in the study of emerging cultural complexity," Dahlin sought to explore the possibility that trade anchored Chunchucmil's economy and, joined by codirector Traci Ardren in 1998, began work on several difficult tasks: creating a comprehensive, exchange-based economic model for Chunchucmil's growth, securing grant money to test the model over I2 field seasons, and putting I2 field crews on the ground to collect the data, all in a milieu where most Mayanists were not receptive to the premise that commerce played such a central role in the economy of a large Maya city.

Over the last Is years, many Mayanists have embraced Dahlin's idea of the importance of marketplaces in Classic-period economies, in part because of the research at Chunchucmil (King and Shaw 2015; Masson and Freidel 20I2; Shaw 2012). Postclassic-period commercialism did indeed have roots in the Classic period and potentially earlier (Masson 2002a:9-10; Masson and Freidel 2012:463; Tokovinine and Beliaev 2013:172). This book presents the research at Chunchucmil that helped bring about this change in our view of Classic Maya economies, and it does so in a comprehensive, multidisciplinary fashion. We draw from these findings the central conclusion that market-based commerce was critically important in the rise and maintenance of the Chunchucmil urban center. We define market-based and other terms below; right now we explain what we mean by critically important. Commerce did not just move exotic luxury goods into and out of the site; it moved staple goods needed by everyone and it moved these goods dozens of kilometers. At the same time, we do not claim that marketing was the sole mechanism of exchange: "it is sophomoric to argue whether [archaic states] had marketplace exchange or governmental redistribution; they most assuredly had both" (Isaac 1996:331). Without question, Mesoamerican households received goods through many different forms of exchange (Hirth 1998; McAnany 1992).

We also do not claim that market-based exchange was as important at other Maya cities as it was at Chunchucmil. We do, however, believe that our findings at Chunchucmil join the results of other studies in forcing a revision not just of our understanding of ancient Maya economies, but of ancient Maya life as a whole. As work at sites such as Tikal (Jones 1996, 2015), Motul de San José (Halperin et al. 2009), Caracol (Chase and Chase 2004:I18-I19, 2014), El Perú/Waka' (Eppich and Freidel 2015), Trinidad de Nosotros (Dahlin et al. 20ro), Calakmul (Carrasco Vargas, Vásquez López, and Martin 2009), Buenavista (Cap 2015), Mayapán (Masson and Freidel 2012; Masson and Peraza Lope 2014; Terry et al. 2015), Cobá (Coronel et al. 2015), Maax Na (Shaw and King 2015), Chichén Itzá (Braswell and Glascock 2002; Cobos and Winemiller 2001:289), Palenque (Barnhart 2007:115), Xunantunich (Keller 2010), Lubaantun (Hammond 1972b, but see West 2002:16016I), Ceibal (Bair 2010), Quiriguá (Jones and Sharer 1986), and elsewhere reveals 
the importance of market-based exchange, our models of political economy and social organization must change in order to accommodate these revelations. To the extent that Maya economies were embedded in the rest of Maya life-and recent work shows that economies were embedded to a great extent (McAnany 20ro; Wells 2006) - new findings in the economic domain demand new thinking about other domains, including politics, ritual, and identity. Thinking just about identity, for example, there is good reason to believe that Maya women played many important roles in commerce (Clendinnen 1991; McCafferty and McCafferty 1988; Wurtzburg 2015). Our argument that commerce was critical to Chunchucmil's economy therefore highlights another potential avenue by which women gained power in antiquity.

The central conclusion of this book - that market-based commerce was critically important to Chunchucmil—builds from several supporting points. Chunchucmil and its hinterland had a high peak population (chapters 5 and 8) that, given the quality of local land (chapter 6) and water (chapter 7), would have had trouble deriving all of its food from its immediate surroundings (chapter 9; Dahlin et al. 2005). Yet the Chunchucmil region provided a number of resources that could have been traded for staple foods (chapter Io). Furthermore, a large, permanent, physical marketplace existed at the center of Chunchucmil and most of Chunchucmil's households relied on this marketplace (chapter II; Dahlin et al. 2007; Hutson et al. 20I0). Finally, Chunchucmil was a port of trade that integrated long-distance, middle-distance, and short-distance exchange (chapter 12; Dahlin and Ardren 2002). The current book's systematic presentation of the results of the various branches of the PREP allows us to tie together these different points and put these conclusions and consequences into the kind of broad context that makes them relevant for other studies. Independent of conclusions regarding Maya economies, this book contributes to archaeology and other fields by providing (I) a thorough demographic and chronological study of an ancient Maya city (chapters 2 through 5); (2) a regional cultural ecology (chapters 6 through 9); and (3) a detailed dataset in economic anthropology (chapters io through I2).

Finally, we hope this book contributes to the epistemological question of how we can study ancient economies when the bulk of what was produced and consumed has not been preserved. Over the years, PREP has deployed several methods to mitigate the preservation problem. These involve geochemistry, hydrology, remote sensing, close attention to artifact distribution, and more. The chapters that follow discuss each of these methods in greater detail; we devote the remainder of the current chapter to broader themes. We first define key terms, such as market, and we explain why the notion of ancient markets faced an uphill battle in anthropology as a whole and in the Maya area in particular. We then review data that support 
the existence of a market economy during the Classic period in other parts of the Maya area and data gathered by other projects in the Maya area. Finally, we provide thumbnail sketches of the chapters in the book and the lines of evidence they contribute to the central conclusion.

\section{DEFINITIONS AND DELAYS IN ECONOMIC ANTHROPOLOGY}

The definition of market is no small matter because past definitions, notably that used by Karl Polanyi, have ruled out the possibility of markets in the ancient world and therefore delayed serious analysis of ancient exchange (Feinman and Garraty 2010:169; Garraty 2010:15). Though few scholars today rule out the possibility of precapitalist markets, it is important to sift through Polanyi's legacy and the responses it engendered because they teach lessons about markets and human action that must be kept in mind when considering premodern, non-Western people like the ancient Maya.

Garraty's 2010 essay (see also Feinman and Garraty 2010), which introduces a well-received volume on markets in the ancient Americas (Garraty and Stark 2010), serves as a useful starting point for defining key terms. For the phrase market exchange, Garraty relies on a definition provided by Frederic Pryor in 1977: transactions in which the forces of supply and demand affect prices (Pryor 1977). According to this definition, barter in contexts with established systems of equivalency but shortages of currency (Graeber 2011:40) counts as market exchange. Other kinds of barter are not market-like at all and it should be noted that barter is rarely a major part of any economy (Graeber 2011:29-33; Humphrey 1985; cf. Stanish and Coben 2013). Garraty then defines a market as an institution predicated on the principles of market exchange. The term institution refers to the fact that market exchange takes place within a social context that affects pricing. In other words, supply and demand do not exclusively determine price: a number of other factors might intervene, such as social relations (good or bad) between buyer and seller and the influence of guilds or governments. Polanyi is best remembered for his insistence that exchange is always embedded in institutions. Since it is difficult to imagine market exchange taking place in the absence of a social context, variables beyond supply and demand always affect prices. In other words, market exchange cannot be separated from markets. We therefore use the terms market and market exchange interchangeably. A marketplace is a physical space where multiple buyers and sellers congregate to exchange a variety of goods. The presence of a marketplace presupposes market exchange but people can participate in market exchange in the absence of a marketplace (Dahlin 2003:134; Hirth 2010:229). There are several perspectives on the origins of marketplaces and their degree of independence from government 
(Blanton and Fargher 2010; Graeber 2011; C. A. Smith 1976). Yet there is likely no single answer to the question of whether marketplaces arose in bottom-up fashion, as when the number of buyers and sellers grows to a point where convenience demands a marketplace, or top-down fashion, as when governments create markets to convert tax and tribute (Graeber 2011:50). Chapter 13 returns to the topic of topdown vs. bottom-up origins of markets.

In the middle of the twentieth century, Karl Polanyi made the notion of premodern markets unpalatable. He had a large impact on how anthropologists think about markets because he pioneered the first systematic theory of premodern exchange (see Polanyi 1944, 1957; deeper accounts of Polanyis legacy can be found in Halperin [1994] and Garraty [2010]). Polanyi’s theory appealed to anthropologists because it treated non-Western people as essentially moral and kind-hearted human beings. Polanyi developed his theories as a rebuttal to the kind of mentality found in the classic works of Adam Smith. For Smith, maximization of benefit and minimization of cost drive human behavior. In contrast to this position, which became known as formalist, Polanyi developed the substantivist position: economic behavior was embedded in culturally specific values and institutions and therefore did not always follow an abstract logic of maximization. (It should be noted that Smith's writing shows an appreciation of the influence of social values on economic behavior [Evensky 2005]).

More specifically, Polanyi thought that in small societies with strong webs of kinship and social solidarity, the market mentality would threaten community wellbeing. In other words, rational maximizing led to ruthless haggling and the search for individual gain at others' expense, which in turn led to the kind of hostility and antagonism that, far from advancing the interests of the community as a whole, would tear it apart. In this vein, Polanyi thought that powerful authorities were required to regulate prices in premodern societies. With such heavy-handed regulation of prices, the role of supply and demand in determining price would have been minimized. Thus, if markets only exist when supply and demand play a heavy role, then Polanyi's followers (Carrasco 1978) could argue that premodern marketplaces such as that of the Aztec capital were in fact not part of market economies. Furthermore, less-complex premodern societies that lacked strong authorities to regulate marketplaces would not be expected to have marketplaces at all.

Polanyi famously concluded that the dominant mode of exchange in village societies was reciprocity and the dominant mode of exchange in chiefdoms was redistribution. Markets only dominated in modern states. Polanyi carefully chose the phrase "dominant mode of exchange" as opposed to "only mode of exchange" in order to leave room for clearly documented cases of markets in premodern societies. The Aztec case is a clearly documented one that may in fact challenge the model 
as a whole. Research on the Basin of Mexico during the Postclassic shows that several marketplaces existed in the Early Aztec period before the rise of the powerful Aztec state and continued in the Late Aztec period with minimal state intervention (Blanton 1996). In Polanyi’s model, marketplaces should not occur independently of powerful Aztec state control. As Garraty (2010) points out, Polanyi's allowance for some degree of marketing in premodern societies does not sit well with his insistence that market exchange cultivates self-serving behavior inimical to those societies. This potential contradiction can be dismissed, however, because the actual definition of markets that Polanyi gave appears to rule out the existence of premodern markets: the key feature of markets for Polanyi (1957:247) was that "all goods and services, including the use of land, labor and capital, are available for purchase." Such a definition essentially restricts the existence of markets to the nineteenth century and afterward since very few premodern markets featured the exchange of land and labor. This is like saying that swap meets are not marketplaces if they don't take credit cards or PayPal. Polanyi's definition is therefore too narrow and slowed the development of nuanced discussions of how markets develop in the ancient world and the diverse ways in which markets are conditioned by political, social, or religious institutions (Feinman and Garraty 2010:169).

Moving beyond the problem of definition, Polanyi's core idea about the embeddedness of economies appeals to anthropologists because we are committed to the recognition of cultural diversity and the assertion that universal claims about human nature, such as Adam Smith's market mentality, are in fact culturally specific. In a society in which economists have tremendous influence, what member of the anthropological tribe would not relish the chance to side with Polanyi and tout an enduring virtue of our discipline: a more subtle understanding of economies and societies? Yet the entirely tenable idea of the embeddedness of premodern economies entailed the nontenable position that premodern people were very different from modern people. This created an unproductive situation in which agreement with Polanyi's core anthropological principal of embeddedness predisposed one to believe that markets only exist in modern times. Such logic not only encourages the assumption that the ancient Maya had no markets, it also discourages an empirical test of this assumption. Furthermore, it establishes a false polarity between superrational, self-gain-obsessed moderns and reactionary, custombound, self-sacrificial premoderns.

Polanyi's polarized views of ancient and modern economies founder on the realization that modern markets are not independent of social relationships and ancient forms of exchange are not enslaved to tradition. Regarding the modern context, Granovetter (1985) has shown that modern market exchange, just like exchange in other epochs, is everywhere embedded in institutions (see also Fischer 200I). 
Regardless of what form these institutions take (government regulations, social relations between parties to an exchange, or something else), they play a role, alongside the calculus of supply/demand, in determining prices. "The idealized conception that an economic (market) system is just the cumulative effect of atomistic market transactions between individual buyers and sellers who act based solely on personal self-interest and independent of social relationships ... rarely, if ever, conforms to actual practice" (Feinman and Garraty 2010:172). Several economists have moved beyond Homo economicus, the notion of humans as self-interested maximizers, and considered the importance of cooperation in economic action (Marshall 20I0; Brandenburger and Nalebuff 1996). Such work is no longer on the fringes of social science: Elinor Ostrom (1992) and Oscar Williamson's (1985) research on cooperation and collective action earned them the 2009 Nobel Prize in economics.

Regarding the premodern context, the other side of Polanyi's modern/premodern polarity, Blanton and Fargher (2010) detect in Polanyi's writings an idealization of premodern communities reminiscent of the "herd mentality" of villagers described in Marx's Asiatic mode of production. The occupants of these communities were said to be mired in customs and values that provided easy opportunities for exploitive despots. Such villagers lacked a sense of private enterprise and therefore refused to produce more than what was necessary for subsistence, communal ritual, or elite extraction and shunned all trade not directly related to household provisioning. In short, Blanton and Fargher charge that ancient people in Polanyi's model were not agents: they could recognize neither exploitation nor opportunity and therefore could not act strategically in response to either (see Sahlins 1972 for a broad reappraisal of precapitalist economies).

The point is not that ancient and contemporary economies and actors are the same, but rather that their differences have been overstated. These considerations should have encouraged Mayanists to move beyond the simple question of whether or not there were Classic-period markets and into more nuanced questions regarding origins, scale, degree of centralized oversight, and so on (Shaw 2012; King and Shaw 2015; see chapter II, this volume). Archaeologists in Central Mexico have been engaging such questions for quite some time (Berdan 1983; Blanton 1983, 1985; Feinman et al. 1984; Hodge and Minc 1990) - benefiting from a large body of eyewitness accounts dating from the arrival of the Spaniards 500 years ago-about the existence of what Europeans referred to as marketplaces. In the Maya area, the ethnohistorical evidence is not as strong. When the Spaniards established a colony in northern Yucatán in the I540s, European diseases had already infected local populations. Furthermore, local political and economic organization had already been deeply disrupted by the fragmentation of the Mayapán confederacy in the fifteenth century and a variety of droughts and famines (Masson and Freidel 2013). Thus, 
conquest-era Maya marketplaces and marketing were not as developed as those in Central Mexico. This may account for Farriss's comment, quoted in the epigraph, that so little marketing took place in the Maya lowlands.

The fact that research on markets in the Maya area has not picked up as strongly as it has in Central Mexico results from more than just holes in the archives. In addition to working amidst the general antimarket climate established by Polanyi, Mayanists interested in ancient forms of exchange have had to get out from under a set of misleading, Maya-specific assumptions to which we now turn.

\section{RESISTANCE TO MAYA MARKETS}

Archaeologists have often thought that markets appear in contexts with high ecological diversity and high population density. Initially the Maya were thought to lack both of these, thus making markets seem improbable. Furthermore, too much focus on leaders and not enough focus on people of lower status have also slowed consideration of markets. We unpack each of these three causes-misunderstanding of ecology, underestimation of population density, and lack of focus on common people-for the delay in thinking about ancient Maya markets, beginning with ecology (see also King and Shaw 2015).

In an area with high environmental diversity, communities located relatively close to each other may each control a unique environmental resource. Assuming that each community desires access to the resources controlled exclusively by other communities, a marketplace that makes each of these resources available serves the interests of all communities. At the same time, one could argue that high environmental diversity lends itself not to a market, but to the evolution of powerful centralized authorities that serve to control the distribution of the resources from each patch in the mosaic (e.g., Sanders 1977). Regardless of the mechanism of exchange (markets versus redistribution) responsible for circulating goods in such a context, Sanders and Price (1968) argued that highland Mesoamerica exhibited significant environmental diversity and that the Maya lowlands did not.

The Maya lowlands were thought to be characterized by resource redundancy. However, several studies have shown that resources in the Maya lowlands are not as evenly dispersed as once thought (Dunning et al. 1998; Fedick 1996; Gomez Pompa et al. 2003; McAnany 1993). Lowland resources such as salt (A. P. Andrews 1983; McKillop 2002), chert (Potter and King 1995; Shafer and Hester 1983), and cacao (McAnany et al. 2002) are famously patchy. But even in areas without such assets, other features such as escarpments (Dunning et al. 2003), swamp edges (Kunen 2004), karst depressions (Kepecs and Boucher 1996; Munro Stasiuk and Manahan 2010), rivers (Siemens 1996), terrace-able hills (Chase and Chase 1998), and 
fracture zones (Fedick et al. 2000) each permit local resource specializations. Such resource diversity and community specialization have fueled market-based models of ancient Maya economies: "By combining the variety and abundance of specialized production at a marketplace ... a greater region of communities obtained the necessary balance of resources for a sustainable harvesting of an otherwise fragile environment" (Scarborough and Valdez 2009:2II; see also King and Shaw 2015).

High population density encourages markets for two reasons. First, in urban contexts with high population density, farmland is distant and presumably not all residents are farmers: some are administrators, craft specialists, or nobles and retainers. Though some of these actors may get food via tribute, a marketplace would help provision the others (Appleby 1976) and could convert tribute goods into food (Brumfiel 1980). Second, it becomes more cost-effective for someone to sell goods when many consumers live nearby (Blanton and Fargher 2010; Hirth 20I0; Skinner 1964). If consumers do not live near the seller, the cost of transporting goods to consumers reduces the seller's profitability. In such a situation, marketing would only work with the kinds of goods that make a large profit with each transaction (Sanders and Webster 1988:542). On the other side of the coin, if the seller is not itinerant, the cost to the consumer of traveling to multiple different sellers for household needs is prohibitive, thus discouraging production for trade and encouraging greater self-sufficiency and reciprocity. Of course, markets (and marketplaces) can still develop in areas of low population density. If people from all over congregate in central places from time to time for ceremonial or other occasions, marketing can take place on the side (Freidel 198I). Yet markets develop more robustly when lots of people are always close together-that is, when there are cities. And, as all Mayanists know, the strongly held point of view that major Maya sites were vacant ceremonial centers as opposed to cities (Willey and Bullard 1965) forestalled the recognition that Maya ritual centers were also demographic centers. Thanks to easier survey conditions and the abundance of ethnohistorical documents, archaeologists have always been aware of the existence of demographic centers in Central Mexico. But only in the 1960s did the maps of Tikal (Carr and Hazard 1961), Mayapán (Pollock et al. 1962), and Dzibilchaltún (Stuart et al. 1979) show that the Maya also had urban centers.

By the 1980 os there was "a growing consensus that the great lowland Maya centers were considerably more like true cities than some of the opponents of this idea had originally supposed" (Ashmore and Willey 1981:I6). Yet the possibility of markets did not catch on because of restrictive notions of Maya cities and the assumption that larger populations must have been fed not by commerce but by more intensive forms of agriculture. On the basis of Old World data, Fox (1977) defined three types of cities (regal-ritual, administrative, or mercantile) that influential 
Mesoamericanists found attractive (Sanders and Webster 1988; see also Marcus 1983). Fox defined mercantile city in a way that allowed Sanders and Webster to suggest that no Maya cities were mercantile. Sanders and Webster labeled all Maya cities regal-ritual, which is to say that they were little more than the locus of royal ceremonies and the extended family of the king and his servants. This move aroused much disagreement (Chase et al. 1990) and may have discouraged the search for marketplaces in Maya cities. Fox's city types were not supposed to dictate the kinds of activities found within them. In other words, even if a city fits Fox's "regal-ritual" category, this does not mean it could have no mercantile activity whatsoever.

Once it was clear that the ancient Maya had many large cities with tens of thousands of inhabitants, attention shifted to the question of how people in large cities acquired food. Archaeologists proposed that food came locally from agricultural techniques that were more intensive than the slash-and-burn techniques practiced in modern and historic times. Debates followed over the nature of the intensive techniques and how widespread they were (Harrison 1996; Pope and Dahlin 1989; Pope, Pohl, and Jacob 1996; Turner 1974). Yet, as Dahlin et al. (2010:193; see also King and Shaw 2015) note, "Hardly a thought was given to the possibility that critical segments of these urban populations were supplied through food supplements circulated through modes of exchange other than redistribution." Ancient city dwellers in other parts of the world often acquired food imported to marketplaces (Alston 1998; Brumfiel 1980), yet few Mayanists considered this option (cf. Freidel and Shaw 2000).

Finally, the historical tendency for Mayanists to focus on kings, nobles, palaces, and temples as opposed to the lives and residues of the rest of Maya society has also delayed research that explicitly tests market models. Merchants rarely appear in noble culture (hieroglyphic inscriptions, palace scenes). This scarcity signifies not the absence of merchants but rather their lower status (Masson and Freidel 2013:209; McAnany 2010:256; Tokovinine and Beliaev 2013:172). The often adversarial nature of interactions between the Classic-period god of merchants, God L, and the divine patrons of royalty, such as the sun god, the maize god, and the hero twins, reflects "ambivalence in the Classic Maya attitude toward trade and traders" (Tokovinine and Beliaev 2013:194). Speal (2014:107) speculates that since markets often took place in plazas that doubled as ceremonial precincts, "Classic Maya elites may well have felt burdened at times with keeping throngs of common vendors out of the patio areas they wished to keep sacred."

Although the archaeology of non-noble households has become common in the last 30 years, a corresponding shift in the modeling of Maya political economies has not always followed. In other words, until very recently, most models placed redistribution at the center of the political economy and therefore envisioned elites as the key economic agents and decision-makers. If archaeologists instead envision 
non-noble households as active participants in decisions regarding production and consumption (see Lohse and Valdez 2004; Hirth 2010; Masson 2002b; Robin 2012; Scarborough and Valdez 2009; Shaw 2012:139; Sheets 2000), then marketbased models of exchange gain more popularity. This point of view resembles a bottom-up perspective that foregrounds the needs of common households and recognizes that households may strive to be self-sufficient but rarely achieve this. From this perspective, households are likely to engage in all kinds of exchange, including marketing (regardless of whether there are formal marketplaces) in order to provision themselves. As more archaeologists bring to their household-based case studies the kind of theoretical perspectives appropriate to such case studies-for example, relational notions of power that view common people as agents and structurationist stances that valorize the everyday practices and needs of such agents-we expect markets will play a larger role in the reconstruction of ancient economies.

\section{APPROACHES TO MARKET EXCHANGE AMONG THE CLASSIC-PERIOD MAYA}

Thus far we have explored why Polanyis legacy delayed research explicitly focused on non-Western markets in various parts of the world and we have explored why certain assumptions about and approaches to the ancient Maya discouraged research on markets among the ancient Maya. Despite these disincentives, several research projects beyond PREP have strengthened the idea that markets played an important role among the Classic-period Maya. We explore these lines of argument as a way of setting the stage for a more detailed discussion of PREP.

Linguistic evidence suggests that the Classic-period Maya immersed themselves in market exchange (Wurtzburg 1991:94-97). Tokovinine and Beliaev (2013) note that native cognate words for buying (man), selling (chon), bartering (k'ex), trading/ profiting ( $\left.p^{\prime} \circ l\right)$, and market (k'iwik, which can also mean "plaza") are found in Maya languages known to have split from each other by the end of the first millennium BCE. This means that "market exchange played a significant role in Classic Maya society, with all the essential terms for trade-related activities already in place by the first millennium CE" (Tokovinine and Beliaev 2013:172). In a parallel yet independent study, Speal (2014:105, 107) concludes "that there was a complex of cognate words relating selling activity to patios, platforms, or plazas ... around the middle of the Late Formative period" and that "the florescence of commercial terminology, if not the initial appearance of 'commerce' itself, in Mayan languages," dates to between 1100 and $800 \mathrm{BCE}$.

Ken Hirth (1998) wrote the pioneering article regarding the archaeological identification of ancient markets. Hirth presented four approaches. The configurational 
approach refers to the use of data from specific locales suspected to be marketplaces. The contextual approach focuses on the identification of features (large cities, craft specialists) that benefit from the efficiency of marketplace exchange. The distributional and spatial approaches examine the distribution of goods at the level of the site and the region, respectively. Another approach, which Stark and Garraty (2010) label the production-distribution approach, also takes a regional perspective and infers markets by assessing the logistics necessary to move products from producers to consumers. Among Classic-period sites, archaeologists have drawn heavily on the configurational, distributional, and contextual approaches. Each of these entails a set of expectations that can be tested using the archaeological record. For example, in the configurational approach, one would expect to find physical spaces that qualify as marketplaces based on their size, layout, accessibility, and presence or absence of specific artifacts, features, and chemical residues (King 2015; Shaw 2012). Chapter II in this volume provides detailed expectations for the configurational, contextual, and distributional approaches while chapter 12 discusses the spatial approach.

Using the configurational approach, archaeologists suggested that particular plazas at several Classic-period Maya sites served as marketplaces. The urban center of Calakmul, located in the southern interior of the Mexican state of Campeche, furnishes very strong configurational evidence for the identification of a marketplace. Along with Tikal and Caracol, Calakmul stood as one of the three largest Classic-period Maya centers in the southern lowlands (Folan, Fletcher et al. 2001). Not merely a demographic heavyweight, Calakmul emerged alongside of and in competition with Tikal as one of two "superstates" in the southern lowlands, holding sway over several lesser kingdoms (Martin and Grube 1995). At the core of Calakmul, on the north side of the plaza that contains the site's largest building (Str. II) and its palace (Str. III) lies what Carrasco Vargas, Vásquez López, and Martin (2009) refer to as the Chiik Nahb complex, a 2.5-ha space containing 68 buildings, most of which sit low to the ground, organized in rows running north/ south. Folan, Fletcher, and colleagues (2001:234) suggest that this complex may be a marketplace: the rows of low structures could be market stalls. In 2004, Carrasco's excavations of the tallest structure in the complex (Str. I, named Str. 29M-97 in Folan's map) recovered spectacularly preserved murals depicting scenes of men and women giving, receiving, and consuming a variety of goods. Hieroglyphs close to each person read as labels_ “tamale person," "maize gruel person," "clay vessel person," "salt person," "tobacco person" (Carrasco Vargas and Cordeiro Baqueiro 2012; Carrasco Vargas, Vásquez López, and Martin 2009; Martin 2012) — not unlike the way the Aztecs referred to sellers of goods at their markets. Such scenes have been interpreted as depicting feasts, but the location of the murals among architecture that resembles market stalls strengthens the argument that the scenes depict a 
marketplace. Other examples of possible market stalls come from the East Plaza in the Tikal site core (Jones 1996), and the east plaza of Buenavista del Cayo (Cap 2015), not to mention Area D of Chunchucmil (chapter II, this volume; Dahlin et al. 2007). We note that a lack of stalls does not imply the absence of a marketplace (Coronel et al. 2015:105). Since the word for market (k'iwik) is the same as the word for plaza (Speal 2014; Tokovinine and Beliaev 2013), it is likely that some plazas used as marketplaces on certain days would be used for other events on other days. This means that marketing often took place without permanent stalls and may also have occurred only occasionally, as suggested by Freidel (198I).

The distributional approach assumes that if a particular good is exchanged at a marketplace, if most households have the means to purchase that good, and if most households desire it, archaeologists should find that good distributed more or less evenly across the different areas of a site and across the social-status spectrum. Using the distributional approach at Motul de San José, Guatemala, Halperin et al. (2009) believe that figurines were exchanged at centralized marketplaces that took place as part of fairs that drew people from a radius of up to $32 \mathrm{~km}$. Moderate accumulations of chemical residues associated with markets in Motul's main plazas (Bair and Terry 20I2) and the lack of a space with dedicated market features (e.g., stalls) support the pilgrimage-fair model (Freidel 198I). In this model, markets are held periodically in plazas that also have other uses. The multifunctional nature of such plazas precludes the construction of permanent stall-like architecture seen at sites such as Calakmul, Tikal, and Chunchucmil. Additional Classic-period Maya case studies that use the distributional approach come from Cerén (Sheets 2000), Tikal (Masson and Freidel 2012; West 2002), El Perú/Waka' (Eppich and Freidel 2015), Palenque (West 2002), and Chichén Itzá (Braswell and Glascock 2002; Braswell 20I0), not to mention Chunchucmil (chapter II, this volume; Hutson et al. 2010).

The contextual approach "infers the existence of marketplaces from the presence of cultural features believed to require the provisioning and distribution functions of the market to exist, for example, large cities and full-time craft specialists" (Hirth 1998:453). As an example of the contextual approach in the Classic Maya area, we highlight Tikal, for which configurational and distributional evidence are also present. Tikal was a large city with over 60,000 people in an area with limited arable land (Culbert et al. 1990) and it likely contained residents who earned their living through craft specialization. Becker's (2003) research on residential group $4 \mathrm{~h}-\mathrm{I}$ and its neighbors provides a plausible case of full-time specialization in the production of fine pottery. Group $4 \mathrm{~h}-\mathrm{I}$ and its neighbors form a dense cluster of houselots on a peninsula bounded by seasonally inundated swamps (bajos). Becker argues that these households chose to settle on the peninsula in order to get access to clay and fuel (from palm trees) for kilns, both of which come from the bajos. 
The farming resources in this peninsula are minimal, suggesting a full-time commitment to potting. However, such full-time specialization does not necessarily imply markets. If these potters were specialists attached to and controlled by palace elites, redistribution, as opposed to markets, could support such specialization. However, unlike attached specialists elsewhere in the Maya area (Inomata and Triadan 2000), Group $4 \mathrm{~h}-\mathrm{I}$ and its neighbors lived in modest buildings located far from a palace, thus suggesting they were not attached specialists.

Chase and Chase's work at the massive center of Caracol, Belize, combines contextual, distributional, and configurational data. As for contextual data, excavations in a sample of over roo domestic contexts revealed that most households focused on one of many possible economic specializations, including lithics, shell, cloth, bone, and woodworking (Chase and Chase 2001:278, 2004:14I). As for distributional data, the distribution of goods indicates that each household had access to most of the goods produced in other households located near the same marketplace. As for configurational data, Caracol has causeways that extend approximately $3 \mathrm{~km}$ out from the site center in all directions and end in public plazas around which residences cluster. Noting that such plazas are conveniently located for exchange and that they lack ritual or domestic debris, Chase and Chase (2001, 2004; 2014; Chase et al. 2015) have proposed that they are the marketplaces at which interhousehold exchange took place. Chase and Chase believe that market exchange at Caracol followed Carol Smith's solar model (C. A. Smith 1976) in which Caracol's authorities controlled exchange, seldom opening it to merchants from beyond the polity.

What Stark and Garraty (2010) call the production-distribution approach combines aspects of both the contextual and distributional approaches. Market exchange is inferred in the context of large, complex settlements, where goods produced in or obtained from a variety of locations, near and far, are shown to be widely distributed across the site in question. The logic behind this inference is that authorities could not manage such a wide and complex circulation of goods coming from so many different places. In other words, redistributive systems could not pull off such a task (see also Dahlin et al. 2010; McAnany 2010:263). Only markets can account for such intricate patterns of exchange. Masson and Freidel demonstrate this approach using Classic-period data from Tikal. They show that the degree of "occupational specialization, surplus production, household and community interdependency, and ease of access to valuable goods" at Tikal is similar to that of Mayapán, a Postclassic site said to have well-developed markets (Masson and Freidel 20I2:455). It is important to note that even if an elite-centered redistribution system could not have produced such complex patterns of exchange, elites could still have been involved in exchange by sponsoring markets (Freidel I98I; Masson 2002a:4; cf. Pyburn 2008). 


\section{THE CONTEXT FOR MARKETS AT CHUNCHUCMIL}

Thus, marketplace exchange has been inferred from a number of perspectives at a number of Classic-period Maya sites. As we now discuss, several lines of evidence independent of the research conducted by PREP suggest that Chunchucmil was well-positioned to fill the role of a major marketplace. The Gulf Coast, located 27 $\mathrm{km}$ to the west of Chunchucmil, was a vigorous maritime trade route. Situated at the interface of perennially dry land and seasonal wetlands, Chunchucmil could not have been located any closer to the Gulf Coast without a substantial part of the city flooding in the rainy season (figure 1.2). Yet more significant than mere propinquity to the coastal trade is Chunchucmil's positioning with regard to two natural features on the coastline to the west: the Celestún salt flats and the last protected harbor for another $100 \mathrm{~km}$ to the north (chapter I2, this volume; Dahlin and Ardren 2002). Before PREP began, one could propose three things on the basis of location alone: (I) that Chunchucmil harvested salt; (2) that Chunchucmil traded the salt along the Gulf Coast and inland; and (3) that the harbor near Chunchucmil was a natural place for coastal merchants traveling northward to go ashore and trade their goods.

These propositions assume the existence of voluminous seaborne Gulf Coast trade and a high demand for salt elsewhere in the Maya area. We revisit these assumptions in greater detail in chapters Io and I2 but summarize them presently. Regarding the assumption of voluminous seaborne trade, researchers often state that such trade became more common in the Postclassic (McKillop 1996; Sabloff and Rathje 1975). Turner and Sabloff (2012) go so far as to say that the shift from land-borne to seaborne trade at the end of the Classic period played the most important role in the Terminal Classic collapse of southern lowland polities. Nobody doubts, however, the existence of seaborne trade prior to the Terminal Classic. In fact, evidence for the importance of Classic-period trade along the Gulf Coast has increased since Hammond's synthesis (1972a) of evidence in support of such a trade route (e.g., A. P. Andrews and Gallareta Negrón 1986; A. P. Andrews and Mock 2002). For example, research at the site of Emal (Kepecs 1998), on the north coast of the Yucatán Peninsula, shows an abundance of Late Classic ceramics (Celestún Red, Chablekal Fine Gray) that predate the Terminal Classic rise of Chichén Itzá and originate on the southern Gulf Coast in the Mexican states of Campeche and Tabasco. Even stronger evidence for a large volume of Classic-period coastal trade comes from the site of Xcambo, also on the north coast, located approximately halfway between Emal and Chunchucmil's harbor. During the Early Classic period, Xcambo received dozens of polychrome ceramic vessels resembling pottery from the Petén district in northern Guatemala. Furthermore, Xcambo's site center contained buildings that exhibit several similarities with buildings in the Petén (Sierra Sosa 1999). 


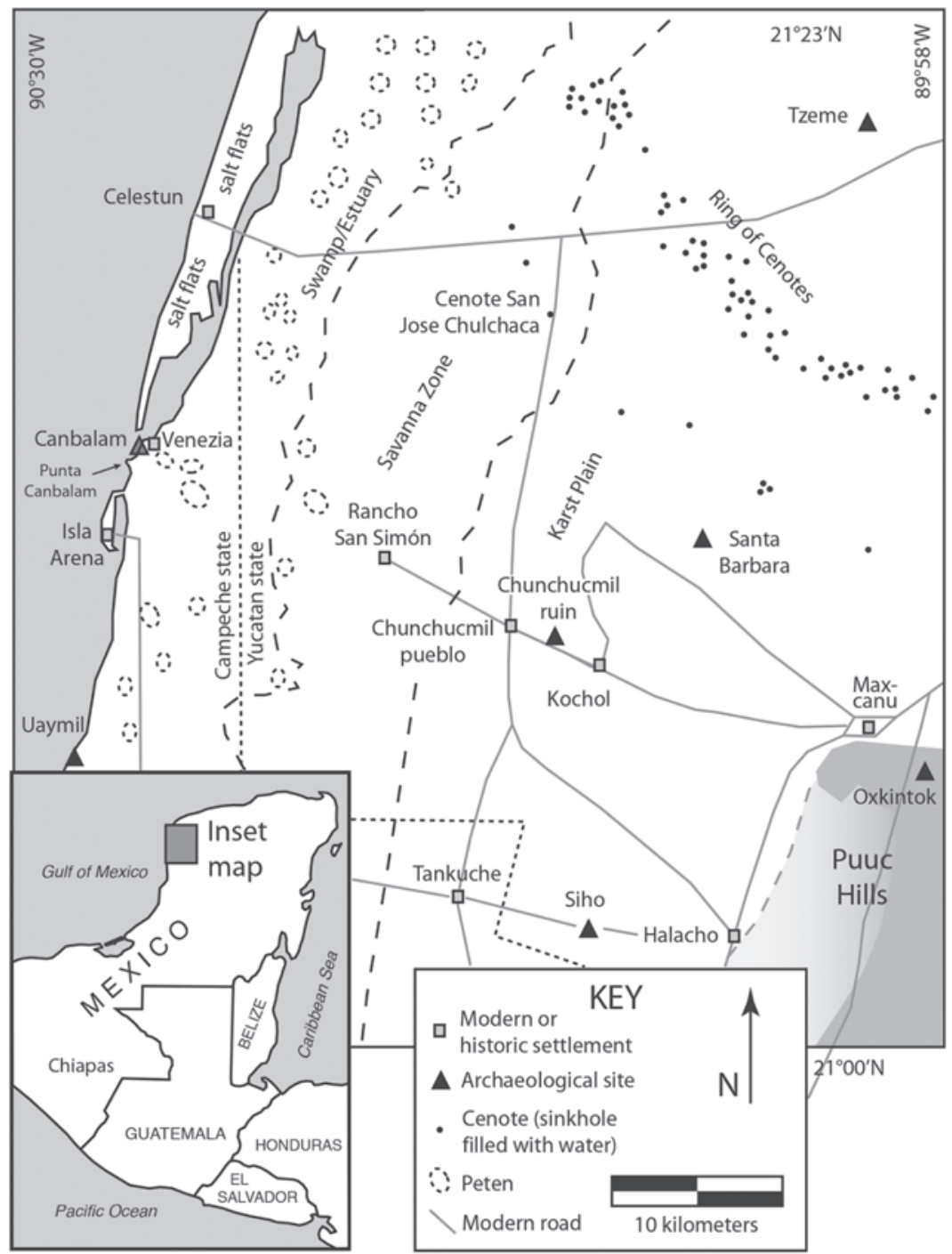

FIGURE 1.2. Map of the region immediately around Chunchucmil, showing modern roadways, key towns, archaeological sites, and environmental features.

The assumption of a high demand for salt elsewhere in the Maya area continues to withstand critical scrutiny. Salt has long been recognized as a critical import in the densely populated southern lowlands (Rathje 197I), where salt from scarce game animals or from burning palm leaves (Marcus 1983:477) is not enough to replenish 
the sodium of the hardworking, perspiring farmers of the Petén (A. Andrews 1983, 1984). The massive salt flats of the northern lowlands-shallow pools from which salt crusts can be collected easily when seawater evaporates in the dry season-have been suggested as the main supplier. The discovery at Belizean coastal sites of facilities for the production of salt by cooking brine does not change this picture, as such facilities produced comparatively little salt and at much greater cost (A. P. Andrews and Mock 2002). Salinas de los Nueve Cerros, on the western edge of the Petén, could have met much of the demand though relatively little pottery at the site dates to the Early Classic (Woodfill et al. 2015).

In summary, research beyond PREP has defended two baseline assumptions regarding the viability of Chunchucmil as a major trade center: (I) vigorous coastal trade with Maya cities far to the south passed close to Chunchucmil; and, (2) Chunchucmil had a resource in high demand at these southern cities: salt. The chapters of this book report on archaeological research that tests Chunchucmil's role in trade more directly.

\section{CONTENTS OF THIS BOOK}

PREP explored Chunchucmil's economy using a multidisciplinary research design. A very detailed map of the site served as a baseline for much of the rest of the work. Over PREP's I2 seasons of fieldwork between 1993 and 2006, the creation of the Chunchucmil site map received more effort than any other operation. The map grew with each season until, by the end of 2006 , we had covered $11.67 \mathrm{~km}^{2}$. We discuss the map, mapping methods, and settlement nomenclature in chapter 2. The map itself appears in the University Press of Colorado online supplement (http:// upcolorado.com/university-press-of-colorado/item/3076-ancient-maya-com merce). Of course, a static map of past settlement doesn't say much if we do not know when the different parts of the site were occupied. Therefore, a second pillar of the research design was a test-pitting program that would provide chronological data from a representative sample of occupational contexts. Chapter 3 discusses this sampling strategy and then chapter 4 presents the chronology of the site.

After establishing in chapter 4 that the vast majority of the architecture on the map in chapter 2 was occupied contemporaneously at the end of the Early Classic, we present in chapter 5 a variety of patterns in the map and begin to interpret them. We divide the site into a series of zones. Three of these zones-the site center, the residential core, and the residential periphery-comprise urban Chunchucmil. The pattern of monumental architecture in the site center suggests a form of political organization that differs sharply from the regal-ritual model seen at many other Classic Maya centers and lends itself to intriguing suggestions regarding the political economy. Broad excavations in the residential zones show 
that most of the densely packed structures in these areas were indeed residences. The chapter then uses these data to estimate that at least 30,000 people lived in urban Chunchucmil's is $\mathrm{km}^{2}$.

Chapter 6 surveys nearby environmental zones, including the semiarid karst plane on which Chunchucmil sits but also the beach barrier zone, perennial wetlands, and seasonal wetlands to the west. Chapter 7 adds to the environmental picture by discussing water resources and water quality in the region. Presentation of the results of regional settlement survey (chapter 8) follows the discussion of Chunchucmil's natural resource zones (chapters 6 and 7) because these surveys show the extent to which people actually settled in the different econiches beyond Chunchucmil. The presence of villages in the seasonal wetlands, for example, suggests that wetland resources played a critical role in Chunchucmil's regional economy. The survey of land to the west of Chunchucmil also identified features that address the question of long-distance trade insofar as any seaborne goods sent from or bound for Chunchucmil would need to cross through this land. The survey to the east of Chunchucmil identified several settlements in the perennially dry hinterland, thus cutting into the farmland available to the city.

Chapter 9 looks closely at local soils and considerations from chapters 6 and 7 in order to determine how the large populations within the site (chapter 5 ) and across the region (chapter 8) could provision themselves. Though several uncertainties plague the task of calculating agricultural carrying capacity and deciding whether or not local farming could supply the city and its regional settlement, many lines of data indicate that people needed to import food. Since they would have had to trade material to get food, these considerations amount to contextual support (sensu Hirth 1998) for a market.

Chapter Io discusses specific resources and craft goods that the people of Chunchucmil could have traded in exchange for food. Given the demographic data from chapters 5 and 8 , exchanging these goods exclusively through a centralized system of redistribution would have been very complex. Given Chunchucmil's political organization, also discussed in chapter 5 , the site appears to lack the kind of centralized authority that could have handled such a complex task. Thus, the production/distribution approach would suggest that markets accounted for a substantial portion of exchange at Chunchucmil. Chapter in provides configurational, contextual, and distributional evidence (Hirth 1998) for a market system at Chunchucmil. Stated differently, the chapter presents data on craft activities at the site, evidence for the positive identification of a marketplace in the Chunchucmil site center, and evidence from the test-pitting program of a distribution of obsidian and ceramics across the site that suggests that people acquired these goods through the market. 
If Chunchucmil was deeply involved in long-distance trade, we would expect evidence of contact with people beyond the Maya lowlands. Furthermore, this evidence should exceed the mere presence of goods, such as obsidian, that came from afar and manifest itself in a number of additional ways, such as the use of international styles of artifacts and architecture. Chapter 12 presents these data. Chapter I3 concludes the book by summarizing the mechanics of trade in salt, obsidian, and foodstuffs, exploring how Chunchucmil's commercial economy developed and declined, and commenting on the significance of the Chunchucmil case study for broader subjects such as ancient Maya politics and gender relations.

\section{NOTE}

I. The word Pakbeh refers to the walls and streets (singular pak' and beh in Yucatec Maya) that are common at the site. Since most the ruins lie on land pertaining to villages other than the modern village of Chunchucmil, we did not use the name Chunchucmil in the title of the project. 



\section{The Map of Chunchucmil}

Scott R. Hutson and Aline Magnoni

The map of Chunchucmil can be found as a series of ro blocks, each containing approximately $\mathrm{I} \mathrm{km}^{2}$ (see below), accessible as supplementary electronic files (http://upcolorado.com/university-press-of-colorado/item/3076-ancient-maya -commerce). The features on the map and the methods used to create it are presented below. We begin this chapter by putting the Chunchucmil map in context with other large mapping projects. For information on Chunchucmil's broader geographic, ecological, hydrological, and pedological contexts, see chapters 6, 7, and 9 .

The number of large Maya sites that have been systematically mapped and published can be counted on two hands: Tikal, Mayapán, Dzibilchaltún, Copán, Calakmul, Cobá, and a couple others depending on how one defines terms like "large" and "systematic." The list remains small because overgrown vegetation in the Maya area makes it extremely expensive and time-consuming to map more than a few square kilometers. This list will grow quickly, however, due to LiDAR, a relatively new remote-sensing technique that sees through the vegetation and quickly produces digital elevation models that sometimes show many prehispanic features (Chase et al. 20II; cf. Prufer et al. 2015). Prior to LiDAR, mapping a big site required chopping hundreds of kilometers of paths and walking nearly every square meter. Using these methods, Folan, Fletcher, et al. 200r map of $30-\mathrm{km}^{2}$ Calakmul took 87 months to compile. Since basic analyses (estimating population and establishing settlement hierarchies) can be done through sampling, research designs involving full-coverage mapping require additional justification. 
In the late I970s, Ed Kurjack, Silvia Garza, and Dave Vlcek provided two justifications for the kind of irregularly intensive mapping project that we undertook at Chunchucmil. First, by ground-truthing aerial photos north of the Chunchucmil site center, they showed that Chunchucmil's settlement density seemed too high to be supported by swidden farming (Kurjack and Garza Tarazona de González 1981; Vlcek et al. 1978; see also chapter 8, this volume). Yet no conclusions could be made about Chunchucmil's economy without excavations in a representative sample of residential compounds. Selecting a representative sample of residential compounds for excavation (see chapter 3 ) required baseline knowledge of the quantity, location, and configuration of the compounds available to sample: the sampling universe. Getting this knowledge required a map that covered most of the site. Second, Kurjack and colleagues noticed that boundary walls-albarradas (described in depth later in this chapter)-delimit residential compounds, that adjacent compounds share albarradas, and that narrow alleys snaked between the compounds. Few Classic-period sites have large numbers of boundary walls delimiting residential groups (Cobá [Folan et al. 1983] and Becán [Thomas 198I] are the best examples) and fewer have shared albarradas (see Magnoni et al. 2012:316). Alleyways are found only in the Postclassic (e.g., Mayapán; Pollock et al. 1962). Chunchucmil has very little Postclassic occupation (see chapter 4). Documenting and analyzing the variation in residential compounds and how the alleys connected them with other parts of the site would tell precisely how people moved through the heterogeneous spaces of the city and therefore provide a finegrained understanding of the urban experience (Hutson 2010, 2016; Hutson and Magnoni 20II; Magnoni et al. 20I2). Such analyses require a contiguous map of a very large chunk of the site. Settlement transects alone would not be enough.

Dahlin set a goal of mapping a 4-by-4-km square at Chunchucmil. Based on earlier aerial-photo analyses (Vlcek et al. 1978 ), the $16-\mathrm{km}^{2}$ goal promised to capture the majority of the site and most, if not all, of the variation within its settlement.

A mapping trial run in 1993, the first field season of PREP, led to the formalization of mapping methods (see below), which were first deployed in earnest in the 1996 field season. Mapping continued in each of the nine subsequent field seasons. By 2006, when the tenth and final season of mapping was complete, we had mapped $11.67 \mathrm{~km}^{2}$ (figure 2.I). In comparison, Stuart et al. (1979) mapped $19 \mathrm{~km}^{2}$ at Dzibilchaltún, Folan, Fletcher, et al. $200 \mathrm{r}$ mapped $30 \mathrm{~km}^{2}$ at Calakmul, Carr and Hazard (196I) mapped $9 \mathrm{~km}^{2}$ at Tikal (Puleston [1983] later added to the map), and Chase and others (20II) mapped $23 \mathrm{~km}^{2}$ at Caracol. In contrast to these sites, the density of archaeological features at Chunchucmil is much higher (see chapter 5 ). We return to sampling issues shortly. We mapped with a high level of detail. Though no map can be a mirror image of the terrain (Monmonier 199I), some maps include 
more details than others. The amount of detail one strives to include presents a tradeoff. Given a finite set of resources, one can include more detail at the expense of covering less ground, or one can cover more ground at the expense of including less detail. Having chosen to include more detail, we moved slowly and were not able to cover as much ground as we originally intended. For example, in each of the 1,167 ha of our map, we documented all visible examples of albarradas, a rather ubiquitous feature at Chunchucmil. In comparison, at Dzibilchaltún (Stuart et al. 1979), albarradas were not mapped and other details (such as platform height) were not noted, allowing a faster pace and coverage of more ground.

The area that we mapped does not encompass the entire site. In fact, our II.67 $\mathrm{km}^{2}$ cover only 60 percent of what we consider to be the site. Nevertheless, the mapping strategy we deployed gives us confidence that our I1.67- $\mathrm{km}^{2}$ sample succeeded in capturing most of the variation in settlement at the site. The strategy combined two forms of coverage: a $9.3-\mathrm{km}^{2}$ polygon of terrain anchored in the center of the site, and five sampling transects that extended up to $2 \mathrm{~km}$ beyond the edge of the $9.3-\mathrm{km}^{2}$ polygon. The goal of the transects was to sample areas of the site that could not be mapped completely and to locate the edges of the site in areas where the $9.3-\mathrm{km}^{2}$ polygon failed to do so. In areas where the $9.3-\mathrm{km}^{2}$ polygon had already pinpointed site edges, the goal of the transects was to get a sample of "intersite" settlement patterns.

\section{METHODS FOR MAPPING THE 9.3-KM² POLYGON}

In the field, our methods were driven by relics of previous land-use that allowed us to establish points of reference: mecate markers and planteles. A mecate is a 20-by20-m unit of measure that was extensively used in Yucatecan plantations in historic times, and it has its origins in the prehispanic Maya vigesimal system. Nearly all of the area that we mapped was at one time under henequen cultivation and henequen workers gridded fields into mecates. Henequen laborers were generally paid by the number of mecates worked, or the area covered. At the corner of each mecate, they erected a stone cairn (mojonera in Spanish) as a marker. In most places, the markers are still preserved today. High-precision GPS equipment showed that rows of 25 mecate markers, which should each measure $500 \mathrm{~m}$ long, came to within a meter or two of being $500 \mathrm{~m}$ long. We accepted this level of error and therefore used the mecates to orient our measurements.

Planteles are polygons, often oddly shaped, that contain anywhere from 20 to 80 ha (between about 500 and 2,000 mecates). The mecate grids were normally oriented within is degrees of the cardinal directions, but the specific orientation of the mecate grid in one plantel was often different from the specific orientation 
of the mecate grid in another plantel. Therefore, we mapped one plantel at a time and within a particular plantel, we assigned grid coordinates to each mecate marker, labeling them with flagging tape. Our workmen cut brechas (narrow paths) between mecate markers in order to connect each mecate marker with its north, south, east, and west neighbors. Cutting such brechas represented a substantial investment (theoretically $307 \mathrm{~km}$ of brech a for the central $9.3-\mathrm{km}^{2}$ polygon!), though in some places recent brush fires or cattle grazing eased the job. In a minority of the planteles, mecate markers were not available. In these planteles, we laid out 100-by-100-m grid squares using a theodolite. Using these larger squares for control, workmen established a $20-$-by-20-m grid within the squares by triangulating with measuring tapes.

To draft features in the field, we transferred the mecate grid to graph paper (or mylar laid on top of graph paper) at a scale of I:I,000. Thus, each 20-by-20-m mecate occupied a 2-by-2-cm square on the graph paper. We sketched features onto the graph paper by pacing their displacement (along both the $x$-axis and $y$-axis of the grid) from the nearest mecate marker. Heights of features were estimated. For features below $2 \mathrm{~m}$, we often rounded our estimates to the nearest $0.25 \mathrm{~m}$. Such estimates likely carry an error of up to plus or minus $20 \mathrm{~cm}$, although we did not test to see what our average error was. Since the accuracy of our height estimates probably diminished for features above $2 \mathrm{~m}$ high, such features were normally estimated to the nearest half meter. The heights of most features above $5 \mathrm{~m}$ were measured with a theodolite.

Once an entire plantel was mapped, the graph paper sheets were conjoined and retraced either manually or digitally to create a composite map of the entire plantel. High-precision GPS points ${ }^{1}$ were taken at the corners of the each plantel as well as other salient points. Using these GPS points, each plantel map was geo-referenced in ERDAS Imagine and ENVI, thus allowing us to combine all the plantel maps into a single composite map. To create the maps in this book, all mapped features were traced into vector format using Adobe Illustrator. A separate GeoMedia Professional GIS database was created to store, analyze, and display all archaeological data collected during mapping and excavations (Magnoni and Hixson 2010). ${ }^{2}$

\section{METHODS FOR MAPPING THE TRANSECTS}

Five transects were mapped beyond the central $9.3 \mathrm{~km}^{2}$ (figure 2.I; see online content for transect maps). As mentioned above, the goal of these transects was to locate the edges of the site and sample the periphery of the site. The five transects include four cruciform transects (cf. Puleston 1983; Ringle and Andrews 1990) oriented approximately 45 degrees off the cardinal directions, and a fifth transect placed opportunistically alongside a modern road running eastward in the direction of Oxkintok, a large site $27 \mathrm{~km}$ away. The northeast transect measured $200 \mathrm{~m}$ wide, the other four 


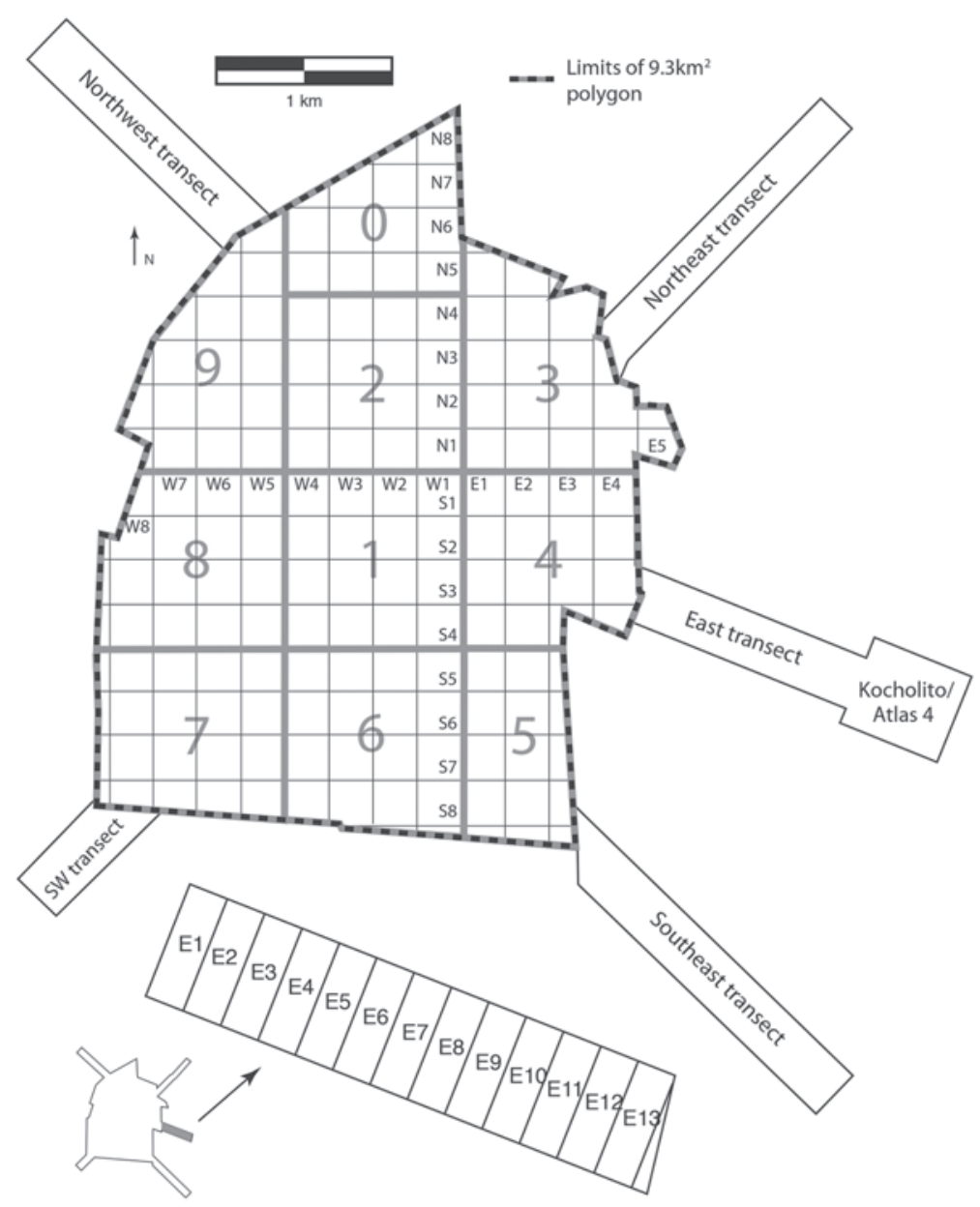

FIGURE 2.I. Map showing the extent of Io०\%-coverage mapping at Chunchucmil, as well as the subdivisions within the $9.3-\mathrm{km}^{2}$ polygon (250-by$250-\mathrm{m}$ quads and $\mathrm{I}-\mathrm{km}^{2}$ blocks) and subdivisions along a sample transect (below). Online component is available here: http://upcolorado.com/ university-press-of-colorado/item/3076-ancient-maya-commerce.

measured $300 \mathrm{~m}$ wide. The area mapped by these transects is $2.37 \mathrm{~km}^{2}$, bringing the total size of Chunchucmil's mapped area to $11.67 \mathrm{~km}^{2}$. The northwest transect $(0.48$ $\left.\mathrm{km}^{2}\right)$ is $1.6 \mathrm{~km}$ long and extends $3.47 \mathrm{~km}$ from the site-center datum. The northeast transect $\left(0.54 \mathrm{~km}^{2}\right)$ measures $1.8 \mathrm{~km}$ long and extends $2.94 \mathrm{~km}$ from the site-center datum. The southeast transect $\left(0.60 \mathrm{~km}^{2}\right)$ is $2 \mathrm{~km}$ long and extends $3.97 \mathrm{~km}$ from the 
site-center datum. The southwest transect $\left(0.18 \mathrm{~km}^{2}\right)$ is $0.6 \mathrm{~km}$ long and extends 3.35 $\mathrm{km}$ from the site-center datum. The east transect $\left(0.57 \mathrm{~km}^{2}\right)$ connects to a cluster of mounds, named Kocholito, on a o.6-by-0.5-km milpa. When combined, the mapped milpa and east transect are $1.9 \mathrm{~km}$ long, extending $2.95 \mathrm{~km}$ from the site-center datum. Each transect was mapped using the "fishbone" survey method, which consisted of cutting a baseline (the "backbone") running the length of the transect and narrow lines ("ribs") running perpendicular to the baseline, crossing it every $100 \mathrm{~m}$ (Puleston 1983). Three to five staff members walked from one rib to the next, with $20 \mathrm{~m}$ spacing between each walker. Any feature found while combing the ribs was mapped with handheld GPS, measuring tape, and compass.

\section{SUBDIVISIONS OF THE MAP}

A blank stela located $50 \mathrm{~m}$ southwest of the site's tallest building (the Chakah pyramid) serves as the site-center datum. The map has been gridded into blocks that are either exactly or approximately $\mathrm{I} \mathrm{km}^{2}$, as well as 250-by-250-m quads (figure 2.I; since the $9.3-\mathrm{km}^{2}$ polygon is an odd shape, most of the quads at the edges of the map are not $250-$ by-250 m). The square-kilometer blocks are numbered o to 9 . These blocks, never before published, are available as supplemental digital files, currently in jpeg format (http://upcolorado.com/university-press-of-colorado/item/3076-ancient-maya -commerce). We use such blocks to stratify our excavation sample spatially (see chapter 3 ) and to refer to general areas of the site. The 250-by-250-m quads establish a system of spatial reference. Each 250-by-250-m quad takes its name from its position north/south and east/west of the site-center datum. The quad immediately northeast of the site center datum is named $\mathrm{N}_{\mathrm{I}} \mathrm{E}_{\mathrm{I}}$. The quad directly north of this quad is named $\mathrm{N}_{2} \mathrm{E}_{\mathrm{I}}$. The quad directly west of $\mathrm{N}_{2} \mathrm{E}_{\mathrm{I}}$ is named $\mathrm{N}_{2} \mathrm{~W}_{\mathrm{I}}$, and so forth. These quad names are used in providing distinct names for each building on the map (see below). We did not use quads to subdivide the transects. Rather, we divided each transect into Ioo-m strips (see figure 2.I). For example, on the east transect, the strip closest to the site core takes the name EI. Since the NW, SW, SE, and $\mathrm{E}$ transects are each $300 \mathrm{~m}$ wide, each strip measures 300 -by-100 $\mathrm{m}$.

\section{FEATURES OF THE MAP}

We classify mapped features into six categories: buildings, linear features, depressions, special stones, historic features, and excavations. Figure $\mathbf{2 . 2}$ contains a key showing how these and other features are represented. The following sections describe these features, provide quantitative data (in most cases) for the features, and, when necessary, elaborate on naming conventions and representational conventions. 
Key

Foundation braces (ancient
structures with no elevation)
with elevation

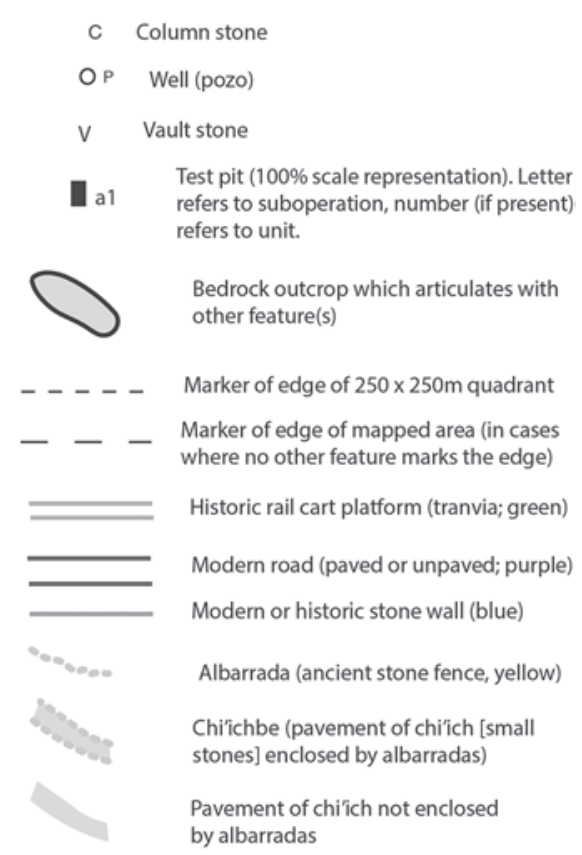

Sample Architectural group with excavations labeled: N4E1-H

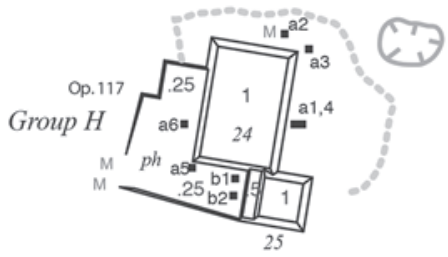

FIGURE 2.2. Key to the detailed Chunchucmil site map and a sample group ( $\left.\mathrm{N}_{4} \mathrm{EI}-\mathrm{H}\right)$. Online version of this figure shows the proper colors and is available here: http:// upcolorado.com/university-press-of-colorado/item/3076-ancient-maya-commerce.

\section{BUILDINGS}

We mapped 10,163 buildings in $11.67 \mathrm{~km}^{2}$. This category contains three different elements: structures, platforms, and chich mounds. We do not include all built features into the category "building." For example, we placed sacbes, callejuelas, albarradas, and chichbes (each defined below) in the category "linear feature." The total number of buildings mapped is large compared to the number mapped at other 
sites: 6,345 in $30 \mathrm{~km}^{2}$ at Calakmul (Folan et al. 2008:299); 6,595 in $17.5 \mathrm{~km}^{2}$ (2I $\mathrm{km}^{2}$ for all zones) at Cobá ${ }^{3}$ (Folan et al. 2009), 8,390 in $19 \mathrm{~km}^{2}$ at Dzibilchaltún (Kurjack 1974:94), and 3,382 in $16 \mathrm{~km}^{2}$ at Tikal (Rice and Culbert 1990:table I.I). The Chunchucmil map shows that buildings very often cluster into what we call groups. Unlike most other features on the map, each building and group received a distinct name. Furthermore, the conventions for representing structures and platforms are complex. Therefore, this section contains not just descriptions of the three types of buildings and the criteria by which we identified groups, but also discussions of naming conventions and representational conventions.

\section{Structures}

Structures are bound spaces that served one or more of a number of functionshousing, food preparation, ritual, storage, and so on. Structures take the form of mounds (a pile of rocks elevated above the ground surface) or foundation braces (stone outlines of buildings with no elevation). We also assume that there were ancient structures that are no longer visible (Chase 1990). Such invisible structures include buildings made entirely of perishable materials and placed on top of platforms as well as perishable and/or nonperishable buildings that have been buried by means of cultural or natural formation processes. We address buried structures in the section below on sources of error. Though not all invisible Maya structures were residences (Tourtellot 1988:437), many could have been (Johnston 2004; Pyburn et al. 1998:42). We account for invisible structures in chapter 5 by increasing our tally of residences by 5 percent when estimating population. This adjustment is purposefully small because of minimal vegetation and soil accumulation as well as the abundant use of rock for construction. Both mounds and foundation braces can be either polygonal (the most common shape being a quadrilateral) or apsidal (shaped like an oval or circle). Several mounds are "split-level": one portion will have a different elevation than another. If one level has a rather small surface area (less than $20 \mathrm{~m}^{2}$ ), that level is called an "extension" of the structure. If both levels have a large surface area, we consider the building to be two separate structures, particularly if the building takes the shape of an L, and each arm of the L has a separate elevation. Mounds usually represent the collapsed ruins of buildings that had stone walls, but can also serve as bases on top of which a perishable superstructure was built. In this latter case, the base would have nearly the same surface area as the superstructure. A total of 7,677 structures were mapped in the $11.67-\mathrm{km}^{2}$ area.

\section{Platforms}

Platforms are stone mounds that usually support several structures and therefore have a much larger surface area than do structures. Also, whereas most 
structures had roofs, platforms probably never did; their surface areas would have been too large. The structures that stood on the same platform were often arranged on the edges of the platform, leaving a partially enclosed courtyard or patio in the center of the platform. This makes their arrangement equivalent to patio groups (Ashmore 198I). Platforms are sometimes built up from the natural ground surface on all sides, though they are often more like terraces, being built up from the ground surface on some sides but grading imperceptibly into the natural ground surface on others. A total of 1,350 platforms were mapped in the II. $67-\mathrm{km}^{2}$ area.

\section{Chich Mounds}

Chich mounds are low, oval or circular piles of chiich, a Yucatec word meaning "limestone cobbles" (usually < 15-cm diameter) and gravel (Barrera Vásquez 1980:134; Bricker et al. 1998:83). They rarely measure more than $35 \mathrm{~m}^{2}$. A chich mound is different from similarly-shaped apsidal structures because chich mounds do not have larger (usually $>25-\mathrm{cm}$ diameter) facing stones clearly delimiting the edges of the mound. Larger chich mounds could serve as platforms for permanent residences (Pyburn et al. 1998) or temporary fieldhouses (Kunen and Hughbanks 2003). Because chich mounds allow tree roots to gain purchase and provide good drainage in clayey soils, they may also serve as planting surfaces for tree crops (Kepecs and Boucher 1996). All buildings (structures, platforms, chich mounds) are represented by black lines (see note on representational conventions below), though the line for a chich mound is dashed. A total of 1,136 chich mounds were mapped in the 11.67$\mathrm{km}^{2}$ area, yet this number is not as accurate as the number of structures and platforms. Whereas the aligned stones of the retaining walls of platforms and structures often make these features unmistakable in the field, it is hard to be certain that a low, vaguely circular or oval-shaped pile of small rocks is an intentionally built chich mound or just a naturally degraded bedrock outcrop.

\section{Groups}

Groups can be more of a construct of the archaeologist than a discreet feature left by the ancient Maya. This is because a group consists of a collection of features-be they buildings or linear features or something else-that has been grouped together by the archaeologist by processes of both lumping and splitting. Furthermore, the collections of features that we identify as groups take many forms at Chunchucmil. The most easily identifiable form consists of structures that cluster together to form a patio group (Ashmore 198I). Though we first mentioned patio groups in the context of platforms, many patio groups do not contain 
a platform (and some groups contain multiple platforms). At Chunchucmil, we benefit from an additional set of features absent at most other sites that help identify groups: stone walls. Such walls, described further below as albarradas in the section on linear features, often encircle a set of structures, making it easy to distinguish one group from another. When the Maya themselves built a cluster of structures that share a patio and a similar alignment, or when they built a stone fence around a set of structures, we can argue strongly that such groups are not just the constructs of archaeologists but housed a social unit—usually an extended family household - that was meaningful to the ancient Maya. In chapter 5 we use excavation data to discuss what kind of social units inhabited some groups at Chunchucmil. Nevertheless, even with patio groups and albarradas, it can be difficult to draw boundaries between groups. For example, the same two patio platforms that would be designated as separate groups in the absence of albarradas must be considered a single group if a single albarrada wall surrounds them (see Group S5 W6-G). When structures do not cluster into patio groups and when albarradas are absent, there is more room for error in delimiting groups. Isolated structures were not considered to be a group unless they were large $\left(>100 \mathrm{~m}^{2}\right)$ or if they were affiliated with some other feature, such as an albarrada fragment, a metate, or a chich mound. Clusters of chich mounds were not considered a group unless they had a grinding stone or were at least partially encircled by an albarrada. Excavations of a group of chich mounds (Op. 84, Group $\mathrm{N}_{3} \mathrm{E}_{7}-\mathrm{A}$ ) suggest that, unlike other groups, these may not be the remains of households in themselves but a part of a household or other social group centered elsewhere. To reiterate, these considerations mean that we did not assign certain isolated structures to any group. A total of $\mathrm{I}, 477$ groups were inferred in the $11.67-\mathrm{km}^{2}$ area. Of these groups, perhaps a dozen were not completely mapped because portions of them extended beyond the bounds of our map.

\section{NAMING CONVENTIONS FOR BUILDINGS AND GROUPS}

\section{STRUCTURES}

Within each 250-by-250-m quad, structures are named numerically, beginning with the number I. Thus, a sample structure name would be $\mathrm{N}_{4} \mathrm{E}_{1}-25$. On the $\mathrm{N}_{4} \mathrm{E}$ I quad map, the number 25 appears next to this structure (figure 2.2). Structure numbers are to the side of buildings and they are italicized and presented in a font with serifs, whereas the numbers that indicate structure heights (when present) are at the top of the building and not italicized and are represented with a non-serif font. In the full-color digital maps, structure numbers are black and height numbers are purple. 


\section{Groups}

Names of groups include the name of the quad they are in plus a distinct letter. Thus, structure $\mathrm{N}_{4} \mathrm{E}_{\mathrm{I}-25}$ pertains to Group $\mathrm{N}_{4} \mathrm{E}_{\mathrm{I}}-\mathrm{H}$. On the $\mathrm{N}_{4} \mathrm{E}_{\mathrm{I}}$ quad map, the label "Group H" appears at the group (figure 2.2). Groups that have been excavated (see table 3.5) carry an additional "Op." label (see below: "Excavations/ Operations"). For example, group $\mathrm{N}_{4} \mathrm{E}_{\mathrm{I}} \mathrm{H}$ received eight I-by-I-m test pits. The label "Op. II7" refers to these excavations. Therefore, on the map, the label "Op. in7" accompanies the label "Group H." Finally, the first 40 or so groups to receive test pits were also given informal names, taken from Yucatec Maya names for trees and animals. Operation numbers supersede this earlier nomenclature, though most of these names can still be found on the map.

\section{Platforms}

Platforms are labeled with a $p$ and then the letter of the group that they are a part of. In other words, the platform in Group $\mathrm{H}$ of quad $\mathrm{N}_{4} \mathrm{E}_{\mathrm{I}}$ is named $\mathrm{N}_{4} \mathrm{E}_{\mathrm{I}}$-ph (figure 2.2). On the map itself, only the label $p h$ appears. If a group, such as Group $\mathrm{N}_{I} \mathrm{E}_{\mathrm{I}} \mathrm{G}$, has more than one platform, they are labeled sequentially: $p g_{I}, p g_{2}$, and so on. If what appears to be a single platform has two separate elevations and the difference is $20 \mathrm{~cm}$ or greater, each area with a distinct elevation is considered a distinct platform. In some cases, the same platform supports enough structures to delimit two or more courtyards that are completely sealed off from one another. As long as the elevation of each courtyard is the same, each courtyard is considered to be part of the same platform. In order to provide a system of reference that distinguishes between sealed-off courtyards, however, the first courtyard of $N_{I} E_{I}$-pgi will be labeled $p g I a$ and the second $p g_{I} b$.

\section{Chich Mounds}

We assigned names to chich mounds in roughly the same way that we assigned them to structures, but chich mound names always carry the preface $c h$. For example, the full name of the fifth chich mound in quad $S_{5} W_{7}$ is $S_{5} W_{7}$-ch5. On the map, most chich mounds also have the label $c h$ inside them so that the number given to them is clearly understood to be a chich number as distinct from a structure number.

\section{Conventions for Representing Platforms and Structures}

In one of Jorge Luis Borges's (1975) fictional worlds, the emperor's cartographers make a map that is the same size as the empire itself. In the world of nonfiction, however, all maps are reductions. Not only are they smaller than what they represent, 
they carry less information. Much like other maps of Maya sites, the conventions for representing features at Chunchucmil are standardized. The standardization of representational conventions contributes to the reduction of the amount of information carried by the map. For example, the inhabitants of Chunchucmil used a variety of techniques to construct stone boundary walls of various sizes (see below for more information on albarradas). However, in our map, we use a representational convention that communicates only the length and direction of albarradas, regardless of variation in width, height, or construction technique. The most notorious standardization found in maps of Maya and other sites is the convention used to represent ancient mounds whose specific dimensions and other details-such as presence or absence of rooms - are not apparent before excavation. This convention uses nested polygons to represent mounds-which today look like disorderly piles of stone-as geometric prisms. Prisms are not straightforward representations of what is on the ground today. Some of the earliest makers of Maya maps noted that buildings that were once rectangular took on the shape of ovals after they collapsed (Bandelier I884:316). In his map of Copán, Maudslay (I889-1902:1:18) noted that the "lines on the plan are more regular than those presented to the eye at the ruins." Though explorers such as Stephens and Catherwood used prisms well before Teobert Maler, the turn-of-the-century explorer, some archaeologists colloquially refer to the use of prisms as Malerization. Unlike our technique for representing albarradas, the use of prisms is not a straightforward reduction because the goal is not to represent, in simplified form, the shape of the disorderly stone piles as they appear today. Rather, the goal is to extrapolate from these piles the clean, polygonal shapes that the buildings had before they crumbled. Therefore, creating prisms requires more than just sketching what is on the ground. It requires "professional vision" (Goodwin 1994): interpretative judgment informed by prior experience with Maya architecture.

Different archaeologists follow different procedures for transforming what they see on the ground into prisms. In other words, prisms represent a family of techniques, rather than a single technique. Published commentary on procedures for drawing prisms is rare (G. Andrews 1984; Carr and Hazard 1961; see Wolf 1997 for the most thorough history of Maya maps). This no doubt contributes to the existence of multiple and conflicting versions of prisms, which means that it not always possible to infer certain dimensions of the building that a prism represents. In our map, the outer polygon of the prism represents what we believe is the outer edge of the original building. With low mounds, the stones that mark the actual edge of the building are often visible before excavation. However, with high mounds, the actual edge stones are often buried, which means that the higher the mound, the more room for error in our placement of the edge. We follow Carr 
and Hazard (196I) in using the distance between the outer polygon and the inner polygon to communicate the height of the mound as is visible today. Thus, for a 2-m-high mound, the distance between the inner and outer polygons of the prism will be two scaled meters. The height of most mounds is also written on top of the mound. Because of the convention that the distance from the outer polygon to the inner polygon represents the height, prisms give the impression that the slope between the base and the top of the building is a constant 45 degrees. This impression is often not correct (Hutson 2012a).

\section{LINEAR FEATURES}

Linear features consist of albarradas, callejuelas, callejones, chichbes, and sacbes (for additional detail about these features, see Magnoni et al. 2012). Each of these falls under Ashmore's (1981:45) category of integrative features: "entities which serve to channel access whether by facilitating movement or impeding it." All are human built, though they sometimes take advantage of natural features such as bedrock outcrops. Albarradas are alignments of rough-cut or unworked stone resembling stone field walls though nearly always completely collapsed (figure 2.3). They are represented as yellow lines with rounded dots on the digital map and gray lines with rounded dots in print figures. Most albarradas serve to encircle, at least partially, a group of structures, though a few do not appear to be affiliated with any particular structures. Given that they are most often associated with architecture, they are distinct from the field walls common all along the east coast of Yucatán at sites such as Cozumel, Xcaret, and Tulum. When an albarrada encircles a group of domestic structures, we refer to the enclosed land and architecture as a houselot. Figure 2.4 shows several examples of ancient houselots. Houselots enclosed by stone walls are common in villages across Yucatán today. Toward the center of the site, where settlement density is highest, most albarradas that encircle groups of structures also serve as boundary walls shared by the bordering houselot. Albarradas enclosed structures at other Classic-period sites such as Cobá (Benavides Castillo and Manzanilla 1987; Folan et al. 1983), Dzibilchaltún (Kurjack 1974; Kurjack and Garza Tarazona de González 198I), Becán (Thomas 198I), the Río Bec region (Turner 1983), Cuca (Kurjack and Garza Tarazona de González 198I), and Calakmul (Folan et al. 2008). At these sites, however, albarradas were not as extensive and were rarely shared between houselots (see Magnoni et al. 2012:316 for information on albarradas at Terminal Classic and Postclassic sites). We documented $200 \mathrm{~km}$ of albarradas within the $9.3-\mathrm{km}^{2}$ polygon.

Callejuelas are pairs of albarradas running parallel, delimiting walkways that serve as critical paths for movement from one part of the site to another. In other words, 


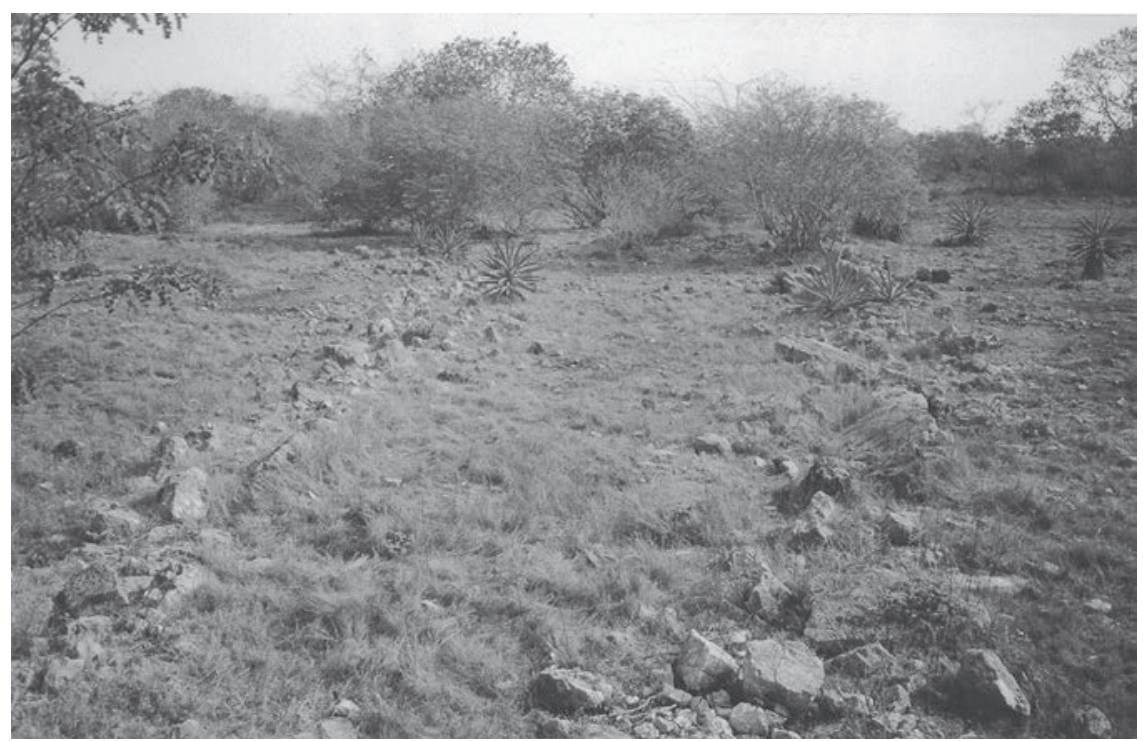

FIGURE 2.3. Photo of an example of paired albarradas that make up a callejuela.

callejuelas are like the public streets of a city. A callejón is a short callejuela that connects a group of structures to another callejuela or open space. A modern analogy would be a driveway that connects a house to a road. A chichbe is like a callejuela or a callejón that has a fill or pavement of small stones $(<\mathrm{I} 5 \mathrm{~cm})$ in between the albarradas that define its sides (figure 2.3). However, whereas callejuelas and callejones serve as walkways, not all chichbes at Chunchucmil have this function; some appear to serve as boundary walls around houselots. In fact, around some residential groups a portion of the group is enclosed by an albarrada/callejuela and a portion by a chichbe. At other sites, features resembling chichbes appear to have served exclusively as walkways and are therefore called andadores (Benavides Castillo I98I; Vargas Pacheco, Santillan, and Vilalta 1985). Some of the chichbes at Chunchucmil may have been used as andadores, to facilitate walking. We documented $43 \mathrm{~km}$ of chichbes within the $9.3-\mathrm{km}^{2}$ mapped polygon block. Chichbes are represented as callejuelas - a pair of lines with rounded dots-but with gray shading in between the lines.

Sacbes are raised, relatively straight causeways that connect directly with large architectural compounds. They consist of a rubble core held in place by a pair of retaining walls made of cut stone. Sacbes are represented by black lines and labeled on the map with numbers, beginning with Sacbe I. We have documented 20 sacbes at Chunchucmil, 19 of which are in the central $9.3 \mathrm{~km}^{2}$ (figure 2.5 ; Sacbe 20 is on the SE transect). Whereas albarradas, callejuelas, callejones, and chichbes meander, 


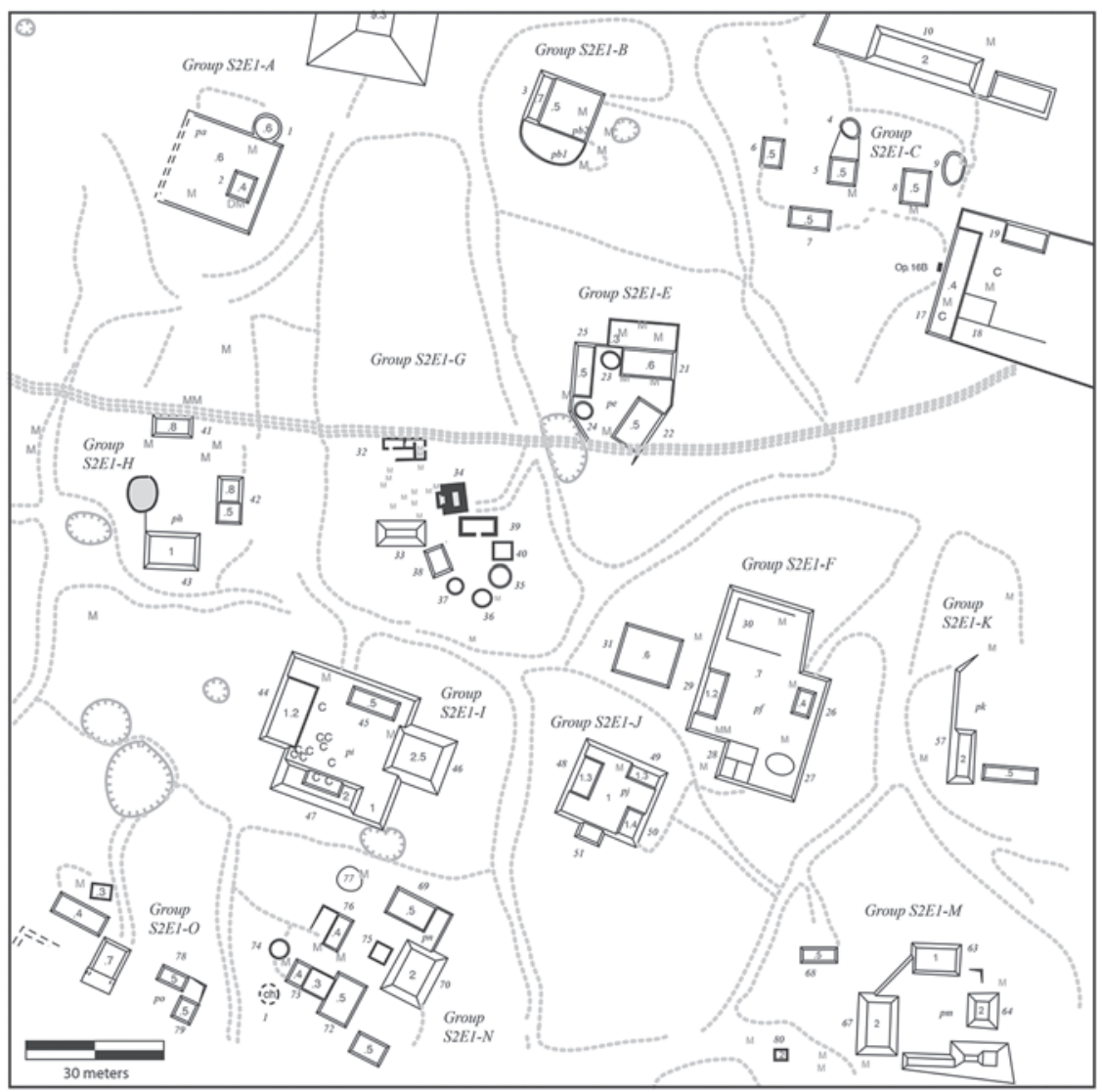

FIGURE 2.4. Map showing examples of houselots in Chunchucmil from quad $S_{2} E_{1}$, in the residential core directly south of the site center.

sacbes generally run very straight (Shaw 2008). Three sacbes at Chunchucmil (I, 8 , and Io) are composed of segments with different orientations. The most pronounced change in orientation is on Sacbe 8, which makes a 28-degree turn as well as some smaller turns. The fill of a sacbe often consists of the same small stones as the surface of a chichbe, but sacbes are straighter and have worked stones on their edges. Sacbes are also wider; they range from $4 \mathrm{~m}$ to $25 \mathrm{~m}$ wide whereas most chichbes are between $3 \mathrm{~m}$ and $5 \mathrm{~m}$ wide. Modern construction has damaged three of the sacbes ( 14,16 , and 17 ) and Late/Terminal Classic people damaged Sacbe $\mathrm{I}_{2}$ in the process of constructing later platforms. Two sets of features (the dotted lines to the west of Group $\mathrm{S}_{2} \mathrm{E}_{2}-\mathrm{A}$ and linear features to the east and west of Group $\mathrm{S}_{\mathrm{I}} \mathrm{W}_{2}-\mathrm{A}$ ) could 


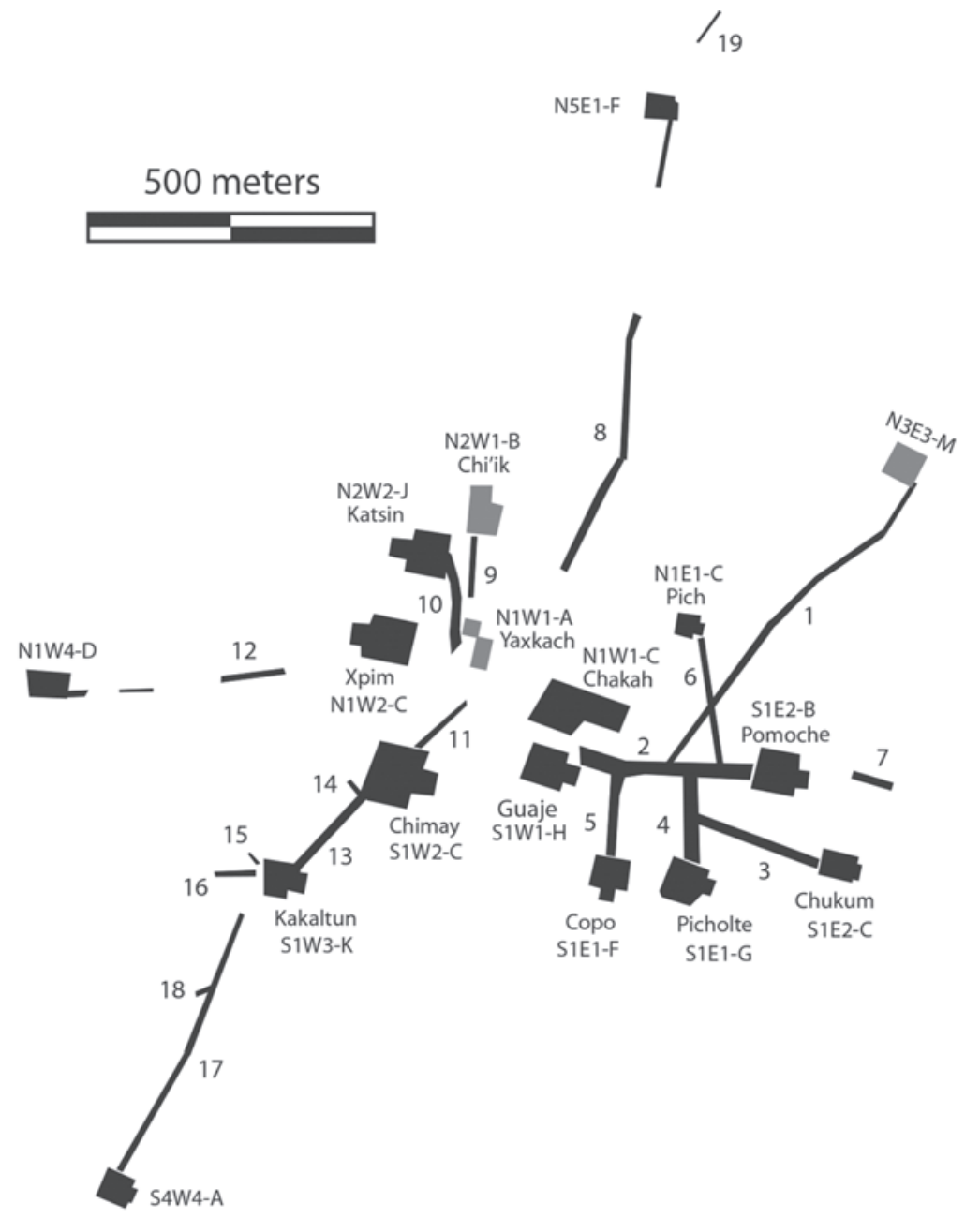

FIGURE 2.5. Map of the numbered sacbes at Chunchucmil as well as the quadrangles and other monumental groups (in gray) with their labels.

also potentially count as sacbes damaged by the ancient people of Chunchucmil, but the features by Group $\mathrm{S}_{2} \mathrm{E}_{2}$-A have almost no elevation and the features by Group $\mathrm{S}_{\mathrm{I}} \mathrm{W}_{2} \mathrm{~A}$ might instead be a callejuela. All but Sacbes is and 20 have well-defined destinations-architectural groups or other sacbes-at both ends. For Sacbe I5, modern damage as well as ancient reuses of space make it difficult to determine the intended western endpoint of Sacbe I5. Sacbe 19 , the northernmost, appears not to 
have been completed in ancient times: it connects to a residential group on its west side but runs $60 \mathrm{~m}$ to the east, not aligned with anything farther to the east, before stopping in an area with no visible features. Fourteen sacbes have a monumental architectural compound at one or both of their ends, and I2 of these compounds are quadrangles, which we define in chapters 3 and 5 as the most common configuration of monumental architecture at the site. Sacbe 8, the longest one, measures $790 \mathrm{~m}$, although it exists as a callejuela for $150 \mathrm{~m}$ and disappears for $100 \mathrm{~m}$. The second longest is Sacbe I, measuring $650 \mathrm{~m}$. Sacbe is is the shortest, measuring $30 \mathrm{~m}$.

\section{Subsurface Features}

Subsurface features include depressions, wells, quarries, and sascaberas. The latter three features are all marked on the digital map by green lines with hachures. Chapter 5 discusses their distribution across the site. Beginning in 1998, we added the labels $Q$ and $S$ to distinguish quarries and sascaberas, respectively. Unfortunately, the approximately 47 ha mapped in 1996 and 1997 do not contain these distinctions. This area is located in the NE corner of the map, in block 3, consisting of quads $\mathrm{N}_{1} \mathrm{E}_{5}, \mathrm{~N}_{2} \mathrm{E}_{5}, \mathrm{~N}_{2} \mathrm{E}_{4}, \mathrm{~N}_{2} \mathrm{E}_{3}, \mathrm{~N}_{3} \mathrm{E}_{4}, \mathrm{~N}_{3} \mathrm{E}_{3}, \mathrm{~N}_{3} \mathrm{E}_{2}$, and $\mathrm{N}_{4} \mathrm{E}_{3}$ and small portions of neighboring quads $\mathrm{N}_{2} \mathrm{E}_{1}, \mathrm{~N}_{2} \mathrm{E}_{2}, \mathrm{~N}_{3} \mathrm{E}_{1}$, and $\mathrm{N}_{4} \mathrm{E}_{2}$. The lack of such distinctions in this sector of the map means that the counts of quarries and sascaberas given below are slightly lower than the actual count.

\section{Depressions}

There are no cenotes (karstic sinks that extend to the water table, providing pooled water) or dzadzes (karstic sinks that extend close enough to the water table that the soil at the bottom is muddy; Houck 2006) and no major natural caves (Kepecs and Boucher 1996) at the site. Some depressions on the map are marked with an $R$ for rejollada. Rejolladas, like cenotes, also result from dissolved limestone, but near Chunchucmil, they are relatively shallow (less than $2 \mathrm{~m}$ deep) and small (less than $20 \mathrm{~m}$ wide) and therefore are not comparable to the deeper (10-20 $\mathrm{m}$ deep), broader (sometimes more than $100 \mathrm{~m}$ wide) rejolladas found in the center of the northern plains (see chapter 6 for more information on rejolladas). Depressions with no evidence of cut rock whose sides have a slope of less than 90 degrees show up on the digital map with the customary green hachured lines, but with no letter. A total of 435 of these were mapped. Most of these are probably natural features for drainage of water, though some could be human-made quarries. The map likely underrepresents these depressions as their non-human-made appearance caused mappers to ignore them from time to time, particularly when they were not in association with buildings or linear features. 


\section{Wells}

Ancient wells are infrequent but often distinguishable from wells built after the conquest because they normally have large stone blocks around the surface. Most modern wells can be distinguished based on the engineering of the shafts and building materials around their rims. Sometimes, however, mappers could not determine on the spot whether a well was ancient or historic. We located I 8 ancient wells, three wells that may or may not be ancient, and dozens of modern wells in the $9 \cdot 3-\mathrm{km}^{2}$ polygon. The water table occurs at about $3 \mathrm{~m}$ below the surface. It is possible that ancient wells were reused in modern times. The number of ancient wells we found is small, considering the size of the site and density of occupation. An unknown number of wells were probably filled in and were therefore invisible to us in the field.

\section{Quarries}

Depressions with at least one vertical or near vertical face (e.g., 90-degree slope) with exposed stone were recorded as quarries and labeled with a $Q$. Since there are natural bedrock formations that resemble what we labeled as quarries, we admit that some depressions which we labeled as quarries may actually be natural features. A total of 2 ro quarries were mapped.

\section{Sascaberas}

Depressions with at least one overhanging face were recorded as sascaberas. A sascabera is a location where people have dug underneath the capstone to extract sascab, a soft, friable limestone used to manufacture plaster (Littmann 1958; see also chapter 6, this volume, for additional details). Sascaberas were labeled with an $S$. There is wide variation among sascaberas. Some were dug so intensively as to leave caves with multiple passages (Dahlin et al. 20II). Though it is quite rare, some sascaberas extend to the water table. Others were shallow and small, not very distinct from what we recorded as quarries, though erosion and collapse of the capstone may have concealed a larger cavity. By the same token, such erosion and collapse could have concealed sascaberas to a degree that they are not recognizable at all. A total of 270 sascaberas were mapped.

\section{Metates, Columns, and Other Distinctive Stones}

Special stones include metates, querns, double metates, columns, vault stones and Puuc stones. A metate is a broad stone with a trough in the middle made by grinding various materials with a handheld stone called a mano. Metates at Chunchucmil can be subdivided into those with rectangular troughs ("trough" metates; Pritchard Parker 1994) and those with have circular or oval troughs ("basin" metates; see 
Watanabe 2000 for metric variation among metates at Chunchucmil). We made no distinction between trough and basin metates while mapping the site but Watanabe's subsequent detailed study of metates, reviewed in chapter Io, explores this difference further. A total of 2,708 metates were mapped in the $11.67-\mathrm{km}^{2}$ area. Chapter 5 discusses their distribution across the site. We classify 74 of these 2,708 metates as querns. Querns are similar to basin metates but the profile of the interior side of the basin is concave, such that the rim of the basin has an overhang. Querns also have spillways leading outside of the basin. We attempted to distinguish querns from other metates while mapping but admit that it was not always clear in the field whether or not to classify a metate as a quern. Stones with two troughs, usually side by side, are called double metates. Of the 2,708 metates, we classify 22 as double metates. In other words, we found II stones at Chunchucmil that each hosted a pair of metates. Columns are circular stone discs of variable diameter and height. Some were found in situ. Vault stones have a vaguely triangular or boot-shaped profile and pertain to Late and Terminal Classic corbel vaults. Stones from vaults of earlier buildings are not nearly as diagnostic. Thus, we assume that our map grossly underrepresents the number of true vault stones and therefore the number of vaulted buildings at the site. Puuc stones are very finely worked architectural stones with flat faces or faces with geometric designs. There are relatively few of these and they cluster near platforms with lots of diagnostic ceramics from the Late/Terminal Classic periods (see chapter 3 ).

\section{Historic Features}

A series of features were built after the Spanish conquest. Most were built in the twentieth century. These include stone fences, wells, corrals, feeding troughs, quarries, and, more than anything else, dozens of kilometers of tranvias: low, linear, stone platforms for rail carts that carried agave spears to the hacienda at the beginning of the twentieth century. The key in figure 2.2 shows how we distinguish these modern features on the digital map.

\section{ExcAVATIONS/OpERATIONS}

The map shows the location of excavations. When PREP began, each of the different kinds of archaeological work received an operation number. Operation I was mapping, operation 2 was surface collections, operation 3 was test pits, operation 4 was excavations of sascaberas, operation 5 was excavations of ancient wells, operation 6 was excavations of natural drainage features, operation 7 was soil pits, operation 8 was cleaning of looters' pits, and operation 9 was broad excavations of buildings. Letters after each of these numbers referred to the location of the operation. The 
first group to receive test pits would therefore carry the operation label $3 a$, and the first group to receive horizontal excavations would carry the operation label 9a. To accommodate the fact that the number of test-pit operations soon greatly exceeded the number of letters in the alphabet and to simplify cases where the same structure group carried more than one operation designation-for example group $S_{2} E_{2}-F$ contains both Op. $3 \mathrm{~g}$ and Op. 9c-we changed the system in 2000 so that each structure group to be excavated received only one operation designation, regardless of the type of excavation. As noted above, the first 40 or so groups to receive test pits were also given informal names, taken from Yucatec Maya names for trees and animals, for ease of reference in the field. Where possible, we gave suboperation designations to particular buildings and the space around them within a structure group, and each excavation square within the suboperation had its own number. Thus, Op. I $7 \mathrm{~b}_{2}$ refers to the second excavation unit in suboperation b (near structure 25) of Op. I17, which took place in Group $\mathrm{N}_{4} \mathrm{EI}_{\mathrm{I}} \mathrm{H}$ (see figure 2.2). In total, I67 areas of the site received at least one form of excavation and this includes ${ }_{16}$ I specific architectural compounds in the $9.3-\mathrm{km}^{2}$ polygon (see the discussion of sampling strategy in chapter 3 and the tables in that chapter).

The map shows the location of every test pit and block excavation dug at Chunchucmil, not including $50-\mathrm{cm}$ by $50-\mathrm{cm}$ shovel tests. Such shovel tests were extensively deployed in five groups- $\mathrm{S}_{2} \mathrm{E}_{2}-\mathrm{K} / \mathrm{X}$ nokol (Op. $\left.9 \mathrm{~b} /{ }_{3} \mathrm{f}\right), \mathrm{S}_{2} \mathrm{E}_{\mathrm{I}}-\mathrm{G} / \mathrm{Kaab}$ (Op. 9d/3h), S2E2-F/Aak (Op. 9c/3g), S2E2-C/Muuch (Op. Io) and S4W8-F/ Balam (Op. 33) (Hutson et al. 2007; Magnoni 2008). Excavations are represented at their correct scale. Each excavation operation contains both the operation label (e.g., Op. II7) and the name of the structure group where the operation was located.

\section{SOURCES OF ERROR}

We are confident that we succeeded in finding most of the built features that have had the good fortune of being preserved as visible features on the current land surface. We are also confident that our maps accurately show where these features are located. We believe our map represents an improvement over the work at Dzibilchaltún, where albarradas were not recorded and where some spaces between large clusters within the $19-\mathrm{km}^{2}$ map were never surveyed (Kurjack 1974:80). We also believe our map compares favorably with Folan's maps of Cobá, where the maps from zones II, III, IV, and XIII do not show actual spatial relations between features (Folan 1983:8). Furthermore, recent work (Magnoni 2015) as well as comparisons between Folan's zone I map and Garduño Argueta's (1979) maps reveal inaccuracies with the zone I map. Nevertheless, several conditions generated sources of error at Chunchucmil. We begin by discussing vegetation. Folan (1983:7-8) has argued that 
the map of Cobá improves upon Puleston's (1983) survey work at Tikal because of better visibility at Cobá. At Chunchucmil, grazing animals, frequent wildfires, and mild vegetation (due to less soil, less rainfall, and more bedrock) made visibility even better. Low-scrub forests in some parts of the site occasionally made walking difficult, but maneuverability on such terrain is far easier than in the henequen fields that covered Dzibilchaltún when that site was mapped. Visibility was generally good enough that we did not systematically take notes on visibility conditions. Stark and Garraty (2008) distinguish topographic visibility (ability to detect minor changes in elevation) from surface visibility (ability to see the ground surface). In the $9.3-\mathrm{km}^{2}$ contiguous polygon, rare patches of knee- to waist-high grass impeded both topographic and surface visibility, probably causing us to miss surface features such as metates and topographic features such as low $(<0.2 \mathrm{~m})$ buildings. Patches of high, thick brush with poor topographic and surface visibility occurred on the transects, though these patches were rarely larger than a few thousand square meters.

Beyond vegetation, burial by sediment also causes mappers to miss ancient features (Johnston 2004). Fortunately, the absence of rivers and the extremely flat topography at Chunchucmil mean that natural alluviation and colluviation have had little or no effect. Natural sedimentation and soil-formation processes consist mostly of the weathering of bedrock and wind-blown deposition of volcanic ash and Saharan dust (Muhs et al. 2007; Perry et al. 2003), processes that rarely bury ancient features. Bioturbation can also bury features, but the extremely shallow biomantle depth around Chunchucmil (average $30 \mathrm{~cm}$ ) limits the degree to which stone buildings sink and soil rises. The main contributor to the burial of ancient features is later construction by the ancient Maya, and in this case, later structures are directly on top of earlier structures. Of the 800 plus test pits that were dug in areas that today appear to have had no mounds whatsoever, only one test pit recovered a buried structure. In this particular case (Operation 32/Group NiW 2-E), the buried structure was within $5 \mathrm{~m}$ of the edge of a later structure. Since the later structure was not excavated, we cannot tell precisely how the earlier structure was buried, but we suspect that it was intentionally buried by the later builders in order to create a flat space.

Though we feel that very few features were overlooked in our mapping efforts, we concede the effects of human error. About a dozen different people mapped features in the field. Though all people who contributed to the map were given ample training, double checking of work revealed mistakes of two different kinds. First, aspects of features were overlooked. For example, double-checking the work of a less-experienced mapper revealed that a split level platform in which one side is $25 \mathrm{~cm}$ higher than another was represented as having a single, constant height. Or, a low apsidal/oval structure was represented as being rectangular. The second 
kind of error involves dismissing small, somewhat ambiguous, artificial features as natural features or classifying natural features as artificial features. We believe such errors are few, however, because mappers who struggled were soon assigned to other tasks and much of their work was redone by people with more experience. Those who ended up doing most of the mapping were those who proved themselves to have an excellent eye in the field. Good mappers, however, are also fallible. Taylor (1974:39) has shown that different people mapping the same feature map it in slightly different ways simply because of small differences in how people see things on the ground. Furthermore, we have found that the same person might see something differently after many years. Both of the coauthors of this chapter, who have done more mapping than anyone at Chunchucmil, have had the experience of returning to an architectural group mapped years before and seeing in one's own early map a detail or two that ought to be fixed. Such experiences instigated another quality-control measure. As we got to know more and more of the site and had a better idea of what spatial patterns were normal and what patterns were abnormal, we double-checked some areas of the map that, even if mapped by experienced mappers, struck us as abnormal, suggesting that they may have been mapped incorrectly. Unfortunately, we were not able to double-check all such areas. An area with abnormal configurations of buildings that was not fully double-checked is at the south edge of the map, in a densely settled area in the south central portion of block 6 .

Human alterations to the landscape also mitigate the accuracy of our map. We refer to these disturbances in the following section.

\section{DISTURBANCES OF THE RUINS}

Luckily, the ruins of Chunchucmil have suffered rather little disturbance over time. The main sources of disturbance are prehispanic modifications to earlier prehispanic features, and twentieth-century activities. The former source of disturbance has been discussed above and in detail by Magnoni (2008; Magnoni et al. 2008). Modern disturbance consists of damage from several activities, listed from most destructive to least destructive: henequen harvesting, the construction of transportation features, ranching, and irrigation projects for citrus and papaya. Much of the land occupied by the ancient ruins was under henequen cultivation in the first half of the twentieth century. To move agave spears from the fields to the processing facilities at the core of the Chunchucmil hacienda, laborers built an impressive system of tracks for rail carts (marked as green parallel lines on the map). The rail tracks are common in blocks $0,1,2,6,7,8$, and 9, and are usually less than 2 $\mathrm{m}$ wide. Though they plow right through any structure that is less than $2 \mathrm{~m}$ high, 
they usually swerve to avoid taller structures. Transportation features consist of a paved road connecting the contemporary villages of Chunchucmil and Kochol and three unpaved roads originally built as rails but traversable today by automobiles. Both types of road are marked as blue parallel lines on the map. Long double parallel black lines on the map are ancient Maya roads: sacbes. The paved road (and an earlier, parallel, unpaved road immediately to the south) has destroyed all features along a roughly east/west swathe that measures anywhere from is to $30 \mathrm{~m}$ wide, cutting through blocks I, 4, 8, and 9. The three unpaved roads (running north/south in blocks I and 2, north/south in blocks I, 3, and 4, and east/west in blocks 6 and 7), each about $4 \mathrm{~m}$ wide, have damaged portions of buildings. Ranching has resulted in the salvaging of stones from archaeological features in order to construct long fences (marked as blue lines on the map) throughout the site and small features such as troughs and sheds. Irrigation projects have resulted in the construction of dozens of wells, most of which are south of the paved road. The wells are small (no more than $2 \mathrm{~m}$ in diameter) and are usually placed in areas without architecture.

\section{CONCLUSIONS}

Perhaps the most important conclusion drawn from the results of the map of Chunchucmil is the large number of buildings (over 10,000) found within a relatively small space (less than $10 \mathrm{~km}^{2}$ ). This finding suggests that the city had a large, dense population and poses the question of how so many people fed themselves. We cannot go further along this line of thought, however, until other pieces of the puzzle are in place. For example, we cannot estimate population until we know what portion of the city was occupied contemporaneously and where the site's high densities drop off. Therefore, subsequent chapters discuss the chronology of the site (chapter 4) and the shape of the city (chapter 5), with particular attention to thresholds in settlement density, which assist in delimiting the city's edges and estimating population. Furthermore, we cannot talk about a city's food supply until we understand the local environment and the crucial links between those who lived at Chunchucmil and those who lived in its hinterland. Thus, chapters 6 and 7 discuss the natural resources near Chunchucmil and chapter 8 discusses Chunchucmil's hinterland settlement.

\section{NOTES}

I. GPS points were collected with a Trimble 4700 receiver and differentially corrected with a secondary receiver, which provided coordinates with an accuracy of I $\mathrm{cm}$ horizontally. We thank UNAVCO for loaning us the equipment. 
2. See Magnoni and Hixson 2010 for a technical review of tools and technologies used for the recording, storage, processing, analysis, and visualization of the archaeological data of Chunchucmil.

3. The figure of $17.5 \mathrm{~km}^{2}$ was arrived at by georeferencing the Cobá survey zones for which mapping methods have been described (zones I, II, II, IV, XIII: see Folan I983: figure I.3). An additional area of at least $3.5 \mathrm{~km}^{2}$ has been surveyed, though the survey methods have not been described. 


\title{
Architectural Group Typology and Excavation Sampling within Chunchucmil
}

\author{
Scott R. Hutson, Aline Magnoni, And Bruce H. Dahlin
}

As the mapping described in the previous chapter progressed, excavations began. A basic goal of the excavations was to build the chronology of the site. Temporally diagnostic pottery is the cornerstone of the chronology, as we explain in the next chapter. Given that relatively few sherds are visible on the ground surface at Chunchucmil, surface collections were deployed only twice: in quads $\mathrm{N}_{4} \mathrm{E}_{2}$ and $\mathrm{N}_{3} \mathrm{E}_{2}$ of block 3 (Dahlin 1997) and in Group S2E2-F, located in block 4 (Hutson et al. 2007). Obviously we could not excavate every structure at Chunchucmil, so we needed a sampling strategy to determine where to excavate. We sought to design a strategy that would provide a systematic, representative sample of the site as a whole and, therefore, a firm foundation for the chronology. This chapter discusses the sampling strategies (opportunistic as well as stratified random) that guided the choice of where to excavate. Since we based the sampling strategy on the different kinds of architectural groups visible prior to excavation, this chapter also describes the kinds of architectural groups that are most common at Chunchucmil and how they compare to other architectural configurations in the Maya area.

\section{ARCHITECTURAL GROUP TYPES AT CHUNCHUCMIL}

During the first stage of excavation, from 1997 to 2000 , sampling was opportunistic: notable architectural groups (e.g., the ballcourt [Op. $\left.{ }_{3} \mathrm{~B}\right]$ and a megalithic platform in the site core [Op. $3 \mathrm{~A}]$ ) and natural resource features (e.g., an irregularly 
large sascabera $[\mathrm{Op} .4 \mathrm{~A}]$ and a drain in a residential context [Op. $5 \mathrm{~A}]$ ) received test pits. Based on the findings of the test pits or the requirements of particular research questions, some tested areas received block excavations in subsequent seasons.

By the year 2000 , enough of the site map had been completed to attempt a classification of architectural groups (see chapter 2 for the definition of a group). The goal was to create a classification that captured the variation visible on our map prior to excavation. We wanted to group like with like and separate different kinds of architectural groups into different types. Several other typologies of Maya architectural groups exist (Ashmore 1981; Becker 1991; Harrison 1981; Willey and Leventhal 1979), and in proposing our own typology we did not seek to reinvent the wheel. In fact, our typology shares aspects of these other typologies and we highlight these below. However, most of these typologies are based on what is found in specific regions or specific sites and they therefore do not travel well beyond the locale where they were generated. Predictably, the broadest typologies, such as that proposed by a group of Maya archaeologists at a 1977 seminar held at the School of American Research (SAR) in Santa Fe (Ashmore 198I), succeed in establishing some common terms of reference, such as informal group versus patio group, but, as we show below, these very general terms cannot be applied in a way that captures the diversity of the architecture at Chunchucmil. So we felt that it was necessary to create a typology that would allow us to grasp this variation. We stress that this typology applies to architectural groups within a site and is entirely different from the typology of sites provided in chapter 8 or in other publications (Adams and Jones 1981; Bullard 1960; Garza and Kurjack 1980; Hammond 1975)

We needed a typology not just as shorthand for referring to the variation in architectural groups at the site, but to guide the selection of groups to excavate. Put simply, we wanted to make sure that we excavated a decent sample of all of the different kinds of groups that we perceived while mapping. The variation that we perceived can be reduced to seven variables. First, some architectural groups had monumental architecture, some didn't. We defined monumental architecture as any building that stands $6 \mathrm{~m}$ or higher today. The second variable is the number of buildings in the architectural group: some groups have two or three buildings while others have a dozen or more. Occasionally we find a single, isolated building that does not form a group with other buildings. The third variable is the layout of buildings within a group. Most groups consist of structures arranged around one or more patios but some are broad platforms. The fourth variable is albarradas: most groups have them, some don't. Fifth is contiguity or lack of contiguity with other architectural groups, sixth is the presence or absence of a sascabera, and seventh is the number of metates. We understood that some of these distinctions, such as presence of albarradas, might in the end turn out to be meaningless. Imagine, for example, 
two architectural groups that are alike in every way except that one has an albarrada around it and the other doesn't. Excavations might reveal no systematic differences in artifact inventories between these two groups. Nevertheless, we would have had no way of knowing this before excavation. Plus, since albarradas are a common feature at the site, groups without them could perhaps be special in some way. Thus, we included this variable in our typology so that our sampling strategy would ensure that a good number of groups both with and without albarradas were excavated.

These seven major axes of variation overlapped in such a way that we initially created 16 types. As work progressed two types ( 7 and II) were eliminated. We created these two types to accommodate groups with many metates, but we soon found that there was no clear cutoff point between groups with many metates and groups with few. Also, one type was subdivided, yielding a total of is types. Table 3.I presents the types and a guide to illustrated examples throughout this book (see also figures 3.I and 3.2). Very briefly, the first five types consist of architectural groups with monumental architecture (mounds $6 \mathrm{~m}$ or more in height). Type 6 consists of broad platforms. Types 8, 9, IO, I2, I3, I4a, and I4b consist of houselots (domestic groups encircled by albarradas; see chapter 2) of different sizes and qualities. Types I5 and 16 consist of buildings not enclosed by albarradas. Table 3.2 presents exhaustive detail of the number of groups per type and per $\mathrm{I}-\mathrm{km}^{2}$ block. Table 3.2 also presents data on the number of groups per type and per $\mathrm{I}-\mathrm{km}^{2}$ block that received excavations. Table 3.3, which summarizes the data in table 3.2 by group type, shows that type 8 (houselots with five or fewer structures) had the most groups $(n=783)$, more than half of the total number of groups mapped.

\section{RESEMBLANCES BETWEEN CHUNCHUCMIL'S TYPES AND OTHER MAYA ARCHITECTURAL GROUPS}

Many of our types resemble types already known in the literature. At the same time, the large discrepancies between established typologies and what we see at Chunchucmil justify our decision to create our own typology. We now highlight these resemblances and discrepancies. The types presented by Ashmore (198I) are worth exploring as a benchmark because they result from a consensus of the Mayanists who attended the 1977 SAR seminar. Of the different SAR types, Chunchucmil's architectural groups most resemble the patio groups that are common in the southern Maya lowlands and consist of "several structures sharing a single central ambient space" (Ashmore $198 \mathrm{r}: 49$ ). Figures 3.2b, 5.7, and $\mathrm{I} 2.7$ show textbook examples of patio groups at Chunchucmil. Nearly all members of all types at Chunchucmil except types 4, 5, 6, and 16 are either patio groups or groups with multiple patios. This is remarkable because maps of architectural groups from other 
TABLE 3.I. Classification of architectural groups at Chunchucmil

\begin{tabular}{|c|c|}
\hline Type $\mathbf{I}(n=8)$ & $\begin{array}{l}\text { Simple quadrangle: Compounds with a tall pyramid (usually }>8 \mathrm{~m} \text { ) on one } \\
\text { side of a large patio; long, lower structures on each of the other three sides; a } \\
\text { central altar; and usually a connection to a sacbe (see figures } 3.1 \text { a and I } 2.5 \mathrm{~d} \text { ). }\end{array}$ \\
\hline Type $2(n=7)$ & $\begin{array}{l}\text { Extended quadrangle: same as type I but has more than one patio and more } \\
\text { structures (see figure } 5.2 \text { ). }\end{array}$ \\
\hline Type $3(n=28)$ & $\begin{array}{l}\text { Mini-quadrangle: like types I and } 2 \text { but with a lower pyramid }(5-8 \mathrm{~m}) \text { and } \\
\text { usually no sacbe or central altar (see figure } 3 . \mathrm{Id}) \text {. }\end{array}$ \\
\hline Type $4(n=2)$ & $\begin{array}{l}\text { Problematic monumental context: Large structure(s) that do not appear to } \\
\text { be associated with a residential unit. }\end{array}$ \\
\hline Type $5(n=6)$ & $\begin{array}{l}\text { Pyramid Group: Compound that has a large pyramid }(>5 \mathrm{~m}) \text { not associated } \\
\text { with the kind of patio seen in quadrangles (see figure } 3.2 \mathrm{a}) \text {. }\end{array}$ \\
\hline Type $6(n=24)$ & $\begin{array}{l}\text { Broad platform, usually over I } \mathrm{m} \text { high and over } 500 \mathrm{~m}^{2} \text {, not encircled by } \\
\text { albarradas. Often found to date to the Late/Terminal Classic periods (see } \\
\text { figure 3.Ib). }\end{array}$ \\
\hline Type $8(n=783)$ & $\begin{array}{l}\text { Small houselot/albarrada group: One to five structures surrounded by an } \\
\text { albarrada (figure } 2.4 \text { contains several examples; see also figures I } 2.6 \text {, and I 2.7.) }\end{array}$ \\
\hline Type $9(n=262)$ & $\begin{array}{l}\text { Medium houselot/albarrada group: Six to I o structures surrounded by an } \\
\text { albarrada (see group } \mathrm{S}_{2} \mathrm{E}_{\mathrm{I}}-\mathrm{N} \text { in figure } 2.4 \text {; see also figure } 5.4 \text { ). }\end{array}$ \\
\hline Type 10 $(n=47)$ & $\begin{array}{l}\text { Large houselot/albarrada group: More than io structures surrounded by an } \\
\text { albarrada (see figure 3.Ic). }\end{array}$ \\
\hline Type $\mathbf{2}(n=\mathrm{I} 26)$ & Sascabera group: any residential group with a sascabera (see figure $3.2 \mathrm{~b}$ ). \\
\hline Type $13(n=16)$ & $\begin{array}{l}\text { Isolated albarrada group: similar to } 8,9 \text {, and io except separated from the } \\
\text { nearest neighboring houselot by at least } 50 \mathrm{~m} \text { (see figure } 5.7 \text { ). }\end{array}$ \\
\hline Type $\mathbf{1 4 a}(n=\mathrm{I} 2)$ & $\begin{array}{l}\text { Small houselot cluster: a pair of contiguous houselots with albarradas but } \\
\text { separated from the nearest neighboring houselot by at least } 50 \mathrm{~m} \text { (see figure } \\
\text { 3.2c). }\end{array}$ \\
\hline Type I $\mathbf{4} \mathbf{b}(n=14)$ & $\begin{array}{l}\text { Larger houselot cluster: three or more contiguous houselots with albarradas } \\
\text { but separated from the nearest neighboring houselot by at least } 50 \mathrm{~m} \text {. }\end{array}$ \\
\hline Type $15(n=56)$ & $\begin{array}{l}\text { Non-albarrada groups: a cluster of two or more structures or platforms } \\
\text { without an albarrada (see figure } 3.2 \mathrm{~d} \text { ). }\end{array}$ \\
\hline Type $16(n=10)$ & $\begin{array}{l}\text { Isolated building: a single structure or platform (may be accompanied by } \\
\text { chich mounds) without an albarrada (see figure } 3.2 \mathrm{e} \text { ). }\end{array}$ \\
\hline
\end{tabular}

northern lowland sites that predate or overlap Chunchucmil in time show that the most common residential unit is a large platform that would have supported perishable superstructures (Mathews and Maldonado C. 2006; Ringle and Andrews 1988; Stuart et al. 1979). Residential units with non-perishable buildings that face a patio are the exception, whereas at Chunchucmil they are the rule. Our recent research in other parts of the northern lowlands such as the Izamal/Ucí/Aké area 


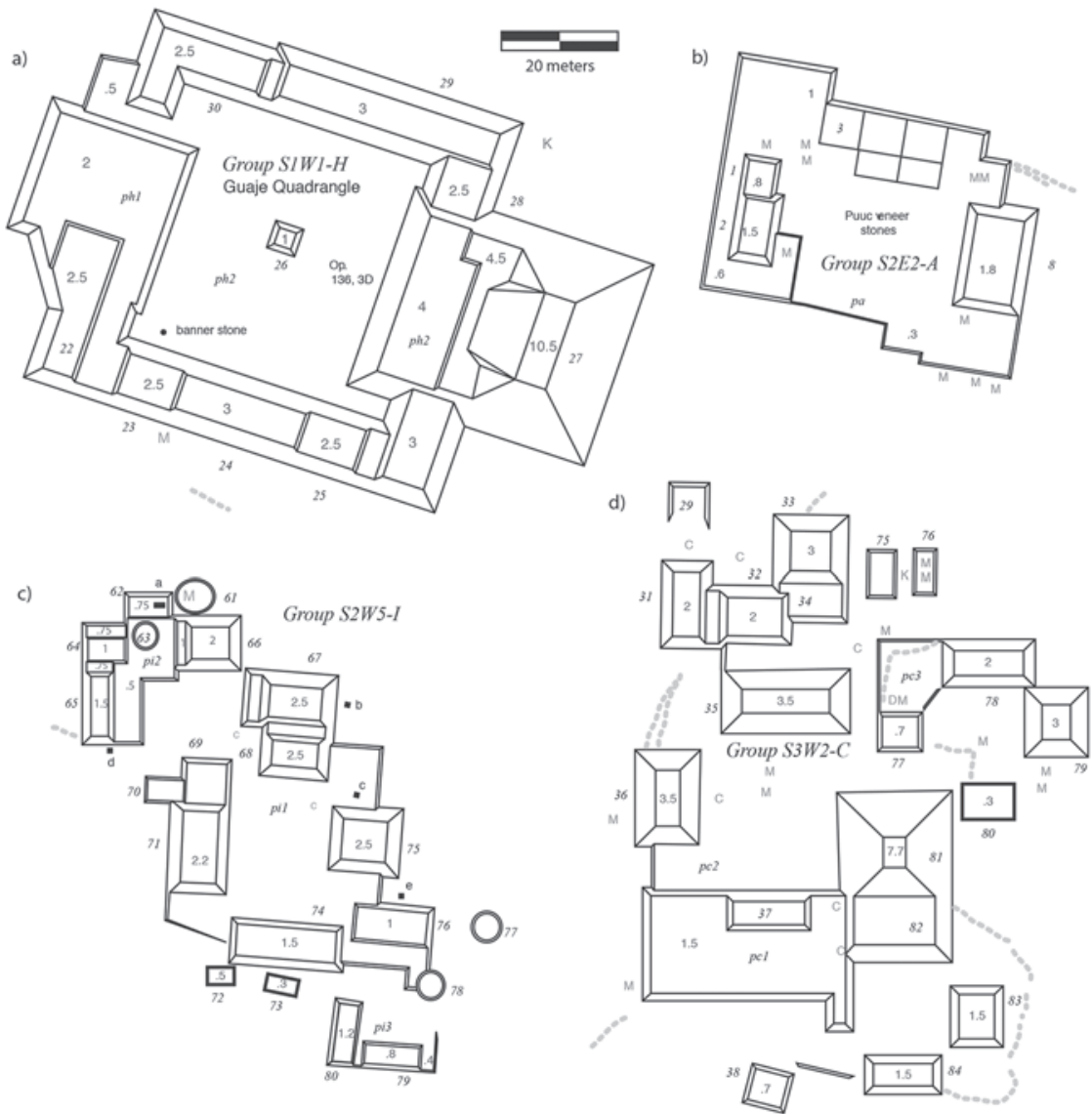

FIGURE 3.I Examples of group types at Chunchucmil: (a) type I (simple quadrangle); (b) type 6 (broad platform); (c) type 3 (mini-quadrangle); (d) type Io (large houselot/albarrada group).

(Hutson and Welch 2014), the Yaxuná/Yaxcabá area (Stanton and Magnoni 2014, 2015) and Cobá (Coronel et al. 2015; Magnoni 2015) constantly reminds us that Chunchucmil's (and Cobås) architectural groups look much more like those from the southern lowlands than they do those from the northern lowlands.

Despite the many patio groups at Chunchucmil, "patio group" does not work as a type for this site because there is so much variation within Chunchucmil's patio groups. Some have monumental temple pyramids, most don't. Some have sascaberas, some don't. Some of this variation likely implies different functions, as Ashmore noted (1981:50), a point to which we return shortly. There is also an issue with scale. 
a)
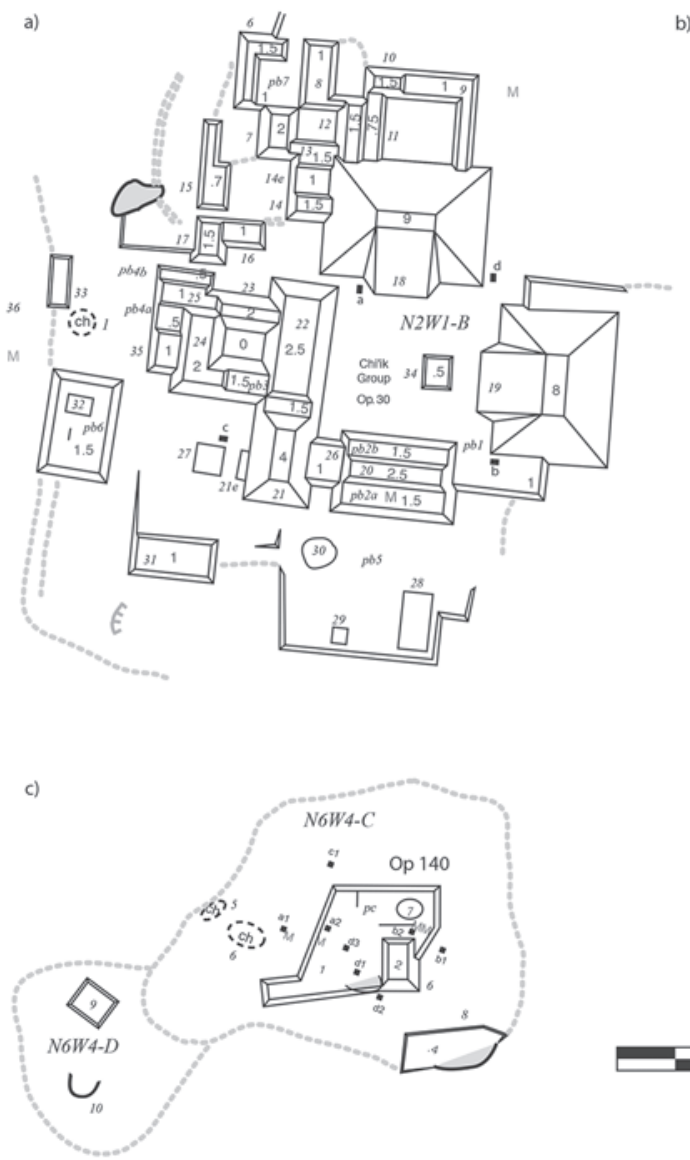

b)

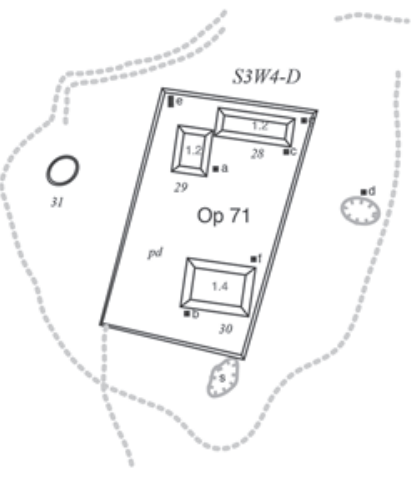

d)

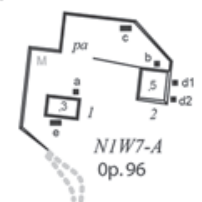

e)

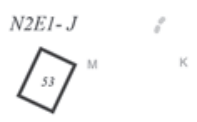

FIGURE 3.2 Examples of group types at Chunchucmil: (a) type 5 (pyramid group); (b) type I2 (sascabera group); (c) type I4a (houselot cluster); (d) type is (non-albarrada group); (e) type I6 (isolated building).

The patio group as defined by the 1977 seminar is one of three minimal residential units (MRUs). MRUs house a single nuclear family. In the 1977 typology, households with more than one family reside in clusters, a typological level above the MRU (Ashmore 198I). Yet while some patio groups at Chunchucmil housed single nuclear families, many housed extended family households (see chapter 5 for examples) and these are not clusters as defined in 1977 . Chunchucmil is not alone here, as many archaeologists after the 1977 seminar agreed that a single patio group can house extended family households (Haviland I988; Tourtellot 1988). To handle the 


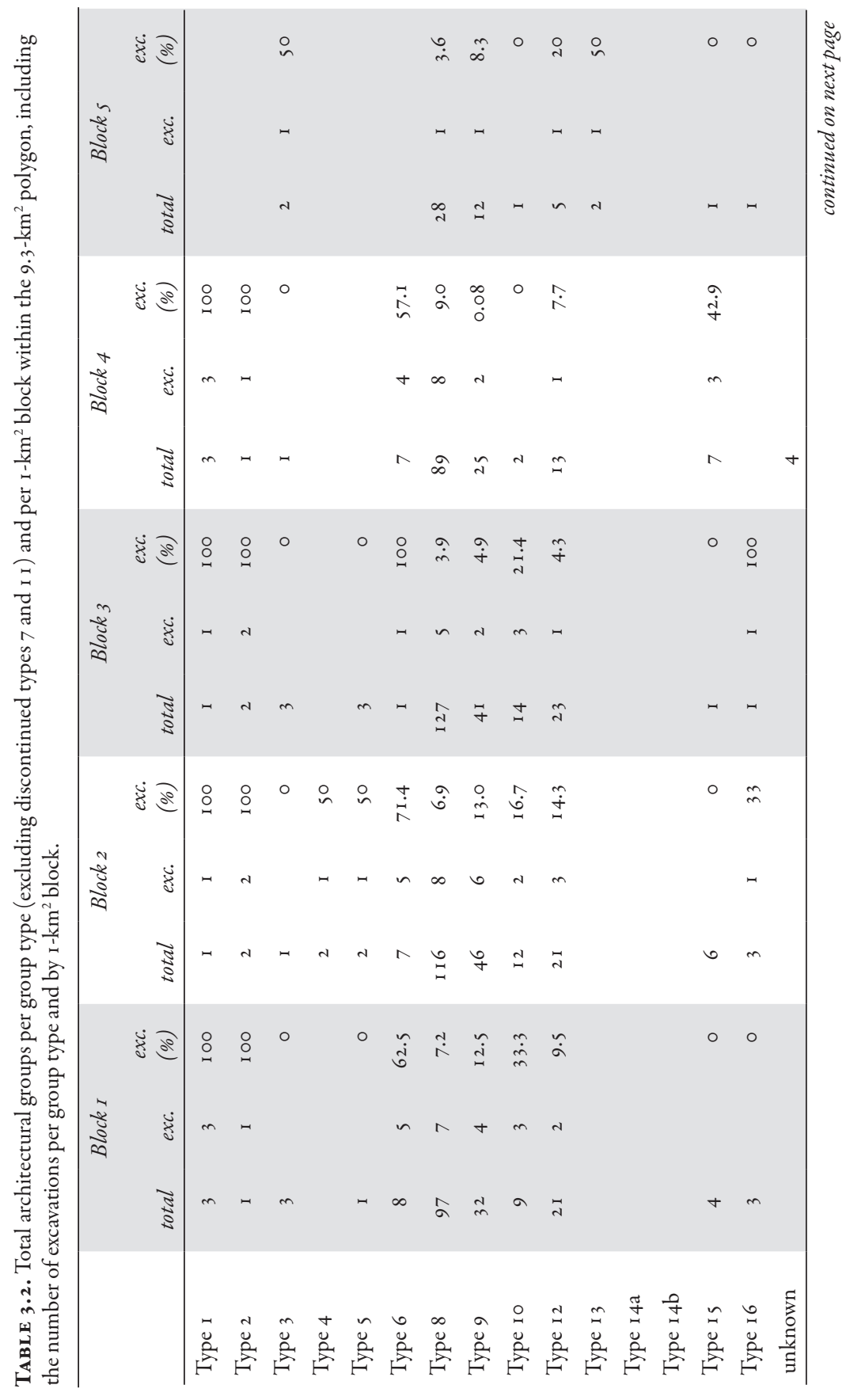




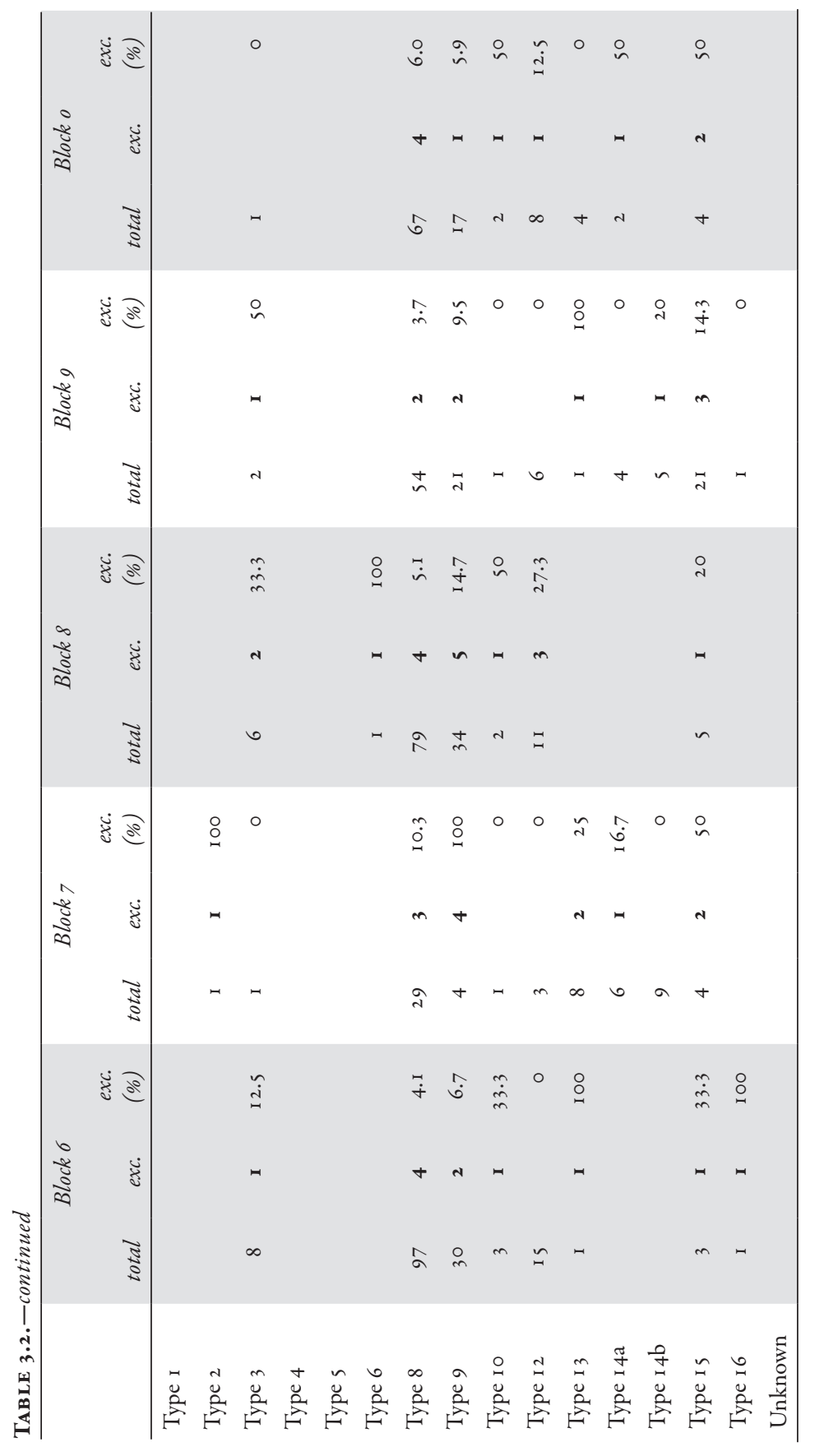


TABLE 3.3. Total architectural groups per group type within the $9 \cdot 3-\mathrm{km}^{2}$ polygon, showing percentage of groups excavated per group type.

\begin{tabular}{|c|c|c|c|}
\hline Group type & Groups per type (n) & $\begin{array}{l}\text { Groups excavated } \\
\text { pertype (n) }\end{array}$ & Groups excavated (\%) \\
\hline Type I & 8 & 8 & 100 \\
\hline Type 2 & 7 & 7 & 100 \\
\hline Type 3 & 28 & 5 & 17.9 \\
\hline Type 4 & 2 & I & 50 \\
\hline Type 5 & 6 & I & 16.7 \\
\hline Type 6 & 24 & 16 & 66.7 \\
\hline Type 8 & 783 & 47 & 6.0 \\
\hline Type 9 & 262 & 29 & II.I \\
\hline Type iо & 47 & I 2 & 25.5 \\
\hline Type I 2 & I 26 & I 2 & 9.5 \\
\hline Type 13 & 16 & 5 & 31.3 \\
\hline Type I 4a & I 2 & 2 & 16.7 \\
\hline Type $14 b$ & I 4 & I & 7.1 \\
\hline Type is & 56 & I 2 & 21.4 \\
\hline Type 16 & IO & 3 & 30 \\
\hline Unknown & 4 & $\circ$ & $\circ$ \\
\hline Total & 1,405 & 161 & 11.5 \\
\hline
\end{tabular}

issue of scale, we differentiate small (five or fewer structures) domestic groups from medium-sized ones (six to Io structures) from large ones (II or more structures).

The large domestic groups (Type Io; they all have albarradas) usually have more than one patio, thus inviting a comparison to the different types of clusters enumerated by the members of the 1977 seminar. Yet the concept of the cluster also does not apply well to Chunchucmil. A cluster is an assemblage of five to I2 residential groups, representing extended family households or aggregates of households, surrounded by open space (Bullard 1960). Chunchucmil has very few clusters that are surrounded by open space, so the typology of clusters proposed at the 1977 seminar doesn't fit. Also, the average houselot at Chunchucmil has fewer than four residences, as compared to the five to I2 residential groups (which could translate to an even higher number of residences) in a cluster. Furthermore, the clusters pictured by Ashmore (see figures 3.4, 3.5, 3.6 of her 198I chapter) consist of distinct patio groups. Though an individual architectural group at Chunchucmil may consist of 
multiple patios (see figures 3.Ic, 3.Id, 3.2a, and 5.2, this volume), such a group usually does not consist of distinct patio groups because the patios are linked (as in figures 3.Ic and 3.2a), or a single structure opens onto two patios (as in figure 5.2), or all the structures and patios share the same basal platform. The architectural group in figure 3.Id comes closest in appearance to the clusters illustrated by Ashmore (see the bottom of figure 3.6 in Ashmore 1981). At the same time, this particular architectural group at Chunchucmil is smaller than most clusters as Bullard (1960) defined them. Most architectural groups at Chunchucmil with more than one patio are smaller than the group in figure 3.Id. Much of Chunchucmil can indeed be assigned to large aggregates of households, but these consist of multiple architectural groups that share access to the same callejuela, not clusters surrounded by open space (Hutson 2016:102-108).

As Ashmore (1981:49) notes, the term patio connotes enclosure, yet many patio groups all over the Maya area are not enclosed on all sides and this is very often the case at Chunchucmil. Since the word plaza does not imply enclosure, Thompson's (1931) term plazuela group, referring to structures surrounding a small plaza, would fit most of Chunchucmil's architectural groups. For those groups that are relatively enclosed, Mayanists have used the term quadrangle. For example, Leventhal (1981:196) defines a quadrangle as "three to four large mounds at right angles around a court closed off at two or more corners." When the PREP team began mapping the site core in the late 1990 s, the largest architectural compounds did indeed conform to Leventhal's definition. Thus, we refer to these architectural groups as quadrangles (types I and 2 in table 3.I). In particular, the quadrangles at Chunchucmil have a large pyramid on one side of the court/ patio and therefore resemble a recurring type of quadrangle noted by Harrison (1981:277) in southern Quintana Roo. Closer to Chunchucmil there are versions of quadrangles with tall temples on one side at Puuc sites to the southeast such as Dzehkabtun (G. Andrews 1985), Muluchtzekel (the North Group; Pollock 1980), Yakal Chuc (G. Andrews 1985), Uxmal (the Cemetery Group; Pollock 1980), Chac (the Grand Plaza; Smyth and Ortegón Zapata 2006), and Kabah (the Structure 2Ai group; Pollock 1980).

As mapping progressed, we found that the quadrangles with the tallest pyramids have an altar in the center of the main court/patio and connect with a sacbe. In other words, the quadrangle is a rather specific form at Chunchucmil. Once mapping was complete, we noticed that five of the is architectural groups that we named quadrangles actually had central patios/courts with fewer than two enclosed corners. Yet we continue to refer to them as quadrangles because they share other basic components: tall pyramid on one side of a large patio with long, lower structures on each of the other three sides, a central altar, and a connection to a sacbe. 
Plaza Plan 2 (PP2; Becker 1991; 2003) is another architectural type defined elsewhere in the Maya area and present at Chunchucmil. PP2s consist of patio groups with a relatively square and tall structure on the east side. Beyond Chunchucmil these are also found at other sites in northern Yucatán, though often not referred to as PP2s (e.g., Kurjack and Garza Tarazona de González 1981). When excavated, the east structures usually contain burials and are often called shrines. This is indeed the case at Chunchucmil. Our excavations in such eastern mounds, which are often but not always higher than other structures in their respective group, show that these are shrines with burials (chapters 5 and I2, this volume; Hutson et al. 2004; Magnoni et al. 2012). In a sample of 392 houselots completely or nearly completely enclosed by an albarrada at Chunchucmil, I34 clearly have tall, approximately square buildings on the east side. However, we did not create a PP2 type, for several reasons. First, in II 8 of those 392 houselots, we were not certain whether the layout conformed to a PP2. For example, a group might have a taller structure on the east side, but that structure might be far from square. Second, the architectural groups with the largest eastern structures (which we call quadrangles at Chunchucmil) also have central altars, which would qualify them as Plaza Plan 4 from Becker's typology. Though $\mathrm{I} 2$ of the quadrangles have a tall and square structure on the east, three have them on other sides of the patio. Finally, questions of scale and function complicate the usage of $\mathrm{PP}_{2}$ as a type at Chunchucmil. If we were to classify quadrangles that have pyramids on their east sides into the same group type as non-monumental houselots that nevertheless have probable shrines on their east sides, we would be conflating two very different entities. The size of quadrangles made them ideal for rites and ceremonies attended by hundreds of people. The range structures on the sides of the main patios in quadrangles and, for type 2 quadrangles, the additional structures found in auxiliary patios may have served as storage spaces. Like smaller houselots, quadrangles may have been residences with burials in the east shrine, but their ability to host crowds and store large quantities of goods suggest that quadrangles were headquarters for large political factions and/or commercial enterprises (see chapters 5, I2, and 13). For all of these reasons we did not lump all architectural groups with potential eastern shrines into a single $\mathrm{PP}_{2}$ type.

The presence of PP2s at architectural groups of various sizes does highlight an important issue. Though there are qualitative and functional differences between quadrangles and other groups at Chunchucmil, many architectural groups with large eastern structures may be only quantitatively different from smaller architectural groups with smaller eastern structures. For example, compared to a type I or 2 group, a type 3 group is qualitatively (it lacks either an altar or a sacbe connection) and quantitatively (its pyramid is usually smaller) different, but the difference between type 3 groups and houselots (groups in types 8-14) might be merely 
quantitative. The pyramid in a type 3 group is only a few meters taller than some of the pyramids in the largest houselots. In fact, there is formal continuity in the basic arrangement of structures from small houselots (type 8) to medium houselots (type 9) to large houselots (type io) to type 3 monumental groups, (see also Hendon 2002; Lucero 2003). Nevertheless, we follow the logic of Willey and Leventhal's (1979) typology for Copán by splitting groups of different size into different types. The logic here is that groups with more and larger buildings likely housed groups with more people and greater access to labor and other resources.

Typologies such as that from Copán, which sort according to size, have been criticized for not looking, for example, at formal variation (Maca 2002; Pyburn 1989). However, we stress that our own typology does emphasize form: it separates quadrangles from other monumental groups, it separates broad platforms from houselots, and it separates groups with albarradas from groups without. We also stress that our typology is heuristic, not final, in that our database of groups gives us the flexibility to reconfigure the types depending on the particular research question. For example, houselots with sascaberas fall into type 12 regardless of the number of structures in the houselot. In other words, our typology would lump a large houselot with I4 structures (normally a type io) together with a small houselot with two structures (normally a type 8 ) if both houselots have a sascabera. The typology is therefore set by default to isolate architectural groups with sascaberas. This is helpful for research questions that focus on local economic resources, such as sascaberas. A research question that requires all houselots to be accurately sorted into size categories, regardless of the presence of a sascabera, would require resorting type 12 groups into other types. Fortunately, this can be done easily in the database, and we do precisely this for the analysis of the distribution of obsidian in chapter II. Thus, other archaeologists with other goals could easily create a different yet equally valid typology.

\section{EXCAVATION SAMPLING STRATEGY AND COVERAGE}

The classification of groups into types represented a critical step forward in our chronological work because it enabled us to shift from an opportunistic to a representative sampling strategy for selecting groups to excavate. In other words, once we got a handle on the variability in architectural groups, we could design a sampling strategy that systematically tested each of the different kinds of groups. Using our typology, we deployed a stratified random sampling strategy as an attempt to acquire an excavation sample that would produce representative results for the site as a whole. The architectural groups were stratified with respect to location (using the $\mathrm{I}-\mathrm{km}^{2}$ blocks described in chapter 2) and group type. For example, all of the 


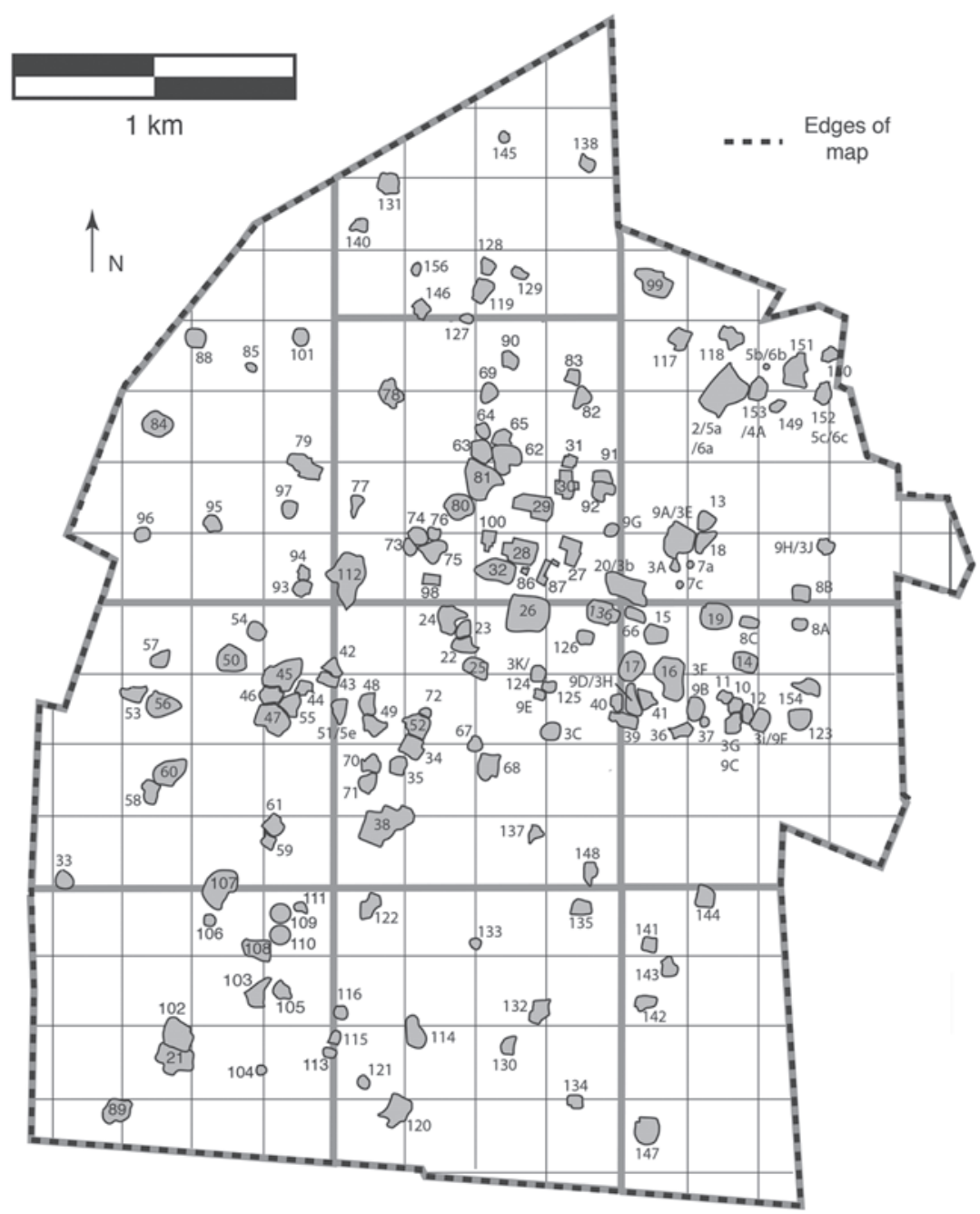

FIGURE 3.3. Map showing all the excavation operations within the $9 \cdot 3-\mathrm{km}^{2}$ map of Chunchucmil.

architectural groups from a specific group type located in a specific $\mathrm{I}-\mathrm{km}^{2}$ block were given numbers and a sample of these numbers was randomly drawn from a hat.

By the end of the project, excavations had been completed in 167 contexts (figure 3.3). These include $\mathrm{I} 6 \mathrm{I}$ of the $\mathrm{I}, 405$ architectural groups within the $9.3-\mathrm{km}^{2}$ polygon (an $11.5 \%$ sample), five of the 72 groups found on the transects (Ops. 139, 156, 157, 
TABLE 3.4. Total architectural groups per $\mathrm{I}-\mathrm{km}^{2}$ block within the $9.3-\mathrm{km}^{2}$ polygon, showing percentage of groups excavated per $\mathrm{I}-\mathrm{km}^{2}$ block.

\begin{tabular}{|c|c|c|c|}
\hline Block \# & Groups per block (n) & $\begin{array}{c}\text { Groups excavated per block } \\
\text { (n) }\end{array}$ & Groups excavated (\%) \\
\hline I & 182 & 25 & 13.7 \\
\hline 2 & 219 & 30 & 13.7 \\
\hline 3 & 217 & I 8 & 8.3 \\
\hline 4 & 152 & 22 & 14.5 \\
\hline 5 & 52 & 5 & 9.6 \\
\hline 6 & 158 & I I & 7 \\
\hline 7 & 66 & 13 & 19.7 \\
\hline 8 & 138 & 17 & 12.3 \\
\hline 9 & II 6 & IO & 8.6 \\
\hline ० & 105 & IO & 9.5 \\
\hline Total & 1,405 & 161 & 11.5 \\
\hline
\end{tabular}

I58, and 159), and one of the 20 sacbes (Op. 7, Sacbe I; see figure 2.5). About 40 groups were chosen opportunistically before or during the implementation of the stratified random sampling strategy. Table 3.2 shows the number of excavations by group type and by $\mathrm{I}-\mathrm{km}^{2}$ block. Table 3.3 summarizes the data in table 3.2 by group type, showing percentage of groups in each group type that received excavation. Table 3.4 summarizes the data in table 3.2 by $\mathrm{I}-\mathrm{km}^{2}$ block, showing the percentage of groups in each block that received excavation. Each excavated group received an operation number; table 3.5 expands on table 3.2 by presenting the operation numbers for each excavation, organized by group type and $\mathrm{I}-\mathrm{km}^{2}$ block, including the five groups excavated on the transects. Table 3.6 matches group labels (as discussed in chapter 2) with operation numbers for each of the 167 operations while also giving the surface area of excavation per operation and nicknames for operations. The exact placement of excavations, shown to scale, within each architectural group (and, of course, the plan of each group) can be found on the site map (see chapter 2).

In theory, the stratified random sampling strategy would ensure that some examples of every group type in every $\mathrm{I}-\mathrm{km}^{2}$ block of the site would be excavated. Tables 3.3 and 3.4 show the robustness of the sample: we excavated groups from every type and groups in every $\mathrm{I}-\mathrm{km}^{2}$ block. At the same time, table 3.2 shows that some particular group types in a particular $\mathrm{I}-\mathrm{km}^{2}$ block did not receive excavations. In some cases this was due to limited resources. In the case of houselots (types 8 through I4), this is usually due to our tendency to exclude from the sampling universe groups 


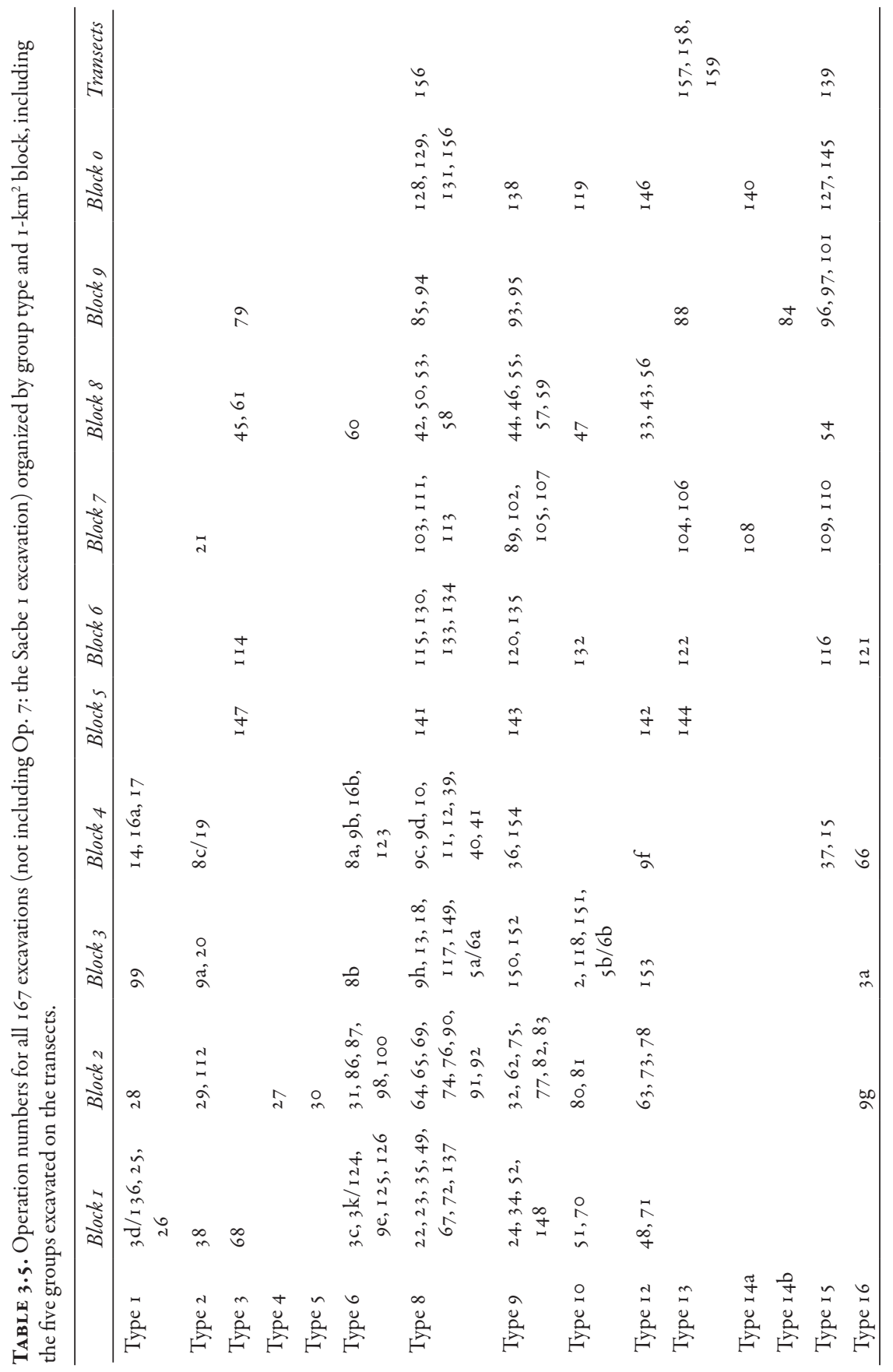


TABLE 3.6. Group labels for each operation number.

\begin{tabular}{|c|c|c|c|c|c|c|}
\hline \multicolumn{3}{|c|}{ Group label } & \multirow{2}{*}{$\begin{array}{r}\text { Op.number } \\
2\end{array}$} & \multirow{2}{*}{$\begin{array}{l}\text { Type } \\
\text { Iо }\end{array}$} & \multirow{2}{*}{$\frac{\text { Digarea }\left(m^{2}\right)}{6}$} & \multirow[t]{2}{*}{ Nickname } \\
\hline $\mathrm{N}_{3}$ & $\mathrm{E}_{2}$ & A & & & & \\
\hline $\mathrm{N}_{I}$ & $\mathrm{E}_{\mathrm{I}}$ & $\mathrm{H}$ & $3 \mathrm{~A}$ & 16 & 2 & \\
\hline$S_{2}$ & $\mathrm{~W}_{\mathrm{I}}$ & $\mathrm{N}$ & ${ }_{3} \mathrm{C}$ & 6 & 2 & \\
\hline $\mathrm{N}_{4}$ & $\mathrm{E}_{2}$ & G & $5 \mathrm{~A} / 6 \mathrm{~A}$ & 8 & 2 & \\
\hline $\mathrm{N}_{4}$ & $\mathrm{E}_{3}$ & M & ${ }_{5} \mathrm{~B} / 6 \mathrm{~B}$ & Io & 2 & \\
\hline Sacbe I & & & 7 & Sacbe I & 6 & \\
\hline$S_{\text {I }}$ & $\mathrm{E}_{3}$ & B & $8 \mathrm{~A}$ & 6 & 2 & \\
\hline $\mathrm{N}_{\mathrm{I}}$ & $\mathrm{E}_{3}$ & $\mathrm{~N}$ & $8 \mathrm{~B}$ & 6 & 2 & \\
\hline $\mathrm{N}_{\mathrm{I}}$ & $\mathrm{E}_{\mathrm{I}}$ & $\mathrm{C}$ & ${ }_{9} \mathrm{~A} /{ }_{3} \mathrm{E}$ & 2 & 410 & Pich \\
\hline$S_{2}$ & $\mathrm{E}_{2}$ & $\mathrm{~K}$ & ${ }_{9} \mathrm{~B} /{ }_{3} \mathrm{~F}$ & 6 & 16 & Xnokol \\
\hline$S_{2}$ & $\mathrm{E}_{2}$ & $\mathrm{~F}$ & ${ }_{9} \mathrm{C} /{ }_{3} \mathrm{G}$ & 8 & 369 & $\mathrm{Ak}$ \\
\hline$S_{2}$ & $\mathrm{E}_{\mathrm{I}}$ & G & ${ }_{9} \mathrm{D} /{ }_{3} \mathrm{H}$ & 9 & 332 & Kaab \\
\hline$S_{2}$ & $\mathrm{~W}_{2}$ & A & ${ }_{9} \mathrm{E}$ & 6 & 4 & \\
\hline$S_{2}$ & $\mathrm{E}_{3}$ & $\mathrm{~L}$ & ${ }_{9} \mathrm{~F} / 3 \mathrm{I}$ & I 2 & 70 & Chiwool \\
\hline $\mathrm{N}_{2}$ & $\mathrm{~W}_{\mathrm{I}}$ & $\mathrm{F}$ & ${ }_{9} \mathrm{G}$ & 16 & 4 & \\
\hline $\mathrm{N}_{\mathrm{I}}$ & $\mathrm{E}_{3}$ & $\mathrm{E}$ & ${ }_{9} \mathrm{H} / 3 \mathrm{~J}$ & 8 & I 2 & Kuutz \\
\hline$S_{2}$ & $\mathrm{E}_{2}$ & $\mathrm{C}$ & IO & 8 & 249 & Muuch \\
\hline$S_{2}$ & $\mathrm{E}_{2}$ & B & II & 8 & 8 & \\
\hline$S_{2}$ & $\mathrm{E}_{2}$ & $\mathrm{E}$ & I 2 & 8 & 8 & Gredo \\
\hline $\mathrm{N}_{2}$ & $\mathrm{E}_{2}$ & $\mathrm{~N}$ & I 3 & 8 & 307 & Lool \\
\hline$S_{\text {I }}$ & $\mathrm{E}_{2}$ & C & I 4 & I & 8 & Chukum \\
\hline$S_{I}$ & $\mathrm{E}_{\mathrm{I}}$ & $\mathrm{H}$ & 15 & 15 & 382 & Marketplace \\
\hline$S_{\text {I }}$ & $\mathrm{E}_{\mathrm{I}}$ & G & I $6 \mathrm{~A}, \mathrm{E}, \mathrm{F}, \mathrm{G}$ & I & I 2 & Picholte \\
\hline$S_{2}$ & $E_{I}$ & $\mathrm{D}$ & $16 \mathrm{~B}, \mathrm{C}$ & 9 & 4 & \\
\hline$S_{\text {I }}$ & $E_{I}$ & $\mathrm{~F}$ & 17 & I & I 4 & Copo \\
\hline $\mathrm{N}_{I}$ & $\mathrm{E}_{2}$ & $\mathrm{~F}$ & I 8 & 8 & 4 & \\
\hline$S_{\text {I }}$ & $\mathrm{E}_{2}$ & B & 19 & 2 & 8 & Pomoche \\
\hline $\mathrm{NI}_{\mathrm{I}}$ & $E_{I}$ & G & $20 / 3 \mathrm{~B}$ & 2 & I 4 & Chakah \\
\hline$S_{7}$ & $\mathrm{~W}_{7}$ & $\mathrm{~b}$ & $2 I$ & I & 8 & Ceiba \\
\hline$S_{\text {I }}$ & $\mathrm{W}_{3}$ & $\mathrm{E}$ & 22 & 8 & 4 & Ulum \\
\hline$S_{I}$ & $\mathrm{~W}_{3}$ & $\mathrm{D}$ & 23 & 8 & 8 & Sina'n \\
\hline$S_{\text {I }}$ & $\mathrm{W}_{3}$ & $\mathrm{C}$ & 24 & 9 & 4 & K'ek'en \\
\hline
\end{tabular}


TABLE 3.6.- continued

\begin{tabular}{|c|c|c|c|c|c|c|}
\hline \multicolumn{3}{|c|}{ Group label } & \multirow{2}{*}{$\frac{\text { Op.number }}{25}$} & \multirow{2}{*}{$\frac{\text { Type }}{\mathrm{I}}$} & \multirow{2}{*}{$\frac{\text { Digarea }\left(m^{2}\right)}{8}$} & \multirow{2}{*}{$\begin{array}{l}\text { Nickname } \\
\text { Kalkaltun }\end{array}$} \\
\hline$S_{I}$ & $\mathrm{~W}_{3}$ & $\mathrm{~K}$ & & & & \\
\hline$S_{\text {I }}$ & $\mathrm{W}_{2}$ & $\mathrm{C}$ & 26 & I & 8 & Chi'may \\
\hline $\mathrm{N}_{\mathrm{I}}$ & $\mathrm{W}_{\mathrm{I}}$ & A & 27 & 4 & 6 & Yaxkach \\
\hline $\mathrm{N}_{\mathrm{I}}$ & $\mathrm{W}_{2}$ & $\mathrm{C}$ & 28 & I & I 2 & Xpim \\
\hline $\mathrm{N}_{2}$ & $\mathrm{~W}_{2}$ & $\mathrm{~J}$ & 29 & 2 & IO & Kats' in \\
\hline $\mathrm{N}_{2}$ & $\mathrm{~W}_{\mathrm{I}}$ & B & 30 & 5 & IO & Ch'ik \\
\hline $\mathrm{N}_{3}$ & $\mathrm{~W}_{\mathrm{I}}$ & $\mathrm{O}$ & $3 \mathrm{I}$ & 6 & 8 & Pak \\
\hline $\mathrm{N}_{\mathrm{I}}$ & $\mathrm{W}_{2}$ & E & 32 & 9 & 8 & Choc'bih \\
\hline $\mathrm{S}_{4}$ & W8 & $\mathrm{F}$ & 33 & I 2 & 26 & Balam \\
\hline $\mathrm{S}_{3}$ & $\mathrm{~W}_{3}$ & A & 34 & 9 & IO & Keh \\
\hline $\mathrm{S}_{3}$ & $\mathrm{~W}_{4}$ & C & 35 & 8 & 6 & Xtabai \\
\hline $\mathrm{S}_{2}$ & $\mathrm{E}_{I}$ & $\mathrm{~L}$ & 36 & 9 & 2 & Holon \\
\hline$S_{2}$ & $\mathrm{E}_{2}$ & $\mathrm{~J}$ & 37 & 15 & 2 & Chimes \\
\hline$S_{4}$ & $\mathrm{~W}_{4}$ & A & 38 & 2 & IO & Subin \\
\hline $\mathrm{S}_{2}$ & $\mathrm{E}_{\mathrm{I}}$ & I & 39 & 8 & 2 & $\mathrm{Am}$ \\
\hline$S_{2}$ & $\mathrm{E}_{I}$ & $\mathrm{H}$ & 40 & 8 & 7.5 & Sinik \\
\hline $\mathrm{S}_{2}$ & EI & $\mathrm{E}$ & $4 \mathrm{I}$ & 8 & 7.5 & Koxol \\
\hline$S_{I}$ & $\mathrm{~W}_{4}$ & M & 42 & 8 & 5 & \\
\hline $\mathrm{S}_{2}$ & $W_{5}$ & $\mathrm{D}$ & 43 & I 2 & 4 & \\
\hline $\mathrm{S}_{2}$ & $\mathrm{~W}_{5}$ & $\mathrm{C}$ & 44 & 9 & 2 & \\
\hline$S_{2}$ & $\mathrm{~W}_{5}$ & A & 45 & 3 & 9 & \\
\hline $\mathrm{S}_{2}$ & $\mathrm{~W}_{5}$ & B & 46 & 9 & 6 & \\
\hline$S_{2}$ & $\mathrm{~W}_{5}$ & I & 47 & IO & 6.5 & \\
\hline$S_{2}$ & $\mathrm{~W}_{4}$ & B & 48 & I 2 & 9 & \\
\hline$S_{2}$ & $\mathrm{~W}_{4}$ & I & 49 & 8 & 6 & \\
\hline$S_{\text {I }}$ & $\mathrm{W}_{7}$ & $\mathrm{D}$ & 50 & 8 & 6 & \\
\hline$S_{2}$ & $\mathrm{~W}_{4}$ & $\mathrm{H}$ & $5 \mathrm{I}$ & IO & 8 & \\
\hline$S_{2}$ & $\mathrm{~W}_{3}$ & $\mathrm{~J}$ & 52 & 9 & 7 & \\
\hline $\mathrm{S}_{2}$ & $\mathrm{~W}_{7}$ & C & 53 & 8 & IO & \\
\hline$S_{\text {I }}$ & W6 & B & 54 & 15 & 5 & \\
\hline$S_{2}$ & $W_{5}$ & $\mathrm{H}$ & 55 & 9 & 9 & \\
\hline$S_{2}$ & $\mathrm{~W}_{7}$ & G & 56 & I 2 & 10 & \\
\hline
\end{tabular}


TABLE 3.6.- continued

\begin{tabular}{|c|c|c|c|c|c|c|}
\hline \multicolumn{3}{|c|}{ Group label } & Op.number & Type & Digarea $\left(m^{2}\right)$ & Nickname \\
\hline$S_{\text {I }}$ & $\mathrm{W}_{7}$ & $\mathrm{~F}$ & 57 & 9 & 4 & \\
\hline$S_{3}$ & $\mathrm{~W}_{7}$ & $\mathrm{E}$ & 58 & 8 & 9 & \\
\hline $\mathrm{S}_{4}$ & $W_{5}$ & B & 59 & 9 & 7 & \\
\hline $\mathrm{S}_{3}$ & $\mathrm{~W}_{7}$ & $\mathrm{D}$ & 60 & 6 & Is & \\
\hline $\mathrm{S}_{4}$ & $W_{5}$ & A & 61 & 3 & Io & \\
\hline $\mathrm{N}_{3}$ & $\mathrm{~W}_{2}$ & $\mathrm{O}$ & 62 & 9 & 9 & \\
\hline $\mathrm{N}_{3}$ & $\mathrm{~W}_{2}$ & $\mathrm{P}$ & 63 & I 2 & 6 & \\
\hline $\mathrm{N}_{3}$ & $\mathrm{~W}_{2}$ & K & 64 & 8 & 8 & \\
\hline $\mathrm{N}_{3}$ & $W_{2}$ & $\mathrm{~L}$ & 65 & 8 & 7 & \\
\hline$S_{\text {I }}$ & $\mathrm{E}_{\text {I }}$ & A & 66 & I5 & 4 & \\
\hline $\mathrm{S}_{2}$ & $\mathrm{~W}_{2}$ & K & 67 & 8 & 6 & \\
\hline$S_{3}$ & $\mathrm{~W}_{2}$ & A & 68 & 3 & 3.6 & \\
\hline $\mathrm{N}_{3}$ & $\mathrm{~W}_{2}$ & A & 69 & 8 & 9 & \\
\hline $\mathrm{S}_{3}$ & $\mathrm{~W}_{4}$ & B & 70 & IO & 7 & \\
\hline $\mathrm{S}_{3}$ & $\mathrm{~W}_{4}$ & $\mathrm{D}$ & 71 & I 2 & 8 & \\
\hline$S_{2}$ & $\mathrm{~W}_{3}$ & I & 72 & 8 & 7 & \\
\hline $\mathrm{N}_{\mathrm{I}}$ & $\mathrm{W}_{3}$ & B & 73 & I 2 & 7 & \\
\hline $\mathrm{N}_{\mathrm{I}}$ & $\mathrm{W}_{3}$ & A & 74 & 8 & 6 & \\
\hline $\mathrm{N}_{\mathrm{I}}$ & $\mathrm{W}_{3}$ & $\mathrm{D}$ & 75 & 9 & 2 & \\
\hline $\mathrm{N}_{\mathrm{I}}$ & $\mathrm{W}_{3}$ & $\mathrm{C}$ & 76 & 8 & 5 & \\
\hline $\mathrm{N}_{2}$ & $\mathrm{~W}_{4}$ & $\mathrm{~J}$ & 77 & 9 & 4 & \\
\hline $\mathrm{N}_{3}$ & $\mathrm{~W}_{4}$ & C & 78 & I 2 & 6 & \\
\hline $\mathrm{N}_{2}$ & $W_{5}$ & A & 79 & 3 & 7 & \\
\hline $\mathrm{N}_{2}$ & $\mathrm{~W}_{3}$ & I & 80 & IO & 8 & \\
\hline $\mathrm{N}_{2}$ & $\mathrm{~W}_{2}$ & A & $8 \mathrm{I}$ & IO & 6 & \\
\hline $\mathrm{N}_{3}$ & $W_{I}$ & B & 82 & 9 & 4 & \\
\hline $\mathrm{N}_{4}$ & $W_{I}$ & $\mathrm{O}$ & 83 & 9 & 8 & \\
\hline $\mathrm{N}_{3}$ & $\mathrm{~W}_{7}$ & A & 84 & $\mathrm{I} 4 \mathrm{~b}$ & 8 & \\
\hline $\mathrm{N}_{4}$ & W6 & B & 85 & 8 & 6 & \\
\hline $\mathrm{N}_{\mathrm{I}}$ & $\mathrm{W}_{2}$ & $\mathrm{D}$ & 86 & 6 & 4 & \\
\hline $\mathrm{N}_{\mathrm{I}}$ & $W_{I}$ & E & 87 & 6 & 6 & \\
\hline $\mathrm{N}_{4}$ & W6 & A & 88 & I 3 & 9 & \\
\hline
\end{tabular}


TABLE 3.6.- continued

\begin{tabular}{|c|c|c|c|c|c|c|}
\hline \multicolumn{3}{|c|}{ Group label } & \multirow{2}{*}{$\frac{\text { Op. number }}{89}$} & \multirow{2}{*}{$\begin{array}{c}\text { Type } \\
9\end{array}$} & \multirow{2}{*}{$\frac{\text { Digarea }\left(m^{2}\right)}{\text { Io }}$} & \multirow[t]{2}{*}{ Nickname } \\
\hline S8 & W8 & A & & & & \\
\hline $\mathrm{N}_{4}$ & $\mathrm{~W}_{2}$ & M & 90 & 8 & 8 & \\
\hline $\mathrm{N}_{2}$ & $W_{I}$ & $\mathrm{D}$ & $9 \mathrm{I}$ & 8 & 6 & \\
\hline $\mathrm{N}_{2}$ & $\mathrm{~W}_{\mathrm{I}}$ & E & 92 & 8 & 5 & \\
\hline $\mathrm{NI}_{\mathrm{I}}$ & $W_{5}$ & F & 93 & 9 & I I & \\
\hline $\mathrm{N}_{\mathrm{I}}$ & $W_{5}$ & $\mathrm{D}$ & 94 & 8 & 8 & \\
\hline $\mathrm{N}_{2}$ & W6 & $\mathrm{C}$ & 95 & 9 & 7 & \\
\hline $\mathrm{N}_{\mathrm{I}}$ & $\mathrm{W}_{7}$ & A & 96 & I5 & 8 & \\
\hline $\mathrm{N}_{2}$ & $W_{5}$ & I & 97 & 15 & 8 & \\
\hline $\mathrm{N}_{\mathrm{I}}$ & $\mathrm{W}_{3}$ & $\mathrm{~K}$ & 98 & 6 & 6 & \\
\hline $\mathrm{N}_{5}$ & $\mathrm{E}_{\mathrm{I}}$ & F & 99 & I & I I & \\
\hline $\mathrm{N}_{\mathrm{I}}$ & $W_{2}$ & A & 100 & 6 & 5 & \\
\hline $\mathrm{N}_{4}$ & $W_{5}$ & F & IOI & Is & Io & \\
\hline$S_{7}$ & $W_{7}$ & a & 102 & 9 & 8 & \\
\hline S6 & W6 & $\mathrm{C}$ & 103 & 8 & 8 & \\
\hline$S_{7}$ & W6 & b & 104 & 13 & 8 & \\
\hline S6 & $W_{5}$ & b & 105 & 9 & 8 & \\
\hline$S_{5}$ & W6 & b & 106 & 13 & 8 & \\
\hline $\mathrm{S}_{5}$ & W6 & $\mathrm{g}$ & 107 & 9 & 8 & \\
\hline$S_{5}$ & W6 & $c, d$ & 108 & I $4 \mathrm{a}$ & 8 & \\
\hline$S_{5}$ & $W_{5}$ & $\mathrm{C}$ & 109 & 15 & 8 & \\
\hline $\mathrm{S}_{5}$ & $W_{5}$ & A & I IO & 15 & 8 & \\
\hline $\mathrm{S}_{5}$ & $W_{5}$ & F & I I I & 8 & 8 & \\
\hline $\mathrm{N}_{\mathrm{I}}$ & $\mathrm{W}_{4}$ & $\mathrm{D}$ & I I 2 & 2 & 9 & \\
\hline$S_{7}$ & $W_{5}$ & A & 113 & 6 & 8 & \\
\hline$S_{7}$ & $W_{3}$ & A & I I 4 & 3 & 8 & \\
\hline$S_{7}$ & $\mathrm{~W}_{3}$ & G & IIS & 8 & 8 & \\
\hline S6 & $\mathrm{W}_{4}$ & B & II 6 & 15 & 7 & \\
\hline $\mathrm{N}_{4}$ & $\mathrm{E}_{\mathrm{I}}$ & $\mathrm{H}$ & I 17 & 8 & 8 & \\
\hline $\mathrm{N}_{4}$ & $\mathrm{E}_{2}$ & A & I I 8 & IO & 8 & \\
\hline $\mathrm{N}_{5}$ & $W_{2}$ & P & 119 & IO & 4 & \\
\hline S8 & $\mathrm{W}_{4}$ & $\mathrm{D}$ & I 20 & 9 & 9 & \\
\hline
\end{tabular}


TABLE 3.6.- continued

\begin{tabular}{|c|c|c|c|c|c|c|}
\hline \multicolumn{3}{|c|}{ Group label } & \multirow{2}{*}{$\frac{\text { Op.number }}{\mathrm{I} 2 \mathrm{I}}$} & \multirow{2}{*}{$\frac{\text { Type }}{16}$} & \multirow{2}{*}{$\frac{\text { Dig area }\left(m^{2}\right)}{8}$} & \multirow[t]{2}{*}{ Nickname } \\
\hline$S_{7}$ & $\mathrm{~W}_{4}$ & $\mathrm{E}$ & & & & \\
\hline$S_{5}$ & $\mathrm{~W}_{4}$ & B & 122 & 13 & Io & \\
\hline $\mathrm{S}_{2}$ & $\mathrm{E}_{3}$ & $\mathrm{H}$ & 123 & 6 & 4 & \\
\hline$S_{\text {I }}$ & $\mathrm{W}_{2}$ & $\mathrm{H}$ & $124 / 3 \mathrm{~K}$ & 6 & 6 & \\
\hline$S_{2}$ & $W_{I}$ & A & 125 & 6 & 4 & \\
\hline$S_{\text {I }}$ & $W_{I}$ & $\mathrm{~F}$ & 126 & 6 & 3 & \\
\hline $\mathrm{N}_{5}$ & $\mathrm{~W}_{3}$ & $\mathrm{~K}$ & 127 & 15 & 8 & \\
\hline $\mathrm{N}_{5}$ & $\mathrm{~W}_{2}$ & A & I 28 & 8 & 9 & \\
\hline $\mathrm{N}_{5}$ & $\mathrm{~W}_{2}$ & $\mathrm{D}$ & 129 & 8 & 5 & \\
\hline$S_{7}$ & $\mathrm{~W}_{2}$ & $\mathrm{C}$ & 130 & 8 & I 2 & \\
\hline N6 & $\mathrm{W}_{4}$ & A & I 3 I & 8 & I 2 & \\
\hline S6 & $\mathrm{W}_{2}$ & I & 132 & Io & I 8 & \\
\hline $\mathrm{S}_{5}$ & $\mathrm{~W}_{2}$ & $\mathrm{~J}$ & 133 & 8 & 16 & \\
\hline S8 & $\mathrm{W}_{\mathrm{I}}$ & B & 134 & 8 & 12 & \\
\hline $\mathrm{S}_{5}$ & $\mathrm{~W}_{\mathrm{I}}$ & $\mathrm{E}$ & 135 & 9 & 8 & \\
\hline$S_{\text {I }}$ & $\mathrm{WI}_{\mathrm{I}}$ & $\mathrm{H}$ & $136 / 3 \mathrm{D}$ & I & 8 & Guaje \\
\hline$S_{4}$ & $\mathrm{~W}_{2}$ & B & 137 & 8 & 4 & \\
\hline $\mathrm{N}_{7}$ & $\mathrm{~W}_{\mathrm{I}}$ & $\mathrm{F}$ & 138 & 9 & 6 & \\
\hline \multicolumn{3}{|c|}{ NW transect } & 139 & I5 & 3 & \\
\hline N6 & $\mathrm{W}_{4}$ & $\mathrm{C}$ & I 40 & I $4 \mathrm{a}$ & 8 & \\
\hline $\mathrm{S}_{5}$ & $\mathrm{E}_{\mathrm{I}}$ & $\mathrm{E}$ & I $4 \mathrm{I}$ & 8 & 7 & \\
\hline S6 & $\mathrm{E}_{\mathrm{I}}$ & $\mathrm{F}$ & I 42 & I 2 & 13 & \\
\hline S6 & $\mathrm{E}_{\mathrm{I}}$ & B & I 43 & 9 & 7 & \\
\hline$S_{5}$ & $\mathrm{E}_{2}$ & A & I 44 & I3 & 9 & \\
\hline $\mathrm{N}_{7}$ & $\mathrm{~W}_{2}$ & B & 145 & 15 & 7 & \\
\hline $\mathrm{N}_{5}$ & $\mathrm{~W}_{3}$ & $\mathrm{O}$ & I 46 & I 2 & 8 & \\
\hline S8 & $\mathrm{E}_{\mathrm{I}}$ & A & 147 & 3 & 5 & \\
\hline $\mathrm{S}_{4}$ & $W_{I}$ & $\mathrm{~L}$ & I 48 & 9 & 7 & \\
\hline $\mathrm{N}_{3}$ & $\mathrm{E}_{3}$ & A & I 49 & 8 & 8 & \\
\hline $\mathrm{N}_{4}$ & $\mathrm{E}_{3}$ & $\mathrm{H}$ & 150 & 9 & 6 & \\
\hline $\mathrm{N}_{4}$ & $\mathrm{E}_{3}$ & $\mathrm{~K}$ & IS I & Io & IO & \\
\hline $\mathrm{N}_{3}$ & $\mathrm{E}_{3}$ & $\mathrm{H}$ & $152 / 5 \mathrm{C} / 6 \mathrm{C}$ & 9 & I0 & \\
\hline
\end{tabular}


TABLE 3.6.- continued

\begin{tabular}{|c|c|c|c|c|c|c|}
\hline \multicolumn{3}{|c|}{ Group label } & Op.number & Type & Dig area $\left(m^{2}\right)$ & Nickname \\
\hline $\mathrm{N}_{4}$ & $\mathrm{E}_{2}$ & K & $153 / 4 \mathrm{~A}$ & I 2 & 30.5 & \\
\hline $\mathrm{S}_{2}$ & $\mathrm{E}_{3}$ & $\mathrm{~B}$ & I 54 & 9 & 4 & \\
\hline eastt & & & 155 & $\mathrm{I} 4 \mathrm{~b}$ & 3 & \\
\hline $\mathrm{N}_{5}$ & $\mathrm{~W}_{3}$ & $\mathrm{D}$ & 156 & 8 & 4 & \\
\hline SE ti & & & 157 & 13 & 4 & \\
\hline SE t & & & 158 & 13 & 2 & \\
\hline east & & & 159 & 13 & 3 & \\
\hline
\end{tabular}

that are not reasonably well enclosed by albarradas. Why did we exclude such groups? When the albarrada walls of a houselot are fragmentary it is sometimes difficult to know which buildings and other features (metates, sascaberas) pertain to which architectural group. Chunchucmil's relatively high settlement density contributes to this difficulty: open spaces among buildings are often too small to serve as a guide for drawing boundaries between groups of buildings. (In areas with enough open space, usually toward the edges of the site, we could draw boundaries when albarradas did not exist at all, which is the case for types is and I6.) In areas where boundary walls were incomplete, we would not be sure which buildings pertained to which social units. In turn, excavations in such groups with unclear boundaries might not be useful because we would not understand the nature of the social group to which the excavation data pertained. Thus, within types 8, 9, IO, I2, I3, and I4, we sampled groups that were completely or nearly completely enclosed by albarrada walls as opposed to groups that were partially enclosed. For example, we did not excavate any of the three type I2 groups in Block 7 because these three groups were not well-encircled by houselot walls.

The opportunistic side of our sampling strategy meant that some group types were sampled more exhaustively than others. For example, we decided to test-pit each of the is quadrangles (types I and 2) since most of the site's largest buildings were part of quadrangles and we wanted to be able to speak to the chronology of construction of these large compounds. We also tested most ( 16 of 24 ) of the broad platforms comprising group type 6 . Since these groups often represented the only substantial buildings dating to after the abandonment of most of the site (see chapter 4), they represented our best opportunity for understanding the drastic demographic decline of Chunchucmil (Magnoni 2008).

Once we chose which architectural groups to excavate, minimum amounts of excavation per group were systematized. As a result, I4I excavation locales received a minimum of six I-by-I-m test pits or yielded large enough quantities of sherds 
(always over $4 \mathrm{~kg}$ ) to cease digging after completing fewer than six pits. The amount of excavation in some of the first operations (those dating to the 1990s) was low, with a few groups receiving no more than a single test pit. At the other end of the spectrum, seven groups were excavated horizontally: $\mathrm{NIEI}_{\mathrm{I}} \mathrm{C} / \mathrm{Op}$. 9a (the Pich group), $S_{2} E_{2}-F / O p .9 c$ (the Aak group), $S_{2} E_{1}-G / O p .9 d$ (the Kaab' group), $S_{2} E_{3}-\mathrm{L} /$ Op. 9 h (the Chiwool group), $\mathrm{S}_{2} \mathrm{E}_{2}-\mathrm{C} / \mathrm{Op}$. Io (the Muuch group), $\mathrm{N}_{2} \mathrm{E}_{2}-\mathrm{N} / \mathrm{Op}$. I3 (the Lool group), and $\mathrm{S}_{\mathrm{IE}} \mathrm{I}-\mathrm{H} / \mathrm{Op}$. Is (the marketplace). Furthermore, five groups-three of which were excavated horizontally ( $\mathrm{S}_{2} \mathrm{E}_{2}-\mathrm{F} / \mathrm{Op} .9 \mathrm{c}, \mathrm{S}_{2} \mathrm{E}_{\mathrm{I}}-\mathrm{G} /$ Op. 9d, $\left.S_{2} E_{2}-C / O p . ~ I 0\right)$, two of which were not ( $\mathrm{S}_{2} \mathrm{E}_{2}-\mathrm{K} / \mathrm{Op}$. $9 \mathrm{~b}$ [the Xnokol group] and $S_{4}$ W8-F/Op. 33 [the Balam group; see chapter 5 , this volume])-each received at least $10050-$ by- $50-\mathrm{cm}$ shovel tests at the corners of 5 -m grids placed over non-architectural space. The total surface area of all excavations at Chunchucmil is approximately $3,300 \mathrm{~m}^{2}$. The total volume of excavation is likely to be about 2,000 $\mathrm{m}^{3}$, but it is difficult to calculate more precisely given that note-taking was not standardized for excavations in the I990s.

\section{SUMMARY}

Chunchucmil's architectural groups share many similarities with architectural groups elsewhere in the lowlands, but with enough differences to merit a sitespecific typology. Our typology reflects differences in form and function between architectural groups as well as differences in the status of the social groups that lived in them (usually extended family households; see chapter 5 ) and the physical resources available to them. We used this typology as the basis for the excavation sampling strategy, which included both opportunistic and stratified random components. The goal of the sampling was to select for excavation a set of architectural groups that was representative of the variation in the site as a whole. We therefore completed an unusually large set of excavations spread broadly across the site and across the different kinds of architecture. Few large sites (Tikal, Caracol) have been excavated so systematically. Shortcomings of the sampling strategy were mitigated in a variety of ways. As seen in the next chapter, these excavations permit the diachronic reconstruction of Chunchucmil and give us confidence in economic conclusions drawn in later chapters. 


\title{
Chunchucmil Chronology and Site Dynamics
}

\author{
Socorro Jiménez, Aline Magnoni, Eugenia Mansell, \\ AND TARA BOND-FREEMAN
}

Chunchucmil was first occupied in the Middle Preclassic and, like most other large prehispanic Maya cities, it had a long-lasting, complex history. In basic outline, this history began with a very minor occupation in the Middle Preclassic period (the Xpim phase: $700-400 \mathrm{BCE}$ ). Chunchucmil's occupation was also small during the ensuing Late Preclassic period (the Pich phase: 400 BCE-250 CE) and the early facet of the Early Classic period (Early Aak: $250-400 \mathrm{CE}$ ). Chunchucmil reached its apogee in the Late Aak phase $(400-630 \mathrm{CE})$. A reduced number of people occupied the site in the Late Classic (the Kaab' phase 630-750/800 CE), followed by an even smaller occupation in the Late/Terminal Classic period (the Xnokol phase 750/800-IIOO CE). There is no clear evidence for a Postclassic (IIOO-I542 CE) occupation since only a scattering of sherds from this period were retrieved. The dates for the Chunchucmil ceramic sequence generally follow the chronology proposed by Andrews and Robles Castellanos (2014) for the peninsula of Yucatán yet some dates were modified based on the local data from Chunchucmil and nearby Oxkingtok. Table 4.I shows each of these phases along with the ceramic groups assigned to each phase and the quantities of sherds per group.

In this chapter, we discuss the data that support this outline. Our data come from ceramics recovered almost exclusively from the excavation sample discussed in the previous chapter, chronologically diagnostic architectural traits, and two radiocarbon dates. Eugenia Mansell, Tara Bond-Freeman, Socorro Jiménez, Chris Rayle, Iliana Ancona Aragón, Aline Magnoni, and Scott Hutson all participated in 
TABLE 4.I. Ceramic groups at Chunchucmil, listed by time period and quantity.

\begin{tabular}{|c|c|c|c|c|}
\hline Period & Dates & Phase & Group & Amounts \\
\hline \multirow{8}{*}{$\begin{array}{l}\text { MIDDLE } \\
\text { PRECLASSIC }\end{array}$} & \multirow{8}{*}{ I $000-400 \mathrm{BCE}$} & \multirow{8}{*}{$\mathrm{CHACAH}$} & Sapote & 2 \\
\hline & & & Almeja & 2 \\
\hline & & & Kin & 8 \\
\hline & & & Chunhinta & 155 \\
\hline & & & Dzudzuquil & 413 \\
\hline & & & Joventud & 648 \\
\hline & & & Muxanal & I \\
\hline & & & El Llanto & 9 \\
\hline \multirow{8}{*}{ LATE PRECLASSIC } & \multirow{8}{*}{$400 \mathrm{BCE}-250 \mathrm{CE}$} & \multirow{8}{*}{$\mathrm{PICH}$} & Saban & 1,583 \\
\hline & & & Hubila & 25 \\
\hline & & & Tipikal & 44 \\
\hline & & & Unto & 85 \\
\hline & & & Sierra & 501 \\
\hline & & & $\begin{array}{l}\text { Unspecified } \\
\text { (Xuch Black and Red) }\end{array}$ & 8 \\
\hline & & & Polvero & 414 \\
\hline & & & Flor & 16 \\
\hline \multirow{14}{*}{ EARLY CLASSIC } & \multirow{14}{*}{$250-400 \mathrm{CE}$} & \multirow{14}{*}{ EARLY AAK } & Oxil (flattened rims) & 3 \\
\hline & & & Xanabá & I,914 \\
\hline & & & Percebes & 6 \\
\hline & & & Carolina & 9 \\
\hline & & & Salamanca & 29 \\
\hline & & & Huachinango & I 4 \\
\hline & & & Shangurro & 244 \\
\hline & & & Iberia & 4 \\
\hline & & & Timucuy (tetrapods) & 2 \\
\hline & & & Tituc & I 28 \\
\hline & & & Corona & I \\
\hline & & & Pucte & 22 \\
\hline & & & Balanza & 337 \\
\hline & & & Aguila & $36 I$ \\
\hline
\end{tabular}


TABLE 4.I.-continued

\begin{tabular}{|c|c|c|c|c|}
\hline Period & Dates & Phase & Group & Amounts \\
\hline \multirow{11}{*}{$\begin{array}{l}\text { EARLY CLASSIC } \\
\text { CONTD. }\end{array}$} & \multirow{11}{*}{$400-630 \mathrm{CE}$} & \multirow{11}{*}{ LATE AAK } & $\begin{array}{l}\text { Timucuy } \\
\text { (annular bases) }\end{array}$ & 882 \\
\hline & & & Aak & 50 \\
\hline & & & Chencoh & 2,674 \\
\hline & & & Acú & 325 \\
\hline & & & Kochol & 2,223 \\
\hline & & & $\begin{array}{l}\text { Unspecified } \\
\text { (appliqué-cream) }\end{array}$ & I \\
\hline & & & Chuburna & 3,512 \\
\hline & & & $\begin{array}{l}\text { Kanachen } \\
\text { (Early and Late forms) }\end{array}$ & 2,573 \\
\hline & & & $\begin{array}{l}\text { Hunabchen (Early and } \\
\text { Late forms) }\end{array}$ & $\mathrm{I} 3,2 \mathrm{I} 7$ \\
\hline & & & $\begin{array}{l}\text { Maxcanu } \\
\text { (Early and Late forms) }\end{array}$ & 15,845 \\
\hline & & & $\begin{array}{l}\text { Oxil } \\
\text { (Early and Late forms) }\end{array}$ & 62,249 \\
\hline \multirow{16}{*}{ LATE CLASSIC } & \multirow{16}{*}{$\begin{array}{l}550 / 630- \\
750 / 800 \mathrm{CE}\end{array}$} & \multirow{16}{*}{ KAAB' } & Unspecified (Acanceh) & I \\
\hline & & & Katil & 16,278 \\
\hline & & & Chumul & I \\
\hline & & & Arena & I I 2 \\
\hline & & & Vista Alegre & 3 \\
\hline & & & Chimbote & 2 \\
\hline & & & Saxche & 4 \\
\hline & & & $\mathrm{K}^{\prime}$ inich & 422 \\
\hline & & & Azcorra & I \\
\hline & & & Baca & 276 \\
\hline & & & Nimun & 19 \\
\hline & & & Koxolac & 2 \\
\hline & & & Dzitbalche & 16 \\
\hline & & & Enzil & 17 \\
\hline & & & Teabo & 768 \\
\hline & & & Dzitya & 84 \\
\hline
\end{tabular}

continued on next page 
TABLE 4.I.-continued

\begin{tabular}{|c|c|c|c|c|}
\hline Period & Dates & Phase & Group & Amounts \\
\hline \multirow{5}{*}{$\begin{array}{l}\text { LATE CLASSIC } \\
\text { CONTD. }\end{array}$} & \multirow{5}{*}{$\begin{array}{l}550 / 630- \\
750 / 800 \mathrm{CE}\end{array}$} & \multirow{5}{*}{ KAAB' } & Chablekal & 429 \\
\hline & & & Unspecified & , \\
\hline & & & Jalpa & 2 \\
\hline & & & Yalkox & I \\
\hline & & & Calatrava & I \\
\hline \multirow{14}{*}{$\begin{array}{l}\text { TERMINAL } \\
\text { CLASSIC }\end{array}$} & \multirow{14}{*}{$\begin{array}{l}750 / 800- \\
\text { IIOO CE }\end{array}$} & & Muna & 244 \\
\hline & & & $\begin{array}{l}\text { Maxcanu } \\
\text { (slip white-gray) }\end{array}$ & 2,559 \\
\hline & & & Chum & 14,315 \\
\hline & & & Ticul & 432 \\
\hline & & & Holactun & 152 \\
\hline & & & Silho & 366 \\
\hline & & & Altar & 4 \\
\hline & & & $\begin{array}{l}\text { Unspecified (fine paste, } \\
\text { slip black-brownish) }\end{array}$ & 4 \\
\hline & & & Yalcox & 3 \\
\hline & & & Tohil & 2 \\
\hline & & & Balancan & 13 \\
\hline & & & Dzitas & 69 \\
\hline & & & Dzibiac & I \\
\hline & & & Sisal & 272 \\
\hline \multirow{4}{*}{$\begin{array}{l}\text { POSTCLASSIC- } \\
\text { HISTORIC }\end{array}$} & \multirow{4}{*}{ I IOO-I $542 \mathrm{CE}$} & & Kukula & 76 \\
\hline & & & Mama & IIS \\
\hline & & & Navula & 107 \\
\hline & & & Yuncu & 2 \\
\hline
\end{tabular}

the ceramic analysis, with Mansell, Bond-Freeman, and Jiménez doing most of the work. We analyzed at least 296,032 sherds from Chunchucmil. Mansell and Rayle also analyzed a few thousand sherds from excavations at sites beyond Chunchucmil. The ceramics from these excavations beyond Chunchucmil are not reported here (see chapter 8 , this volume). A little over half $(n=147,716)$ of the sherds from Chunchucmil could be classified according to the type variety system (R. E. Smith 
et al. 1960). The other 148,316 sherds were tabulated with varying degrees of specificity. At the low end of specificity, we have categories such as eroded. At the middle of the spectrum we have categories such as red slip and Preclassic. At the high end of specificity we have categories like eroded thin slate, which we could probably have assigned to a ceramic group but, conservatively, did not.

In addition to type-variety analysis, we also subjected a subset of the rim sherds to attribute analysis. As we discuss below, changes in modes of certain attributes have helped refine the ceramic chronology. Furthermore, architectural styles of buildings across the site (e.g., Proto-Puuc, Early Puuc, Classic Puuc; G. Andrews 1985) associated with ceramic debris serve as a corroborating line of evidence for chronological dating.

Our heavy dependence on ceramic types and modes for chronology carries two basic shortcomings. First, sealed contexts and good stratigraphy were rare in our excavations. As noted in the previous chapter, a large portion of the excavations consisted of off-mound test pits. On average, these test pits went between 30 and 40 $\mathrm{cm}$ deep before hitting bedrock. The soils and sediments lacked cultural stratigraphy, showed heavy bioturbation, and usually contained no more than two natural strata: A and B horizons. Architectural excavations succeeded in locating sealed deposits below floors, but the amount of ceramics beneath floors was low. Second, many of the ceramic types found at Chunchucmil, such as Sierra Red, Saban Unslipped, and Maxcanú Buff, were produced and used for many centuries, thus reducing their value as precise chronological indicators.

Where did Chunchucmil's pottery come from? Though Ronald Bishop and Erin Sears subjected a sample of sherds to INAA (instrumental neutron activation analysis), parallel chemical analysis of local clays has not been undertaken and the ceramics do not match compositional groups from more distant clay sources. As we discuss below, Chunchucmil's pottery shares many similarities with pottery from Oxkintok, located $27 \mathrm{~km}$ to the east. Could Chunchucmil's pottery have been imported from Oxkintok? For a number of reasons, we believe that most of Chunchucmil's pottery was made closer to Chunchucmil. Analysis of soils and sediments at Chunchucmil reveals that local clays were acceptable for making pottery (Tim Beach, personal communication 2015). Loya González and Stanton (2013) provide a precedent for trade of a common pottery type by showing that Arena Red pots were traded from Yaxuná to Cobá $(99 \mathrm{~km})$, but the authors note that this trade was limited. At Tikal and Palenque, two sites with some of the best-known ceramic sourcing research, most pottery was produced from local clays by potters residing within Is km of these sites (Fry 1979; Rands and Bishop 1980). Closer to Chunchucmil, INAA shows that most of the Puuc wares found at Sayil come from clays available at or nearby Sayil (Smyth, Dore, et al. 1995). 


\section{MIDDLE PRECLASSIC: XPIM PHASE (700-400 BCE)}

The Middle Preclassic in Yucatán spans from 1000 to 400 BCE, though Chunchucmil lacks pre-Nabanche pottery that pertains to the early part of the Middle Preclassic. Middle Preclassic pottery has been found in the lowest levels of excavations in the central portion of the site, yet the Middle Preclassic occupation is limited. Middle Preclassic sherds $(n=1,238)$ make up less than I percent of the total sherds classified to type at Chunchucmil. The ceramics of the Xpim phase consist of the Joventud ( $n=649$ sherds), Chunhinta ( $n=155$ sherds), and Dzudzuquil ( $n$ $=413$ sherds) groups, which for the most part show characteristics similar in form and surface finish (figure 4.Ib, c, d) to the Preclassic ceramics of the Early and Late Nabanche horizon (E. W. Andrews V 1989; E. W. Andrews V and Bey 2011; Bey 2006; Gallareta Negrón and Ringle 2004). Of these groups the Joventud Group presents some differences in slip and paste with respect to the Early Nabanche at Komchen (Ceballos Gallareta and Robles Castellanos 2012). Compared to the Nolo variety of Joventud Red (Andrews et al. 1989), Chunchucmil's Joventud Group ceramics have a more fragile paste and a waxier slip that also adheres better to the vessel. This type of paste and slip also has been identified at Sihó and Oxkintok (Ancona Aragón 2014; Jiménez 2007; Varela Torrecilla 1998). At these two sites Middle Preclassic ceramics were also found in plaza fills that were remodeled as part of later constructions in the monumental part of the site (Jiménez 2007; Varela Torrecilla 1998).

Ceramics from at least two of the three Middle Preclassic ceramic groups come from excavations in 22 operations (figure 4.2). Middle Preclassic sherds make up 9 percent or more of the total classified sherds in seven of these 22 operations (table 4.2). These seven operations include two quadrangles (Ops. 26 and 28), a non-quadrangle monumental group (Op. 30), a medium-sized albarrada group (Op. 32), a large albarrada group (Op. 80), an isolated platform (Op. 3a), and Sacbe I (Op 7 A). We provide details of some of these operations in the next paragraph. Figure 4.2 shows that these seven operations are clustered at the center of the site in an area of about $0.5 \mathrm{~km}^{2}$. Figure 4.2 also shows that 20 of the 22 operations that yielded pottery from at least three Middle Preclassic groups cluster within a bit less than a square kilometer, also at the site center. Small amounts of Middle Preclassic sherds have been found scattered in other parts of the site.

Regarding details of the operations that yielded significant amounts of Middle Preclassic pottery, the isolated platform (Op. $\left.3 \mathrm{~A} / \mathrm{N}_{\mathrm{IE}} \mathrm{-H}\right)$ exhibits megalithic construction, a form of architecture that the Maya of the northern lowlands began to build toward the end of the Late Preclassic (Mathews and Maldonado C. 2006). Op. $32 / \mathrm{NIW}_{2}$-E is a type Io group centered on a large $\left(2,000 \mathrm{~m}^{2}\right)$ basal platform with a subsidiary patio containing smaller structures to the east. A test pit on the 


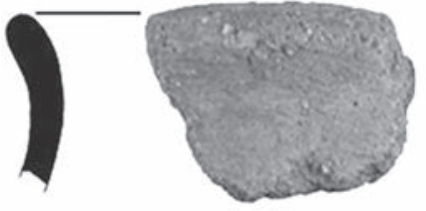

a

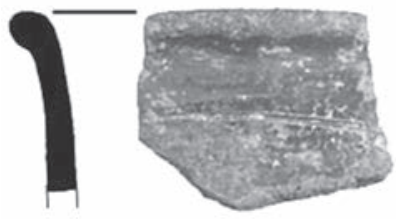

c
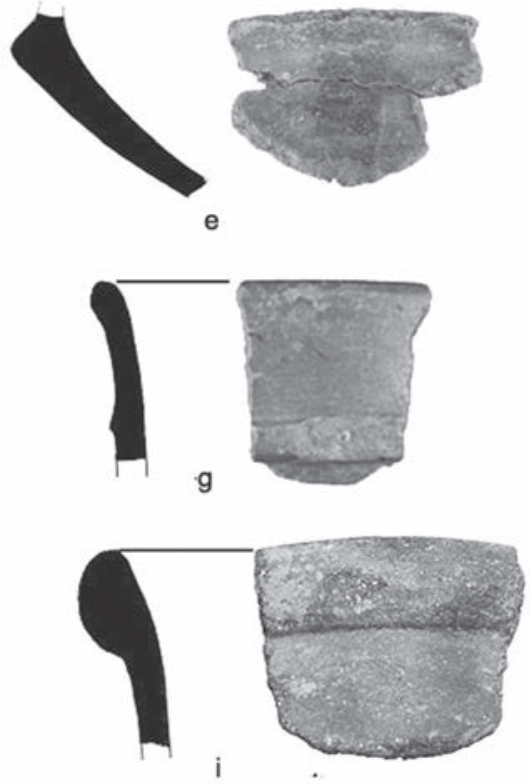
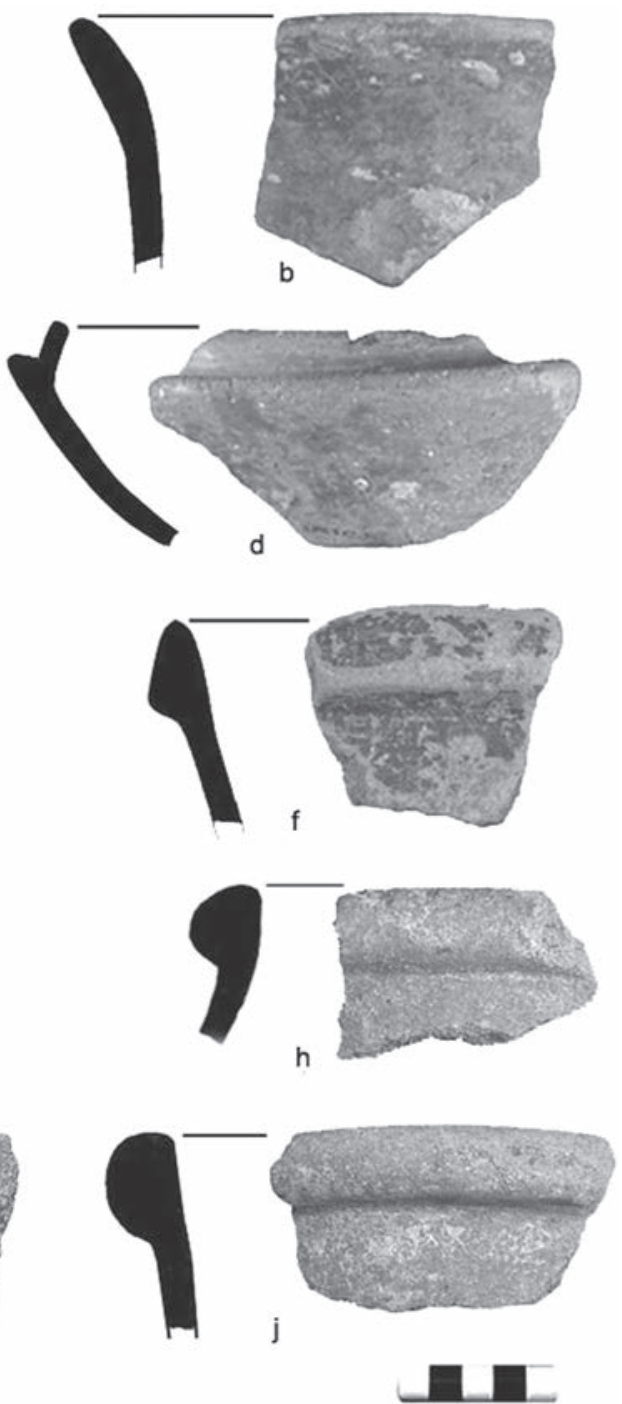

FIGURE 4.I. Common ceramics types from Chunchucmil I: (a) Saban Unslipped: Unspecified; (b) Joventud Red: Unspecified; (c) Petjal Red on Black and Cream to Buff: Petjal; (d) Sierra Red: Unspecified; (e) Repasto Black on Red: Unspecified; (f) Sierra Red: Flaky; (g) Sierra Red: Unspecified; (h) Elote Striated-Impressed: Unspecified; (i) Oxil Unslipped; (j) Oxil Unslipped. (Photography by Pedro Tec Chim.) 


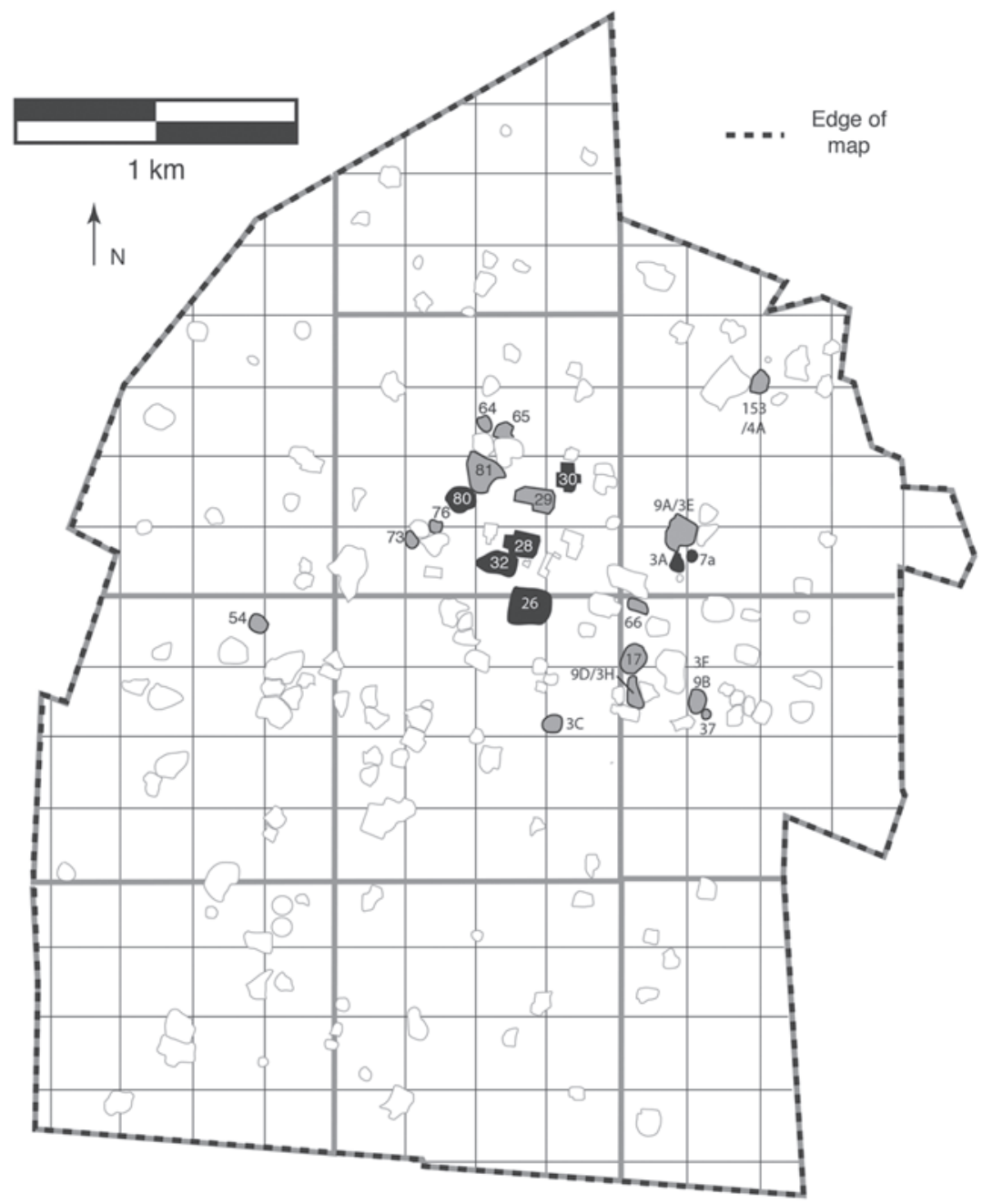

FIGURE 4.2. Map highlighting groups with significant quantities of Middle Preclassic pottery. For the groups in black, at least $9 \%$ of the pottery recovered is Middle Preclassic. Groups in gray have much less Middle Preclassic pottery but have sherds from at least three Middle Preclassic ceramic groups.

north side of the basal platform uncovered a buried structure with a plaster floor and non-megalithic masonry walls still standing $60 \mathrm{~cm}$ high. The fill beneath this plaster floor represents one of only two sealed Middle Preclassic contexts excavated at the site. The other sealed Middle Preclassic context comes from the architectural 
TABLE 4.2. Excavation operations in which at least $5 \%$ of classifiable ceramics date to the Middle Preclassic.

\begin{tabular}{|c|c|c|c|c|c|c|c|}
\hline Op.\# & Chunbinta & Dzudzuquil & Joventud & $\begin{array}{c}\text { Total } \\
\text { Middle } \\
\text { Preclassic } \\
\text { sherds }\end{array}$ & $\begin{array}{l}\text { Total } \\
\text { sherds }\end{array}$ & $\begin{array}{c}\text { Middle } \\
\text { Preclassic } \\
\text { sherds (\%) }\end{array}$ & $\begin{array}{c}\text { Group } \\
\text { type }\end{array}$ \\
\hline $7 \mathrm{a}$ & I & I & 5 & 7 & 80 & 8.8 & sacbe \\
\hline 80 & 16 & 68 & 65 & I 49 & 1,567 & 9.5 & IO \\
\hline $3 a$ & I & 4 & I & 6 & 60 & 10.0 & 16 \\
\hline 32 & 32 & 24 & I I 3 & 169 & $\mathrm{I}, 844$ & 9.2 & 9 \\
\hline 26 & 5 & $2 I$ & 44 & 70 & 653 & 10.7 & 2 \\
\hline 30 & I 2 & 76 & 68 & 156 & 795 & 19.6 & 5 \\
\hline 28 & 5 & 68 & 132 & 205 & 323 & 63.5 & I \\
\hline
\end{tabular}

compound immediately to the northeast of Op. 32. This is the Xpim quadrangle (Op. 28/ $\mathrm{NIW}_{2}-\mathrm{C} / \mathrm{Xpim}$ ), located $500 \mathrm{~m}$ west of the site datum. Here, Middle Preclassic ceramics were recovered in a sealed context below two floors inside the patio. Since no architecture has been excavated at this group it is difficult to reconstruct its construction history. We know that a patio floor with a considerable amount of fill below it (50-100 cm deep) was built in the Middle Preclassic at this group, although we are uncertain of the architecture associated with it. Test pits at this quadrangle revealed that Middle Preclassic ceramics comprised nearly twothirds of the classifiable ceramics. The rest came from the Late Preclassic and Early Classic periods. The Middle Preclassic sherds in the fill of Sacbe I/Op. 7 A (see also Sacbe 2/Op. 66) were mixed with Late Preclassic sherds and Classic-period sherds. It is important to note that all the groups that have Middle Preclassic ceramics also show later occupation. Perhaps further archaeological excavations could further define the Middle Preclassic occupation and the origins of the site beginnings.

\section{LATE PRECLASSIC: PICH PHASE ( 400 B CE-250 CE)}

The Late Preclassic occupation consists mostly of ceramics from the Saban $(n=$ I,489), Sierra $(n=499)$, Polvero $(n=414)$, Unto $(n=85)$, and Tipikal $(n=46)$ groups (figure 4.ra, e-g). The sherds in these ceramic groups total 2,679, which represent 1.8 percent of the total sherds from Chunchucmil classified to type. The groups Sierra, Polvero, Unto, and Tipikal continue into the Early Classic whereas a portion of the Xanaba Group pottery currently attributed to the Early Classic was likely made in the Late Preclassic. Seventy-three of the excavation operations have 
TABLE 4.3. Excavation operations that have at least $4 \%$ Late Preclassic sherds.

\begin{tabular}{|c|c|c|c|c|}
\hline $\begin{array}{l}\text { Operation } \\
\text { name }\end{array}$ & $\begin{array}{l}\text { Total classified } \\
\text { sherds }\end{array}$ & $\begin{array}{c}\text { Late Preclassic } \\
\text { sherds }\end{array}$ & $\begin{array}{l}\text { Late Preclassic } \\
\text { sherds }(\%)\end{array}$ & $\begin{array}{l}\text { Architectural } \\
\text { group type }\end{array}$ \\
\hline $7 \mathrm{~A}$ & 62 & 34 & 54.8 & sacbe \\
\hline 54 & 315 & IOI & 32.1 & IS \\
\hline 30 & 795 & 198 & 24.9 & 5 \\
\hline 66 & 288 & 50 & 17.4 & IS \\
\hline 55 & 77 & 13 & 16.9 & 9 \\
\hline 65 & 238 & $3 I$ & 13.0 & 8 \\
\hline 80 & 1,567 & 201 & I 2.8 & IO \\
\hline 28 & 323 & 40 & I 2.4 & I \\
\hline 64 & 123 & IS & $\mathrm{I} 2.2$ & 8 \\
\hline 73 & 444 & 45 & IO.I & I 2 \\
\hline 32 & 1,857 & 175 & 9.4 & 9 \\
\hline 59 & 539 & 48 & 8.9 & 9 \\
\hline 75 & 1,508 & I IO & $7 \cdot 3$ & 9 \\
\hline 44 & 223 & IS & 6.7 & 9 \\
\hline 17 & 283 & 16 & 5.7 & I \\
\hline 24 & 326 & 16 & 4.9 & 9 \\
\hline${ }_{9} \mathrm{~F} / \mathrm{Chiwol}$ & $I, 46 I$ & 71 & 4.9 & 8 \\
\hline I9 & 169 & 8 & $4 \cdot 7$ & 2 \\
\hline 49 & 106 & 5 & 4.7 & 8 \\
\hline 97 & 430 & I 8 & 4.2 & IS \\
\hline 20 & 839 & 35 & 4.2 & 2 \\
\hline${ }_{9} \mathrm{D} / \mathrm{Kaab}$ & 11,968 & $48 \mathrm{I}$ & 4.0 & 9 \\
\hline
\end{tabular}

no Late Preclassic sherds and another 24 have only one or two sherds. Table 4.3 lists the 22 operations in which Late Preclassic ceramics comprise at least 4 percent of the total classifiable sherds. Figure 4.3 shows the location of these 22 operations on the map. Operations in which Late Preclassic sherds make up more than ro percent of the total classifiable sherds are in dark gray, those with between ro percent but more than 4 percent are in light gray.

Excluding Operation 59, the groups that have at least 4 percent Late Preclassic sherds cluster at the site core in an area of a little less than $1.5 \mathrm{~km}^{2}$. There are both continuities and disjunctions between the Middle Preclassic and Late Preclassic occupation. For example, two operations with high percentages of Middle 


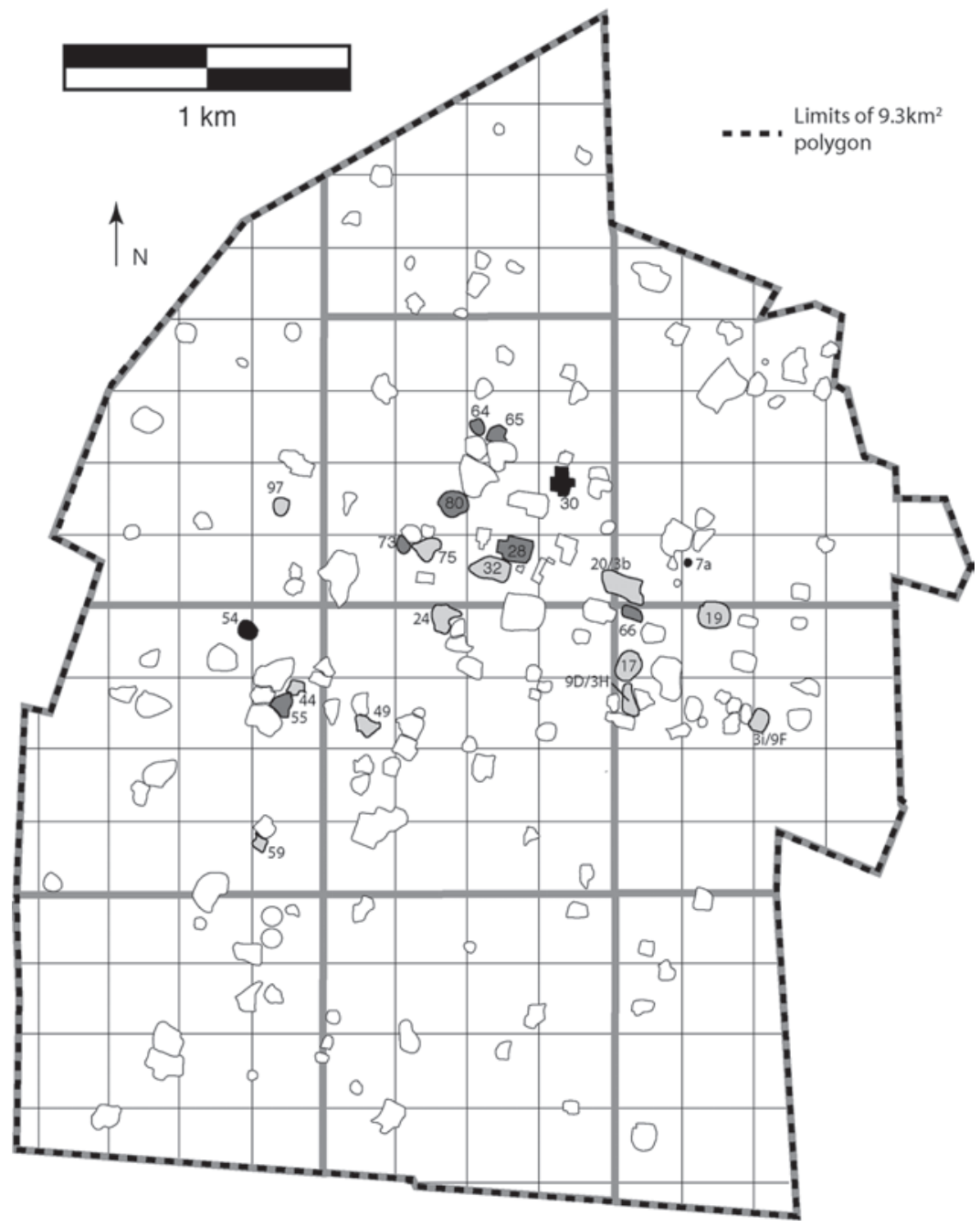

FIG URE 4.3. Map highlighting groups with significant quantities of Late Preclassic pottery. For the groups in dark gray, over $10 \%$ of the pottery identified is Late Preclassic. For the groups in light gray, between $4 \%$ and $10 \%$ of the pottery identified is Late Preclassic.

Preclassic pottery, Ops. 28 and 30, also have high percentages of Late Preclassic ceramics. Likewise, the pits in Sacbes I and 2 turned up appreciable amounts of both Middle and Late Preclassic pottery, although these are fill contexts that also 
contain later ceramics, suggesting that the sacbes were in fact built in the Classic period. In Ops. $3 \mathrm{~A}$ and 26, Io percent and i percent, respectively, of the identifiable pottery was Middle Preclassic but only about I.5 percent dates to the Late Preclassic. This is interesting for Op. $3 \mathrm{~A}$, whose architecture is megalithic. Although megalithic structures in Yucatán are often built toward the end of the Late Preclassic, they can also be built in the Early Classic. Furthermore, some groups with more than 4 percent Late Preclassic pottery, such as Ops. 19, 20, and 24, had little or no Middle Preclassic pottery.

Of the 22 groups with more than 4 percent Late Preclassic ceramics, four are quadrangles. Thus, about a fourth of Chunchucmil's quadrangles had Late Preclassic settlement, even though it does not appear that the architecture of the quadrangles visible on the surface was Late Preclassic.

In sum, the Late Preclassic occupation of the site is relatively minor, though at least one Preclassic sherd was recovered from almost half of the architectural contexts tested. We refrain from going as far as offering a population estimate for the Late Preclassic because many Late Preclassic ceramic groups continued into the Early Classic (e.g., a Sierra Red sherd does not necessarily mean a Late Preclassic date of manufacture) and because low quantities of Late Preclassic sherds (2 or 3 or 4 ) at a building may not indicate that the building was occupied during that period. No architecture definitively dated to the Late Preclassic has been excavated so far. Well-planned civic architecture, including sacbes, is known from other Preclassic sites across northern lowlands, such as Komchen (Ringle and Andrews 1990), Xocnaceh (Gallareta Negrón and Ringle 2004), Poxilá (Robles Castellanos in press), Yaxuná (Stanton and Freidel 2005), and Xtobó (Anderson et al. 2012), so it might have been present at Chunchucmil in the Preclassic.

Sierra Group sherds from the Pich phase show two kinds of surface finish: one in which the slip adheres very well to the surface (Unspecified variety) and one with a flaky slip (Flaky variety) that can be differentiated from the Joventud Group on the basis of its slip color, paste, and characteristic forms. It should be mentioned that these two groups (Sierra and Joventud) were defined by comparisons with ceramics from other settlements from the same phase, taking into consideration that many ceramic groups that pertain to the Late Preclassic period continue in use during the following epoch. At Chunchucmil, ceramics assigned to the Late Preclassic are sometimes associated with ceramics from later periods, such as Tixcacal Polychrome or the Xanaba and Shangurro groups, which delimit the beginning of the Early Classic ceramic traditions of the Yucatán Peninsula.

The concrete phenomenon of continuity in ceramic traditions from one epoch to the next is common in various Maya sites. At the same time, one must take into consideration that the fragmentation and erosion of a large portion of the Preclassic 
materials at Chunchucmil makes it nearly impossible to identify details of form, surface finish, and decoration on sherds that might have helped clarify details on the site's ceramic typology. Finally we should not discount the possibility of recycling of ceramic materials from different periods that served as construction fill for the diverse buildings and architectural modifications at Chunchucmil.

\section{EARLY CLASSIC: EARLY AAK (250-400 CE) AND \\ LATE AAK (400-630 CE) PHASES}

Some of the most common pottery groups found at Chunchucmil-Maxcanú ( $n$ $=7,872)$, Hunabchen $(n=11,668)$, Oxil $(n=62,249)$-are part of what Carmen Varela Torrecilla (1998) has identified as the Oxkintok Regional Complex, which she dates to between 500/550 and 600/630 CE. Since Chunchucmil's most abundant pottery is extremely similar to the pottery of Oxkintok, which is located $27 \mathrm{~km}$ east of Chunchucmil, we begin with a close discussion of the ceramic sequence of Oxkintok. This sequence was developed by members of the Spanish Archaeological Mission at Oxkintok, which worked at the site in the late 1980s. Yet members of this project disagree on some aspects of the sequence. These differences arise from discrepancies in how different investigators valued the variety of chronological data available: architectural phases, epigraphy, ceramics, and differences in the patterns of how buildings were used. These disagreements in the ceramic sequence manifest themselves in the epoch of transition between the Early Classic and Late Classic (500/550-630 CE), which Project Director Miguel Rivera Dorado (1992) calls the Noheb I Complex and which project ceramicist Carmen Varela Torrecilla (1998) calls the Middle Classic Oxkintok Regional Complex.

For Varela Torrecilla (1996, 1998), Oxkintok's ceramic sequence can be correlated with architectural dates. In Varela Torrecilla’s view (1993, 1998), the Ichpá ceramic complex dates to the Early Classic and the Oxkintok Regional Complex pertains to an approximately 100-year-long period (500/550-630 CE) that is intermediate between the Early Classic and the Late Classic. Varela Torrecilla treats this as an independent ceramic complex with significant modifications in pottery making. This stage matches up with the Proto-Puuc A architectural style and a hiatus in the epigraphic record.

Rivera Dorado (1992, 1996) does believe that there is an intermediate period at Oxkintok, but that the Proto-Puuc architectural style associated with this period has strong connections with later periods. He also sees greater similarities between Oxkintok Regional ceramics and later ceramics: for this reason, he places the ceramic groups that form Varela Torrecilla's Oxkintok Regional Complex into the Noheb I Complex (early Late Classic), which is followed by the Noheb II Complex. 
García Campillo and Fernández (1995:136) propose that the Early Classic should be broken into two phases: Ichpá I (300-450 CE) and Ichpá II (450-600 C E). For them, the Oxkintok Regional Complex was a ritual and funerary subcomplex pertaining entirely to the Early Classic. Robles Castellanos and Andrews (2000:206207) came to the same conclusion, arguing that it is not appropriate to use the term Middle Classic as a time period because of the lack of sufficient arguments and contexts that would corroborate the temporal isolation of the cultural characteristics of the Middle Classic.

Later, Varela Torrecilla and Braswell (2003) proposed that the term Oxkintok Regional Complex be used to refer to a conjuncture of ceramic groups with a manufacturing technology specific to western Yucatán. This ceramic repertoire has foreign characteristics that relate to other areas, such as Teotihuacan, the Petén of Guatemala, and Campeche, and can be dated between approximately 500/550 and $630 \mathrm{CE}$. Varela Torrecilla and Braswell 2003 proposed that during this period Oxkintok's elites acquired political control of the surrounding region and, on ritual and funerary ceramics, imposed a style that contained local interpretations of foreign attributes. The characteristics that they considered foreign date to the Tzakol 3 ceramic horizon, which is the final part of the Early Classic, and persist into the following Late Classic period. The period from 500/550 to 630 CE at Oxkintok is now seen as a late moment of the Early Classic and presents local imitations of Teotihuacan ceramic forms and architecture, often filtered through southern Maya lowland versions of such foreign attributes (Ringle 2014:252).

Following these more recent interpretations, we place the Chunchucmil ceramics that fit the description of the Oxkintok Regional ceramics into the latter part of the Early Classic period. Contrary to Varela Torrecilla (1998), we do not call this the Middle Classic because we have not seen strong evidence of a Teotihuacan intervention, though there is certainly evidence that some people at Chunchucmil embraced pottery and architectural styles often associated with Teotihuacan (see chapter II). We therefore split the Early Classic at Chunchucmil into two phases: Early Aak and Late Aak.

Like the pottery from the Preclassic phases, Early Aak ceramics at Chunchucmil are scarce. The site reached its apogee in the Late Aak phase, which we date to 400-630 CE. Late Aak pottery comprised a majority of the ceramic assemblages from all but one excavation operation ( $7 \mathrm{a}$, a test pit in Sacbe $\mathrm{I}$ ). The excavation operations that are shaded gray in figure 3.3 represent locations with a strong Late Aak occupation. Put differently, the pottery from nearly every architectural group that we dug was dominated by Late Aak ceramics. Such a date range receives a boost from radiocarbon dates as well as architectural data. An animal bone in a sealed context in association with Oxkintok Regional sherds from the Lool residential 
compound $\left(\mathrm{N}_{2} \mathrm{E}_{2}-\mathrm{N}\right)$ yielded a radiocarbon date of $1550 \pm 40 \mathrm{BP}$ (calibrated at $2 \sigma$ to $420-6$ IO CE).

In terms of architecture, residential complexes in which Maxcanú, Hunabchen, and Oxil Group ceramics dominate invariably exhibit the Early Oxkintok/ProtoPuuc A architectural style, which George Andrews (1985) places between 550 and $650 \mathrm{CE}$. The dominant configuration of architecture during this time period is the plazuela, or patio group: a set of structures that surround one or more central patios. As we discuss in the next chapter, such patio groups often housed extended families. Most patio groups can also be called houselots because they are partially encircled by houselot walls and therefore fall into architectural group types 8 through $\mathrm{I} 4$ (chapter 3).

The Early Aak phase is marked by Usil Ware, which is characterized by a brittle paste with calcite temper. Two slipped groups pertaining to this ware, Xanaba $(n=$ $\mathrm{I}, 878)$ and Shangurro $(n=244)$, are native to the northern lowlands. The somewhat frequent presence of thick-walled Xanaba cajetes (plates) and jars and Shangurro bichrome, composite silhouette cajetes with ring bases, suggests that Chunchucmil was well-integrated into the northern lowland interaction sphere. It is possible that in the later part of the Early Classic, Chunchucmil continued to use ceramics that were common across the northern lowlands. Xanaba and Shangurro pottery may have been replaced slowly during the latter part of the Early Classic with a later version of Usil Ware. Chuburna Group pottery, described below, is probably the later version of Usil that replaces the Xanaba Group ceramics.

Timucuy Polychrome $(n=879)$, which has been considered autochthonous to the northern lowlands (Brady et al. 1998; R. E. Smith 1971; Varela Torrecilla 1998:39), was also present at Chunchucmil during the Early Aak phase. Although Timucuy Polychrome has similarities to southern lowland ceramics, this northern lowland ceramic group is less lustrous and is distinct in terms of paste and slip. This pottery has a fragile paste with many carbonates and is generally very pale brown (IoYR $8 / 3$ ). The slips, which do not adhere well to the surface, range from yellowish red (5YR 8/4) to reddish yellow (7.5YR $7 / 8)$. The slip is applied over a calcareous wash of lighter color. The basic decoration of the Timucuy Group is geometric designs painted in red (2.5YR 5/8) and brown ( 5 YR $5 / 8$ ) over a red/orange background. Two forms of Timucuy cajetes have been recovered from Chunchucmil: those with tetrapod supports (Early Aak phase) and those with ring bases (Late Aak phase).

At Oxkintok, the cessation of Timucuy indicates a key marker of the end of the Ichpá ceramic complex of the Early Classic (300-500/550 CE; Varela Torrecilla 1998), precipitating a shift to monochrome and Oxkintok Regional Complex ceramics. At Chunchucmil we do not have concrete dates that indicate that 
Timucuy ceased to be used at the beginning or middle of the sixth century, ( $500 / 550$ $\mathrm{CE})$. Chunchucmil has small quantities of several southern lowland pottery typesBalanza Black $(n=277)$, Lucha Incised $(n=45)$, Paradero $(n=8)$, Pital Incised $(n=$ 8), Dos Arroyos Orange Polychrome $(n=85)$, and San Clemente Gouged/Incised $(n=3)$ that date to the Tzakol $3(400-600 \mathrm{CE})$ tradition.

Unslipped pottery from the Oxil Group, a Yucatán unslipped ware established by Varela Torrecilla (1998), is abundant at Chunchucmil ( $n=62,249$; figure 4.Ii, j). We find Oxil Group ceramics commonly associated with Proto-Puuc A architecture and other Oxkintok Regional ceramic groups at Chunchucmil, not to mention a late Early Classic/early Late Classic radiocarbon date (previously discussed), suggesting that it dates to the Late Aak phase. Further below we note that some Oxil was likely produced in the early part of the Early Classic, with some being produced at the beginning of the Late Classic period. Oxil ceramics are coarse, characterized by a smoothed exterior and a slightly compact, red (2.5YR 5/6 6/6) paste with abundant fine gray and white calcite particles. Jar fragments have fine striations that occasionally combine with incisions resembling corncob impressions (Elote Striated: variety not specified; figure 4.Ih) and, less frequently, incisions in the style of wavy lines (Elote Striated: Mulix variety). Corncob impressions on Oxil at Chunchucmil are less common than at Oxkintok. The typical form of Oxil jars during the Early Classic period is a composite silhouette with elongated neck and short, divergent, thickened rims. Some of the rims found at Chunchucmil have a lip with a shallow groove. In addition to jars, large basins (cazuelas) with ring (annular) bases and bolstered rims are also common. They exhibit carefully smoothed surfaces with fine, oblique striations (Yalchak Striated). Less common in the Oxil Group at Chunchucmil are incensarios with stucco decoration, smoothed and striated with pill-shaped appliqués (Pech Appliqué type).

New studies focusing on form and decoration have established that Oxil ceramics are not merely local to Oxkintok and Chunchucmil. They also have been found at sites in and around modern-day Mérida. Furthermore, at the excavations of the Cathedral of Mérida, Oxil has been found in association with Sierra Red and Chancenote Striated (Jiménez and Ceballos 2000). The rims of these early Oxil pots have a fragile paste, are much shorter and flatter, and often show impressions from the fingers of the potters. A few rim fragments of this kind found at Chunchucmil suggest that some Oxil pottery may date to the Early Aak phase. At Chunchucmil, the paste characteristics and surface treatment of Early Aak Oxil sherds (the ones with the short, flat rims) are basically identical to those of Late Aak Oxil-phase sherds. Therefore, when we assigned Oxil body sherds to the Late Aak phase, we often did so based on the other ceramics that the Oxil sherds were associated with as opposed to the physical characteristics of the pottery. Basically, the ceramic 
pastes of the Oxil group are homogeneous in color and texture. Nevertheless, a petrographic analysis might help to identify differences between Oxil pastes from different phases or to propose that these differences result from local production versus importation from elsewhere.

During the Late Aak phase at Chunchucmil new vessel forms identical to those of Oxkintok emerge. Examples of these forms include the ring-base Maxcanú cazuela with a "double bevel" rim (a projection/flange immediately below an exterior thickened rim), large pitchers, tripod plates with basal flanges and conical or slab supports, and very shallow cajetes with ring bases. This repertoire of forms manifests itself in the Maxcanú, Hunabchen, Kanachen and Aak Groups (figures 4.4f-i; 4.5b-e; 4.6b-e).

Maxcanú Group ceramics from the Early Classic have a medium texture, light red (IoR 6/6, 7/6) paste covered by a slightly lustrous pink (7.5YR 8/4) or yellowreddish (7.5YR 6/6) slip. Maxcanú slip colors get darker over time. Hunabchen Group ceramics have a medium texture, light red (2.YR 6/8) paste with gray calcite particles and a red ( 5 YR 5/8) slip. Sherds from the Kanachen Group $(n=2,573)$ have pastes that are similar to those of the Hunabchen Group but have a slip whose color ranges from very dark grayish brown $\left(2.5 \mathrm{Y}_{3} / \mathrm{I}\right)$ to black (5Y 2.5/I), with abundant pale yellow $\left(5 Y_{7} / 4\right)$ spots.

Two other common Late Aak-phase pottery groups at Chunchucmil are Chuburna $(n=3,503)$ and $\operatorname{Aak}(n=1,768)$. Ceramics in the Aak pottery group were initially classified as Batres Red. Aak forms, such as those in the Ch'ikam type (figures $4.4 \mathrm{~b}$ and 4.5a), are similar to those of the Aguila, Hunabchen, and Maxcanú Groups. Aak has a compact, yellowish red (5YR 5/8) paste similar to that of the Teabo Group and that of the Chaac variety of the Timucuy Group. Chuburna is represented by cajetes with ring bases, cazuelas with double bevels, and jars with short exterior thickened necks (Dzununcan type, figures 4.4a, c, e and 4.5g). Chuburna pastes have carbonates and the slip is smooth to the touch, exhibiting multicolored shades and abundant fire-clouding, which makes it difficult to know if the original color was yellow (2.5Y 8/4), red (2.5YR 5/8), yellowish brown (roYR $5 / 8$ ), or black (roYR 8/I). Finally, the Late Aak phase at Chunchucmil also contains thin ware ceramics from the Chencoh $(n=2,673)$, Kochol $(n=2,323)$, and Acú ( $n$ $=325)$ Groups, which are part of the Oxkintok Regional Complex at the site of Oxkintok (figure 4.5f-i).

In summary, during the Early Classic, the pottery of Chunchucmil is very similar to Oxkintok pottery, as classified by Varela Torrecilla (1998), indicating that residents of both these sites interacted with people and products from the southern Maya lowlands and the Mérida area. Based on our findings, the Aak phase at Chunchucmil can be related in a general manner to the Cochuah horizon of the northern lowlands (Jiménez 2007, Varela Torrecilla 1998). 


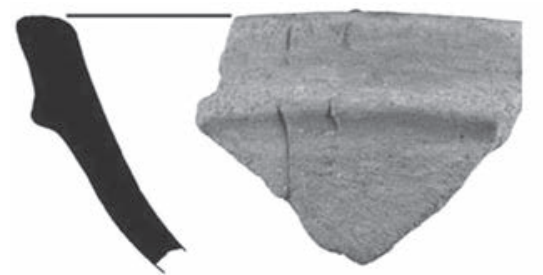

a
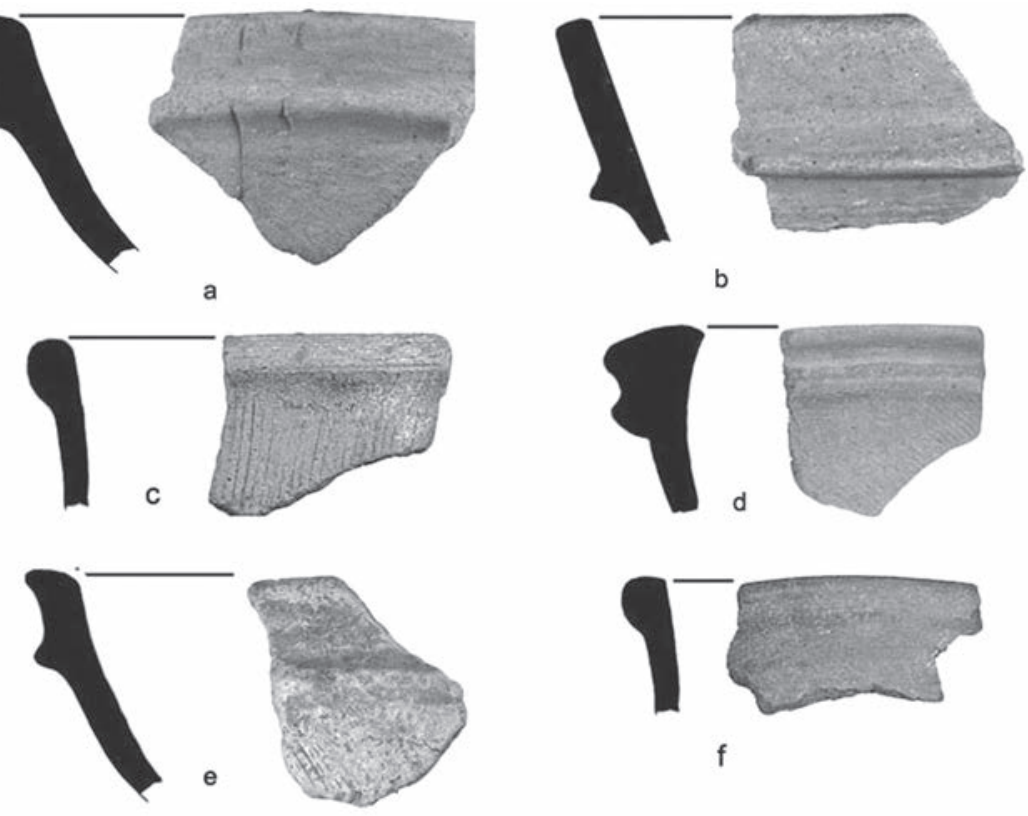

f
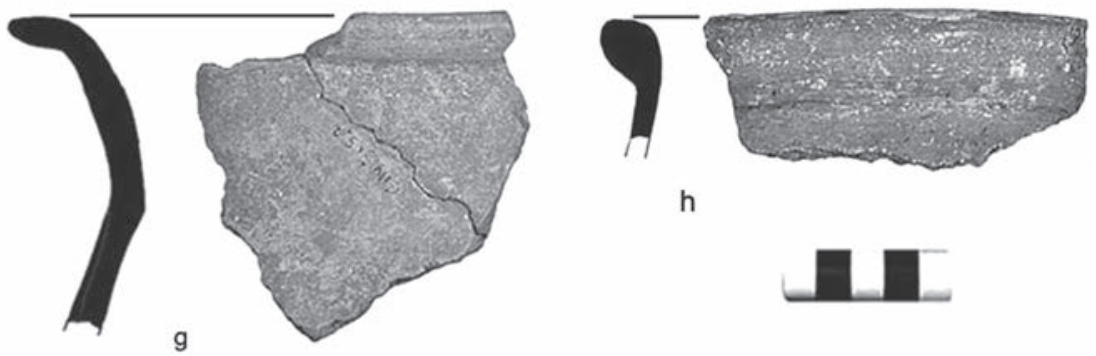

$\mathrm{h}$
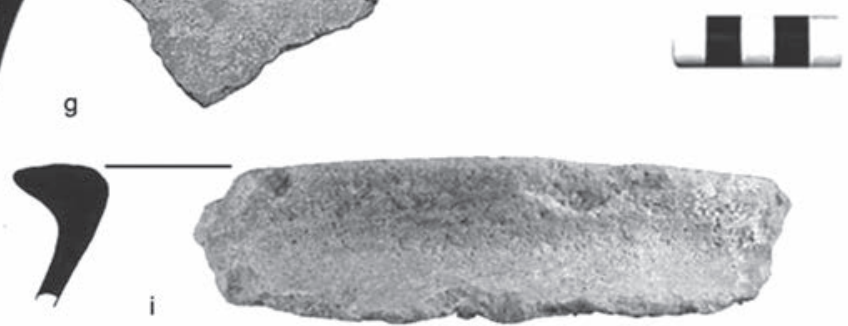

FIGURE 4 4 . Common ceramics types from Chunchucmil II: (a) Dzununcan Striated: Dzununcan; (b) Ch'ikam Composite: Ch'ikam; (c) Tec Composite: Tec; (d) Tiznuk Composite: Tiznuk; (e) Dzununcan Striated: Dzununcan; (f, g) Hunabchen Orange: Unspecified; (h) Hunabchen Orange: Xcamal; (i) Maxcanú Buff: short neck. (Photography by Pedro Tec Chim.) 

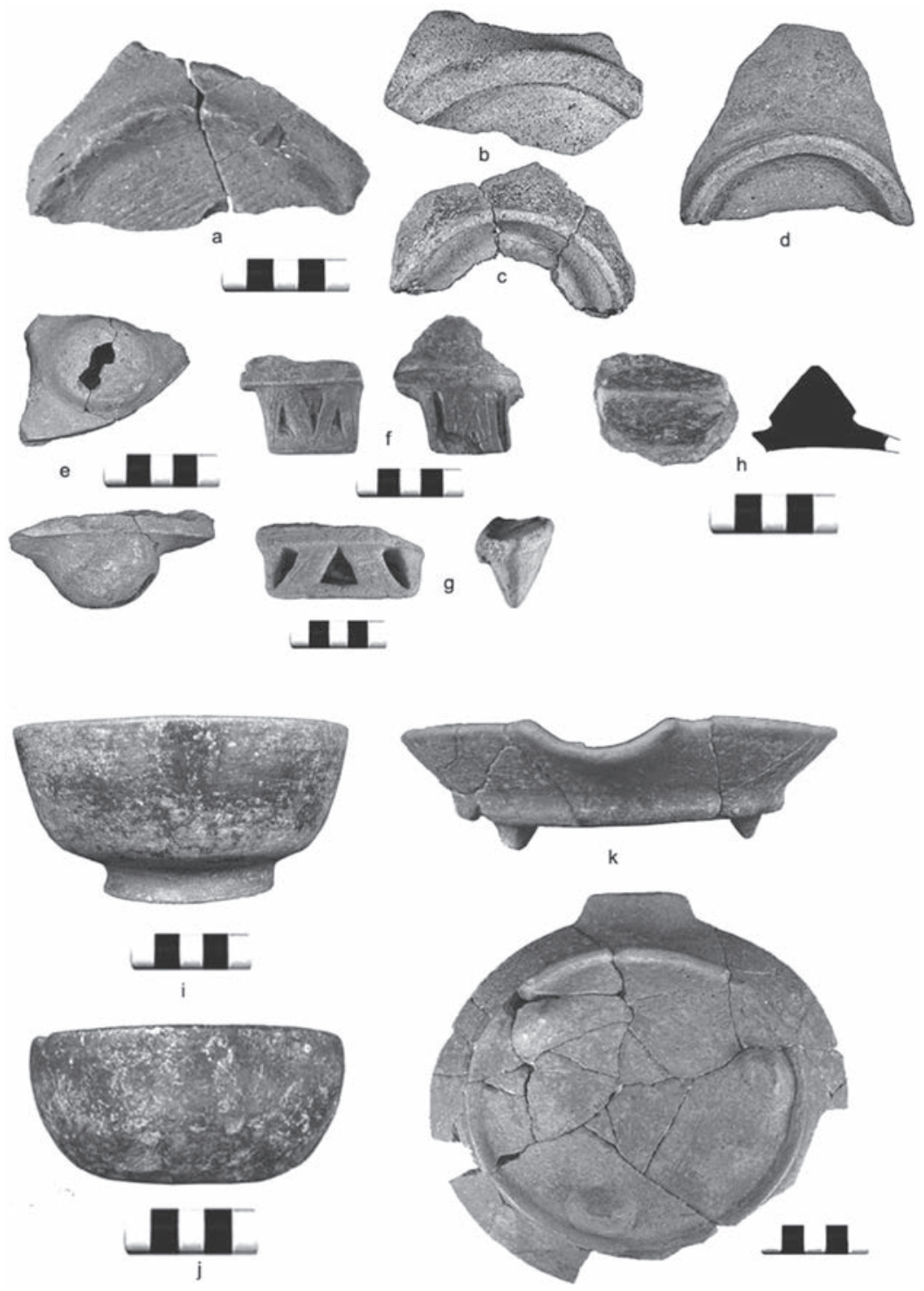

FIGURE 4.5. Common ceramics types from Chunchucmil III: (a) Ch'ikam Composite: Ch'ikam (annular base); (b-c) Kanachen Brown-Black: Unspecified (annular base); (d) Hunabchen Orange: Unspecified; (e) Hunabchen Orange: Unspecified; (f, h) Kochol Black; (g) Chuburna Brown: Chuburna; (i) Chencoh Thin Orange: Chencoh (Structure Kaab 32); (j) Dzibical Black on Orange: Dzibical (Structure Kaab 34); (k) Hunabchen Orange: Unspecified (Structure Kaab 32). (a-g photographed by Pedro Tec Chim; i-k photographed by Aline Magnoni.) 


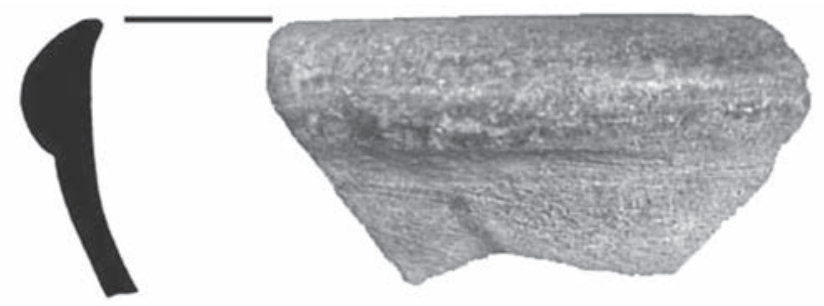

a

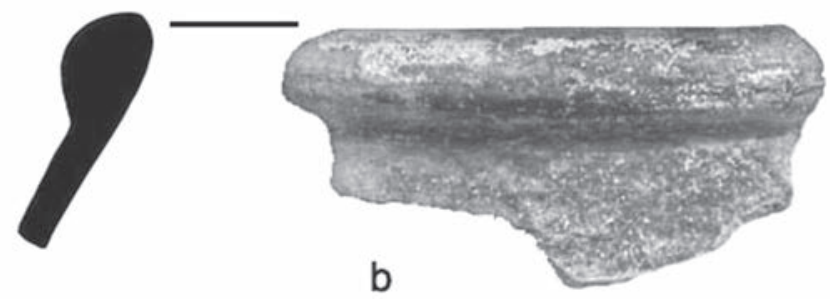

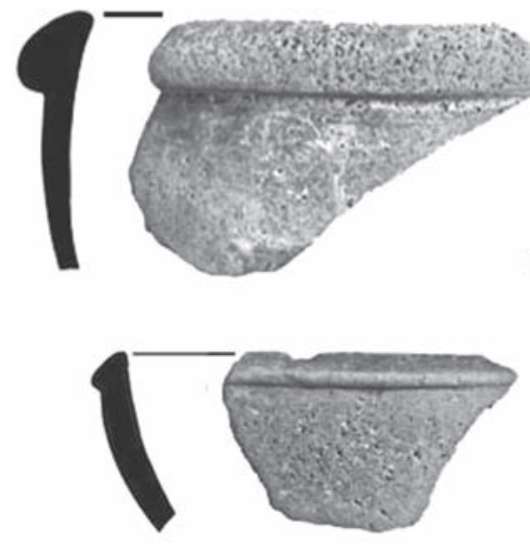

d
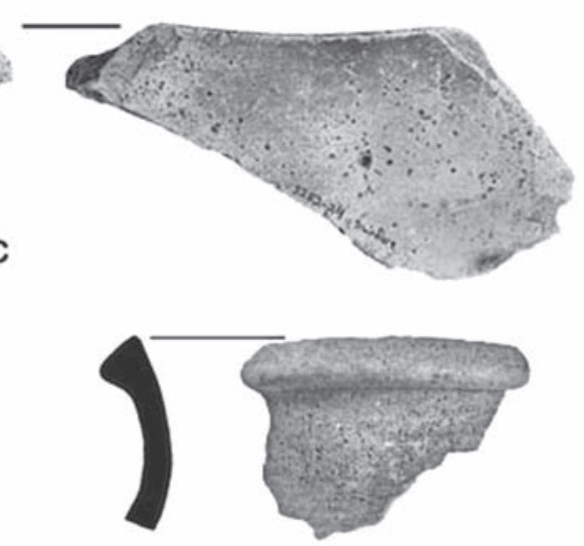

e

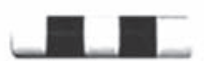

FIG URE 4.6. Common ceramics types from Chunchucmil IV: (a) Yaxuna Pre-pizarra: Unspecified; (b) Hunabchen Orange: Unspecified; (c) Maxcanú Buff: Gray Slip; (d) Chunchictok Striated: Unspecified; (e) Maxcanú Buff: Gray Slip. (Photography by Pedro Tec Chim.)

Chunchucmil reached its apex during the Late Aak phase. Quantifying this in terms of ceramics is difficult for a number of reasons, including that the body sherds from unslipped coarsewares are sometimes difficult to type correctly and the amount of preserved sherds that date to a particular period may say more about the 
durability of pottery from that period or the pottery economies of that period than the intensity of occupation during that period. Nevertheless, looking at slipped sherds alone, anywhere from about 70 percent to 80 percent (the variation depends on what portion of Maxcanú is placed in the Late Aak phase or the subsequent Kaab' phase) of the pottery classified to the type level at Chunchucmil dates to the late part of the Early Classic period. The Late and Terminal Classic periods account for anywhere between Io percent and 20 percent (depending on how the Maxcanú Group is split up) of the slipped pottery from the site.

Albarradas add an important detail to the chronology of the site. In the residential core (see chapter 5 ), where domestic settlement is most dense, albarrada walls act as relatively clear boundary walls that encircle domestic compounds. The albarradas form an interlinked and intelligible system of boundaries and circulation routes (callejuelas) through the site. The fact that these albarradas are intelligibly interlinked throughout the site suggests that they were once part of a living, contemporaneous system. The fact that many of the encircled groups were dominated by Late Aak-phase ceramics suggests that the system of albarradas dates to the Late Aak phase as well. To the extent that the albarradas are a signature feature of the site's spatial organization, we again get the sense that Chunchucmil reached its fullest expression in the Late Aak phase. The fact that the albarradas exhibit a pattern of "filling in" (Hutson 2010; Stanton and Hutson 2012) suggests more specifically that the site reached its apex at the end of the Late Aak phase, which is to say the beginning of the seventh century $\mathrm{AD}$.

Many of Chunchucmil's architectural compounds, such as $\mathrm{S}_{2} \mathrm{E}_{\mathrm{I}} \mathrm{-G} / \mathrm{Kaab}$ ' and $\mathrm{S}_{2} \mathrm{E}_{2}-\mathrm{C} / \mathrm{Aak}$, also were occupied in the early part of the Late Classic (i.e., the seventh century). In both compounds, however, the major architecture was constructed in the late Early Classic. For instance, at Kaab', a Chencoh bowl and a Hunabchen plate with basal flange and slab supports were found in the construction fill of structure 34, the domestic shrine (figure 4.5i, $\mathrm{k}$ ). The fill underneath the floor of Structure 22 in Group $S_{2} E_{2}-\mathrm{F} /$ Aak consisted of sherds coming exclusively from the following groups: Maxcanú, Hunabchen, Kanachen, Timucuy, Chuburná, Aak, Tituc, and Sierra. Though Maxcanú continues into the Late Classic, it is found in association with different pottery during that period (Bond-Freeman and Mansell 2006), as the following section describes.

\section{LATE CLASSIC: KAAB' PHASE (630-750/800 CE)}

The Kaab' phase of the Late Classic period at Chunchucmil consists of ceramic types first established at Oxkintok. On the basis of ceramic offerings from Tomb 7 (Structure $\mathrm{CA}_{5}$ ) and ceramics associated stratigraphically with buildings from 
the Proto-Puuc B architectural subphase and at Structures $\mathrm{CA}_{3}$ and the Satunsat, Varela Torrecilla $(1993,1998)$ defined two ceramic complexes at Oxkintok that pertain to the Late Classic period: Noheb (630-750 CE) and Ukmul I (750-850 CE). Four wares from the Noheb Complex at Oxkintok are common at Chunchucmil: Katil Unslipped (Motul Striated and Acanceh Appliqué-impressed types), Yucatán Glossware (Maxcanú Buff and Hunabchen Orange types), transitional slate (Sat Preslate type), and thin slate (Sabero Thin Preslate type). We have one radiocarbon date, $1392 \pm 76 \mathrm{BP}$, calibrated at $2 \sigma 436-806 \mathrm{CE}$, that likely pertains to the Kaab' phase. The date comes from a burial of an elderly female in Structure 32 of Group $S_{2} E_{1}-G / K a a b$. The burial (Burial I, see also chapter 5) contained two vessels-a Kinich tripod plate and a Dzibical Black on Orange bowl (figure 4.5j) from ceramic types that are rare at Chunchucmil but date to the Late Classic at other sites. Though the $2 \sigma$ range extends back into the Late Aak phase, the pottery offered with this burial suggests that the actual date of this building falls in the latter half of the range.

We begin with the coarse ceramics, which show technological changes over the course of their nearly two-century developmental trajectory in the Late Classic. In this time period at Chunchucmil we see fragments of coarse globular jars with elongated, outcurving necks with striated surfaces (Motul Striated type, figure 4.7g, h; Varela Torrecilla 1993) or smoothed surfaces (long-neck variety of the Oxil Unslipped type, figure 4.7e, f).

A very common ceramic group at Chunchucmil, likely dating to the Late Classic Kaab' with perhaps some production in the Early Classic Late Aak phase, is Katil $(n=16,304$, figure 4.7d, this volume; Magnoni 2008:293). All but one of the Katil Group sherds pertain to the Motul Striated type. The other sherd pertains to Acanceh Appliqué-Impressed. Katil Group jar fragments have deep striations on their surface, giving them a rough texture. Compared to Oxil, Katil sherds are more durable, the calcite temper is more transparent, and the jars have outcurving necks. Katil Group jars typically have shorter necks than Oxil jars.

The Oxil Unslipped type begins in the early Classic and only the long-necked variety of this type (figure 4.7a) continues into the Kaab' phase/early facet of the Late Classic. The number of Oxil sherds reported previously in the Aak phase is likely artificially high because some of the Oxil long-necked variety sherds were accidentally included. It is likely that a small number of Oxil sherds that pertain to the Kaab phase were counted as Aak-phase Oxil sherds. The long-necked variety of Oxil has a light red $(2.5 \mathrm{Y} \mathrm{R} 6 / 4 ; 6 / 8)$ paste with a slightly coarser texture than that of Elote Striated-Impressed from the Early Classic (figure 4.7c). Late Classic Oxil pottery has larger and more angular calcite grains than Early Classic Oxil, giving the later Oxil pottery a rougher texture. Corncob impressions from the Early 


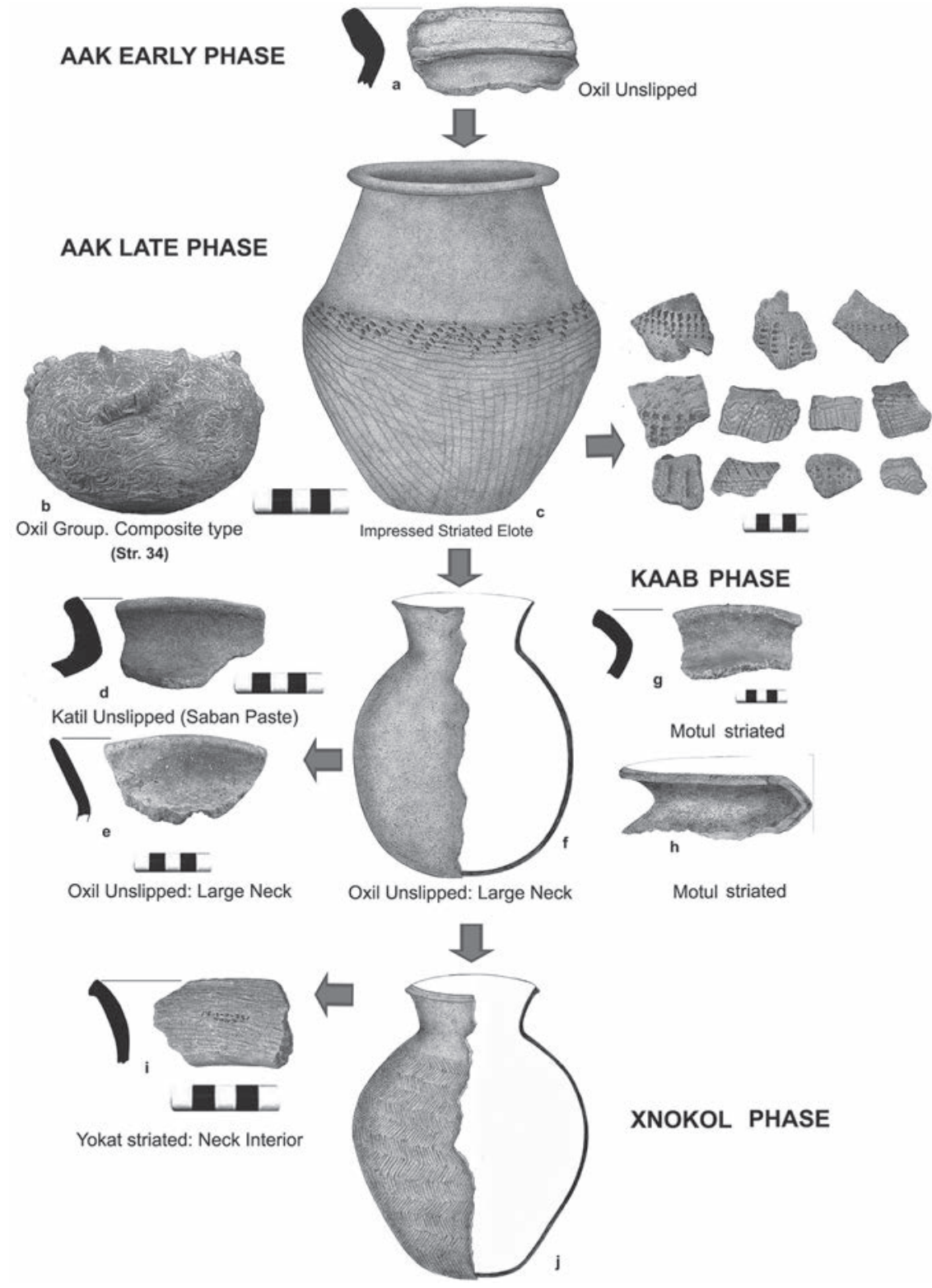

FIGURE 4.7. Technological development of unslipped wares of Chunchucmil. (Photography by Pedro Tec Chim. Drawings by Belem Ceballos Casanova.) 
Classic Oxil Group disappear in the Late Classic, during which only striated and smoothed surface finishes continue.

Yucatán Glossy Ware, another important Kaab'-phase pottery, has a beige/buff slip (Maxcanú Buff) or an orange slip (Hunabchen). Chunchucmil's Maxcanú Buff pottery exhibits a variety of finishes and slip tones, from reddish brown (2.5YR 5/4) to light yellowish brown (IoYR 6/4). Late Classic Maxcanú pottery from Chunchucmil generally lacks the vitrified slips common in Maxcanú Group ceramics from Oxkintok (Varela Torrecilla 1998). Chunchucmil's Maxcanú pottery has lustrous, semilustrous, and cracked slips. This variation suggests that glossy wares with beige slips came from various locations or potting centers.

In the Kaab' phase, Maxcanú cazuelas continue to be made with an exterior flange just below the exterior bolstered rims, although these features are thinner and vessels with this flange (Tiznuk Striated type) no longer have annular bases. Another cazuela form, this time with a very heavily bolstered double rim, appears during this time period as well. These cazuelas are part of the Yaxuná Preslate type, which, similar to earlier types, have roughly striated and smoothed walls (figure 4.6a). Jars from this period (Maxcanú Buff: Conkal variety) no longer feature composite silhouettes, are of globular form, and have thinner, outcurving necks with pinched rims. Tripod plates from the Maxcanú and Hunabchen groups show certain characteristics from the prior period but also display differences. Changes include slightly thinner walls and smaller supports, with Teotihuacan-style supports no longer being used. Also, the basal flange is less prominent.

During the Kaab' phase, two new forms appear, both in the Maxcanú Group. We see basins with lightly thickened rims, folded to the exterior (Chunchintok Striated: variety unspecified; figure 4.6d). These basins have striations but no slip on the exterior. The second form consists of thin-walled bowls similar to TiculThin Slateware that we call Maxcanú Buff: thin-walled variety. The slip of Maxcanú Buff: thin-walled variety is soapy to the touch and very pale brown ( $10 Y R$ 7/4), so translucent in color that a reddish slip color $(5 \mathrm{YR} 6 / 6)$ is visible underneath. The early forms are composite silhouettes from the beginning of the Classic period (Ticul/Sabero) while its late forms, dating to the Late and Terminal Classic period at Chunchucmil, are bowls with beaded rims. Pottery similar to Maxcanú Buff: thin variety at Chunchucmil is found at the site of Oxkintok, which has been considered a production locale (Ancona Aragón 2014:163). Thin-walled bowls similar to Ticul-Thin Slateware have been amply documented in the region; based on paste difference, perhaps some should be reassigned to the Maxcanu Buff: thin variety.

Important Late and Terminal Classic groups such as Muna $(n=2,73 \mathrm{I})$ begin during the early part of the Late Classic and continue for at least four centuries. Kaab'phase slatewares exhibit certain similarities with early slatewares reported by Varela 
Torrecilla (1993). These similarities include deep tripod plates with thick walls and cazuelas with marked cavities in the interior walls and annular bases with flattened lips. These slates are generally monochrome; when they are bichrome, the trickle painting technique is so subtle that it is nearly unnoticeable.

\section{LATE/TERMINAL CLASSIC: XNOKOL PHASE (750/800-1,100 CE)}

By the eighth century $\mathrm{CE}$, Chunchucmil's landscape had undergone significant transformations. Although many residential groups and some quadrangles continued to be occupied into the early part of the Late Classic, nearly all of them were abandoned by the late part of the Late Classic. However, this time period, which we combine with the Terminal Classic, experienced the construction of new buildings that differed significantly from previous architecture. It is difficult to separate ceramics from the early part of the Late Classic (seventh century and early eighth century) from the late part of the Late Classic (late eighth century and the ninth century) and the Terminal Classic because certain groups (e.g., Chum, Muna, and Teabo) were produced throughout the Late Classic and often later. If forced to specify the number of sherds that could be placed in the Xnokol phase, we have I8,512 sherds (12.5\% of the pottery that has been classified at Chunchucmil). The most common pottery from this phase comes from the Chum $(n=14,315)$ and Maxcanu $(n=2,559)$ Groups.

Buildings constructed in the Xnokol phase consist of basal platforms measuring about 40-by-40 m, usually standing between I and $2 \mathrm{~m}$ high. All of these fall into architectural group type 6 (see Magnoni 2008 for more extensive details). We have excavated 16 type 6 platforms and 13 of these have substantial quantities of Xnokol-phase pottery (figure 4.4). In addition to these 13 confirmed Xnokol-phase platforms, we place six other unexcavated type 6 platforms in the Xnokol phase based on the presence of Puuc stonework (three cases), Xnokol-phase pottery on the surface (one case), and close formal resemblance to other Xnokol-phase platforms (two cases; Magnoni 2008). All of these platforms are located close to the site center (figure 4.8). Xnokol-phase platforms differ from earlier constructions in many ways. First, they are generally higher than earlier basal platforms. Second, they are never encircled by houselot walls. On the contrary, the builders of these platforms often located them in such a way that they disrupted earlier patterns of albarradas, streets, and sacbes. The builders often scavenged stone from these earlier features as well. Third, many of them have Early Puuc veneer stonework that is still standing, tumbled Classic Puuc cut stones found in association, or Puuc-style banner stones. Early Puuc and Classic Puuc architectural styles date from 650 to 1050 CE (G. F. Andrews 1985). Fourth, these platforms have more metates than earlier 


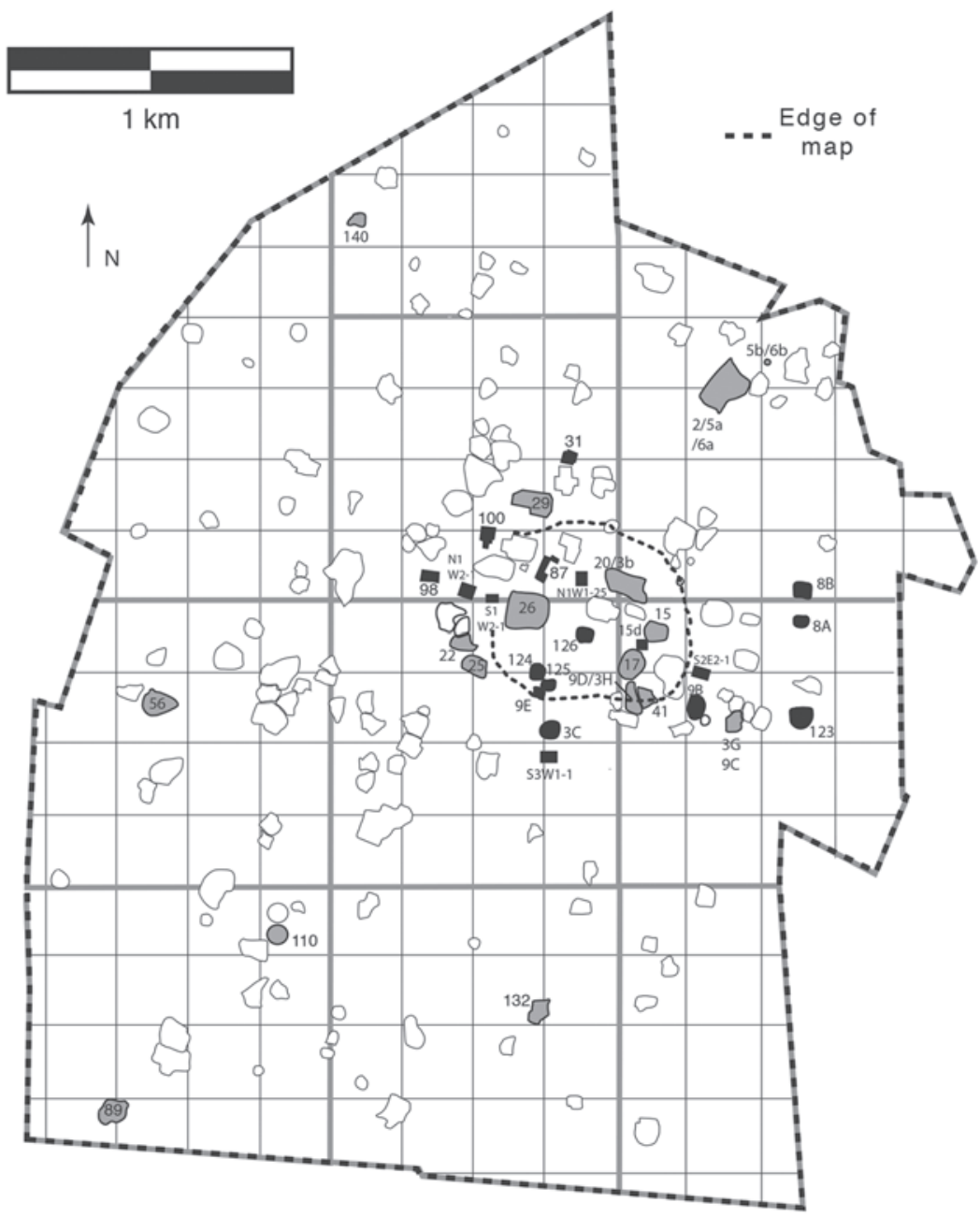

FIGURE 4.8. Map highlighting groups with Late/Terminal Classic pottery. The I 9 groups in black consist of platforms built in the Late/Terminal Classic. The groups in gray were built in the Early Classic but 10\% of their classifiable pottery tentatively dates to the Late/Terminal Classic. The dotted ring shows the location of the defensive barricade.

architectural groups: an average of io per platform compared to the site average of two metates per architectural group. Finally, none of these constructions features Plaza Plan 2 arrangements (Becker 199I), a common layout in earlier Chunchucmil houselots in which a shrine is located on the east side of the group. In Xnokol-phase 
platforms, the amount of Late and Terminal Classic sherds as a proportion of the total classifiable sherds ranges from 1.6 percent to 46.I percent. The high amounts of earlier ceramics recovered from these platforms suggests that in many cases the Late/Terminal Classic platforms engulfed earlier constructions.

Several Late Aak-phase patio groups also have respectable amounts of sherds from the pottery groups that we place in the Xnokol phase, indicating that they could have been occupied in the Xnokol phase. For example, table 4.5 lists 17 architectural groups that lack the kind of Late/Terminal Classic construction discussed above but that have io percent or more of their pottery assigned to the Late/ Terminal Classic (figure 4.8). These data suggest that the Late/Terminal Classic occupation of the site was not limited to the 19 broad, high, Xnokol-phase platforms. In these groups it is not clear what architecture would have been associated with this later occupation. Extensive excavations on structures would be necessary to understand if the Early Classic architecture still visible on the surface of these residential groups was still in use during the Late/Terminal Classic.

Beginning in 850/900 CE, Chunchucmil's ceramics show important changes in manufacturing technology as well as in decorative styles. Maxcanú Group pottery in the Xnokol phase changes in paste texture and surface finish. The paste is hard and compact and shows a nucleus that is pink (7.5 YR 8/3), light grayish (IOYR 7/2), or red (2.5YR 5/6) while the edges are lighter (pale yellow, 2.5Y/2/8.5). The paste contains abundant small inclusions as well as medium-sized white calcite. The slip is gray $(4 / \mathrm{N})$, light gray $($ IoYR $7 / \mathrm{I})$, or light gray/brown (IOYR 6/2) with abundant reddish gray (2.5YR 6/I) fire-clouds. The slip is porous and its texture ranges from rough to lightly soapy (Gray/White Slipped variety of Maxcanú Buff type). The changes in color and surface finish in the Maxcanú Group have been documented previously in the ceramics of Sihó (Jiménez Álvarez et al. 2006:487, figure 3) and Santa Bárbara (Stanton and Jiménez 2007).

The Late/Terminal Classic Maxcanú Group retains many of the forms and decorations of the previous Kaab' phase. Cazuelas with massively bolstered rims of the Yaxuná Preslate type, bowls with lightly thickened rims folded to the exterior (Chunchintok Striated type), and jars with outcurving necks and pinched rims (Maxcanú Buff: Conkal variety) continue to be produced but now with a lighter and less glossy slip color. These forms are not present in Muna Slate pottery. Although differences exist in paste, form, and finish between Muna and Maxcanú, these differences can be subtle and confusion between Maxcanú pottery and Muna Slateware can exist if special attention is not paid when examining the two ceramic groups.

Maxcanú decorations from the Kaab' phase continue to appear in the Xnokol phase. In this phase, black trickle paint becomes more common and the same impressed motifs are found on jars and drums. Black trickle paint is only found on 
TABLE 4.4. Platforms built in the Late and Terminal Classic periods. The two at the bottom are probable but not confirmed.

\begin{tabular}{|c|c|c|c|c|c|c|c|}
\hline $\begin{array}{c}0 \\
\frac{0}{2} \\
\frac{2}{3} \\
5 \\
5\end{array}$ & 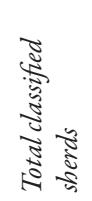 & 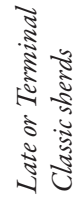 & 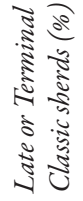 & 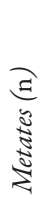 & 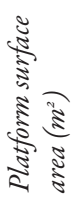 & $\begin{array}{l}\sqrt{5} \\
\frac{5}{5} \\
\frac{5}{5} \\
\frac{5}{5} \\
\frac{5}{5}\end{array}$ & 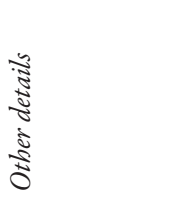 \\
\hline 98 & $I, 570$ & 724 & 46.1 & 8 & 2,204 & $\mathrm{I} .3$ & Column drum \\
\hline $8 B$ & I 47 & 64 & 43.5 & 8 & $\mathrm{I}, 324$ & 0.6 & $\begin{array}{l}\text { Puuc } \\
\text { stonework }\end{array}$ \\
\hline $8 \mathrm{~A}$ & I 86 & 56 & 30.1 & 22 & $\mathrm{I}, \mathrm{I} 7 \mathrm{I}$ & I.O & $\begin{array}{l}\text { Puuc } \\
\text { stonework }\end{array}$ \\
\hline $\begin{array}{l}{ }_{9 \mathrm{~B} /} \\
\text { Xnokol }\end{array}$ & 4,720 & 1,306 & 27.7 & 19 & 2,162 & I.O & $\begin{array}{l}\text { Puuc } \\
\text { stonework }\end{array}$ \\
\hline 87 & 962 & 264 & 27.4 & 0 & 2,556 & 1.0 & $\begin{array}{l}\text { Puuc } \\
\text { stonework }\end{array}$ \\
\hline 90 & 100 & $2 I$ & 21.0 & 8 & 725 & I.O & \\
\hline $3 \mathrm{I}$ & I 2,406 & $\mathrm{I}, 8 \mathrm{I} 3$ & I 4.6 & IO & $\mathrm{I}, 882$ & I.O & $\begin{array}{l}\text { Puuc } \\
\text { stonework }\end{array}$ \\
\hline 100 & 5,983 & 873 & I 4.6 & IO & $2,05 \mathrm{I}$ & I. 6 & $\begin{array}{l}\text { Puuc } \\
\text { stonework }\end{array}$ \\
\hline${ }_{3} \mathrm{C}$ & $I, 425$ & 136 & 9.5 & 6 & 1,670 & 2.3 & $\begin{array}{l}\text { Puuc } \\
\text { stonework }\end{array}$ \\
\hline 123 & 2,439 & IOI & $4 \cdot I$ & 9 & 3,058 & 0.6 & Column drum \\
\hline 126 & $\mathrm{I}, 594$ & 63 & 4.0 & 17 & 1,406 & I. 2 & $\begin{array}{l}\text { Puuc } \\
\text { stonework }\end{array}$ \\
\hline I $24 / 3 \mathrm{~K}$ & 1,730 & 57 & $3 \cdot 3$ & I 3 & 1,257 & 1.5 & $\begin{array}{l}\text { Puuc } \\
\text { stonework }\end{array}$ \\
\hline 125 & 364 & 6 & I. 6 & 9 & $\mathrm{I}, \mathrm{I} 25$ & I.O & Column drum \\
\hline $\mathrm{S}_{2 \mathrm{e} 2-\mathrm{A}}$ & na & na & na & IO & 2, I I I & I.O & $\begin{array}{l}\text { Puuc } \\
\text { stonework }\end{array}$ \\
\hline SIW2-A & na & na & na & 3 & 983 & I.O & $\begin{array}{l}\text { Puuc } \\
\text { stonework }\end{array}$ \\
\hline $\begin{array}{l}\mathrm{N}_{\mathrm{I}} \mathrm{W}_{\mathrm{I}}- \\
\text { 25/west } \\
\text { Chakah }\end{array}$ & na & na & na & 7 & 2,076 & 2.0 & $\begin{array}{l}\text { Puuc } \\
\text { stonework }\end{array}$ \\
\hline $\begin{array}{l}\mathrm{S}_{\mathrm{I}} \mathrm{E}_{\mathrm{I}-\mathrm{D} /} \\
\text { Op. I } 5 \mathrm{D}\end{array}$ & na & na & na & IS & $\mathrm{I}, 2 \mathrm{IO}$ & I.O & $\begin{array}{l}\text { Late/Terminal } \\
\text { Classic pottery } \\
\text { on surface }\end{array}$ \\
\hline$s_{3} W I-A$ & na & na & na & I 3 & 900 & $\mathrm{I} .8$ & \\
\hline niw3-O & na & na & na & I I & 2,907 & I.O & \\
\hline
\end{tabular}


TABLE 4.5. Excavation operations with Late Early Classic/Early Late Classic architecture that nevertheless have significant amounts ( $10 \%$ or more of the entire assemblage) of Late Classic/ Terminal Classic ceramics.

\begin{tabular}{|c|c|c|c|}
\hline Operation & Total classified sherds (n) & $\begin{array}{l}\text { Late or Terminal } \\
\text { Classic sherds (n) }\end{array}$ & $\begin{array}{l}\text { Late or Terminal } \\
\text { Classic sherds (\%) }\end{array}$ \\
\hline 26 & 656 & I 89 & 28.8 \\
\hline 132 & 1,852 & 486 & 26.2 \\
\hline I7 & 283 & 70 & 24.7 \\
\hline 2 & 740 & 182 & 24.6 \\
\hline 25 & 201 & 44 & 21.9 \\
\hline 20 & 839 & I 54 & I 8.4 \\
\hline 22 & I 54 & 27 & 17.5 \\
\hline Aak & 17,335 & 3,005 & 17.3 \\
\hline I IO & 107 & 16 & 15.0 \\
\hline 89 & 78 & II & I 4.I \\
\hline 56 & 492 & 69 & I 4.0 \\
\hline $4 \mathrm{I}$ & 61 & 8 & I3.I \\
\hline Kaab & II, 968 & 1,565 & I3.I \\
\hline 15 & 109 & I 3 & II .9 \\
\hline I 40 & 164 & I 8 & II.O \\
\hline 29 & 1,223 & I 27 & 10.4 \\
\hline $5 b / 6 b$ & 268 & 27 & IO.I \\
\hline
\end{tabular}

cazuelas: in the jars and drums it shows up as almost imperceptible dark brown, vertical lines, possibly painted before firing. This pottery has been classified as Sacalum Black on Slate in various ceramic collections from northern Yucatán, such as the Oxkintok collection in the INAH Yucatán Ceramoteca. At Chunchucmil, we refer to it as Tacopate Trickle, Gray/White Slip variety (part of the Maxcanú Group).

The Xnokol-phase pottery from Chunchucmil also consists of rough pottery with long, outflared necks (Yokat Striated: Interior Neck variety, figure 4.7i, j), Dzitas Slateware, and slates with forms that are common to slatewares from elsewhere in northern Yucatán (chultun-like ollas, tripod plates, and ring-base bowls with beveling on the exterior rim). The Gray/White Slipped variety of Maxcanú often comes in these same forms. The paste of slatewares from Chunchucmil is less compact than true Muna Slatewares and has visible gray and white calcite particles. With the exception of the paste, these plates and chultun-like jars are physically similar to Muna Slate pottery and have been preliminarily placed into the Muna Group. 
We have found fine orange paste pottery in association with Maxcanú and Muna at Chunchucmil. Fine gray pottery appears at Chunchucmil with characteristics that are typical of the lower Usumacinta River. Since Chunchucmil's fine gray pottery exhibits similarities with fine gray pastes reported in other parts of the Maya area, we assign it to $750 \mathrm{CE}$ or after (Ancona Aragón and Jiménez Álvarez 2005; Muñoz 2006; Rands et al. 1982).

The majority of Xnokol-phase ceramics come from off mound test pits and are found intermixed with earlier materials. In some of these excavations one can distinguish abundant quantities of Muna or Maxcanú of the Gray/White variety also in association with the Kukulá Group and a bit of Sotuta Complex pottery. This is interesting because such associations suggest a later date within the $750 / 800$ to 1000 CE time range. Only three test pits penetrated the construction fill of the Xnokol platform and these reveal more or less pure Xnokol-phase pottery. In contrast, pottery deposits from construction fill of most of the earlier buildings are mixed, consisting of sherds from multiple periods, Preclassic to Late Classic (Magnoni 2008).

\section{POSTCLASSIC PERIOD (1100-1542 CE)}

Archaeological evidence for the Postclassic period (IIOO-I55O CE) is limited to small amounts of sherds found at a few locations across the site. Our excavations have produced a total of 297 Postclassic sherds, classified to the Mama $(n=114)$, Navulá $(n=107)$, and Kukulá $(n=76)$ groups. This pottery comes from I 8 different operations at Chunchucmil (see table 4.6, figure 4.9). Although only 13 Postclassic sherds came from Op. 4I (Group S2EI-E), these sherds make up 21.3 percent of the pottery that has been identified to type from this operation. Approximately 75 percent of the pottery from this group dates to the Late Aak and Kaab' phases and the size and layout of the buildings resemble those of other groups dating to the Classic period. Thus, it appears that the architecture we see today was not built in the Postclassic. Rather, the area could have been used in some small capacity during the Postclassic period. In the other 17 operations that yielded Postclassic pottery, these sherds never make up more than 5 percent of the total.

No clear evidence for permanent occupation and no definite structures in use during the Postclassic have been identified. Excavations as part of the regional survey (see chapter 8) have also not revealed any Postclassic occupation. A Postclassic depopulation was also documented by Costa Maya surveys conducted in the region north of Chunchucmil by A. P. Andrews and Robles Castellanos (2004). Whereas the Costa Maya project found I3O sites with Terminal Classic occupation, only 21 sites had Postclassic sherds. The major contact-period sites in the Costa Maya survey region-Kinchil, Tetíz, Hunucmá, Ucú, and Caucel—are villages and towns 
TABLE 4.6. Excavation operations that uncovered Postclassic pottery.

\begin{tabular}{|c|c|c|c|c|c|c|}
\hline Operation & Kukula & Navula & Mama & $\begin{array}{c}\text { Total } \\
\text { Postclassic } \\
\text { sherds (n) }\end{array}$ & $\begin{array}{c}\text { Total } \\
\text { classified } \\
\text { sherds (n) }\end{array}$ & $\begin{array}{l}\text { Postclassic } \\
\text { sherds (\%) }\end{array}$ \\
\hline $4 I$ & & IO & 3 & 13 & 6I & 21.3 \\
\hline 66 & & I & 17 & I 8 & 288 & 6.3 \\
\hline $4 a$ & & 2 & 13 & 15 & 312 & 4.8 \\
\hline $3 c$ & & 49 & 9 & 58 & 1,425 & 4. I \\
\hline Xnokol & 67 & 16 & 46 & I 29 & 4,720 & 2.7 \\
\hline $9 \mathrm{e}$ & & I & I & 2 & 100 & 2.0 \\
\hline 15 & & I & I & 2 & 109 & I. 8 \\
\hline${ }_{9 f}$ & 2 & 4 & 16 & 22 & $I, 46 \mathrm{I}$ & 1.5 \\
\hline $6 \mathrm{~b}$ & & 2 & 2 & 4 & 268 & 1.5 \\
\hline 36 & & I & & I & 137 & 0.7 \\
\hline $8 \mathrm{~b}$ & & I & & I & I 47 & 0.7 \\
\hline 38 & & I & & I & 201 & 0.5 \\
\hline 20 & & 2 & & 2 & 839 & 0.2 \\
\hline 26 & & & I & I & 656 & 0.2 \\
\hline 60 & & 2 & & 2 & $\mathrm{I}, 348$ & 0.1 \\
\hline 136 & I & & I & 2 & 3,644 & 0.1 \\
\hline Aak & I & 3 & 4 & 8 & 17,335 & 0.0 \\
\hline $3 \mathrm{I}$ & 4 & & & 4 & $\mathrm{I} 2,406$ & 0.0 \\
\hline Totals & 75 & 96 & II4 & 285 & 45,457 & 0.6 \\
\hline
\end{tabular}

that still exist today and likely conceal underlying Postclassic settlement.

\section{HISTORIC-PERIOD CHUNCHUCMIL}

The village of Chunchucmil is the closest modern settlement to ancient Chunchucmil, lying $2 \mathrm{~km}$ to the west of the site core. Archival research by Tony Andrews (200I) provides information about the historic-period occupation of Chunchucmil. The earliest documentation of any settlement where the contemporary village of Chunchucmil is located comes from 1783 , when a resident of Maxcanú who owned the ranch at Kochol, located about $4 \mathrm{~km}$ to the southeast of the ancient site core (see figure I.2), established a ranch at what would become the village of Chunchucmil by buying a well and the land surrounding it. We are less familiar with the historic 


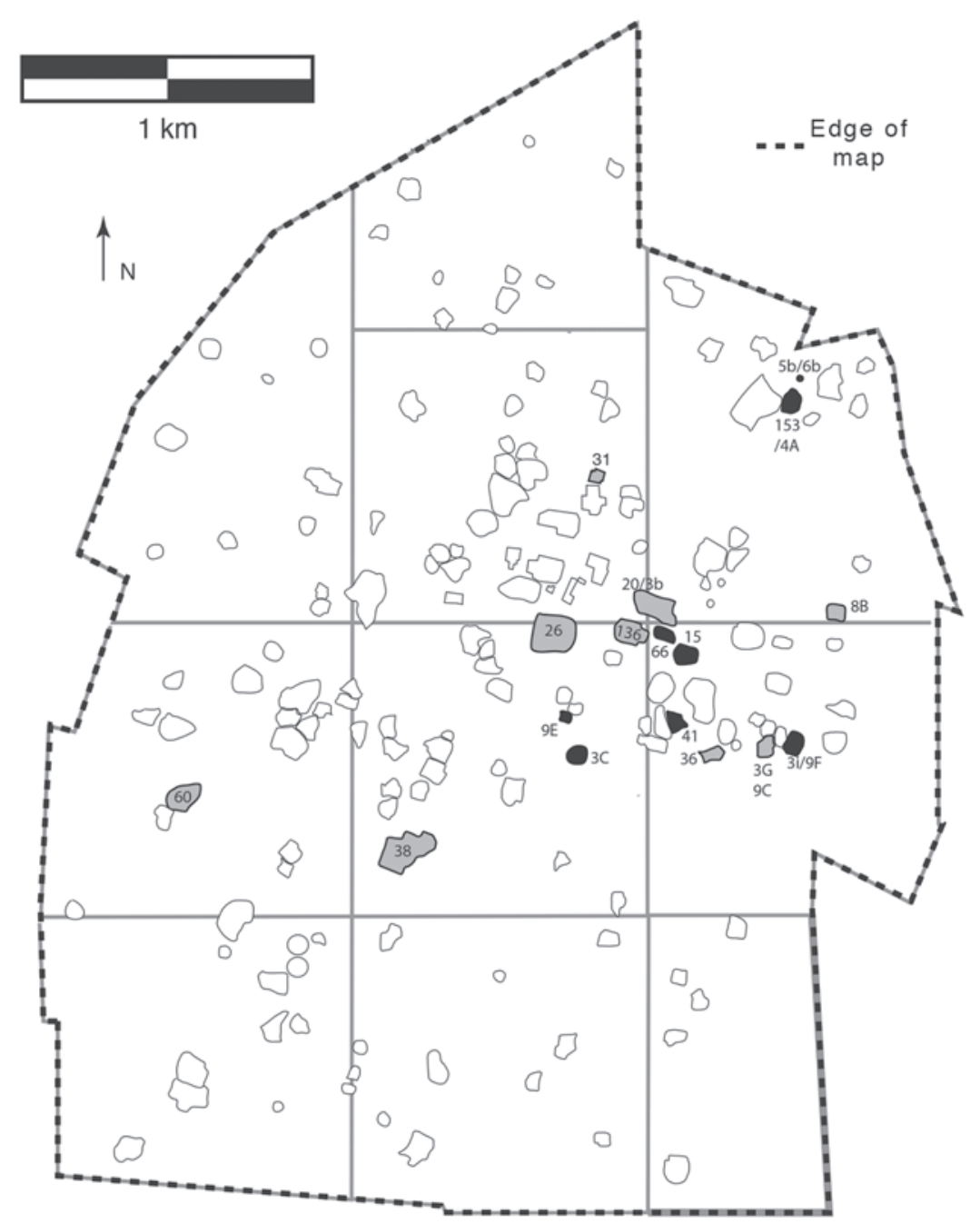

FIGURE 4.9. Map highlighting groups with Postclassic pottery. In the groups in black, at least $\mathrm{I} \%$ of the pottery recovered dates to the Postclassic. Groups in gray have at least one Postclassic sherd but Postclassic pottery makes up less than $\mathrm{I} \%$ of the classifiable sherds.

occupation of Kochol, today a modern village, though we know that it dates at least to the early eighteenth century. In a 1798 map of the area, an unnamed town appears in the precise location of the modern village of Chunchucmil. The core of the Classicperiod ruins is located about $2 \mathrm{~km}$ to the east of the modern-day village. In the early 
I80os, Simon Peon acquired Chunchucmil. The powerful Peon family owned several haciendas in what is now northern Campeche and western Yucatán and held on to Chunchucmil until the mid-twentieth century. In I828, Chunchucmil, with 46 residents, appears in the documents as a parish of Maxcanú. On Simon Peon's invitation, Stephens and Catherwood visited Halachó, Sihó, Maxcanú, and Oxkintok, all visible in figure 1.2, but not Chunchucmil (Stephens 1843:109-145). The large buildings visible in the center of contemporary Chunchucmil began to be built in I872, under the direction of Rafael Peon Losa, who established Chunchucmil as a henequen plantation, or hacienda. By 1906, when Mexican president Porfirio Díaz visited Chunchucmil, the hacienda consisted of, among other things, a house (the casa principal) for Peon Losa's family, buildings for processing and storing henequen fiber, a chapel, a store, small living quarters for the more-or-less enslaved Maya labor force, and a network of narrow-gauge rails to cart agave spears from the fields to the hacienda. In the late 1930 s, as part of nationwide land reform, most of the hacienda land was expropriated and became the core of the Chunchucmil ejido, a communal land-holding corporation controlled by former hacienda workers. Today, approximately I,200 people live in Chunchucmil, which is in the municipality of Maxcanú. In the nineteenth and twentieth centuries, Chunchucmil's economy was connected to the coast in ways that we believe resemble ancient Chunchucmil's Classic-period economy. We explore these resemblances in chapter 12.

\section{DEFENSIVE BARRICADE}

One of Chunchucmil's most intriguing settlement features has been only roughly dated thus far: a rubble wall enclosing 35 ha of the site core (see figures 4.8, 5.I). Dahlin (2000) proposed that this was a defensive barricade, explaining that a 340-m gap on its west side exists because the people of Chunchucmil, not anticipating an attack, constructed it in haste, confronting enemies coming from the east. In some cases the wall was built on top of sacbes and structures. The wall was definitely erected after the Kaab' phase, since it ran over Structure 32 of the group $S_{I} E_{2}-E /$ Kaab', which was built in the Kaab' phase. The group as a whole was occupied until the beginning of the Xnokol phase. We do not think the barricade could have been built across the Kaab' architectural group while it was still occupied. This gives the wall a Late/Terminal Classic terminus post quem, likely being built when most of Chunchucmil was abandoned and the population consisted of the occupants of the I9 type 6 platforms listed in table 4.4 and a small number of houselots. Such a late construction date for the barricade would explain why several large architectural groups dating to the Early Classic, including the quadrangle with the second-largest pyramid ( $\mathrm{S}_{\mathrm{IE}}$ 2-B/Pomoche/Op. 19), were left outside this walled enclosure. It is 
unclear, though, exactly when the wall was built, since it does not clearly articulate with architecture of a specific time period. The wall might have been built after the Late/Terminal Classic, since the builders left more type 6 platforms from the Late/ Terminal Classic period outside of the wall than inside.

\section{CONCLUSION}

Though we recovered ceramics from the Middle Preclassic to the Postclassic, Chunchucmil's major occupation occurred during the late facet of the Early Classic. Population boomed in the fifth century and reached its apogee at the end of sixth century. An appreciable but much-reduced occupation in the seventh century eventually dwindled in the eighth century to less than a tenth of the site's previous maximum size. In the following chapter we discuss the size, zonation, and demography of Chunchucmil when the city was at its peak and reflect on urban life in its three zones. 


\title{
Chunchucmil's Urban Population
}

\author{
Scott R. Hutson, Aline Magnoni, Traci Ardren, \\ Chelsea Blackmore, and Travis W. Stanton
}

The previous chapter established that nearly all of what we mapped at Chunchucmil was occupied at the end of the Early Classic period. This allows us to combine mapping and excavation to discuss the structure of the city at this critical time. As we explain below, settlement in and around Chunchucmil was not homogeneous. We lump this settlement into five zones each with different characteristics: (I) site center, (2) residential core, (3) residential periphery, (4) settlement fingers, and (5) hinterland. This chapter presents the characteristics (size, settlement density, kinds of occupation) of these zones and then supplies a population estimate. One of the most surprising characteristics of the first zone we discuss-the site center-is that it lacks the features of a regal-ritual center. In other words, unlike many other Maya sites, Chunchucmil was not built to host massive ceremonies celebrating the glory of a ruler. Whereas such ceremonies are said to have attracted people to other Maya cities, something else must have drawn people to Chunchucmil.

The very high density of structures in the next zone-the residential core, with over I,000 structures per square kilometer-suggests that quite a lot of people were indeed drawn to Chunchucmil. Settlement in the residential periphery is less than half as dense as settlement in the residential core, but still high compared to many Maya cities (Culbert and Rice 1990:table 1.2). We estimate Chunchucmil's population after completing two tasks. First, we need to get a better handle on the functions of the structures in these zones. We cannot assume that every building was a house (Haviland 1966). Therefore, in addition to discussing each zone 
in the aggregate, we also describe one excavated architectural group from each of the most populous zones: the site center, the residential core, and the residential periphery. These descriptions communicate a deeper sense of what life was like in the city. Second, since our map does not cover the entire city, we have to estimate how much of the city lies beyond our map and project what portions of that area pertain to what zones. Though the residential core encircles the site center and the residential periphery encircles the residential core, Chunchucmil is not concentric in the sense discussed by Burgess (1925): the two ring-like residential zones contain neither different industries nor people of different social classes or ethnicities. After distinguishing the residential periphery from the final two zones-settlement fingers and hinterland-we conclude with population estimates.

\section{THE SITE CENTER}

The site center as we have drawn it in figure 5.1 covers approximately $0.55 \mathrm{~km}^{2}$. The site center boundary in figure 5.I should not be considered sharp. Both the site center and the zone that encircles it - the residential core-have albarradas, callejuelas, and residential groups. However, the site center stands out in many ways. First, it has a heavy concentration of sacbes, open spaces, and buildings over eight meters tall, all three of which are much less common in the residential core. Second, the site center contains the site's major marketplace and the only ballcourt. Finally, the stone barricade (figure 4.8) roughly follows what we consider to be the approximate boundaries of the site center, even though this feature was built late in the site's history (see chapter 4 ).

Table 5.I shows that the site center also differs from the residential core in subtle ways. For example, compared to the residential core, the site center has more structures per group ( 8.29 vs. 5.26) and more platforms per group (I.25 vs. 0.94). The fact that the site center has more monumental compounds and that some of these compounds have relatively large numbers of structures and platforms explains this discrepancy. The site center also has double the amount of metates per group compared to the residential core (4.2 per group vs. 2.I per group; see table 5.I). The gross number of metates per structure is also higher in the site center. Removing the Xnokolphase platforms (which have lots of metates) from the calculation does not alter this conclusion. Extra food preparation for ceremonies in the site center might explain this abundance of metates in the site center. Finally, the number of quarries, sascaberas, and depressions per group is larger in the site center than the other zones, but when measured per structure, the site center and the residential core have remarkably similar numbers of these features. Both have fewer than the residential periphery (table 5.I). We did not calculate the volume of quarries, sascaberas, and depressions. 


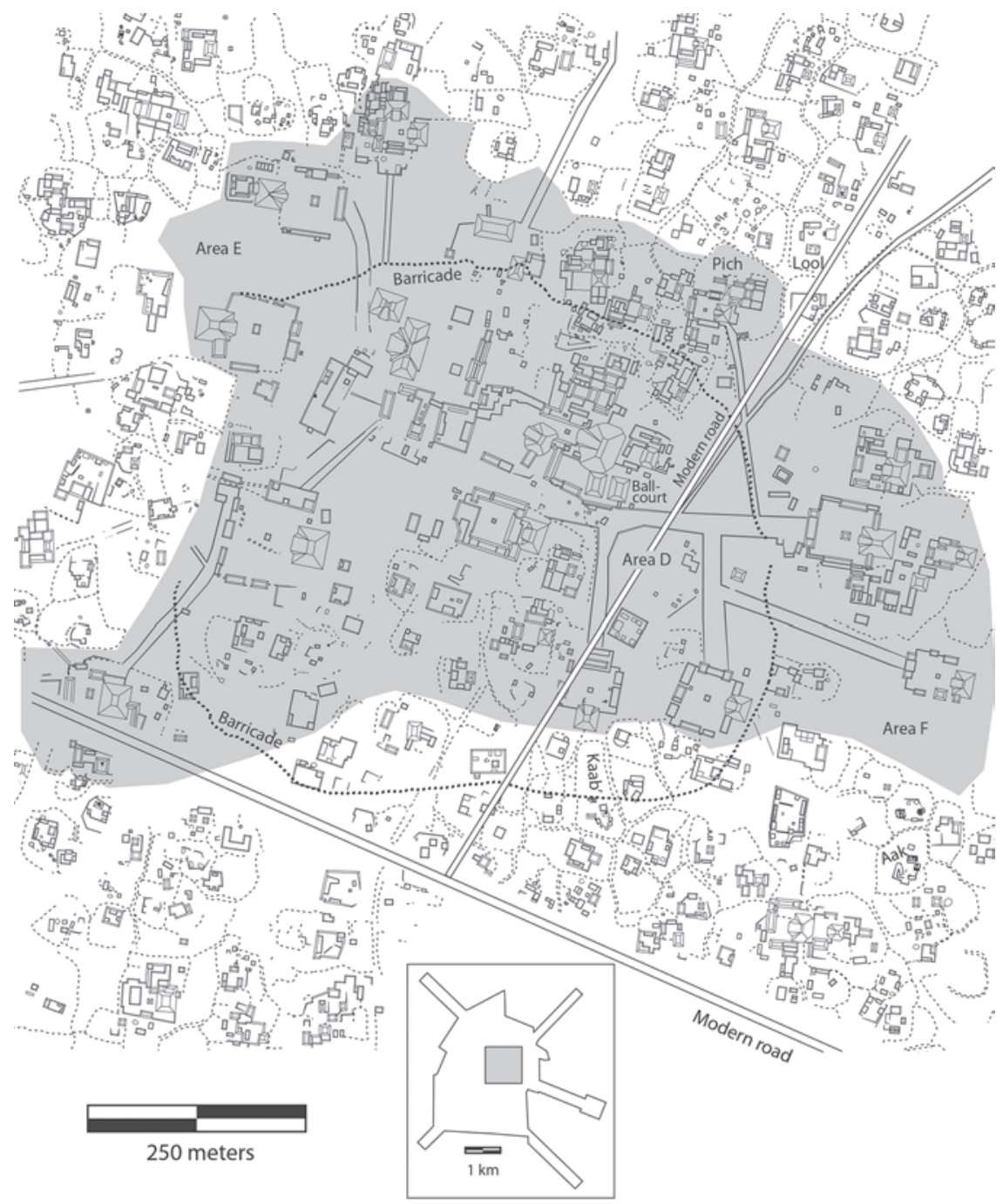

FIGURE 5.I. A portion of the Chunchucmil map showing the site center (shaded in gray) and a portion of the surrounding residential core. The inset box at the bottom of the figure shows the location of this portion within the fully mapped area at Chunchucmil.

As noted in the introduction, Chunchucmil's site center does not look like that of a regal-ritual site. According to Sanders and Webster (1988), who draw upon Fox (1977), the function of a regal-ritual center is to demonstrate the power of the king. Since power was demonstrated though ritual performance, a regal-ritual center 
TABLE 5.I. Quantities of mapped features and their distribution across the three major zones of Chunchucmil.

\begin{tabular}{|c|c|c|c|}
\hline & Site center & Residential core & Residential periphery \\
\hline Groups & 63 & 1,005 & 325 \\
\hline Structures & 522 & 5,287 & 1,383 \\
\hline Structures per group & 8.29 & 5.26 & 4.26 \\
\hline Platforms & 79 & 946 & 271 \\
\hline Platforms per group & 1.25 & 0.94 & 0.83 \\
\hline Chich mounds & 15 & 496 & 498 \\
\hline Chich mounds per structure & 0.03 & 0.09 & 0.36 \\
\hline Chich mounds per group & 0.24 & 0.49 & 1.53 \\
\hline Metates & 267 & $208 \mathrm{I}$ & 279 \\
\hline Metates per structure & $0.5 \mathrm{I}$ & 0.39 & 0.20 \\
\hline Metates per group & 4.24 & 2.07 & 0.86 \\
\hline Querns & Io & 52 & 12 \\
\hline Sascaberas & 17 & 178 & 6I \\
\hline Sascaberas per structure & 0.03 & 0.03 & 0.04 \\
\hline Sascaberas per group & 0.27 & 0.18 & 0.19 \\
\hline Quarries & 13 & I 3 I & 51 \\
\hline Quarries per structure & 0.02 & 0.02 & 0.04 \\
\hline Quarries per group & 0.21 & 0.13 & 0.16 \\
\hline Depressions & 29 & 285 & 99 \\
\hline Depressions per structure & 0.06 & 0.05 & 0.07 \\
\hline Depressions per group & 0.46 & 0.28 & 0.30 \\
\hline Hectares & 43.75 & 496.78 & 353.14 \\
\hline
\end{tabular}

should have at its core a great plaza with grandiose architecture and sculptural art. Chunchucmil lacks these (Dahlin 2009:347; Dahlin and Ardren 2002:268-270). For a large Maya site, Chunchucmil's public spaces look remarkably secular-they are not places for masses of pilgrims to visit and residents to worship. Instead of a great public plaza framed by a single complex of enormous temples, Chunchucmil has over a dozen monumental compounds in its site center. While the tops of a number of pyramids are conspicuous against the skyline from almost anywhere in the site, none exceeds $20 \mathrm{~m}$ high, relatively low for a major center. As the population 
estimates at the end of this chapter show, Chunchucmil certainly had a large enough labor force if its leaders wanted to build the kind of grandiose ceremonial temples, palaces, and acropolises that grace other ancient Maya centers. As discussed in chapter 3, most of Chunchucmil's largest temple complexes-quadrangles-have the same configuration-a square patio with a pyramid (ranging between 8 and 17.5 $\mathrm{m}$ tall) usually on the east side, long platforms on the other three sides, and a low square platform in the center (Dahlin and Ardren 2002:268). The map in figure 2.5 shows the location of all but one quadrangle and their spatial relationships to sacbes. The quadrangle not located in figure 2.5 (Group $\mathrm{S}_{7} \mathrm{~W}_{7}-\mathrm{B}$ ) is located on the southwest side of the residential periphery. As noted in chapter 3 (see table 3.I), we subdivide quadrangles into two group types. Quadrangles in group type $\mathrm{I}(n=8)$ have no subsidiary patios; those in group type 2 do $(n=7)$. Eleven of the is quadrangles are found in the site center. Based on diagnostic ceramics recovered from test pits placed in each of the site's quadrangles, all of the quadrangles were built in the Early Classic period, most likely the latter part, but several, such as the Xpim quadrangle ( $\left.\mathrm{N}_{\mathrm{I}} \mathrm{W}_{2}-\mathrm{C} / \mathrm{Op} .28\right)$, have Preclassic ceramics, indicating that they could have been built in Late Preclassic. In some of the quadrangles occupation continued into the first part of the Late Classic.

The performance spaces inside the main patio of each quadrangle were small, averaging $2,500 \mathrm{~m}^{2}$. Moreover, these spaces were, for the most part, deliberately shielded from public view by other still-extant buildings and walls (Dahlin et al. 2007). Though the quadrangle with the tallest temple-the Chakah quadranglealso has the most subsidiary patios and the site's only ballcourt (the ballcourt is labeled in figure 5.I; the Chakah temple is directly north of the ballcourt), it too lacks a large performance space. Beyond the quadrangles, there are empty spaces in the site center, such as Areas E and F in figure 5.I, that are large enough to have hosted public ceremonies. Yet Areas $\mathrm{E}$ and $\mathrm{F}$ are unmodified, containing uneven bedrock outcrops, whereas the patios of quadrangles have been artificially flattened. (Area D, the marketplace discussed in chapter II, was artificially flattened and contained with several buildings.) Furthermore, unlike quadrangles, Areas E and F do not have temples or viewing stands facing them. They are hardly conducive to witnessing the kinds of liturgical dramas that priests and kings performed elsewhere in the Maya world.

Despite the lack of a major performance space, Chunchucmil's streets (callejuelas) usher large numbers of people into the site center. They extend outward from the sacbes and the mundane empty spaces into the residential zones like spokes on a wheel. In the absence of a major ceremonial nucleus, why the concern to funnel people into the site center? Certainly, some attended the ceremonies held within the quadrangles. Area D in figure 5.I holds another answer. In chapter II, we present 
multiple lines of evidence that Area $\mathrm{D}$ was a marketplace attended by people all over the site and beyond.

Though quadrangles are not the only architectural compounds in the site center, they dominate the site center. We therefore present the results of excavations in the Pich Group, a type 2 quadrangle, as a way of describing what was going on in one of these architectural compounds.

The Pich Group (NIEI-C, Op. ${ }_{3} \mathrm{E} /{ }_{9} \mathrm{~A}$ ) is a complex quadrangle (e.g., group type 2) consisting of a main patio, several smaller patios with adjacent structures to the northeast, and another patio to the south (figure 5.2). The main patio, which has an area of $625 \mathrm{~m}^{2}$, contains an 8.5-m-high pyramid on the east side (Str. NIEI27), four range structures, and a small central platform. The group is enclosed on three sides by an albarrada, or low-lying boundary wall characteristic of the site. Although the albarrada does not extend around the southwestern portion of the group, smaller structures and platforms along Pich's southern edge restrict access to patio areas. Sacbe 6, originating from the site center, intersects the group's southeast corner, allowing controlled access to the main activity areas from the center of the site. While one of the smaller quadrangle groups at Chunchucmil, the Pich Group contains a layout that is so similar to other quadrangles that we believe data from Pich can be effectively considered representative of the quadrangle groups overall.

Initial testing of architecture at the Pich Group was focused on the establishment of a chronology for the major construction. Small units were placed in the main patio floor (Op. $\left.{ }_{3} \mathrm{E}_{2}\right)$, the westernmost structure $\left(\mathrm{N}_{\mathrm{IE}} \mathrm{E}-22\right)$ across from the pyramid (Op. $9 \mathrm{Ar})$, and a possible residential structure in one of the smaller adjacent patios (Op. 9 $\left.\mathrm{A}_{2}\right)$. These units provided a ceramic sample that confirmed that these major elements of the group were all constructed in the Early Classic period. Operation 9AI revealed that Str. $\mathrm{NIEI}_{\mathrm{I}-22}$ consisted of a well-made open room with a wide doorway that faced the pyramid. It had a series of plaster floors and masonry walls preserved to a height of over $\mathrm{I} \mathrm{m}$. The remains of a wide central staircase on the patio side of the structure were visible from the surface. These features suggested to us that the main Pich patio area was not a purely residential space, nor were the structures flanking the patio all platforms or work areas. This large open room, with plenty of interior private space yet easily accessible from the main patio of the group was an early indication that the quadrangles may have been an arena for activities and interactions that did not fit easily within traditional models for either "elite" or "residential" architectural settings at Classic Maya urban centers.

Later horizontal excavations at Pich focused on Structures $\mathrm{NIEI}_{1}-23$ and $\mathrm{NIEI}_{\mathrm{I}}-$ 29, two quite different structures than those previously sampled. Both were selected to expand the range of data available to us on the types of activities conducted at 


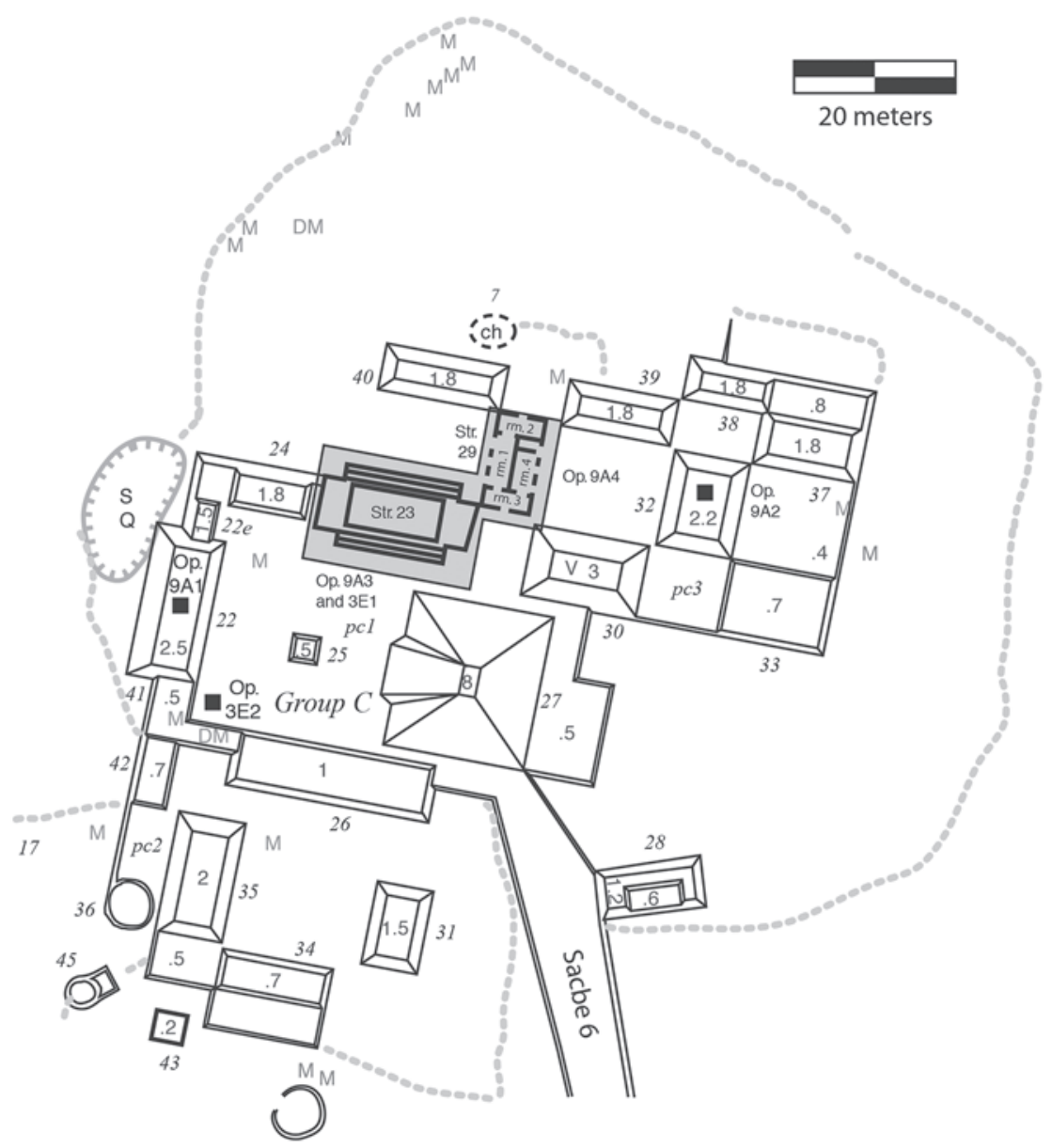

FigURE 5.2. Map of Group NiEI-C/Pich, an example of a type 2 group (complex quadrangle). Areas shaded in gray represent extent of horizontal excavations. Solid black squares represent test pits.

quadrangles, especially the daily activities that might best help us to understand the nature of who lived in this particular group, and how quadrangle groups fit into the overall settlement pattern of the city. Structures $\mathrm{NIEI}_{\mathrm{I}}-23$ and $\mathrm{N}_{\mathrm{IEI}}-29$ represent at least two different types of activities that we believe occurred at quadrangle groups. Structure 23 is a large low-lying rectangular platform that measures $19.1 \mathrm{~m}$ long by $8.3 \mathrm{~m}$ wide. The platform acts as the northern boundary between the main patio and a smaller patio directly north. Staircases to the north and south provided access into and out of these two areas. The platform was covered in multiple fine plaster 
surfaces but did not contain any evidence of a superstructure. In its final phase, the platform was covered by red stucco across the summit and adjacent staircases.

Although the platform underwent a number of construction episodes to amplify the available surface space, ceramic evidence indicates they were a series of closely spaced events confined to the Late Aak phase (late Early Classic). Initially, Structure 23 was smaller, nearly $4.7 \mathrm{~m}$ shorter in length and I $\mathrm{m}$ shorter in height. While the southern staircase was part of this earliest phase, the northern staircase was added later during the construction of Structure 29. The addition of the staircase coincided with the extension of the platform to the west when the platform was raised to its current height of $2.2 \mathrm{~m}$. Artifactual evidence of the activities that may have occurred at Structure 23 was scarce although it clearly offered a large open space visible to those inside the group and adjacent areas as well as access in and out of two patio areas. Hardly private, anyone standing on the large open and elevated surface of Structure 23 would have been easily seen from a distance. But the design of the quadrangle made access to Structure 23 very difficult to anyone but those allowed into the main patio area.

Located on the northeast corner of Structure 23, Structure 29 is a four-room building, measuring II.5 $\mathrm{m}$ long and $5.5 \mathrm{~m}$ wide. Like Structure 23, the entire building, exterior and interior, was covered in red painted stucco. A central wall divides the building into two parallel sets of rooms with smaller rooms at either end. The larger rooms, labeled Rooms I and 4, measure $6.5 \mathrm{~m}$ long and $\mathrm{r} .8 \mathrm{~m}$ wide. Each of these rooms contains three doorways that allow access to their respective patio areas. On its north side, Room 4 contains a stucco bench, approximately $58 \mathrm{~cm}$ high, that spanned the width of the room. As the southeast corner of the bench projected into the middle of Doorway ı, we believe that the bench was part of a later construction episode.

The smaller set of rooms on the northern and southern ends of Structure 29, labeled Rooms 2 and 3, both measure $4.2 \mathrm{~m}$ long and $1.55 \mathrm{~m}$ wide. While they act as corridors between Rooms I and 4, they also provide access to the exterior of the building. Room 3's exterior door provides immediate access to the northeast corner of the main patio. Room 2's exterior door allows a person to leave the architectural spaces of the Pich Group and access a broad $\left(1,500 \mathrm{~m}^{2}\right)$ unbuilt space to the north of the buildings, enclosed by Pich's albarrada. There are nine metates and a double metate in this space. Although artifacts were found throughout the four rooms, Room 2 appears to have been a locus of activity, especially food preparation, within the structure. In the western third of the room, we identified an unusual feature that may represent debris from a hearth. It was characterized by an ashy soil matrix and an extensive concentration of burnt ceramic sherds, limestone, and calcified animal bone and shell. Although the feature was only is $\mathrm{cm}$ deep, it contained over 4,000 
grams of ceramics, remnants of at least two deer (Odocoileus sp.), and a number of shell fragments from edible marine species. The rest of the room was littered with similar material, although not in the same quantity, and a large limestone metate was adjacent to the possible hearth materials. Limestone fragments were placed underneath the metate in order to angle the spout closer to the floor. Ceramics from this feature include a high percentage of broken domestic wares such as nearly complete examples of a Chumayel cazuela, Maxcanu olla, Oxil olla, Xanabá cajete, and Hunabchen cajete.

The spatial relationship between Structures 23 and 29 indicates a high degree of mobilization in and between the main patio and the adjacent patios to the northeast. The association of the bench and material remains found in Structure 29 suggests that this structure may have been a residential area within the Pich Group, where food preparation and other domestic activities occurred. The design of this structure is consistent with local Early Classic architectural traditions in the use of parallel rooms open to patio areas via multiple doorways. Few of the other unexcavated structures in the Pich Group are likely candidates for residential buildings, given their sharply sloping profiles. A number of the structures in the adjacent area northeast of the main patio resemble Structure 22, the high-walled, large, open room across from the pyramid.

The main patio was largely empty of material evidence that might contribute to a better understanding of what activities occurred there. However, soils analysis of the main patios of three other quadrangles (Groups $\mathrm{S}_{\mathrm{I}} \mathrm{W}_{\mathrm{I}-\mathrm{H} / \text { Guaje, NIEI-G/ }}$ Chakah, and $\mathrm{S}_{\mathrm{I}} \mathrm{E}_{2}-\mathrm{C} / \mathrm{Chukum}$ ) suggests that feasting took place in quadrangle patios (Dahlin et al. 2010:2II-2I2). Although a number of mano fragments were found along the eastern edge of Structure 23, that is also the area closest to Structure 29, where food preparation likely occurred. We have not been able to find evidence of a particular commodity or trade good associated with the Pich quadrangle. The types and forms of ceramics recovered from Structure 23 are consistent with construction fill from across the site (highly eroded sherds from domestic forms) and do not shed light on activities conducted on this platform. Chronological indicators are more definitive and demonstrate that the structures around the main patio of the Pich quadrangle were likely constructed first, early in the Early Classic period. Within a short period of time, the platform that formed the northern boundary of this quadrangle was expanded a number of times and a spacious residential area was added to the group. The residential structure was also modified repeatedly during the Early Classic period, with original doorways sealed off and access to the patio areas increasingly restricted.

We are confident that quadrangles were multifunction spaces that accommodated domestic functions as well as commercial activities. Whereas McAnany (2004:155) 
argues that at Caracol and Tikal food for ceremonies was prepared well beyond the central ceremonial spaces, there is ample evidence of food preparation within the Pich Group. The 16 metates and two double metates within the group attest to extensive corn grinding while Structure 29 had ample evidence for the preparation of food and a bench feature characteristic of mid-elite residential space. The location of this building adjacent to, but separate from, the main patio suggests to us that other activities took place within the quadrangle patio, perhaps activities that required an open area for the display of goods. Elite nodes of sites such as Calakmul (Robin 2004), Aguateca (Inomata and Triadan 2000), and Tikal (Moholy Nagy 1997) show evidence of crafting fine goods. Material evidence of crafting or ritual is not preserved at Structure 23 but the design of this platform provided ample area for interactions that were visible to those within the group, yet shielded from the rest of the occupants of the city. Crafting perishable goods such as woven-fiber products (textiles or baskets-see chapter Io) could have occurred in this space as could the display of goods as part of exchange negotiations that we argue upheld the city.

The precise activities that took place in the Pich Group and the other quadrangles at Chunchucmil remain difficult to identify based upon artifact evidence. Historic records suggest further avenues for exploration. Sixteenth-century ethnohistorical documents such as the Códice de Calkiní and Bishop Diego de Landa's Relación de las Cosas de Yucatán both mention that in the first years of European contact, Maya centers had storehouses filled with products such as fish, honey, beeswax, cloth, and thread (Landa 1978; Piña Chan 1978). At Calkini, $35 \mathrm{~km}$ southeast of Chunchucmil, the halach uinic (lord) gathered so large jars of honey to give as tribute to Francisco Montejo in I54I. While these documents describe practices that occurred many centuries after the main occupation of Chunchucmil, they speak to the resources of the native Maya economy. Large open rooms such as Structure 22 could have been storage facilities for the warehousing of local resources exchanged for trade goods, such as bushels of salt, honey, beeswax, dried fish, plant-fiber products, or cloth. Alternatively, these rooms might have held precious trade items out of sight during economic negotiations.

In his review of ethnohistorical documents relevant to a reconstruction of the Postclassic Maya economy of Yucatán, Roman Piña Chan reports that, at Mayapán, there was a house of commerce and trade where visiting merchants took their goods to meet with the stewards of local lords who knew what their lord needed (Piña Chan 1978:43). In Landa's writings, we find a description of these same stewards who were in charge of provisioning the chief's house, which also functioned as a setting of official authority and business (Landa 1978:12). In 1582, Landa's main Maya informant on indigenous culture also authored his own brief description of Maya 
customs that mentions that visitors to Maya settlements were always housed and fed by their hosts, and merchants were the only class of visitor from whom payment for these services was expected (Tozzer 1941:23I).

The Postclassic economy of Yucatán was different in many important ways from the system in operation at Chunchucmil in the Early Classic period many hundreds of years earlier. However, it is intriguing to consider the Pich Group and the other quadrangles at Chunchucmil in light of these descriptions of the native economy. If the systems of tribute that emerged late in the prehispanic period originated in earlier indigenous economic systems of production, as most scholars believe, then facilities for the storage of goods prepared for trade as well as amenities for merchants should be expected in the archaeological record of the Classic period. Structure 29, in the heart of the Pich Group, might be a location where such merchants were fed and housed, close to the facilities where their goods were safely stored. On the other hand, Structure 23, a large open area, and Structure 22, the private room, likely functioned as areas for the display of trade items and commodities prepared for exchange. We favor an interpretation of quadrangles that acknowledges the combination of both private and semipublic spaces inherent in their design (Ardren 20I5; Ringle and Bey 200I). The patios and platforms of quadrangles provided arenas for the performance of elite activities such as the many forms of diplomacy and hospitality that accompany trade negotiations. Patios in the larger quadrangles could have held several thousand people for occasional neighborhood or district-level ceremonies (see below). Evidence for feasting in patio areas, formalized and restricted access to interior areas, and the presence of large open architectural features indicate a plan to accommodate small numbers of people within elite settings for largely performative activities.

\section{THE RESIDENTIAL CORE}

The residential core (figure 5.3) surrounds the site center on all sides yet the boundary between the site center and the residential core is fuzzy. Houselots-domestic groups consisting of small platforms usually facing a patio and surrounded by drylaid stone walls called albarradas (see chapter 2)-dominate the residential core. Chunchucmil's houselots bunch together like the cells of a honeycomb, clearly visible in the northeast and south/southeast portions of figure 5.I (see also figure 2.4).

Spatial features within the residential core permit tentative identification of large corporate groups. As described in chapter 2, alleyways called callejuelas weave through the residential core, connecting houselots to sacbes and open spaces in the site center. Because the major callejuelas at the site are like spokes emanating from the site center and because there are no lateral callejuelas that link different spokes, 


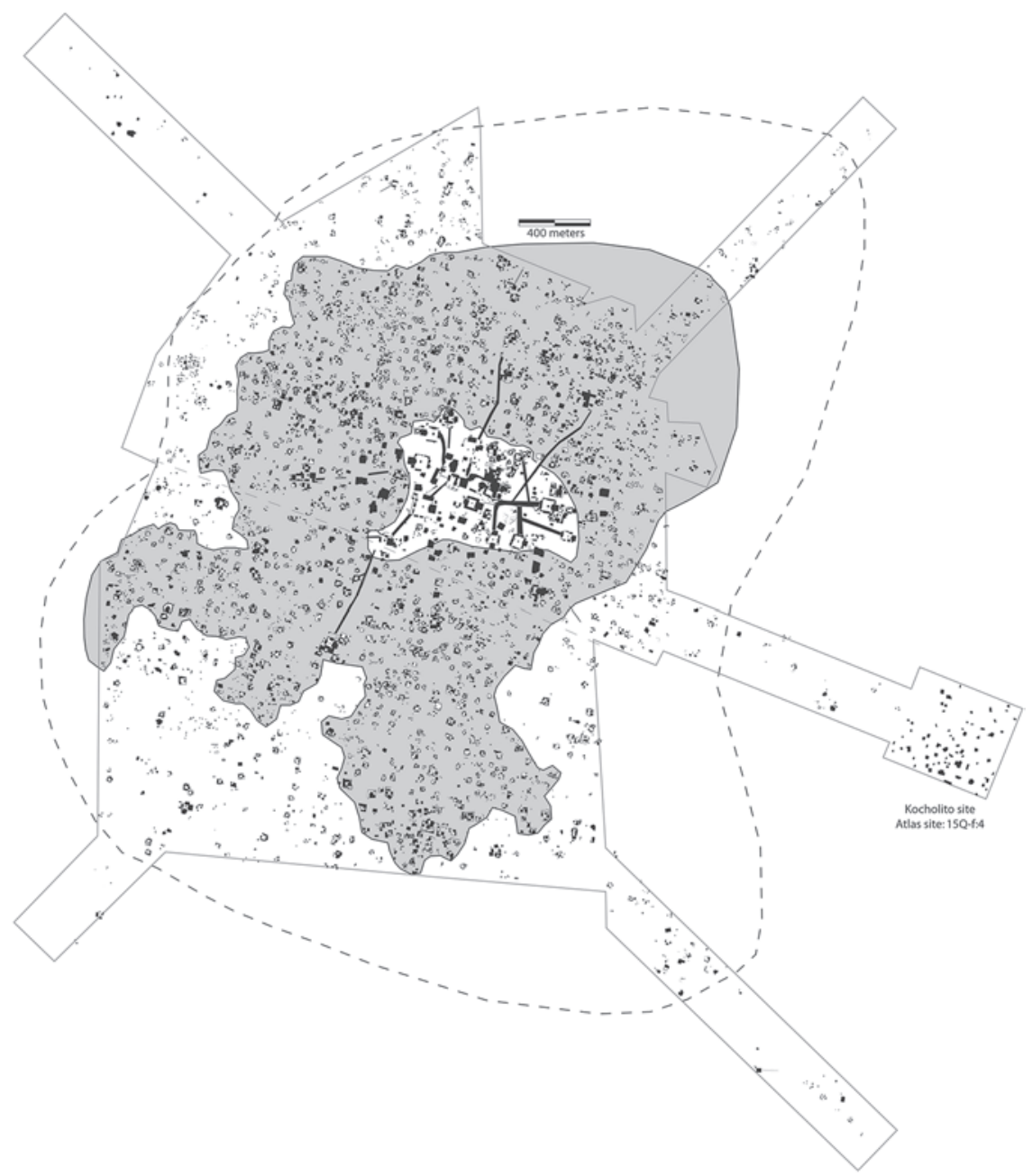

FIGURE 5.3. Map of architecture from the entire $11.67-\mathrm{km}^{2}$ map. The gray area represents the residential core while the dotted line encircles the residential periphery.

people who lived on the same spoke saw more of each other than people living on other spokes. These frequent interactions among a predictable set of people sharing the same spoke probably resulted in the creation of neighborhoods containing between 200 and 800 people or districts with over I,000 people (Hutson 2016). Such potential corporate groups at Chunchucmil are larger than the lineages (Hageman 2004) and communities (Peuramaki-Brown 2013; Yaeger 2000) 
discussed by other archaeologists but equivalent in size to the barrios in sixteenthcentury towns in northern Yucatán described by Roys (1957). The people living in these neighborhoods and districts probably attended ceremonies at a particular quadrangle, thus further solidifying corporate identity.

Intensive excavations within five houselots in the residential core (and one houselot within the next zone, the residential periphery) reveal that most were multiple-family compounds with ancestor shrines (Hutson et al. 2004; Hutson et al. 2006; Magnoni 2008). Diagnostic ceramics from test pits in II9 additional houselots from all areas of the site show that they were occupied during the late part of the Early Classic, contemporaneous with the quadrangles. Most houselots were occupied only during this period (see chapter 4).

The main distinction between the residential core and the residential periphery is settlement density (table 5.2). Our calculations of settlement density within the core are inexact because the boundary between the residential periphery and the residential core is fuzzy in many places (it is fuzziest and most arbitrary on the eastern and northern edges of the map, where settlement density tapers gradually). Though we have drawn this boundary sharply in figure 5.3, the edges should be considered approximate. To arrive at settlement densities for Chunchucmil's three main zones (site center, residential core, and residential periphery), we calculated the settlement density for each 250-by-250-m map quad (see figure 2.I) and assigned each quad to one of the three zones. We assigned 8I of the I59 quads to the residential core. The total number of structures in these $8 \mathrm{I}$ quads is 5,287 and the area covered by these quads is $5.06 \mathrm{~km}^{2}$, yielding a settlement density of I,064 structures per square kilometer (table 5.2). If the 496 chich mounds in these 8I quads are considered structures, structure density rises to I,I64 structures per square kilometer. In contrast, the density of the 62 quads that we assigned to the residential periphery is 392 structures per square kilometer ( 532 structures per $\mathrm{km}^{2}$ if chich mounds are included). This is a strong difference in structure density ( $\mathrm{r}, 064$ per $\mathrm{km}^{2}$ vs. 392 per $\mathrm{km}^{2}$ ) but the actual settlement densities in both zones vary quite a bit. Within the residential core, the density of structures per quad ranges from 527 per square kilometer to 1,984 per square kilometer (median is 992 per $\mathrm{km}^{2}$ ). Within the periphery, the density of structures per quad ranges from 64 per square kilometer to 928 per square kilometer (median is 352 per $\mathrm{km}^{2}$ ). Though these data show that some quads assigned to the periphery actually have a higher settlement density than quads assigned to the residential core, much of this results from the fact that some of the 250-by-250-m map quads contain areas that grade from one zone to the next. In any case, a histogram of settlement densities per quad (table 5.3) shows a mode between 300 and 400 (the residential periphery), a mode between 900 and $\mathrm{I}, 000$ (the residential core), and a clear gap between these two modes. 


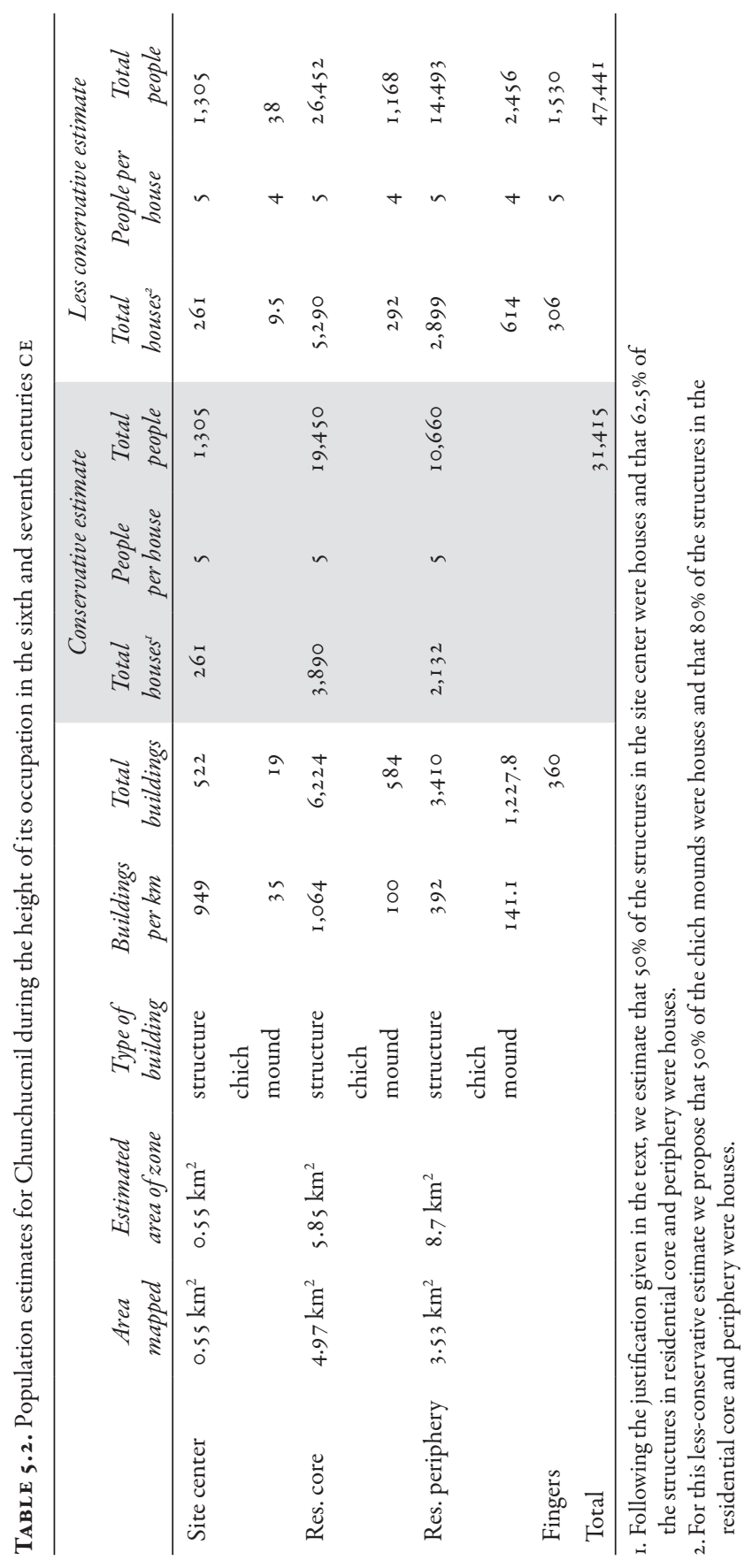


TABLE 5.3. Histogram of structure densities per 250-by-250-m quad.

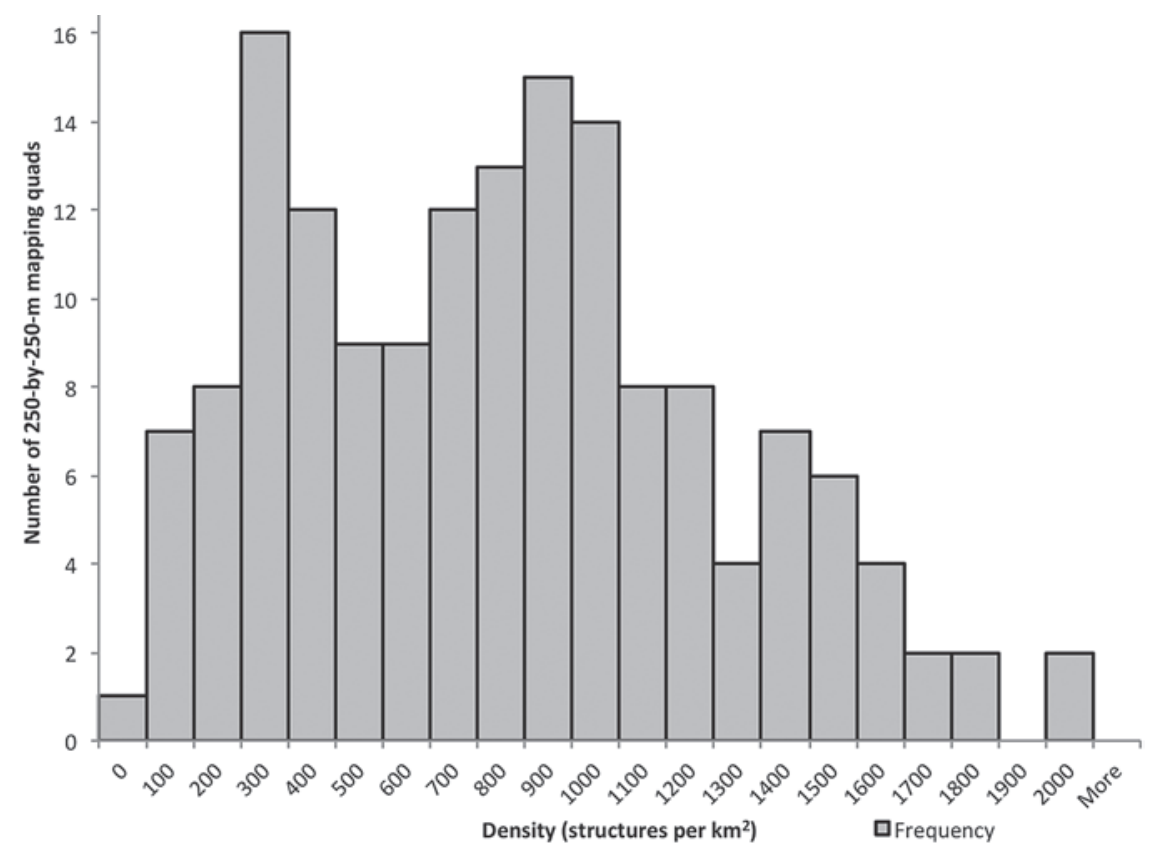

In addition to having a higher structure density, the residential core has more metates and more chich mounds per group and per structure than the residential periphery (table 5.2). On the other hand, the residential periphery has slightly more quarries, sascaberas, and depressions than the residential core (table 5.2).

As figure 5.3 shows, the residential core extends to the northeast beyond the edge of the $9.3-\mathrm{km}^{2}$ block. The northeast transect, however, helps delimit the approximate extent of the residential core in this direction. At a point $600 \mathrm{~m}$ from the beginning of the transect and $1.74 \mathrm{~km}$ from the site-center datum, structure density drops from 925 per square kilometer to 384 per square kilometer. In the areas to the west and south of this point, where we lack mapping coverage, we have interpolated the boundaries of the residential core. The area contained within the residential core boundary line as drawn in figure 5.3 contains about $6.4 \mathrm{~km}^{2}$. Subtracting the $0.55 \mathrm{~km}^{2}$ that pertains to the site center leaves an area of $5.85 \mathrm{~km}^{2}$ for the residential core (this is larger than the $5.06 \mathrm{~km}^{2}$ that pertain to the $8 \mathrm{r}$ quads, because some of the residential core lies beyond the map).

We conducted intensive excavations in five houselots in the residential core (the Lool Group [ $\left.\mathrm{N}_{2} \mathrm{E}_{2}-\mathrm{N}, \mathrm{Op} .{ }_{13}\right]$, the Aak Group [ $\mathrm{S}_{2} \mathrm{E}_{2}-\mathrm{F}, \mathrm{Op} .{ }_{9} \mathrm{C} /{ }_{3} \mathrm{G}$ ], the Kaab' Group [ $\mathrm{S}_{2} \mathrm{EI}_{\mathrm{I}} \mathrm{G}, \mathrm{Op} .{ }_{9} \mathrm{D} /{ }_{3} \mathrm{H}$ ], the Muuch Group [S $\mathrm{S}_{2}-\mathrm{C}$, Op. Io], and the 
Chiwol Group [ $\left.\mathrm{S}_{2} \mathrm{E}_{3}-\mathrm{L}, \mathrm{Op} .{ }_{9} \mathrm{~F} / 3 \mathrm{I}\right]$ ). The following discussion of the results of the excavations in the Kaab' Group provides a sense of what life was like in a houselot in the residential core during Chunchucmil's peak population (see also Hutson 2010 for extended treatment of daily life in other houselots).

The Kaab' Group (S2EI-G, Op. $9 \mathrm{D} / 3 \mathrm{H}$ ) is located near the south-central edge of the site core (figure 5.I) and consists of nine structures (group type 9) grouped into two patios (figure 5.4). The largest of the group's structures-32, 33, and 34-face the north patio whereas the rest encircle the south patio. The group's albarrada walls enclose $4,300 \mathrm{~m}^{2}$ of space, which is close to the average size-4,45 $\mathrm{I} \mathrm{m}^{2}$-of Chunchucmil's houselots. Aline Magnoni (2008) directed $353 \mathrm{~m}^{2}$ of excavation within the Kaab' Group. These excavations consisted of complete exposures of Structures 32 and 34, partial exposure of six other structures, test pits in the two patios, and dozens of $50-$ by- $50-\mathrm{cm}$ pits placed at the corners of a 5 -by- $5-\mathrm{m}$ grid covering the non-architectural space of the houselot. Extensive geochemical sampling of floors and outdoor areas provides critical information for the reconstruction of activity areas and use of space.

The buildings with the most stonework-32, 33, and 34-are also the locations of the three earliest constructions detected at the group, dating to the latter part of the Early Classic. Late Preclassic ceramics in construction fill indicate an earlier occupation, but we have no other evidence from this phase at the Kaab' Group. Of the three earliest buildings, two ( 33 and 34 ) feature massive boulders, indicating a specific choice of architectural style, distinctive from other groups at Chunchucmil. In its earliest construction stage, Structure 34, on the east side of the patio, featured a square platform supporting a C-shaped superstructure with walls $1.5-1.8 \mathrm{~m}$ thick. Rough boulders lined the interior faces of these walls, possibly to recreate the semblance of a cave. The C-shaped structure originally enclosed a 4-by-4-m space with an opening to the west in the direction of the patio. Several deposits during the first construction stage sacralized the structure: a burial in the substructural platform, a cache of burnt sherds underneath the floor in the center of the platform, and a Chencoh Thin Orange bowl cached under the step at the interface between the patio and the structure (figure 5.5). These deposits, an altar-like bench built during the second construction stage, the structure's square shape, its placement on the east side of the patio, and its cave-like interior all suggest that Structure 34 served as a shrine (Becker 1991; Leventhal 1983). On the basis of mapping alone, many but not a majority of houselots at Chunchucmil appear to have had shrines and those houselots with shrines share a more orderly spatial layout (Magnoni et al. 20I2). Also during the Early Classic, Structure 33 stood on the south side of the patio and consisted of a boulder-lined platform (figure 5.6), measuring I2-by-6 m, with a perishable 


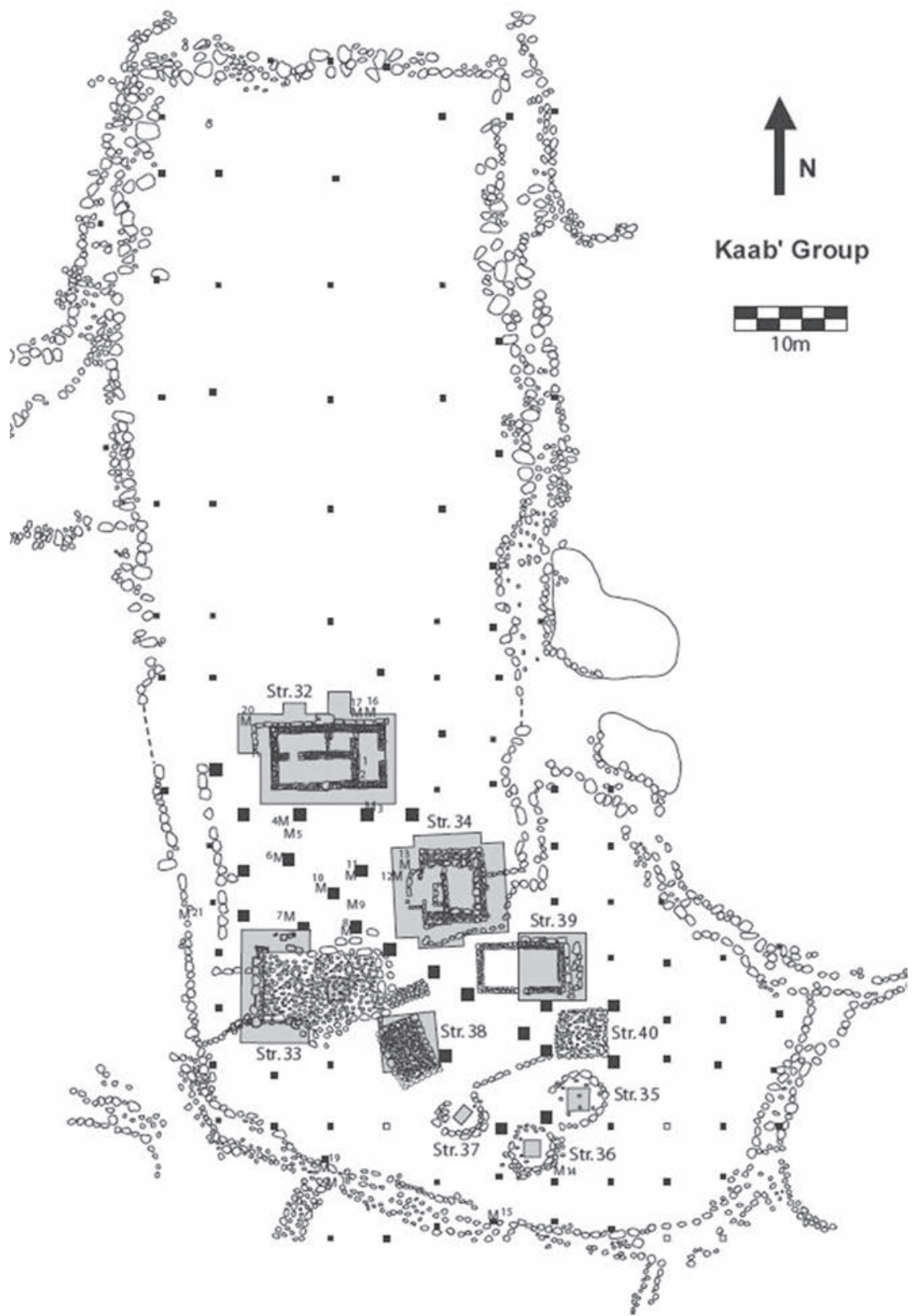

FIGURE 5.4. Map of Group S2EI-G/Kaab', a type 9 group (medium houselot/albarrada group). Black squares and areas shaded in gray represent excavations. 

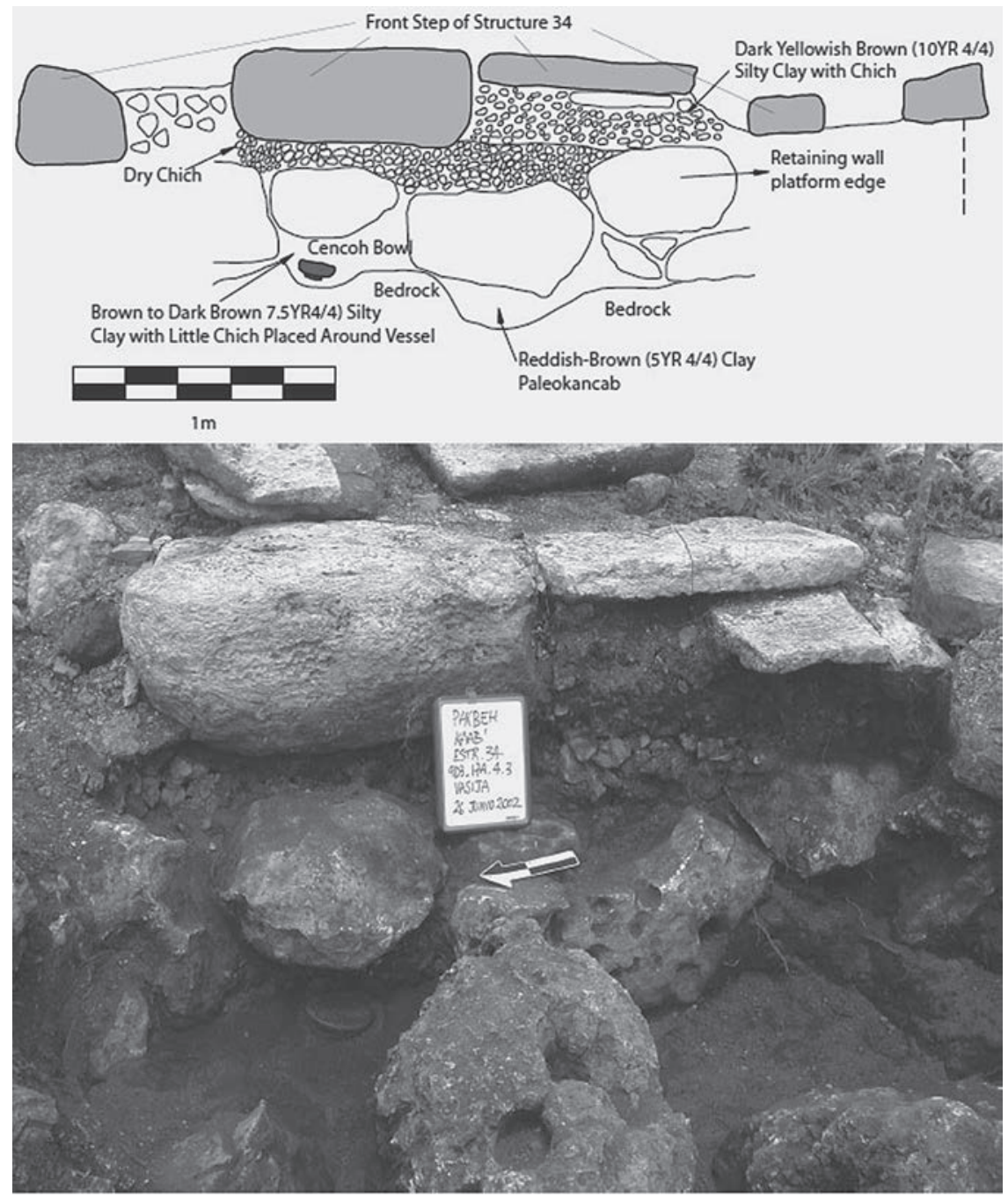

FIGURE 5.5. Drawing and photo showing the placement of the cached Chencoh bowl under the front step of structure $\mathrm{S}_{2} \mathrm{E}_{\mathrm{I}}-34$.

superstructure. Structure 32 -sub stood on the north side of the patio and consisted of a plaster floor supporting a perishable superstructure.

At the very beginning of the Late Classic period, the inhabitants of the Kaab' Group modified their built environment in many ways. On top of Structure 32-sub's original plaster floor they built a four-room masonry structure with a vaulted roof. 

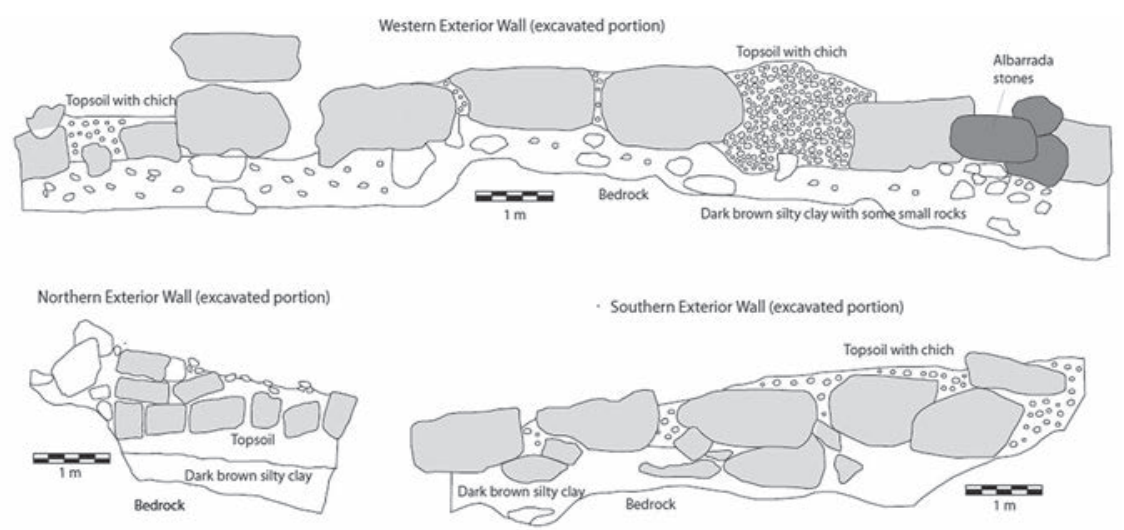

FIGURE 5.6. Exterior profiles of excavated portion of Structure $S_{2} E_{I}-33$ (showing only the first and second course of in situ boulders).

The new Structure 32 was the group's most elaborate residence and likely housed Kaab's lead family. All other houselots that have been extensively excavated at Chunchucmil (Aak, Muuch, Lool, Balam, Chiwool) have elaborate residences (see also Hendon 1991). Other Late Classic Kaab' families probably lived on top of Structure 33, but also in smaller residences on the newly constructed south patio. The structures framing this patio include three small, round, auxiliary structures, one of which (36) served as the Kaab' Group's kitchen, two rectangular structures ( 38 and 39), and a square one (40) consisting of stone platforms with perishable superstructures. Excavations at Structure 38, whose platform was lined with boulders, yielded high densities of obsidian and chert tools, as well as high phosphate and manganese levels, suggesting the working of organic materials and some other undetermined materials. In addition to serving as a work space, Structure 38 may have also served as a residence, though this is not clear. Structure 39 , a crudely shaped boulder platform supporting the cut-stone foundation braces for a residence, yielded evidence of shell-working, especially on the eastern terrace. Thus, Structure 39 likely served both as a residence and work space. Structures 35, 37, and 40 were likely used as storage facilities, given the low level of phosphates and artifacts found inside them.

Back at the north patio, Structure 32 also contains evidence for mixed uses. Of Structure 32's four rooms, one was probably for sleeping, one for storage, one for greeting visitors, and one for craft activities (as evidenced by two metates, high phosphate levels, and a few shells), although each room may have had additional uses. Structure 32 was ritually terminated and carefully torn down in the first part of the Late Classic. A series of events accompanied this episode, including the burial of the 
bundled bones of an older child (7-II years old), the placement of complete ceramic vessels, and the destruction of several large jars in conjunction with tearing down the vault and the building's walls. After destruction and abandonment of Structure 32 , residents continued to inhabit the group and the northern patio floor was raised. The northern patio contained II grinding stones (metates) and grinding-stone fragments. Chemical analysis of the patio surface suggests that these metates were used to process both organic and inorganic materials in two separate production areas.

The inhabitants of the Kaab' Group kept their patios clean and tossed much of their garbage into what has been called an intermediate zone: an area along the edges of the patios and behind the structures (Arnold 1990; Deal 1985; Hayden and Cannon 1983; Killion 1992). Interestingly, the intermediate zone does not show a strong correlation between phosphates and ceramic debris, suggesting an intentional separation of organic remains (concentration of phosphate close to structures and platform edges) and inorganic remains (ceramics, shells, obsidian, and high levels of manganese clustered in two accumulations, one located between Structures 34 and 39 and the other between Structures 33 and 38 ). Most of the space within the albarradas that delimit the Kaab' houselot lies beyond the structures, patios, and intermediate areas. Much of this area was probably devoted to gardening and arboriculture, as has been documented in the non-built spaces of the Aak Group (Hutson et al. 2007). The portions to the south, which were closer to the living quarters, were likely the fertilized garden areas, as indicated by higher phosphate levels, while the northern portion of the garden, with low phosphate levels, was likely used for arboriculture.

Several themes about life in a Chunchucmil houselot arise from this brief overview of the construction history and activities within the Kaab' Group. In terms of production, the data show a nuanced domestic economy typical of what Hirth (2009a) has called "multi-crafting." Shell-working, gardening, intensive grinding, and intensive processing of organic materials may have positioned the Kaab' Group to take advantage of local markets, while also making the group economically resilient.

Regarding social organization, a household on the scale of an extended family occupied the Kaab' houselot. Following Ashmore and Wilk (1988), households are groups of people who participate together in a polythetic set of activities including production, consumption, residence, and social and physical reproduction. Inequality existed among the nuclear families within the Kaab' household. One family lived in a large, vaulted house with multiple rooms (Structure 32). Another family lived in a perishable house that was nevertheless rather large and built on top of a substantial stone platform (Structure 33). The other families lived in small, perishable buildings. The families in Structures 32 and 33 shared the more prestigious patio of the group: the one with the group's domestic shrine (Structure 34). 
Given that the structures on the north patio were the first to be occupied, it stands to reason that the higher status of the families living on the north patio derives in part from their longer tenure in the group (see also Haviland 1988; Hendon 1991; McAnany 1995). This same pattern (variation in size and cost of the different houses, with older houses being more elaborate) also holds for the other intensively excavated houselots at Chunchucmil (Hutson 2010). The destruction of Structure 32 suggests that relations among the families within Kaab' were dynamic, that the lead family, the one residing in elaborate Structure 32, could not reproduce its standing indefinitely. Excavations in the Aak Group also suggest changes in group leadership (Hutson et al. 2004)

Despite the varied statuses of the families within the Kaab' houselot, several factors solidified bonds among them and produced a distinct identity. The houselot walls themselves mark perhaps the most obvious evidence of corporate identity: Kaab's inhabitants delineated their own shared space by using stone fences to divide themselves from the rest of the site. Household identity was realized and reproduced through the daily practices and routines in the material settings of the houselot, the buildings, and the extramural spaces. Kaab' Group members ate from the same kitchen and participated in the same ritual activities at the shared shrine: Structure 34. The shrine itself, with its unusually thick, boulder-lined walls, was likely a material focus of the Kaab' Group's distinct corporate identity. Excavations elsewhere at Chunchucmil show that household shrines take unique forms from houselot to houselot. Boulders at the Kaab' Group are not limited to Structure 34; builders used them to different degrees in all of the group's three to four probable residences: Structures 32, 33, and 39 (and possibly 38 ). The dedicatory events in Structure 34 were essential in the establishment of the group and its associated territorial and membership rights at this specific location in the wider Chunchucmil landscape (Gillespie 2000; McAnany 1995). Furthermore, the incorporation of mortuary deposits in Structure 34 provided the household with a place for the preservation of the memory of important ancestors, as well as the continuous reproduction of the household identity through time (McAnany 1995). The veneration of these ancestors was the focal point for the collective identity of the corporate group (Gillespie 2000). Continuity of social memory was perpetuated with the erection, dedication, and continued use, by different generations of house members, of the dwellings and shrines that harbored ancestors or their heirlooms (Gillespie 2000).

\section{THE RESIDENTIAL PERIPHERY}

Houselots encircled by stone albarrada walls dominate the residential periphery, just as in the residential core, but in the periphery, alleyways/callejuelas are rare, 
open space is abundant, and average settlement density- 392 structures per square kilometer-is nearly a third of that in the residential core. Compared to the residential core, the periphery also has triple the number of chich mounds per group (see table 5.2). We therefore find a very strong inverse correlation between settlement density and chich mounds. Chich mounds are much more common when there is more space, and this relation may provide a clue to their function. Metates are far less common in the periphery than in the core ( 0.86 per group vs. 2.07 per group). This is odd given that the core has only slightly more structures per group than the periphery ( 5.26 vs 4.26 ; see table 5.2 ).

A drop to between 67 and 39 structures per square kilometer, a density equivalent to areas labeled "intersite" in other surveys (Rice and Rice 1990), marks the outer edges of the residential periphery. Figure 5.3 shows the edge of the residential periphery, though this edge is approximate because much of it has been interpolated through unmapped areas (see Tourtellot 1993:233 for the risks involved in interpolation based on transects). We base our interpolation of the edge on data from the mapping transects, which, with the exception of the east transect, provide a clear view of the drop to low settlement densities (see Hutson et al. 2008 for extensive details on the transects). Eight hundred meters out on the SE transect, settlement density drops from 350 to 64 structures per square kilometer. The middle segment of the NE transect has a density of 384 structures per square kilometer whereas the final $200 \mathrm{~m}$ of the transect has a density of 50 structures per square kilometer. Though $200 \mathrm{~m}$ is a small area for this judgment, informal reconnaissance beyond the edge of the transect reveals very little settlement. The entire $1.6-\mathrm{km}$-long northwest transect and the entire $0.6-\mathrm{km}$-long southwest transect have densities of 64 and 39 structures per square kilometer, respectively. The area within the residential periphery boundary line as drawn in figure 5.2 contains about $15.1 \mathrm{~km}^{2}$. Subtracting the $6.4 \mathrm{~km}^{2}$ that pertains to the residential core and site center leaves an area of 8.7 $\mathrm{km}^{2}$ for the residential periphery.

Although the residential periphery is less dense than the residential core, the periphery does not lack large, wealthy houselots. In other words, Chunchucmil does not exhibit the spatial pattern discussed by Bishop Landa, in which the richest and most powerful people live closest to the site center (Diane Chase [1986] notes that Landa's account, rather than an accurate description of precolonial settlements in Yucatán, may have been plagiarized from earlier descriptions of colonial towns elsewhere in Latin America). Archaeologists have debated whether this spatial pattern, often called concentric, existed at Classic-period sites such as Tikal, Cobá, and Dzibilchaltún (Arnold and Ford 1980; Folan et al. 1982, 2009; Haviland 1966, 1970, 1982; Hutson 2016; Kurjack 1974). At Chunchucmil, houselots with substantial architecture (group type 10), implying greater control of resources, are just as 
common in the residential periphery as they are in the residential core (Hutson et al. 2006; Magnoni et al. 20I2). Parenthetically, houselots with larger architecture also have more space within their albarrada walls, implying larger gardens, craft spaces, and/or orchards. Throughout the site houselots with substantial resources are interspersed among houselots with fewer resources (Hutson and Magnoni 20II; Magnoni et al. 2012).

Though many houselots in the residential periphery have been test-pitted, one houselot, nicknamed "Balam," received intensive mapping and extensive shovel testing. We describe this houselot in detail in order to communicate a deeper sense of what life may have been like in the residential periphery.

The Balam Group (S4W8-F/Op. 33 ) is located about 2.I km southwest of the site center. As figure 5.7 shows, a chichbe (pair of stone alignments with a cobble surface in between; see chapter 2 for fuller discussion of chichbes) encircles the houselot. One neighboring group to the south $\left(\mathrm{S}_{5} \mathrm{~W} 8-\mathrm{C}\right)$ is contiguous with the houselot and appears to share a portion of the chichbe (see site map online). Another neighboring group $\left(\mathrm{S}_{4} \mathrm{~W} 8 \mathrm{-E}\right)$ lies to the north, $35 \mathrm{~m}$ beyond the north edge of the Balam chichbe, but there are no neighbors for at least $100 \mathrm{~m}$ to the east and west. The chichbe delimiting the Balam houselot encloses $2810 \mathrm{~m}^{2}$. The houselot consists of four structures arranged around an artificially elevated, four-sided patio that rises $40 \mathrm{~cm}$ above the natural ground surface. The structure on the west of the patio $\left(\mathrm{S}_{4} \mathrm{~W} 8-17\right)$ had a vaulted stone roof whose rubble stands nearly $3 \mathrm{~m}$ high. It appears to be an "elaborate residence": compared to other residences, elaborate residences were built at greater cost (a vaulted roof, for example) and have larger floor plans (Hendon 1991). The north structure $\left(\mathrm{S}_{4} \mathrm{~W} 8-20\right)$, which measures about II-by-6 m, had a perishable roof and masonry walls delimiting several rooms. It appears to be residential as well. The south structure $\left(\mathrm{S}_{4} \mathrm{~W} 8-\mathrm{I} 9\right)$ is a low platform with stone foundation braces and a perishable superstructure. It may have been a residence or perhaps a kitchen. The east structure ( $S_{4}$ W 8-18), measuring 5.5-by-5.5-by-1.2 m, is a platform presumably topped with a perishable superstructure. The platform is higher than the north and south structures: much of the elevation of the north structure seen in figure 5.7 results from the collapsed masonry walls built above the platform. The east structure appears to have had a ritual focus, based on its square shape, its higher platform, and its position on the east side of the patio (Becker I991; Leventhal 1983). A callejón/stone-lined walkway (see chapter 2) links the northeast corner of the patio to the east edge of the chichbe, establishing that the primary entrance to the houselot was on the east side, facing the site center. The Balam Group has a $65-\mathrm{cm}$ deep sascabera north of the patio.

Excavations in the Balam houselot began with 95 pits measuring $50-b y-50 \mathrm{~cm}$. The pits were located on the corners of a 5-by-5-m grid blanketing the non-architectural 

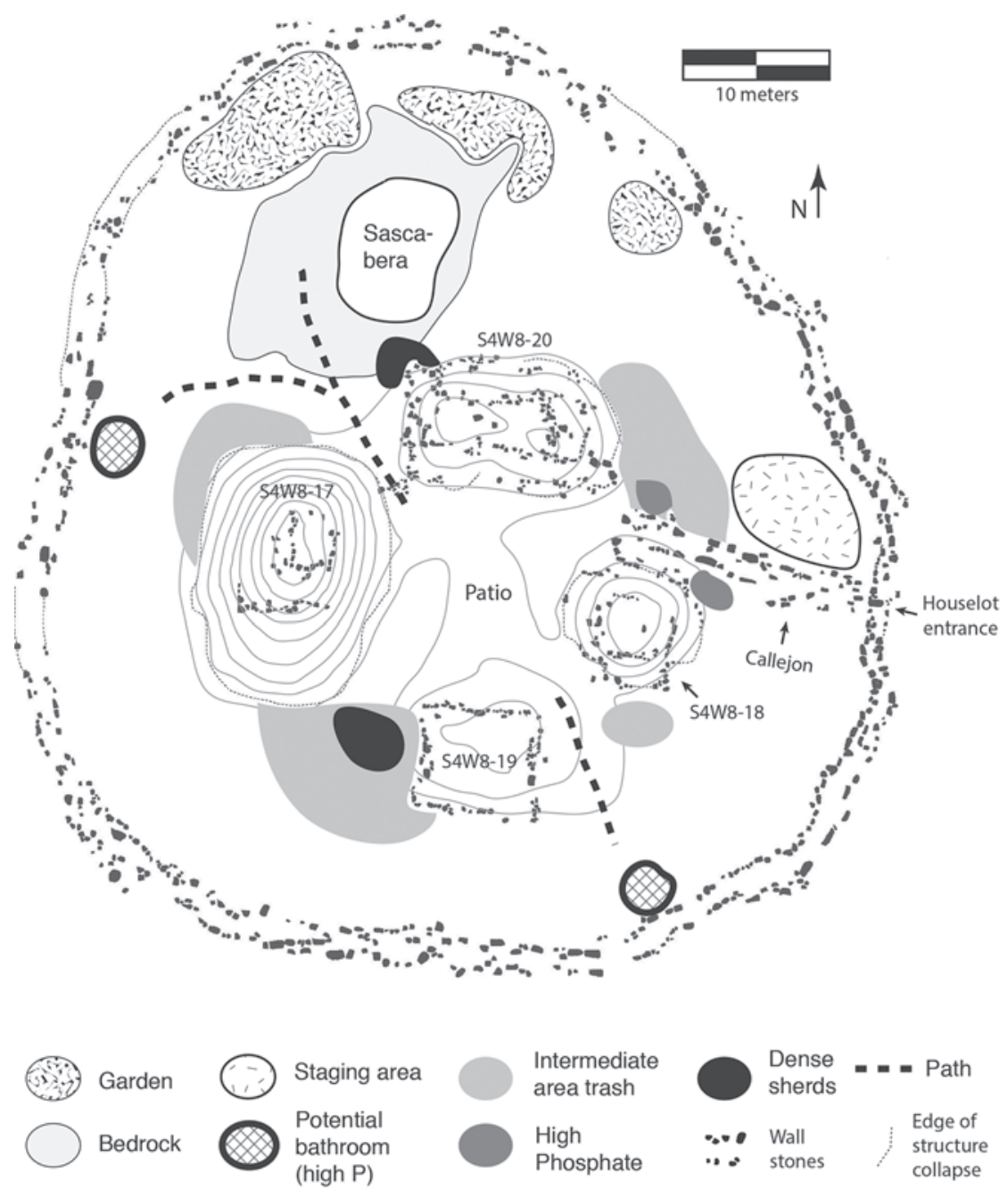

FIGURE 5.7. Map of Group $S_{4}$ W8-F/Balam, a type io group (small houselot/albarrada group). Activity areas and discard areas have been highlighted. Contour lines represent $30-\mathrm{cm}$ topographic intervals. A callejón is a path delimited by stone alignments.

spaces of the houselot. The two pits with the most ceramic debris were later expanded to 2-by-I-m test pits. Like most houselots, the Balam Group was occupied at the end of the Early Classic and vacated during the early portion of the Late Classic. We did not excavate standing architecture. Mehlich II phosphate analysis (see Terry et al. 2000) was conducted on soil samples from each of the 95 pits. 
The grid of excavations and phosphate tests helped build a sense of how the spaces in the houselot were used (figure 5.7). Light scatters of broken pottery and above-average levels of phosphate were found along the edges of the patio, with the exception of the northwest corner. In ethnoarchaeological studies of twentieth-century Maya houselots, such scatters develop as people move debris off the patio surface and deposit it along the edges, beside the structures, where it is not as much of a nuisance (Deal 1985; Hayden and Cannon 1983; Hutson et al. 2007). The fact that soil samples from the patio had no phosphate buildup matches the expected chemical signature of a frequently cleaned and maintained space (Barba and Ortíz 1992:77; Middleton and Price 1996:679). By analogy with modern houselots that exhibit the same pattern of debris, the garbage along the edge of the patio is most likely in secondary context. The densest accumulation of pottery is on the west side of the south structure $\left(\mathrm{S}_{4} \mathrm{~W} 8-18\right)$. Of the 250 sherds that came from the 2-by-I-m test pit at this spot, most were body sherds not diagnostic to vessel form. Identifiable vessel forms include jars, large dishes, cajetes, and bowls, with no particular form dominating. Such an assemblage suggests preparation, storage, and service of food, thus lending support to the suggestion that Structure $\mathrm{S}_{4} \mathrm{~W} 8$ - I8 may have been a kitchen.

The highest phosphate levels near the patio came from an area just east of the northeast edge of the patio, at the end of the callejón leading to the east boundary of the houselot. A swath of high phosphates also extends eastward along the callejón. Two processes may contribute to the higher phosphate readings in this part of the houselot. First, since this area is connected to the houselot's east entranceway, and since the area immediately to the east of the houselot has no architecture, it is possible that crops grown past the east edge of the houselot were brought into the houselot using the east callejón and processed next to the callejón. If so, the organic debris from crop processing might have contributed to the high phosphate readings. Other organic matter (neglected scraps of fuel, building materials, etc.) coming into the houselot along the callejón and left in that space may also have contributed to the higher phosphate readings. The sole obsidian artifact recovered from the Balam Group, a fragment of a prismatic blade, was found on the western edge of this proposed processing/activity area, what Killion (1992) would call a "staging area." Alternatively, the high phosphates in this area may result from deposition of organic material generated on the patio or perhaps at Structures 19 and 20 . However, the fact that the elevated phosphates extend eastward along the callejón, $10 \mathrm{~m}$ past the patio edge, gives more support to the suggestion that this was a staging area.

The shortest route from the sascabera to the patio enters the patio at its northwest corner. The fact that this northwest corner had neither trash nor phosphate buildup supports the idea that this was in fact used as a walking path. We found 
the second-highest concentration of sherds just off this path between the sascabera and Structure 20. This trash accumulation probably resulted from people depositing debris from the patio as they walked north along the pathway. The sascabera, a $65-\mathrm{cm}$-deep pit that is by far the lowest spot in the houselot, had relatively little trash in it, thus differing from ethnoarchaeologically based expectations that people dump trash in areas of lower elevation (Hayden and Cannon 1983:126; Arnold 1990:918).

The five highest phosphate concentrations in the entire houselot came from five spots on the north edge of the houselot. One of these phosphate samples was fractionated (see Eidt 1977; Lillios 1992; Miller and Gleason 1994; Schuldenrein 1995) and the results indicate artificial enrichment in the ancient past. Above-average phosphate readings came from nearby shovel tests as well. Our interpretation of this broad cloud of high phosphate concentrations in the northern sector of the Balam Group is that they represent artificial fertilization for gardening. This interpretation is strengthened by the fact that there is very little hard inorganic refuse in the vicinity to dull agricultural tools and the fact that, though there is bedrock nearby, none of the soils in this area are less than $15 \mathrm{~cm}$ deep. The next-highest phosphate readings came from a shovel test along the western edge of the houselot and a shovel test along the southeast edge of the houselot. The phosphates from the unit on the western edge were fractionated and shown to represent ancient phosphate enrichment. Neither of these spots co-occur with inorganic trash. Since the soils here are not as deep as the proposed garden area to the north, we think that these two spots are where the houselot residents went to the bathroom. At the same time, we acknowledge that without botanical data, it is difficult to distinguish a bathroom from a garden area.

\section{SETTLEMENT FINGERS}

In the discussion of the residential periphery, we noted that the east transect does not show a clear distinction between the residential periphery and the lower-density hinterland. Not counting the more-dense settlement at the western end of the east transect, settlement density for the rest of the transect is I2O structures per square kilometer. This is twice the density of settlement beyond the residential periphery on the other transects. Settlement density on the east transect remains constant for I $\mathrm{km}$ until, at $2.35 \mathrm{~km}$ east of the site-center datum, settlement density increases. Here, the transect connects with Kocholito (figure 5.3), a cluster of mounds first recorded by the Archaeological Atlas of Yucatán, in the 1970s, as a site separate from Chunchucmil: site ${ }_{5}$ Q-f-4 (Garza Tarazona de González and Kurjack 1980). Settlement density in the $\mathrm{I}-\mathrm{km}$ stretch between Chunchucmil and Kocholito may represent a corridor, or "finger," of settlement that links Kocholito with the rest of 
Chunchucmil. Two test pits date a patio group on the western edge of Kocholito to the late part of the Early Classic period, the same period in which Chunchucmil became an urban center. Another settlement finger may connect Chunchucmil to the site of Yokop (see chapter 8) to the southwest. We estimate that such fingers cover at least $3 \mathrm{~km}^{2}$. If we consider these fingers to be part of Chunchucmil, then they would add to the estimate of Chunchucmil's population size, but not by much since the density of settlement on them is relatively low (I2O structures per $\mathrm{km}^{2}$ ).

\section{HINTERLAND}

As noted in the section on the residential periphery, the hinterland consists of space whose structure density ranges from 39 to 67 structures per square kilometer, similar to densities of "intersite" areas in other surveys (Rice and Rice 1990). Chunchucmil's hinterland, however, is not homogeneous. Based on patterns in the presence or absence of albarradas and in the distribution of obsidian, we divide the dispersed area beyond the residential periphery into an inner hinterland and an outer hinterland. Regarding albarradas, surveys conducted by Hixson and Mazeau (see chapter 8) show that the number of houses encircled by houselot walls drops precipitously at a distance of $5 \mathrm{~km}$ beyond the site-center datum (Hutson et al. 2008:33). The $5-\mathrm{km}$ radial distance also marks a significant drop in access to obsidian: hinterland houses within the $5-\mathrm{km}$ radius yielded more than six times as much obsidian per cubic meter of excavation than houses beyond the $5-\mathrm{km}$ radius (see chapter 13 for a consideration of what this distance implies for the hinterland reach of Chunchucmil's marketplace). At the same time, the amount of obsidian per cubic meter of excavation from inner hinterlands is still three times less that of the site center, the residential core, and the residential periphery.

\section{SYNTHESIS: URBAN CHUNCHUCMIL AND GREATER CHUNCHUCMIL}

As many writers have concluded, the boundaries of Maya cities are not always clear due to the dispersed nature of Maya settlement patterns (Freidel I98I; Isendahl and Smith 2013; Sanders 198I). The foregoing discussion about the settlement zones of Chunchucmil affirms that the boundaries of Chunchucmil are also not very clear. At the same time, three lines of data (settlement density, access to obsidian, and presence/absence of albarradas) allow us to propose two different boundaries. The first boundary separates the site center, the residential core, and the residential periphery from the hinterland (both inner and outer). This boundary delimits what we call urban Chunchucmil, which covers $15 . \mathrm{I} \mathrm{km}^{2}$. Settlement density is at least six times higher within urban Chunchucmil and access to obsidian is three times 
higher. The difference in settlement density may seem merely quantitative and not meaningful to people in the past. Joyce Marcus (1983, 2000; Marcus and Sabloff 2008) has argued many times that the Maya did not distinguish between city dwellers and those living in rural outskirts (but see Restall 1997:20). Nevertheless, we have argued (Hutson et al. 2008) that the drop in settlement density at the edge of the site had effects on social relations that make for a qualitatively different life experience. The drop in density from 350 to 60 structures per square kilometer results in different intensities of interaction on either side of the threshold: beyond it, residences are diffusely situated, therefore making interpersonal contact less frequent. Within the threshold, houselots have many next-door neighbors, implying frequent contact. The higher frequency of interpersonal contact implies a more dense social fabric. Sharp drops in settlement density are thus more than fodder for etic distinctions. They have a proxemically experienced component shared all across the site. This shared experience may have been the basis for a generalized urban identity (either imagined or understood unconsciously) not found beyond the site (Ardren 2015; Magnoni et al. 2014). Nevertheless, the boundary between urban Chunchucmil and beyond is still blurry in places, particularly where settlement fingers extend from Chunchucmil out to other nearby sites.

Greater Chunchucmil consists of urban Chunchucmil as well as the inner hinterland. This term acknowledges that there are similarities-sharing of albarradas, better access to obsidian - between urban Chunchucmil and many of the dispersed hinterland houselots located within $5 \mathrm{~km}$ of the Chunchucmil site-center datum. Greater Chunchucmil covers approximately $64 \mathrm{~km}^{2}$, though survey and transects suggest that this $64 \mathrm{~km}^{2}$ contained many large pockets without architecture.

\section{POPULATION ESTIMATES}

In this section, we provide a population estimate for urban Chunchucmil. To reiterate, urban Chunchucmil consists of the site center, the residential core, and the residential periphery, though possibly also the settlement fingers. In the Maya area, most researchers estimate population by determining the number of houses at a site and then multiplying by the number of residents per house. The commonly used figure of 5.6 people per house comes from Redfield and Villa Rojas's (1934) ethnographic study of the Yucatec Maya village of Chan Kom, Yucatán. This figure was used at Mayapán (A. L. Smith 1962) and at Tikal (Haviland 1970). Alternative figures have been put forward based on sixteenth-century ethnohistorical accounts (e.g., the Cozumel census of 1570; Roys et al. 1940), such as Haviland's (1972) figure of 4.9 individuals in a nuclear family. Mayanists have applied this figure, rounded up to five, at Tikal (Haviland 1972) and Late Classic Seibal (Tourtellot 1988). Sanders 
(in Rice and Culbert 1990) has suggested the lower figure of four individuals per house based on sixteenth-century Mexican census data. Other colonial census data suggest anywhere from 6 to 13.58 individuals per house (Roys et al. 1940; Ringle and Andrews 1990:table ir.7). Here we use the most commonly used figure of five persons per residential structure.

Having settled on the quantity of people per residence, we now need to estimate what proportion of structures at Chunchucmil were residences. We should reiterate from chapter 2 that basal platforms, on top of which structures sat, were tabulated apart from structures, so they already do not figure in the count. Excavations of the Kaab' and Balam residential groups described above as well as other groups at Chunchucmil (Hutson et al. 2004) show that such groups contained one or more residential structures as well as auxiliary structures that were used as kitchens, storage spaces, and processing areas, and the occasional shrine. Most buildings were arranged around one or more common patios. Since a group of leading archaeologists argued that ancient houses must have had at least $20 \mathrm{~m}^{2}$ of roofed space to support a family of four to five people (Ashmore 1981:47; see also Kolb 1985; Tourtellot 1983:37), we considered structures with less than $20 \mathrm{~m}^{2}$ of surface area to be auxiliary structures as opposed to residences. Extensive excavations in four residential groups have corroborated the notion that smaller structures were non-residential and were used for a variety of other purposes (Magnoni et al. 2004; Hutson 2010; Hutson et al. 2004). We found that 16.5 percent of structures in the $9.3 \mathrm{~km}^{2}$ have less than $20 \mathrm{~m}^{2}$ of surface area. Domestic shrines were eliminated from the count. Though shrines are sometimes recognizable by their eastern location in the residential group, their square dimensions, and their often relatively tall architecture (Becker 1991; Hutson et al. 2004), it is not possible to detect all of them without excavation. In a closely tabulated sample of 392 houselots containing 1,767 structures, we identified 134 structures as shrines and another II 8 structures as potential shrines. Assuming half of the potential shrines were actually shrines, this means 193 of I,767 structures were shrines, or II percent (Magnoni et al. 2012:appendix I). Finally, just to be conservative, we presume that another 5 percent of structures were also not residences.

In summary, we believe 32.5 percent of structures were not residences ( $16.5 \%$ auxiliary structures measuring less than $20 \mathrm{~m}^{2},{ }_{11} \%$ shrines, and $5 \%$ other). For Tikal, Haviland (1965) concluded that 16.5 percent of total structures were non-residential. For Seibal, Tourtellot $(1983,1990)$ put the percentage of non-residential structures at I4.3 percent. Thus, when estimating population density, these researchers reduced the structure count by about is percent. Since we reduce our count by 32.5 percent and since we do not include chich mounds, we consider our population estimates to be conservatively low. 
Yet we are not through reducing the structure count because we cannot assume that all structures were contemporaneous. Following our conclusions in chapter 4, we agree that the vast majority of Chunchucmil was occupied at the end of the Early Classic, so we apply a correction factor of only s percent to account for noncontemporaneous structures. Finally, we should also consider that not all structures within a residential group were actually in use at all times because of changing household life cycles. Thus, we apply another 5 percent correction factor to account for this. In sum, we reduce the structure count by another io percent to account for lack of contemporaneity.

On the other hand, we have to consider that the number of houses may have been undercounted since structures made of perishable materials do not preserve and are archaeologically invisible. We infer their presence, however, because several basal platforms, which were not part of our structure count, had no visible structures on top. We assume that these platforms supported perishable structures. To account for the invisibility of perishable structures, we add 5 percent to our count of residences. Because of the shallow soils and lack of alluviation or colluviation, we believe that the construction of later buildings was the only major process that buried structures at Chunchucmil. In over 800 off-mound test pits and about 500 off-mound shovel tests we failed to find more than a single buried structure. Thus, we believe that there were almost no "invisible structures" (Chase 1990; Johnston 2004; Pyburn et al. 1998) hidden by soil. Finally, because of the low amount of vegetation and extremely intense mapping methods (see chapter 2 ) we feel that we found nearly all visible features. Thus, although we add 5 percent for residences made of perishable materials, we do not add a positive correction factor for buried or missed structures.

In summary, to convert the number of structures to a number of contemporaneously inhabited residences, we take out 32.5 percent for non-residential structures and io percent for possible lack of contemporaneity. But, we add 5 percent to account for perishable structures that disappeared. Combined, these adjustments move us to reduce the total number of structures by 37.5 percent to arrive at the number of contemporaneous residences.

Table 5.2 shows the remaining calculations. Given that the residential core covers $5.85 \mathrm{~km}^{2}$ and has $\mathrm{I}, 064$ structures per square kilometer, the total number of structures for the core would be 6,224. After the 37.5 percent reduction, we have 3,890 houses. With five people per house, this comes to 19,450 people for the residential core. Given that the residential periphery covers $8.7 \mathrm{~km}^{2}$ and has 392 structures per square kilometer, the total number of structures in the periphery would be 3,410. The 37.5 percent reduction leaves 2,I32 houses. With five people per house, this comes to I0,660 people for the residential periphery. The site center contains 522 structures, but, due to the presence of a greater proportion of temples and non-residential 
structures, as well as the fact that most of the 19 Late/Terminal Classic platforms are in the center, we use a 50 percent correction factor. This leaves 26I residences and a total of $\mathrm{I}, 305$ people. Combined, the population of the $15 . \mathrm{I}-\mathrm{km}^{2}$ area we call urban Chunchucmil—site center, residential core, and residential periphery-is 31,415.

For three reasons, our estimate of 31,415 people is conservative. First, if we assume that the settlement fingers, with a density of about 120 structures per square kilometer, are part of urban Chunchucmil and that these fingers cover $3 \mathrm{~km}^{2}$, then they add 1,530 people to the estimate, this time using a is percent reduction factor (see below). Second, our estimate did not account for chich mounds. In their population estimate for Sayil, Tourtellot et al. (1990) consider every chich mound, regardless of size, to house a family of four. As noted in chapter 2, it is likely that some chich mounds were indeed residences. For example, at Komchen, Ringle and Andrews (1990) found a chich mound with a burial; burials are most often found in residences. Having found chich mounds with plaster floors and caches, Pyburn et al. (1998) consider chich mounds to be permanent residences as opposed to temporary field houses. If the large chich mounds we mapped in the residential core and residential periphery are residences, they are also unlikely to be temporary field houses, since they are located within the city. If we consider that half of the estimated I, 830 chich mounds within urban Chunchucmil were occupied by a family of four (and that the other half were arboricultural features [Kepecs and Boucher 1996] and/ or auxiliary structures), then these 915 chich residences would house 3,660 people. Third, if we follow the common southern lowland is percent reduction as opposed to the 37.5 percent reduction discussed above, this would add another 10,836 people to the population estimate. Combined, these three adjustments would increase our population estimate to 47,44I people for the residential core and residential periphery (see table 5.2). We consider this figure an upper limit for the population. Following Cowgill's (1990) advice that population estimates should be presented as a range between rounded numbers in order to avoid the spurious impression of precision (see also Ringle and Andrews 1990:219), we believe between 31,000 and 48,000 people lived at Chunchucmil during the Late Aak phase (late Early Classic) (see also Magnoni 2007). These figures yield a settlement density of between 2,000 and 3,000 people per square kilometer. For the $5.85-\mathrm{km}^{2}$ residential core alone, the settlement density would be between 3,300 and 4,520 people per square kilometer.

\section{SUMMARY}

If the map presented in chapter 2 provides a skeletal understanding of Chunchucmil, in this chapter we added flesh and blood to that skeleton in two ways. First, we organized the map into five zones (site center, residential core, residential periphery, 
settlement fingers, and hinterland) and described the general features of each zone. Second, we used excavation data from a quadrangle and a pair of houselots to give a sense of what life was like in each of the three largest zones. Several findings emerged from this analysis. We now recap three of them. First, Chunchucmil's site center does not match the expectations of a regal-ritual center. Chunchucmil lacks a grand plaza for royal performance and rather than having a single massive acropolis or palace complex fit for a king, Chunchucmil has many quadrangles of similar layout and scale. Second, Chunchucmil was not organized concentrically as Folan and others define it: large, wealthy houselots are just as likely to be located near the center of the site as they are on the edges and in between. Third, and perhaps most important, density calculations coupled with the chronological data from chapter 4 permit a conservative estimate of 31,000 people living in $15 \mathrm{~km}^{2}$. Whereas the site center contained many ceremonial groups, houselots dominate the extremely dense residential core and moderately dense residential periphery.

This conclusion underlines Chunchucmil's status as a major urban center and one of the largest Maya cities. For example, the estimated number of people living in the central $16 \mathrm{~km}^{2}$ of Tikal-13,275 (Culbert et al. 1990)—is less than half the number of people living in $\mathrm{Is}^{\mathrm{km}}{ }^{2}$ at Chunchucmil. Closer to home, Dzibilchaltún has 8,390 structures in $19 \mathrm{~km}^{2}$ (Kurjack 1974:94). If we apply the same reduction factor to convert structures to houses and assume five people per house, we get about 26,000 people for Dzibilchaltún; at least 4,000 fewer than Chunchucmil in an area that is 27 percent larger.

Several questions arise from our conclusions about Chunchucmil's large size and high settlement density. First, what opportunities did the local environment provide for feeding all of these people? Second, did the people of Chunchucmil have all of these resources for themselves, or did they have to share them with a sizable rural population? Third, would there have been enough food for everyone? We answer the first question in the next two chapters ( 6 and 7 ). We answer the second question in chapter 8 , and we answer the third question in chapter 9. In short, we believe that the people of Chunchucmil had to trade with other regions for a portion of their food. The food shortage and the fact that Chunchucmil was not a regal-ritual center bring up a final question. If Chunchucmil's growth and urban development were not driven by abundant food resources or the public rituals of a divine king and his retinue, what attracted people to the city? In chapters II and I2, we make the case that Chunchucmil's growth and urban development were driven by long-distance trade of salt, obsidian, and other items, that the success of this trade attracted a population that eventually exceeded regional carrying capacity, and that growing food deficits were compensated by a burgeoning market economy in staple supplies (Dahlin et al. 2007:369). 


\title{
Environmental Heterogeneity in the Chunchucmil Economic Region
}

\author{
David R. Hixson, Timothy Beach, Sheryl Luzzadder-Beach, \\ AND BRUCE H. DAHLin
}

The Pakbeh Regional Economy Program (PREP) focused on a broad area named the Chunchucmil Economic Region (or CER, see figure I.2). The CER was defined as the $2,500-\mathrm{km}^{2}$ area that covered the various ecological zones from the base of the Puuc hills to the Gulf Coast (east to west) and from the modern town of Celestún in the north to just south of the archaeological sites of Siho and Uaymil, thus encompassing all of the potential economic resource zones within reach of Chunchucmil (Dahlin and Ardren 2002:254). All of the environmental zones discussed below could be reached by a sojourner from downtown Chunchucmil within a single day (or slightly more during the height of the rainy season). PREP researchers did not presume that Chunchucmil controlled all of this terrain politically. Oxkintok, which had a strong occupation contemporaneous with Chunchucmil's apogee, may have controlled the terrain a few kilometers to the west of the base of the Puuc hills (Velázquez Morlet and López de la Rosa 1995). Likewise, Siho, which has a carved monument dating to $652 \mathrm{CE}$, was probably an independent political entity.

When Dahlin and others initiated the PREP, their principal goal was to address the questions and hypotheses raised by members of the Archaeological Atlas of Yucatán project (Garza Tarazona de González and Kurjack 1980). Specifically Dahlin wanted to understand how Chunchucmil, a densely populated city, was not only able to survive, but apparently thrive in such an agriculturally impoverished region. As summarized by Magnoni (2008:46), "PREP adopted a two-pronged approach to answer this question: first, comparing the agricultural carrying 
capacity of the region against the best estimate of population size to test whether Chunchucmil residents could have been supported by subsistence agriculture alone. Second, PREP focused on gathering as much information as possible on the role of trade in the growth of Chunchucmil to compensate for agricultural limitations."

One of the first aspects of the regional settlement pattern noticed by Dahlin was the apparent asymmetrical distribution of sites as registered by the Atlas project (figure 6.I). Later he wrote: "Nine Rank IV sites are known in the roughly I,000$s q-\mathrm{km}$ area to the west [of Chunchucmil], and four of them are on the coast. No less than 32 Rank III and IV sites were recorded within just a Io $\mathrm{km}$ radius to the east" (Dahlin and Ardren 2002:255). Rank III sites correspond roughly with the "stratified community (regional node)" type described in chapter 8 while Rank IV sites correspond roughly with the "stratified community" type described in chapter 8. These site types have no connection to the architectural group types discussed in chapter 3. Dahlin noted that the asymmetrical distribution of sites in figure 6.I likely had environmental roots such as climate and sea-level change and the risk of flooding, since the area between Chunchucmil and the coast was dominated by seasonal and perennial wetlands (chapter 9). He also believed, as did Vlcek et al. (1978) and A. P. Andrews (1990), that Chunchucmil's location at the western edge of its regional population base may have economic implications-that Chunchucmil may have developed in that location due to its increased access to the coast, thus allowing its inhabitants to exploit the lucrative salt beds of the Celestún Peninsula, and possibly act as a market or trading node, funneling products from the coastal trade routes into the interior from its port at Punta Canbalam (Dahlin et al. 1998; Dahlin and Ardren 2002; see also Kurjack and Andrews (1976) and Kurjack (1974) for a similar conclusion regarding other major inland sites in close proximity to the coast). In order to better understand this apparent distribution of known sites, the hinterland of Chunchucmil was studied by various members of PREP over the following decade through remote sensing tasks, soil chemical analyses, and archaeological surveys and excavations.

To ascertain why this large population was attracted to the CER in the first place, we made a concerted effort to understand its environmental diversity. This chapter reports on environmental diversity within the CER. While it mentions soils in various places, chapter 9 analyzes soils in much greater detail and with an eye toward their agricultural productivity and carrying capacity. The region contains six vegetation zones: beach ridge, swamp/estuary, petén, tzekel, savanna, and karst plain, all of which we discuss in greater detail below. From west to east, the vegetation changes from low thorn scrub, mangrove, and grasses and sedges near the coast, to tall deciduous forest in the tzekel and tall and complex forests of petenes (karstic features with fresh water supporting lush vegetation within areas of inundation), to 


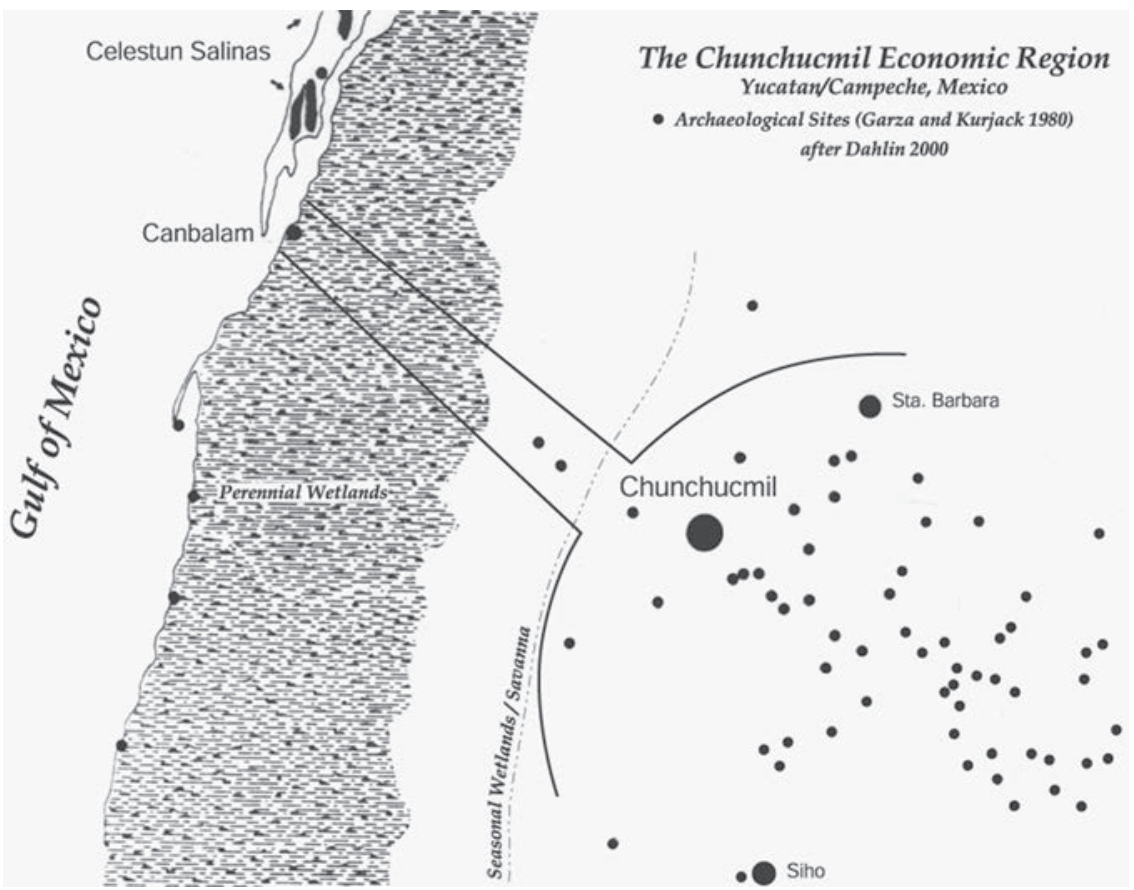

FIGURE 6.I. The Chunchucmil Economic Region (CER), showing the distribution of sites identified prior to the Pakbeh regional surveys reported in chapter 8. See figure 8.I for an updated map of sites.

low deciduous forest with grasses and sedges in the savanna, and then to taller deciduous forest in the karst plain (Rico-Gray 1982; Durán 1987). Since some of these six zones are patchy and can be interspersed within other zones (e.g., tzekeles are patches of high ground within the savanna), we have simplified these six zones into four discrete geomorphic provinces. From west to east, these provinces are as follows: (I) the coastal barrier beaches; (2) the perennially inundated wetlands (which contain swamp/estuary and some petenes); (3) the seasonally inundated savannas and tzekeles (which also contain some petenes); and (4) the semiarid plain, which terminates at the base of the next physiographic province outside of the CER - the Puuc hills (figure 1.2). This chapter reports environmental resources within these provinces and establishes an environmental baseline for chapter 8 , which presents regional survey results, allowing a discussion of spatial associations between human settlements and environmental resources. We further investigated the relationships between specific geomorphic features within these provinces-soils, water resources, natural drainage features, rejolladas, and sascaberas - to see if any of 
them perhaps offered households, neighborhoods or barrios, or even whole communities unique economic opportunities. We then sought to illuminate how these provinces, features, and their respective vegetative complexes might have changed through time as climate and sea levels fluctuated. We discuss contemporary climate and rainfall in the section below on the semiarid plains.

\section{THE COASTAL ZONE}

The coastal beach ridges of northern Campeche and western Yucatán, also called xeric beach ridges, are relatively young in geologic time, arriving at their general current configuration in the late Holocene, during the last 5,000 years (A. P. Andrews 1983:22; Eaton 1978:I1; Beach 1998a). These active and slowly shifting beach ridges border and protect the broad cienega/estuarine zone described below. As the trade winds and the Yucatán current push westward, parallel with the north coast of the Yucatán Peninsula, sediments deposit in the lee of the peninsula, where it turns almost 90 degrees to the south. Here sediment progrades into recurved spits of the Celestún Peninsula and Isla Arena, molded by the longshore current and low-energy wave action. These landforms provide limited terra firma for coastal communities when compared to the expansive beaches of the north or east coasts of the Yucatán Peninsula (the Celestún peninsula is roughly $24 \mathrm{~km}$ long and about 2 to $4 \mathrm{~km}$ wide, while Isla Arena is approximately $13 \mathrm{~km}$ long and about 0.2 to $0.75 \mathrm{~km}$ wide). Recent formations and shell sands have limited soil horizons on the beach ridges, as discussed in chapter 9. But these barrier beaches were-and still are-critical for the Maya.

Most germane to the research conducted at Chunchucmil, the Celestún Peninsula overlies the second-most productive salt beds in all of Mesoamerica (A. P. Andrews 1983; Dahlin et al. 1998). Salt was a precious and necessary commodity for the ancient Maya, not only fulfilling direct dietary needs, but also required to preserve, package, and transport perishable products in the hot and humid climate of southern Mesoamerica. Historic accounts from the contact and early colonial periods demonstrate without question that salt from northern Yucatán was traded extensively during the Maya Postclassic period. In the late Postclassic and contact periods, this corner of northwest Yucatán (and the interior land once dominated by ancient Chunchucmil during the Classic period) was part of the Ah Canul province (Roys 1957). Colonial sources note that salt was a tightly controlled commodity for the province (Piña Chan 1978). Although direct physical evidence for widespread trade in such a perishable resource is very scarce (Bezanilla 1995; Dahlin 2009), salt-bed exploitation likely extends well into earlier periods and was critical to the rising populations in the north (A. P. Andrews 1983:122; Eaton 1978; see also Sierra Sosa 1999), possibly as far back as the Middle or Late Preclassic. 


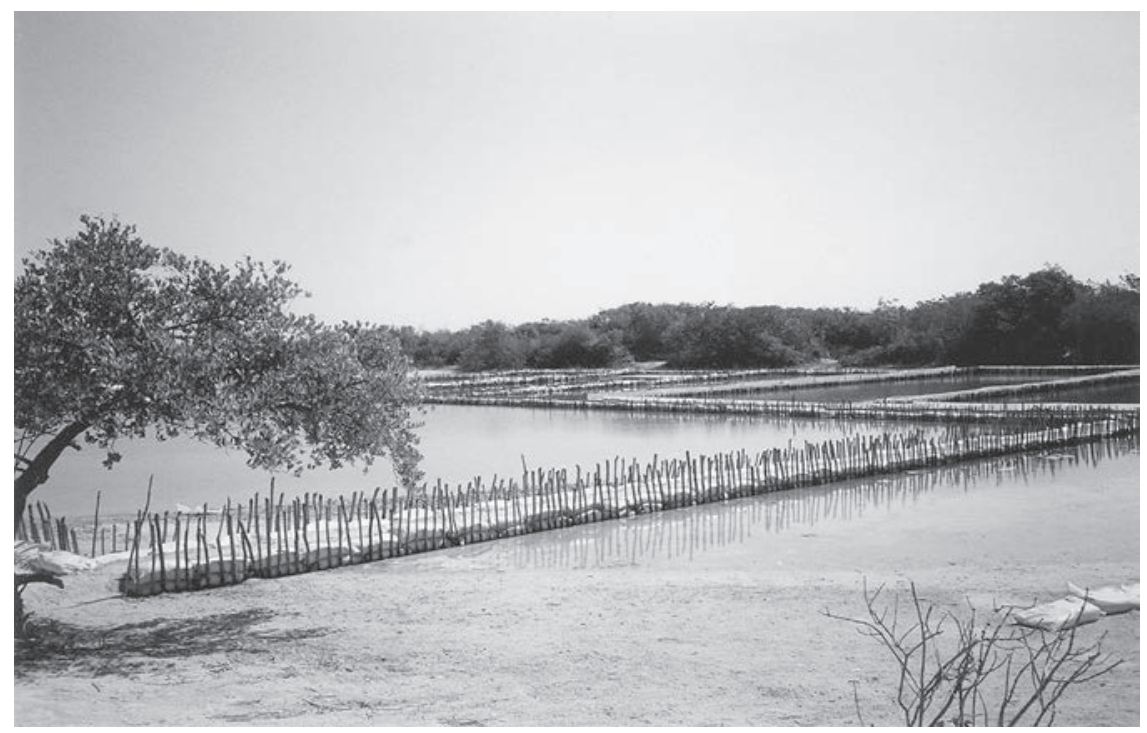

FigURE 6.2. Salt pans, or charcas, of the Celestún Peninsula.

The salt beds of northwest Yucatáan require limited (however strenuous) labor input, but the valuable commodity yields a high return on the investment. Today, as in the past, the Maya excavate large shallow pans (or charcas) in the lower beach lagoons and line them with low berms, often reinforced using simple wooden stakes (figure 6.2). There are hundreds of these charca features on the Celestún peninsula, some long abandoned. "Solar pumping" from the exposed surfaces of these charcas and low tides lowers the water table below pmsl (present mean sea level), causing seawater to infiltrate laterally through unconsolidated sands of the beach ridges separating them from the Celestún estuary and the Gulf of Mexico on either side. The seawater enters the salt pans at about 36 ppt (parts per thousand) salinity (Merino 1997) and this concentration must rise by a factor of 10 to reach salinity saturation. When this occurs, salt precipitates in layers several centimeters thick and a salt sludge or foam forms near the charca shores. During the height of the dry season, workers rake the salt layers, sludge, and/or foam into piles on the beach to await packaging and transport. Salt is exported to other regions or used by the local fishermen of Celestún and nearby coastal communities. The Celestún salinas undoubtedly played some role in the dense settlement and the resultant complex economy of the region. This is not only because of salt's high value as a preservative, a seasoning, and a nutritional necessity, but salt is also an ideal consumable currency, used as such throughout much of the preindustrial world; thus, the Celestún salinas are where "money grew in the water." 
In addition to salt production, fishing is (and likely always was) an important economic activity in this area. During the early colonial period, Spanish chroniclers noted that in some coastal Maya villages, large fleets of canoes were put to sea every day to supply both coastal and inland communities (Noyes 1932, as cited in Eaton 1978:13; Piña Chan 1978). Today, many Chunchucmil villagers migrate to Celestún seasonally in order to work the salt beds-when they can spare time from inland milpas. From these and other trips to the coast, they return with fresh, dried, and salted fish and mussels, still preferred meals among Maya farmers living in the dry interior around Chunchucmil (see chapter 8). Our bone isotope analyses indicate such a mixed diet may have been present in the ancient populations of Chunchucmil as well (Mansell et al. 2006).

This seasonal transhumance along with the economic/subsistence interrelations between the coast and the interior extends into the religious realm as well. Today, during the yearly festivals of the Catholic saints (or the "fiesta cycle"), the patron saints of some inland village churches travel to meet their counterparts along the coast, linking inland and coastal communities through the Catholic fiesta cycle.

Finally, the slowly shifting barrier beaches also provided safe harbors for small coastal watercraft, creating secure trading ports along the well-documented coastal canoe routes of the ancient Maya (A. P. Andrews 1998; Dahlin et al. 1998). A large scattering of ceramic sherds and obsidian blade fragments have been found at a minor spit of land just south of the Celestún peninsula, called Punta Canbalam (figures 6.3 and 8.2). While lacking architecture or other hallmarks of the Maya, this site may have been a very large coastal town in its day. As discussed in chapters 8 and I2, Canbalam could have been the port of trade for Chunchucmil (Dahlin et al. 1998), as well as a critical communication node in Chunchucmil's control of the Celestún salt flats.

\section{THE PERENNIALLY INUNDATED ZONE}

Immediately along the coast and/or behind the barrier beaches of the Gulf of Mexico lie the coastal mangrove estuaries. The mangrove swamps vary from a few hundred meters to several kilometers in width (Eaton 1978; Pope et al. 200I). Except where the natural or anthropogenic canals cut through the landscape, the mangrove environment is difficult to navigate for humans; yet it once teemed with abundant estuarine resources such as fish, mussels, mammals (such as manatee), and birds. The bird population is particularly striking with 7 I varieties of migrating birds and 159 varieties of native waterfowl and shorebirds currently residing in what is now known as the Celestún Biosphere Reserve. This implies a great diversity of birds within the CER that were either edible or used for their plumage (or both). 


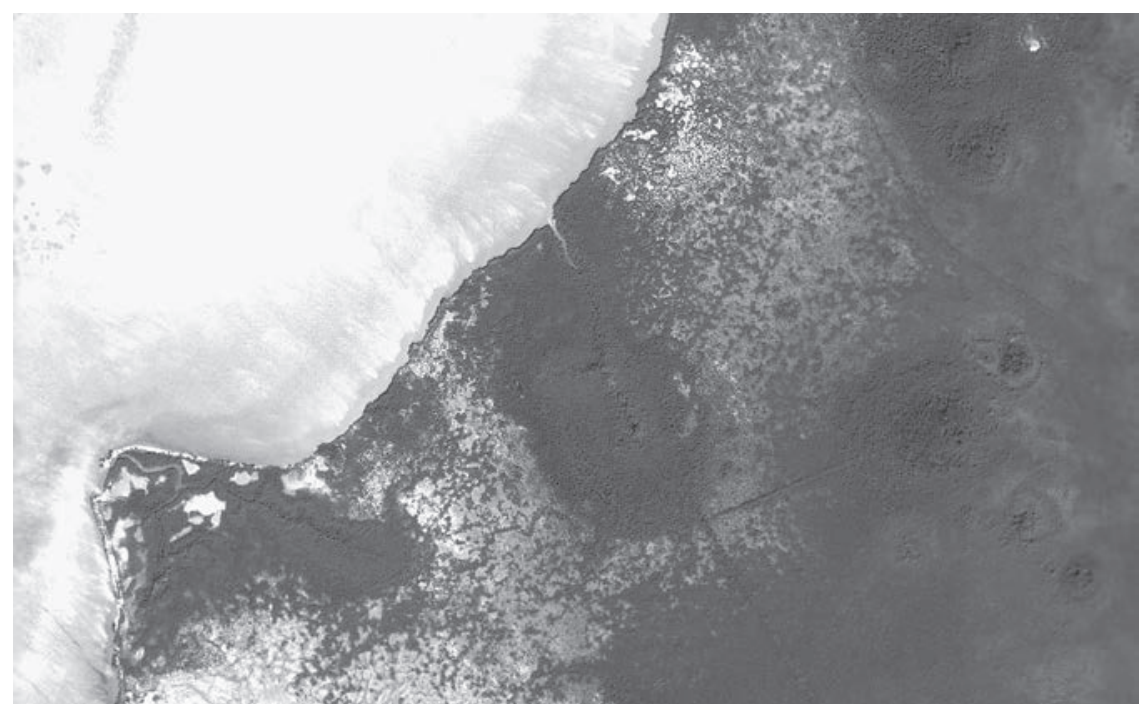

FIG URE 6.3. Aerial photo of the coastline west of Chunchucmil, with Punta Canbalam at bottom left (see figure I.2), showing petenes (at right) and natural and man-made waterways linking them to the coast.

Directly east of the mangrove estuary rests a narrow strip of open mud flats, devoid of most vegetation and accessible only by swamp-friendly boats. According to the remote-sensing data acquired by the PREP, this strip of mud flats extends from Punta Canbalam all the way south to Campeche City (itself once a large prehispanic center). It is possible there existed an inland route for shallow canoes up the Gulf Coast, protected from the ocean by the mangrove estuary, though lower sea level may have negated this.

Archaeologist Roman Piña Chan appears to have reached a similar conclusion regarding a possible inland waterway between Campeche City and Canbalam, since his map of Postclassic Maya trade routes includes this inland path (unfortunately without detailed discussion; Piña Chan 1978). Dahlin et al. (1998) pointed out that kayakers and indigenous informants showed a comparable inland waterway from the northern tip of the Celestún estuary to port towns along the north coast such as Sisal.

Farther inland from the mud flats, as the ground slowly creeps up toward the surface of the water; the perennial wetlands become dominated by flood-tolerant grass species such as sawgrass and cattail, as well as rings of mini tropical forests of broadleaf evergreen trees surrounding the freshwater petenes (Rico-Gray 1982).

The Yucatán aquifer feeds the wetlands between Chunchucmil and the coastal beaches (see chapter 7 ). In the most basic terms, the Yucatán aquifer is a lens of 
fresh water, fed by rains that fall upon the karstic central peninsula and percolate down through the porous limestone to rest upon an underlying layer of seawater. Individual regions (and microregions) have their own particular surface morphology that will affect the yield of groundwater after evapotranspiration. Eventually this groundwater flows on the gradual downward slope to the coastal shelf. The Yucatán surface becomes a perennial wetland some 13 to $16 \mathrm{~km}$ west of the site center of ancient Chunchucmil and Io to $13 \mathrm{~km}$ east from the coast. The transition from seasonal to perennial wetland occurs over a $3-\mathrm{km}$ zone of raised, dry tzekeles alternating with perennially inundated grasslands. Pope et al. (200I) further differentiated the perennial wetlands into 8 land cover types.

The surface hydrology of the perennial wetlands is relatively stagnant in the dry season, but during the rainy season water may flow slowly in wide drainages toward the sea, creating the very few surface "streams" in the northern lowlands (Wilson 1980). These drainages originate from the upward artesian flow of the aquifer through ojos de agua ("freshwater spring," or petenes). Upstream from these petenes the aquifer is sandwiched between the seawater below and the relatively impermeable limestone cap above (Pope et al. 200I).

When the volume of water forced out of these petenes is sufficient, the surface streams become navigable using small watercraft (figures 6.3 and 6.4). Colonial and later people canalized some of these to provide access to wetland timber products such as hardwoods and dyewoods, specifically Haematoxylum campechianum or "palo de tinte" (see chapter I0; Eaton 1978:30; Millet Cámara 1984, 1994). Some of the longer canals linked up to inland trails, allowing inland cattle ranches to import coastal salt (see chapter I2). In later years, the henequen hacienda owners used these canals and built formal roads to their headwaters in order to directly access coastal ports and resources, thus creating an alternative to the longer overland route through Mérida to the north coast.

\section{THE SEASONAL WETLANDS: SAVANNAS AND TZEKELES}

Between the perennially inundated zone and the semiarid plains around Chunchucmil lies a 6-to-9-km-wide swathe of seasonally inundated savannas and linear bands of tzekeles. The boundary between the semiarid plains and the seasonally inundated zone is approximately $5-6 \mathrm{~km}$ west of the site-center datum for ancient Chunchucmil. It is in this area that, during the rainy season, the discharge from the underground aquifer rises through the petenes as well as through smaller karstic solution sinks (natural wells similar to micro-cenotes) and meets the surface runoff to create a seasonal wetland (Perry et al. 1989; Pope, Rejmankova, et al. 1996). 


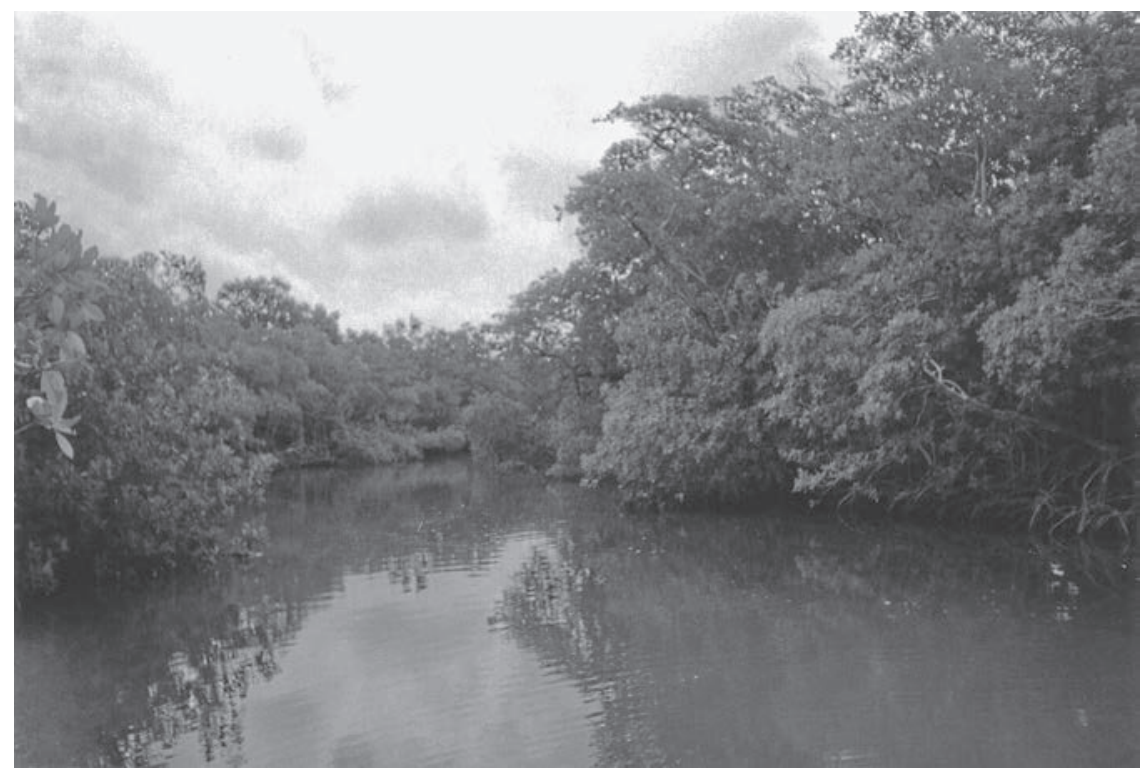

Figure 6.4. A canal near Punta Canbalam.

In this zone, the low-lying savannas are typically characterized by flat troughs of unbroken limestone. These limestone flats are relatively impermeable (unlike the broken and highly porous landscape covering most of Yucatán) due to seasonal redeposition of dissolved calcite, causing surface cementation. This cementation exacerbates localized flooding during the rainy season because it blocks infiltration (Perry et al. 1989; Beach 1998a; Pope et al. 2001). Farther north within the CER (along a vector north from Rancho San Simon; see figures I.2 and 8.I), the surface of the seasonally inundated savannas is more uneven, with slowly dissolving rounded cobbles of limestone covering the majority of the landscape. Due to subsurface cementation, this uneven terrain in the northern savannas also does not drain, but the fractured surface structure allows for expansive naturally occurring groves of flood-tolerant guiro, or calabash trees (Crescentia cujete), that produce gourds that make ready jars and bowls and serve as a favorite food of local deer populations.

What little soil that exists in the savannas is very shallow $(0-30 \mathrm{~cm})$ while surface bedrock is extremely common (Sweetwood et al. 2009), especially in the areas with flat limestone pavements. Contemporary Maya classify savanna soils as sak lu'um, meaning literally "white earth" (Bricker et al. 1998). Sak lu'um is generally a sandy or clayey loam, high in dissolved carbonates, surface salts, and decaying organic matter called periphyton (Novelo and Tavera 2003). Periphyton could be 
colloquially described as "pond scum" that accumulates during the rainy season, composed of a variety of organisms including "algae, bacteria, fungi, and animals, along with organic and inorganic detritus ... [It] represents a vital component of many freshwater wetland ecosystems, providing the main source of food for grazing herbivores, such as gastropods, and contributing significantly to the cycling of nutrients, particularly nitrogen and phosphorus" (Fedick et al. 2000).

In this mildly undulating landscape, small topographic variations, even less than a meter, will greatly influence the surface configuration and microecology. This is due to the proximity of the water table. While freshwater may be reached up to $7 \mathrm{~m}$ below the modern ground surface around Chunchucmil (Luzzadder-Beach 2000; see chapter 7), water can be reached literally centimeters below the surface in some locations within the savanna during the peak of the dry season (late April). If a strong storm, known as a norte, whips the northwest coast of Yucatán during a time of high tide, local Maya hunters often have advanced warning when fresh water wells of the savannas overflow with unusually salinated water (from the upward tidal pumping of the seawater that rests below the freshwater lens of the Yucatán aquifer). During the rainy season (June-November), as rainfall across the region swells the underground aquifer and localized rains no longer have anywhere to drain, the entire savanna may fill up with as much as $100 \mathrm{~cm}$ of water slowly seeking a path to the Gulf Coast.

These savannas regularly alternate with linear topographic rises called tzekeles. The term tzekel in modern Mayan literally means "bare" or "stony" (Bricker et al. 1998) and generally refers to landscapes covered with naturally occurring broken limestone at the surface with skeletal humic soils in its crevasses (see Batun Alpuche [2004] for an example of this use in an archaeological report). In the Chunchucmil region, the term tzekel also refers specifically to the linear formations of slightly elevated broken limestone. Therefore, to avoid ambiguity, we henceforth limit the use of this term to this latter, more specific meaning.

The tzekeles west of Chunchucmil are fossilized beach ridges that parallel the modern coastline of the Yucatán Peninsula (Beach 1998a). We have not encountered any study that estimates the exact age of each fossilized beach ridge, but considering the ages of the modern beach ridges along the coast (over the last 5,000 years), along with the highly fossilized nature of the tzekeles' shelly conglomerate of biotic limestone, and the relatively large distance between the tzekeles and the coast ( $10-18 \mathrm{~km})$, it is certain that they formed long before the arrival of humans in this area. We would posit that the tzekeles were likely created during the last major interglacial period (129,000 to 120,000 years ago) when the ocean was much as 6 $\mathrm{m}$ above pmsl (Chen et al. 1991; Rohling et al. 2008). This would be in line with estimates for similar fossilized beach ridges along the coast of Florida documented 
by NASA using remotely sensed imagery (Short and Blair 1986). Based upon flood simulations conducted by Hixson using NASA's SRTM data, it would take a rise of $4+m$ above pmsl for the ocean to encroach the necessary horizontal distance to reach the outer tzekeles (Hixson 2011).

Tzekeles, despite their rocky appearance, contain within their matrix a rich dark soil known to the Maya as box lu'um ("dark soil"). Beach (1998a:779; and chapter 9, this volume) describes box lu'um horizons within the karstic plain as having "higher amounts of organic carbon, carbonate, higher $\mathrm{pHs}$, less clay, and ... darker colors, often very dark brown $\left(\mathrm{IOYR}_{2} / 2\right)$." As one approaches the interior of the peninsula, portions of the savannas in between tzekeles have deeper kancab (calcareous reddish brown soil) soil horizons (as opposed to the skeletal sak lu'um soils farther out in the seasonal wetlands). Soil structural and chemical analyses by Sweetwood et al. (2009; chapter 9, this volume) indicated that the kancab flats would be more productive for agriculture than the box lu'um soils of the tzekeles. Yet, after centuries of working the soils around Chunchucmil, the local Maya have learned that these kancab flats support dense grasses that choke out most native crops, and these flats tend to puddle quickly after a heavy rain due to subsurface cementation. Therefore, farmers today avoid kancab flats in favor of the higher rocky hillocks of the tzekeles (and of course the ancient mounds themselves, which contain organic matter and deep clay pockets) (Beach $1998 \mathrm{a}$ ).

The broken limestone cobbles and box lu'um soils of the tzekeles provide a welldrained surface and ample room for deep root structures of supported vegetation. These rises (often only a meter or two above the surrounding terrain) make the difference between the low stagnant troughs of the intervening savannas and the comparatively lush forests of the tzekeles. The tzekeles sustain a moderate canopy of tropical deciduous, semideciduous, and evergreen trees, and plentiful limestone for building materials. These tzekeles also host the majority of archaeological sites within the seasonal wetlands. A few archaeological sites rest just above the level of seasonal inundation on natural bedrock outcrops similar to tzekeles. Archaeological features associated with wetland resource extraction and communication routes, however, have been located within the inundated savannas themselves (see chapter I2 for a discussion of andadores).

Natural resources of the savannas and tzekeles are abundant and diverse. A farfrom-comprehensive list of valuable plant resources from the seasonal wetlands includes thatch palms for roofing materials, hardwoods for house construction and tool manufacturing, gourds for storage and serving vessels, grasses and reeds for woven mats and basketry, medicinal plants (including one epiphyte that the local Maya use for aches and pains), as well as numerous fruit- and nut-bearing trees such as ramón (Brosimium alicastrum). 
Wild animal resources are equally varied and abundant, so we will list only those that we know are (or were) of use to the Maya and that were personally encountered during our surveys: deer, peccary, tepezcuintle (lowland paca), pizote (a white-nosed coati in the same family as the raccoon), tigrillo (a relative of the ocelot or margay), jaguar, snakes, crocodile, iguana, freshwater edible mollusks such as the apple snail, ocellated turkey, chachalaca, and a plethora of migratory and wetland birds whose range includes the aforementioned Celestún Biosphere Reserve.

Even the overabundance of insects in a wetland environment, a nuisance or even a health risk today, may have been a critical dietary supplement to an ancient population with limited agriculture. Parsons's (2006) study of aquatic-insect harvesting in Central Mexico has demonstrated that Mesoamerican civilizations living in or near wetland environments likely made full use of the insect population. One interesting protein source Hixson ingested during his surveys west of Chunchucmil was wasp larvae (eaten roasted in the nest).

Finally, it is critical to note that this seasonally inundated zone is highly preferred by the modern Maya for apiculture (beekeeping). There are two main reasons for this: freshwater and flowering plants. Some readers may not realize that bees require fresh water to drink (this is why one should never approach a freshwater well in this part of Yucatán during the heat of the day-a lesson quickly learned). Most of the modern settlements, as well as the majority of ancient archaeological sites (including ancient Chunchucmil) are located farther inland, in the semiarid plains zone (see below). According to local beekeepers from the villages of San Mateo and Chunchucmil, while natural and man-made water sources exist inland, the proximity to groundwater in the seasonal wetlands makes apiculture more profitable and reduces risk from inland droughts. More important, flowering plants are much more plentiful in the seasonal wetlands due to the frequency of petenes, aguadas, natural wells, and the simple fact that standing water dominates the landscape for months on end. Apiculture was a major industry for the Ah Canul province during the Postclassic period of Maya prehistory (Piña Chan 1978), and likely extends back to the Classic and Preclassic periods.

\section{THE SEMIARID KARSTIC PLAINS}

The ancient Maya site of Chunchucmil is located on a narrow band of semiarid terrain that stands sandwiched between the seasonal wetlands and the Puuc hills (figure 1.2). This particular environmental zone is among the driest in the Maya area, with annual rainfall varying from 700 to $1000 \mathrm{~mm}$ (Beach 1998a:762). High rates of evapotranspiration and rapid downward seepage through the highly porous karstic limestone of the semiarid interior further reduce this figure to $600-800$ 
$\mathrm{mm}$ for the area's annual water-budget deficit. In addition, precipitation is highly variable within the year (with $80-90 \%$ falling from May through October), as well as from year to year and from location to location, due to the nature of convectional rainfall near the Gulf Coast and the Puuc hills (Me-Bar and Valdez 2003). Indeed, a weather station located within the modern village of Chunchucmil indicates that actual mean rainfall at that location (averaged over 17 years) is only $640.1 \mathrm{~mm} /$ year, well below the cited range (Magnoni 2008). Anecdotally, while working for many years in this region, PREP members commonly observed rain falling over the Puuc hills to the east, and/or over the coast near Celestún, while nary a drop would fall on Chunchucmil. This region of arid terrain is clearly visible as a stunted band of drier vegetation within all multispectral satellite imagery acquired by this project, from the 1980 s to the present. The average annual temperature is $27.2^{\circ} \mathrm{C}$ (Querejeta et al., 2007), which contributes to very high evapotranspiration.

Compounding these harsh arid conditions, nearly 50 percent of the surface around Chunchucmil is exposed limestone bedrock (Beach 1998a:78r; Dahlin et al. 2005). Even where there is a soil cover, its thickness is often a few centimeters (Sweetwood 2008:4). According to local Maya farmers, the best soils (box luium) are located upon the archaeological mounds themselves and likely developed over the last I,000 years since Chunchucmil's collapse and abandonment (Beach 1998a). Clearly these relatively young anthropogenic soils would not have been available to the ancient inhabitants of Chunchucmil. To the east of the site, agricultural potential improves only moderately as one moves into areas of deeper, more productive soils near the base of the Puuc hills (Vlcek et al. 1978; Sweetwood et al. 2009).

\section{THREE SPECIFIC GEOMORPHIC FEATURES OF THE SEMIARID PLAINS}

Besides our studies relating to freshwater wells within the semiarid karstic plains (see chapter 7), three other geomorphic features within this physiographic region deserve attention: natural drains, rejolladas, and sascaberas (figure 6.5). Natural drains of all sizes benefit the many low-lying areas that might otherwise flood to a meter or more in the wet season. These drains also provide an easier entry for either accessing the freshwater supply as a naturally occurring seasonal well or to support deep-rooted economic tree species like ramón or avocado, which would have benefited from constant contact with the groundwater (Fedick 2014). We excavated three small ( $\mathrm{I}-\mathrm{I} .6 \mathrm{~m}$ in diameter x $\mathrm{I} .35-0.9 \mathrm{~m}$ deep) natural drainages in conjunction with wells in residential contexts within the residential core, northeast of the site center (Groups $\mathrm{N}_{4} \mathrm{E}_{2}-\mathrm{G}$ [Op. 6a], $\mathrm{N}_{3} \mathrm{E}_{3}-\mathrm{H}$ [Op. 6b], and $\mathrm{N}_{4} \mathrm{E}_{3}-\mathrm{M}$ [Op. 152/6c]). These shafts had fills of loose, dark brown soil with a moderate amount of large rock, roots, and shells from edible land-snails. Cultural materials were not found in two 


\section{Chunchucmil \\ Idealized Landscape Cross-Section}

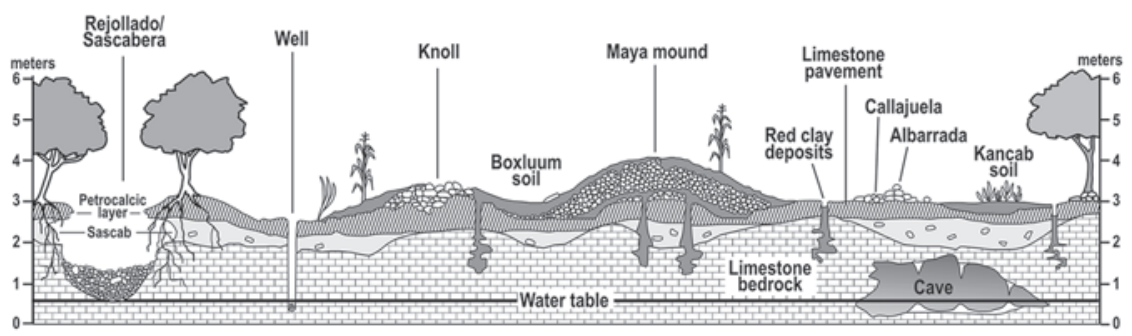

FIG URE 6.5. Idealized landscape cross-section, highlighting karst features, shallow soils, buried soils, and ancient stone platforms.

of them (perhaps because they once supported large economic trees?). The other, which was located adjacent to the back of a I-m-high mound and platform, contained heavily mixed (i.e., not stratified) midden materials within it, indicating it may have been open and accessible during its period of use as a naturally occurring seasonal freshwater well and subsequently filled through natural processes.

Rejolladas are dolines that tend to be much larger depressions that also may fill up with deeper soils (see chapter 2). They are, in effect, soil-filled karstic sinks similar to cenotes, although they formed without hitting the water table. The 9.3- $\mathrm{km}^{2}$ site map marks few depressions as rejolladas; most are sascaberas (a total of 270), quarries (a total of 210), or miscellaneous depressions (a total of 435 ), 70 percent of which range in size from 20 to $100 \mathrm{~m}^{2}$. Rejolladas in the center of the peninsula range from $400 \mathrm{~m}^{2}$ to $8,000 \mathrm{~m}^{2}$ with depths averaging around $\mathrm{ro} \mathrm{m}$, and many have suggested these as fertile locations for growing cacao and other crops because their depth creates advantageous microclimates and soil-moisture storage capacity (Dunning and Beach 1994; Kepecs and Boucher 1996; Munro-Stasiuk and Manahan 2010). The much smaller, shallower rejolladas in the Chunchucmil area would not have been as suitable for cultivation of cacao but they are still closer to the water table and have more soil than surrounding locations.

The largest rejollada mapped in the region as a whole was found within a suburban settlement known as Yokop, on the western periphery of Chunchucmil. The central architecture at Yokop includes a sizable pyramid and plaza adjacent to a $\mathrm{I}, 000-\mathrm{m}^{2}$ rejollada, indicating that this suburban center at the edge of Chunchucmil grew around this particular karstic feature.

In addition to quarrying for building stone within these rejolladas, chambers known as sascaberas (see below) were sometimes dug off to the sides under the 
caprock to extract sascab (chemically dissolved limestone used as sand within architectural floors and other construction projects) or gravel.

We suspect that freshwater wells were dug into the floors of many depressions, although we found only two such wells. One was found in a houselot at Chunchucmil (Group $\mathrm{S}_{2} \mathrm{~W}_{7-G}$ ), inside a cave-like chamber of a sascabera. The other was noted during regional survey at the base of the grand rejollada at Yokop, where in 2005 a gasoline-powered pump was being used to draw water out of the ancient Maya well. The well provided freshwater from the aquifer to a stand of papaya trees that were being grown within the relatively deep box lu'um soils of the rejollada. Similar silvicultural programs within rejolladas may have been equally productive in the ancient past (Munro-Stasiuk and Manahan 2010), albeit without gasoline-powered pumps.

Pockets of weathered limestone, or sascab, dot the landscape. When these pockets are quarried they are known as sascaberas (see chapter 2). We mapped a total of 270 sascaberas at Chunchucmil, and almost all of them occur within private houselots. Only about 20 percent of households were fortunate enough to have had a sascabera and it was obviously considered to be a valuable resource because albarradas often stretch and wrap around them. Sascab served as building material and possibly as mulch for gardens. Low grade, chert-like nodules often included in the sascab made expedient cutting implements. Also, some of the soil clays from depressions are ideal for ceramic manufacture. The high humidity inside sascaberas could facilitate the weaving of cordage products. Lastly, given the paucity of evidence for wells and the fact that the bottoms of some sascaberas yield water in the wet season, we hypothesize they also functioned to gain access to the water table.

\section{CONSIDERATIONS OF PALEOENVIRONMENTAL CHANGE}

Many of our interpretations of economic patterns in the CER presume environmental stability. Dahlin, however, was a keen student of climate and mindful of the possibility of environmental changes. The primary agents of environmental change include climate and sea-level fluctuations. Chapter 9 discusses a third possible change: soil erosion. The most complete climate record in the region comes from two lake-bottom cores at Cenote San José Chulchaca, $40 \mathrm{~km}$ to the north (figure I.2; Leyden et al. 1996). Significant lacunae remain in the paleoenvironmental data. Ongoing research on speleothems has helped to clear up some of these uncertainties by reconstructing a high-resolution picture of climate changes (Medina-Elizalde et al. 2010; Medina-Elizalde and Rohling 2012; Webster et al. 2007). All currently available data suggest that today's environmental conditions were not substantially different from those of the Classic period (Beach 1998a; Dunning 1992; Dunning 
and Beach 2000; Isphording and Wilson 1973; Wilson 1980). Conditions before and after the Classic period were likely different. For example, Medina-Elizalde and Rohling's (20I2) study of a speleothem from a cave near Mayapán found that rainfall dropped by $25-40$ percent during the Terminal Classic, and Medina-Elizalde et al. (2015) found two long, severe droughts in the Late Preclassic. Drought from Maya-induced and/or natural drivers certainly coincided with the Late Preclassic, Late/Terminal Classic, and Postclassic (Beach, Luzzadder-Beach, Cook, et al. 20I5; Kennett and Beach 2013; Hodell et al. 2005). While several authors have argued that these droughts affected the course of Maya civilization (Dahlin 2002; Gill 2000; Hodell et al. 1995), these droughts would not have affected Chunchucmil deeply because its population was relatively small during the Late Preclassic and the Terminal Classic, and it had ready access to groundwater.

Another proposed difference between the Classic-period environment and that of today is sea level (Beach 1998a; Dahlin et al. 1998; Hodell et al. 1995; Leyden et al. 1996, 1998). Paleoecological indicators, local beach terraces, and submerged archaeological sites along the coast all imply that the sea level may have fluctuated substantially during the late Holocene (Dahlin et al. 1998:II). Though we lack an accurate sea level curve for this region, some evidence suggested sea level peaked in the Early Classic (circa AD 250-500) to as much as $137 \mathrm{~cm}$ above pmsl (Dahlin et al., 2005), but dropped $60 \mathrm{~cm}$ below pmsl in the Late Classic. This could have affected inland inundation and Chunchucmil's access to potable groundwater and arable land by raising or lowering the Yucatán aquifer. At the higher sea level stands, Chunchucmil would have had even easier access to groundwater but would have suffered more from flooding and potential saltwater intrusion. At lower sea level stands, the wetlands would likely have migrated west. The salt flats of Celestún would have been further south than their current configuration, as would the mouth of the estuary, leading to the hypothesis that the original location of Canbalam is currently eroded and submerged at the tip of the Celestún Peninsula. While this would have left Chunchucmil within an even wider band of semiarid terrain with significantly less access to the hydrological features noted above, it could also have increased its access to arable land perched above the seasonal inundation.

\section{CONCLUSIONS}

Despite its initially perplexing location within the semidesertic plains of northwest Yucatán, the sprawling Maya city of Chunchucmil appears to be advantageously located at the confluence of multiple ecological zones that would have afforded its residents a great variety of natural resources to exploit. From the salt beds, fishing villages, and sheltered trading ports along the Gulf of Mexico, to the diverse flora 
and fauna of the perennial and seasonal wetlands, Chunchucmil's location (as close to the inundation as possible without significant risk of flooding) appears almost purposeful. Even within the dry rocky plains, the ancient Maya of Chunchucmil made the most out of shallow karstic features that pierced the hard limestone cap, revealing portions of the watery underworld below that were so critical for sustaining life and maintaining power.

In essence, the key to Chunchucmil's environmental heterogeneity literally lies just below the surface at the interface between Yucatán's rocky shell and the freshwater below, where a topographic change of only a meter or two meant all the difference. Whether sea level during Chunchucmil's apogee was comparable to today remains unresolved to our complete satisfaction and awaits the results of further study. Indeed, at this point the evidence for a higher Early Classic sea stand seems unlikely, but Bruce Dahlin and this project concluded that we desperately need a more accurate sea-level curve to answer many of the questions about the Chunchucmil region. We eagerly await this study. 



\title{
Hydrology on the Edge of the Chicxulub Crater \\ Chunchucmil and Uci-Cansahcab Groundwater Resources
}

\author{
Sheryl LuZzadder-BeACH ANd Timothy BeACH
}

One of the driving questions for studying the ancient Maya site of Chunchucmil and others nearby is how these communities sustained a large human population in a marginal environment. Where today stands a small village of about $\mathrm{I}, \mathrm{0} \mathrm{o}$ persons, there once sprawled a site of 30,000 or more (see chapter 5 ). We began our work at Chunchucmil with this challenge in mind. Questions of sustainable resource availability and use led us to examine the building blocks of agriculture, soils, and water (Beach 1998a; Luzzadder-Beach 2000; Dahlin et al. 2005). This chapter discusses the accessibility and quality of groundwater at Chunchucmil, and compares it to that of similarly situated ruins near modern-day Motul on the northeast side of the crater's Ring of Cenotes: Ucí and Cansahcab (see figure I.I). The main goal is to understand groundwater suitability for domestic and agricultural use. We compare accessibility and quality for these ancient settlements' water supplies. These results are relevant today because many thousands of people still depend on groundwater in the contemporary towns of Chunchucmil and Motul and all across the Yucatán Peninsula. The two regions today have similar water qualities despite the fact that Motul has an order of magnitude higher human population, which may tell us something about these two ancient regions. Although ancient Ucí was about $5 \mathrm{~m}$ removed from the water table, this fact may have benefited its health because the groundwater table was more remote from surface contamination. At Chunchucmil the water table was flushing quickly near the outer margins of the Chicxulub crater, but the water table was near the porous surface; the waste of large populations 
was therefore in near contact with the water table. We have insufficient evidence to know how this influenced the course of Maya history at these sites, but we can be sure it was a factor.

\section{BACKGROUND AND STUDY REGION}

Chunchucmil, Ucí, and Cansahcab are ancient Maya sites situated just outside and to the southwest, and just inside and to the north, of the Chicxulub impact crater, a 65-mya bolide-impact site crossing the northwest corner of the modern Yucatán Peninsula (Luzzadder-Beach 2015a; Pope, Ocampo, et al. 1996; Perry et al. 1995). Our research in this region began in 1994 in the Chunchucmil vicinity and in $201 \mathrm{I}$ in the Ucí-Cansahcab area. Chunchucmil was densely populated at the end of the Early Classic and beginning of the Late Classic periods (see chapter 4 ), and depended heavily on groundwater (Luzzadder-Beach 2000). Ucí and Cansahcab were Late Preclassic and Early Classic sites linked by an i8k-m-long network of raised stone causeways (sacbeob). The overall goal of the studies was to investigate the sites' economic status and integration, and to evaluate the natural resource base.

The Chicxulub crater is relevant to human history because its geologic structure controls groundwater flow through the region, including flow through a ring of cenotes, or sinkholes, in the karstic limestone surface, mirroring the slumping and faulting around the impact crater structure below (Pope, Ocampo, et al. 1996). The series of cenotes, also known as the zona de cenotes, offers access to groundwater, and also due to greater porosity and permeability in their vicinity, to groundwater flows through the arc of cenotes and out to sea via springs or ojos de agua at the ends of the crescent. This permeable and porous zone serves as a hydraulic diversion, drawing water quickly through the limestone aquifers circling northwest to the zona de cenotes, thereby diverting water that otherwise would pass northwest into the inside of the crater. Hence the inside of the crater zone has slower groundwater flow, and a deeper water table closer to the permeable cenote zone (Luzzadder-Beach 2000 , 2015a, 2015b). In addition to ready access at natural cenotes, the ancient Maya also dug wells and constructed casings of cut stone (figure 7.I).

We mapped the depth to the groundwater table and assessed water quality to develop a model of what kind of water supply was available to the ancient Maya for domestic and agricultural use, in addition to seasonal rainfall. Seasonal rainfall is meager, averaging $900 \mathrm{~mm}$ per year, with a distinct dry season between January and April, and peak rainfall between June and September (Luzzadder-Beach 2000; chapter 6 , this volume). With variable amounts of rainfall throughout the year, and despite rainwater-runoff capture and storage in ancient structures such as chultunes, groundwater offers a ready and more consistent supply. 

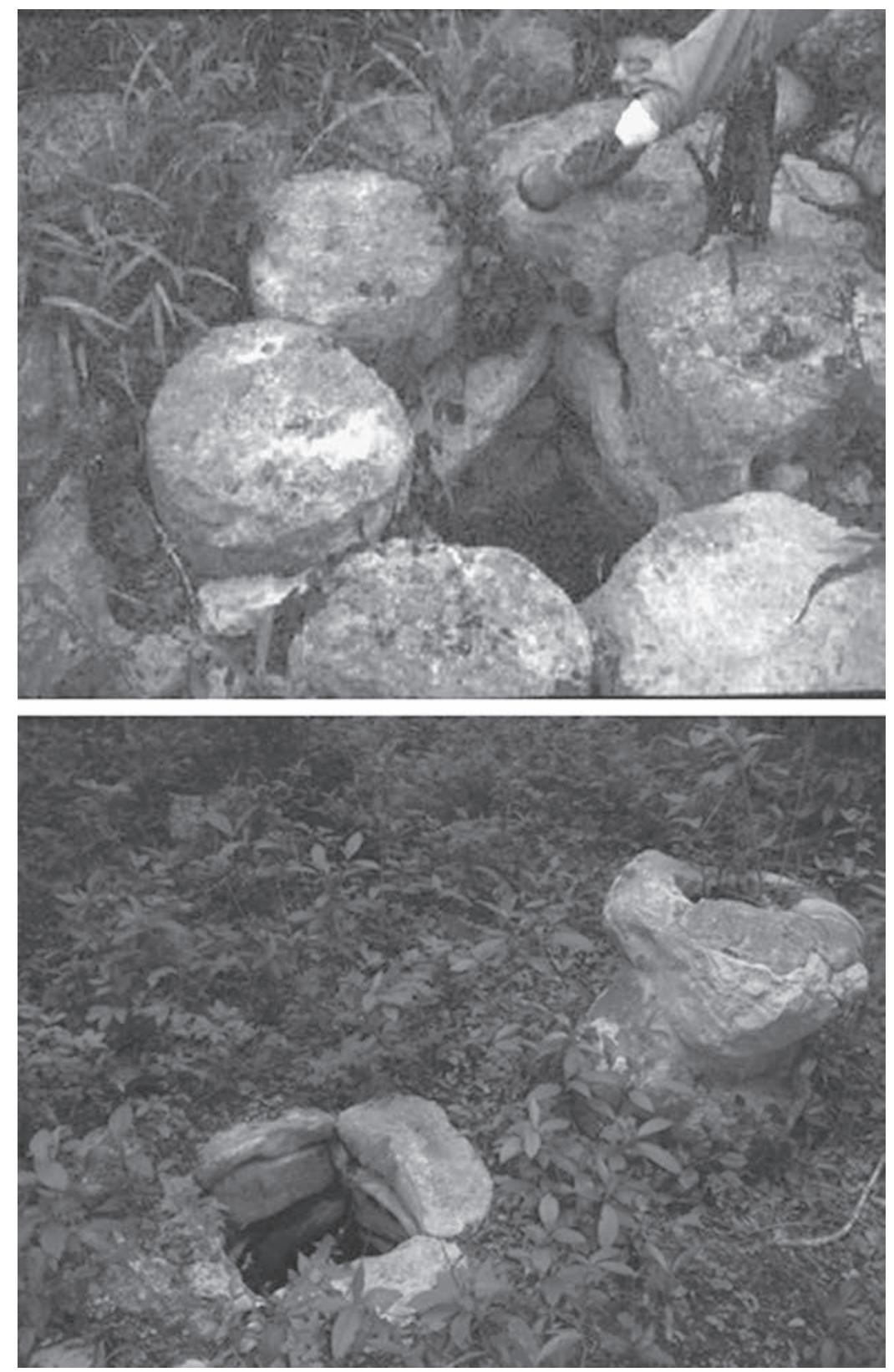

FigURE 7.I. Typical ancient Maya wells at (a) Chunchucmil, edged with ancient pillar stones from a former Puuc-style building, and (b) Ucí, stone-edged and -lined. (Photos Courtesy of Sheryl Luzzadder-Beach.) 
Luzzadder-Beach (2000) explained the field sampling strategies and the laboratory methods used for the Chunchucmil study area (figure 7.2), and provided the first comprehensive water-quality and water-table data for the Chunchucmil archaeological research site. We used these same methods from Luzzadder-Beach (2000) in the Ucí-Cansahcab study (figure 7.3). In the course of our summer 2011 field season, we sampled $4 \mathrm{I}$ water wells and cenotes in a transect from Ucí in the west, to Tizimin in the east, crossing the crater interior and the eastern boundary of the Ring of Cenotes. At each well we took GPS points, measured the depth to the groundwater surface (in meters, $\mathrm{m}$, as an indicator of ease of access), and collected samples for field and laboratory study (figure 7.3). The parameters we measured included electrical conductivity (EC $\mu \mathrm{S}$ ), total dissolved solids (TDS, $\mathrm{mg} / \mathrm{liter}$ ), salinity (Sal, ppt), and the mineral elements and compounds chloride ( $\mathrm{Cl})$, sulfate $\left(\mathrm{SO}_{4}\right)$, calcium $(\mathrm{Ca})$, magnesium $(\mathrm{Mg})$, and nitrate as $\mathrm{NO}_{3}$ (all measured in $\mathrm{mg} /$ liter). These are diagnostics for water use, aquifer sources, for mapping flow direction, and testing for seawater influence (Luzzadder-Beach 2000).

Earlier studies from Perry et al. (1995) and Back and Hanshaw (1970, II wells) provided regional contexts and comparison for Yucatán regional water quality and hydrology. The 1994-1997 Chunchucmil results (Luzzadder-Beach 2000) provide a comparison with the $201 \mathrm{I}$ results from the Ucí-Cansahcab study for a broader regional understanding of water resources.

\section{RESULTS AND DISCUSSION}

\section{Water Table and Field Hydrology Findings}

Table 7.I presents the mean and median depths to the water table of wells measured in Chunchucmil in $1994(n=14), 1997(n=22)$, and $1998(n=17)$, and in the 20 II Ucí-Cansahcab transect $(n=4 \mathrm{I})$. The mean and median depths were $1.37 \mathrm{~m}$ and $1.7 \mathrm{I} \mathrm{m}$, respectively, in the Chunchucmil region in 1997 , and $6.99 \mathrm{~m}$ and $7.0 \mathrm{~m}$, respectively, in the Ucí-Cansahcab transect in 20II. Considering this greater depth and the wide variability of access through bedrock and sascab, the Uci-Cansahcab region has a greater challenge to reach groundwater via natural access points and well construction. Groundwater depths across the region conform to findings of Perry et al. (1995) for increasing depth closer to the Ring of Cenotes (LuzzadderBeach 2000). This is because of higher permeability in the limestone aquifer material nearest the Zone of Cenotes (Perry et al. 1995).

In terms of field measurements of EC, the mean and median at Chunchucmil were 1,219 $\mu S$ and $996 \mu S$, respectively, in 1997 and Ucís mean and median were 1,120 $\mu S$ and I,072 $\mu$ S, respectively, in $201 \mathrm{I}$ (table 7.I). Chunchucmil has a wider range of measures, but there is little difference between the two regions. These EC levels (a proxy 
* 1997 water sample

\# 1994 water sample

$\square$ Contemporary pueblo

Contemporary road
$9^{4}$

Kilometers
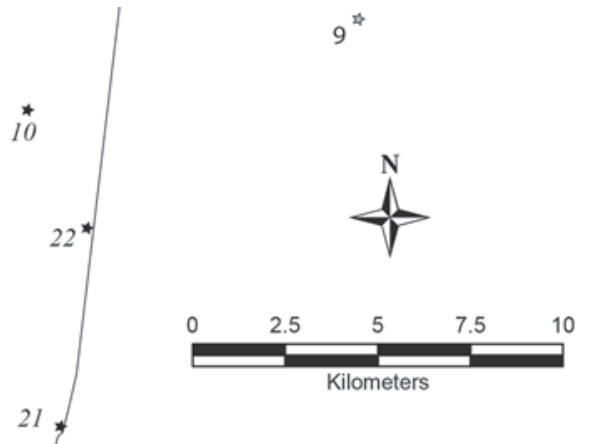

$\Leftrightarrow 1$

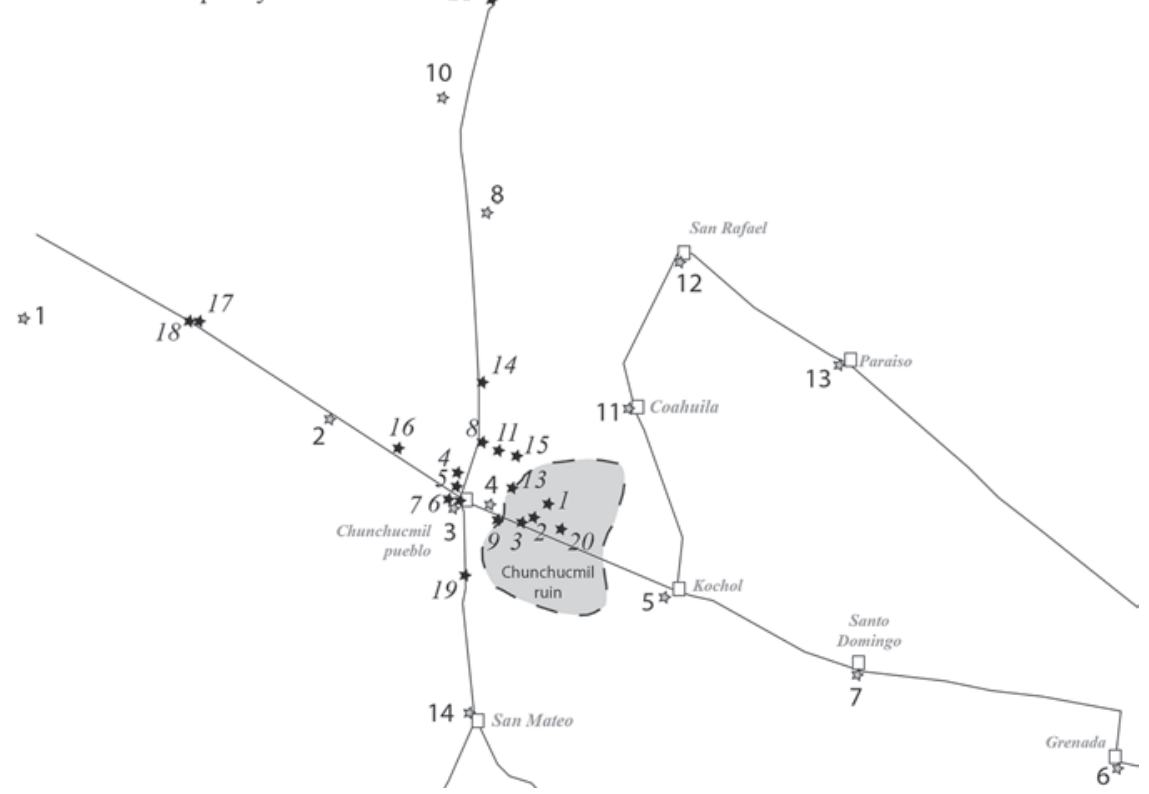

FIGURE 7.2. Chunchucmil groundwater sample sites, 1994 and 1997. Stars represent wells. (After Luzzadder-Beach [2000], S. Hutson, Cartography.)

measure for the total of all dissolved ions, or dissolved solids) indicate high TDS, which is a limit on agriculture (Luzzadder-Beach and Beach 2008). Salinity was measured in the field at Ucí in $201 \mathrm{r}$ and most wells and cenotes had a trace, with an average of $0.55 \mathrm{ppt}$ and a range from 0.2 to $1.6 \mathrm{ppt}$. There were 19 wells with salinity above 0.5 $\mathrm{ppt}$, three of these ranged from 1.2 to $1.6 \mathrm{ppt}$. Salinity of $0-0.5 \mathrm{ppt}$ is considered the range for freshwater; from 0.5 pp to 5.0 is considered "oligohaline"; waters in this category compare to estuarine. Ocean water salinity is about $30.0 \mathrm{ppt}$ for comparison (USEPA 2006). In an unpublished 1998 field study we measured groundwater salinity 


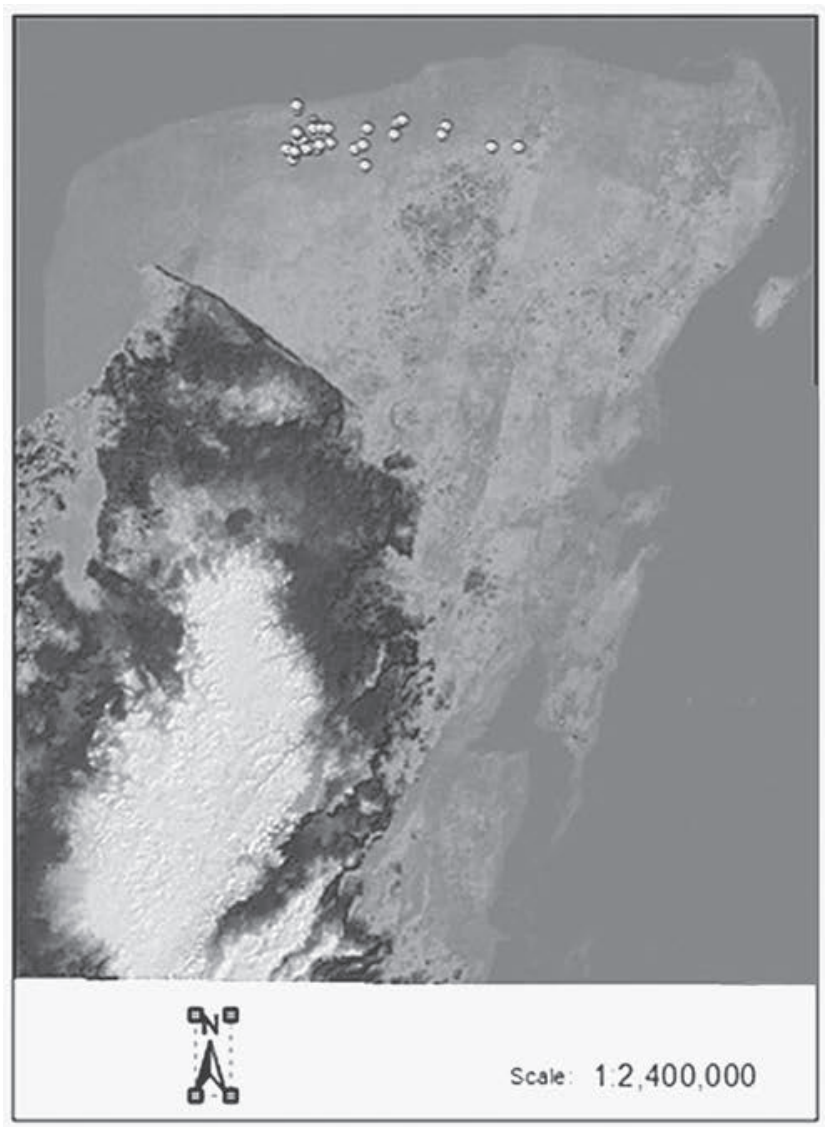

FIGURE 7.3 • 20 II Hydrologic study area: (a) UcíCansahcab water sample well sites (r:2,400,000 DEM) and (b) digital elevation model (close up). Dots represent wells. (After Luzzadder-Beach et al. [2012], K. Doctor, Cartography.)

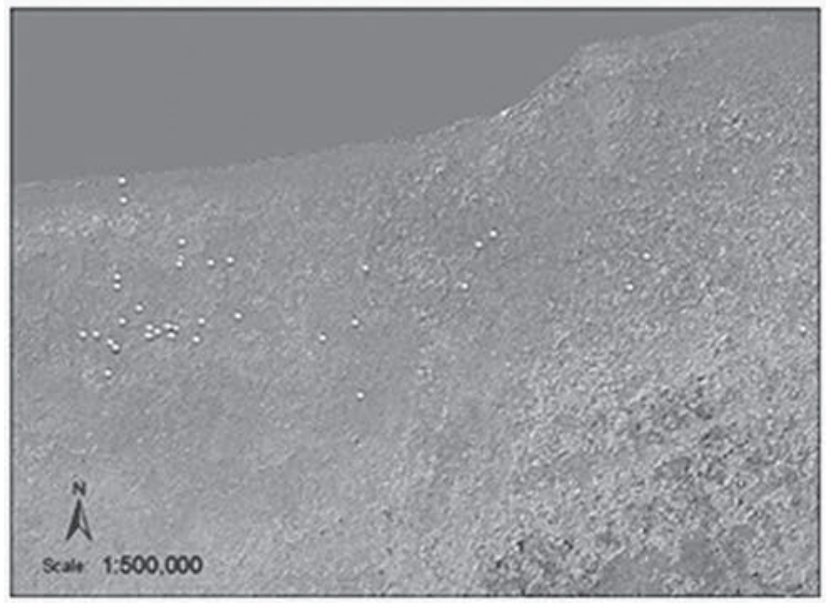


TABLE 7.I. Field measurement summary: depth, electrical conductivity (EC), and salinity (Sal).

\begin{tabular}{lccc}
\hline & Depth $(m)$ & $E C(\mu S)$ & Sal (o/oo) \\
\hline $\begin{array}{l}\text { Chunchucmil Regional Study, } \\
\text { I994 (mean, median) }\end{array}$ & $(2.7,2.56)$ & $($ I I60, I370) & - \\
$\begin{array}{l}\text { Chunchucmil Intensive Study, }{ }^{1} \\
\text { I997 (mean, median) }\end{array}$ & $($ I.37, I.7 I) & $($ I 219, 996) & - \\
$\begin{array}{l}\text { Chunchucmil Field Study } \\
\text { I998 (mean, median) }\end{array}$ & $(2.12,2.34)$ & $($ I690, I393) & $(0.87,0.7)$ \\
$\begin{array}{l}\text { Ucí-Cansahcab Transect 20 I I } \\
\text { (mean, median) }\end{array}$ & $(6.99,7)$ & $($ II 20.7, I072) & $(0.55,0.5)$ \\
\hline
\end{tabular}

I. See Luzzadder-Beach (2000) for field and analytical methods and for data sets.

in Chunchucmil wells and cenotes. The 1998 mean value was $0.87 \mathrm{ppt}$, the median was 0.7 ppt. The 1998 salinity range was 0.1 to 3 (table 7.I), with II of 17 wells exhibiting oligohaline salinity (above $0.5 \mathrm{ppt}$ ). Six wells of $\mathrm{I} 7 \mathrm{had}$ salinity in the range of $\mathrm{I}-3 \mathrm{ppt}$; these were located from the modern town center of Chunchucmil to northwestward.

\section{Water Quality Findings}

We also summarize and compare water chemistry (table 7.2), between UcíCansahcab and Chunchucmil. Nitrate $\left(\mathrm{NO}_{3}\right)$ contamination is typically an indicator for animal waste, fertilizers, or sewage, and poses a danger of methemoglobinemia in infants (see Luzzadder-Beach 2000; Rajagopal and Tobin 1989). Since $\mathrm{NO}_{3}$ contamination comes from fecal sources, it also may have increased E. coli and other potentially harmful microbes. We should note a history of and the potential for cholera, giardia, hepatitis, and typhoid in Yucatán groundwater (Pacheco A., Cabrera S., and Marín 2000; Delgado et al. 20II). $\mathrm{NO}_{3}$ means and medians are an order of magnitude less in the Ucí-Cansahcab transect inside the Ring of Cenotes, (mean of $0.34 \mathrm{mg} /$ liter and range of $0-1.4 \mathrm{mg} / \mathrm{liter}$ ) when compared with the $\mathrm{NO}_{3}$ in Chunchucmil groundwater outside of the Ring (mean of $2.5 \mathrm{mg} /$ liter and range of $\mathrm{O}-\mathrm{I} 2 \mathrm{mg} / \mathrm{liter}$ ). No individual well in either region, however, exceeded the health standard of $45 \mathrm{mg} / \mathrm{liter}$. The maximum for Ucí was $\mathrm{I} .4 \mathrm{mg} / \mathrm{liter}$ and for Chunchucmil was $12 \mathrm{mg} / \mathrm{liter}$; the vast majority of wells in the Ucí region had concentrations of $<1.0 \mathrm{mg} / \mathrm{liter}$, and for Chunchucmil 16 of 22 wells had concentrations of $\mathrm{NO}_{3}$ below $3 \mathrm{mg} /$ liter. Concentrations in both regions are therefore not as high as might be expected for this karstic region. Nevertheless, waterborne microbial diseases have a steady impact today, and likely were a major problem in the past though ancient Maya populations did not have 
to contend with the diseases introduced from Europe in the sixteenth century (Delgado et al. 20II).

The nitrate contamination potential of groundwater is high in this karstic region, yet the actual concentrations were moderate in Chunchucmil (modern population I,000; ancient population from $30,000+$ centrally to $60,000+$ regionally ca. AD 600, see chapter 8, this volume; Luzzadder-Beach 2000) and even lower in the Ucí region. The modern population of Motul is about 23,000 (Brinkhoff 2015) but cannot serve as a modern analogue for the magnitude of settlement for ancient Chunchucmil because groundwater is lower and farther from contamination by about $5 \mathrm{~m}$ of limestone in most places. Also, Luzzadder-Beach (2000) concluded that throughflow in the Ring of Cenotes vicinity effectively dilutes, diverts, and disperses contamination away from the sites.

Sulfate $\left(\mathrm{SO}_{4}\right)$ levels in Ucí-Cansahcab ranged from o to $205 \mathrm{mg} /$ liter, and only 3 of 4I wells exceeded $100 \mathrm{mg} /$ liter. None of these wells was over the domestic consumption limit of $250 \mathrm{mg} / \mathrm{liter}$. For Chunchucmil, sulfate ranged from o to $295 \mathrm{mg} /$ liter, with two wells exceeding the USEPA limit of $250 \mathrm{mg} / \mathrm{liter}$, and these were on the far western (seaward) edge of the transect (Luzzadder-Beach 2000). Overall $\mathrm{SO}_{4}$ concentrations were higher in Chunchucmil than in Ucí. High $\mathrm{SO}_{4}$ levels could also indicate fertilizer inputs and natural bedrock sources from volcanic and from estuarine sources. These sites at the edge and within the Chicxulub crater are low in sulfur because they consist of limestone deposited after the creation of the impact crater, but ejecta blankets from the impacts to the south in Yucatán, Belize, and Guatemala have extremely high levels of sulfur that imposed limits on some crops (Luzzadder-Beach and Beach 2009, Pope et al. 1999).

The other mineral constituents we measured to compare the two regions' groundwater quality were $\mathrm{Ca}, \mathrm{Mg}$, and $\mathrm{Cl}$. For the Ucí Transect, calcium $(\mathrm{Ca}$, mean $=27 \mathrm{I}$ $\mathrm{mg} /$ liter $)$ and magnesium $(\mathrm{Mg}$, mean $=8 \mathrm{I} . \mathrm{I} \mathrm{mg} /$ liter $)$ levels were typically double those of the Chunchucmil region (Ca mean = I13.5 mg/liter; $\mathrm{Mg}$ mean = $39.3 \mathrm{mg}$ / liter; see table 7.2). On the other hand chloride $(\mathrm{Cl})$ and $\mathrm{SO}_{4}$ (discussed above) mean concentrations were higher in Chunchucmil $(\mathrm{Cl}=188.5 \mathrm{mg} / \mathrm{liter})$ than in $\mathrm{Ucí}(\mathrm{Cl}=\mathrm{I} 43.2 \mathrm{mg} /$ liter$)$ on average, posing a potential limit on agriculture (see Luzzadder-Beach 2000, and Luzzadder-Beach and Beach 2008 for more discussion on agriculture limitations posed by mineral constituents in groundwater).

Limitations on agriculture can occur from $\mathrm{Cl}$, TDS, and salinity in selected wells across the region (Luzzadder-Beach et al. 2012). These water quality conditions would limit intensive, irrigated, pot agriculture and orchard crops. These levels would have fewer potential impacts on the region's staple crop, maize, but our scant ancient bone evidence indicates that the prehispanic population relied less on maize here than elsewhere (Mansell et al. 2006). 
TABLE 7.2. Laboratory groundwater quality results: Chunchucmil $(\mathrm{Ch})$ and Ucí-Cansahcab (Ucí-C) intensive studies (means, medians, and ranges).

\begin{tabular}{|c|c|c|c|c|c|}
\hline & $\mathrm{NO}^{3} \mathrm{mg} /$ liter & Ca mg/liter & Mg mg/liter & $\mathrm{Clmg/liter}$ & $\mathrm{SO}^{4} \mathrm{mg} /$ liter \\
\hline \multicolumn{6}{|l|}{$\mathrm{CH} 1997^{1}$} \\
\hline mean & 2.5 & I 13.5 & 39.3 & 188.5 & $79 \cdot 3$ \\
\hline median & 2 & 107 & 35.4 & 141.5 & 52.5 \\
\hline range & $0-12$ & $64-218$ & I $8.3-84.2$ & $8-65 \mathrm{I}$ & $0-295$ \\
\hline \multicolumn{6}{|l|}{ Ucí-C } \\
\hline mean & 0.34 & 271.3 & $8 \mathrm{I} . \mathrm{I}$ & 143.2 & 40.9 \\
\hline median & 0.3 & 272 & 67 & I 2 I & 29 \\
\hline range & $0-1.4$ & I $46-472$ & $4-230$ & $21-655$ & $0-205$ \\
\hline
\end{tabular}

I. See Luzzadder-Beach (2000) for field and analytical methods and for data sets.

\section{POTENTIAL FOR SEAWATER MIXING}

The chloride-to-sulfate ratios $\left(\mathrm{Cl}\right.$ epm $\left./ \mathrm{SO}_{4} \mathrm{epm}\right)$ revealed that groundwater quality is not affected by seawater mixing despite tidal fluctuation in groundwater elevations both at Chunchucmil and elsewhere in the Yucatán Peninsula (LuzzadderBeach 2000, Perry et al. 1995). Selected wells exhibit high $\mathrm{Cl} / \mathrm{SO}_{4}$ ratios in both regions (see table 7.3), but the majority of wells have a ratio lower than seawater (9.6; see table 7.3), and are low-ion enough to indicate very little seawater mixing. All wells in both regions, except for one in Ucí-Cansahcab at 0.93 , had a $\mathrm{Ca} / \mathrm{Mg}$ ratio $>\mathrm{I}$, which also indicates no seawater mixing (table 7.3; see Luzzadder-Beach 2000, and Perry et al. 1995).

\section{CONCLUSIONS}

Although these karstic plains of the Yucatán Peninsula exhibit thin soils (Beach 1998a), low rainfall, and limited surface water (Luzzadder-Beach 2000), the groundwater resources are an asset to settlement and to agriculture and domestic consumption. There are few limitations imposed except for salinity, total dissolved solids as expressed by electrical conductivity, and chloride (LuzzadderBeach 2000; Luzzadder Beach et al. 20I2). Nitrate is remarkably low in this fractured limestone region, whose geology has a high dispersal potential. The Ring of Cenotes plays a significant role in the hydrogeology of the region, and allows dilution and dispersal of these contaminants via throughflow. The next steps of research should focus on biological contaminants and their diffusion and persistence in the system, to have a better idea of modern water quality and safety for human consumption. We do know from other studies that waterborne diseases 
TABLE 7.3. Laboratory groundwater quality regional results: Chunchucmil (Ch) and UcíCansahcab (Ucí-C), $\mathrm{Ca} / \mathrm{Mg}$ and $\mathrm{Cl} / \mathrm{SO}_{4}$ ratios (epm), means, medians, and ranges

\begin{tabular}{lrc}
\hline & $\mathrm{Ca} / \mathrm{Mg}$ epm Ratio & ${\mathrm{Cl} / \mathrm{SO}_{4} \text { epm Ratio }}$ \\
\hline $\mathrm{CH}$ & 2 & 8.82 \\
mean & 1.6 & 3 \\
median & $0.9-4.2$ & $0-1 \mathrm{I} 7^{1}$ \\
range & 2.4 & 3.0 \\
Old Village Well & & \\
Ucí-C & 3.47 & 9.4 \\
mean & 2.58 & 5.64 \\
median & $0.93-30$ & $0.39-86.7$ \\
range & &
\end{tabular}

Other Yucatán Sites, Groundwater $\mathrm{Cl} / \mathrm{SO}_{4}$ epm ratios $^{2}$

\begin{tabular}{lccc}
\hline & $\mathrm{Cl}($ epm) & $\mathrm{SO}_{4}($ epm $)$ & ${\mathrm{Cl} / \mathrm{SO}_{4} \text { epm Ratio }}$ \\
\hline Seawater & 563 & 58 & 9.6 \\
Celestún & $\mathrm{I} 8.8$ & 6.5 & 2.9 \\
Chocola & 9.6 & 2.6 & 3.7 \\
Kopoma & $\mathrm{I} 5.3$ & 7 & 2.2 \\
Mama & 5.2 & 3.2 & 1.6 \\
Mérida $^{2}$ & 6.5 & 0.8 & 8.2 \\
Opichen $^{2}$ & I2.1 & 8.1 & 1.5 \\
\hline
\end{tabular}

I. 117 is a $\mathrm{Cl} / \mathrm{SO}_{4}$ ratio outlier; 14.9 is the next-highest value. In 19 of 22 wells the ratios were < 3.8 .

2. See Perry et al. (1995). Perry notes that the Mérida data are from Back and Hanshaw (1970).

create a disease burden on the Yucatán region, especially the areas with a water table that is close to the surface. Thus Chunchucmil with its near-surface water table was likely in greater threat from pathogens than was Ucí-Cansahcab, which was about $5 \mathrm{~m}$ farther removed from the water table and surface contamination. Ucí-Cansahcab's water characteristics inside the Ring of Cenotes differ in some specific respects from those of Chunchucmil outside of the Ring and the modern population is an order of magnitude larger, but the quality of water overall is not significantly different. Salinity is a moderate limitation of the groundwater in about half of the wells at Ucí. The findings for the Ucí-Cansahcab hydrology transect support the conclusions for our Chunchucmil study (Luzzadder-Beach 2000) that groundwater quality was likely not severely limited for the ancient 
populations. Therefore, both ancient and modern settlements on both sides of the Ring of Cenotes have reasonable access to useable water resources, worthy of continuing study and protection from harm. 



\title{
Hinterland Settlement Patterns within the Chunchucmil Economic Region
}

\author{
David R. Hixson and Daniel E. Mazeau
}

In 2001, Hixson initiated a regional survey to the west of Chunchucmil to test the fan-shaped distribution and to document settlement patterns in the various ecological zones between the coast and the semiarid plains. In 2002, Mazeau initiated a regional survey to the east of Chunchucmil to assess the density, chronology, and major features of occupation in this area and also to understand the dynamics of Chunchucmil's relation with the well-known center of Oxkintok (Velázquez Morlet and López de la Rosa 1995), located 27 km to the east. Due to Yucatán's scrubby vegetation, neither survey was able to implement the broad, systematic methods developed in places like the Valleys of Mexico and Oaxaca. Instead, both surveys relied on remote sensing and local informants to locate new sites. Hixson identified $\mathrm{is}$ new sites in an approximately $\mathrm{I} 60-\mathrm{km}^{2}$ area, bringing the total number of known sites in that area up to 20 (figure 8.I). Mazeau's survey area included two blocks, one immediately northeast of Chunchucmil, the other to the east/southeast of Chunchucmil, beginning about $7 \mathrm{~km}$ from the Chunchucmil site core. Mazeau identified 28 new sites in an area of approximately $100 \mathrm{~km}^{2}$, bringing the total number of known sites in that area to 38 (figure 8.I).

The survey projects support a complex picture of Chunchucmil's regional settlements, one that allows for both inter- and intraregional mechanisms of procuring subsistence goods and other commodities. The western seasonal wetlands have proven to be much more than just a barrier to cross for long-distance exchange, while the eastern hinterland is even more densely settled than previously thought. 
With so many neighbors trying to live off the same land, Chunchucmil's agricultural options were limited (see chapter 9).

The hinterland settlements documented by the Pakbeh project are best described alongside the regional ecological variation outlined in chapter 6 , beginning at the coast with its trading ports and salt flats, through the perennial and seasonal wetlands, to the semiarid interior that ends at the edge of the Puuc hills. Each ecological zone contains a distinct set of settlement characteristics, emphasizing the notion that the denizens of Chunchucmil were not only crossing each zone for interregional trade, but also using the resources in each zone to diversify their subsistence base.

\section{SETTLEMENTS OF THE COASTAL ZONE}

In the mid-r990s, Bruce Dahlin, along with Anthony Andrews and a team of archaeologists, geologists, geographers, hydrologists, and other specialists, conducted archaeological and environmental studies of the coastal site of Punta Canbalam, located at the western edge of Chunchucmil's hinterland (Dahlin et al. 1998). Previous coastal surveys (e.g., Eaton 1978) had written off the area between Celestún and its nearest neighbor to the south, Uaymil, as a nearly impenetrable wall of coastal mangrove, a "backwater" region (Dahlin et al. 1998:I) broken only by the natural and man-made canals that cut from east to west, draining the wetlands into the Gulf of Mexico. Punta Canbalam, however, lies at a potentially critical nexus of trade, production, and communication networks and therefore provides a notable exception to this categorization (see also chapter I2).

The exact location of the original prehispanic settlement of Canbalam is not fully known. All artifacts encountered during both surface surveys and test excavations were found in secondary contexts, having been pushed, pulled, rolled, and crushed by the tides over many centuries (Dahlin et al. 1998). Due to the prevailing southerly flow of ocean currents in this area (especially during the most tumultuous storms, known as nortes), combined with the project's verification that a significant portion of the site is currently under water, it is possible that the modern distribution of artifacts along a $10-\mathrm{km}$ stretch of onshore beach is entirely secondary in nature, and that its original location has been eroded by the tides, or was once farther offshore on one of the barrier sand bars that has since eroded and become submerged (snorkel surveys revealed artifacts up to Ioo m offshore in very shallow waters). The lack of any architectural stones or metates makes the question of Canbalam's original location that much more puzzling (Dahlin et al. 1998:6).

Regardless of its precise position, the ancient community of Canbalam commanded an important strategic location at the mouth of the Ría Celestún. This estuary, protected from the open ocean by the barrier beach of the Celestún 


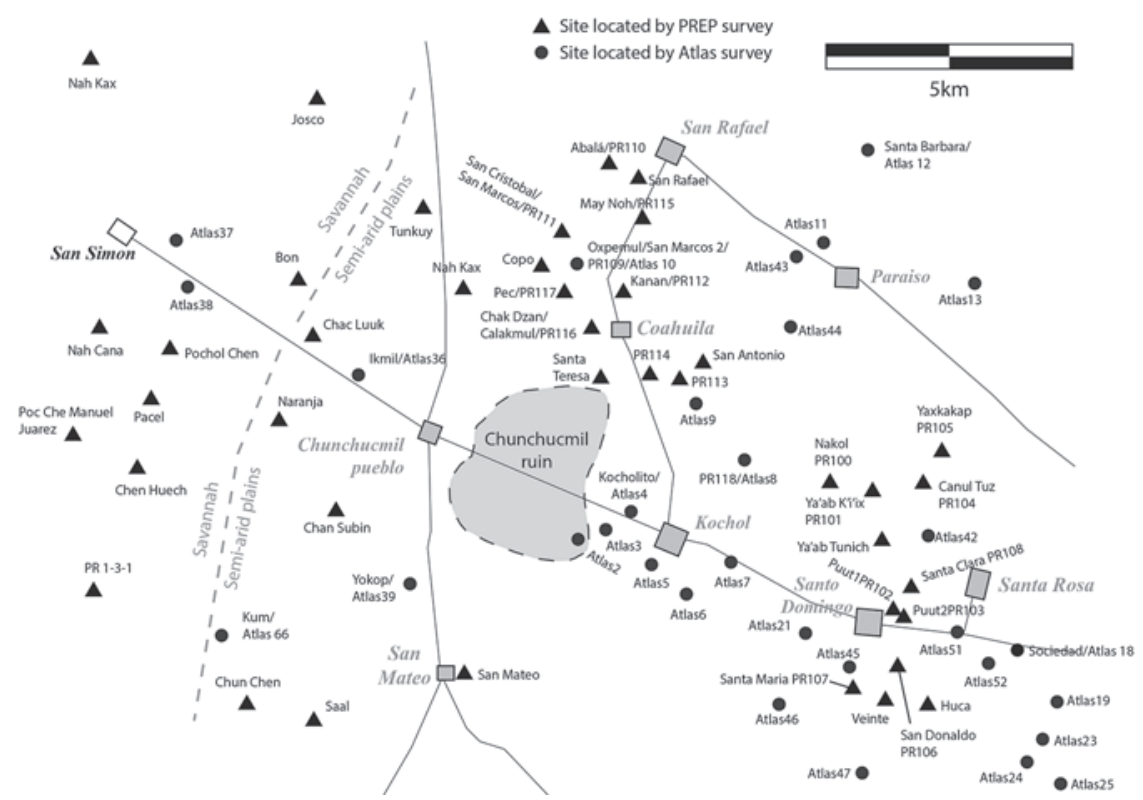

FIG URE 8.I. Map of sites found by the Pakbeh regional surveys as well as sites recorded previously by the Archaeological Atlas of Yucatán. Most sites were located using satellite imagery, aerial photography, and local informants.

Peninsula, was once the last major protected harbor for canoe-based merchants for approximately $80 \mathrm{~km}$ to the north (Dahlin et al. 1998:8). If satellite imagery and modern informants are correct, this estuary may have afforded long-distance traders an inland water route north from Canbalam to large seaports along the north coast of the Yucatán Peninsula, and south to the next major habitable shore at the location of modern Campeche City.

As documented by Dahlin et al. (1998), the site of Canbalam was relatively rich in imported items from distant Mesoamerican lands. Fine-paste ceramics (Fine Orange, Fine Gray), slatewares, and plumbates all indicate a participation in interregional trade from the Late to Terminal Classic and into the Postclassic periods (Dahlin et al. 1998:4). Obsidian blades abound on the surface (one must wear foot protection on this beach), while a few imported chert tools and even jade items were uncovered during the survey. None of these items was locally available, and many came from as far as rooo+ $\mathrm{km}$ away. When taken together, the imported ceramics, obsidian, chert, and jade, concentrated within a coastal community at the mouth of an important harbor and perfectly positioned to exploit, manage, or control the second-largest salt beds in Mesoamerica, paint a picture of a major coastal 
port of trade that "should be accorded the same rank as Jaina and some north coast sites such as Isla Cerritos" (Dahlin et al. 1998:6).

The full chronology of Canbalam is less clear. Due to the secondary deposition of all artifacts, the lack of any stratigraphic integrity, and the water-rolled erosion of all ceramics, a detailed chronology would be nearly impossible to reconstruct. Between 66 and 8I percent of all ceramics were unidentifiable due to the complete lack of any slip or other surface treatment (Dahlin et al. 1998:4). Of the remaining is to 34 percent, most were identified due to their unique paste (e.g., Fine Orange and Fine Gray), while the very few with traces of identifiable slip were exclusively plumbate (which has a remarkably resilient slip). Thus, using the initial type-variety analysis conducted in the late 1990 s, it is certain that Canbalam had a significant Late to Terminal Classic component. A more recent reanalysis of sherds from Canbalam indicate that many forms may date to the Late Preclassic and Early Classic. ${ }^{1}$

\section{SETTLEMENTS OF THE PERENNIALLY INUNDATED ZONE}

While no comprehensive archaeological survey has ever been conducted in this area, the perennially inundated zone is perhaps one region that can be reasonably assumed devoid of widespread ancient occupation. That being said, small hunting or extraction camps, or sitios de paso (rest or relay stops along trade and communication routes), are possible throughout this perennially inundated zone. The most likely targets for future studies of archaeological remains in the perennial wetlands are the petenes or ojos de agua. Modern Maya hunters and traders utilize these oases as needed on their treks to and from the coast for sources of freshwater, wild game, and hardwoods.

One example of an archaeological site located upon a peten is Uaymil, located at the southern border of the Chunchucmil Economic Region (CER). Under the direction of Rafael Cobos Palma (INAH), Armando Francisco Inurreta Díaz (2004) described the site of Uaymil as a port of trade that likely funneled products from the coastal canoe routes to the interior at Siho (see figure I.2) during the Late to Terminal Classic periods (much like the relationship proposed here between Canbalam and Chunchucmil during earlier times). Connected to the coast via a natural canal that springs from the petenes of the perennially inundated wetlands, it would have provided a safe harbor for canoes and an ideal starting point for the trek into the interior. Unlike Canbalam, it was better protected from the ocean currents by the intervening stands of mangrove. Therefore the architecture and artifacts were accordingly better preserved, allowing Cobos and his team to make direct comparisons to other known ports of trade from the Late to Terminal Classic times, such as Chichén Itzás port at Isla Cerritos. 
Two possible peten sites were rumored to exist within the heart of the CER. The Canbalam project was repeatedly told that there was a small nucleated settlement called "Tres Iglesias" between Canbalam and Chunchucmil, yet no one could lead the project to its location (Dahlin et al. 1998; chapter I, this volume). During his hinterland survey, Hixson was led on a two-day excursion to locate a site called "Trapiche," which was known among the elders of the village of San Mateo as a small cluster of mounds near the interface of the perennially and seasonally inundated zones. One mound was estimated by these Maya villagers to stand approximately 5 $\mathrm{m}$ tall, composed of dark rich soil without any visible stones. We were never able to locate Trapiche. The truly remote location and difficult walking conditions through the perennial wetlands make these petenes a veritable frontier in Maya archaeology, remaining underexplored by the academic world.

\section{SETTLEMENTS OF THE SEASONALLY INUNDATED SAVANNAS AND TZEKELES}

After several seasons of pedestrian and remote sensing surveys, the most drastic change to the Atlas project map of the regional settlement pattern was observed in the distribution of sites in the seasonal wetlands immediately west of Chunchucmil. The Atlas project (figure 6.I; Garza Tarazona de González and Kurjack 1980) had noted only two diminutive settlements in this particular ecological zone, both along a trajectory leading directly to Punta Canbalam from Chunchucmil. This had provided a deceptively clear template for Dahlin to envision the seasonal wetlands as a vacant uninhabitable and uncultivable zone with only two minor sites acting as sitios de paso along a direct trade route to the coast. Yet, the Atlas project had as its goal to plot the locations of every archaeological site in the entire state of Yucatán, and therefore performed limited ground surveys in this endeavor. The two Atlas sites leading to Canbalam were fortuitously found (Kurjack, personal communication, 2005) along the road between the modern village of Chunchucmil and a large cattle ranch called San Simón, a historic link in the transportation route to the coast created by the hacienda owners of this region in the late nineteenth century.

When PREP members explored the areas to the north and south of this historic road, I2 new savanna sites in the wetlands were recorded (figure 8.2): three stratified sites that likely acted as regional nodes (Múuli Mis, Josco, and Pochol Ch'en); one stratified site without any pyramidal architecture (Pacel); three non-stratified multifamily communities (Nah Cana, Chak Luuk, and Naranjo); one non-stratified isolated household compound (Bon); and four loci of ephemeral occupation that may represent field houses associated with wetland/tzekel resource extraction (Nah 
Kax, Chen Huech, Poc Che Manuel Juarez, and PR I-3-I). Still others remain to be properly documented.

While a statistical analysis of settlement density is not possible (due to the methods used in the regional reconnaissance, which focused upon the efficacy of remote sensing to locate specific archaeological sites), settlements in the seasonal wetlands are generally restricted to the tzekeles (the fossilized beach ridges described in chapter 6). Nearly every tzekel encountered during our surveys contained some form of ancient settlement or landscape manipulation. These range from small domestic sites with a handful of houses, to relatively large communities with pyramids and plazas. A sample of these newly discovered sites is described below. The areas between the tzekeles are not free of archaeological features. The sac lu'um bajos contain dozens, if not hundreds of rock alignments that functioned as pathways through the inundation between communities and resources (figure 8.2; see chapter 12).

\section{Múuli Mis}

In 2004 , our survey crew targeted a satellite signature that indicated ancient architecture approximately $3 \mathrm{~km}$ into the seasonal wetlands west of Rancho Sinkeuel, and $13.5 \mathrm{~km}$ north-northwest of Chunchucmil's site center (figure 8.2). This particular site was also highlighted as a peak in the AIRSAR digital elevation model. Not only are these among the largest pyramidal structures found west of Chunchucmil, ${ }^{2}$ but the site's ballcourt is one of only four encountered in the entire CER. The other three ballcourts include an oddly tall specimen at the epicenter of urban Chunchucmil, another immediately west of Chunchucmil at the Preclassic site of Ikmil, and a newly discovered ballcourt found by Daniel Mazeau at Grupo Abalá, east of Chunchucmil. These data stand in stark contrast to the results of the CostaYuc Project (A. P. Andrews and Robles Castellanos 2004), directly north of the Chunchucmil region, where dozens of Middle Preclassic ballcourts have been found.

The presence of a ballcourt was the first indication that this site was likely not from the same time period as the apogee of Chunchucmil (i.e., the late Early Classic and the early Late Classic). Ballcourts are typically seen as architectural markers of sociopolitical power in the Maya region, but they are underrepresented in Chunchucmil's center and do not appear to have been integral to the sociopolitical development of that site's elite. It is expected that regional occupation contemporaneous with Chunchucmil would result in the mimicry and/or adoption of the larger settlement's symbols of social and political power by regional elites. Instead, at Múuli Mis we see the use and emphasis of an architectural symbol infrequently used at Chunchucmil, but found in abundance during the Middle Preclassic farther 


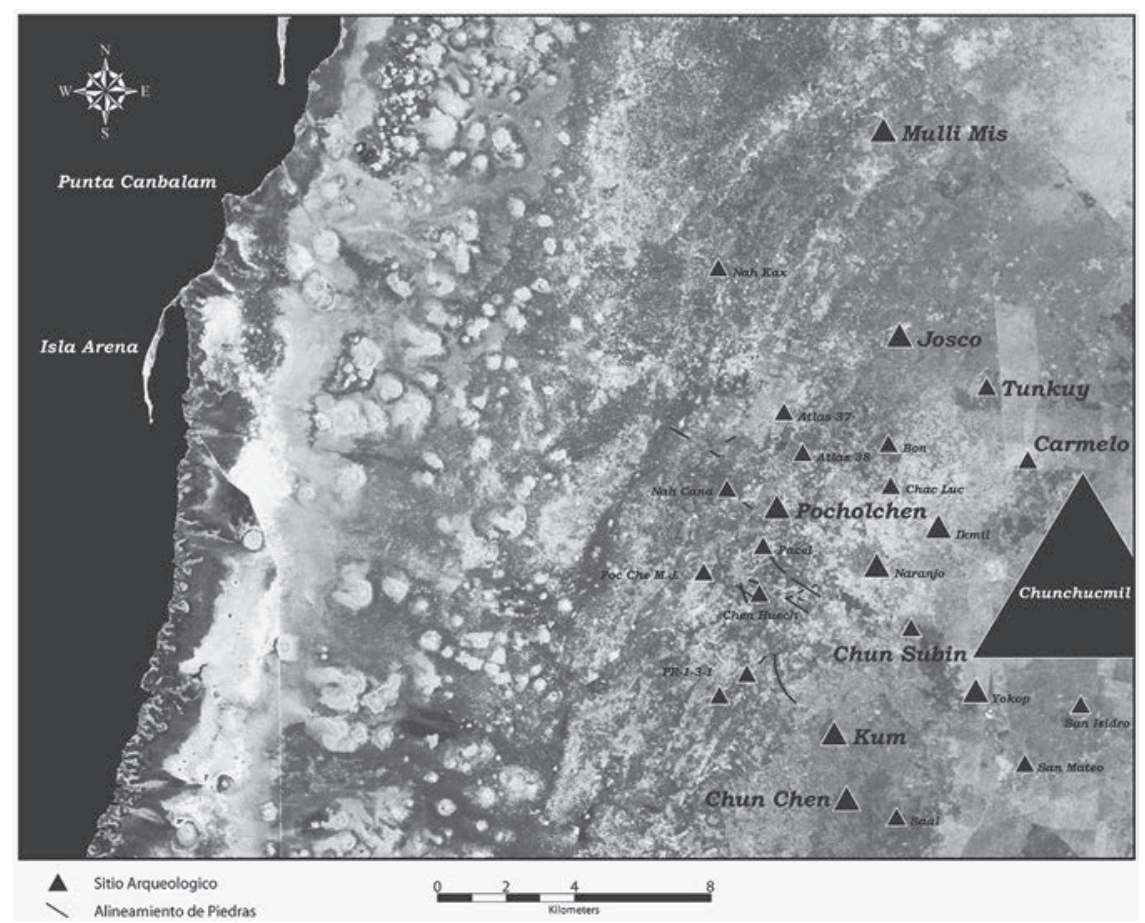

FIGURE 8.2. Map of regional sites and rock alignments between Chunchucmil and the Gulf Coast, overlaid upon a LANDSAT multispectral composite image.

north (A. P. Andrews and Robles Castellanos 2004), suggesting the likelihood of different occupational periods that conferred divergent symbolic value on various architectural features.

Ceramics encountered during the mapping operation and in subsequent test excavations support the proposition that Múuli Mis was instead occupied during the Preclassic period. Joventud Red sherds were plentiful in our ceramic sample and provided preliminary evidence that Múuli Mis was once one of the many Middle Preclassic ballcourt sites in northwest Yucatán, comparable to those recently discovered through the work of the CostaYuc project. Low platforms (likely housemounds) were observed during treks to the west, north, and south of the central core of Múuli Mis, indicating that the site extends at least $100 \mathrm{~m}$ beyond the central core mapped by PREP. The presence of these ballcourt sites within and adjacent to the wetlands (including Ikmil) supports the point that wetlands were not a hindrance to early Maya civilization, but likely a challenging resource that helped in its development (Turner and Harrison 1983). 


\section{Pochol Ch'en}

Approximately io km west-northwest of Chunchucmil's site center our survey crew encountered a very compact yet impressive settlement known locally as Pochol Ch'en. These ruins sit atop a narrow rise associated with the tzekeles. Approximately 17 ha were mapped, containing approximately 140 structures. Although this rise is at times less than a meter above its surrounding terrain, it is sufficient to keep the site dry during the rainy season. The orientation of structures adheres to the landform (extending from the northeast to the southwest). For a site with such a small geographical footprint the number and density of structures is quite notable (figure 8.3).

At the center of the site stands a small pyramidal platform, its slopes containing fallen column drums and displaced wedge-shaped veneer stones. The veneer stones indicate that the final phase of this site was likely in the Late and/or Terminal Classic (G. Andrews 1995). However, test excavations alongside residential structures and within the main plaza indicate that Pochol Ch'en was occupied from the Middle Preclassic through the Terminal Classic. The central pyramidal structure is fronted by a relatively large artificially raised and leveled plaza, complete with a substantial range structure along its northern edge and a small central focal platform similar to the central platforms of Chunchucmil's elite quadrangle groups. This architectural arrangement was certainly the site center of Pochol Ch'en, and was likely positioned to access and/or control the freshwater well of the same name that borders the east side of the plaza.

The dominant architectural form at Pochol Ch'en is referred to by some northern Maya researchers (J. G. Smith 2000) as an "eyeglass structure." The prototypical eyeglass structure is composed of two circular or rectangular foundations connected by a single anterior wall, often with a chich mound (minor platform of chich [gravel], see chapter 2) between the lateral structures. This form, including variations with more than two rooms, was clearly preferred by the builders of Pochol Ch'en. Many of the anterior foundation walls are often quite well preserved at the site. They were formed of roughly cut flagstones, some nearly a meter tall, still anchored in their original upright positions. Several of these structures also displayed surprisingly clear room divisions, marked by smaller undisturbed foundation stones (as opposed to the more amorphous rubble foundations visible on the surface of unreconstructed mounds in the Chunchucmil region).

Pochol Ch'en is also notable for its eastern wall. This wall measures over I $\mathrm{m}$ high, and is slightly less than I m thick. It was constructed by planting two parallel lines of large flat boulders in the ground, and filling the space in between with dry core fill. In some sections, additional large flat stones were placed across the top as if to form a cap. This wall extends for the entire length of Pochol Ch'en, roughly half a kilometer 

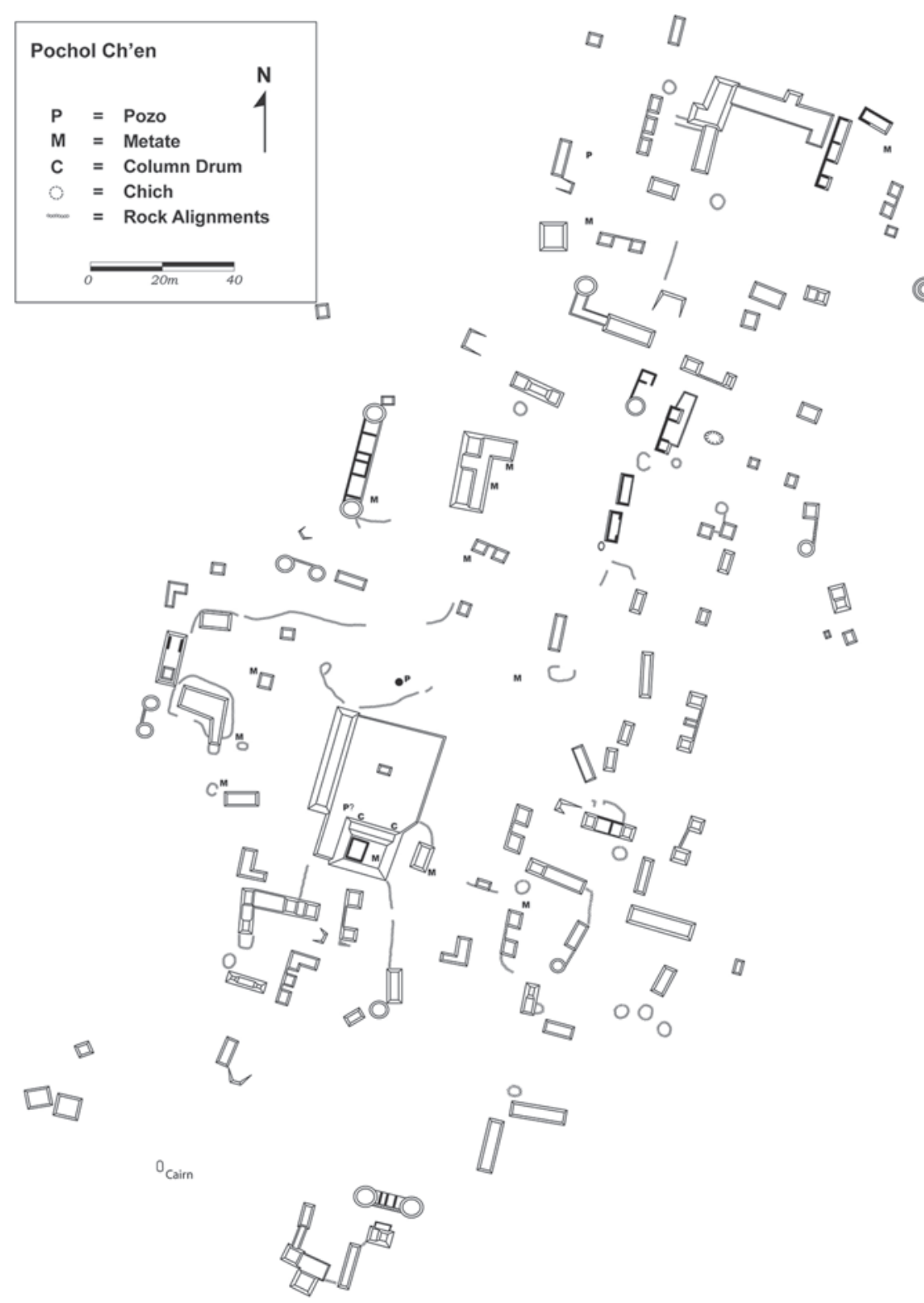

FigURE 8.3. Map of Pochol Ch'en, upon a tzekel west of Chunchucmil. 
north-south (figure 8.4), but stands approximately $300 \mathrm{~m}$ to the east of the site center. It has a gate near its center, forcing east-west traffic to funnel through this point.

Even though the wall is somewhat distant from the site center of Pochol Ch'en, additional reconnaissance found very sparse architecture between the previously mapped area and the wall, including a large circular enclosure that resembles those documented by Batún-Alpuche (2004) at Buena Vista (Cozumel island, Quintana Roo), which he demonstrated were used to protect apiaries. Other than the sparse architectural remains, the area enclosed by Pochol Ch'en's wall appears to be prime agricultural land, since it sits relatively high above the water table and currently supports some of the more lush upland vegetation in the region. To the east of this wall, the landscape dips quickly into a seasonally inundated trough, as it likewise does to the north and south of its termini.

The wall does not completely enclose the site. It only runs along the east side and was not very tall. Thus, it would not have made a substantial defensive feature against violent attack. Therefore this wall may have functioned as a formal boundary marker and to funnel traffic along a preferred path into the settlement. It would have kept travelers from randomly wandering through private or valuable property (gardens and apiaries). This hypothesis assumes a certain amount of traffic through the western wetlands, which is supported by the number and orientation of ancient stone walkways, or andadores, through the wetlands (see chapter 12).

The gate in the center of Pochol Ch'en's wall is also strikingly formal. It is not simply an opening or gap between sections to allow free passage. The shape, when viewed in plan, appears similar to a "Barbican" style gate, extending outside the main wall, similar to the main defensive gate at the Late Postclassic site of Mayapán (Russell 2008). However, the diminutive height of Pochol Ch'en's wall and the fact that it only extends along the eastern portion of the tzekel argues against a military defensive function. There are also two extremely small parallel stone features immediately inside the gate oriented perpendicular to the wall's axis (and almost appearing like a toy ballcourt) with space between them for only one or two persons to pass at a time. These features are oriented directly toward the central platform and freshwater well of Pochol Ch'en. It is likely that the gate, along with the parallel stone features, were again intended to lead travelers along a proscribed path into the site while the wall itself prevented visitors from wandering into valuable productive lands.

At this point it is worth noting that both the Pochol Ch'en wall and Chunchucmil's barricade are open to the west. In the case of Chunchucmil, this may have been simply an incomplete defensive measure (Dahlin 2000). But it is telling that construction of the Chunchucmil barricade must therefore have begun on the east, indicating a vector for the greatest perceived threat. Likewise, the builders of the wall at Pochol Ch'en did not seem as concerned about interlopers from the west. 


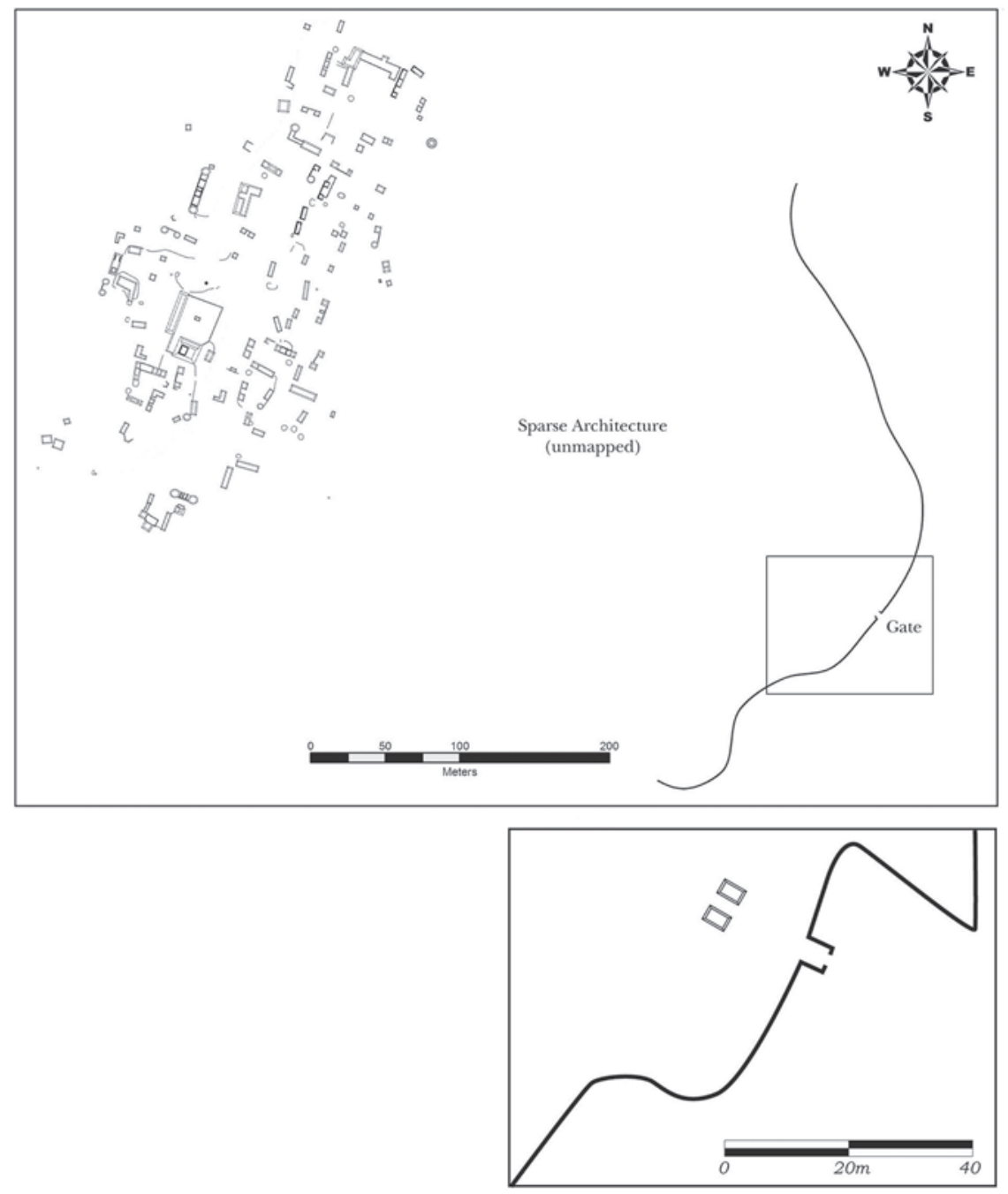

FIG URE 8.4. Map of Pochol Ch'en in relation to its eastern wall. Inset (below) shows details of the wall's central gate.

Poc Che Manuel Juárez

Not all sites in the seasonal wetlands were found to be as substantial as Múuli Mis or Pochol Ch'en. One multispectral satellite image provided a weak but present signature indicating a cultural landscape on a distant tzekel. There we found Poc Che Manuel Juárez. The people of San Mateo have given this land that name after 
the old man who lived there many generations ago (probably in the early twentieth century). It is said he would leave the town of Halacho (see figure I.2) on foot at the end of every dry season to clear this portion of the tzekeles. He lived there by himself, perched upon the ancient low mounds throughout the rainy season, tending to his crops and collecting various resources from both the forest and wetlands. After harvest time, he would load all of the commodities he hadn't consumed onto a large back-rack suspended on a tumpline, and he walked his load back to Halacho (a distance of roughly $30 \mathrm{~km}$ ).

While Poc Che Manuel Juárez was one of the last of his kind for this region, during his youth this practice was apparently more common. His story shows that seasonal transhumance and the transportation of wild resources and agricultural surplus from the seasonal wetlands to the interior are all possible scenarios to consider when investigating the ancient functions of these remote archaeological sites (see also chapter Io). According to oral history, these activities were also economically profitable, at least at the household level (Hixson 20II).

The site consists of two clusters of architecture located $60 \mathrm{~m}$ apart (figure 8.5). Each cluster contains approximately io structures and covers an area of almost a hectare. The structures are connected to each other or to natural resources (such as a freshwater well) using linear rock alignments. Unlike the albarradas of downtown Chunchucmil, these do not appear to enclose any house lots. Instead they extend between structures and other features, or between one group of mounds and another, clearly serving a connective rather than divisive function. We call them andadores. The intrasite andadores at Poc Che Manuel Juárez are but one example of a larger network of andadores that connected the outskirts of Chunchucmil with wetland settlements and resources, and likely led travelers all the way to the coast at Canbalam (see chapter I2). The andadores to the west of Chunchucmil contrast with those found in the Yalahau region of Quintana Roo, which appear to have controlled water movement and soil accumulation for agricultural purposes (Fedick et al. 2000).

The seasonal wetlands were clearly not a barrier to settlement. Sites were found scattered throughout this ecological zone. In fact, some form of settlement (from casas del campo to substantial hamlets or villages) were found perched upon every tzekel, little more than a meter above the seasonally flooded savannas. Furthermore, andadores (rock alignments that functioned as stepping stones) criss-crossed the savannas, linking areas of habitation with localized resources such as aguadas and freshwater wells. Chunchucmil can no longer be considered the westernmost point in an asymmetrical fan-shaped regional settlement pattern, as was indicated in the Atlas maps. Instead, the ancient city appears as a central node in a settlement pattern that straddles the interface between the western seasonal wetlands and the semiarid plains to the east. 

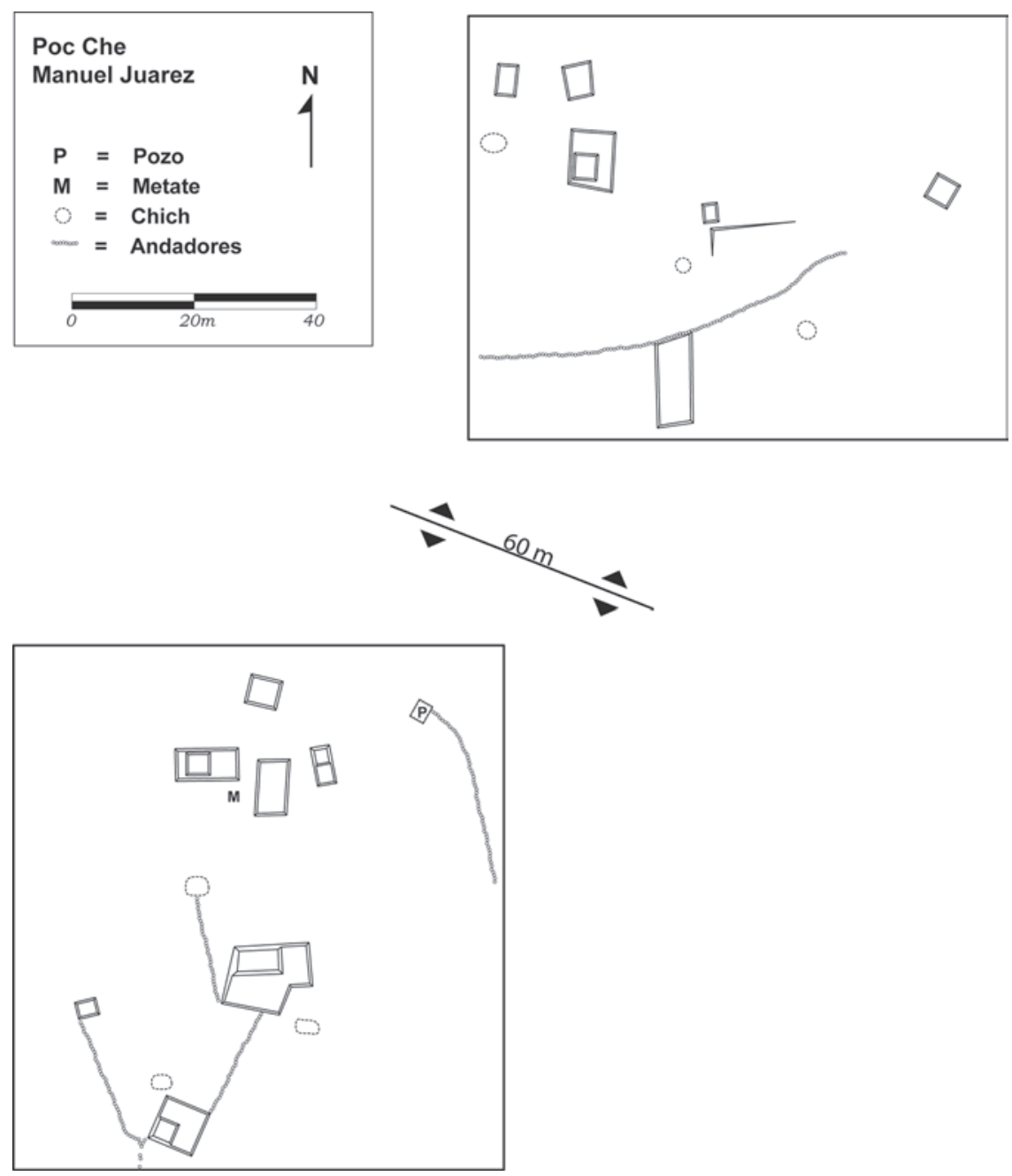

FIG URE 8.5. Map of Poc Che Manuel Juárez, west of Chunchucmil along a tzekel.

\section{SETTLEMENTS AT THE INTERFACE BET WEEN THE SEMIARID PLAINS AND THE SEASONAL WETLANDS}

The epicenter of urban Chunchucmil was located approximately $5-6 \mathrm{~km}$ east of the seasonal inundation (assuming a relatively static sea level), allowing most residents to avoid the most severe annual floods. Yet, the western suburbs of Chunchucmil abut the very edge of seasonal inundation. The main plaza at the site of Yokop (see below) was even built using upturned flagstones to raise the plaza above the 
easily puddled kancab flats. Furthermore, sections of the urban residential zone of Chunchucmil appear to have had regular problems with flooding, as the callejuelas in certain parts of the city were transformed into minor causeways we call chichbes (callejuelas raised upon beds of gravel to traverse flooded terrain between houselots placed upon bedrock highs; see chapter 2). We present three sites located at the edge of the seasonally inundated savanna: Yokop, Kum and Chun Chen. These sites are physically connected to each other through intervening architecture that also links them with Chunchucmil. We liken this to a metropolitan center (such as Washington, DC) where it would be difficult to distinguish one suburb from another in the urban sprawl along its fringes. Rather than avoiding the wetlands west of Chunchucmil, the Maya appear to have embraced them, as we found nearly continuous occupation along the western edge of the semiarid plains. Still, the most densely settled areas remain east of the site core of Chunchucmil.

\section{YoKOP}

First registered by the Archaeological Atlas of Yucatán (Garza Tarazona de González and Kurjack 1980) as a separate site labeled ${ }_{15} \mathrm{Qf}(9): 39$, the area of Yokop is located at the eastern edge of the seasonally inundated zone, $4 \mathrm{~km}$ from the site-center datum of Chunchucmil. The name is derived from the large depression at the center of the site (figure 8.6). This depression is a large rejollada (a dry karstic sinkhole with deeper soils relative to the surrounding terrain; see Kepecs and Boucher 1996), with a freshwater well (called Chen Yokop) at the base of the rejollada. The largest building at Yokop, measuring approximately $25-$ by-20 m, with an elevation of $5 \mathrm{~m}$, stands adjacent to this depression. The 18 ha of the site that was mapped by Hixson contained I 40 structures.

This rejollada appears to be the principal reason for the location of the peak in the size, volume, and density of structures at Yokop. The depression itself measures over $40 \mathrm{~m}$ in diameter (the largest rejollada documented by PREP researchers in the entire region). The well at its base appears to be an original feature created during the prehispanic era, but clearly was refortified during the historic ranching days and is still used today. Kepecs and Boucher (1996) noted the agricultural benefits of farming within rejolladas in the Emal district (a region also exhibiting albarradas).

While the center of Yokop was located adjacent to this rejollada, the eastern periphery of Yokop likely connects with the southwestern edges of Chunchucmil, and should be considered a connected suburb of the ancient city. Sizable mounds and albarrada groups were observed throughout the region between Yokop and the southwest portion of the Chunchucmil map. In addition, a salvage survey conducted by INAH for the widening of the Chunchucmil-San Mateo road found the greatest 


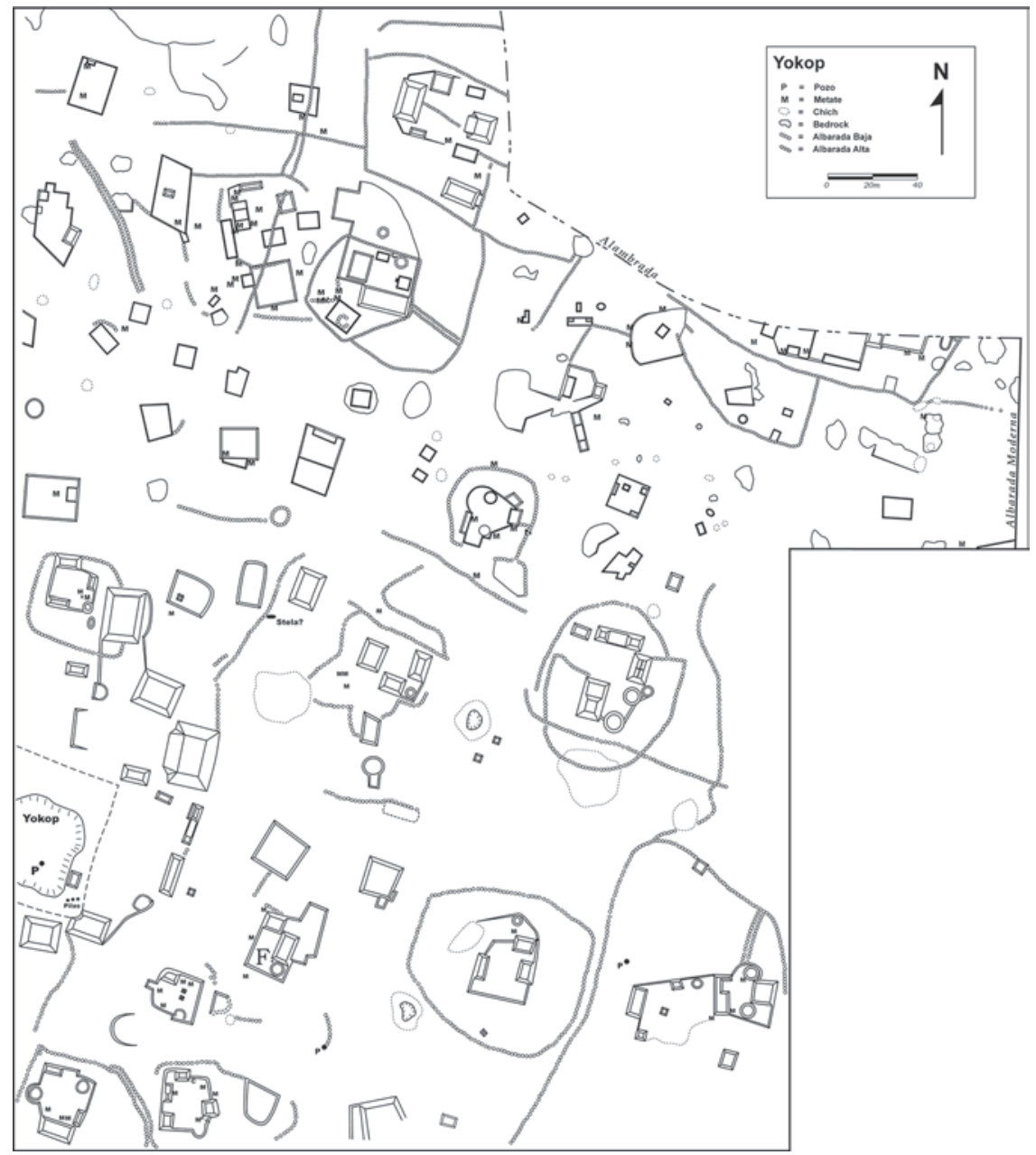

FIGURE 8.6. Map of Yokop/Atlas 39, southwest of Chunchucmil

density of structures in an area directly between Yokop and Chunchucmil's southwestern periphery, indicating where one of the fingers extends out from the residential periphery and crosses the modern road (Hutson et al. 2008:figure 9; Hixson 20II). The II test excavations throughout the mapped area of Yokop demonstrated that the community was coeval with the rise and fall of Chunchucmil (late Early Classic to early Late Classic, with modest indications of earlier and later occupation). The surface remains at Yokop are notable, as the site contains quadrangular architectural arrangements, column drums, basin-shaped metates, slab-vaulted 
masonry, and albarradas that form enclosed solares (figure 8.6). These are the more common and salient features from Chunchucmil, with the largest difference being the size of solar and the density of architectural remains. Architectural density is slightly lower at Yokop when compared to downtown Chunchucmil. While enclosed albarrada groups are still common at the suburban site of Yokop, they exhibit some physical distance from other such groups, and have more of a "buffer zone" around each household. This is much like the elite residential district at Cobá (Fletcher 1983; Fletcher and Kintz 1983), where settlement density is lower and the "honeycomb" appearance of epicentral Chunchucmil is replaced by distinct walled house lots.

\section{Kum}

The suburban site of Yokop is in turn connected through intervening domestic architecture to the hinterland site of Kum ( $5 \mathrm{~km}$ west-southwest of Yokop). Kum was first registered by the Archaeological Atlas of Yucatán project ( $\operatorname{site}{ }_{15} \mathrm{Qf}(9): 66$; Garza Tarazona de González and Kurjack 1980), and, like most sites in this region, takes its name from its well, which is currently used as a watering hole for a modern apiary. However, it also contains an aguada ( $\mathrm{Ha}$ ' Kum) that must have provided not only freshwater but rich soils, mussels, reeds, and so on. Much like Yokop, Kum stands at the edge of the seasonally inundated zone, as close to the water's edge as would be possible for a secondary center.

The site is focused upon a quadrangular pyramid-plaza arrangement with a 7-m-high pyramid and a 40-m-long, 4-m-high range structure (figure 8.7). Though only about 4 ha were mapped, the site contains several additional hectares of additional settlement. Completely enclosed albarrada groups are absent. This area (while physically connected to the urban center of Chunchucmil through Yokop) is no longer considered part of the city, nor the suburbs of "greater Chunchucmil."

\section{Chun Chen}

Kum is then connected through intervening architecture to the site of Chun Chen, located $2 \mathrm{~km}$ to the south. This site boasts a double-pyramid group. These two pyramids, each measuring about 20-by-20-by-4 m, face each other across a broad plaza and a central circular altar (figure 8.8). A sacbe measuring $70 \mathrm{~m}$ long and $5 \mathrm{~m}$ wide connects the main group to a triadic group to the north while a $20-\mathrm{m}$-long sacbe connects the main group to a smaller architectural group to the east. The site of Chun Chen, like Kum and Yokop, sits as close as possible to the seasonal inundation without risk of flooding, and is also centered upon a freshwater well and an 


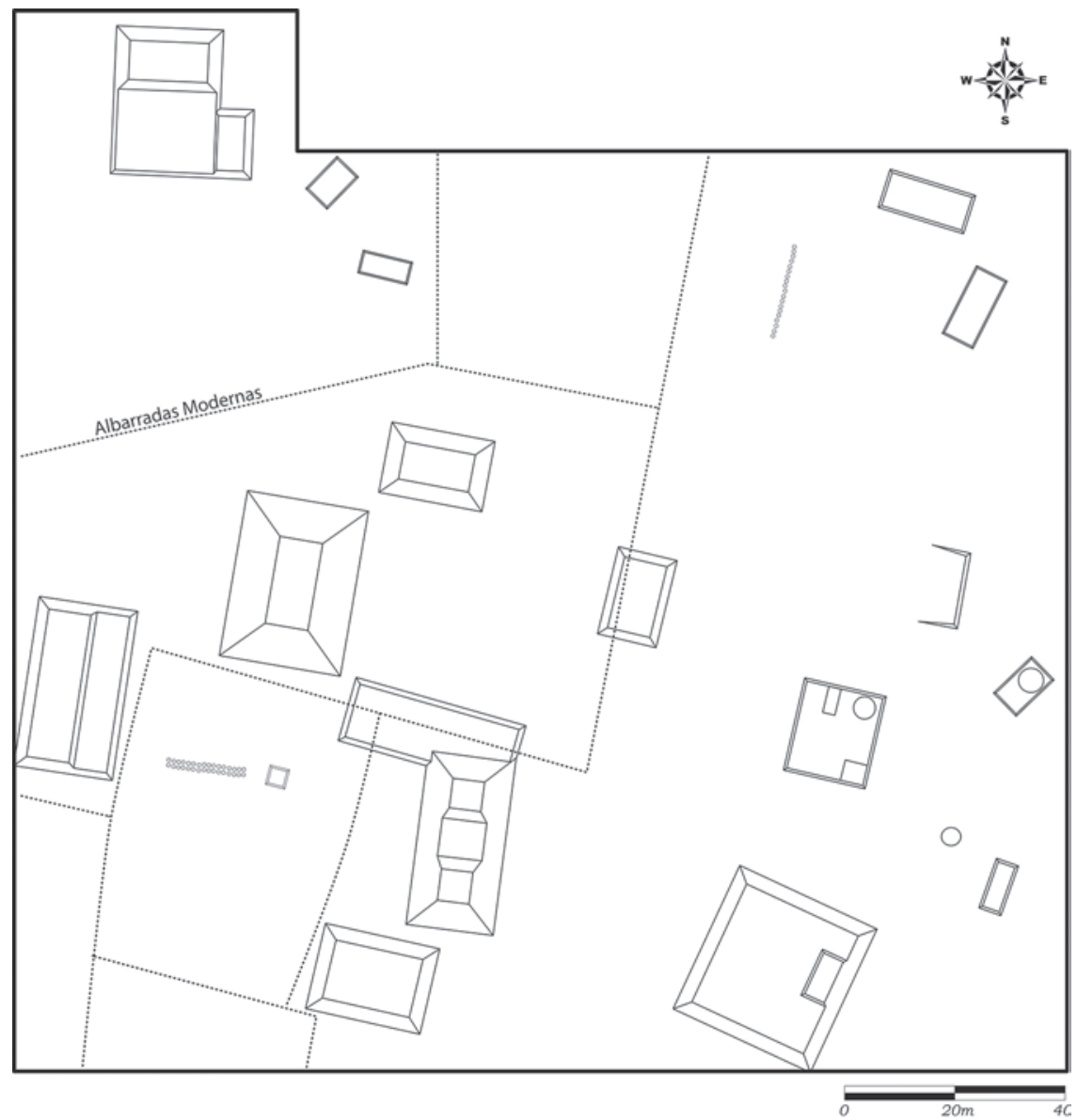

FIGURE 8.7. Map of Kum/Atlas 66, southwest of Chunchucmil on the edge of the savanna

aguada. This interconnected chain of sites that extends to the west-southwest of Chunchucmil's periphery could be argued to represent the extreme western "suburbs" and suburban sprawl of Chunchucmil, edging up against the seasonally inundated zone and focused upon easily accessible freshwater resources.

\section{SETTLEMENTS OF THE SEMIARID PLAINS}

The soils of the semiarid plains are skeletal and the rainfall is low (see chapter 6) yet the barren rocky ground is filled with cultural mounds of the ancient Maya. 
While the Atlas maps underestimated the occupation of the western seasonal wetlands, they appear to be correct that the settlement density is in fact greater east of Chunchucmil than in the western wetlands.

Mazeau's survey in the eastern and northern periphery of Chunchucmil visited, mapped, and/or tested 38 sites. Of these, ro sites were previously reported (but not detailed) in Garza Tarazona de González and Kurjack's (1980) Atlas project, while the remaining 28 were newly identified sites. Regional sites varied in size and complexity, ranging from isolated structural arrangements to more complex stratified communities, several of which exhibit a central core surrounded by outlying settlement. Large-scale architecture, consisting of relatively tall pyramids, large platform complexes, and non-residential civic-ceremonial architecture was rare but documented at several sites. The majority of regional architecture consisted of low-lying residential platforms and small mounds. Five possible monument stones (stelae) were identified at three sites, one each at Oxpemul and Ya'ab K'i'ix, and three at Yaxkakap.

Four site types were identified during the survey of Chunchucmil's northern and eastern hinterland. These types have minimal connection with the architectural group types presented in chapter 3 since those group types describe architectural compounds within a site whereas the four categories below are sites of their own. These types were based on number and types of structures, platforms, and platform complexes present, and whether social stratification, inferred from the presence or absence of large-scale domestic and/or monumental architecture or features, occurred at a particular settlement. Survey projects in Central Mexico, Oaxaca, and the Maya area (Millon et al. 1973; Blanton et al. 1982; Burgos Villanueva, Covarrubias Reyna, and Estrada Faisal 2004) have used between 100 and $300 \mathrm{~m}$ of empty space to identify the edges of sites. During the regional survey outside of Chunchucmil, a minimum distance of $250 \mathrm{~m}$ of empty space between occupations was used to distinguish them as distinct sites. The four site types, into which 36 of the 38 sites surveyed can be fitted (the remaining two were largely destroyed), are described below (numbers in parenthesis indicate the number of sites identified) and, following that, examples of each site type are provided.

Isolated household (9). Settlements containing a single platform complex that would have housed a single or extended familial unit.

Non-stratified community (II). A cluster or aggregation of platform complexes that indicate the presence of multiple family units but lack large-scale architecture that suggests the sociocultural prominence of any constituent family. 


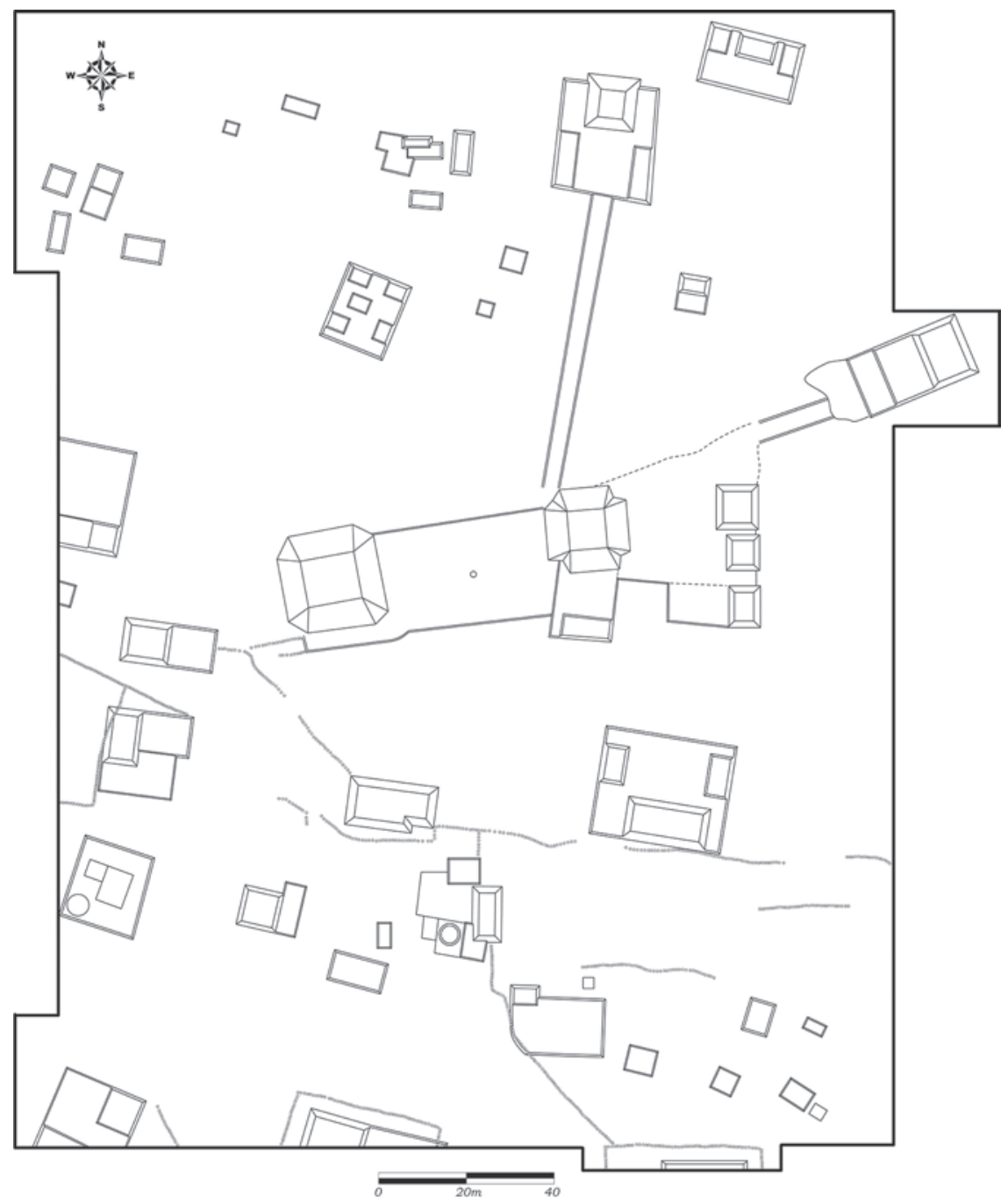

FIGURE 8.8. Map of Chun Ch'en, southwest of Chunchucmil

Stratified community (1о). A cluster or aggregation of platform complexes that indicate the presence of multiple family units with at least one structural complex containing large-scale architecture, thereby suggesting the sociocultural prominence of at least one constituent family. 
Stratified community (regional node) (6). A cluster or aggregation of structural complexes that contain both elite and non-elite residential complexes, as well as non-residential/non-domestic large-scale or monumental architecture, such as pyramids, narrow-top mounds or platforms, or ballcourts.

Albarradas. A defining component of Chunchucmil's settlement pattern, present at $8 \mathrm{I}$ percent of the mapped sites in the northern and eastern hinterland. These walls, however, were not always used to enclose houselots or platform complexes, and often appeared fragmentary in nature (the possible result of repurposing stones for historic or modern construction). They do enclose houselots or platform complexes, much in the way seen at Chunchucmil, in 36 percent of the mapped sites.

\section{YA'AB K'I'IX}

Ya'ab K'i'ix is an isolated household located $8.2 \mathrm{~km}$ east of the Chunchucmil site core in an area of dense vegetation. It is located $500 \mathrm{~m}$ east of Nahkol, a stratified community and the closest settlement mapped near Ya'ab K'i'ix during regional survey. The site consists of associated structures and platforms that are nearly completely enclosed by an albarrada (figure 8.9). The site has a core of four large platforms (ca. 1.5-2 $\mathrm{m}$ in height), and ro additional structures range around the complex's core, nearly all of which are either connected or enclosed by the albarrada.

A broad platform on the southern side contained a C-shaped suprastructural foundation and a possible monument stone. A single metate was observed in association with two broad platforms in the northeast part of the complex, possibly suggesting that area was used for food production. No additional structures were observed within $200 \mathrm{~m}$ of Ya'ab K'i'ix, and sascaberas or quarries were likewise not observed in association with the residential complex or within $200 \mathrm{~m}$ of it.

Based on ceramics collected during testing, the occupation of Ya'ab K'i'ix spanned from the Middle Preclassic until the end of the Late Classic, indicating its occupation was coterminous with that of the initial settlement and florescence of Chunchucmil. Ceramics from later periods were absent.

\section{KANAN}

Kanan is a non-stratified community consisting of three platform complexes, two of which are completely enclosed by albarradas, located $4.5 \mathrm{~km}$ north of Chunchucmil. The site is situated in a region of karst plain dominated by limestone 


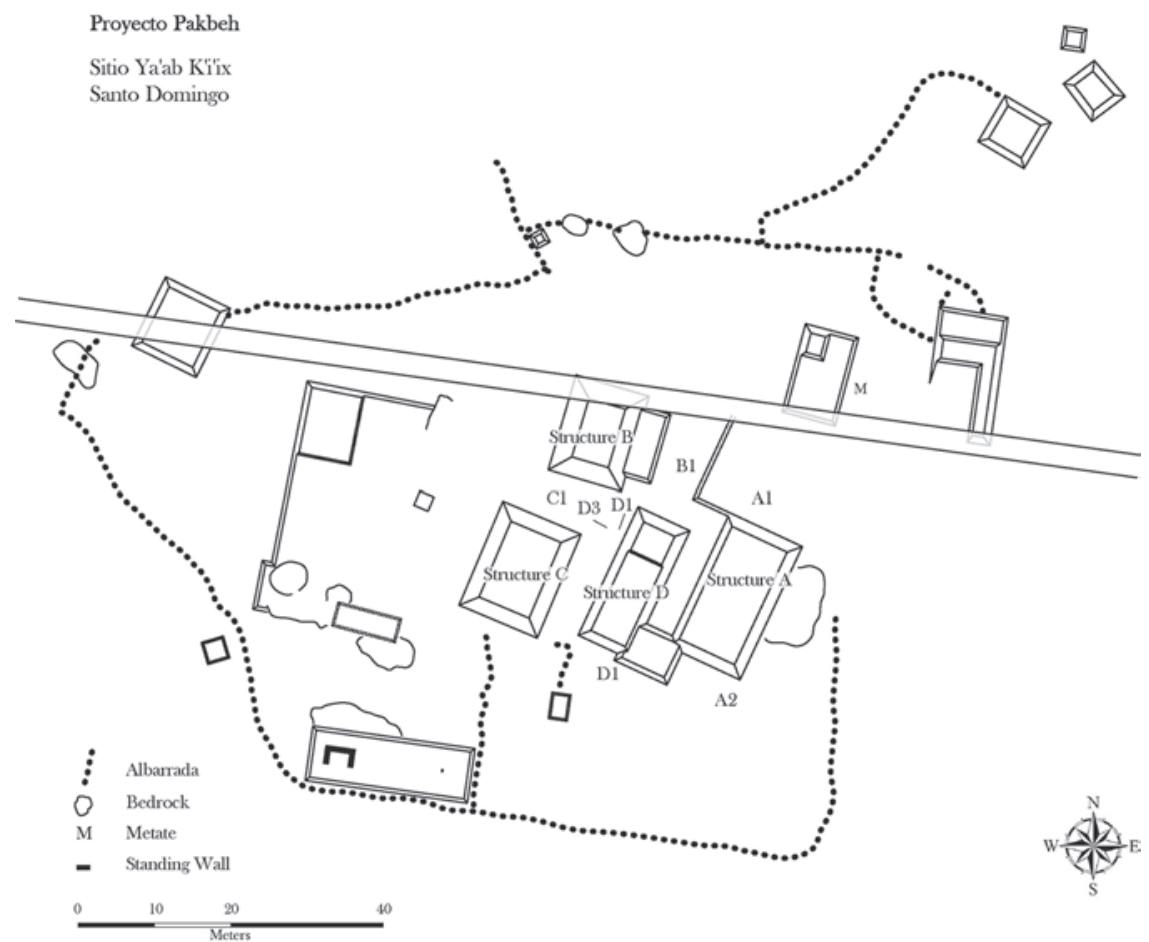

FIGURE 8.9. Map of Ya'ab K'i'ix, an example of an isolated household, east of Chunchucmil

pavement and occasional elevated bedrock outcroppings. The area burns annually, resulting in a lack of vegetation and, consequently, high visibility at the site. The cluster of platform complexes at Kanan was surrounded by $250 \mathrm{~m}$ of unoccupied space, a distance after which several somewhat isolated structures and complexes (Kanan 2, 3, and 4) were located to the north and east.

The three complexes at Kanan consist of Group A (the northeast), B (the northwest), and C (the southern group). Figure 8.ro depicts Groups A and B. All three are multitiered platform arrangements, and a prominent domestic expression indicated by a number of metates found at Kanan. Albarradas individually encircle both of the northern two groups, while the southern group is partially enclosed. A chichbe is located along the northern edge of Group B, and a callejuela approaches the southern group (C) from the west. Ceramic data obtained during the site's testing indicate that it was primarily occupied during the late Early Classic and the early part of the Late Classic, an occupational time frame consistent with Chunchucmil's apogee. 
Very similar in their general configuration, Groups A and B contain large central platform complexes with a number of smaller suprastructures and platforms. Both central platform complexes feature larger mounds on their east side, indicating potential loci of familial shrines. Such family shrines are common at Chunchucmil (see, for example, $\mathrm{S}_{2} \mathrm{EI}_{\mathrm{I}} \mathrm{G} / \mathrm{Kaab}$ and $\mathrm{S}_{4} \mathrm{~W} 8-\mathrm{F} /$ Balam [chapter 5 ] and $\mathrm{N}_{2} \mathrm{E}_{2}-\mathrm{N} /$ Lool and $\mathrm{S}_{2} \mathrm{E}_{2}-\mathrm{F} /$ Aak [chapter I2]; see also Becker 199I). Small auxiliary structures are associated with Group A but are absent within Group B. Bedrock outcrops and pavements are interspersed throughout the site, and one such example was modified and architecturally incorporated into the northern side of Group B. One metate was located in association with Group A.

Group C differed from A and B in its configuration and likely occupation. First, Group $C$ had a higher number of smaller suprastructures situated on top of the central base platform, including io small platforms and perishable structure foundations. Second, a large mound is noticeably absent from the platform complex. Third, most of the metates (three of four) identified at Kanan were located in Group C. These were directly associated with a structure foundation wall situated within the main platform's central space, and suggest a primacy of domestic or economic activities.

Open and available space between the site and other nearby settlements, as well as immediately within the structural nucleus of Kanan, perhaps suggests that Kanan's inhabitants were agrarian producers, consisting of up to three related (or unrelated but cooperating) lineages (one based at each group); alternatively, the southern group may have been non-residential, and might have served as a space shared by the inhabitants of Groups A and B for the performance of economic and/or domestic tasks. The site's distance from Chunchucmil's site center (ca. $4.5 \mathrm{~km}$ ) is not particularly far, and would have provided them ready access to the central markets as well as the secondary and tertiary markets that likely existed on the outskirts of the city.

\section{PuUt}

Puut is a stratified community located $9.6 \mathrm{~km}$ southeast of Chunchucmil's site center. Situated near the modern-day village of Santo Domingo, Puut has been subjected to numerous disturbances, including the loss of albarrada and architectural stone for historic and modern-era construction, intensive agricultural production (papaya fields), and looting. Ceramic data obtained from testing at Puut indicate the site was primarily occupied during the later portion of the Early Classic and throughout the Late Classic.

The site's settlement consists of numerous structures and platform complexes roughly organized into two clusters (northwest and southeast) separated by no 


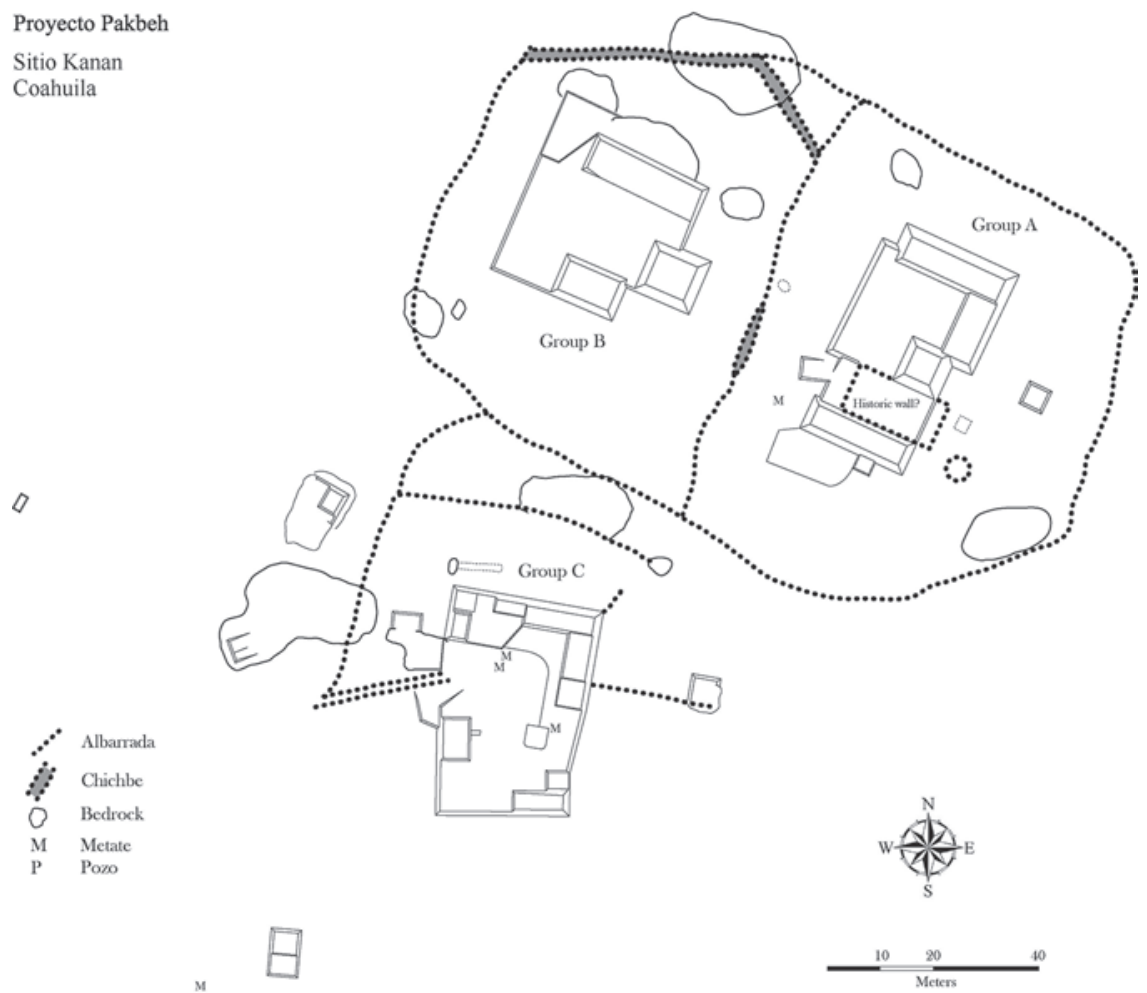

FIGURE 8.I O. Map of Kanan, an example of a non-stratified community, northeast of Chunchucmil

more than $100 \mathrm{~m}$ of unoccupied space (figure 8.II). Hallmarks of elite architecture are present in the southeast cluster, where a large basal platform roughly $2 \mathrm{~m}$ in height (Structure A) supported a number of additional platforms and possible perishable wall foundations. Additional platform complexes and structures are associated with Structure A, and with it they form a loosely defined central courtyard, the southwest corner of which is enclosed by an albarrada. Large auxiliary mounds and platforms are associated with this grouping, and a small cenote that opens into a small underground pond and a large quarry/sascabera is located on the eastern fringe of the cluster. Metates are present on top of Structure A and are incorporated into nearby historic features (albarrada and tranvía roads).

The northwest cluster of structures at Puut lacked large-scale construction, such as that seen at Structure A in the southeast cluster. Instead, the northwest portion consisted of scattered platforms, artificially modified bedrock rises or pavements, 


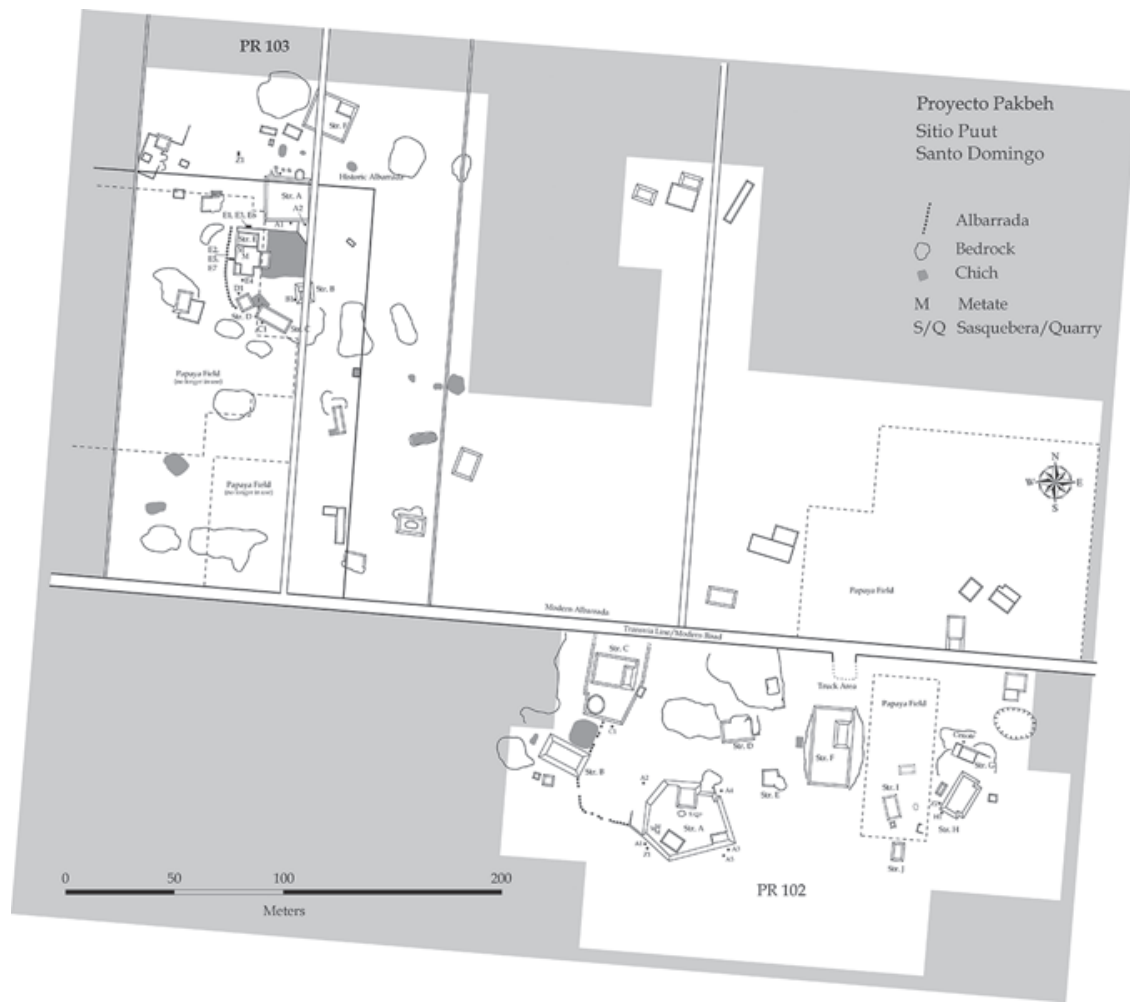

FIG URE 8.II. Map of Puut, an example of a stratified community, east of Chunchucmil

and a grouping of associated platforms in the northern section. Metates are present among these buildings, as are intact portions of in situ, though fragmentary, albarradas (most stone was likely used for the construction of historic-period walls and roads).

The northern extent of Puut is approximately $300 \mathrm{~m}$ south of another site surveyed by this project, Santa Clara. Santa Clara, though not detailed here, was classified as a stratified community (regional node) due to the presence of several exceptionally large platforms, including a 5 -m-tall narrow-topped structure roughly $25 \mathrm{~m}$ long and ro $\mathrm{m}$ wide. Ceramic data obtained from Santa Clara indicate occupations occurred during the Middle Preclassic, the Late Preclassic, the later portion of the Early Classic, and throughout the Late Classic. If Puut, which postdates the initial settlement of Santa Clara, was not physically connected to the settlement sprawl of Santa Clara, it likely interacted with the larger settlement in some manner, be it economic, sociopolitical, or ideological. 


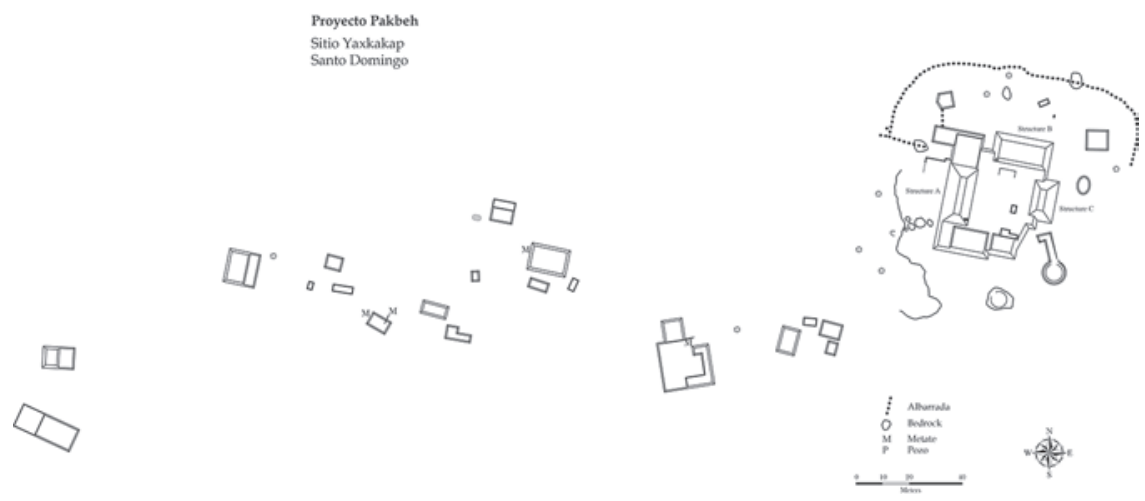

FIG URE 8.1 2. Map of Yaxkakap, an example of a stratified community (regional node), east of Chunchucmil

\section{YAXKAKAP}

Yaxkakap is a relatively large site classified as a stratified community (regional node) located I0.7 km east of the Chunchucmil site core. Located within a dense vegetated secondary forest, Yaxkakap's site center featured a very large raised platform complex containing numerous large and narrow-topped structures, multileveled platforms, and a broad elevated courtyard with two possible monument stones (figure 8.12). Testing at Yaxkakap yielded ceramics that suggest the site was occupied during the late portion of the Early Classic and during the early portion of the Late Classic.

Yaxkakap's primary architectural complex consisted of a broad, artificially raised platform between $\mathrm{I} .5$ and $2 \mathrm{~m}$ in height with a footprint measuring approximately 40 by $50 \mathrm{~m}$. Flanking the platform are several structures that bound and enclose the broad central plaza, which covers an area of over $650 \mathrm{~m}^{2}$. The complex's western structure (Structure A) is tall, physically and visually dominating the entirety of the complex. It is raised approximately $3 \mathrm{~m}$ above the raised platform and 4.5-5.0 $\mathrm{m}$ above the flat bedrock pavement and low-lying settlement west of the structure. Structure A's upper surface has been extensively destroyed by numerous looter pits that, however, revealed intact dry-laid walls and a plaster floor. The looters likely sought burials and their associated grave goods, as their excavation went below the extant plaster floor and stopped shortly thereafter.

To the north of the central platform complex is an approximately $135-\mathrm{m}$-long crescent-shaped albarrada that encloses a broad and level space containing a number of small and low-lying platforms, three ancient wells, and another possible monument stone. To the west-southwest of the central complex is an area covered by bedrock pavement; within this area are three additional wells. 
During mapping, it was clear that the site center of Yaxkakap was accompanied by settlement radiating outward from it. A 340-by-80-m transect was then mapped, radiating west from the central platform complex. Settlement within this transect consisted of is structures, two ancient wells, and three metates, though dense vegetation coverage may have obscured additional metates.

The transect dimensions resulted in a mapped arm with an area of $.027 \mathrm{~km}^{2}$. The I9 structures identified within the transect equates to a minimal structural density of $698 / \mathrm{km}^{2}$. This density level is quite high, and falls just below the density of Chunchucmil's urban residential areas. Minor walk-through survey to the north and northwest of the site led to the identification of additional low-lying platforms, though these were not mapped.

\section{DISCUSSION: REGIONAL SETTLEMENT PATTERNS AND ECOLOGICAL HETEROGENEITY IN THE CER}

Taken together, the survey work discussed in this chapter greatly increases the amount of known settlement and our knowledge of the kinds of settlement located to the east and west of Chunchucmil. Several large sites within $15 \mathrm{~km}$ both east and west of the Chunchucmil, such as Yaxkakap and Yokop, had hundreds of structures and populations perhaps surpassing a thousand. Most of this settlement dates to the time of peak population at Chunchucmil. Beyond these large sites, the landscape was dotted with dozens of villages.

One of the most important conclusions from this chapter regards the occupation to the west of the urban center. Fingers of settlement running southwest of Chunchucmil extended as far west as was physically possible for a major metropolitan area without the risk of major widespread flooding. Chun Ch'en, Kum, and Yokop appear to have purposefully hugged the edge of the seasonal wetlands, rather than avoided them. Furthermore, the seasonal wetlands themselves were not a no-man's land, vacant of habitation and viewed only as an obstacle to transit between the coast and the interior. In fact, there were dozens of sites perched upon minor rises within the wetlands. While a few of the most remote minor settlements may have been seasonally occupied, others, such as Pochol Ch'en, appear to have been true secondary centers with pyramids and plazas, possibly located to service passing traders while extracting the bounty of resources available in the wetlands.

The entire network of andadores within the seasonally inundated savannas does indeed point along a vector between Chunchucmil and Canbalam, passing through the outskirts of Pochol Ch'en. But individual alignments of these stepping stones lead to dozens of minor spits of land within the wetlands that were not only 
habitable, but likely exploited to support the concentration of urbanites living in the nearby semiarid plains where standard swidden agriculture could not have fed the masses who thronged to this mercantile center.

Occupation to the eastern interior is certainly more densely occupied than the western wetlands, and even more densely occupied than what the Atlas project suggested. Thus, while Chunchucmil's population was not evenly distributed across the landscape of the CER, its location appears to be geographically central to its regional and extraregional resources. The eastern half of its immediate hinterland resided in the semiarid plains, its residents likely eking out a meager living from the parched and skeletal soils of the karstic plain, while more dispersed residents in the western half perched themselves upon the tzekeles of the seasonal wetlands, extracting resources unique to this more dynamic and diverse environment. Each portion of Chunchucmil's immediate sustaining area contributed critical commodities for the sustenance of daily life in this challenging setting, its site center forming a natural and necessary nexus for intraregional trade.

Though the survey methods did not have the goal of recovering a representative sample of the ancient population, we can still propose some preliminary population estimates for the Chunchucmil's hinterland. In the semiarid plains east of Chunchucmil, there are many areas where one cannot venture beyond a site without encountering a homestead-a cluster of four or five structures, perhaps housing io people-every two or three hundred meters. This converts to about 16 homesteads per square kilometer. Excavations and surface collections in this area as well as demographic considerations (see Rice and Culbert 1990) suggest that at least half of these homesteads would have been occupied contemporaneously during the time period when Chunchucmil was at its peak population. In other words, some of the area in the hinterlands east of Chunchucmil, would have had about 80 people per square kilometer, not counting dense clusters of settlement such as Yaxkakap (see above) and Kocholito (see chapter 5). For comparison, in approximately $18 \mathrm{~km}^{2}$ of systematic hinterland survey conducted about $110 \mathrm{~km}$ to the northeast of Chunchucmil, in the vicinity of Ucí, settlement density ranged from 3.8 to 18.5 homesteads per square kilometer, with an average 13 homesteads per square kilometer. Systematic transect mapping in the hinterland immediately beyond Chunchucmil's residential periphery (see chapter 5:figure 5.3) revealed settlement densities similar to that found by Mazeau in the semiarid plains east of Chunchucmil. These surveys located between 39 and 67 structures per square kilometer (Hutson et al. 2008). Such densities are similar to what has been found in hinterland surveys elsewhere in the Petén lakes area: Rice and Rice's (1990) transect surveys located between 36 and 82 structures per square kilometer. Taking the low end of the Chunchucmil transect surveys ( 39 structures per square kilometer), 
reducing this by two-thirds to account for contemporaneity and the fact that not all structures are houses, and then multiplying by five people per house yields an estimate of 65 people per square kilometer.

If we draw a Thiessen polygon around Chunchucmil (a polygon whose edges are found half the distance between Chunchucmil and Tzeme to the northeast, Oxkintok to the east, and Siho to the south), we find that about $400 \mathrm{~km}^{2}$ within this polygon falls within the semiarid plains. Since Chunchucmil was much larger than Tzeme and Siho during the late facet of the Early Classic, Chunchucmil's hinterlands probably extended beyond the Thiessen polygon, perhaps resulting in $600 \mathrm{~km}^{2}$ of land in the semiarid plains (see also chapter 9). If population density of the semiarid plains is between 65 and 80 people per square kilometer, then Chunchucmil's hinterland population in the semiarid plains was between 39,000 and 48,000. Adding the population from savanna sites as well as dense sites within the semiarid plains, such as Yokop and Kocholito, drives the hinterland population even higher. In sum, regional survey suggests that the total population in Chunchucmil's hinterland was likely higher than the population of Chunchucmil itself. To be on the safe side, however, we conclude that hinterland population was about the same as that of Chunchucmil: 30,000 .

In the context of subsistence resources, this means not only that some of Chunchucmil's potential hinterland acreage was taken up by houses and houselots, but that farmland around Chunchucmil had to help support both the city and its not insubstantial rural population. The next chapter presents the consequences that this relatively high regional population density had for feeding Chunchucmil's populace.

\section{NOTES}

I. Future researchers may wish to study the statistical distribution of sources and bladeplatform preparation techniques on the obsidian from the Canbalam collection in an effort to compare such ratios with Chunchucmil and other more securely dated sites.

2. The pyramidal structure located on the southern end of the main plaza at Múuli Mis measured approximately 20 -by- $12 \mathrm{~m}$ at its base, rising to $8 \mathrm{~m}$ in height. The western structure measured approximately $20-$ by- $10 \mathrm{~m}$ at its base, rising to $6 \mathrm{~m}$ in height. These measurements are comparable to the more modest quadrangle groups located within the site core of Chunchucmil. 


\title{
Soils and Agricultural Carrying Capacity
}

\author{
Timothy Beach, Sheryl Luzzadder-Beach, Ryan V. Sweetwood, \\ Patrice Farrell, Daniel E. Mazeau, and Richard E. Terry
}

\section{A HISTORY OF SOIL AND RELATED STUDY}

The modern environment of Chunchucmil challenges farmers today and probably challenged ancient farmers because of its aridity and skeletal soils (see chapter 6 for a discussion of potential differences between modern and ancient sea level and rainfall). For decades, researchers (Beach 1998a; Dahlin et al. 2005; Dunning and Beach 2010; Farrell et al. 1996; Hixson 20II; Hutson et al. 2007; Vlcek et al. 1978; Magnoni 2008; Ardren 2003; Sweetwood et al. 2009) have investigated the economy and soil resources of the Chunchucmil region as part of the Pakbeh Regional Economy Program (PREP) in order to understand the reasons Chunchucmil prospered from the Early Classic to the Middle Classic. All of these investigations conclude that subsistence was difficult here because of the large population, both at Chunchucmil (chapter 6) and its hinterland (chapter 8), living in this environmentally challenged region. The present chapter endeavors to solve this riddle of how the ancient Maya of Chunchucmil fed themselves through the lenses of soils, food, water, and sustainability practices. Whereas chapter 6 provided a broad portrait of the different vegetative and geomorphic zones within the Chunchucmil Economic Region (CER), this chapter looks very closely at soils and carrying capacity.

The paucity of soil resources, the low rainfall, the enormity of the site, and the substantial settlement in Chunchucmil's hinterland has led us to reevaluate the assumption that Maya households were agriculturally self-sufficient (Drennan 1984a, 1984b; Sanders and Webster 1988). Chunchucmil project participants sought multiple lines 
of evidence to examine and reexamine the subsistence economy (Dahlin et al. 2005). For example, Beach (1998a) and Dahlin et al. (2005) suggested that the lack of food-producing structures, insufficient sustaining area, and poor soil resources may indicate that agriculture was based on atypical crops or methods, or that food trade would have been required to supplement the food resources that could not have been produced at Chunchucmil under traditional agricultural methods.

To answer the subsistence conundrum of Chunchucmil, we set the following main objectives:

I. Determine the areas of agricultural importance through physical, chemical, and fertility analyses of soil.

2. Determine water quality and availability (chapter 7 ).

3. Identify probable areas of ancient agriculture through soil analyses and ancient settlement patterns.

4. Identify evidence of agricultural intensification of soils (e.g., night soiling [fertilizing with fecal matter], soil amendments with charcoal, soil retention structures, etc.).

5. Determine if some changes had occurred in these landscapes that made them appear less productive today than in ancient Maya times.

\section{AGRICULTURE TODAY}

As discussed in chapter 5, our evidence suggests that few people have lived near Chunchucmil since the Terminal Classic. Some historic human disturbances included henequen plantations and, more recently, a few minor agricultural programs supported by the Mexican government: papaya (Carica papaya), aloe (Aloe vera), citrus (Citrus spp.), and chili (Capsicum spp.) (Dahlin 2003). The contemporary village of Chunchucmil has about I,000 people (Luzzadder-Beach 2000), of which a small percentage currently practice milpa agriculture (shifting cultivation, slash-and-burn agriculture) (Beach 1998a), while the rest supplement their income with ranching or jobs in nearby cities. These few milperos (maize farmers) have the opportunity to cultivate the more fertile soils of the region, and yet compared to the average world maize yields of 5.55 MT (metric tons)/ha (USDA 2015), their yields are still extremely low and erratic: as high as 0.25 to I MT/ ha in a good year (Beach 1998a) and as low as $0 . \mathrm{I} \mathrm{MT} / \mathrm{ha}$ (Shuman 1974). Even during the henequen era, the plantation at Chunchucmil produced half as much as those plantations farther east (Vlcek et al. 1978). We are unsure if ancient agriculture was more productive in the ancient Maya lowlands (Hester 1953), though evidence is growing for many new crops from ancient Maya studies (Dunning et al. 2015; Beach, Luzzadder-Beach, Cook, et al. 2015). 
As discussed in chapter 6, the northwest Yucatán receives little rain. Annual rainfall for the region has been reported to vary between 700 and $1000 \mathrm{~mm}$, yet the average rainfall recorded at a weather station in the village of Chunchucmil over the last 17 years is $640 \mathrm{~mm}$ (see also chapter 6). In contrast, southern Belize's annual rainfall is between 3,000 and 4,000 $\mathrm{mm}$. The Chunchucmil region has enough water to grow maize, but it lies close to the maize minimum of $500 \mathrm{~mm}$ per year (Wellhausen, Fuentes, and Hernández 1957) and a small reduction in rainfall could greatly diminish maize yields. In addition, 80-90 percent of that rainfall occurs from June to October, and is highly variable and localized. All point to marginal circumstances for traditional maize cultivation today. We should note that our knowledge of water availability at Chunchucmil is limited by a shortage of data regarding contributions from the nearby water table (perhaps about I $m$ deeper in antiquity). Furthermore, as we discuss below, soils might have been deeper in the past and therefore with greater water-holding capacity.

Early studies of the modern Yucatec Maya showed that maize made up about 85 percent of their diet (Emerson 1953), which equates to a little more than 0.2 MT of maize per year per capita (Shuman 1974; Steggerda 194I). This equates with a land requirement of $0.2-2 \mathrm{ha} /$ capita in an area with crop yields of O.I-I MT/ha. Dahlin et al. (2005) conservatively estimated the sustaining area of Chunchucmil to be $1,600 \mathrm{~km}^{2}$ using a Thiessen polygon, but he stated that what was actually available to them must be significantly less because of major overlapping with Siho's and Oxkintok's sustaining areas to the south and east, respectively. The area drops to roughly $800-\mathrm{I}, 200 \mathrm{~km}^{2}$ when we exclude structures and areas with no soil cover $(25-50 \%)$. The seasonally inundated savanna is considered unfit for cultivation (Garza Tarazona de González and Kurjack 198I) and reduces the sustaining area to Beach's (1998a) proposed estimate of $600 \mathrm{~km}^{2}$.

Our teams observed several families about $5 \mathrm{~km}$ east of Chunchucmil growing dry-season maize in May 2006. Farmers carried groundwater in buckets to every stalk nearly every day. This is labor intensive but similar to what we would expect in ancient Maya dry-season farming. We hypothesized that if ancient farmers incorporated dry-season maize into Chunchucmil's subsistence systems, we should find a plethora of wells or sascaberas dug to the water table. As discussed in chapter 2, we found i 8 unquestionably ancient wells. There may have been many more that are now obscured by soil or collapsed architecture. Of the 270 sascaberas mapped, we do not know how many of them reach the water table. To complicate the situation further, intensive irrigation on milpas or home gardens could potentially reduce crop yields and damage susceptible crops (especially seedlings) due to salt accumulation (Luzzadder-Beach 2000). The groundwater at Chunchucmil has an average electrical conductivity (EC) of $\mathrm{I} .2 \mathrm{dS} / \mathrm{m}$ and ranges of 0.3 to $3 . \mathrm{dS} / \mathrm{m}$. This 
means Chunchucmil groundwater is hard and has a high dissolved ion load that can reduce maize yields up to 35 percent if exclusively applied (Luzzadder-Beach, 2000). In areas at the higher EC range, water quality would have limited maize agriculture near Chunchucmil, but we did observe farmers irrigating healthy crops with this water. Moreover, what little we can say from the few bone data indicates Chunchucmil relied less on maize than Yaxuná and sites in the Petén and Belize (Mansell et al. 2006).

The typical model we use for swidden agriculture indicates maize cultivation can produce one crop per year for about two to three years. Several studies have attributed the short cultivation period to the diminution of crop yield from decreased organic matter, soil moisture, and nutrient availability, and to increased weed competition (Emerson 1953; Cowgill 1960; Reina 1967; Reina and Hill 1980; Beach 1998a; Weisbach et al. 2002; Dahlin et al. 2005; Dalle and de Blois 2006).

During fallow, secondary growth of shrubs, weeds, vines, grasses, and young trees quickly overtakes the milpa and allows soil organic matter and nutrient renewal (Emerson 1953; Dalle and de Blois 2006). Although in a wetter part of the Maya world, research on Lakandon Maya swidden suggests a highly complicated system with multiple uses and management of the fallow and longer planting periods (Nigh and Diemont 2013). But the time required for fallowing depends on the type of soil and the length of time of cultivation (Weisbach et al. 2002). Historically, the system requires seven to is years of fallow for every two to three years of cultivation in the Maya lowlands, a need of two to seven times more land in fallow than in cultivation (Reina, 1967; Reina and Hill, 1980). Weisbach et al. (2002) concluded that for northwest Yucatán a I2-year fallow restored most of the nutrient status, but recommended a 25 -year fallow to have the most significant improvement. Recent demand for increased crop production has dictated that the recommended fallow time be cut in half or more, requiring about a ro-year fallow (Dahlin et al. 2005). Nigh and Diemont (2013) suggest careful management could increase the cropping to eight-year fallow cycles in an area with greater soil resources.

\section{S SOIL TRANSECTS}

For more than a decade from 1994, we sampled soils across this broad landscape from the current coastline at Celestún eastward to the Sierrita de Ticul, along the edge of the Puuc hills, trying to capture the diversity of soilscapes in the region's six vegetation zones (figure 9.I): beach ridge, swamp-estuary, peten, tzekel, savanna, and karst plain (Farrell et al. 1996; Beach 1998a; Dahlin et al. 1998). Vlcek (1978) characterized much of the region as having little or no soil. In 1994, Bruce Dahlin led a field trip across soil landscapes from the coast to the Sierrita de Ticul. Tim Beach, 


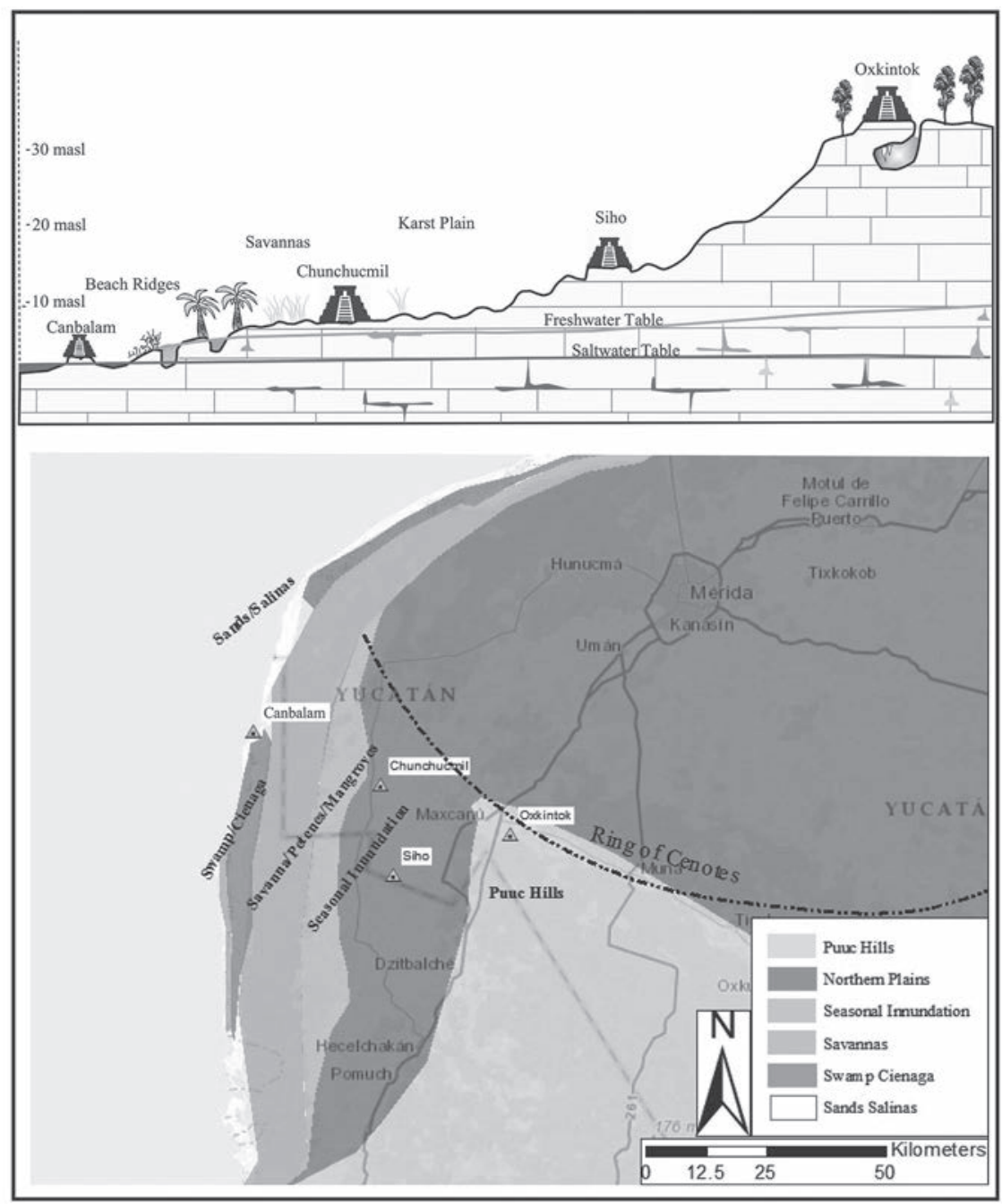

FIGURE 9.I. (a) Landscape elevation model from the Gulf Coast to the Sierrita de Ticul and (b) vegetation zones traversed by that transect.

Sheryl Luzzadder-Beach, Pat Farrell, and Bruce Dahlin followed this up with soil pits in a typology of soil landscapes (Farrell et al. 1996). The goal of this work was to find the regional resource base and soil diversity. Our work started on the Celestún peninsula because Dahlin had connected Chunchucmil with this broader hinterland and the sea, including the port site of Canbalam. We interpreted that 
the Celestún Peninsula's berms and swales had accreted sometime after sea level rise stabilized about 5,000 years ago and may have produced a soil chronosequence of older soils farthest inland to younger ones progressively closer to the Gulf of Mexico. We also reasoned that these soils held some evidence for past usage and found some elements of anthrosols in one of the soils (Dahlin et al. 1998). Indeed, there was the possibility of agricultural soils in the central zone of the peninsula, less influenced by salt water and more by fresh groundwater.

Along the coast are beach ridges along with swamp and estuary lands with petenes or freshwater springs (figure 9.I). The beach ridges and swales have high concentrations of surface salts, as much as $14 \mathrm{dS} / \mathrm{m}$ in one swale soil, because of a high water table, making swales unfit for cultivation, though the central part of the peninsula may have had lower salinity in antiquity with the lower sea levels. The soils of the swamp/estuary zone vary between histosols, inceptisols, and entisols, and the swale zones are often covered with periphyton (algal detritus and minerals that accumulate in shallow water) (Beach 1998a; Dahlin et al. 2005; Sedov et al. 2007). Some have argued ancient Maya farmers used periphyton for fertilizers, which is plausible, given its high nutrient levels and organic matter (Sedov et al. 2007). We noted in our work that indeed Maya farmers today borrow organic matter from wetlands (Beach 1998a), which could well have meant collection of periphyton. This hypothesis still needs testing at Chunchucmil, potentially through biomarkers, stable isotopes, and fossil shells (Dahlin et al. 2005). Morrison and Cozatl-Manzano (2003) did the latter at Yalahau and found some evidence for allochthonous shells, perhaps indicating human transplantation.

The beach-ridge soils formed along a soil toposequence across each ridge and chronosequence from younger to older soils across the more than 120 beach ridges and swales that span the nearly 3 -km-wide Celestún Peninsula (Beach 1998a; Dahlin et al. 1998). Because these beach ridges and swale complexes prograded since the middle Holocene to form the recurved peninsular spit, we assume the soils get younger westward from the Ria Celestún. A survey of in berms from the coast to the middle of the peninsula found increased melanization across this $1,047-\mathrm{m}$-long transect (figure 9.I). These soils are shelly, calcareous sand to fine sandy loam, and classify as aquents, psamments, and aquepts (Dahlin et al. 1998; Beach 1998a).

We found very little evidence for modern agriculture in this zone, and indeed local informants say most people mainly used the area as a source of organic matter to borrow for their gardens (Beach 1998a). We found one significantly more mature soil in the landscape near Hacienda Real de Salinas (see figure 1.2). A 300-m-long road-cut exposure near here had a well-developed paleosol buried by $89 \mathrm{~cm}$ of eolian deposition, which in turn had evidence of two episodes of topsoil formation at $47 \mathrm{~cm}$ and at the surface. The surface A horizon (from $\circ$ to $20 \mathrm{~cm}$ ) was faintly 
melanized with pale brown (IoYR 6/3) silt loam on a C horizon (to $47 \mathrm{~cm}$ ) of lighter ( $10 Y R$ 7/2) silt loam, which in turn lies above a granular Ab horizon (48-55 $\mathrm{cm}$ ) that is more melanized, brown ( $10 \mathrm{YR}_{5} / 3$ ) and built upon a $2 \mathrm{C}$ horizon (to 89 $\mathrm{cm})$ that is a very pale brown $(\mathrm{IOYR} 7 / 3)$ fine sandy loam. The buried soil below this had a thicker, more granular, darker ( $10 Y R$ 3/2) A horizon $(89-100 \mathrm{~cm}$ ) built on columnar, very pale brown ( roYR $_{7} / 3$ ) Bw horizon. These buried soils represent the oldest soils we studied on the peninsula because of their well-developed A and Bw horizons, perhaps columnar because of high quantities of sodium.

\section{SOIL TRANSECTS IN THE $2000 \mathrm{~S}$}

We base most of the findings and discussion below on research conducted in the 2000 s. The bulk of these findings came from three approximately $2-\mathrm{km}$ transectsnortheast, east, and northwest—starting within the core area of Chunchucmil and collecting soil profiles every roo m. We also sampled rural sites such as Bon and Nah Caña, two tertiary sites without site cores or temples, and at Pocholchen and Ikmil, medium secondary sites that possessed both site cores and pyramid structures (Hixson 20II). These sites are about 6 to $12 \mathrm{~km}$ west of ancient Chunchucmil through several different ecosystems and soil types.

\section{SOIL CLASSIFICATION}

The Yucatec Maya developed a soil classification based on what they could see and feel such as color, texture, and stoniness (Dunning and Beach, 2004; Bautista et al., 2005). Sabkab lu'um or saklu'um (sak, "white"; lu'um, "earth or soil"), boxlu'um (box, "light black"), and kancab lu'um (kan, "yellowish"; cab, "reddish syrup") are the three dominant soil types in ancient Chunchucmil's sustaining area (Weisbach et al., 2002). Much like modern classification systems, there are subgroups, but given that we have classifications distant in time and space, we use these broad groups to describe the general sustaining area. In reality, the Chunchucmil region is a complex mosaic of shallow soils, buried soils, structures, and rock outcrops (figures 9.1a and b).

Soil development began in the Late Miocene to Pliocene (Pope, Ocampo, et al. 1996). With an average annual soil temperature of $29.4^{\circ} \mathrm{C}$, the soil temperate regime is isomegathermic and the soil moisture regime is ustic (Van Wambeke 1987; Eswaran et al. 1997). Ustic moisture regimes are moisture limited except during a certain period, here the June to January wet season (Soil Survey Staff 2003).

Saklu'um consists of extremely shallow $(3-17 \mathrm{~cm})$, moderately well-drained calcareous soils over caliche or petrocalcic pavements. Saklu'um is grayish brown 
(2.5Y 5/2), sandy clay loam (endoaquent and petraquept) with effervescence, and slightly alkaline $\mathrm{pH}$. These soils formed in sandy and loamy marine sediments from the Quaternary and Pliocene (Dahlin et al. 2005). Saklu'um is found in the swamp and in areas of the tzekel that are seasonally inundated. Clay content is on average 29 percent.

Kancab consists of shallow $(8-50 \mathrm{~cm})$, moderately well-drained soils over a caliche or petrocalcic horizon $(\mathrm{Km})$ underlain by less dense, frail carbonate rock (sascab) (Beach 1998a). Kancab is reddish brown (5YR 4/4), clay loam (paleustalfs, paleustolls, and haplustalfs) that is noneffervescent with neutral $\mathrm{pH}$. Clay content is 32-34 percent in the younger and shallower savanna kancab and increases to 34-36 percent in the karst plain.

Boxlu'um consists of extremely shallow $(3-52 \mathrm{~cm})$, well-drained soils over fractured limestone. Boxlu'um is black ( 10 YR $2 / \mathrm{I}$ ), skeletal, very gravelly clay loam (calciustolls, paleustolls, and haplustolls) with slightly alkaline $\mathrm{pH}$. Boxlu'um is most commonly found on raised areas, as in the tzekel (tzekel lu'um [tzekel, "flat stone"]) or in areas of ancient limestone structures. Clay content is on average 28 percent; however, clay content in many of the boxlu'um soils of the tzekel is difficult to determine because of hydrous oxides and high organic matter. The very fine granular aggregates were hydrophobic and would not wet and disperse.

Field reconnaissance of densely occupied areas of ancient Chunchucmil showed that boxlu'um was present on the house mounds and platforms despite the presiding vegetative zone and surrounding kancab soils. Even in areas of boxlu'um of the tzekel, the boxlu'um within settlement structures differed in soil structure, color, and chemical properties from the boxlu'um outside settlement. The boxlu'um on the house mounds and platforms, hereafter called boxlu'um-o (o, occupied), developed after abandonment in lime plaster. Our surveys found no areas of intentional black-earth formation and we think the boxlu'um soils simply developed in the abandoned structures; hence ancient farmers would not have had boxlu'um-o to exploit in ancient times. Boxlu'um-u (u, unoccupied) developed before, during, and after occupation.

\section{SOIL DEPTH}

The most distinctive features of the soils of Chunchucmil are their absence and thinness (Beach 1998a; Dahlin et al. 2005; Weisbach et al. 2002). Approximately $55-80$ percent of the area has thin to no soil, and between 25 and 50 percent lacks any soil at all (Dahlin et al. 2005). With slopes of less than I percent, this area has the thinnest soils and is the most planar area of all of the Maya lowlands (Beach 1998a; Dahlin 2003). Often in the Maya lowlands shallow soils result from erosion 
(Beach, Luzzadder-Beach, Cook, et al. 2015), but the lack of slope here suggests slow soil erosion rates. Rather, Kellman and Tackaberry (1997) ascribe thin soils to the porous nature of the karst topography and slow soil development.

Curtis et al. (1996) and Beach (1998a) hypothesized that the present fertility and depth of the soils would not have been much different from the Maya occupation period because no substantial soil erosion previously existed, due to low gradient slopes and clayey soils. Yet, research in 2006 in modern quarries near Chunchucmil and conversations with Dr. Sergey Sedov (UNAM) about his work in northeastern Yucatán spurred us to reinterpret this hypothesis (Dunning and Beach 2010; Cabadas Báez et al. 2010). Although San José Chulchaca, the nearest coring site to Chunchucmil, shows no increase in sedimentation during the Maya Classic and slow sedimentation over all (Leyden et al. 1996), this site is $25 \mathrm{~km}$ north of Chunchucmil and erosion would be highly local in this flat terrain. Although the regional surface gradient is low, the gradient from the surfaces into sinkholes is locally steep over short distances. Over the years of the Chunchucmil projects, we measured deep sediments in many small sinks, and during the last years of the project we began to observe deep soil deposits in modern quarries near Chunchucmil. Soils in these cavities could have derived from slow erosion after limestone bedrock arose from the ocean or from periods of accelerated erosion either during devegetation from climate change or land-use change. We also observed that areas of so-called limestone pavements (similar to karren or lapis), which are all bare limestone karst features, cover some 25-50 percent of the landscape but that much of the stone surface of this zone also has deep-red staining indicative of oxidized iron in tropically weathered soil profiles. Hence, we hypothesize that the soil cover extended over these areas sometime in the past, and the most likely period of soil erosion was during the period of Maya land-use changes. Indeed, Cabadas Báez et al. (2010) have argued this from their findings from a series of quarries in northeastern Yucatán, based on several lines of evidence, including two AMS dates from soils buried in cavities from the Maya Classic. This is not a new idea, because two publications (Conservation Foundation 1954; Robles Ramos 1950) suggested this much earlier (Beach et al. 2006). In sum, soils around Chunchucmil may have been deeper and thus potentially more fertile and better at storing moisture in antiquity (Dunning and Beach 2010). In this scenario ancient farming would have shifted sediment from the ground surface to cavities in the bedrock (compare with Fedick 2014).

The rate of soil formation for boxlu'um-o in and around Chunchucmil can be estimated since the site's decline (i.e., post-AD 700; Dahlin, 2003). Average soil profile depth at Pochol Ch'en, located in the savanna (see chapter 8), for boxlu'um-u is $6 \mathrm{~cm}$ and for boxlu'um-o, $12 \mathrm{~cm}$. Soil accumulation above a large platform floor at a profile in Nah Caña, also located in the savanna (figure 7.I), and above a patio floor 
in Chunchucmil at Profile NTI2, was 6 and II cm deep, respectively (Sweetwood et al. 2009). The soils formed in Nah Caña and Chunchucmil during i,roo years of abandonment at a rate of $0.05 \mathrm{~mm} / \mathrm{yr}$ and $0.10 \mathrm{~mm} / \mathrm{yr}$. Other areas in the Maya lowlands, such as the Petexbatún (Beach 1998b) and Piedras Negras (Fernández et al. 2005), exhibit comparable rates: 0 to $0.1 \mathrm{~mm} / \mathrm{yr}$ and $\circ$ to $0.096 \mathrm{~mm} / \mathrm{yr}$, respectively. Johnson et al. (2007) calculated soil formation rates of $0.12-0.15 \mathrm{~mm} /$ year above a patio floor at Aguateca.

Where soil profiles were present, profile depth generally increased from $6 \mathrm{~cm}$ in an area $5 \mathrm{~km}$ west of Chunchucmil to approximately $29 \mathrm{~cm}$ deep in an area $3 \mathrm{~km}$ east of the site. The site center of Chunchucmil was dominated by thin boxlu'um-o with thicker soils at foot slopes and especially near areas of plaster mass wasting. Since much of the site center matches the depth of soil that would have formed at the calculated soil formation rate after abandonment, much of Chunchucmil was likely denuded of soil cover during the period of occupation. It is likely that patios and high-traffic areas were swept clean of soil but thin soils could have been purposely placed and maintained in garden areas (Beach 1998a). The denseness of structures and lack of soil likely limited central Chunchucmil to small home gardens, except for certain fruit trees that survive adequately in sparse soils (Hutson et al. 2007).

\section{SOIL MOISTURE}

The farmers of Chunchucmil today prefer boxlu'um for agriculture (Dahlin et al. 2005), but other farmers in northwest Yucatán have stated that kancab is more productive (Weisbach et al. 2002). These seemingly contradictory statements find validation in the strong link between soil moisture and nutrient availability. Low soil moisture reduces the mobility of nutrients and decreases plant uptake. Since boxlu'um tends to have low soil moisture and hydrophobic properties in the upper horizons, the available nutrients do not reflect the fertility of this soil class. Both boxlu'um and kancab hold moisture in their subhorizons longer through most dry seasons. This plays out in contemporary milpa management by modern Maya farmers because milperos tend to have multiple milpas in diverse locations to ensure crop success and decrease the probability of a disaster from variable amounts of rain (Nigh and Diemont 2013).

We can test water repellency (hydrophobicity) by using the water droplet penetration test (WDPT), which tests the amount of time water takes to penetrate the soil (King 198I). For water repellency there are the following seven classes: Class 0 , wettable, non-water repellent (infiltration within $5 \mathrm{~s}$ ); Class I, slightly water repellent ( $5-60$ s); Class 2, strongly water repellent (60-600 s); Class 3, severely water repellent $(600-3,600 \mathrm{~s})$; and extremely water repellent $(>\mathrm{I} h)$, which is further 
subdivided into Class $4(\mathrm{I}-3 \mathrm{~h})$, Class $5(3-6 \mathrm{~h})$, and Class 6 (> $6 \mathrm{~h})$ (Dekker et al. 200I). Boxlu'um-o (I s), kancab (o s), and saklu'um (I s) are wettable and non-water repellent. Boxlu'um- $u$ is severely water repellent at $39 \mathrm{~min}$ or more for droplet penetration (Sweetwood et al. 2009, 1,215-1,216).

Nearly half of boxlu'um-u soils, mainly developed in the tzekel, are hydrophobic. Hydrophobic or water-repellent soils have negligible water-holding capacity and are generally infertile. Water-repellent soils are seasonal. During the rainy season the hydrophobicity eventually can disappear, but if the soil is given time to dry out, the hydrophobicity can return (Quyum 2000). This is problematic for northwest Yucatán, since rain is variable, with a dry period in the middle of the rainy season, although fire management can reduce repellency and the land is so flat that water can eventually run off.

Quyum (2000) thought that water repellency occurred because hydrophobic soil organic matter (SOM) covers soil particles. Other factors associated with hydrophobicity are fungal growth, soil microorganisms, and plant type (Quyum 2000), but we have not found studies of the causes of hydrophobicity in northwest Yucatán.

\section{SOIL FERTILITY}

Neutral to alkaline soils similar to those of Chunchucmil often exhibit deficiencies of potassium $(\mathrm{P})$, iron $(\mathrm{Fe})$, manganese $(\mathrm{Mn})$, boron $(\mathrm{B})$, copper $(\mathrm{Cu})$, and zinc $(\mathrm{Zn})$. Nitrogen $(\mathrm{N})$ may also be deficient, especially where there is insufficient fallow from the region's legume-rich natural vegetation. About 30-50 percent of the trees are legumes (Rico-Gray et al. 1988), which maintain healthy (low) C:N (carbon:nitrogen) ratios in undisturbed soil (Beach 1998a). After only one year of cultivation, however, total $\mathrm{N}$ is reduced by approximately 20 percent in soils of the Yucatán (Weisbach et al. 2002). Soil N quickly becomes a limiting nutrient in the already nutrient-limited soil.

From 89 A-horizon samples, Sweetwood et al. (2009) compared the concentrations of extractable macronutrients $(\mathrm{P}, \mathrm{K})$ and micronutrients $(\mathrm{Cu}, \mathrm{Zn}, \mathrm{Mn}, \mathrm{Fe})$ to general fertility recommendations (Havlin et al., 2005). Boxlu'um surface samples $(n=36)$ had average $\mathrm{P}, \mathrm{K}, \mathrm{Zn}, \mathrm{Mn}$, and Fe concentrations of I3.9, I 43.8, I.3, I6.6, and $18.6 \mathrm{mg} / \mathrm{kg}$, respectively, which are sufficient for plant growth. Average Cu concentrations of $0.6 \mathrm{mg} / \mathrm{kg}$ were marginal. Nine surface horizons of saklu'um had average chelate extractable micronutrient concentrations of $0.7,6.8$, and $33.6 \mathrm{mg} / \mathrm{kg}$ for $\mathrm{Cu}$, $\mathrm{Mn}$, and Fe, respectively, and these nutrients are also sufficient. Average P, K, and Zn concentrations of II.I, II7.7, and $0.8 \mathrm{mg} / \mathrm{kg}$, respectively, were marginal. Kancab samples $(n=44)$ had average concentrations of $0.7,24.2$, and ${ }_{1} .4 \mathrm{mg} / \mathrm{kg}$ for $\mathrm{Cu}$, $\mathrm{Mn}$, and $\mathrm{Fe}$, respectively, and these nutrients are sufficient. Average concentrations 
of 0.8 and $84.5 \mathrm{mg} / \mathrm{kg}$ for $\mathrm{Zn}$ and $\mathrm{K}$, respectively, were marginal and average concentrations of $6.4 \mathrm{mg} / \mathrm{kg}$ for $\mathrm{P}$ were deficient.

Although several macro- and micronutrients were greater in boxlu'um and saklu'um than kancab, concentration doesn't account for quantity. Kancab of the area were on average 50 percent deeper than the other two soil types and therefore could potentially provide more plant nutrients. The effective root zone is critical for soil fertility. Under typical circumstances a maize root system will grow laterally i $\mathrm{m}$ in all directions and will penetrate the soil to depths of $2 \mathrm{~m}$ (Feldman 1994).

We also evaluated each Maya soil class with the land-capability classification system developed by the USDA (Klingebiel and Montgomery 196I). Kancab was in class III with severe limitations that reduce the choice of crops or require special cultural practices. The limitations included shallow depths to bedrock and low fertility. Farmers would need to amend these class III soils with soil organic matter (SOM) and they should not be worked when wet. Boxlu'um was in class IV with very severe limitations that restrict the choice of crops and require very careful management. There limitations were again shallowness and low moisture-holding capacity, and, in some places, salinity. Class IV soils in subhumid and semiarid areas may produce adequate yields during years of above-average rainfall, low yields during average rainfall, and failures during years of below-average rainfall. Fruit and ornamental trees and shrubs may be suitable for some class IV soils. Saklu'um soils were in class $\mathrm{V}$ with little to no erosion hazard but their use is limited to rangeland, woodland, wildlife, and watershed. Some limitations included ponded areas and nearly level stony soils.

Many of the physical and chemical properties of both boxlu'um-o and boxlu'um- $u$ were significantly different $(P<0.05)$. Boxlu'um-o had greater values than boxlu'um$u$ for calcium carbonate $\left(\mathrm{CaCO}_{3}\right)$ equivalent, black carbon $(\mathrm{BC}), \mathrm{Cu}, \mathrm{Mn}$, and $\mathrm{Zn}$, and was strongly effervescent, whereas boxlu'um-u had greater levels of total $\mathrm{N}$, total soil organic carbon (SOC, usually 58 percent of organic matter), P, electrical conductivty (EC), and sodium $(\mathrm{Na})$, and was very slightly effervescent.

The greater values in boxlu'um-o of $\mathrm{CaCO}_{3}$ equivalent (24\%), BC (0.9 g BC/kg soil), and SOC (1.०\% BC of SOC), Cu ( $0.8 \mathrm{mg} / \mathrm{kg}), \mathrm{Mn}(20 \mathrm{mg} / \mathrm{kg})$, and $\mathrm{Zn}$ (1.7 $\mathrm{mg} / \mathrm{kg}$ ) were $\mathrm{I}_{54}, 43,225,2,392, \mathrm{I} 46$, and 588 percent greater than boxlu'um-u, respectively, and could be explained by ancient human activities. Higher $\mathrm{CaCO}_{3}$ equivalent resulted from the broken-up and weathered building materials and stucco.

Boxlu'um-u had nearly roo percent more exchangeable $\mathrm{Na}(17.4 \mathrm{mg} / \mathrm{kg})$, total SOC (23.2\%), total N (1.8\%), and P (22.9 mg/kg), and 50 percent higher EC (1.5 $\mathrm{dS} / \mathrm{m}$ ) than boxlu'um-o. The greater values of total $\mathrm{N}$, total SOC, and P in boxlu'um$u$ are explained by interactions of soil chemical and physical properties. In general, the increased concentrations of both $\mathrm{P}$ and $\mathrm{N}$ in the soils were significantly related 
to increased levels of SOC $(P<0.05)$. Retention of SOC is often attributed to clay content, base saturation, the chemistry of the soil organic matter (SOM), and microbial activity rates (Oades 1988).

Higher EC and Na in boxlu'um- $u$ can be explained by depth to water table. Pochol Ch'en is in the tzekel zone, and in the encompassing area of boxlu'um-u the water table was visible in large fractures of the bedrock at depths of approximately io to I5 $\mathrm{cm}$ from the soil surface during the dry season. Close proximity allows wicking of groundwater and deposition of salts. The water table was not visible in the site of Pochol Ch'en. Soil profiles revealed fill for ancient patio groups, which increased depth to the water table and possibly reduced upward soil water movement.

\section{INTENSIVE AGRICULTURE}

To increase yields and shorten fallow time for agricultural self-sufficiency, Chunchucmil would have needed large inputs of plant-essential nutrients and SOM. Agricultural intensification like soil importation, soil amendments, and fertilizing with organic amendments over centuries would have left an imprint on the soils of Chunchucmil. Intensive agriculture could have elevated or decreased certain soil properties or chemical residues above natural background concentrations, such as ${ }^{13} \mathrm{C}$ isotope, biomarkers, $\mathrm{P}$, and $\mathrm{BC}$. On the other hand, if the farmers at Chunchucmil maintained high-input agriculture for centuries and also had high harvests, and possibly higher harvests toward their abandonment, little or no increase of P might be evident. This would be especially difficult to identify with the overprint of subsequent land uses, thin and possibly eroded soils, and highly mixed, bioturbated soils.

\section{CARBON ISOTOPES}

One way to delineate probable areas of ancient agriculture is through carbon isotopic ratios $\left({ }^{13} \mathrm{C} /{ }^{12} \mathrm{C}\right)$, and several studies have used these at other sites in the Maya lowlands (Beach et al. 20II; Beach, Luzzadder-Beach, Cook, et al. 2015; Beach, Luzzadder-Beach, Guderjan, and Krause 2015; Burnett et al. 2012a, 2012b; Fernández et al. 2002; Fernández et al. 2005; Lane et al. 2008; Webb et al. 2004, 2007; Wright et al. 2009). Ancient long-term maize cultivation leaves a distinct isotopic signature in the $\mathrm{SOM}$. A maize $\mathrm{C}_{4}$ signature is formed when long-term cultivation of maize, $\mathrm{a}_{4}$ grass, takes place in a normally $\mathrm{C}_{3}$ vegetative region, which leaves a $\delta^{13} \mathrm{C}$-enriched horizon.

We ran stable carbon isotope analyses of soil profiles on our soil survey transects and on a typology of ancient land uses around Chunchucmil. For the transects, the 
$\delta^{13} \mathrm{C}$ values of surface A horizons varied significantly $(P<0.0 \mathrm{I})$ according to soil type and vegetation zone. Nearest the Gulf of Mexico is the swamp/estuary zone with highly organic soil profiles. Surface horizons of these soils had average $\delta^{13} \mathrm{C}$ values of $-27.18 \%$, which indicates that this zone is dominated by $\mathrm{C}_{3}$ vegetation. East of the swamp/estuary zone are the tzekel hillocks, which had average surface soil $\delta^{13} \mathrm{C}$ values of $-25.44 \%$. This zone has mainly a high canopy with few grasses but enough $\mathrm{C}_{4}$ vegetation to shift slightly from $\mathrm{C}_{3}$. A small ancient rural site called Bon (see figure 7.I) with deep boxlu'um soils in the savanna had average surface horizon $\delta^{13} \mathrm{C}$ values of $-23.67 \%$. Surface horizons of kancab in the karst plain and savanna were analyzed and had average values of $-22.39 \%$. The decrease in discrimination of the ${ }^{13} \mathrm{C}$ isotope across Chunchucmil's landscape from west to east follows the change in vegetative zones and is an indication of increasing $\mathrm{C}_{4}$ vegetation distribution near the site.

Next, we compared $\delta^{13} \mathrm{C}$ values of surface horizons from within structure groups of central Chunchucmil to control samples from 4 to $6 \mathrm{~km}$ north of Chunchucmil. Some historical depth came from buried surface-horizon samples beneath ancient structures. Surface soils from structure groups in central Chunchucmil had average $\delta^{13} \mathrm{C}$ values of $-23.50 \%$, which was similar to that of boxlu'um and control samples with average $\delta^{13} \mathrm{C}$ values of $-22.59 \%$. The buried A horizons under Classic structures had average $\delta^{13} \mathrm{C}$ values of $-24.00 \%$. Statistically there were no differences between surface soils from structure groups, buried A horizons, and control samples $(P=0.90)$.

Of six grasses collected in the Chunchucmil region, four were $\mathrm{C}_{4}$ and two were $\mathrm{C}_{3}$. This mix of $\mathrm{C}_{4}$ vegetation prevents the use of stable carbon isotopes to delineate zones of ancient maize agriculture in the savanna and karst plain of northwest Yucatán. The mixed $\mathrm{C}_{3} / \mathrm{C}_{4}$ vegetation produced humin with $\delta^{13} \mathrm{C}$ values similar to values in soil horizons of suspected ancient maize growth in a predominately $\mathrm{C}_{3}$ vegetative region. In the shallow soils of northwest Yucatán, it would be impossible to differentiate between ancient milpas and native vegetation. Soil depth complicates the situation further because of a high rate of bioturbation and the inability to observe a change with depth. Soil samples are usually taken every $10 \mathrm{~cm}$ of depth for the carbon isotope analysis; however, average profile depths for boxlu'um, kancab, and saklu'um near Chunchucmil were 12, 21, and $10 \mathrm{~cm}$, respectively. Even with the shallow soil of the tzekel, if long-term maize cultivation took place, then we would assume that average $\delta^{13} \mathrm{C}$ values would be similar to those of the savanna and karst plain. Instead, the $\delta^{13} \mathrm{C}$ values suggest that tzekels rarely grew maize.

We also ran stable carbon isotope analyses on and adjacent to several landscape types at Chunchucmil, including sascaberas, an ancient apsidal house base, a sacbe, a callejuela, modern solar, infields, savannas, reservoirs, the market plaza (Area D 
in figure II.I), metates, and querns, which are metates with spillways (see chapter 2). Since the sample size is so small for these, we can only suggest further study. The savanna site, as in the transects above, produced the lowest, most $\mathrm{C}_{3}$-dominated $\delta^{13} \mathrm{C}$ signature $(-27.3 \% 0)$, followed by the aguada sediments (-26.1\%o), and the sascabera $\left(-24.3 \%\right.$ ). The highest $\delta^{13} \mathrm{C}$ signatures, closest to $\mathrm{C}_{4}$ species, were a surface sample in the central market place $(-20.5 \%)$ and the three querns $(-22.0 \%)$. The market-place sample conceivably could have been influenced by ancient maize use or recent planting of tropical grasses for pasture (Beach, Luzzadder-Beach, Guderjan, and Krause 2015). The metates were $-23.1 \%$, which is similar to the querns but also the mean for the surface typology $(-23.7 \%)$. The one significant finding from this work was the mean of buried soils at Chunchucmil (-21.6\% with Io samples, versus the mean for surface samples, $-23.7 \%$ for 23 samples). These may indicate more-intense maize cultivation in the recent past $\mathrm{C}_{4}$ plants, or the processing and consumption of maize within the city.

For comparison with our Chunchucmil sites we evaluated samples from transects at the slope of the Sierrita de Ticul ( $20^{\circ} 22^{\prime} \mathrm{N}$ latitude) about $27 \mathrm{~km}$ southeast of Chunchucmil. These samples come from an area with few structures or artifacts. This area consisted of dry scrub forest, again mostly $\mathrm{C}_{3}$ plant species but some grasses and cacti as well. Parts of these slopes may have been farmed and possibly stripped in antiquity, and indeed only the depression soils have deeper profiles with $\mathrm{Bt}$ horizons. The slopes in this region had an average $\delta^{13} \mathrm{C}$ of $-24.7 \%$ overall $(n=35),-25.6 \%$ for A horizons $(n=24)$, and -22.8 for lower horizons $(n=1 \mathrm{I})$, which is nearly a $3 \%$ increase in these profiles. Most soils had only A and AC horizons, but three karst depression soils had deeper sequences. The 60-cm-deep soil profile that was designated the North transect ( $125 \mathrm{~m}$ ) had a change in $\delta^{13} \mathrm{C}$ from $-26.3 \%$ in its upper A horizon to $-22.3 \% 0$ and $-21.8 \%$ at the $25-\mathrm{cm}$ and $45-\mathrm{cm}$ depths, respectively. This is an increase of $4.5 \%$, reflecting ancient $\mathrm{C}_{4}$ vegetation and possible maize agriculture in this deep kancab soil. The profile designated the East transect $(25 \mathrm{~m})$ had a similar pattern with a surface $\delta^{13} \mathrm{C}$ of $-26 \%$ that increased to $-22.7 \%$ at $25 \mathrm{~cm},-22.3 \%$ at $45 \mathrm{~cm}$, and $-22.6 \%$ at $75 \mathrm{~cm}$. The soil profile at $2 \mathrm{~W}$ had $-25.3 \%$ in the upper $\mathrm{A}$ and $-22.3 \%$ at $30 \mathrm{~cm}$ in the B horizon. Both of these soils have $\delta^{13} \mathrm{C}$ increases of more than $3 \%$, which provides moderate evidence of the impacts of ancient $\mathrm{C}_{4}$ plants. This region produced similar results to those in a similar sloping forested area in Belize, with mostly $\mathrm{C}_{3} \delta^{13} \mathrm{C}$ signatures except for two deeper-depression soils that also had significant $\delta^{13} \mathrm{C}$ enrichment in the lower soil (Beach, Luzzadder-Beach, Guderjan, and Krause 2015). The increase in $\delta^{13} \mathrm{C}$ within the deep soils was comparable to the increases within the buried soils at Chunchucmil, which in both cases may mean more maize or $\mathrm{C}_{4}$ species in antiquity, due to either drier climate or anthropogenic impacts. 


\section{BLACK CARBON}

Large regions in Amazonia and some in Africa have terra preta soils, which have copious amounts of charcoal, or black carbon (BC), such that they are still highly fertile today (Woods et al. 2009; Costa et al. 2004; Schaefer et al. 2004). If the Chunchucmil Maya had used charcoal to amend soils, there would be differences in $\mathrm{BC}$ concentrations from unoccupied and occupied areas with higher levels of $\mathrm{BC}$ in the ancient fields.

BC, a product of incomplete combustion (Brodowski et al. 2005), is almost entirely made up of aromatic C (Schmidt and Noack 2000) that resists chemical and microbial decomposition and persists through geological time-scales (Taylor et al. 1998; Glaser and Amelung 2003; Glaser et al. 200ra; Dai et al. 2005). The accumulation of $\mathrm{BC}$ is related to climate, textural properties, concentration of $\mathrm{SOM}$, and soil moisture (Glaser and Amelung 2003). BC enhances soil fertility by increasing the soil nutrient-holding capacity (Glaser and Amelung 2003; Glaser et al. 2001a), which has greatly improved crop yields of infertile Amazonian soils (Glaser et al. 200ra).

There is no doubt that the Maya produced charcoal, but little shows up. Three hypotheses might explain this absence:

I. The Maya collected the charcoal and transported it to their milpas.

2. The Maya deposited the charcoal in their home gardens.

3. The Maya did not do anything except discard it as waste or produced little because of more complete burning.

We made a preliminary test of these hypotheses by mapping $B C$ with respect to distance from settlement. If long-term soil amending occurred in milpas, we should observe elevated concentrations in unoccupied areas. Soil profiles were categorized as off-mound (no ancient structures within $\sim 20 \mathrm{~m}$ ), near-mound (within $20 \mathrm{~m}$ of ancient structures), and on-mound. We assigned a numerical value to each category and then compared their BC concentrations. Soil profiles from rural sites of Ikmil, Pocholchen, and Nah Caña were analyzed.

One transect centered over the site center of Ikmil, a large secondary site, reached to the unoccupied areas west and east of the site. A regression analysis of position versus $\mathrm{BC}$ concentrations shows that there is a significant correlation with proximity to ancient structures $\left(P=0.00, R^{2}=0.59\right)$. $\mathrm{BC}$ concentrations increased from off-mound ( $0.62 \mathrm{~g} \mathrm{BC} / \mathrm{kg}$ soil), to near-mound ( $0.78 \mathrm{~g} \mathrm{BC} / \mathrm{kg}$ soil), and then to on-mound ( $\mathrm{r} . \mathrm{g} \mathrm{BC} / \mathrm{kg}$ soil). $\mathrm{BC}$ concentrations also increased from off-mound (0.6 g BC/kg soil) to near-mound ( $0.90 \mathrm{~g} \mathrm{BC} / \mathrm{kg}$ soil) in Pocholchen $\left(P=0.0 \mathrm{I}, R^{2}\right.$ $=0.45)$; no on-mound samples were taken.

The positive gradient of $\mathrm{BC}$ concentrations toward ancient structures suggests an incidental effect of ancient human activities. Cooking fires and charcoal incidental 
to the burning of old thatch and to stucco production may have been major sources of BC in near-mound and on-mound soils.

Sweetwood et al. (2009) used the BC digestion and analysis method of Glaser et al. (200Ib) to determine that surface soils surrounding Chunchucmil contained between 0.37 and $\mathrm{I} .37 \mathrm{~g}$ BC/kg soil. These Yucatán soil results were about an order of a magnitude lower in the surface horizon compared to the terra preta soils of the Brazilian Amazon region ( $\sim_{\text {II }}$ g BC/kg soil). Even the BC concentrations of the control samples surrounding the terra preta soils were approximately twice as high as $\mathrm{BC}$ concentrations at Chunchucmil. There was also no significant differences between the BC contents of boxlu'um-u ( $0.7 \mathrm{~g} \mathrm{BC} / \mathrm{kg}$ soil), kancab (0.5 g BC/kg soil), and saklu'um ( $0.6 \mathrm{~g} \mathrm{BC} / \mathrm{kg}$ soil) soils $(P=0.47)$. The even distribution of $\mathrm{BC}$ throughout unoccupied rural Chunchucmil suggests that the major source of natural BC has been rotating milpa and natural fires.

The source of the dark color of boxlu'um is likely related to the retention of SOM rather than to BC. Average organic C contents for boxlu'um, saklu'um, and kan$c a b$ were I5.I, 8.8, and 6.4 percent, respectively. Of the soil properties analyzed, as the exchangeable multivalent cations $\mathrm{Ca}$ and $\mathrm{Mg}\left(P=0.00, R^{2}=0.55\right)$ and clay content $\left(P=0.00, \mathrm{R}^{2}=0.44\right)$ increased, SOM also increased. One mechanism of organic matter retention is cation bridging between clays and organic colloids (Oades 1988). The accumulation of SOM through introduced multivalent cations may explain the islands of dark brown soil of anciently occupied areas among the reddish brown soils of the savanna and karst plain. The dissolution of broken-up limestone from the construction of patio groups, the stucco used by the ancient Maya, and the lime used for food preparation were the major sources for elevated $\mathrm{Ca}$ and $\mathrm{Mg}$ (Fernández et al. 2002). The long-term liming effects of the stucco and other construction materials has apparently enhanced the accumulation of SOM content of house-mound soils (Oades 1988; Beach 1998a).

It is common to report $\mathrm{BC}$ as a proportion of SOC, because it helps describe factors of $\mathrm{BC}$ accumulation (Dia et al. 2005). Terra preta soils of Amazonia have up to 35 percent BC as a proportion of the SOC (Glaser et al. 2001a). In contrast, boxlu'um, kancab, and saklu'um had much lower values of 0.71 , 2.35, and 0.57 percent BC of SOC, respectively, but were significantly different between each soil class $(P$ $=0.00$ ). Kancab generally had greater soil moisture than saklu'um and boxlu'um during the dry season. Clay content was also greatest in kancab. These two factors tend to play a role in BC accumulation (Glaser and Amelung 2003). These three soils also represent three very different vegetative zones, which may greatly differ in the quantity and type of plant material, and frequency of burning. 


\section{PHOSPHORUS CONCENTRATIONS AND BIOMARKERS}

Because so many people lived in relatively tight quarters at Chunchucmil and they had few fertilizer choices, it seems likely that farmers used night soils. To test this, we analyzed stanol biomarkers and P. An enrichment of one or both properties should appear in areas of ancient croplands if amended with fecal residues (Fernández et al. 2002), though we also recognize that coprostanol would likely decompose and $P$ was in short supply in this environment. Coprostanol is formed in the intestinal tract of most mammals, and has considerable potential as an indicator of ancient manuring and night soiling (Bull et al. 1999). Hutson et al. (2007) and Sweetwood et al. (2009) examined to surface samples from both contemporary and ancient houselots at Chunchucmil for stanol biomarkers that could indicate ancient human waste disposal and manuring.

Extractable Soil P concentrations correlated with the change in vegetation and with densely populated regions, but there existed no anomalies of elevated $\mathrm{P}$ above normal background concentrations in potential outfield areas. Soil P concentrations were naturally elevated in the swamp/estuary $(9.3-14 \mathrm{mg} / \mathrm{kg})$ and tzekel $(\mathrm{I} 4 . \mathrm{I}-22.3 \mathrm{mg} / \mathrm{kg})$ and then declined in the savanna $(5.7-6.4 \mathrm{mg} / \mathrm{kg})$ and karst plain $(6.5-7.2 \mathrm{mg} / \mathrm{kg})$. Of the 104 soil profiles collected, the range of soil $\mathrm{P}$ was $2-46 \mathrm{mg} / \mathrm{kg}$. Soil P concentrations found in middens and suspected marketplaces in central Chunchucmil reached concentrations upwards of $250 \mathrm{mg} / \mathrm{kg}$ (Dahlin et al., 2007). There is no evidence of increased accumulation of $\mathrm{P}$ above background levels that would suggest the ancient Maya performed widespread night soiling.

\section{GEOSTATISTICAL ANALYSES}

Dense settlement of ancient Chunchucmil left an imprint of both physical and chemical properties. This is most notable when observing selected soil properties mapped over part of Chunchucmil's sustaining area $\left(52 \mathrm{~km}^{2}\right)$ using geospatial analysis in ArcMap ${ }^{\oplus}$. Along with soil P, we explored K (Olsen method), trace elements, $\mathrm{Cu}, \mathrm{Mn}, \mathrm{Zn}$, and Fe (Diethylenetriamine-pentaaceticacid [DTPA] method), exchangeable ions, $\mathrm{Ca}, \mathrm{Mg}, \mathrm{Na}$, and $\mathrm{K}$, and several other physical and chemical soil properties as possible indicators of human activity in occupied areas and land usage in unoccupied areas. Two separate methods (Olsen and DTPA extractable) allowed us to compare the effectiveness of $\mathrm{K}$ to indicate ancient activity.

The urban outline of Chunchucmil coincided with concentration isopleths of each soil chemical property, and intensity of these concentrations generally increased toward the center of the site. For example, centered over Chunchucmil was an elevated island of P (7.3-9.2 mg/kg), K (Olsen; $116-262 \mathrm{mg} / \mathrm{kg}), \mathrm{SOC}(8.4-$ $13.0 \%)$, and $\operatorname{Mg}(26-63 \mathrm{mg} / \mathrm{kg})$. 
Exchangeable Ca was also elevated in Chunchucmil, greater than $56 \mathrm{I} \mathrm{mg} / \mathrm{kg}$, and background concentrations decreased gradually from east to west, from $538 \mathrm{mg} / \mathrm{kg}$ in the karst plain to $489 \mathrm{mg} / \mathrm{kg}$ in the swamp/estuary. Conversely, percent $\mathrm{CaCO}_{3}$ equivalent decreased from west to east of the site, from greater than 40 percent in the swamp/estuary to 4-II percent in the karst plain. Ikmil and Chunchucmil had slightly elevated $\mathrm{CaCO}_{3}$ equivalent, but the contrast from background levels is not as pronounced as exchangeable $\mathrm{Ca}$.

There are probably many reasons for elevated concentrations of $\mathrm{P}, \mathrm{K}$ (Olsen), SOC, $\mathrm{Mg}$, and $\mathrm{Ca}$ in central Chunchucmil. Soil $\mathrm{P}$ and $\mathrm{K}$ initially accumulated after centuries of discarded food and waste. Increased SOM, likely caused by increased polyvalent cations from broken-up limestone and stucco, stimulated the retention of additional $\mathrm{P}$ and $\mathrm{K}$.

Exchangeable K (DTPA) gradually increased from west $(13.4 \mathrm{mg} / \mathrm{kg})$ to east $(31.9$ $\mathrm{mg} / \mathrm{kg}$ ) but did not share the same patterns as $\mathrm{K}$ (Olsen). Fernández et al. (2002) used exchangeable $\mathrm{K}$ in soils from a modern Maya house lot and discovered that exchangeable $\mathrm{K}$ was elevated in food-preparation areas beneath a thatched roof. From an abandoned house lot with three years of exposure to weather, exchangeable $\mathrm{K}$ was slowly leached and concentrations were only slightly elevated above background levels. Thus after a millennium of disuse at Chunchucmil, we cannot measure ancient human activity with exchangeable $\mathrm{K}$. Ancient human activity is illegible with DTPA extractable K but K (Olsen) may be a more efficient indicator of ancient human activity within settlement for this area.

The isopleth maps of extractable $\mathrm{Fe}$ and $\mathrm{Cu}$ did not follow vegetation change as well as other soil properties because of high variability. Even with the greater variation, some patterns emerged. In general, there were elevated concentrations of both $\mathrm{Fe}$ and $\mathrm{Cu}$ in the swamp/estuary $(40-52 \mathrm{mg} / \mathrm{kg}$ and $\mathrm{I.O}-\mathrm{I} .7 \mathrm{mg} / \mathrm{kg}$, respectively) and mildly elevated concentratons in central Chunchucmil $(23-34 \mathrm{mg} / \mathrm{kg}$ and $0.7-1.7 \mathrm{mg} / \mathrm{kg}$, respectively), and background concentrations were II-23 mg/ $\mathrm{kg}$ and $0.4-0.7 \mathrm{mg} / \mathrm{kg}$, respectively.

Soil concentrations of DTPA extractable $\mathrm{Zn}$ exhibited a peculiar pattern. Concentration gradients were high in the swamp/estuary zone $(\mathrm{I} . \mathrm{I}-2.9 \mathrm{mg} / \mathrm{kg}$ ) and low $(0.4-0.9 \mathrm{mg} / \mathrm{kg})$ in the tzekel, savanna, and karst plain except for two locations. Concentrations were high ( $\mathrm{I} . \mathrm{I}-2.9 \mathrm{mg} / \mathrm{kg}$ ) in between Ikmil and Chunchucmil and on the northeast periphery of Chunchucmil.

Soil concentrations of $\mathrm{Mn}$ were relatively even throughout the mapped region, between 7 and $19 \mathrm{mg} / \mathrm{kg}$, except northeast of Chunchucmil, where concentrations rise sharply to 3 I to $44 \mathrm{mg} / \mathrm{kg}$. Although Linderholm and Lundberg (1994) connected Mn, $\mathrm{Zn}, \mathrm{Fe}$, and $\mathrm{Cu}$ with ancient human activity, the anomalies here are more likely inconsistencies in parent material and/or an increased cation exchange capacity (CEC). 
Maya soils often retain the footprint of society in the physical and chemical properties of each site, despite nutrient cycling or minimal post-ancient Maya cultivation. A lack of some chemical such as phosphorous in cultivable land may suggest, but does not prove, the lack of agricultural intensification.

\section{SPATIAL ANALYSIS}

Land settlement patterns can illustrate preferences of agricultural resources (Fedick 1995). Based on vegetation, we could predict to which potential Maya soil class each site pertained. The majority of secondary sites, 21 of 24, were in kancab, two were in boxlu'um, and one was in saklu'um. Tertiary sites exhibited a similar pattern with II sites in kancab, two in boxlu'um, and 3 in saklu'um. The majority of the rural sites on the karst plain lie on kancab soils.

If we assume the major occupation for the rural population was agriculture and settlement location was in close proximity to milpas, then the ancient Maya preferred cultivating in kancab north and east of Chunchucmil. The soil east of Chunchucmil is deeper, has a slightly better capability class, and is laterally more continuous than the savanna or tzekel.

The sparse ancient settlement in the tzekel and swamp/estuary with their shallow soils confirmed that these areas were not preferred for cultivation; rather, the ancient Maya probably used the tzekel zone for wood and other forest products and for hunting and gathering. It would have been better to use the tzekel zone for certain economic species, like agave, nopal, and fruit trees, that do not require deep soils (Hutson et al. 2007). Nearly all secondary and tertiary sites in the savanna lie on the edge of the tzekel in an ecotone between cultivable land to the east and hunting and gathering land to the west.

Rural settlement and land use is an issue of interest for many geographers (Chisholm 1979). Research from all over the world of prehistoric and historic land use has shown that agricultural activity occurs concentrated within a I-to-2-km radius from settlement and beyond, and activities decline with distance and often terminate at around $5 \mathrm{~km}$ (Stone 1991).

Modern Maya milperos follow a similar trend and generally choose locations for cultivation based on location, soil type, and distance to milpa (Reina 1967). To minimize movement costs, these milperos live near their milpas and arrange them so that they spend no more than an hour on the trail traveling between each milpa (Reina 1967). With a radius of $5 \mathrm{~km}$, the area of cultivable land surrounding all known ancient settlement in the savanna and karst plain at Chunchucmil would be $445 \mathrm{~km}^{2}$, below the initially proposed sustaining area of $600 \mathrm{~km}^{2}$ (Beach 1998a). 
At optimum crop yields and shortest fallow, this area would only sustain 22,250 persons using Conklin's (1957) equation. For the 42,400 Maya in the core area of ancient Chunchucmil, the land requirement using the highest crop yields for this region and lowest fallow cycle would have been $848 \mathrm{~km}^{2}$. This estimate does not include areas with no soil cover, which would raise the estimate to over 1,000 $\mathrm{km}^{2}$. The enormous land requirement for just the core area means that a milpero would have been required to walk as much as $25 \mathrm{~km}$ from Chunchucmil if agriculture solely took place in the savanna and karst plain. Even without suburban and rural population estimates, it is improbable that the ancient Maya traveled this great distance to cultivate. Known rural settlement only extended as much as $13 \mathrm{~km}$ away from Chunchucmil. But even after more than 20 years from the start of the Chunchucmil project, the great unknowns for subsistence remain possibly unnoticed evidence for agricultural intensification and of deeper soils that would have had more fertility and greater water-storage capacity.

\section{CONCLUSIONS}

The many lines of evidence used to assess the agricultural resources surrounding Chunchucmil make us question its agricultural self-sufficiency. It is reasonable to conclude that poor building materials, shallow rocky soils, low fertility, variable rains, seasonal inundation, and water-repellent soils would deter any sustained large and dense population as it does today. Historic agricultural yields using traditional methods could not have supported the ancient population during Chunchucmil's major period of occupation. But we also recognize that past farmers could have used any of a number of intensification techniques to increase crop production. We also hypothesize that the ancient Maya soil environment might have been one more conducive to crop production, which may have been eroded some time during the Maya period and might be a part of the answer to the riddle of Chunchucmil's subsistence and even to its decline in the Late Classic period. These are testable hypotheses, which we hope to test with further study of quarries, dating of buried soils, and estimating how long bare surfaces were exposed by cosmogenic nuclide dating using ${ }^{36} \mathrm{Cl}$ (Matsushi et al. 2010).

Of the three dominant Maya soil classes, we found that kancab was the most consistently cultivable soil in Chunchucmil's sustaining area. Saklu'um had high salts, level stony soils, and ponding, and is unsuitable for cultivation. Boxlu'um-u had greater concentrations of nutrients for crop growth than kancab, but the often hydrophobic SOM, low soil moisture, and shallow depth negate the higher concentrations, especially when precipitation is already low or variable. Besides the fact that $k a n c a b$ covers a greater region, kancab must have been agriculturally important 
for the ancient Maya because it provided some security with higher soil moisture, greater soil depth, and improved nutrient transportation. There still exist complications with some areas with kancab, mainly ponding that can hinder crop development (Beach 1998a). Where we could excavate deeply enough, soils are deeper and bedrock had more and larger fractures east of Chunchucmil, away from where case hardening inhibits water and gas movements through soils. This may explain why most of the rural settlement is east of Chunchucmil.

Carbon isotopic signatures of ancient maize agriculture proved unsuccessful in delineating agricultural soils of the area surrounding Chunchucmil. Shallow soils and native and introduced vegetation of $\mathrm{C}_{4}$ and $\mathrm{C}_{3}$ plants mask the isotopic signature of maize.

The land-use capability of the karst plain with kancab was ranked as more favorable than all other main soil types. The land capability has severe limitations in the swamp/estuary and tzekel. The lack of rural settlement within these zones suggests little ancient use for cultivation.

We found no evidence of agricultural intensification of Chunchucmil soils by night soiling and soil amendments with charcoal. The stanol biomarkers likely decomposed quickly in the warm, seasonally wet environment, if they existed, and soil $\mathrm{P}$ concentrations in unoccupied areas did not exhibit patterns or concentrations of long-term night soiling. $\mathrm{BC}(\mathrm{g} \mathrm{BC} / \mathrm{kg}$ soil) levels were low in comparison to the terra preta soils of Amazonia. We found a few incidentally elevated concentrations of $\mathrm{BC}$ on ancient structures and within settlement but not in the cultivable land surrounding each site. Thus we can infer that the Maya of Chunchucmil did not amend their soils with charcoal.

The distributions of soil physical and chemical properties should have a buildup of chemical residues or altered physical properties if intensive agricultural occurred; however, we found little evidence in the surrounding landscape. The traditional method of shifting cultivation leaves little input of any source and the distribution of soil physical and chemical properties should resemble those observed in Chunchucmil. Based on this, ancient Maya agricultural practices at Chunchucmil were likely shifting cultivation, orchards, and solares, but we also recognize that eroded soil could hold more evidence for intensification.

The ancient Maya of Chunchucmil during the Middle Classic (AD 400-700) have yet to fully reveal their secrets of how they fed themselves. We could find no evidence that the ancient habitants of Chunchucmil used anything other than traditional methods. Atypical crops were possible as an alternative for maize but they would have been subjected to the same poor soil conditions and the same natural hazards like flooding and drought that plague the northwest Yucatán. Based on these findings, it seems more likely that Chunchucmil traded perishable goods to 
places like the nearby $(30 \mathrm{~km}$ ) Puuc hills. After all, Chunchucmil lay between the agriculturally rich Puuc and the maritime and estuary resource-rich Canbalam $(27$ $\mathrm{km}$ west), which was a stop on one of Mesoamerica's major maritime trade routes (Dahlin et al., 1998) for a host of marine and estuary products.

When we started the Chunchucmil project, we planned to study soil, sea levels, world systems connections, water tables, climate changes, and evidence for craft production. We and the broader scientific community made progress on these topics, but there is much left to future research. To answer the question of subsistence at Chunchucmil will require scholars to identify its coastal and interior connections better by characterizing its connections with Canbalam and the Puuc, its world systems networks with distant cities like Teotihuacan, its sea-level contexts over time, and what evidence exists for deeper past soils and their proxies for past soil uses. 



\title{
Perishable Resources Produced for Exchange in the Chunchucmil Economic Region
}

\author{
Bruce H. Dahlin, Traci Ardren, David R. Hixson, \\ AND ANTHONY P. ANDREWS
}

Data from the previous chapter suggest that the agricultural potential of the Chunchucmil Economic Region (CER) fell short of being able to feed the large population of Chunchucmil and its neighbors. Carbon isotope analysis of the bones from a limited sample $(n=5)$ of burials from residential groups suggests that Chunchucmil residents were relying less on maize than residents at Yaxuná in the central portion of the Yucatán Peninsula, or inhabitants of sites in Belize and the Petén region (Mansell et al. 2006). We believe, however, that alternative foods did not entirely make up the dietary shortfall. Both regular and fine screening of excavated contexts failed to recover bones from fish or game. However, it is common practice among fishermen and hunters in Yucatán to butcher their catch or game at or near the site of the catch or kill, which would severely limit the presence of faunal remains in dietary evidence. This will be discussed further below.

Paleoethnobotanical analyses have been limited (see Hutson 2004:122-125), including phytolith analysis of soil samples from two domestic contexts and a pilot macrobotanical study that did not produce useful results. The phytolith analysis revealed evidence of maize and beans, but little clear evidence of other foods. We propose that the people of Chunchucmil acquired additional food by trading with people beyond the CER. We discuss sources of this food in chapter 13 but for now we state merely that food would have been coming from the east, between 30 and $100 \mathrm{~km}$ away; not a short distance but shorter than the proposed maximum distances that food could be moved on foot before becoming too costly (Cowgill 
1993; Drennan 1984a, 1984b; Hirth 2013;). The Puuc hills area to the east was a major granary of Yucatán during the colonial period, and was likely so in prehispanic times as well (Patch 1977; Kurjack et al. 1979; Kurjack and Garza Tarazona de González 1981; Robles Castellanos and Andrews 1986). If Chunchucmil indeed imported food on a large scale, it needed something to give in return. This chapter discusses the mostly perishable products and materials that people at Chunchucmil could have traded. In Blanton et al's (2005) terms, it is a "goods-based approach" to understanding the organization of prehistoric societies.

Part of our discussion of what Chunchucmil traded is frankly speculative because the majority of the Maya prehistoric artifact inventory was made of perishable stuff, difficult to document archaeologically. In terms of non-perishable goods, we know that Chunchucmil imported vast quantities of obsidian relative to other northern Maya sites, and our intensive excavations into housemounds strongly suggest that imports also included jade, pyrite, cinnabar, pottery, and other exotic precious materials or finished objects. We suggest that these non-perishable goods are the tip of the proverbial iceberg, for most tropical and subtropical peoples overwhelmingly make and use implements out of highly perishable materials that rarely survive in the archaeological record due to poor preservation conditions. Thus, ancient Maya artifact inventories tend to hugely underrepresent the most fragile and organic materials.

What perishable items did people from Chunchucmil have and export? We have little evidence of these items, other than ethnohistorical descriptions from Bishop Diego de Landa (Tozzer 1941:94) and others summarized in Scholes and Roys (1948), that the protohistoric province of Ah Canul, in which Chunchucmil is located, exported slaves, cotton, and salt. The Códice de Calkiní, another colonial source, mentions tribute payments of these same goods plus honey and beeswax. The situation regarding perishables is not hopelessly speculative, however. In addition to ethnohistorical hints, a number of lines of evidence can be marshalled to argue for trade in perishables. The presence or abundance of highly valued resources that could have been exported in bulk-for example, salt or plant-fiber products from the savanna adjacent to Chunchucmil-provide clues about long-distance exchange, especially when imports are found broadly distributed throughout a site (see chapter II). The consumption of imports at all levels of society suggests the wholesale production of items to pay for them. The proximity of settlements to resources that are nevertheless narrowly distributed on a regional landscape might also suggest collection or production for exchange, especially where agricultural potentials in the surrounding area are limited. Furthermore, there are slivers of direct artifact evidence at Chunchucmil and elsewhere, as well as information on the available technology required to profitably produce, store, and transport these items for export. Finally, we can consider demand for Chunchucmil's products 
given a hypothetical competitiveness with other export economies during Classicperiod Mesoamerica.

All of these lines of evidence will be pursued here. Some lines of evidence are admittedly weak, but we can hardly hope to understand Chunchucmil and its place in regional and long-distance exchange networks without such speculation. Obviously an almost infinite number of potential goods might be enumerated. Each one of the goods discussed below, however, was selected on the basis of its intensification potentials and the impacts that its commercial production might have had on the organization of society, specifically the emergence of occupational specialization of production units, new ways of allocating labor, and new kinds of relations between production units and political hierarchies and heterarchies. Each item mentioned will then be evaluated according to the demands placed on the local population in order to produce that item. For example, a region might be well situated to produce cochineal, but to make this dye it also had to possess the wherewithal to make the mordants that are necessary to fix it. Similarly, a region might be blessed with perfect growing conditions for cotton, but if the carrying capacity of the land was strained by a large population, or its labor demands conflicted with the production of staple foods, the production of cotton mantles might not be pursued as an occupational specialization.

\section{MINERAL RESOURCES}

\section{SALT}

As is well known, salt is a human necessity of life, particularly in the tropics. Yet some of the most heavily populated regions of the Classic-period Maya world, such as the Petén of northern Guatemala and southern Campeche, Mexico, lacked significant salt sources (A. P. Andrews 1983; Rathje 1971). Though small quantities of salt can be acquired by burning certain species of palm trees and consuming the ash, this is a time-consuming process that would not be able to feed the millions of Classicperiod Maya people on a regular basis (A. P. Andrews 1984). Salt can be found in abundance on the coast of Yucatán at Las Coloradas and Celestún, Mesoamerica's first and second largest saltworks. Compared to the Las Coloradas salt flats, the Celestún salt flats are $250 \mathrm{~km}$ closer to the Petén by boat. At both locations, solar evaporation of seawater in artificially modified salt flats produces thick crusts of salt in the dry season. Salt makers today use salt plucked directly from solar evaporation pans to make table salt but only after washing it in briny water in order to clean it and purify it to meet professional standards. Though Celestún salt is not used for table salt today, it was consumed locally and exported to the Petén in the colonial period (A. P. Andrews 1983). Furthermore, high strontium-isotope ratios indicate that 
people from Tikal consumed sea salt in the Classic period (Wright 2005). Though people from Tikal probably imported some of their salt from the coast of what is now Belize, where salt was produced by boiling water (McKillop 2002), salt from evaporation pans at places like Celestún is of higher quality, is easier to produce/harvest, and may have been consumed by Tikal's elites (MacKinnon and Kepecs 1989).

Salt from Celestún could also be used as a mordant for dyes, as a preservative for fish, shellfish, meat, and other organics (A. P. Andrews 1983; McKillop 2002), and perhaps as salt licks strategically placed in or near agricultural plots to attract game animals. An ethno-archaeological study of contemporary salt extraction on the Celestún Peninsula showed that salt harvesting does not require imperishable tools (Bezanilla 1995).

Metates provide a possible non-perishable line of evidence for talking about salt. Metates have generally been ignored by Maya archaeologists, presumably because they were ubiquitous in households and were used primarily for processing maize, the most important staple crop in Mesoamerica. They were therefore thought to hold very little other information of importance. They piqued our interest because some of the well-bounded residential groups at Chunchucmil seemed to have more of them than could be expected merely for grinding a household's corn. In a sample of 392 architectural groups enclosed by albarrada walls (Magnoni et al. 2012), there is a positive correlation between the number of metates per houselot and the amount of architecture per group $(r=0.36)$. This means that in general, groups with more buildings have more metates. If amount of architecture indicates the number of people living in a group, this correlation could simply be taken to mean that the number of metates in a group rises when there are more people in the group. However, of the 47 groups in the sample of 392 that have five or more metates, half of them $(n=23)$ are relatively small groups (five or fewer structures). Furthermore, although the group $\left(\mathrm{N}_{4} \mathrm{~W}_{\mathrm{I}} \mathrm{Q}\right)$ with the largest number of metates $(n=25)$ has the second-largest number of structures $(n=22)$ in the sample, the groups $\left(\mathrm{S}_{\mathrm{I}} \mathrm{E}_{3}-\mathrm{B}\right.$ and $S_{I} W_{I}-F$ ) with the second and third largest numbers of metates (2O and 18 ) have only six and five structures, respectively. Finally, though the average number of metates per structure in the sample of 392 groups is 0.37 , several groups have two to three times as many metates as structures. In sum, it seems clear that at least some households were using metates for something other than domestic needs.

Watanabe (2000) examined variation among metates in greater detail by analyzing 109 metates and three mano fragments from a sample of 13 residential groups that had a large number of metates. The large number of metates per household does not appear to have been simply the result of accumulation of exhausted metates at groups that had a longer period of habitation. Indeed, of the 109 metates, 25 percent $(n=27)$ were whole, 23 percent $(n=25)$ were broken but with all of the parts 
present, and 52 percent $(n=57)$ were fragmented and incomplete. That over 75 percent of the sample were broken is not surprising as the local limestones are soft and easily broken. However, the 46 percent that were either whole or broken with all their parts present suggest that close to this number were intact and probably in use when these households were abandoned.

As discussed in chapter 2, there are three types of metates: trough metates, basin metates, and querns. Watanabe assigned the metates to these types and measured all aspects of metate interiors and exteriors. Eighty-eight percent of Watanabe's metates $(n=96)$ were trough metates, which is not surprising as they are the most common form throughout northern Yucatán in general. They were produced by using a mano in a back-and-forth motion, which ultimately creates a trough that is longer in one direction than in another. Twelve metates (II\% of the sample) were basin metates with circular depressions created by using a narrower mano in a circular motion. An area with a diameter of about 10 to $15 \mathrm{~cm}$ was worn $3-8 \mathrm{~cm}$ deeper on one part of the floor of the basin where people probably began grinding a substance in its coarsest form. Basin metates, while less frequent, are also found at other Yucatecan sites. Querns are totally unique to Chunchucmil, not only in Yucatán but throughout the rest of Mesoamerica, Central America, and the Caribbean. Querns resemble basin metates in having been created by applying a mano in a circular motion, but they may have interior sides that have been substantially undercut by the edges of the mano, creating overhanging walls. They have a spillway cut through the upper lip, presumably to drain away some of the lighter portion that has risen to the top of the substance being ground. Though we documented only 74 querns at the site, the actual total was likely higher, since spillways are often hard to notice in fragmented metates.

The three forms - troughs, basins and querns - as well as the large variety of sizes, suggest a diversity of uses in addition to maize processing. Archaeological or ethnographical sources document the use of metates to grind salt, pigments, calcite, insects, cacao beans, various herbs and other plant foods, and the meat and bones of animals and fish. Metates are also used as containers for liquids and to wash clothes. Horsfall (1987) observed ethnographically that grinding stones with the smallest grinding surfaces $\left(200\right.$ to $\mathrm{I}, 600 \mathrm{~cm}^{2}$ ) are used for grinding cacao, salt, herbs, and other substances; the middle range $\left(400-2,200 \mathrm{~cm}^{2}\right)$ is typically used for grinding maize; and metates with the largest grinding surfaces $\left(1200-2400 \mathrm{~cm}^{2}\right)$ are used to wash clothes. According to Watanabe's measurements, the area of Chunchucmil's trough metates ranges from 672 to $1,972 \mathrm{~cm}^{2}\left(\right.$ mean $\left.=1,254 \mathrm{~cm}^{2}\right)$, thus accommodating all of the above activities.

Smaller basin metates and querns could have been used for maize processing but these stones were not ideally suited to it. Given the proximity of the Celestún salinas to the Gulf Coast maritime trade route and the high regard with which 
the Maya held salt, salt grinding on basin metates and querns is highly probable. However, salt is best traded and transported in rough chunks or cakes; finer grinding of salt is done just before consumption. For these reasons no prehispanic metates were found in the survey of the Celestún salinas, an extraction area where people did not live. On the other hand, if salt were used as a consumable currency, as it often is worldwide, then it might have been ground regularly at Chunchucmil as part of its market system. Similarly, if salt were regularly used as an industrial product, such as a mordant for pigments and dyes, it might also have been processed at Chunchucmil and supplied to production specialists.

\section{FLORAL RESOURCES}

ACHiote (ANNATTO, RECADo Rojo)

Achiote, a Nahuatl word for Bixa orellana, is the most widely used red food colorant in the world today (Bixa is a Taino word). Achiote is also used as a dye for lipstick, suntan lotion, nail polish, hair oil, lotions, ointments, textiles, soap, candles, leather, floor and shoe polishes, wood stains, brass lacquer, furniture polish, and varnish (Watanabe 2000:80). Its cultivation and use is well-known in both highland and lowland environments throughout the American tropics, and achiote has been used in many ways by historic and ancient populations (Watanabe 2000:679I). It has been used as a dye for fabrics (particularly cotton) and other arts and crafts. Its popularity as a body paint and hair colorant is well-known; in fact, the origin of the term Redskins for the Indians of the New World may derive from their widespread practice of applying achiote pigment to their skins (Coe 1994:I43). It has been used as a pigment in mural painting (Heinerman 1996:20). It has been used as a mosquito repellent, an astringent, an antiseptic, and possibly an expectorant (Oviedo, quoted in Standley 1920:836). It has medicinal properties for several gastrointestinal disorders (Rees 1819; Wisdom 1940:366). It has been used in agricultural rituals in which the tiny seeds (about the size of a grape seed) are associated with rain drops (Hamman 1998:33I). The Lacandon paint their incense burners with it (Tozzer 1907:72-73, I4I). Like salt and cacao, it was used as a form of currency in protohistoric times. Known as ki'wi' or k'uxub in Maya (Barrera Marín, Barrera Vásquez, and López Franco 1976), this red paste or powder is the most widely used condiment in Yucatecan cuisine today, and is often grown in dooryard gardens close to kitchens and domestic structures (see Tozzer 1941:200). It is used as a seasoning in many Mesoamerican dishes, including as a flavoring and coloring for chocolate drinks (Coe 1994:143; Hughes 1672:122; Morton 1960:303).

Achiote is native to Yucatán and well suited to local growing conditions, as limited as they are by thin soils and rainfall deficits (Beach 1998a; Dahlin et al. 2005). 
Today it grows wild around Chunchucmil. Watanabe (2000:83), citing Baer (1976:69), observes that achiote is amenable to commercial production. "B. orellana grows well under cultivation in seasonal tropical climates with well-marked dry periods ... A common practice is to plant the trees in rough terrain and rocky soils where the growing of other crops would be difficult or impossible ... and [it] also grows where inundated or in periodically brackish water." The latter conditions prevail in the savanna and freshwater swamps to the west of the site.

Achiote is a fast-maturing shrubby tree that can be pruned every two or so years to a height of $3-4 \mathrm{~m}$ to make harvesting easier and to increase yields. Therefore, several achiote trees can be crammed into a relatively small space for a tree crop, and each tree yields $\mathrm{I}-5 \mathrm{~kg}$ of seed on average per year (Watanabe 2000:84). Processing entails either grinding the seeds on metates and boiling the powder into a paste (Wisdom 1940:31), or soaking and fermenting first and then grinding into a paste (Morton 1960:305; Standley 1920:835). The paste is formed into loafs or cakes and then sun-dried and either used domestically or traded in that form.

Specialized processing instruments might include wooden tubs for soaking, metates for grinding, and large ceramic jars for boiling and/or soaking. Watanabe makes a strong case that of the three types of metates discussed above, querns are ideal for making achiote. When the seeds are soaked, a soluble yellowish fraction (known as orellin) floats to the top, while the relatively insoluble red pigment (bixin) stays in the bottom of the depression. As the seeds were ground in liquid, the yellow fraction would be pushed out the spillway. The desired red pigment would be collected in the depression after it had dried into either a paste or powder. It could then be mixed with fat or oil solvents or other gums or honey when applying as a dye.

Long-distance exports of achiote to areas outside of its native habitat are widely reported in the ethnohistoric literatures of North, Central, and South America. Because of its ubiquity and the fact that its preparation is not very labor intensive, it would probably not have had a high market value except perhaps in those few areas where it could not be grown. Achiote is said to have been traded widely by the Putún or Chontal Maya who occupied the Gulf Coast (Thompson 1970:156), implicating the Chunchucmil region as a potential major source area.

\section{Cotton}

Cotton (Gossypium hirsutum) played a large role in the exchange of bulk luxuries throughout the prehistory of Mesoamerica (e.g., King 1979:267), and particularly in the Late Postclassic period (Berdan 1987; McAnany 2010; M. E. Smith 2003; Stark et al. 1998). Northern Yucatán in particular was likely a large exporter of cotton in prehispanic times (Roys 1957:II; Tozzer 1941:94). The importance of cotton 
textiles to the Maya is underscored by many painted Classic-period vases that depict men offering textiles to rulers. Women, however, most likely produced both elaborate cotton clothing and plain cotton mantles, thus highlighting the critical role they played in political economies (Ardren et al. 20I0; Clark and Houston 1998; Hendon 1997; Vail and Stone 2002). Throughout the Classic-period artistic corpus, Maya elites are shown wearing loose cotton huipils or loincloths, many of them highly embellished with woven or brocaded designs (Anawalt 1981; Schevill et al. 199I). Richard Blanton and coauthors, citing several primary and secondary sources, list the following uses for cotton cloth: "clothing, household utilitarian, medicinal, decorative hanging, religious offering, mummy bundling, gifting (including those given to commemorate rites of passage), and as armor [and] . . an important commodity form of money" (2005:270). Ethnohistoric sources describe cotton as the second most important product in Yucatán, after salt (Tozzer 194I). The annual local variety (Gossypium birsutum laetifolium Hutch) of cotton grows wild at Chunchucmil today as well as on the sandy soils of the Celestún Peninsula and elsewhere along the north coast.

However, since domestic cotton grows best in areas with between 1,000 and I,500 mm of rain (Purseglove 1968:348), and since Chunchucmil's annual rainfall is normally below this, cotton might only thrive in cultivated plots if it were watered. This may be why Roys (1957:II) notes that specific mentions of cotton growing are sparse in the colonial documents from towns in the vicinity of ancient Chunchucmil. At the same time, Farriss (1984:39) notes that the Maya of Yucatán grew cotton in their milpas without supervision from the Spaniards and their record keepers. It is therefore worth exploring the hypothesis that Chunchucmil produced cotton commercially and exported it in bulk in the Early Classic period.

This hypothesis is problematic, however, because extensive excavations at many Maya sites have produced rather few tools for spinning and weaving thread (McAnany and Plank 2001:96, cf. Ardren et al. 2010). At Chunchucmil, we have found only six ceramic spindle whorls in all excavations and no bone needles, although bone preservation is extremely poor at the site. Extensive excavations at Dzibilchaltún, which is similar to Chunchucmil in terms of climate and soil cover, yielded only five spindle whorls (Taschek 1994:215). Comparable data from the nearest contemporary urban center, Oxkintok, are not available. From Ceibal in the western Petén and Barton Ramie in the Belize River valley, spinning implements recovered by the Harvard projects total nine and five, respectively (Willey 1978:47; Willey et al. 1965:402). In a recent analysis of the spindle whorls of the Yucatán Peninsula, Hernández and Peniche noted a total of 191 items recovered from Io sites, I 47 of which came from Chichén Itzá, the most thoroughly excavated site in the northern lowlands. Hernandez and Peniche note this sample spans the 
Middle Preclassic through Postclassic, and that the frequency of whorls doubles in the Postclassic period (Hernández Alvarez and Peniche May 2008:table I). This confirms a pattern of low recovery rates at earlier sites, but suggests that further excavation may yield larger samples. They also note some spindle whorls were made from lithic materials, or perishable substances such as bone and cocoyol nut wood (Hernández Alvarez and Peniche May 2008). Ardren et al. (2010) recovered 17 spindle whorls from a single Terminal Classic platform at the site of Xuenkal, located along trade routes between Chichén Itzá and the coast. The authors suggest this sample differs so dramatically with earlier patterns in Yucatán due to the processes of economic intensification involved in the tribute-based economy of Chichén Itzá. The presence of 76 spindle whorls in the sample from Cozumel may be explained in the same manner (Phillips 1979). However, only 32 ceramic spindle whorls were recovered from the three major archaeological projects at Mayapán, which is described as a tribute-based center in contact-era ethnohistoric documents (Tozzer 1941; Masson and Peraza Lope 2014:299).

There are at least five ways to explain this paucity of spindle whorls at Classicperiod sites. First, spinning and weaving may have been primarily an elite activity. Spinning and weaving tools are more common in elite contexts (Chase et al. 2008; Halperin 2008; Hendon 1997:44; McAnany 2010:117, 186). On the other hand, ethnohistorical and ethnographic sources describe weaving as an activity for women of all statuses (McAnany 2010:117). Second, as Hernández Alvarez and Peniche May (2008) have noted, spindle whorls were made from perishable organic materials (e.g., bone or wood) rather than from fired clay. Third, it is possible that a great deal of cotton was grown at Chunchucmil-lands a few kilometers to the east have better soils and higher rainfall—but this raw cotton was exported in bulk to be made into cloth elsewhere. Fourth, it is possible that Chunchucmil had an avid interest in the cotton industry and imported already-spun and -woven cotton cloth from elsewhere and perhaps dyed and decorated it here. Finally, it remains possible that Chunchucmil had no real interest in cotton production.

Data from Teotihuacan suggest that the third possibility-exporting of raw or spun cotton-is plausible. Cowgill (2007:282) states that the occupants of the Merchants' Barrio at Teotihuacan likely imported cotton from the lowlands. Though most of the ceramics from the Merchants' Barrio are local Teotihuacan wares, up to Io percent are imports from the Gulf Coast of Veracruz and the Maya lowlands. Very few spindle whorls have been recovered from Teotihuacan, but bone needles for embroidery are more common. Though Teotihuacanos may have used perishable spindle whorls to spin raw cotton into thread, it is also possible that Teotihuacan imported textiles. Some of this cotton, either raw or in the form of textiles, probably came from Veracruz, which produced cotton vigorously in the Classic 
period (Stark et al. 1998). The presence of Maya ceramics at the Merchants' Barrio suggests that some of the cotton may have also come from Yucatán. Chapter I2 documents architectural and ceramic evidence for connections between Chunchucmil and Teotihuacan. So it is possible that the Chunchucmil region exported raw cotton in bulk to Teotihuacan and elsewhere.

Another source of a silky fiber very similar to cotton is the ceiba tree (Ceiba pentandra), which is extremely common in the forest of northern Yucatán, especially in the scrub forests behind the coast. This waterproof fiber was widely used for textile batting or stuffing until the development of polyesters. Ceiba fibers are generally considered too slippery to spin into thread or cloth; however, some historians believe Maya weavers may have been able to ply ceiba with cotton to make a useable thread. Ceiba fluff was likely the material of choice to fill the large cushions that adorned palace thrones, as shown on Classic-period painted ceramic vases. Bark paper, or amate, is made from the wild fig tree (Ficus glabrata) which is native to Yucatán, and was made in the prehispanic era. Although best known as the material from which Maya codices were constructed, it has been suggested that commoners wore bark paper clothing which could have been stamped with geometric designs resembling woven cloth (McAnany 2010:122).

\section{COCHINEAL}

Cochineal, also known as carmine dye, is one of the most light- and heat-stable and oxidation-resistant of all the natural colorants. It is derived from the cochineal insect (Dactylopius coccus), which lives on nopal, a cactus from the genus Opuntia. The 150 varieties of Opuntia are widely dispersed throughout the world, and while the cochineal insect will inhabit all or most of them, it is the Opuntia indicamil that is used as the insect's cultivated host in Mexico; in fact, Opuntia ficus-indica was domesticated in Central Mexico (Griffith 2004). Although most cochineal is derived from farming nopal and caring intensively for the cochineal insect, it can also be collected in the wild (Aldama-Aguilera et al. 2005). The dye, which deters predation by other insects, is extracted from the insect's body and eggs. The existence of wild cochineal species, natural enemies, extreme temperatures, rainfalls out of season, high luminosity, and strong winds make cochineal production difficult (Aldama-Aguilera et al. 2005) and extremely labor intensive. Converting insect to dye involves extracting female cochineal insects from nopal, killing them with hot water, steam, or ovens, drying and pulverizing the insect bodies, and then boiling the powder in a solution with sodium carbonate or ammonia. Depending on purity and how the solution is further treated, cochineal dyes can come out in a variety of tints of orange, red, and purple. 
Demand for cochineal is known to have been high in the Late Postclassic. For example, II Aztec cities conquered by Montezuma in the fifteenth century paid a yearly tribute of 2,000 decorated cotton blankets and 40 bags of cochineal dye each. Demand for cochineal in Europe during the colonial period was even greater (Baskes 2000; Hamnett 197I). Cochineal adheres more firmly and produces a deeper color in wool, introduced to the New World in the colonial period, than in prehispanic fabrics made of cotton and agave fiber. Produced almost exclusively in Oaxaca at that time, cochineal became Mexico's second-most-valued export after silver.

Yucatán was a producer of cochineal in colonial times (Contreras Sánchez 1996). Chunchucmil is an ideal location to produce cochineal in that nopal is an unusually hardy plant that grows in extremely thin soils and seemingly the smallest cracks in large expanses of exposed bedrock. Large expanses of bare bedrock are included in many houselots or solares at Chunchucmil. Try as we might, we have not been able to figure out why it was so apparently important to include these seemingly useless patches within solares. However, many of them currently support wild (uncultivated) nopal and the tell-tale white crust of the cochineal insect's presence is common. Finally, Bernal Díaz del Castillo noted the presence of cochineal in southern Campeche while he was with Cortés crossing the base of the Yucatán Peninsula to get to Honduras in I523. Díaz's comments attest to the use of cochineal in the Maya lowlands. Nopal probably had other uses: today it is widely used as a fence throughout the arid areas of South America (Flores-Flores and Tekelenburg 1995; Matallo et al. 2002) and various forms of cactus are used today in many parts of the Gulf Coast region as fences around houselots. If planted densely around a houselot's perimeter, nopals prickly paddles would provide an almost impenetrable fence. In parts of Chunchucmil, such as the southwest, where chichbes_-slightly raised linear stone surfaces usually 2-3 $\mathrm{m}$ wide (see chapter 2 ) - are common, they often encircle houselots, serving more as houselot boundaries than as alleys. If nopal were cultivated on top of these chichbes, this would make the chichbes' purpose as a boundary much more intelligible. Of course nopal's paddles and fruit are widely consumed today as food. Nopal grown as fences on chichbes could have also been used to harvest cochineal. Given that harvesting cochineal is difficult, having the nopal cacti right outside the house makes this labor more convenient, although, realistically, a few plants in a domestic compound would not yield a significant amount of cochineal dye unless combined across many households.

Thus, Chunchucmil is a good candidate for cochineal dye production. Conditions are excellent for nopal, the plant that hosts the cochineal insect, and nopal was desirable for other reasons as well. Since salt serves as an excellent mordant for dyes, the abundance of salt at Chunchucmil enhances the potential for cochineal dye to have been a significant component of the ancient economy. 


\section{Logwood/PALO de TiNTE Dye}

The heartwood of the palo de tinte tree (Haematoxylum campechianum), or Ek' in Maya (Barrera Marín, Barrera Vásquez, and López Franco 1976) and "logwood" (and sometimes "bloodwood") in English, contains a brilliant red dye called hematoxylin. The chemical composition of hematoxylin is almost identical to brazilin, the dye that comes from brazilwood (Haematoxylum brasiletto). Boiling chips of the heartwood in water produces orange/red crystals. A broad range of colors, including blue, purple, burgundy, and lavender, can be produced by oxidizing the crystals or adding mordants. Palo de tinte, which takes its species name from the Mexican state of Campeche, grows in seasonally inundated wetlands, along river banks, as well as islands, or petenes, in the broad estuaries that shroud most of the peninsular coast (Contreras Sánchez 199I).

There is good evidence that logwood dyes from the Gulf Coast were produced in prehispanic times (Contreras Sánchez 1991:27; cf. also Roys 1943:51; 1957:18). In the sixteenth century the Spanish used native labor to exploit logwood, exporting large cargoes of the valuable heartwood from the coast. Production along the Gulf Coast fell into English hands in the seventeenth century and English logwood cutters established camps in lagoons up and down the coast. The English also cut logwood in Cabo Catoche, Quintana Roo, and in Belize. Spaniards regained control of logwood production on the Gulf Coast in the eighteenth century. Production reached its peak in the nineteenth century, when the highly prized heartwood fetched about roo pounds sterling per ton in England (Contreras Sánchez 199I). When John Lloyd Stephens traveled from Palenque to Mérida in 1840 along the west coast of Yucatán, he reported a dozen ships in the port of Laguna de Términos waiting to be loaded with logwood destined for Europe and the United States (Stephens 1969:391). When Stephens later visited Siho, located I $8 \mathrm{~km}$ south of Chunchucmil, he noticed a high volume of logwood production (see also Roys 1957:18). At the end of the nineteenth century, the logwood industry declined due to the rise of synthetic dyes that were cheaper to produce.

To move the heartwood from the forests and petenes to the coast, producers used rivers whenever possible. On the northern Gulf Coast of Campeche and Yucatán, which lacks rivers, canals that extended for several kilometers were cut out of the mangrove estuaries and swamps in historic times (Millet Cámara 1984). One such canal was cut in from the coast directly west of Chunchucmil in the nineteenth century (see chapter 12, this volume; Hixson 2011:64). In the historic era, one local hacendado also processed the heartwood into dyes at the hacienda of Tankuche (Stephens i843:202), located is km south of Chunchucmil.

In sum, logwood dye stands as another perishable product that people from Chunchucmil produced and exported. As noted in chapter 6, Chunchucmil is 
situated about as close to the seasonally inundated savanna as was possible and this is the natural habitat for palo de tinte. Furthermore, production of palo de tinte boomed quite close to Chunchucmil for hundreds of years. Finally, as was the case with cochineal, Chunchucmil had all the salt it would ever need on hand to serve (or export) as mordants for the dye.

\section{Cordage Products}

The ancient Maya used reeds, grasses, vines, palm leaves, and other plant fibers for an astounding and often overlooked array of goods: hats, sandals, capes, garments, baskets, bins, mats, bags, twine, rope, fasteners, curtains, and more (Ardren, in press). The writings of Bishop Diego de Landa and other ethnohistoric documents, such as the Motul and Vienna dictionaries, confirm that craftspeople used plant fibers for a rich assortment of goods, or what Landa described as "an infinity of things," during the contact period (Landa 1978:102). Baskets, mats, rope, hats, and nets are all well represented in the artistic corpus of the Classic period (Carrasco Vargas, Vásquez López, and Martin 2009; Clark and Houston 1998; Houston 2013; Mefford 1992; Taschek 1994). The central place of cordage products continues into the ethnographic present. Osborne (1965:197) comments that among the twentieth-century Maya, "baskets of all shapes and sizes are necessary to the daily life of Indian and ladino alike from the time he is laid in a basket cradle at birth until his death, when small baskets of food are laid beside him to provide nourishment on his long journey into the afterlife." Today Yucatán is home to expert plant-fiber artisans, who preserve local traditions of plant-fiber processing and use. Within the peninsula there is a rich and diverse tradition of plant-fiber technology—products from many different plant species are used in a wide variety of woven forms and purposes. Yucatecan artisans are famous for specialized products made of henequen and jipijapa, both of which require elaborate processing and expert weaving skills. The bejuco vine is used for a variety of forms, and there are at least seven varieties of palms whose leaves are used for different purposes, including basketry, rope, and of course thatch (Rodríguez Lazcano and Torres Quintero 1992:13).

Plant materials for these goods were available to some degree all over the Maya area. However, the savanna to the west of Chunchucmil and the petenes of higher ground, freshwater, and tall forests, also to the west, provided and continue to provide cordage material in abundance today. The area to the west of Chunchucmil would have been a special resource for Chunchucmil precisely because its inhospitability to farmers helped preserve it as a natural warehouse for cordage material. Maya cities further inland lacked such a cornucopia of plant fiber. Obviously, Chunchucmil itself had a high demand for these goods, but we speculate that the 
people of Chunchucmil had more than they needed and could have exported it to inland population centers.

Stone tool use-wear analysis supports the point that certain households specialized in the processing of fibers. In particular, excavations in the Aak houselot ( $\mathrm{S}_{2} \mathrm{E}_{2}-\mathrm{F}$; see chapter I2) yielded more obsidian than any other context at the site and this high figure does not reflect excavation bias (Hutson et al., 2006). Since over 90 percent of the obsidian recovered from the Aak group consists of prismatic blade fragments, the occupants specialized (sensu Clark 1995), not in working obsidian, but in an activity that used obsidian blades as a tool. To help identify this activity, Hutson examined use wear through high-power magnification (Aoyama 1995; Keeley 1980; Lewenstein 1981, 1987; Semenov 1964) of the cutting edges of a systematic random sample of 66 blades from contexts throughout the site. Microscopic use-wear analyses presume that the materials with which a tool comes into contact and the way in which the tool moves among these materials leave diagnostic wear patterns on the tool itself. To determine how a tool was used (chopping, scraping, cutting, sawing, etc.) and what materials it was used on (bone, meat, wood, grasses, etc.), microscopically observed traces on archaeologically recovered stone tools must be compared with microscopic traces on experimentally used stone tools. In Mesoamerica, experimental archaeology conducted by Suzanne Lewenstein (1987) has produced diagnostic use-wear patterns of obsidian tools used in a variety of ways and on a variety of materials common in the Maya area. Wear patterns on blades at Chunchucmil were compared to those created experimentally by Lewenstein and others. The most obvious difference between the blades from the Aak group and those from other areas of the site is that 82 percent ( 14 of ${ }_{17}$ ) of the blades from the Aak group, as opposed to 22 percent (II of 49) of the blades from the rest of the site, had parallel striations that result from slicing coarse fibers. The coarse fiber in question is most likely agave, given that it grows very well in northwestern Yucatán. We (Dahlin et al. 2005) have suggested agave hearts as an important food at Chunchucmil, and it should also be noted that ancient Maya commoners may have worn clothing made from agave fiber (they may have also worn bark-fiber clothing McAnany 2010). Cotton is too soft to account for the wear patterns. A specific fiber-working activity that might account for the use wear on the obsidian blades is preparing plant fibers for basketry. Baskets would have been in high demand at Chunchucmil for transporting and shipping salt from the coastal salt flats.

\section{RoOFING THATCH}

Though palm leaves are excellent for making some of the cordage products discussed in the previous section, their use as roofing material deserves special note. 
Grasses can also be used to thatch roofs, but in the Chunchucmil region today traditional builders use palm leaves. Several palm species are used, including Sabal yapa Wright ex Beccari (guano, guano macho, xa'anjulok san), Thrinax radiata Loddiges ex Schultes \& Schultes f. (chit), Sabal mexicana Martius (guano, guano bon, xa'an, bon xaian), and Sabal mauritifformis (H. Karsten) Grisebach \& H. Wendland (botan, xa'an). Sabal palms are ubiquitous across the various microenvironments of the peninsula, but they grow best in the wet, rich soils and closed canopy of the savanna zones (Pulido and Caballero 2006). Thus, as with cordage products, Chunchucmil, unlike population centers further inland, was blessed with an abundance of palm in the savanna to the west (Ardren in press). The soft-wooded trunks of these palms are easy to cut and work and therefore are often used as construction materials after their leaf-producing capacities are exhausted.

Given that most ancient houses were made with perishable roofs, as opposed to stone vaults, the demand for palm fronds would have been quite significant. Using figures from modern domestic construction techniques in Yaxuná, Yucatán, which we will assume are relatively similar to thatching techniques of the past, conservatively 4,000 guanos or palm leaves would be required to thatch an $18-\mathrm{m}^{2}$ domestic structure. This type of roof will be under constant maintenance and repair with the entire set of fronds or guano replaced after approximately io years. Thus, a site with a few hundred houses will need about a million palm fronds every decade. Studies of Sabalmexicana and Sabal yapa in Yucatán have shown that these palms produce only about 6-12 leaves per year when managed in a sustainable manner according to traditional Maya forest-management techniques used across the peninsula (Martínez-Ballesté et al. 2008:1322). These techniques are aggressive, and harvest all but a single frond once a year, in part because these palm species regenerate faster when harvested at this rate compared to a less-aggressive harvesting regime or when not harvested at all (Martínez-Ballesté et al. 2008:1323). However this still results in the need for a staggering amount of palms in the forests of the peninsula to accommodate this particular usage of palm fronds.

As almost certainly in the past, few houselot gardens are without several guano trees whose palm fronds can be used to make repairs to roofs, but wholly new roofs require far more than a typical garden can provide; these materials must be brought in from outside. The most likely source of bulk thatch is the savanna, which provides the overwhelming majority of the thatch used in the homes of Chunchucmil's current population. Today, people from the village of Chunchucmil have no trouble acquiring palm leaves. Further inland, however, the scarcity of palm has made palm fronds expensive enough to discourage the construction of houses with thatch roofs. We suggest that the ancient inhabitants of Chunchucmil could have provisioned inland populations with palm fronds for roofs. In historic and modern 
times, guano leaves have been widely used to make brooms (escobas). Whether or not this was the case in prehispanic times is not known.

\section{Other Forest Products}

While the following forest products were probably not exported from the Chunchucmil region, they bear mentioning, because there was no need to import them. The forests of northwest Yucatán have a large number of hardwood trees that have long been exploited for construction lumber, furniture manufacture, and carving canoes. These include mahogany, cedar, habin, bohóm, and zapote. The bark of a small tree, known as chukum, was used for tanning leather. Many trees and smaller plants have medicinal properties, and were widely used since prehispanic times. The region also has numerous native fruit-bearing trees and bushes, which were likely grown in many of the solares of Chunchucmil, including zapote, anona, mamey, guaya, saramuyo, pitaya, papaya, nance, and cocoyol. Finally, the forest and the coastal mangroves were a major source of charcoal and firewood for cooking.

\section{FAUNAL RESOURCES}

\section{Marine FAuna}

Several sixteenth-century towns in the vicinity of the ruins of Chunchucmil, such as Tzemé, Hunucmá, Tetíz, Chochola, and Oxcúm, paid tribute to the Spaniards in the form of fish (Roys 1957:30-33). This was also true of many other towns near the north and west coasts of Yucatán. It was also most likely true for the east coast as well, but we do not have tribute data for that region. Fisherfolk would salt or smoke the fish, so it would last several days after leaving the coast. The practice of coastal communities supplying the interior with fish was likely widespread in prehispanic times, and there is some archaeological evidence to support it. Very small amounts of edible marine fishbones have been reported from Dzibilchaltún, Mayapán, and Chichén Itzá, despite research methodologies that did not specifically aim to recover such fragile remains. The small quantities of fish bones found at sites in the interior may be the result of culturally specific butchery practices. Even today, fishermen clean and fillet fish while they are sailing back to port, removing the head so that only vertebrae would be present in the archaeological record of inland sites. Masson has argued that catfish (but not other species of fish) may have been preserved for export at the Terminal Classic site of Northern River Lagoon, in Belize (Masson 2004:II4). In a robust sample of marine fauna, catfish cranial remains were abundant while vertebrae were present in extremely low numbers. Given the evidence for salt production at Northern River Lagoon, Masson argues catfish were 
prepared for trade to inland sites via cleaning and salting (Masson 2004:II5). A similar differential of skeletal elements in the sample of fish remains from Isla Cerritos in Yucatán has been argued to indicate processing for inland trade (Carr 1989:8). Unfortunately the preservation of bone is so poor at Chunchucmil that very little faunal material was recovered and it is unlikely that small fish bones would survive in a midden context here.

Similar butchering practices continue today in Yucatán, where conch fishermen extract the shellfish from the shell, cut off the foot, and throw both foot and shell overboard. Similar preparation techniques are true as well for sea turtles, which are butchered on a nearby beach, and only the meat and some of the major bones are carted away. The remains of marine mammals, such as dolphins, tropical seals (Monachus tropicalis, now extinct), and manatees, have been reported from coastal sites, but not at communities in the interior (Götz 2012). While fish and turtle bones do commonly appear at coastal sites, transporting these resources to inland communities, even in dried or smoked form, was highly variable throughout the northern Maya lowlands and may have been an inefficient use of such resources. The end result is that fishing or hunting marine fauna leaves little trace in the archaeological record at inland sites. One further complication is the potential to consume vertebrae as part of stews made of dried fish, although such recipes are not known today within Yucatecan culinary traditions. Perhaps most telling is that stable isotope data show that diets of coastal populations during the Classic period were much more diverse than those of people who lived inland (Mansell et al. 2006). Artifacts made from marine fauna are found at sites across the Maya lowlands, such as jewelry made from a variety of species of shell, fish and shark vertebrae, and shark teeth. Stingray spines, used in bloodletting rituals, are also quite common. Since Chunchucmil was very close to the Gulf Coast, it was most likely a major supplier of marine products to communities in the interior of northwest Yucatán.

\section{Apiculture}

During the Postclassic and contact periods, northwest Yucatán was considered part of the Ah Canul province (still a common surname in Chunchucmil and nearby San Mateo). Records indicate that one of the major products for the Ah Canul province was honey (Roys 1957; Piña Chan 1978). The prehispanic bees native to Yucatán (Melipona beecheii) were stingless but produced a thin, slightly sweet honey and of course beeswax. This honey was used for medicinal purposes and in balche, the native fermented beverage. Maya beehives are often in hollow logs capped with removable stone disks at each end. At Cozumel these stone disks have been found in Postclassic archaeological contexts, and at Nakum in Early 
Classic contexts, but to date they have not been found in large numbers within urban Chunchucmil (Źrałka et al. 20I4). Today Maya beekeepers prefer to place their apiaries within the seasonal wetlands on small natural and artificial rises (including ancient house mounds), where the bees have access to fresh water and pollinating flowers for most, if not all of the year. This has obvious implications for the discovery of beehive artifacts.

These apiaries are almost all located within close proximity to natural drains or artificial wells piercing the thin laja (bedrock) that caps the underground aquifer, providing a steady source of water for the bees to drink. During dry spells, beekeepers will fill small basins (similar in shape and size to the basin-shaped metates of the Chunchucmil region) with enough water to last until the rains return. Some ancient metates have been reused for this purpose by contemporary Maya people. Ancient Chunchucmil's proximity to vast wetlands blooming with flowers and fresh water for most of the year would have provided the same ideal conditions that they do today for the villagers of Chunchucmil and San Mateo. It is reasonable to suspect that the ancient Maya of the Chunchucmil region had as great a bounty of honey extracted from their wetland apiaries as is recorded for their counterparts of more recent periods.

Early colonial Spaniards had more interest in beeswax than in honey. Tribute payments were made in beeswax from the western part of the Yucatán Peninsula, where the beeswax was yellow and considered of higher quality than the black beeswax from the eastern peninsula (Patch 2003). In addition to its use as a sealant and source of light, beeswax was in demand during the Postclassic period when lostwax metallurgy spread into Yucatán via Mayapán. Demand during the Early Classic period is less certain.

\section{Other Faunal Resources}

The coastal regions of northwest Yucatán have a large inventory of terrestrial mammals and rodents that have traditionally been hunted in recent and past times for their meat and skins. These include deer, wild pig, peccary, jaguar, puma, ocelot, margay, fox, coatimundi, raccoon, anteater, rabbit, paca, opossum, and smaller mammals and rodents. The coastal and near-coastal regions also have a vast number of species of birds, many of which have been traditionally hunted for their meat and feathers. The estuaries directly west along the coast from Chunchucmil are one of the largest annual mating and nesting habitats for the pink flamingo (Phoenicopterus ruber) and the fourth-most-important wintering ground for over 13 duck species. Reptiles from the region include crocodile, turtles, iguanas, and snakes. In sum, the people of Chunchucmil had ample sources of protein beyond marine fauna. 


\section{CONCLUSION}

The perishable goods presented in this chapter are diverse in many ways. Some goods, such as salt, achiote, and dyes have a higher value per unit of weight than other goods, such as cordage or roofing thatch. Bulkier goods were unlikely to have been traded very far. Some of the items that we believe the people of Chunchucmil produced for export were available elsewhere in Mesoamerica. However, when and where the quality of items coming from further away is best (or better), such non-local versions may be more highly valued and more marketable than those of inferior quality produced closer to the consumer. At the same time, there are gradients in availability. Looking at these gradients gives us some idea of the direction that goods produced at Chunchucmil may have traveled. For example, cordage and roofing thatch can be obtained quite broadly across the Maya lowlands yet they are more abundant in Gulf Coast wetlands. This suggests that rather than trading these goods along the coast, the people of Chunchucmil probably shipped them inland, though probably not more than $100 \mathrm{~km}$, given their bulkiness and the lack of beasts of burden. Since salt is available along the coast to the north and east, the people of Chunchucmil likely shipped large portions of salt along the coast to the south where it would have eventually gone inland to the large population centers of the southern lowlands.

We admit that the manufacture on a commercial scale of highly valued but archaeologically ephemeral products at Chunchucmil remains debatable. Although we feel that the argument for Chunchucmil's specialization and trade in salt is very strong, we admit that the argument for specialization and trade in other products, such as cotton, is less strong. However, the demand throughout Mesoamerica for some of the items discussed in this chapter seems salient in light of the fact that the Chunchucmil Economic Region afforded easy access to all the necessary ingredients and in light of the fact that many lines of evidence suggest that Chunchucmil was a specialized trade center. In the next chapter, we review these lines of evidence in detail. 



\section{Marketing within Chunchucmil}

Scott R. Hutson, Richard E. Terry, And Bruce H. Dahlin

In this chapter we use three approaches-distributional, contextual, and configurational (Hirth 1998) - for researching marketplaces at Chunchucmil. Other approaches, such as the spatial approach (Hirth 1998:454) and the regional production-distribution approach (Stark and Garraty 2010) focus on regions and will be presented in chapter I2. Few other archaeology projects at Maya centers can deploy each of these three approaches because the distributional approach requires systematic mapping of large areas beyond the site center and excavation of a large and representative sample of households (Hirth 2010:24I). Given preliminary indications that markets played a large role in Chunchucmil's economy (Dahlin and Ardren 2002), the Pakbeh Regional Economy Program (PREP) devoted a large amount of its resources precisely to such an excavation sample (see chapter 3 ), thus providing a rare opportunity for marketplace research.

Though this chapter gives strong support for the existence of an ancient marketplace at Chunchucmil, we agree with many researchers (Garraty 2009; Garraty and Stark 2010; Hirth and Pillsbury 2013b; Shaw and King 2015; Wilk 1998) that we need to go beyond simply identifying the presence or absence of marketplaces. In this chapter we also attempt to answer questions about the scale of the marketplace at Chunchucmil, the size of its service area, how often it occurred, and the degree to which it was regulated. 


\section{CONTEXTUAL APPROACH}

According to Hirth (1998:453), "the contextual approach infers the existence of marketplaces from the presence of cultural features believed to require the provisioning and distribution functions of the market to exist, for example, large cities and full-time craft specialists." From a contextual perspective, data presented in chapters 5 through to show how Chunchucmil is an excellent candidate for a market center. As we discuss in greater depth in chapter I2, it is located near a vigorous maritime trade route and had a port site-Canbalam (see also chapter 6) —on this route. We have demonstrated clearly that Chunchucmil was a very large city (chapter 5) located in an area that also had significant rural settlement (chapter 8). Large cities make a marketplace more likely because a vendor will have a better chance to succeed where there is a large-enough population to sustain a high demand for the vendor's products. Marketplaces can also flourish in smaller towns and borderlands (Pohl et al. 1997) but the largest ones with the greatest variety of goods are often found in larger settlements (Blanton 1996). Though economizing logic favors all large cities as marketplace locations, Chunchucmil's extraordinary demography made marketplace exchange unusually critical to its economy. A market was not just likely at Chunchucmil; we argue that Chunchucmil demanded marketplaces for supplying the city and the region with food (see Freidel and Shaw 2000:289 for a discussion of staple food commerce). The land in the Chunchucmil Economic Region (CER) could not have supplied both its urban and rural settlers with sufficient food for everyone. This is partly because the ancient city is located in the driest area of the Maya world (chapters 6 and 7, this volume; Luzzadder-Beach 2000) and the soils are thin and generally of poor quality (chapters 6 and 9). Agricultural resources of the Chunchucmil region were insufficient in the face of high population levels (chapter 9; Sweetwood et al. 2009). We argue that Chunchucmil traded with people $30-100 \mathrm{~km}$ to the east (see chapter 13 ) and with people further away in the Maya highlands and southern lowlands (see chapter I2).

The previous chapter made the case for the production and exchange of "invisible" goods within the CER. Though surplus production of materials such as cochineal, palo de tinte, cordage, and roofing thatch left no traces that we could discern in the archaeological record, our excavations within the city have revealed non-perishable evidence for the production/processing of textiles, shell adornments, lithics, and fibers.

\section{Textiles}

The recovery of spindle whorls, used to spin thread, indicates that people at Chunchucmil spun thread. Nevertheless, as noted in chapter Io, we found only 
five spindle whorls, each from a different architectural group. Spindle whorls were also relatively rare at other sites in northwest Yucatán where major excavations have taken place, such as Mayapán (Masson and Peraza Lope 2014:299) and Dzibilchaltún (Taschek 1994:215). Chapter ro contains additional discussion of the potential cotton industry at Chunchucmil but for present purposes we can safely conclude that we did not locate any architectural groups within the site that specialized in spinning or weaving.

\section{Marine Shell}

A total of 1,313 shell artifacts from 94 excavation operations at Chunchucmil were analyzed. An additional 337 shell artifacts have been tabulated from additional excavation operations but have not been analyzed. Approximately one hundred additional shell artifacts remain untallied from a handful of excavation operations. Marine shell is known to have been absent from 56 excavation operations at Chunchucmil.

Of the 1,313 analyzed shell artifacts, $80 \mathrm{I}$ were not taxonomically identifiable. This is because most of the shell artifacts consist of small fragments. The average length of the $\mathrm{I}, 313$ shell artifacts is $2.5 \mathrm{~cm}$ and the average mass is $2.7 \mathrm{~g}$. Table II.I lists the identified shell from Chunchucmil according to family, genus, or species. By far the most common genera are Strombus $(n=216)$ and Busycon $(n=77)$. The vast majority of the shell from Chunchucmil could be acquired from the west or north coast of the Yucatán Peninsula (E. W. Andrews 1969), both of which are relatively close by. One hundred and seven shell ornaments, either complete or fragmentary, were recovered from excavations at Chunchucmil (see figure II.I). Most of these ornaments are beads/pendants or disks. In recent excavations at Mayapán (Masson and Peraza Lope 2014:32I-325), finished shell objects comprise I2.4 percent of the total shell artifacts $(326$ of 2,632) whereas at Chunchucmil, finished shell objects comprise 6.5 percent of the total tabulated shell artifacts (107 of 1,650). This relatively large proportion of shell debris suggests that people at Chunchucmil specialized in producing shell ornaments, which was also the case at Mayapán.

Table II.2 presents the amount of shell in those excavation contexts with the largest amounts of shell, measured in terms of shells per cubic meter of excavation and per kilogram of potsherds. Table II.2 also compares each context of excavation to the mean by using z-scores. For example, a z-score of $\mathrm{I}$ indicates one standard deviation above the mean, while a $z$-score of -0.2 indicates a fifth of a standard deviation below the mean. Masson and Peraza Lope (2014) considered any contexts at Mayapán with a z-score of I or above to be locations that produced surplus shell products. When applied to shells per cubic meter of excavation at Chunchucmil, 


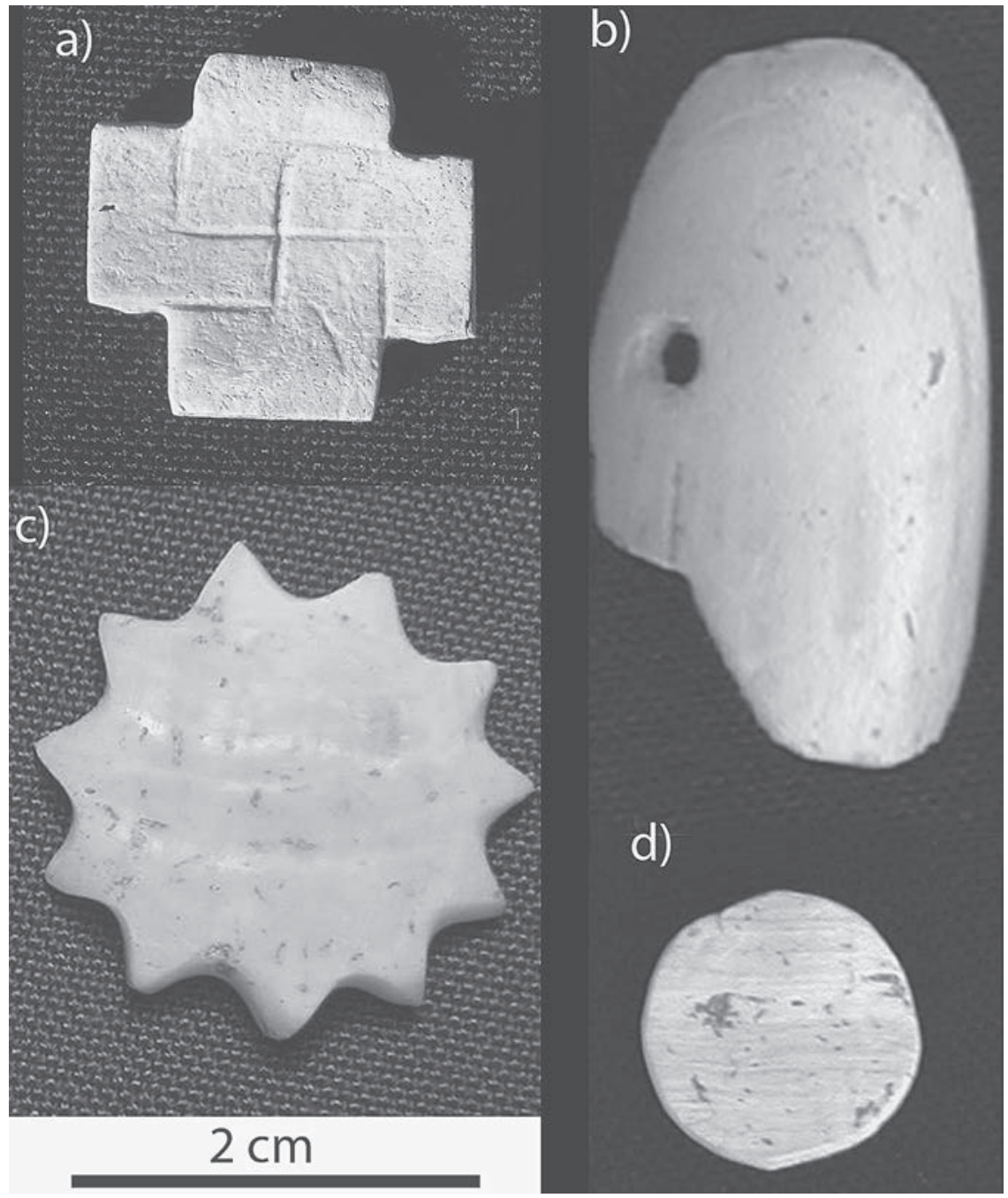

FIG URE II.I. Shell ornaments recovered from Chunchucmil: (a) Aak group, midden, Op. ${ }_{3} \mathrm{G}_{2.4}$; (b) Kaab' group, Str. S2EI-39, 9D4.I-3.2; (c) Aak group, Str. S2E2-23, Op. 9ci.III.2; (d) Kaab' group, Str. 38, Op. 9D9-4-3.I.

this criterion identifies five surplus production locales, as opposed to 17 at Mayapán. The high standard deviations seen in table ir.2 partially account for the lower number of qualifying contexts at Chunchucmil. For example, the mean number of shell artifact per cubic meter of excavation is 2.473 , while the standard deviation is 9.844. Another factor to keep in mind is the type of excavation. The vast majority of 
TABLE I I.I. Quantities of shell artifacts identified to taxa.

\begin{tabular}{|c|c|c|c|}
\hline Taxa & $\begin{array}{c}\text { Number of shell } \\
\text { artifacts }\end{array}$ & Taxa & $\begin{array}{c}\text { Number of shell } \\
\text { artifacts }\end{array}$ \\
\hline Strombus sp. & 216 & Trachycardium sp. & 4 \\
\hline Busycon sp. & 77 & Cardiidae & 3 \\
\hline Spondylus sp. & 29 & Chama sp. & 2 \\
\hline Dinocardium sp. & 23 & Dosinia sp. & 2 \\
\hline Oliva sp. & 19 & Isognomon alatus & 2 \\
\hline Melongena sp. & 17 & Ostrea frons & 2 \\
\hline Chionesp. & 13 & Prunum sp. & 2 \\
\hline Anadara sp. & II & Anomalocardia cuneimeris & I \\
\hline Codakia orbicularis & 10 & ARCIDAE & I \\
\hline Carditamera floridana & 8 & Brachydontes exustus & I \\
\hline Strombus or Busycon & 8 & Cenchritis muricatus & I \\
\hline Lunarca sp. & 7 & Cittarium pica & I \\
\hline Noetia sp. & 7 & Conus sp. & I \\
\hline Cerithium sp. & 6 & CyMATIDAE & 2 \\
\hline Fasciolaria tulipa & 6 & Echinolittorina zicazc & I \\
\hline Turbinella sp. & 6 & Ficus communis & I \\
\hline Arca sp. & 5 & Polinicis lacteus & I \\
\hline Mercenaria campechensis & 5 & Pteria colymbus & I \\
\hline Pleuroploca gigantea & 5 & Charonia variegata & I \\
\hline \multirow[t]{2}{*}{ Tellinidae } & 4 & UNIDENTIFIED & $80 \mathrm{I}$ \\
\hline & & Total & 1,313 \\
\hline
\end{tabular}

architectural groups excavated at Chunchucmil received only test pits, as opposed to horizontal excavations. Masson and Peraza Lope (2014) demonstrate that some architectural contexts showed no evidence of surplus shell production when excavated with test pits, but later horizontal excavations at the same contexts revealed strong evidence for surplus production.

Of the five contexts with $\mathrm{z}$-scores of $\mathrm{I}$ or higher for the number of shells per cubic meter of excavation (Ops. 60/S3 W 7 -D, 36/S2EI-L, 39/S2EI-I, I39/NW transect, and $37 / S_{2} E_{2}-J$ ), two also have $\mathrm{z}$-scores of $\mathrm{I}$ or higher for the number of shells per $\mathrm{kg}$ of potsherds- $S_{3} W_{7}-\mathrm{D}$ and $\mathrm{S}_{2} \mathrm{E}_{\mathrm{I}}-\mathrm{L}$. Only one other context-Op. $28 / \mathrm{N}_{\mathrm{I}} \mathrm{W}_{2}-\mathrm{C}-$ has a z-score above I for number of shells per kilogram of potsherds. We consider $\mathrm{S}_{3} \mathrm{~W}_{7}-\mathrm{D}$ and $\mathrm{S}_{2} \mathrm{E}_{\mathrm{I}} \mathrm{L} \mathrm{L}$ to be excellent examples of surplus production. Of II test pits 
TABLE I I.2. The Io excavation contexts at Chunchucmil with the most shells per cubic meter of excavation.

\begin{tabular}{|c|c|c|c|c|c|c|c|c|}
\hline $\begin{array}{c}\text { Operation } \\
\text { number }\end{array}$ & Map label & $\begin{array}{l}\text { Group } \\
\text { type\# }\end{array}$ & $\begin{array}{c}\text { Pottery } \\
(\mathrm{kg})\end{array}$ & $\begin{array}{l}\text { Shell } \\
\text { artifacts } \\
\text { (n) }\end{array}$ & $\begin{array}{l}\text { Shells } \\
\text { per m }\end{array}$ & $z$-score & $\begin{array}{c}\text { Shells } \\
\text { perkg of } \\
\text { pottery }\end{array}$ & $z$-score \\
\hline I 26 & $S_{I} W_{I}-F$ & 6 & 14.73 & I3 & 6.83 & 0.44 & 0.88 & -0.04 \\
\hline 35 & $\mathrm{~S}_{3} \mathrm{~W}_{4}-\mathrm{C}$ & 8 & 6.39 & 14 & 7.00 & 0.46 & 2.19 & 0.17 \\
\hline $8 \mathrm{I}$ & $\mathrm{N}_{2} \mathrm{~W}_{2}-\mathrm{A}$ & Io & 17.27 & I 2 & 7.50 & 0.51 & 0.70 & -0.07 \\
\hline I 34 & S8 W I-B & 8 & 18.65 & 52 & 9.01 & 0.66 & 2.79 & 0.27 \\
\hline 100 & $\mathrm{~N}_{I} W_{2}-\mathrm{A}$ & 6 & 74.21 & 28 & 10.28 & 0.79 & 0.38 & -0.12 \\
\hline 37 & $\mathrm{~S}_{2} \mathrm{E}_{2-\mathrm{J}}$ & 15 & 14.22 & 8 & 15.27 & 1.30 & 0.56 & -0.09 \\
\hline 139 & NW transect & I5 & 4.95 & I 2 & I 8.75 & 1.65 & 2.42 & $0.2 \mathrm{I}$ \\
\hline 39 & $S_{I} E_{I-I}$ & 8 & 8.29 & 25 & 38.94 & 3.70 & 3.02 & $0.3 \mathrm{I}$ \\
\hline 36 & $\mathrm{~S}_{2} \mathrm{E}_{\mathrm{I}-\mathrm{L}}$ & 9 & 1.05 & 36 & 58.25 & 5.67 & 34.19 & 5.40 \\
\hline \multirow[t]{3}{*}{60} & $\mathrm{~S}_{3} \mathrm{~W}_{7-\mathrm{D}}$ & 6 & 13.61 & $9 \mathrm{I} 2$ & 97.42 & 9.64 & 67.03 & 10.76 \\
\hline & & & & Mean & 2.47 & Mean & I.I 2 & \\
\hline & & & & St. Dev & 9.84 & St. Dev & 6.12 & \\
\hline
\end{tabular}

dug at $\mathrm{S}_{3} \mathrm{~W}_{7}-\mathrm{D}$ in 2004, pit $\mathrm{H}$, a I-X-I-m pit located southeast of the group's main patio, yielded dozens of shells and was expanded to a $10.5-\mathrm{m}^{2}$ exposure in 2005 in order to increase the sample of shells. A total of 912 shells came from the excavations at this group, comprising 55 percent of the 1,650 shells tabulated from the site as a whole. Shells from 14 different genera were identified, though there was only one example from 9 of these genera. The five genera with more than one specimen at $\mathrm{S}_{3} \mathrm{~W}_{7}$-D include Strombus $(n=178)$, Busycon $(n=38)$, Melongena $(n=12)$, Codakia $(n=6)$, and Turbinella $(n=5)$. It is interesting to note that no examples of Spondylus production debris came from Chunchucmil. Nearly all Spondylus-shell artifacts from Chunchucmil came from burials in group $S_{2} E_{2}-F / A a k$.

\section{LiTHICS}

The amount of obsidian recovered from Chunchucmil (2,716 artifacts, most of which are prismatic blades) is large compared to other Classic-period sites in the northern lowlands (Hutson et al. 2010). Yet we recovered relatively few exhausted $\operatorname{cores}(n=15)$ and little debris from core reduction. Three architectural groups yielded more than one core: four from $\mathrm{S}_{2} \mathrm{E}_{\mathrm{I}}-\mathrm{G} / \mathrm{Kaab}$, two from $\mathrm{NIEI}_{\mathrm{I}} \mathrm{C} / \mathrm{Pich}$, and two from 
$\mathrm{S}_{2} \mathrm{E}_{2}-\mathrm{F} / \mathrm{Aak}$. Since these three groups happen to be the most heavily excavated at Chunchucmil, the presence of more than one core at these groups reflects sample bias as opposed to specialization in blademaking. Thus, we do not believe we have found any locations where people produced surplus blades to trade with other households.

A total of 624 artifacts of chert, chalcedony, and mixtures of chert with other substances (quartz, limestone, etc.) were recovered from Chunchucmil. The vast majority of these artifacts, which we henceforth refer to simply as chert, are unretouched debitage (Mazeau and Forde 2004). Only 48 chert artifacts were used as tools, including unifaces, bifaces, and used flakes. In contrast, just one of the three main archaeological projects that have taken place at Mayapán recovered I,497 bifacial and unifacial tools (Masson and Peraza Lope 2014:369). Chunchucmil's high ratio of obsidian blades to chert tools (approximately so to I) greatly exceeds ratios from other Classic-period sites and even exceeds the overall ratio from Postclassic Mayapán, where obsidian is extremely abundant (over 20,000 artifacts recovered) in both the site core (Escamilla Ojeda 2004) and beyond (Masson and Peraza Lope 2014).

Chert cobbles around Chunchucmil are scarce, small, and of very poor quality (Dahlin et al. 201I). Chert is much more abundant in the Puuc hills, which Landa referred to as a "ridge of flint" (Tozzer 1941:186). Chert quality is not great in the Puuc hills. Though some chert outcrops have large nodules, most nodules are relatively small ( $12 \mathrm{~cm}$ or less) and have calcitic impurities and voids that often result in production failures (Potter 1993). Workshops with chert densities as high as those from Colha, Belize (Shafer and Hester 1983), have been found at the Puuc site of Xkichmook, located $120 \mathrm{~km}$ to the southeast of Chunchucmil. Potter (1993) sees a strong possibility that Xkichmook supplied chert to Chichén Itzá and other northern plains sites. Though the Puuc hills contained important centers at the end of the Early Classic, such as Oxkintok and Chac II (Smyth 2006; Smyth and Ortegón Zapata 2006; Varela Torrecilla 1998), Chunchucmil's late Early Classic population dwarfed that of these other sites, suggesting that Chunchucmil could have gained access to Puuc chert by force if necessary. The fact that the people of Chunchucmil did not take much Puuc chert, located as little as $30 \mathrm{~km}$ away, suggests that they used other materials, such as semi-silicified limestone, to make axes and other larger bifacal and unifacial stone tools (Dahlin et al. 20II).

In contrast to the obsidian assemblage, which is dominated by prismatic blades, Chunchucmil's chert assemblage is quite diverse and bears witness to a great variety of manufacturing techniques and strategies (Mazeau and Forde 2004). Since chert artfiacts are distributed relatively evenly across the site and since the total number of chert artifacts is minuscule compared to sites where surplus production of chert tools has been documented (e.g., Shafer and Hester 1983), we conclude that we have not found any specialized chert tool manufacturing at Chunchucmil. 


\section{Fiber Processing}

Though we have not located any lithic workshops, Chunchucmil had a relatively large amount of prismatic blades compared to northern lowland sites (Hutson et al. 20IO) and there are several architectural groups with many more blades than their neighbors. For example, a fourth of the entire assemblage of obsidian comes from a single residential group- $\mathrm{S}_{2} \mathrm{E}_{2}-\mathrm{G} / \mathrm{Aak}$ - which is one of six architectural contexts where the number of obsidian artifacts per kilogram of pottery is at least one standard deviation above the mean. (The other groups are, from most obsidian to least, S5W6-G/Op. 116, S7W6-B/Op. 104, N3 W2-P/Op. 63, NiW5-F/Op. 93, and $\mathrm{N}_{3} /$ $\mathrm{W}_{2}-\mathrm{K} / \mathrm{Op}$. 64.) These groups probably used prismatic blades to produce a surplus of some other product. To determine what these blades might have been used for, Hutson undertook a microscopic use-wear analysis of blades from $S_{2} E_{2}-G$ and blades from an assortment of architectural groups with much less obsidian and found that most blades in the sample analyzed from $\mathrm{S}_{2} \mathrm{E}_{2}-\mathrm{G}$ had wear patterns suggesting the slicing of coarse fibers (Hutson et al. 2007). This wear pattern was far less common in the architectural groups that did not appear to produce surplus goods with obsidian blades (see chapter io). Agave is an excellent candidate for the coarse fiber in question given that it grows very well in northwestern Yucatán. As discussed in the previous chapter, agave hearts may have been an important food at Chunchucmil, and people may have worn clothes made of agave fibers. Reeds used to make baskets are also good candidates for the coarse fiber that was processed at $\mathrm{S}_{2} \mathrm{E}_{2}-\mathrm{G}$.

In summary, of the two features that, according to Hirth, require the provisioning and distribution functions of a market, the evidence for Chunchucmil's status as a large city is indisputable but the evidence for craft specialists is not nearly as strong. Though we lack compelling evidence for full-time specialization, the existence of marine-shell adornment makers and fiber workers, combined with the probable specializations in perishable goods discussed in the previous chapter, suggest the existence of occupational heterogeneity and a complex economy.

\section{CONFIGURATIONAL APPROACH}

Following the configurational approach, we attempt to locate actual marketplaces based on (I) the spatial configuration of marketplaces and other features found within them, (2) the kind of access features that facilitate marketplace exchange, and (3) chemical residues from perishable materials deposited at marketplaces (see also Shaw 2012). In this section we use all three lines of evidence to make the case that Chunchucmil had a single major marketplace located in what we call Area D (see figure II.2). The site may also have had smaller marketplaces that we have not been able to detect. 


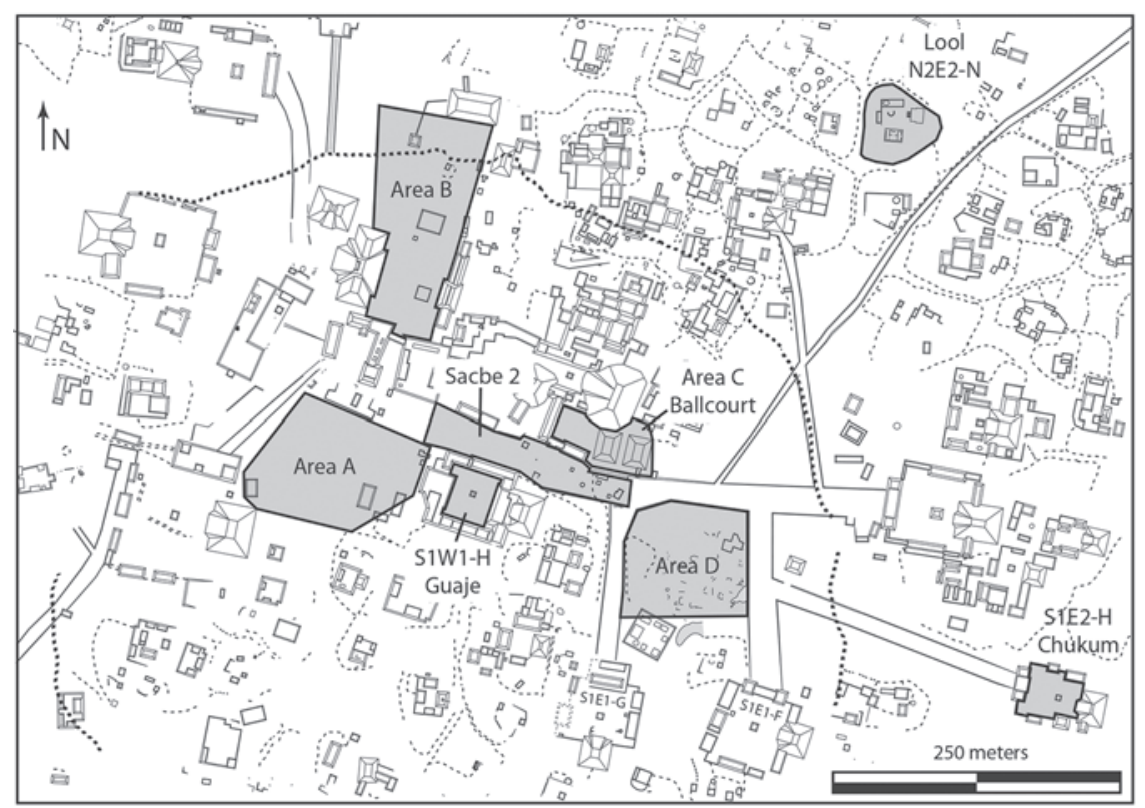

FIGURE II.2. Map of the Chunchucmil site center showing some of the locations of areas (shaded) tested geochemically.

\section{Spatial Configuration and Other Marketplace Features}

Marketplaces can vary tremendously in terms of size, shape, and other features. At the time of European contact, the Yucatec Maya used the same word (k'iwik) for "plaza" and "marketplace" (Barrera Vásquez 1980). Thus, Mayanists tend to identify formal plazas or broad open spaces as candidates for marketplaces. To our knowledge, all spaces in the Maya area for which promising evidence of marketplace activity has recently been presented - for example, Plaza V at Trinidad de Nosotros (Terry et al. 2015), Plaza A of Group D at Cobá (Coronel et al. 2015), Plaza II of Motul de San José (Terry et al. 2015), the West plaza of Maax Na (Shaw and King 2015), the Chiik Nahb Acropolis at Calakmul (Martin 2012), the East Plaza at Tikal (Jones 2015), the north part of the East Plaza at Buenavista (Cap 2015), the Caracol Causeway termini (Chase and Chase 2014), the Lost Plaza at Xunantunich (Keller 2006), Plaza A of Ceibal (Bair 2010), and the square K open space at Mayapán (Masson and Peraza Lope 2014]) - cover at least 0.2 ha each. Nearly all of these spaces are naturally or artificially flat, not counting buildings located in them. Ceremonies of various sorts probably took place in marketplaces, but plazas onto which massive temples face are less likely to have hosted marketplaces and more likely to have been restricted to 
the performance of ceremonies and rituals (Dahlin et al. 2007:370; Shaw 2012:13I). Marketplaces can run on a daily basis, like the Tlatelolco marketplace in Late Aztec Central Mexico (Blanton 1996) or can run much less frequently in a place that is also used for other functions (e.g., Coronel et al. 2015). Both kinds of markets are common in Mesoamerica today (Dahlin et al. 2007, 2010). Marketplaces that do not run every day will probably not leave permanent architectural traces. In markets that take place day after day in the same location, administrators or vendors might build durable stalls. This would result in architectural features such as the arcadelike stone buildings in the East Plaza of Tikal (Jones 1996) or the rows of small buildings on the Chiik Nahb Acropolis at Calakmul (Carrasco Vargas, Vásquez López, and Martin 2009; Tokovinine and Beliaev 2013).

At Chunchucmil, three kinds of spaces may have hosted markets: formal plazas delimited on their sides by buildings, small open spaces in the residential core, and large open spaces at the site center. The patios in Chunchucmil's quadrangles are the only formal plazas that exceed 0.2 ha but they do not make good candidates for marketplaces because they have large temples and central altars (suggesting dedicated ritual spaces), they are not easily accessible (see below), and their chemical signatures do not accord well with marketplace expectations (see below).

In Chunchucmil's residential core there are about 20 small open spaces (Hutson 2016). These were not paved or artificially modified, and do not pertain to any architectural complexes. Though they usually cover less than 0.2 ha and are therefore smaller than any other marketplaces discussed recently in the Maya world, some markets in the contemporary Maya world today take up less than 0.2 ha. We did not excavate in any of these spaces but distributional data presented below suggest that trade in obsidian and ceramics took place at a single, central marketplace as opposed to multiple neighborhood marketplaces.

Large open spaces in the site center are visible in figure 5.I (Areas A, D, E, F) and figure II.2. Dahlin et al. (2007) showed that Area D had been artificially leveled (mostly by adding dirt and stone fill to low spots) at the beginning of the Classic period. Area D therefore differs from Areas A, B, E, and F, which have uneven surfaces, and is a stronger candidate for a marketplace. Like the East Plaza of Tikal or the Chiik Nahb Acropolis at Calakmul, Area D also had stone buildings. Absent at all other open spaces in the Chunchucmil site center, rows of barely visible rock alignments and rock concentrations that approximate the size of market stalls protrude from the Area $\mathrm{D}$ ground surface (figure II.3). Excavation of $382 \mathrm{~m}^{2}$ in Area D located 18 discrete rock piles or alignments, averaging $3-5 \mathrm{~m}$ per side. Given the size of these potential stalls and their dense packing, as many as 500 would have fit in Area D. Area D also contains within it a public well and reservoir, both of which would have been necessary amenities for public gatherings at a marketplace. 


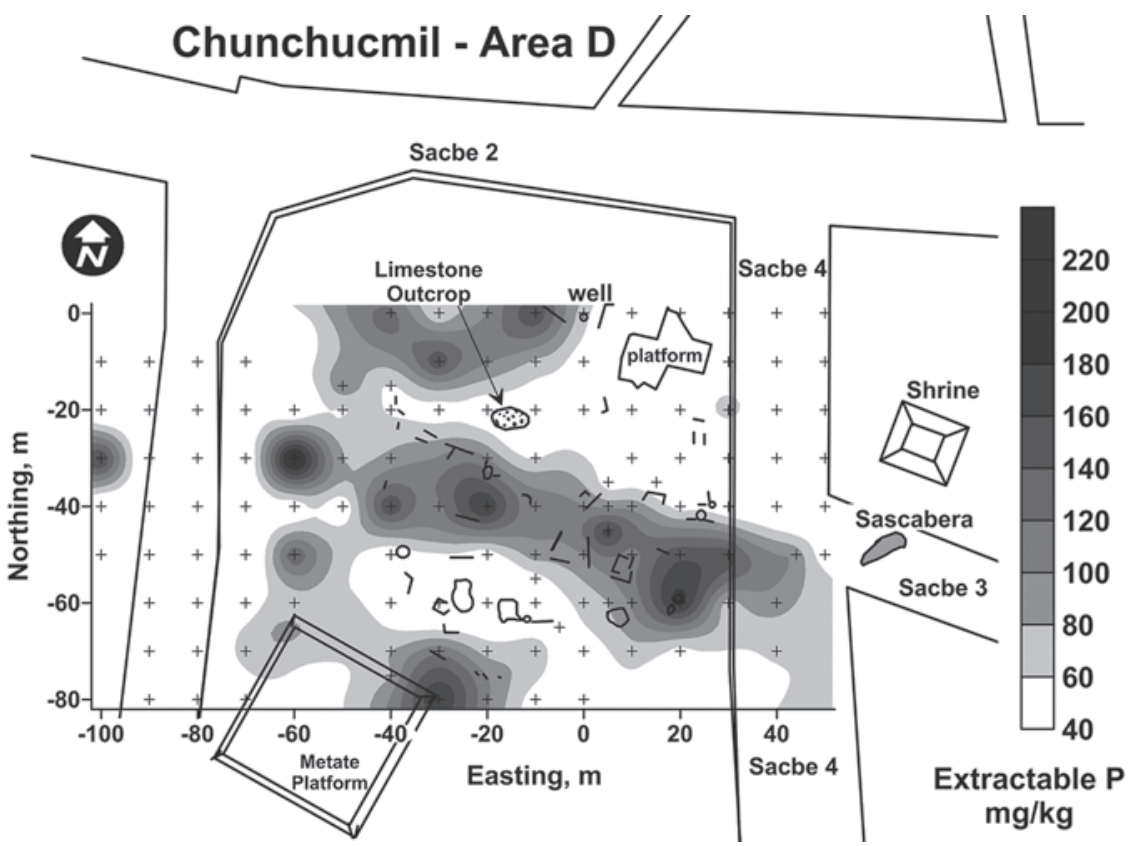

FIGURE II.3. Area D, the marketplace, showing sacbes, rock alignments, soil-sample locations, and the spatial distribution of phosphorus $(\mathrm{P})$ concentrations.

Should marketplace exchange leave an artifact signature? Items traded at contactera marketplaces in Yucatán include, but are not limited to, salt, fish, cloth and clothing, copal, wax, honey, flint, slaves, cacao, stone beads, and feathers (Tozzer 1941:94-97). Additional items sold at the Classic-period Chiik Nahb marketplace at Calakmul include pottery, corn, atole, tamales, needles, textiles, and tobacco (Martin 2012). With the exception of certain kinds of food, these items were brought to the marketplace not to be used and discarded on the spot but to be exchanged and taken elsewhere. Therefore, they should not enter the archaeological record at the marketplace itself. Several authors (Cap 2015; Hirth 2009b; Keller 2006; Shaw 2012:132-134) have suggested, however, that some final production steps of traded items took place at marketplaces and that these production steps would leave behind non-perishable debris such as lithic debris from end-stage reduction. Such debris, except perhaps microdebris trampled into floors (Hirth 2009b:93), would likely be swept away (Dahlin et al. 2010:368), perhaps to the edge of the plaza. If the plaza were used for other purposes on other days, debris with hindrance potential would certainly be removed after market day. Keller (2006:613-616) considers accumulations of chert and obsidian debris at the edge of the Lost Plaza, a possible 
marketplace at Xunantunich, as the residue of lithic production in a market setting. Although it is possible that lithic debris might be found in limited spots within or at the edge of a marketplace, we do not see the presence of this debris as a necessary aspect of marketplaces, since production in household contexts is the norm in the Maya area. For reasons discussed in the previous section (see also Dahlin et al. 2011), lithic production debris is rare at Chunchucmil. Not surprisingly, excavations in Area $\mathrm{D}$ at Chunchucmil did not recover lithic macro- or microdebris. Other kinds of debris, inferred indirectly from chemical residues, were abundant and patterned in ways that we would expect of a marketplace (Dahlin et al. 2007), as we discuss below.

\section{Marketplace Accessibility}

People should be able to get to marketplaces easily. At least three features enhance marketplace accessibility: (I) central location; (2) connections to transportation arteries that easily link the major areas of the city and the hinterland (Hirth 1998:453); and (3) multiple entrances. The best candidate for a marketplace at Chunchucmil-Area D (figure II.2) - meets each of these expectations. Area D is located in the middle of the site center. Most other potential marketplaces in the Maya area are also centrally located, though Caracol may have had a series of marketplaces three or more kilometers from the site core, located at the termini of causeways radiating from the site center (Chase and Chase 2014).

Regarding transportation arteries, Chunchucmil's site center exhibits precisely the kind of access features predicted by the configurational approach. Major callejuela pathways extend from the site center to the edges of the site, like spokes of a wheel emanating from the axle (Hutson 2016). At the site center, some of these pathways feed into open spaces while others feed into the system of sacbes that links all the important architectural complexes (figure 2.5). Area D is bounded by three sacbes (2, 4 , and 5 ) and is fed by two others ( $\mathrm{I}$ and 3 ; figure II.2), making it extremely accessible.

Regarding entrances, Area D appears to be unrestricted. Though it is possible that there were perishable barriers in the past, there are no observable thresholds. Whereas entrance into other centrally located formal plazas, such as those of the $S_{I} E_{I}-G$ and $S_{I} E_{I}-F$ quadrangles, each within $100 \mathrm{~m}$ of Area D (figure II.2), requires passing through one of the buildings that line each of these plazas' sides, one can get into Area D simply by stepping off the sacbe. Makeshift stalls might have even overflowed onto the sacbes, as Chase and Chase (2014:242) report for the Ramonal marketplace at Caracol. Thus, looking at spatial criteria alone, Area $\mathrm{D}$ is easily the best candidate for a marketplace at the site. Some have noted that entrances should be limited so that administrators can control access or even charge an entrance fee (Shaw 2012:128). The apparent lack of any bottlenecks into 
Area D suggests that administrators wanted to encourage as many people to come to the market as possible.

\section{SOIL CHEMistry}

Geochemical analyses of archaeological soils and floors from a broad variety of contexts (kitchen gardens, residential structures, temples, plazas, etc.) have helped in prospection for ancient features such as middens and have provided evidence of ancient human activities that included disposal of waste, sweeping of debris, food preparation and consumption, mineral crafting, rituals, and market exchange (Anderson et al. 2012; Craddock et al. 1985; Dahlin et al. 2007, 2010; Hayes 2013; Hutson and Terry 2006; Luzzadder-Beach et al. 2011; Oonk et al. 2009; Parnell et al. 2001; Parnell, Terry, and Nelson 2002; Parnell, Terry, and Sheets 2002; Terry et al. 2000). Geochemical analyses figure prominently in our attempts to locate marketplaces. Plaza soils and floors absorb and retain phosphorus (P) and certain trace elements in the floor matrix. As foodstuffs were processed, consumed, and disposed, the phosphate and trace element constituents released from the organic matter became fixed in the particle matrix of the soil or floor (Barba 1986; Barba and Ortíz 1992; Middleton 1998; Middleton and Price 1996; Parnell et al. 2001; Terry et al. 2000). Metallic residues from the crafting of stone and mineral pigments for painting were also fixed on soil particles (Holliday and Gartner 2007; Parnell, Terry, and Nelson 2002; Parnell, Terry, and Sheets 2002; Wells et al. 2000). Geostatistical analysis of the patterns of soil chemical residues in public plazas and open spaces within several ancient Maya cities has helped to identify chemical concentration patterns associated with marketplace and other economic exchange activities (Dahlin et al. 2007, 2010). The public and household spaces at Chunchucmil have been the focus of a number of geochemical analysis studies of ancient Maya activities (Bair and Terry 2012; Dahlin et al. 2007, 2010; Hutson et al. 2009; Hutson and Terry 2006). In this section we review previously published geochemical analyses and new, unpublished geochemical data from a number of plazas and large open spaces in the Chunchucmil site center, including Area D.

Dahlin et al. (2010) summarized the soil geochemical analysis of gridded soil and floor samples from seven locations at the Chunchucmil site center. These loca-

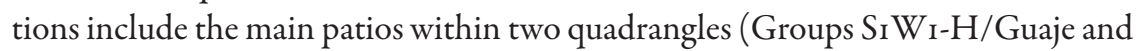
$\mathrm{S}_{\mathrm{IE}}$-C/Chukum; see chapter 3 for a definition of quadrangles), a patio associated with Chunchucmil's ballcourt (Area C), the surface of Sacbe 2, Area D, and two open areas neither neatly bounded nor affiliated with a particular architectural group (Areas A and B; figure ir.2). The surface areas, configurations, and extractable P concentrations of these spaces are listed in table ir.3. Given the presence of 
TABLE I I.3. Extractable phosphorus (P) data and characteristics of a variety of public plazas, sacbeob, and household spaces at Chunchucmil, Yucatán.

\begin{tabular}{|c|c|c|c|c|c|c|}
\hline \multirow[b]{2}{*}{ Location } & \multirow{2}{*}{$\begin{array}{r}\text { Area } \\
\text { (ba) }\end{array}$} & \multirow{2}{*}{$\begin{array}{c}\text { Small } \\
\text { structures }\end{array}$} & \multicolumn{3}{|c|}{ Mehlich P concentrations $(\mathrm{mg} / \mathrm{kg})$} & \multirow{2}{*}{$\begin{array}{c}\text { Patterning of high } \\
\text { Plevels }\end{array}$} \\
\hline & & & Minimum & Maximum & Average & \\
\hline Control soils & & & 4 & 6 & 5 & \\
\hline $\begin{array}{l}\text { Sacbe } 2 \\
\text { eastern end }\end{array}$ & 0.7 & yes & 7 & 96 & 22 & $\begin{array}{l}\text { Off edges and } \\
\text { behind structures }\end{array}$ \\
\hline $\begin{array}{l}\text { Sacbe } 2 \\
\text { western end }\end{array}$ & 0.04 & no & 7 & 58 & 16 & Off edges \\
\hline Area B & 2.6 & yes & 4 & 45 & 9 & Plaza edges \\
\hline $\begin{array}{l}\text { Area C \& } \\
\text { Ballcourt }\end{array}$ & 0.08 & no & 7 & 163 & 20 & One plaza corner \\
\hline $\begin{array}{l}\text { Area D } \\
\text { (marketplace) }\end{array}$ & 1.5 & yes & 8 & 272 & 57 & $\begin{array}{l}\text { Plaza center } \\
\text { parallel to sacbe }\end{array}$ \\
\hline Lool houselot & $0.4 \mathrm{I}$ & yes & 7 & I 5 I & 20 & Edge of patio \\
\hline $\begin{array}{l}\text { Guaje } \\
\text { quadrangle }\end{array}$ & 0.17 & no & 3 & 24 & II & Corner of patio \\
\hline $\begin{array}{l}\text { Chukum } \\
\text { quadrangle }\end{array}$ & 0.28 & no & 4 & 47 & 16 & Corner of patio \\
\hline
\end{tabular}

bedrock outcrops, thin soils, modern disturbance, and uneven terrain in Area A, we did not extract $P$ from soil samples taken in this area, deciding instead to focus our resources on the other areas. Most samples taken from the enclosed patios in the two quadrangles had $\mathrm{P}$ levels below $20 \mathrm{mg} / \mathrm{kg}$. The only notably high spot $(\mathrm{P}=47$ $\mathrm{mg} / \mathrm{kg}$ ) was found in the southwest corner of $\mathrm{S}_{\mathrm{I}} \mathrm{E}_{2}-\mathrm{C} / \mathrm{Chukum}$. Similar P concentration and distributions were found in Area $\mathrm{C}$, the ballcourt.

The highest $\mathrm{P}$ concentration $(\mathrm{P}=163 \mathrm{mg} / \mathrm{kg})$ in Area $\mathrm{C}$ was located between the ballcourt and the base of the largest pyramid at the site (Dahlin et al., 2010). With the exception of a test pit in the center of its alley, we have not excavated the ballcourt. Several thoroughly excavated ballcourts (Fox 1996; Hutson et al. 2015; Lohse et al. 2013) in other regions have yielded evidence of feasting, usually behind the ballcourt. High P concentrations are one of many lines of evidence for feasting residues, but such concentrations could also result from the dumping of organic matter not generated by feasts. The high P concentration at the Chunchucmil ballcourt comes from a single sample at the west edge of the northern end zone, a tight space of perhaps $5-$ by- $5 \mathrm{~m}$, bounded to the south, north, and west by pyramid edges. It is unlikely that this cramped and not particularly accessible space was part of 
a marketplace. The P concentrations along Sacbe 2 were generally highest off the edges of the sacbe and behind Terminal Classic houses built on the sacbe. This pattern suggested waste disposal over the edge of the sacbe and in middens behind houses. Phosphate concentrations in Area B were very low (avg $8.7 \mathrm{mg} / \mathrm{kg}$ ) and the highest concentration was at the edge of a structure.

Given the mapping and excavation data presented earlier for Area D, it may come as no surprise that geochemical analysis strongly suggests that Area D was a marketplace. The concentration isopleths of Mehlich extractable $P$ and chelate (DTPA) extractable trace metals in the plaza floor were reported by Dahlin et al. (2007). The maximum concentrations of $P$ were in the central portion of the Plaza (figure II.3). The most notable pattern of soil P in the suspected marketplace plaza consisted of highly elevated levels of extractable P (100-272 mg/kg) in a band running through the central portion of the built-up plaza (figure Ir.3). This band of elevated $\mathrm{P}$ is parallel to both Sacbe 3 to the east, and with rows of small rock alignments and low rock piles found protruding above ground surface. Excavations showed the rock alignments were not part of retaining walls holding plaza fill. Instead, they were placed directly onto the plaza's floor and served as foundations for small ephemeral structures (Dahlin et al. 2010). A band of extraordinarily elevated phosphates aligned with rock features that resemble market stalls matches very well with marketplace signatures recorded from an ethnoarchaeological study of a twentieth-century open-air marketplace with dirt floors in Antigua, Guatemala (Dahlin et al. 2007). More specifically, areas of food preparation and service had the highest reading of $\mathrm{P}$ within the Antigua market. We conclude that the band of elevated phosphates visible in figure 11.3 pinpoints the ancient foodmarketing and food-service area.

The trace elements contained in foodstuffs include $\mathrm{Fe}, \mathrm{Cu}, \mathrm{Mn}$, and $\mathrm{Zn}$. It is likely that food materials were the major sources of $\mathrm{P}$ and $\mathrm{Zn}$ enrichment in activity areas associated with food but mineral ores and pigments marketed and used by the Maya also contained $\mathrm{Fe}, \mathrm{Cu}$, and $\mathrm{Mn}$. These mineral-based materials were likely used and traded at locations separate from the foodstuffs. Phosphorus and trace elements have limited solubility in the soil and their geospatial distributions provide useful information on ancient human activities related to marketing of food and mineral substances. The concentrations of DTPA extractable Fe ranged from 6 to $103 \mathrm{mg} / \mathrm{kg}$ with a level of $98 \mathrm{mg} / \mathrm{kg}$ adjacent to the small rock outcrop in the north central portion of the plaza. The average concentrations of Fe $(27 \mathrm{mg} / \mathrm{kg})$ in samples from the marketplace plaza were 35 percent greater than the average values of the Lool houselot (N2E2-N/Op. 13) and Sacbe 2 (20 mg/kg). Average concentrations of DTPA extractable $\mathrm{Zn}$ in the soil of the marketplace $(3 \mathrm{mg} / \mathrm{kg})$ were 30 percent greater than those of Lool and Sacbe 2. 
The emerging technology of portable X-ray fluorescence ( $\mathrm{pXRF}$ ) analyses of total element concentrations is finding application in archaeological soils and floors (Coronel et al. 20I4; Davis et al. 20I2; Hayes 2013). Samples from the northern twothirds of Area D were retrieved from storage and subjected to pXRF analysis of total element concentrations (Coronel et al. 2014). Concentration isopleths of total $\mathrm{Zn}$ and total Fe of the northern portion of Area $\mathrm{D}$ are shown in figures II.4 and II.5, respectively. The concentration isopleths of pXRF total $\mathrm{Zn}$ shown in figure II.5 are similar to those of Mehlich extractable P (figure Ir.3). The highest levels of total $\mathrm{Zn}$ appeared in the center of the plaza aligned with Sacbe 3 and the rows of stones. The correlation coefficient of Mehlich $\mathrm{P}$ compared to total $\mathrm{Zn}$ was highly significant $(r$ $=0.60 \mathrm{I} ; p<0.0 \mathrm{I}$ ). The correlation matrix of the comparisons of selected extractable and total element concentrations in the floor of Area D is shown in table Ir.4. Dahlin et al. (2007) reported that the correlations between Mehlich P and DTPA extractable $\mathrm{Zn}$ were not significant $(r=0.069)$ in the samples from Area D but that there was a highly significant correlation between Mehlich P and DTPA $\mathrm{Zn}$ in the floor of the open-air marketplace at Antigua $(r=0.407 ; p<0.01)$. We have compared concentrations of Mehlich extractable $\mathrm{P}$ and both DTPA extractable $\mathrm{Zn}$ and $\mathrm{pXRF}$ total $\mathrm{Zn}$ in a number public plazas at ancient Maya sites. There were highly significant correlations between $\mathrm{P}$ and extractable or total $\mathrm{Zn}$ on the floors of proposed market plazas at Caracol (Horlacher 2013), Kiuic (Horlacher 2013), Mayapán (Terry et al. 2015), Cobá (Coronel et al. 2015), Motul de San José (Bair and Terry 2012), and Ceibal (Bair 2010). There were no significant positive correlations between $\mathrm{P}$ and extractable $\mathrm{Cu}, \mathrm{Mn}, \mathrm{Fe}$, or $\mathrm{Pb}$ at any of these plazas. However, at the central plaza of the contemporary village of Telchaquillo, Mehlich $\mathrm{P}$ was significantly correlated with DTPA extractable and pXRF total forms of Fe and $\mathrm{Zn}$. The patterns of high $\mathrm{P}, \mathrm{Zn}$, and Fe concentrations are found adjacent to a limestone outcrop that is the site of contemporary butchering and meat sale activities in the plaza (Coronel et al., 2014). It is interesting that a limestone outcrop appears in the Chunchucmil Area D surrounded with soils of high $\mathrm{P}, \mathrm{Fe}$, and $\mathrm{Zn}$ (figures II.3, II.4, and II.5, respectively).

In summary, the configurational lines of evidence for the argument that Area $\mathrm{D}$ was a marketplace amount to a slam dunk. Area D's location, its links to sacbes and pathways, and its lack of barriers make it the most central, accessible, and unrestricted place in the site center. This would be perfect for attracting as many buyers and sellers as possible. The area itself was made to be quite inviting as a market place, given its large size, its smooth, artificially leveled surface, and the availability of water. Mapping, excavation, and geochemical analyses revealed what appear to be market stalls aligned in rows with sharp and closely corresponding patterns of phosphate build-up resembling a modern market in Guatemala. Finally, our positive identification of Area $\mathrm{D}$ as a marketplace gets a boost from the fact that the same 


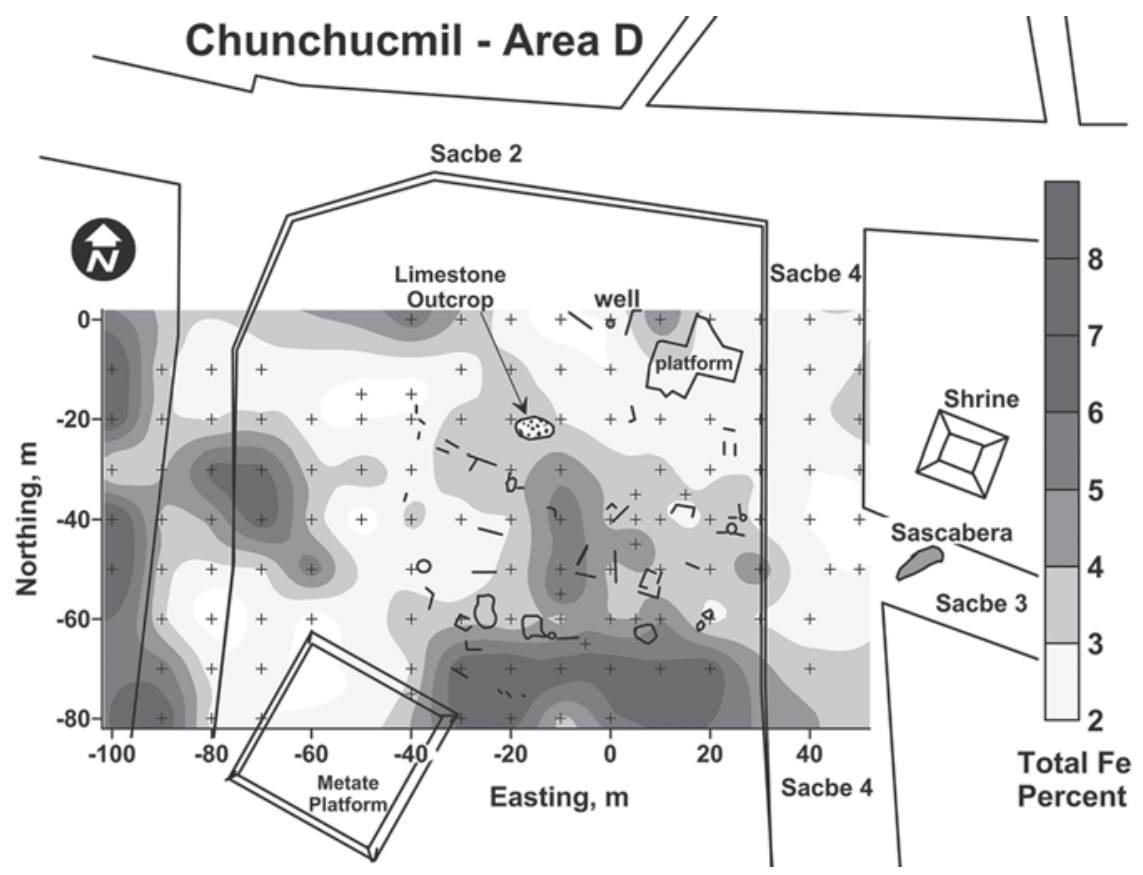

FIGURE II.4. Area D, the marketplace, showing sacbes, rock alignments, soil-sample locations, and the spatial distribution of iron $(\mathrm{Fe})$ concentrations

set of methods did not provide strong evidence for marketplaces in other potential locations of commerce in the site center. Stated differently, our result from Area D is not simply a case of "always finding what you're looking for." These other areas are not artificially raised, do not have evidence of stalls, and lack strong chemical signatures of a marketplace. Nevertheless, occasional buying and selling may have taken place beyond Area D, perhaps when the city celebrated major events, drawing additional crowds from far away.

\section{DISTRIBUTIONAL APPROACH}

Hirth's distributional approach to identifying a marketplace assumes that when a good is available at a marketplace, it should have a broad distribution across the site (Hirth 1998, 2010; see also Masson and Freidel 2012; Shaw 2012; Stark and Garraty 2010). As long as households have the means to purchase that good, archaeologists should find that differences in wealth and/or power among consumers do not skew the distribution of that good. This does not necessarily imply that marketed 


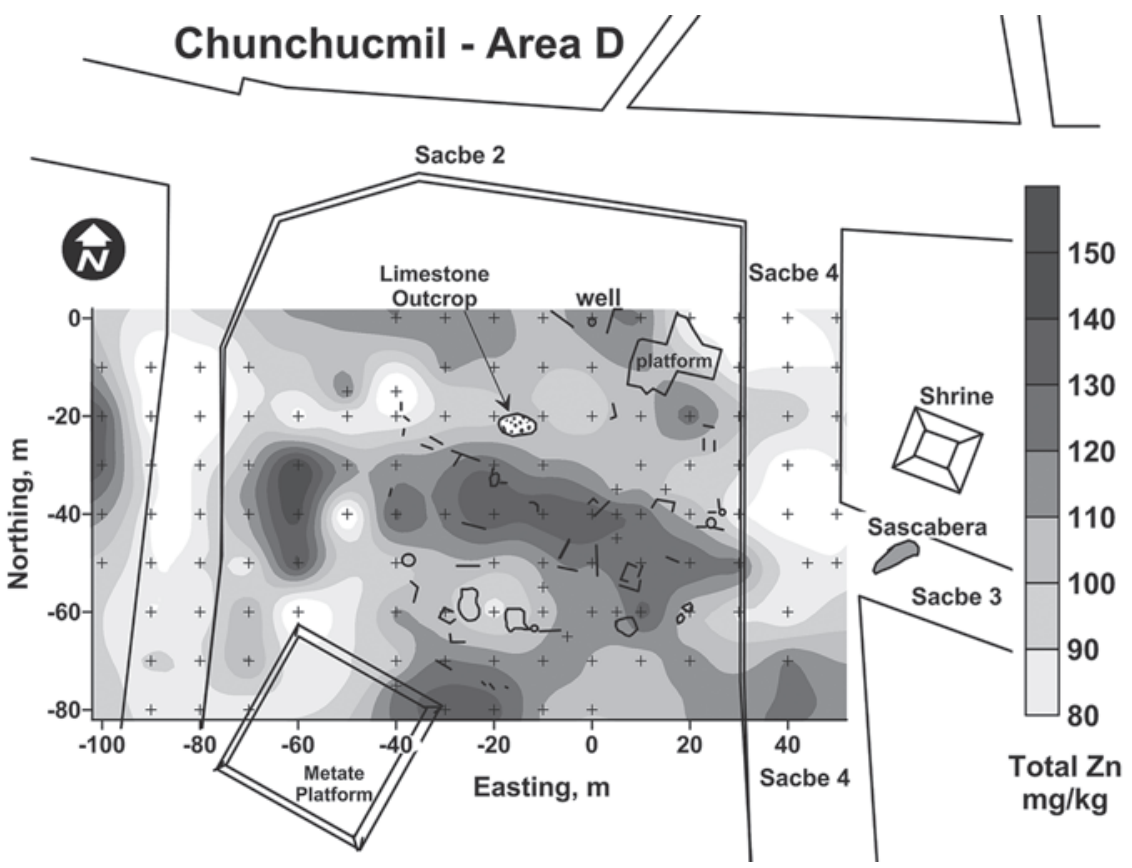

FIGURE II.5. Area D, the marketplace, showing sacbes, rock alignments, soil-sample locations, and the spatial distribution of zinc $(\mathrm{Zn})$ concentrations.

goods are distributed evenly across all households in the site or region. For example, households that need more of a particular tool for specialized production will have more of that tool. Thus, the distributional approach does not locate a marketplace directly, but infers it by showing that the distribution of goods at a site matches what we would expect if they were sold at a marketplace. Garraty (2009) has bolstered this approach in Mesoamerica by showing that the distribution of goods in an area known to have major marketplaces does indeed match what would be expected in Hirth's model. We await test cases showing that the distribution of goods in societies that definitely lack markets does not meet the expectations of the distributional approach (M. E. Smith 1999). Distributional approaches have been applied at other Maya sites (Braswell and Glascock 2002; Eppich and Freidel 2015; Halperin et al. 2009; Masson and Freidel 2012; Chase and Chase 2014), though in some cases the number of households sampled is small.

We use data on the distribution of obsidian and luxury pottery to explore whether these goods were distributed by market exchange at Chunchucmil and, if so, how far into Chunchucmil's hinterland this exchange reached. Obsidian entered the site 
TABLE I 1.4. Correlation matrix of the comparisons of selected extractable and total element concentrations. Significance of regression coefficient $(r)$ is denoted by ${ }^{*}=p<0.05$ or $\dagger=p<0.0 \mathrm{I}$

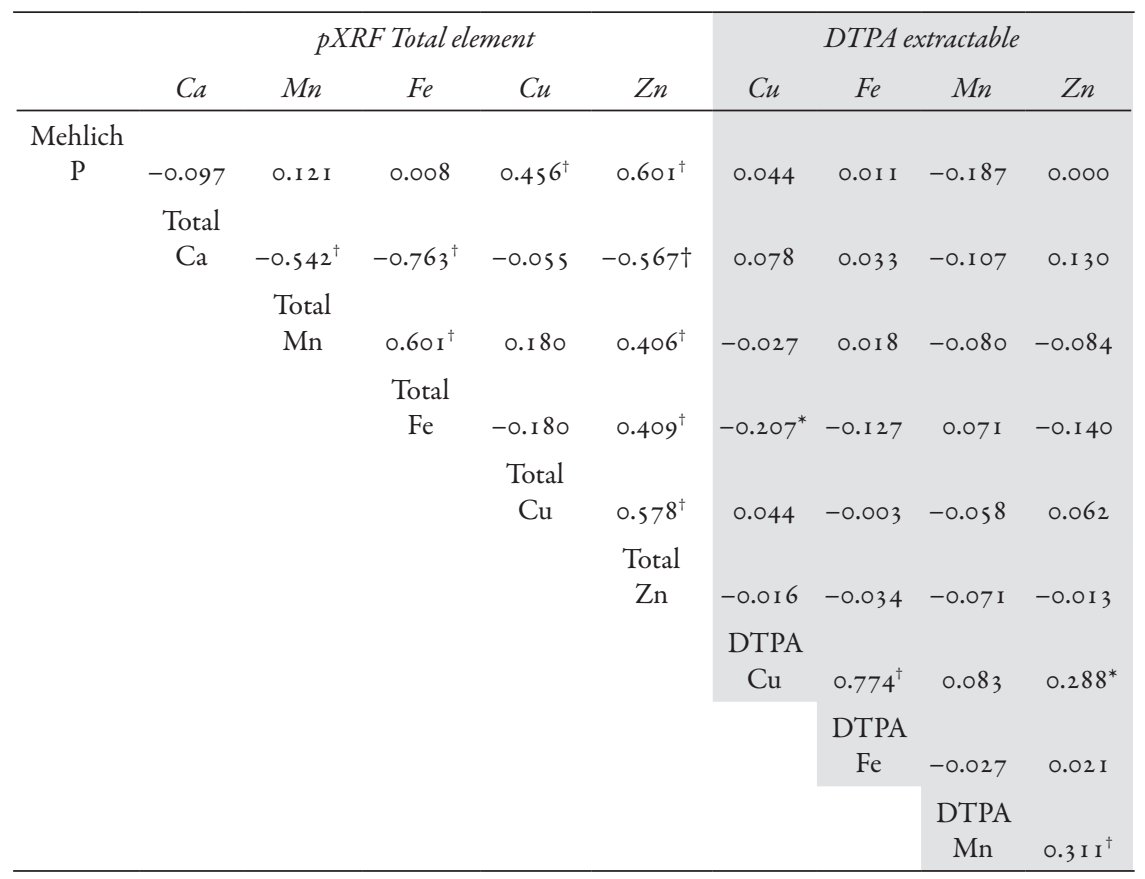

in the form of slightly reduced polyhedral cores. Since blade-production debris was found in a small number of household contexts (see above), some mechanism must have functioned to move blades from the few producers to the multiple consumers. Blades may also have been made at the marketplace. Luxury pottery from the Early Classic consists of polychromes-Timucuy and Tituc-or thin wares-Chencoh, Acu, and Kochol groups (Varela Torrecilla 1998). We found no pottery-production locales (no kilns, no waster sherds), so we do not know who made luxury pots. We presume that at least some of Chunchucmil's pottery was made on site, but we do not know where (see chapter 4). If producers or merchants sold blades and fancy pots at Chunchucmil's central marketplace, we would find these products spread relatively evenly across the site (Hirth 1998 ).

Hirth distinguished marketplace exchange from redistribution and reciprocity by analyzing access to obsidian and foreign and luxury ceramics at Xochicalco. $\mathrm{He}$ divided Xochicalco's excavated households into two categories, elite $(n=14)$ and ordinary $(n=60)$ and then used ANOVA to determine how evenly these artifacts were distributed between the two categories (for a distributional study that 
quantifies variability among domestic contexts using a statistical measure of diversity, see Garraty 2009). Hirth argued that in redistribution, elites control access to a good, keep a lot of that good for themselves, and then pass a smaller portion of it to households that have given them loyalty, labor, or surplus products. If obsidian or foreign ceramics are distributed evenly between the elite and non-elite households, the F-statistic for ANOVA will be low. If there is a high probability that there is a significant difference in access to these goods among elite versus ordinary households, the F-statistic will be higher. Hirth found low values for F in his samples. This meant that household wealth had no effect on exchange, thus suggesting that redistribution was not the main form of exchange for these goods. Hirth also noticed that houses across the site had access to obsidian from multiple workshops. This eliminates reciprocity since in reciprocity we would only expect houses to have obsidian from their nearest workshop. Reciprocity is not a particularly efficient form of exchange and goods distributed via reciprocity usually have a limited spatial distribution across a site (Hirth 1998).

When Hirth's paper came out, we expected that most obsidian at Chunchucmil circulated through redistribution. Obsidian was a low cost, utilitarian commodity at Terminal Classic Xochicalco (Hirth 1998:46I), and this was also the case in the northern Maya lowlands during the Terminal Classic at Chichén Itzá (Braswell and Glascock 2002) and the Postclassic at Mayapán, where "obsidian was not prohibitively expensive and could be obtained without restriction in the marketplace" (Masson and Peraza Lope 2014:349). Yet research in the Maya area has suggested that obsidian in the late Early Classic was a wealth good controlled by elites and not readily accessible to commoners (Aoyama 200ra, 200Ib; Stoltman 1978; Rice 1984). Aoyama infers this at Early Classic Copán from the distribution of production debris and the fact that elites had greater access to obsidian. Rice (1987:80) concludes that "as wealth, obsidian procurement and distribution may have been a narrowly guarded perquisite of high status, the stone being obtained for purposes of making offerings on ceremonial occasions." If obsidian were a ceremonially restricted wealth good at Early Classic Chunchucmil, we would expect to find very little of it beyond Chunchucmil's quadrangles and elite residences. Clark (2003:52-53) has challenged Aoyama's conclusion that elites redistributed obsidian (and gained power from it) at Early Classic Copán and suggests instead that marketplace exchange could explain the distribution of obsidian (see also Stark and Garraty 2010:5I).

Even if the obsidian was not controlled by elites In the Maya region during the Early Classic, obsidian could have been a high-cost good for reasons of both supply and demand. Regarding supply, nearly all of Chunchucmil's obsidian came from the El Chayal source, located far away $(670 \mathrm{~km}$ as the crow flies) in lands not controlled 
by Chunchucmil (see chapter I2 for more information on obsidian sourcing and trade routes). Thus, acquiring obsidian was a complex logistical undertaking and steady access to it in times of distant political upheaval could not be guaranteed. It may in fact be the case that Chunchucmil's seventh-century collapse was tied to the intensified warfare and rivalry between southern lowland polities at this time (see chapter 13). Regarding demand, obsidian's superior sharpness makes it highly desirable, especially in an area with poor chert resources. Let us presume that, despite its potential as a high-cost good, obsidian was not a narrowly guarded perquisite of high status, despite the suggestions of Rice (1987) and Aoyama (2001a, 2001b), and therefore could have been available for sale at a marketplace. Though available for purchase to all, obsidian might not have been distributed evenly across the site. Access to obsidian, as a high-cost good, may have varied with purchasing power. Thus, even with market distribution, the distribution of obsidian might have been skewed toward rich people. Thus, marketing and redistribution models introduce a problem of equifinality (Stark and Garraty 2010:5I). When households of different purchasing power seek an expensive good at a marketplace, households with greater wealth will end up with more obsidian. This dovetails with the expectation of a redistributive system since redistribution replicates status hierarchies (Masson 2002a:7-8).

Excavations across Chunchucmil provide the data to determine whether the distributions of obsidian and luxury pottery conform to patterns we would expect from marketing, redistribution, or reciprocity. As discussed in chapter 3, PREP project members placed excavations in 167 architectural contexts at the site. These contexts include $16 \mathrm{I}$ groups and a sacbe in the $9.3-\mathrm{km}^{2}$ polygon and five groups located on the transects. Though all of these groups received test pits, seven of the groups in the $9.3-\mathrm{km}^{2}$ map were excavated horizontally. These include groups $\mathrm{N}_{\mathrm{IEI}} \mathrm{I}-\mathrm{C} / \mathrm{Op}$. 9a (the Pich group), S2E2-F/Op. 9 c (the Aak group), S2EI-G/Op. 96 (the Kaab group), $\mathrm{S}_{2} \mathrm{E}_{3}-\mathrm{L} / \mathrm{Op}$. $9 \mathrm{~h}$ (the Chiwool group), $\mathrm{S}_{2} \mathrm{E}_{2}-\mathrm{C} / \mathrm{Op}$. 10 (the Muuch group), $\mathrm{N}_{2} \mathrm{E}_{2}-\mathrm{N} / \mathrm{Op} .{ }_{3} 3$ (the Lool group), and $\mathrm{S}_{1} \mathrm{E}-\mathrm{H} / \mathrm{Op} . \mathrm{I}_{5}$ (the marketplace). In addition, five groups (three of which were excavated horizontally) each received about Io० pits measuring $50-b y-50 \mathrm{~cm}$. Of these 167 excavated architectural contexts, I4I received excavations substantial enough to be included in the analysis. By substantial, we mean that at least six I-by-I-m test pits were dug, or in cases with fewer than six pits, excavations yielded large quantities of sherds (always over $4 \mathrm{~kg}$ ). This comprises a 9.5 percent sample of the approximately I, 477 architectural groups mapped at the site. Eleven of these I4I contexts were Late and Terminal Classic type 6 platforms (chapter 3, this volume; Magnoni 2008) and were therefore dropped from the current study to ensure contemporaneity of the contexts.

Following Hirth's example, we divided the remaining 130 contexts into categories that we thought would best represent different wealth levels. The highest wealth 
category included architectural groups with monumental pyramids (group types I and 2, as well as some examples from group types 4 and 5; see table 3.I). Twelve of the is groups in this category are quadrangles. Though the large temples in these groups suggest ritual activities serving larger sections of the population, excavations of the Pich quadrangle/ $\mathrm{NIEI}_{\mathrm{I}}-\mathrm{C}$ (see chapter 5), indicate that these groups were also residences. The other three categories of architectural contexts consist of residential groups with one or more houses often facing onto one or more patios. These groups are not purely residential, because they tend to contain gardens, work areas, and shrines for the veneration of ancestors. These three categories include small groups with five or fewer stone platforms $(n=64)$, medium-sized groups with six to io stone platforms $(n=38)$, and large groups with ir or more stone platforms $(n=$ I3). We initially thought that these three group sizes would correspond roughly to wealth levels because patio groups with more buildings tend to have more residents, implying greater wealth and greater control of labor and resources (Netting 1982). These three categories roughly correspond to group types 8 , 9, and io (see table 3.I), but they have been expanded in the following way: any group from types I2, I3, I4, I5, and 16 that has five or fewer structures was combined with groups from type 8 , any group from types I2, I3, I4, I5, and 16 that has between six and Io structures was combined with groups from type 9 , and any group from types I2, I3, I4, I5, and I6 that has II or more structures was combined with groups from type io (see chapter 3 for more information on types of groups). All but II of the groups in these three categories are encircled by low stone walls. As noted in chapter 2, we refer to such encircled groups as houselots.

Table II.5 shows the numerical data and statistics regarding quantities of obsidian and luxury pottery for each of the four architectural categories. Following Hirth, we used ANOVA to see if there were significant differences in the variance between the categories (see also Eppich and Freidel 2015). Table ir.5 quantifies obsidian in three ways and quantifies luxury pottery as a percentage of total pottery by mass. Although the differences between the three kinds of houselots are quantitative, the differences between the monumental groups and houselots are probably also qualitative. Therefore table II.5 presents F-statistics for just the three categories of houselots as well as F-statistics for houselots and monumental groups.

The results in table II.5 show that there is almost no difference in access to obsidian and luxury pottery among the three categories of houselots. These results resemble those produced by Masson and Freidel (2012) for Tikal. We look first at obsidian. We should note that our analysis of obsidian strays from Hirth's because we do not quantify obsidian source data per architectural group. We skipped this step because El Chayal obsidian dominated all contexts. Whether the quantities of obsidian are measured by count or mass, or as a proportion to kilogram of ceramics 


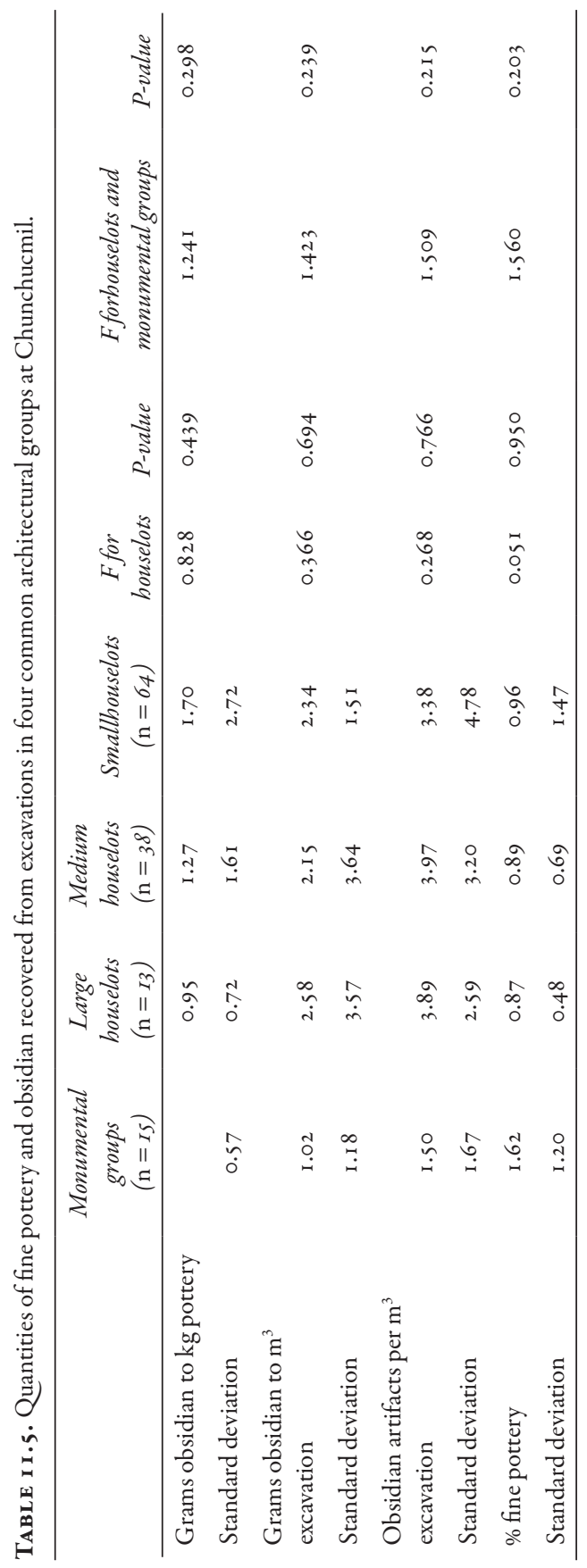


or cubic meter of excavation, the F-statistics are low and the high $p$-values show that the small differences among the categories are far from being statistically significant. Student's $t$-tests confirm that differences in the houselot means for obsidian are not significant. When monumental groups are included in the analysis, the $\mathrm{F}$ statistics climb, but they do not reach a level of statistical significance; $t$-tests show that monumental groups have significantly less obsidian than houselots. When obsidian is quantified as a ratio to ceramics, only the difference in means between monumental groups and small houselots is significant $(t=-2.77, p=0.002, \mathrm{df}=$ 77). When quantified the other two ways, which are admittedly not as informative, $t$-tests between monumental groups and each of the three houselot categories show statistically significant differences.

In summary, the data clearly suggest marketplace distribution of obsidian as opposed to reciprocity or redistribution. In the redistribution model, we would expect the most obsidian in the monumental groups, the second most in the large/ rich houselots, and less obsidian in the final two categories. This is decisively not the case: the poorest houselots have just as much obsidian, if not more, than other houselots. This suggests that obsidian was not a wealth good and that people had open access to obsidian at a marketplace. Though some houselots have more obsidian than others, these houselots are spread evenly across the site, as seen in figure II.6. This eliminates reciprocity as a mechanism for the distribution of obsidian since the inefficiencies of reciprocity predict a limited spatial distribution across the site. The lower quantities of obsidian in pyramid groups may be the product of a sampling error since we did not excavate special deposits in the largest groups. At Tikal and Quiriguá, special deposits contain the lion's share of obsidian (Moholy Nagy 1989; Sheets 1976). However, Moholy Nagy (1997) argues that obsidian in special deposits at Tikal does not necessarily mean that the obsidian was consumed in the architectural compound where the special deposit is located. Such obsidian could have been brought from other compounds at the site. Finally, quadrangles may have had less need for obsidian. In other words, the suite of domestic and workshop activities involving obsidian, such as processing of maguey fiber, woodworking, and so on that took place in other architectural contexts may not have occurred as often at monumental groups.

The data in table II.5 indicate that there is almost no difference in access to luxury ceramics among small houselots, medium houselots, and large houselots. The mean amounts of luxury pottery per group are very similar and the F-statistic is very low. Monumental groups, on the other hand, have more luxury pottery than houselots. The F-statistic is still not high enough to be significant, but $t$-tests between monumental groups and residential houselots have $p$-values of between 0.056 (monumental groups compared to small houselots) and $0.02 \mathrm{I}$ (monumental groups compared 


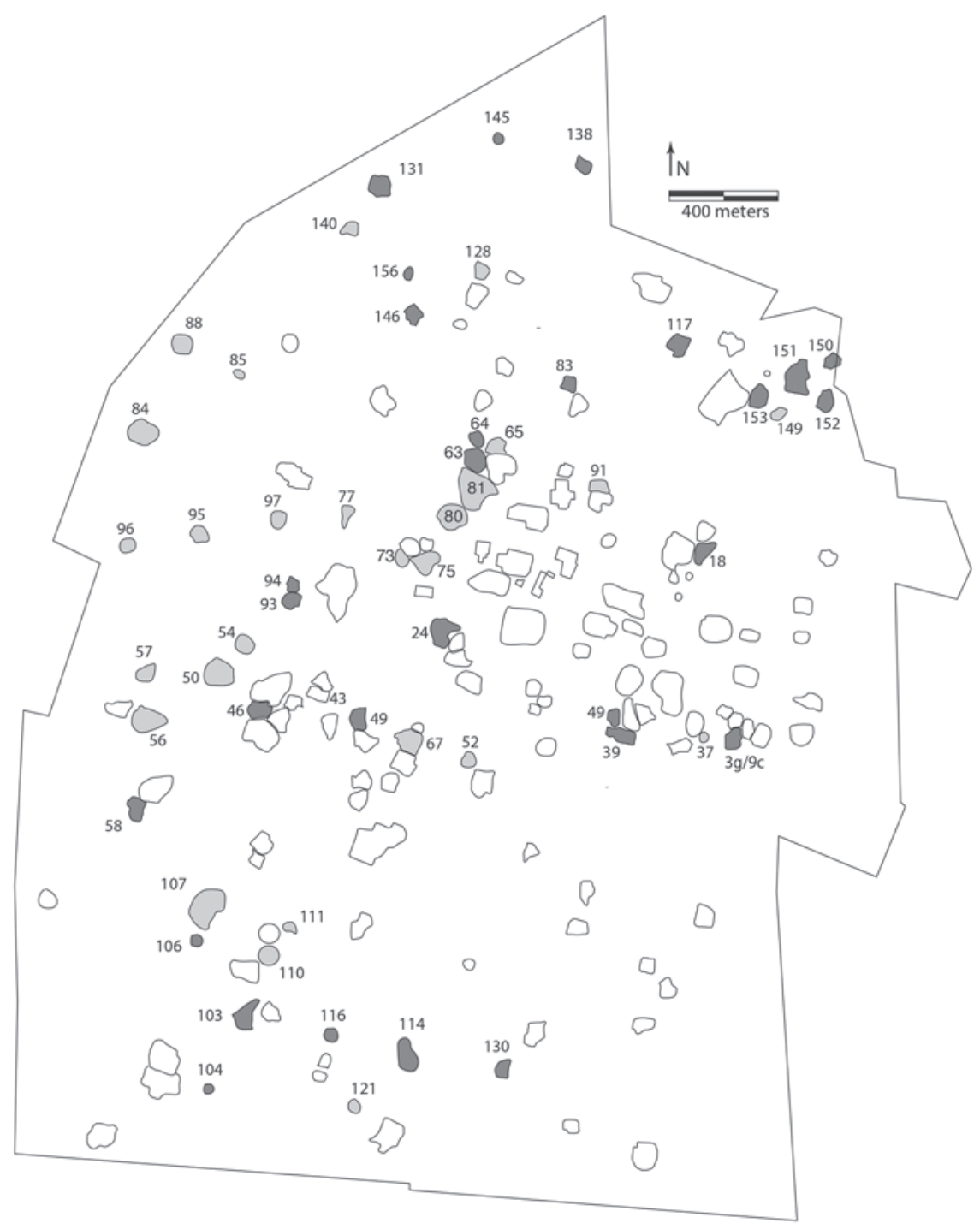

FIGURE II.6. Map of Chunchucmil showing the distribution of excavated architectural contexts with high quantities of obsidian (the top quartile, shaded darkly) and low quantities of obsidian (the bottom quartile, shaded lightly).

to large houselots). Such low $p$-values mean that the chances that the differences in access to luxury pottery between monumental groups and the three other kinds of groups are due to pure chance range between $\mathrm{I}$ in 20 and $\mathrm{I}$ in 50 . This leads us to 
conclude that these differences are real and not just an artifact of sampling error or some other specious process.

Thus, just like the obsidian data, the data on luxury pottery support marketplace distribution. Houselots of all three wealth grades had equal access to luxury pots. At the same time, monumental groups had greater access to luxury pottery. Though this would at first suggest redistribution, this slightly uneven distribution could still occur if luxury pottery were available at a marketplace. Here we run into the problem of equifinality as discussed above. A good that is available at a marketplace may not be distributed evenly if it is a high-cost item, because only wealthy consumers can afford to consume it frequently. Or, a good that is available at a marketplace may not be distributed evenly if certain types of consumers simply have greater demand for it. Both of these conditions might explain why there is more luxury pottery at the monumental groups: monumental groups were the wealthiest in terms of access to labor but they also may have had a greater demand for luxury pottery if they were hosting more celebrations or serving food to important guests.

In conclusion, distributional data support the presence of a marketplace. Nevertheless, there is substantial variation in access to obsidian within the four architectural categories examined. We see this variation in the large standard deviations seen in table II.5 and in the fact that in six of the 64 small houselots we recovered no obsidian, whereas one had over io times the mean. Thus, the relative equality between categories of houselots of different size masks inequality among houselots of the same size. This inequality of access might be explained by the fact that some households consumed more obsidian because they required it for specialized productive activities. Data from the Aak residential group ( $\mathrm{S}_{2} \mathrm{E}_{2}-\mathrm{F} / \mathrm{Op}$. 9c) confirm this. As discussed above, the members of that group specialized in processing cordage and/or fibers (Hutson et al. 2007).

\section{DISCUSSION}

Now that we have presented evidence for the existence of a marketplace at Chunchucmil, the next step is to ask about the nature of the marketplace and what that says about a market economy at Chunchucmil. In this discussion we focus on questions that address the scale, periodicity, organization, and scope of Chunchucmil's marketplace. Not all of these questions have clear answers. We continue to address some topics, such as the degree of government involvement in Chunchucmil's marketplace, in chapter 13 .

How many marketplaces were there at Chunchucmil? Though Chunchucmil does have open spaces throughout the site that could have been used as marketplaces, the results of the distributional approach show that obsidian and pottery styles 
were distributed evenly across the site. This suggests there was a single marketplace (Area D) that everyone at the site had access to. The alternative is that there were many marketplaces spread throughout the site. If this were the case, we might find spatially heterogeneous distributions of marketed items, such that certain kinds of pottery available at one particular market might be found at households near that market but not another market. This is precisely the case at Caracol (Chase and Chase 2004; 2014:245). Fittingly, Chase and Chase argue that there were multiple marketplaces at Caracol (see also Chase et al. 2015). This pattern is not found at Chunchucmil. Different pottery types in the type variety system (e.g., Hunabchen Red, Kanachen Black) are distributed evenly across the site (Hutson 2016).

What was the scale and periodicity of Chunchucmil's marketplace? The discovery of stone footings for what Dahlin believed were market stalls in Chunchucmil's marketplace leads to the conclusion that Area D, like Tikal's East Plaza or the Calakmul's Chiik Nahb Acropolis, was functionally committed to marketing, which could have taken place on a daily base. Area D covered I.5 ha, which places it at the large end of the size continuum of potential Maya marketplaces. The potentially daily periodicity of Chunchucmil's marketplace and its large size accord well with the large number of people that lived at Chunchucmil (see chapter 5) and the broader argument of this book: commerce was an important part of Chunchucmil's livelihood.

How heavily regulated was Chunchucmil's marketplace? Carol Smith (1976) described markets that were minimally regulated ("competitive" markets), markets in which authorities regulated the middle men but not the producers ("administered" markets), and markets in which authorities controlled production ("monopolistic" markets). This last form of marketplace pertains to colonial situations not relevant to Chunchucmil (see also Braswell 2010; Braswell and Glascock 2002). Smith also presented spatial expectations that correlate with market types. Administered markets are usually bounded spatially such that trade does not cross between polities and people have little choice of what marketplace they can attend (this is the "solar central place system"). Competitive markets feature "interlocking" marketplaces such that goods can be traded across political boundaries and consumers can choose to go to multiple different marketplaces.

Classifying marketing at Chunchucmil according to these two categories is difficult, but we offer some suggestions (see also chapter 13). Competitive interlocking market systems tend to feature many markets and goods that flow freely through them. The northern lowlands in the Postclassic period is generally thought to exemplify this type of system (Freidel and Sabloff 1984; Masson and Freidel 2012, 2013; Sabloff and Rathje 1975) and Braswell has suggested that the Terminal Classic period, where obsidian from the same broad variety of sources was available at both 
Uxmal and Chichén Itzá, also pertains to this category. This kind of source analysis does not work well for the northern lowlands in the Early Classic period since the El Chayal source dominates obsidian at all sites. Furthermore, generally low amounts of obsidian across the northern lowlands (not counting Chunchucmil) during this period would suggest anemic long-distance trade. Yet the flourishing port of Xcambo (Sierra Sosa 1999; Sierra Sosa et al. 2014) and the evidence of interaction with Central Mexico at Chunchucmil and other northern lowland sites (Varela Torrecilla and Braswell 2003; Smyth 2006; see chapter I2, this volume) suggest the possibility of a network of interaction as opposed to the clearly bounded interaction spheres typical of solar central place systems. Nevertheless, the distance from Chunchucmil to the next large marketplace would have been much further than the distance between marketplaces in an interlocking market system like that of the Basin of Mexico in the Postclassic period (Blanton 1996). Sheets (2000) has hinted at a competitive interlocking market system at the end of the Early Classic at Cerén, where villagers may have had a choice of which regional centers to attend for marketplace trade. At Copán, exotic green obsidian from the Pachuca source was found only in royal contexts, leading Braswell (2010) to argue that elites closely monitored access to obsidian. This was not the case at Chunchucmil, where 63 of the 2,320 obsidian artifacts visually sourced by Daniel E. Mazeau came from Pachuca. As table II.6 shows, Pachuca obsidian was found in a variety of architectural group types at Chunchucmil and only io percent of it comes from monumental contexts.

As we discuss in the next section, people living over $5 \mathrm{~km}$ away from Chunchucmil do not appear to have participated heavily in Chunchucmil's marketplace. This probably does not reflect administrators' desires to restrict trade beyond a certain boundary (cf. Aoyama 200Ia, 200Ib) and may instead reflect a lower degree of prosperity and purchasing power for the rural population (see chapter 13). We believe that powerful groups organized production and exchange at Chunchucmil (see chapter 13), but these groups may function more like trade corporations as distinguished from market administrators.

How large an area did Chunchucmil's marketplace service? A small body of data allows us to assess the geographical scope of Chunchucmil's central marketplace. Despite even distribution of obsidian within Chunchucmil, the frequency of obsidian drops in its hinterland. At a distance of $2.5-5 \mathrm{~km}$ from the site center, households had a third of the obsidian of those within $2.5 \mathrm{~km}$. Households beyond $5 \mathrm{~km}$ from the site center had one-twentieth of the obsidian of those within $2.5 \mathrm{~km}$ of the site center (Hutson et al. 2008). A decrease in access to blades in the hinterlands has also been documented near Yaxhá (Rice 1986), Copán (Aoyama 200rb), and Tikal (Moholy-Nagy's 1989; personal communication, March 2008). In the Middle Postclassic in the lower Río Blanco region of Veracruz, Mexico, Garraty 
TABLE I I.6. Excavation contexts at Chunchucmil where green obsidian was recovered.

\begin{tabular}{|c|c|c|c|c|c|c|}
\hline Operation & Nickname & Group label & Group type & $\begin{array}{l}\text { Pachuca } \\
\text { blades(n) }\end{array}$ & $\begin{array}{c}\text { Total } \\
\text { blades(n) }\end{array}$ & $\begin{array}{c}\text { Pachuca } \\
\text { blades (\%) }\end{array}$ \\
\hline 136 & & $S_{I} W_{I-H}$ & I & I & 30 & 3.3 \\
\hline $9 \mathrm{a}$ & Pich & $\mathrm{N}_{I} \mathrm{E}_{I}-\mathrm{C}$ & 2 & 5 & 125 & 4.0 \\
\hline I 24 & & $\mathrm{~S}_{\mathrm{I}} \mathrm{W}_{2-\mathrm{H}}$ & 6 & I & I4 & 7.1 \\
\hline I 26 & & $S_{I} W_{I-F}$ & 6 & I & 19 & $5 \cdot 3$ \\
\hline $7 \mathrm{k}$ & & $S_{I} E_{I}-D$ & 6 & I & 2 & 50.0 \\
\hline $9 b$ & Xnokol & $\mathrm{S}_{2} \mathrm{E}_{2}-\mathrm{K}$ & 6 & 4 & I 8 & 22.2 \\
\hline 10 & Muuch & $\mathrm{S}_{2} \mathrm{E}_{2}-\mathrm{C}$ & 8 & 2 & 40 & 5.0 \\
\hline I 2 & & $\mathrm{~S}_{2} \mathrm{E}_{2}-\mathrm{E}$ & 8 & I & 3 & 33.3 \\
\hline 13 & Lool & $\mathrm{N}_{2} \mathrm{E}_{2}-\mathrm{N}$ & 8 & I & 64 & I.6 \\
\hline I 8 & & $\mathrm{~N}_{1} E_{2}-\mathrm{F}$ & 8 & I & IO & 10.0 \\
\hline 39 & & $\mathrm{~S}_{2} \mathrm{E}_{\mathrm{I}-\mathrm{I}}$ & 8 & I & $2 I$ & 4.8 \\
\hline $4 \mathrm{I}$ & & $S_{2} E_{I}-E$ & 8 & I & 6 & I 6.7 \\
\hline $9 \mathrm{c} / 3 \mathrm{~g}$ & Aak & $\mathrm{S}_{2} \mathrm{E}_{2}-\mathrm{F}$ & 8 & 8 & 670 & I. 2 \\
\hline 32 & & $\mathrm{~N}_{I} W_{2-\mathrm{E}}$ & 9 & I & 9 & II.I \\
\hline 36 & & $\mathrm{~S}_{2} \mathrm{E}_{\mathrm{I}-\mathrm{L}}$ & 9 & 2 & 4 & 50.0 \\
\hline $9 \mathrm{~d} / 3 \mathrm{~h}$ & Kaab & $\mathrm{S}_{2} \mathrm{E}_{\mathrm{I}-\mathrm{G}}$ & 9 & 22 & 389 & 5.7 \\
\hline II 9 & & $\mathrm{~N}_{5} \mathrm{~W}_{2-\mathrm{P}}$ & IO & I & 5 & 20.0 \\
\hline${ }_{9} \mathrm{~F} / 3 \mathrm{I}$ & Chiwol & $\mathrm{S}_{2} \mathrm{E}_{3}-\mathrm{L}$ & I 2 & 6 & 46 & 13.0 \\
\hline 146 & & $\mathrm{~N}_{5} \mathrm{~W}_{3}$ & I 2 & I & 8 & I 2.5 \\
\hline 15 & & $S_{I} E_{I-H}$ & I5 & I & 158 & 0.6 \\
\hline
\end{tabular}

(2009:168-169) found a dropoff in access to obsidian $6 \mathrm{~km}$ away from the market center of El Sauce, quite similar to the $5-\mathrm{km}$ radius for Chunchucmil. The radius of the area serviced by markets in the Basin of Mexico in the Postclassic was 4-8 $\mathrm{km}$ (Blanton 1996). Chunchucmil is a very different case than the Basin of Mexico, however, because there were no other large markets Io-I5 $\mathrm{km}$ from Chunchucmil. In sum, Chunchucmil's central market served the city itself better than the hinterlands. At the same time, data presented in the following chapter suggest that Chunchucmil's marketplace linked the city with regions well beyond its hinterland. How much did the people of Chunchucmil depend on the market? Did most households get just a few things from marketplaces (a peripheral market context) or a large portion of their possessions (a fully integrated market context) (Bohannan and Dalton 1962)? In comparison with Caracol (Chase and Chase 2004:I4I) and Tikal 
(Moholy Nagy 1997), fewer of Chunchucmil's households specialized in productive activities that left durable remains (see above; Hutson et al. 2010). Systematic research on refuse patterning at Chunchucmil shows that the absence of durable debris from craft production is not a function of site-formation processes (Hutson et al. 2007). At the same time, many specialized activities may have taken place at Chunchucmil without leaving durable archaeological traces (see chapter Io). Given the phosphate data from Area D and comparisons with modern markets (Dahlin et al. 2007), food was likely to have been an important commodity at Chunchucmil's marketplace. Chunchucmil's predicament of having a large population in an area of marginal agricultural productivity (chapter 9) adds support to the claim of a brisk trade in food. Chapter 13 discusses where some of that food may have come from. To the extent that trade in food was necessary for subsistence, the marketplace was critical to many (most?) of Chunchucmil's households. In contrast to those who might claim that a marketplace like Chunchucmil's exchanged only food (Chase and Chase 2014:240; Speal 2014:92), this chapter has shown that non-food items (e.g., obsidian and pottery) were also traded at Chunchucmil's central marketplace. In sum, we do not have a clear answer to the question of how much of a household's goods came from the Chunchucmil marketplace, although most households probably acquired several things through markets. Probably no Maya sites contained a fully integrated market context since such a context, where households get most of their goods from a market, might not predate capitalism (Hirth 2010:230)

\section{CONCLUSION}

In this chapter, we have established the presence of a marketplace at Chunchucmil from three different approaches-contextual, configurational, and distributionalusing multiple lines of evidence for each approach. Due to the way in which the results from each approach complement each other, Chunchucmil stands as an extremely strong candidate for a Maya marketplace. Tikal and Caracol are perhaps the only other sites where arguments for the existence of marketplaces use all three approaches. Tikal has contextual and configurational data in support of a market (Becker 2015; Jones 2015). Furthermore, Masson and Freidel (2012) make the case that the distribution of polychrome pottery and long-distance goods such as obsidian and shell at Tikal meet the expectations of a distributional approach: households of widely different wealth levels possessed equitable quantities of these items.

To say that there were Classic-period marketplaces in the Maya area might have been revolutionary 25 years ago, when there was fundamental resistance to this idea (see chapter I; Shaw 2012:120). Now that most people agree that Maya economies were more complex than once thought, the question of whether or not a site had 
a marketplace is not as pressing as the more nuanced questions about the role of marketplaces in local economies. Therefore, we have paid attention to important questions regarding the scale, periodicity, organization, geographical scope, and importance of marketplace. At the same time, the mere existence of a major marketplace at Chunchucmil is still remarkable because it dates not to the Late Classic, as do Tikal's and Caracol's marketplaces, but to the end of the Early Classic period (see Tokovinine and Beliaev 2013:172 and Masson and Freidel 2012:463 for suggestions of markets as early as the Preclassic period). The following chapter helps make sense of this anomaly by providing details on the regional and interregional context of Early Classic commerce at Chunchucmil. 



\title{
Connections beyond Chunchucmil
}

\author{
Traci Ardren, Scott R. Hutson, David R. Hixson, \\ AND JUSTIN LOWRY
}

The previous chapter used configurational, contextual, and distributional evidence to demonstrate the presence of a marketplace at Chunchucmil. The even distribution of obsidian presented in that chapter shows that at least a portion of the goods peddled at this market represent long-distance trade. For reasons that we discuss below, the distribution of obsidian on a regional scale (the "spatial approach"; Hirth 1998:454) suggests that Chunchucmil was a gateway site: a key node in the movement of longdistance goods (Hirth 1978). In this chapter, we provide a number of lines of evidence to strengthen the argument that Chunchucmil's marketplace was a center not just for local trade but for long-distance trade as well. In other words, this chapter highlights the macroeconomic scale of commerce at Chunchucmil (see Chase and Chase 2014:246; Feinman and Garraty 2010:179). A deep involvement in long-distance trade should manifest itself in three general ways in the archaeological record. First, there should be compelling evidence that the city was positioned on an important long-distance trade route. Second, Chunchucmil should represent a critical juncture or "gateway" along this route. Third, the material culture at the site should show evidence for long-distance contacts. We begin with the first of these expectations.

\section{CHUNCHUCMIL'S LONG-DISTANCE TRADE ROUTE}

The most archaeologically visible long-distance good at Chunchucmil is obsidian from the El Chayal source in the Guatemalan highlands. Two routes have been 
suggested to connect El Chayal with the northwest corner of Yucatán: an overland route and a Gulf Coast route along the western edge of the Yucatán Peninsula (figure I2.I; Hammond 1972a; Nelson 1989). In this section we reconstruct both of these routes and present features that strongly suggest that Chunchucmil participated in the Gulf Coast trade route. Before discussing these two trade routes, we eliminate doubt about the likelihood of canoe-based merchants plying the west coast of the Yucatán Peninsula in the Classic period.

Descriptions of a trade expedition encountered by Spaniards on the coast of Honduras in 1502 provide details of seagoing merchants. Members of Christopher Columbus's fourth and final voyage to the New World came across a dugout canoe with a thatch roof in the middle, propelled by 25 oarsman and packed with trade goods as well as women and children (we comment on the gendered aspects of commerce in the next chapter). The encounter off Honduras suggests the importance of waterborne trade around the Yucatán Peninsula in the Postclassic. This trade route, which connects the Central Mexican highlands, the Maya highlands, and the southern Maya lowlands with the northern lowlands and lower Central America, is one of Mesoamerica's most vigorous maritime trade routes (Dahlin and Ardren 2002:254), yet several authors once thought that waterborne trade around the Yucatán Peninsula was popular only in the Postclassic period (Nelson 1989; Sabloff and Rathje 1975). Others stated that such trade, including the Gulf Coast route, existed much earlier (Hammond 1972a; Rovner 1976). The peak period for this trade route may in fact have been the Terminal Classic period (AD 800-1roo), when Chichén Itzá and its port, Isla Cerritos, imported obsidian and other products from Central Mexico and brought them to Yucatán in canoes plying the edge of the Gulf Coast (A. P. Andrews and Gallareta Negrón 1986; A. P. Andrews et al. 1989; Ardren and Lowry 2011a; Braswell 2010). The port site of Uaymil, located along the Gulf Coast to the southwest of Chunchucmil, was also part of this Terminal Classic network (Inurreta Díaz 2004).

There is also unequivocal evidence for the use of the Gulf Coast trade route prior to the Terminal Classic (A. P. Andrews and Mock 2002). On the northwest coast of the Yucatán Peninsula, the Costayuc project (A. P. Andrews and Robles Castellanos 2004) discovered a series of port sites-Xcopte, Tzikul, El Cerritoand estuarine settlements-Cerros de Caracoles, Petenes de Xlabarco-between Celestún and Progreso. All of these had Classic-period occupation and were heavily engaged in coastal trading activities as well as collection of salt and marine resources. East of Progreso, Xcambo served as the port for the major Early Classic center of Izamal (Sierra Sosa 1999). Xcambo had an abundance of Petén-style polychromes. The quickest route from Xcambo to the Petén follows the Gulf Coast on the western side of the Yucatán Peninsula, passing near Chunchucmil. Thus, evidence from 


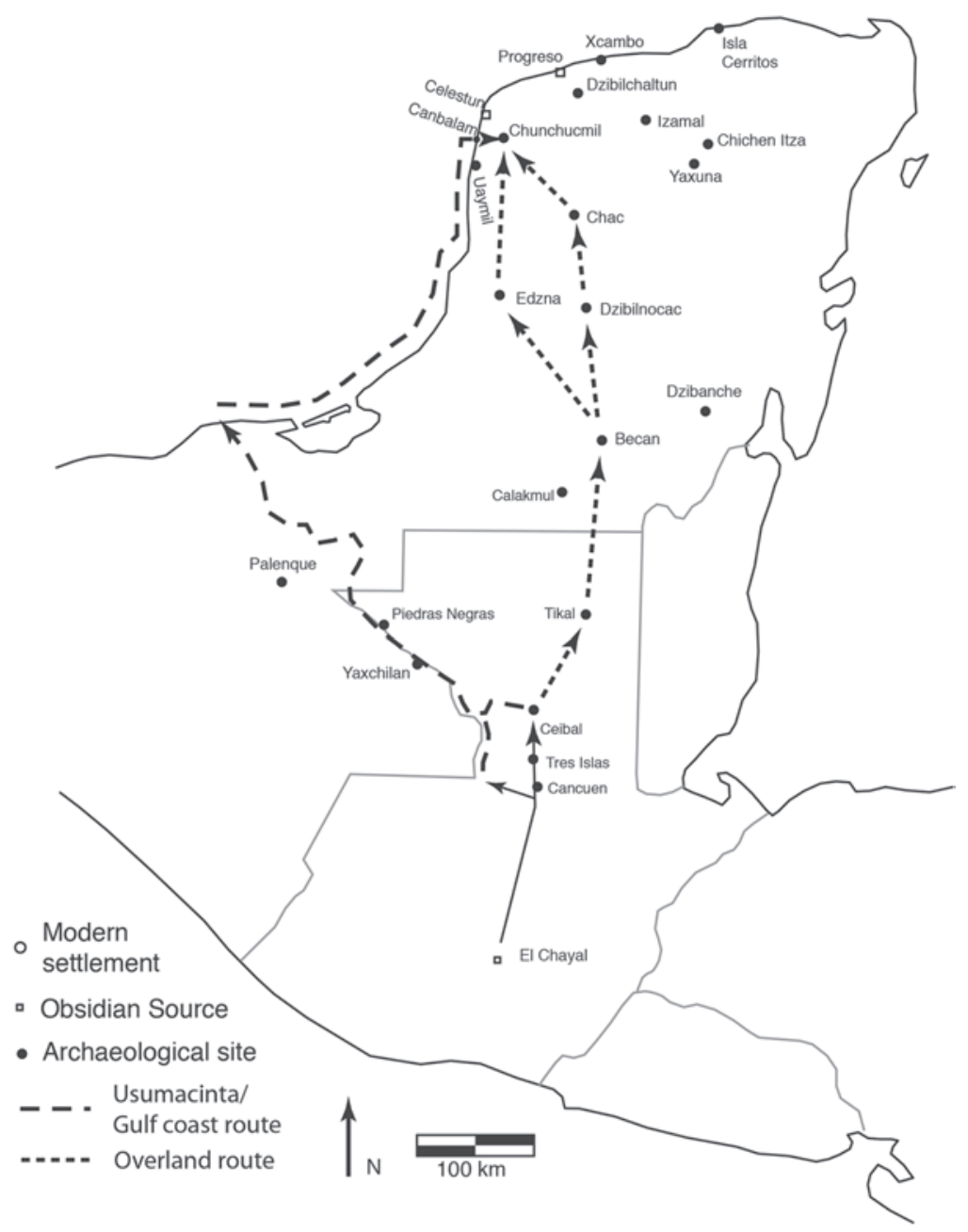

FIGURE I2.I. Map of the Maya area showing potential land-based and seabased trade routes from the highlands to Chunchucmil as well as other sites mentioned in the chapter.

other archaeological projects adds to what we present below about the importance of Gulf Coast trade during the time of Chunchucmil.

Charting the Gulf Coast route as well as the overland route to the Guatemalan highlands begins by asking precisely where in the Guatemalan highlands such routes originated. For obsidian sourcing, we followed the standard practice (e.g., 
Moholy Nagy 2003) of combining instrumental sourcing (I20 artifacts analyzed by X-ray fluorescence) with visual sourcing (of 2,230 artifacts, performed by Daniel Mazeau, who was trained by Geoffrey Braswell). The El Chayal source, located 670 $\mathrm{km}$ from Chunchucmil as the crow flies, near the ruin of Kaminaljuyú, accounted for 96 percent of the obsidian at Chunchucmil. Both of the routes that account for the passage of obsidian from El Chayal to Chunchucmil begin with overland portage from El Chayal north to the Pasión River in the lowlands, passing through the Salama Valley in the Alta Verapaz region. In colonial times, this overland segment was known as the Chinaja trail (Adams 1978:32). Mayanists have discussed this route, which Demarest and Fahsen (2002) call the "Great Western Trade Route," for over 40 years (Hammond 1972a). Alternatively, obsidian could move east from El Chayal toward the Caribbean as part of a seaborne route that runs north along the eastern side of the Yucatán Peninsula (McKillop 1996, 2005), but using such a route to get to Chunchucmil involves a substantially longer journey and is not as well supported by archaeological evidence from the Early Classic period. Once porters completed the Chinaja trail and arrived at the head of the Pasión River, just upriver from Cancuen, material can go by boat downstream, passing Cancuén, Tres Islas, and Ceibal, to the Usumacinta River on the western edge of the Petén. Or, traders could turn westward just before reaching Cancuén and go overland along what is known as the "transversal," the interface between the lowlands and the highlands (Demarest et al. 20I4), eventually linking with the Chixoy drainage, which flows north before its confluence with the Usumacinta. Beyond obsidian, porters could have also carried jade and other highland products.

Woodfill and Andrieu (2012) make a strong argument that Tikal and its allies oversaw the portion of the route between Ceibal and the headwaters of the Pasión in the Early Classic. In the seventh century, Calakmul took over this route (Freidel et al. 2007; Martin and Grube 2008). Though the Early Classic population along this route was minimal, Tres Islas Stela 2 and ceramic deposits in caves along the way show strong iconographic and stylistic similarities to material from Tikal. Tikal had an abundance of obsidian and jade in the Early Classic. El Chayal obsidian was so plentiful that obsidian debitage was more than double the amount of chert debitage in the Early Classic, an extremely unusual circumstance that is also found at Chunchucmil. Regarding jade, 79 percent of Tikal's jade comes from Early Classic contexts and Tikal is the only lowland site at the time that has evidence of jade production. Tikal's association with the Great Western Trade Route helps explain how it amassed so much jade and obsidian during the Early Classic.

Whereas the Usumacinta/Gulf Coast route and the overland route to northern Yucatán both make use of the Great Western Trade Route, the two routes to northern Yucatán diverge at or around Ceibal (alternatively, the Usamacinta/Gulf Coast 
route could instead use the tranversal and the Chixoy, therefore bypassing Ceibal). In the overland route, porters would have taken obsidian, jade, and other products from the banks of the Pasión near Ceibal to Tikal. Though Willey's excavations at Ceibal revealed only two obsidian artifacts-one from El Chayal, the other from Jilotepeque/Río Pixcaya-in Early Classic contexts (Nelson et al. 1978), El Chayal is the dominant obsidian source in recent excavations of Early Classic contexts at Ceibal (Kazuo Aoyama, personal communication to Hutson, October 2015), reinforcing the suggestion that El Chayal obsidian traveled along the Pasión River. From Tikal, Nelson's (1989) map of overland obsidian exchange shows a route to northern Yucatán passing through Becán, Dzibilinocac, and the Puuc hills, where it would finally reach a place like Chunchucmil.

In the Usumacinta/Gulf Coast route, obsidian and other highland goods continue down the Pasión (or Chixoy) River to the Usumacinta River, which drains to the Gulf of Mexico. However, portions of the upper Usumacinta are quite difficult to navigate (Webster and Houston 2003:429), forcing occasional portages parallel to the river. In the seventh and eighth centuries, antagonism between Piedras Negras and Yaxchilán led to fortifications at several sites along the river (Golden et al. 2008). Moving goods along the river at this time period would have been difficult, requiring very delicate political negotiations. However, Chunchucmil's merchants would have been working the river in the fifth and sixth centuries, when things were relatively quiet and outsiders could have passed through without much trouble (Stephen Houston and Andrew Scherer, personal communication, February 2014). Having reached the Gulf, trade goods would have been taken northeast along the coast of the Yucatán Peninsula until they reached the coastal site of Canbalam, at the mouth of the Celestún estuary. From here, goods could continue north and east along the coast, taking advantage of the protected Celestún estuary, or they could go inland to Chunchucmil.

Canbalam would have been critical to Chunchucmil's participation in the Gulf Coast trade route, and the situation therefore requires additional comments. As discussed in chapter 8, the exact location of Canbalam is difficult to pinpoint. Though the densest concentration of artifacts is at Punta Canbalam, located I4 $\mathrm{km}$ south of modern-day Celestún, wave action has spread artifacts across a Io-km stretch of beach (Dahlin et al. 1998). Regardless of where in that stretch Canbalam was, its general location marks it as an important port (see below). As discussed in chapter 8 , the site of Canbalam had access to a variety of items acquired through long-distance trade, such as jade, obsidian, chert, and fancy ceramics, supporting its role as a port of trade. Chapter 8 also notes that the full chronology of Canbalam is less clear. Due to poor preservation of ceramics, most of the potsherds (more than $65 \%$ ) could not be dated. Most of the 19-34 percent of sherds that Tony Andrews 
and Fernando Robles were able to classify in the mid-1990s date to the Late Classic and Terminal Classic periods. Muna slatewares and fine orange and fine gray wares were identified by their pastes. Plumbate, the only pottery whose slip still adhered to the paste, was identified by its distinctive slip. A small amount of Late Preclassic and Early Classic pottery was identified on the basis of distinctive rims and flanges. It is likely that a significant portion of the pottery that was not identified dates to the time when Chunchucmil was at its apex. Knowledge of Early and Late Classic pastes found at Chunchucmil and neighboring sites (Varela Torrecilla 1998) has improved to the point that some of the pottery unidentifiable in the early $1990 \mathrm{~s}$ might now be identifiable by paste alone.

Are there any data that suggest that traders would have turned inland from Canbalam and traveled to Chunchucmil? The likelihood of a well-traveled route between Chunchucmil and Canbalam receives support from history, ethnography, and archaeology.

Maps from the mid-eighteenth century and onward often portray a trail running northwest from the Puuc hills to the coast (A. P. Andrews 200I). The trail usually hits the coast at the mouth of the Celestún estuary about $3 \mathrm{~km}$ north of Punta Canbalam, suggesting that the trail served to bring salt inland from the Celestún salt flats. In some cases, such as a 1798 map drafted by Juan José de León, the trail goes directly through Chunchucmil (A. P. Andrews 200I). In the I890s, a portlet named Venezia was established at the end of the trail at the mouth of the Celestún estuary (figure 1.2). An undated historic canal, used to bring logwood out to the coast, begins at Rancho San Simón and comes within $500 \mathrm{~m}$ of Venezia. In the I890s, the owner of Chunchucmil, Simón Peón, had the Venezia/San Simón canal dredged and built a narrow-gauge rail-a tranvia-alongside it for part of the way from San Simón to Venezia (A. P. Andrews 200I). The tranvia extended eastward from San Simón to the hacienda of Chunchucmil.

The elders of modern-day Chunchucmil still remember using the tranvia during the henequen era of the nineteenth and early twentieth centuries. During this era, monoculture of henequen fiber, which received the name "green gold" because of the riches it brought to plantation owners, limited the food that families could grow. Therefore, ties to the coast were critical for balancing a modest income and produce from the interior. At least one member of each family in Chunchucmil would travel quite extensively afield to make milpa during the henequen boom, providing their families with enough produce to augment the meager servant wages (paid in hacienda monies) and subsistence allowances provided by the hacienda owners. Those who chose to travel west for this venture often augmented their swidden production with wetland extraction and trade with the coast. 
Inland families and communities during the henequen era built up long-lasting trading relationships with coastal fishing communities, becoming accustomed to coastal diets, and helping the coastal communities (who were at that time very isolated from the interior by modern standards) augment their maritime diet with corn, beans, and dooryard products that could not grow in the sandy soils along the coast. A symbiotic relationship grew, with each community (inland and coastal) relying principally upon their immediate environment for their dietary needs, but augmenting what was lacking through regular and repeated trade with the other. During the dry season, when there was less need for labor in the henequen fields or in outfield milpas aside from the felling and burning of trees or overgrowth, men from the interior would (and still do) travel to the coast for seasonal employment collecting salt or fishing. Even today, the villagers of Chunchucmil consider their sister-city to be the coastal village of Isla Arena, while another inland community known today as Tetiz (just north of Chunchucmil) has a historic and long-lasting relationship with the coastal town of Celestún.

To get to the coast, villagers used the tranvias as narrow raised footpaths through the wetlands, carrying loads on their backs using the same tumpline technology depicted in Maya art from the Classic period. For this leg of the journey to the coast, the Classic-period feature analogous to the tranvia system is the network of andadores discovered during our surveys (see below). When the tranvia ended at the edge of the perennial wetlands beyond San Simón, the historic Maya used the canal tow paths (plataformas, designed for beasts of burden to pull cargo down the canals) as footpaths to their destination along the coast. While the straightest of the canals seen today are likely postconquest, this does not eliminate the possibility that the natural canals from which they were created (springing as they did from ojos de agua, and meandering only slightly on their path to the Gulf of Mexico) could not be navigated by ancient Maya watercrafts. This possibility would have made the journey between the interior and the coast as easy, or even easier, in the ancient past as it was in the more recent past, since the economic system of the Classic period would not have precluded a trader's access to boats or additional porters.

A transportation network similar to the historic pattern may be found in the system of andadores linking sites and resources west of Chunchucmil in the western seasonal wetlands. These informal rock alignments, made of roughly hewn stones laid end-to-end (see also chapter 8), act as stepping stones through areas of inundation, disappearing when dry land is reached, then continuing again when reaching another area of inundation (figure I2.2). Figure 12.3 shows a map of andadores crossing a seasonal wetland near the site of Chen Huech, located approximately 8 $\mathrm{km}$ west of Chunchucmil. The compass bearing of the longest alignments nearly parallels the historic tranvia lines and point toward Punta Canbalam, indicating 


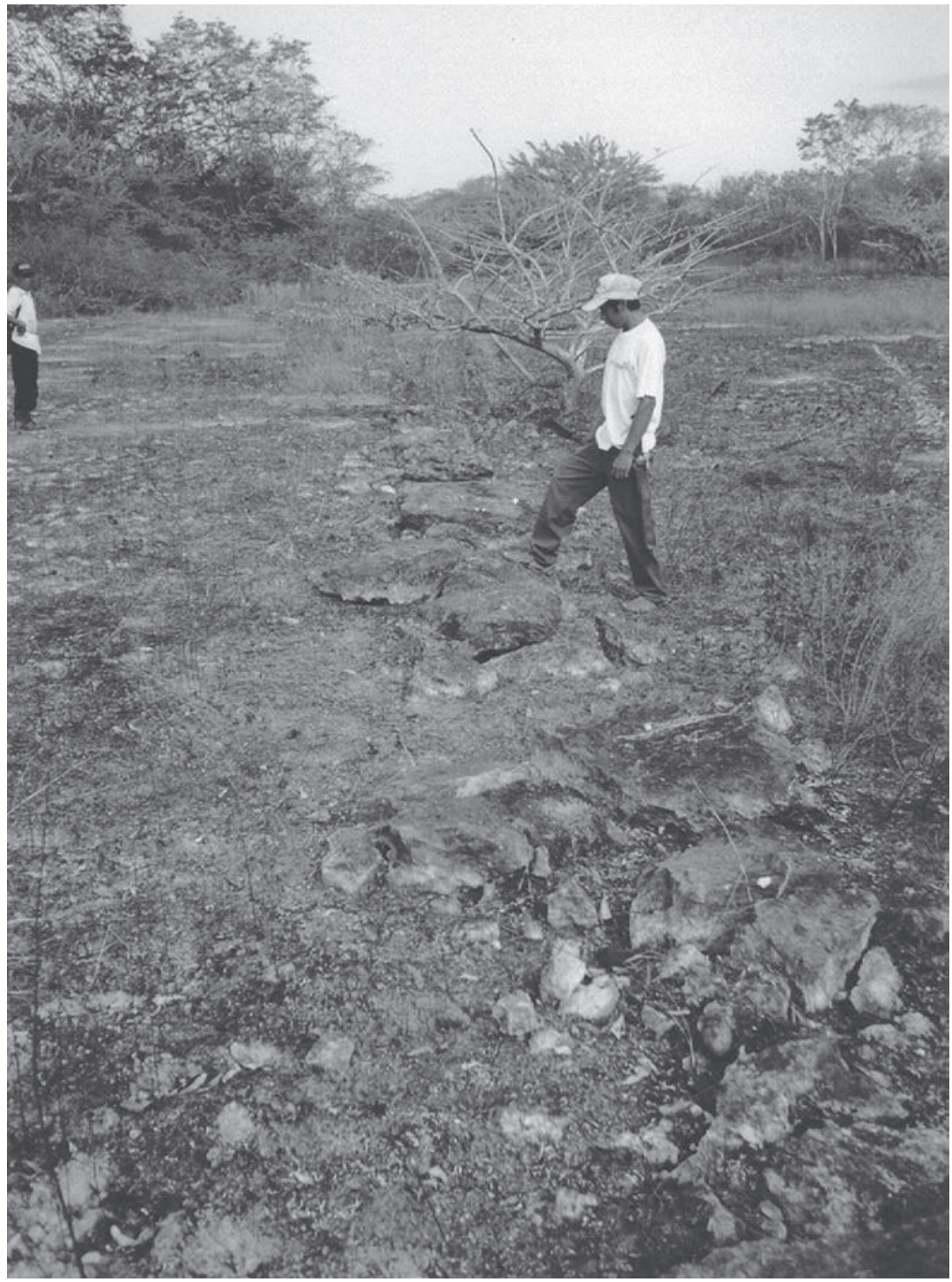

FIGURE 12.2. Photo of an andador.

that the network of andadores as a whole would have facilitated travel between the Chunchucmil hinterland and the coast near the port facility (Hixson 20II).

A. P. Andrews $(1990,2004)$ noted that such andadores are a hallmark of Maya coastal ports of trade along the north coast of Yucatán, as are occasional canals. 


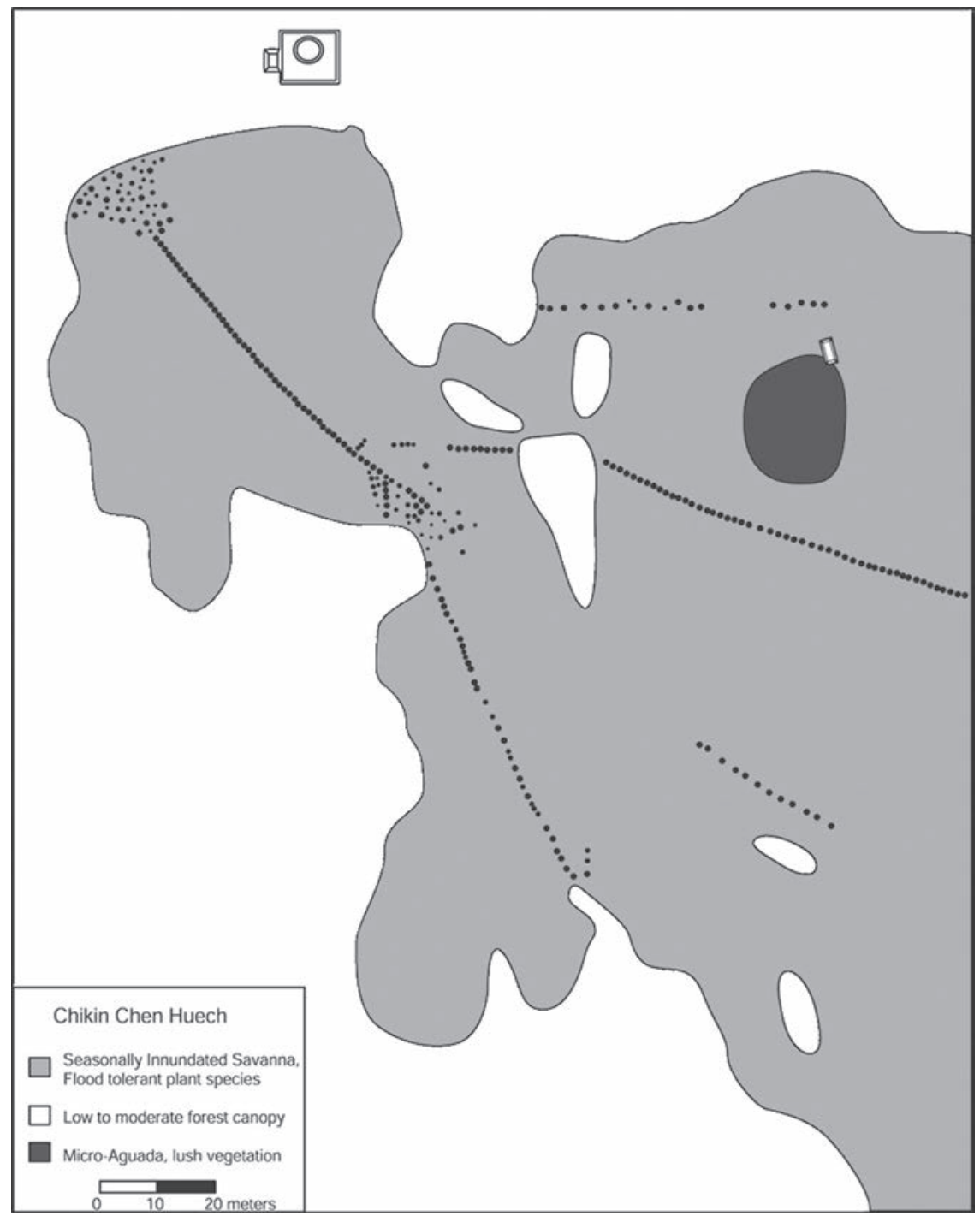

FIGURE 12.3. Map of andadores near Chen Huech, about $8 \mathrm{~km}$ west of Chunchucmil

These features combine to link the interior with the coastal trade route. Sites such as Xcambo (Sierra Sosa 1999), Isla Cerritos (A. P. Andrews 2008), and Vista Alegre (Rissolo 2007) are all connected to the coast through andadores, along with many other proposed ports, including Isla Providencia, Petén Xnuc, and El Muc along the north coast of Yucatán (Covarrubias Reyna et al. 2012). 
The longest andadores of the wetlands west of Chunchucmil extend approximately $2 \mathrm{~km}$ (with small breaks when drier ground is crossed), yet these appear to align with other walkways several kilometers away (figure 8.2). All of the longer alignments are oriented from the southeast near the outskirts of Chunchucmil, to the northwest, pointing directly toward Punta Canbalam. The andadores near Chen Huech (see figure I2.3) show this same orientation. In particular, two of the largest suburban communities southwest of Chunchucmil (Kum and Chun Chen) appear to be the points where these connective avenues begin. Andadores pass near Pochol Chen, the largest site documented thus far in the seasonally inundated savanna to the west of Chunchucmil (see figures 8.I and 8.2).

While these alignments were not surveyed beyond the region of perennial inundation, it is possible that at some point the footpaths end when the water becomes too deep. From that portion of the perennial wetlands, natural navigable streams flow from the petenes and would have functioned like the canal system of the historic era. One such natural stream empties into the Gulf precisely at Punta Canbalam. Therefore, the network of andadores, combined with the streams between petenes, may literally represent the transportation and communication route between Chunchucmil and the coast "set in stone."

\section{CHUNCHUCMIL AS A GATEWAY CENTER}

In the section above, we demonstrated that Chunchucmil had access to the Gulf Coast trade route, a vigorous maritime passage that encircled the Yucatán Peninsula. We now show that Chunchucmil played a major role in trade along this route as opposed to the overland route. Specifically, in this section we argue that Chunchucmil was a gateway through which waterborne goods such as obsidian entered the interior of the Yucatán Peninsula.

According to Hirth's (1978) model, a gateway site is a large settlement that controls the movement of commodities due to its location along a key juncture of a natural trade route. Hirth discussed many expectations that a site should meet if it served as a gateway city. Dahlin and Ardren (2002) used data available in 2000 to suggest that Chunchucmil met several of these expectations. Data from the $200 \mathrm{I}$ to 2006 field seasons, including more mapping at Chunchucmil (chapter 2), a sitewide test-pitting program (chapter 3 ), and regional survey (see chapter 8), enable us to address these expectations more directly. As a result, we can now make a stronger argument for Chunchucmil's status as a gateway city. More specifically, we argue that obsidian and other highland goods that came north along the Gulf Coast entered the northern lowlands at Chunchucmil and were then distributed from there across the western side of Northern Yucatán. 
Our first expectation of a gateway city is straightforward: large volumes of longdistance trade pass through them. As Renfrew (1977) and others have argued (see Dahlin and Ardren 2002:252), sites that serve as major points on trade routes do not merely pass all the trade goods on to other sites: they consume a significant portion of them. Thus, if Chunchucmil were a major gateway on a long-distance trade route, its residents should have enjoyed elevated access to the goods on that route, such as obsidian. On the other hand, if Chunchucmil merely received longdistance goods from the overland route, it should not have much obsidian at all: Chunchucmil is at the very end of the overland route. Thus, we have clear expectations of the relative amounts of obsidian Chunchucmil would consume if it were a gateway city as opposed to the last stop on an overland trade route.

Quantities of obsidian at Chunchucmil and inland sites do not follow expectations for overland trade. Once obsidian left the western Petén rivers and began its overland route north to Chunchucmil, it would pass through a series of central places, beginning with Tikal, as suggested by directional models. In the directional model each central place represents a peak in the multimodal fall-off curve for obsidian (Renfrew 1977:86, figure 5). In other words, the next center after Tikal will have more obsidian than secondary sites in between it and Tikal. Nevertheless, this center will have slightly less obsidian than Tikal: each peak in the directional fall-off curve is lower than the previous peak. Thus, if we look at central places alone and disregard secondary sites, the "law of monotonic decrement" (Renfrew 1977) should prevail: from Tikal to Chunchucmil, each subsequent central place should have less obsidian than the previous center on the route because only a portion of the obsidian entering these sites from the south would get passed on to the north.

The most direct way of measuring access to obsidian at a particular site examines ratios of obsidian to some other entity. Sidrys (1977) measured obsidian as a ratio with volume of excavation and then multiplied the result by distance from the source. Chunchucmil would rank highly in Sidrys's "trade index," but this index does not account for differences in the length of occupation (the ratio of artifact to matrix at Chunchucmil increases the longer the site is occupied due to the relative lack of sources of sedimentation), nor for differences in depositional contexts (Rovner 1989). Expressing obsidian as a ratio to utilitarian artifacts such as pottery avoids this problem. Unfortunately, few sites have quantified obsidian data in a way that is appropriate for intersite comparison.

Given the presence of Tikal-style material culture at sites along the Great Western Trade Route to the El Chayal obsidian source in the Guatemalan highlands (Woodfill and Andrieu 2012), Tikal should have lots of obsidian in the Early Classic. It certainly does. Though obsidian from the University of Pennsylvania project at Tikal was not collected systematically, a recent estimate of well over 
300,000 artifacts seems highly plausible (Moholy Nagy 1997). Unlike the sample at Chunchucmil, most of the obsidian recovered at Tikal is debitage.

Nelson (1989) provides the most detailed model of an overland obsidian trade route from Tikal to northwestern Yucatán. As predicted by the directional model for overland trade, Tikal has more obsidian than the next central place to the north: Calakmul. Yet during the Early Classic, obsidian probably did not pass from Tikal to Calakmul at all. Extensive excavations at four major Calakmul structures, each of which has at least minor Early Classic occupation, recovered only I07 obsidian artifacts (Domínguez Carrasco et al. 1996). This might have to do with the fact that Tikal and the Caan polity, eventually centered at Calakmul, were major enemies in the sixth century (Martin and Grube 1995). Whereas Calakmul was certainly the capital of the Caan polity in the Late Classic, the site of Dzibanche, located further to the east in Quintana Roo, may have been the Caan capital in the Early Classic (Hansen and Guenter 2005; Martin 2003). North of Calakmul, Nelson's proposed overland route stipulates that Becán is the next central place (figure I2.I). Like Calakmul, Becán has far less obsidian than Tikal: 138 artifacts from the 19691971 Tulane excavations, 96 of which come from Early Classic contexts (Dreiss and Brown 1989; Rovner and Lewenstein 1997:119). An additional 147 obsidian artifacts came from excavations in 1973 (Stoltman 1978). Without precise information on the volume of excavation or ratios with ceramics, the Becán data are hard to interpret. Furthermore, most excavation lots at Becán were not screened. Nevertheless, El Chayal is the dominant obsidian source at Becán during the Early Classic and El Chayal obsidian in Belize appears to have arrived from Becán as part of an overland route (Dreiss and Brown 1989).

North of Becán, Nelson's model stipulates Dzibilnocac as the next central place, but excavations at Dzibilnocac revealed almost no Early Classic occupation (Nelson 1973:136). This reflects the fact that for portions of the proposed overland route between Tikal to Chunchucmil, we do not know exactly which sites the route would have passed through. Nearer to Chunchucmil, however, quantitative data are available from Early Classic components at two sites that would be good candidates as central places on the purported overland obsidian chain: Chac and Edzná.

At Chac, Michael Smyth's excavations in Early and Middle Classic contexts yielded II $0.4 \mathrm{~g}$ of obsidian ( 79 artifacts, $8 \mathrm{I} \%$ of which come from El Chayal) and $377.5 \mathrm{I} \mathrm{kg}$ of pottery (Michael Smyth, personal communication, 2008). The ratio of grams of obsidian to kilograms of ceramics is therefore 0.29. At Edzná, 96 obsidian artifacts have been reported from the New World Archaeological Foundation excavations (Nelson et al. 1977, 1983), though only nine of these come from Early Classic contexts. Obsidian data from Ramón Carrasco's more recent project at Edzná are not available. Excavations of approximately $133 \mathrm{~m}^{3}$ in residential contexts 
in the northwest portion of the site yielded six obsidian blades from contexts where Early Classic ceramics dominated or made up a large portion of the ceramic debris (Matheny et al. 1983). Quantification of obsidian as a ratio with ceramics is difficult for Edzná because ceramic weights are not given. Furthermore, not all excavations were screened. However, assuming that each sherd has a mass of $\mathrm{o} g$, the ratio of grams of obsidian per kilogram of sherds at Edzna is o.I5. The representative sample of houselots excavated at Chunchucmil (see chapter 3) put the figures for Chac and Edzná in perspective. Whereas the ratios of grams of obsidian per kilogram of sherds at Chac and Edzná are 0.29 and 0.15 , respectively, the ratio at Chunchucmil is 0.99 . The ratio of obsidian to volume of excavation at Edzná was approximately $0.14 \mathrm{~g}$ of obsidian per cubic meter, as opposed to $2.20 \mathrm{~g}$ of obsidian per cubic meter at Chunchucmil.

Thus, both Edzná and Chac received much less obsidian than Chunchucmil. This does not fit the model of directional trade overland, in which Chunchucmil, located furthest from the source, should have the smallest amount of obsidian. We therefore conclude that the main obsidian trade route for Chunchucmil was not overland. The comparison with Edzná and Chac suggests that Chunchucmil was a gateway community (Hirth 1978) for obsidian that would eventually be distributed across the western side of northern Yucatán (Dahlin and Ardren 2002). In other words, obsidian went to Chunchucmil first via the Gulf route and then to sites with ample Early Classic populations further inland, such as Chac and Yaxuná. Excavations at Yaxuná in the 1990s (Stanton et al. 2010) were of a comparable scale to those of Chunchucmil and recovered a total of only 199 obsidian artifacts (Dave Johnstone, personal communication 2006; see also Braswell and Glascock 2002).

We argue that this regional spatial approach (Hirth 1998:454; Renfrew 1977), which highlights the high quantities of obsidian at Chunchucmil compared to other sites with appreciable Early Classic settlement in northern Yucatán, such as Yaxuná, Edzná, and Chac, suggests that Chunchucmil was a gateway for obsidian that would eventually be distributed across the western side of northern Yucatán. Alternatively, it may be possible to argue that Chunchucmil had more obsidian than other sites because chert was scarce. Yet chapter in makes the case that the relative abundance of obsidian at Chunchucmil has little to do with access to chert. The fact that Chunchucmil has substantially more obsidian than other Early Classic sites in northern Yucatán only makes sense if the obsidian that arrived in northern Yucatán entered the peninsula by sea near Chunchucmil, which acted as a gateway for distribution to sites further inland.

Thus, Chunchucmil meets a major expectation of the gateway model: it had lots of trade goods. Another important expectation is that gateways should stand at a spot in between two natural or cultural regions or at the juncture of two distinct 
legs of a trade route where the cost of moving goods might change. At these junctures, gateway merchants can control the flow of goods. Chunchucmil and its port, Canbalam, meet this expectation because they stand where seaborne goods come inland and begin to travel by foot. Though any port on the coast sits at the juncture between sea and land, Canbalam sits at the entrance to the Celestún estuary and therefore receives protection from the sea by the barrier beach at the southern tip of the Celestún Peninsula. Merchants moving north from Canbalam along the coastline will not find another protected harbor for another $100 \mathrm{~km}$, thus making Canbalam a logical stopping point. The Celestún estuary itself provides a watercourse that parallels the coast and extends northward as far as Progreso. Though this waterway is unstable due to unconsolidated sand dunes, it is protected from the sea and navigable during some parts of the year. Since Canbalam sits at the entrance to the estuary, Chunchucmil could control this waterway.

A third expectation is that gateways should be located at the edge of a region. Chunchucmil satisfies this expectation since it is located as close to the Gulf of Mexico as a large site could possibly be. The land to the west of Chunchucmil, as discussed in chapter 6 , consists of seasonally inundated savanna. Dahlin initially thought that Chunchucmil's hinterland settlement pattern should look like a fan, with the area to the west-the savanna-unoccupied with the exception of a corridor of sites along the route to Canbalam. This string of sites would be the handle of the fan. As chapter 8 shows, there are many more sites in this area than just those on the "corridor" to Canbalam, each with houses perched upon small tzekeles that stay dry year round. Thus, the idea of a fan-shaped distribution is incorrect (see also Hixson 20ri). Nevertheless, since the small size of the tzekeles limits the amount of people who can live in the savanna, it is still the case that a large site like Chunchucmil could not exist any further to the west of where it is currently located. Chunchucmil therefore still meets the expectation of a gateway because it is a large site located at the edge of a distinct ecological region: the semiarid karstic plains.

A fourth expectation is that gateway cities should have facilities that enhance trade and the transport of commodities. Beyond having a major central market, which has been demonstrated at Chunchucmil (Dahlin et al. 2007; chapter II, this volume), such facilities could involve clear paths in and out of the city, constructed routes that facilitate transport across rough terrain beyond the city, and way stations for travelers. The Chunchucmil site-mapping project (chapter 2) and Dave Hixson's regional survey to the west of Chunchucmil (chapter 8) have identified all of these. To the west of Chunchucmil, there are the andadores and way stations, described at the end of the previous section, that assist travelers and porters plying the route to and from Canbalam, on the Gulf Coast. Within 


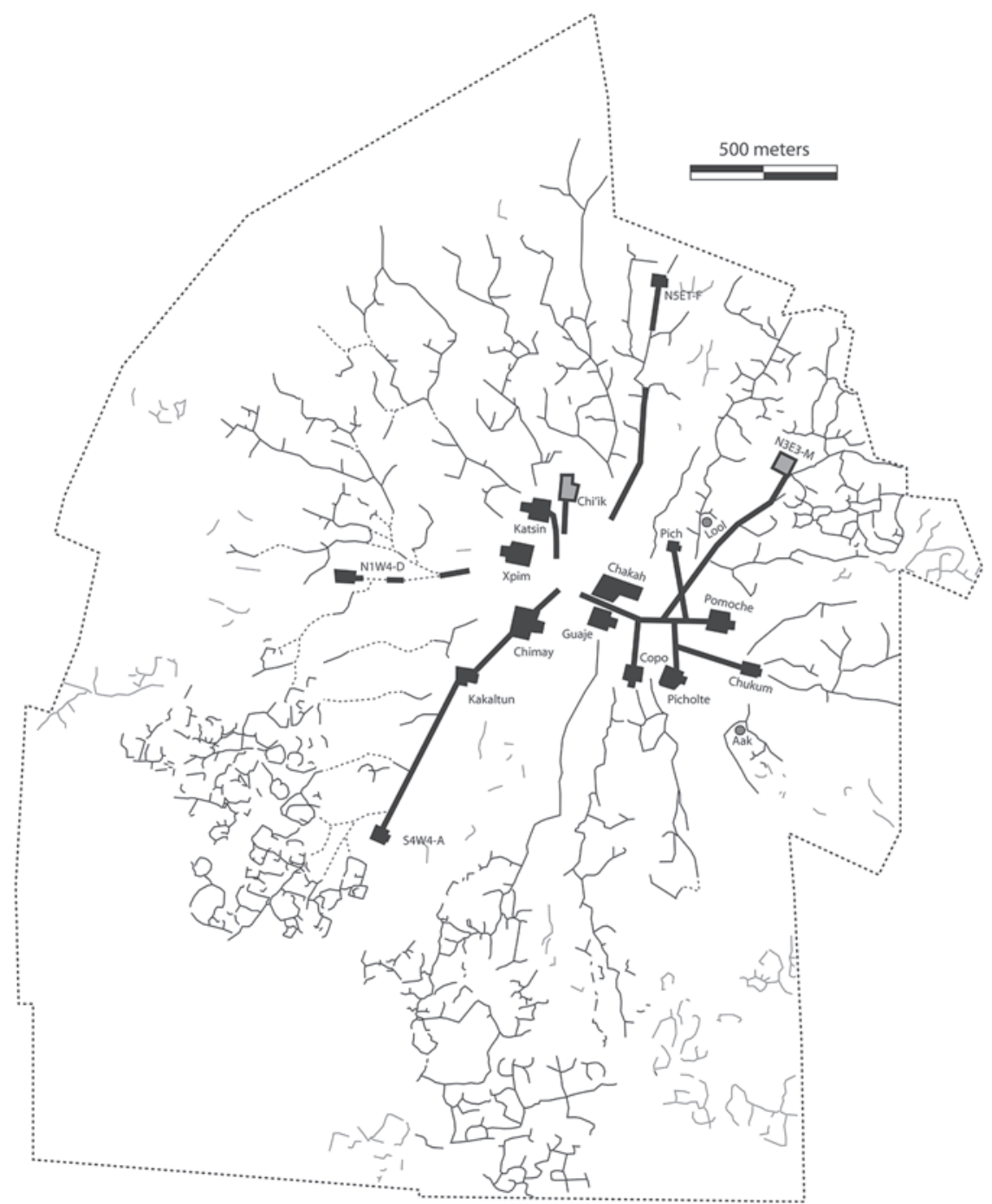

FIGURE 12.4. Map of Chunchucmil showing the hub-and-spoke pattern that connects residential zones to the site center through causeways and callejuelas. With the exception of the Aak and Lool groups, all labeled architectural groups are monumental.

Chunchucmil, callejuelas serve as clear paths in and out of the city. The layout of callejuelas at Chunchucmil resembles a hub-and-spoke pattern, with major callejuelas serving as spokes connecting the site center-the hub-to the edges of the site (figure I2.4). 


\section{NON-LOCAL MATERIAL CULTURE}

For a site deeply involved in long-distance trade, we would expect the material culture at the site to show evidence for long-distance contacts. With regard to ceramics, this might manifest itself in the presence of a high proportion of foreign imports. For example, imports at the Epiclassic market center of Xochicalco make up 3-6 percent of domestic assemblages (Hirth 1998:459). Furthermore, Xcambo, the Early Classic coastal port of trade for the massive inland center of Izamal, had an abundance of Petén-style polychrome pots in its burials (Sierra Sosa 1999). Though Chunchucmil lacks a burial sample comparable to Xcambo, the sample of excavations in over 100 residential groups from the Early Classic revealed that it has far fewer foreign ceramics than Xochicalco's households. However, the ceramics of the Oxkintok Regional Complex, which dominated Chunchucmil's pottery when the city was at its apogee, contains both southern lowland modes (see chapter 4) and details also found in Central Mexican pottery (Hutson 20I2b). In this section we call attention to other forms of material culture that reflect non-local influence. We begin by considering the layout of quadrangles and then move to the two extensively excavated residential groups-Lool and Aak-that have remarkable foreign attributes.

In personal communication, E. Wyllys Andrews V has suggested that the form of Chunchucmil's quadrangles resembles Templo-Patio-Adoratorio (TPA) complexes at Monte Albán and other sites in Oaxaca (see Winter 1986). Figure I2.5 presents an array of TPAs from Oaxaca juxtaposed with a type r quadrangle from Chunchucmil (see chapter 3 for Chunchumcil's architectural types). The authors of this chapter have mixed opinions regarding the notion that the similarities between TPAs and quadrangles result from contact between people from Oaxaca and Chunchucmil. One of us believes that the resemblance between TPAs and quadrangles suggests the expression of ideological connections with pan-Mesoamerican traditions. The dissenting voices among us highlight details that challenge the analogy. First, Winter's exemplars of the TPA category at Monte Albán (Systems IV and M) have a platform on the opposite side of the patio from the temple but not on the flanking sides (figure 12.5a). Some examples of TPAs do not have a dominant temple (figure 12.5b, c). In fact, of the 24 examples of TPAs given by Winter (1986), only four meet the minimal requirements (one large temple, a patio, a central altar, low structures on the other three sides of the patio) of quadrangles as defined at Chunchucmil. Some TPAs, such as that depicted in figure I2.5c, have little in common with quadrangles. In sum, TPAs as defined by Winter are not close, formal analogs for quadrangles. Second, the extensive excavations in the Pich quadrangle ( $\mathrm{NIEI}_{\mathrm{I}} \mathrm{C}$, see chapter 5) failed to recover any artifacts of Oaxacan inspiration.

Finally, the form shared by Chunchucmil's quadrangles could easily be regarded as a manifestation of an architectural tradition found closer to home, within the 
a)

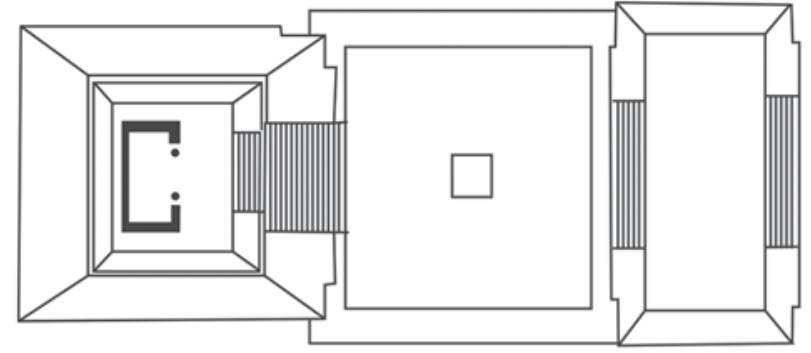

b)

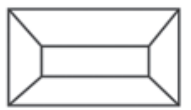

1
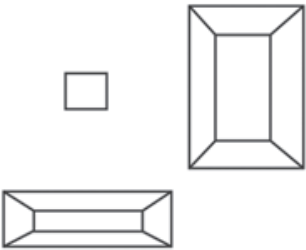

c)

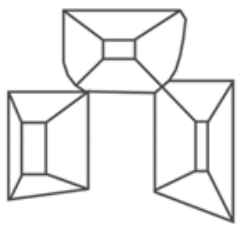

40 meters

d)

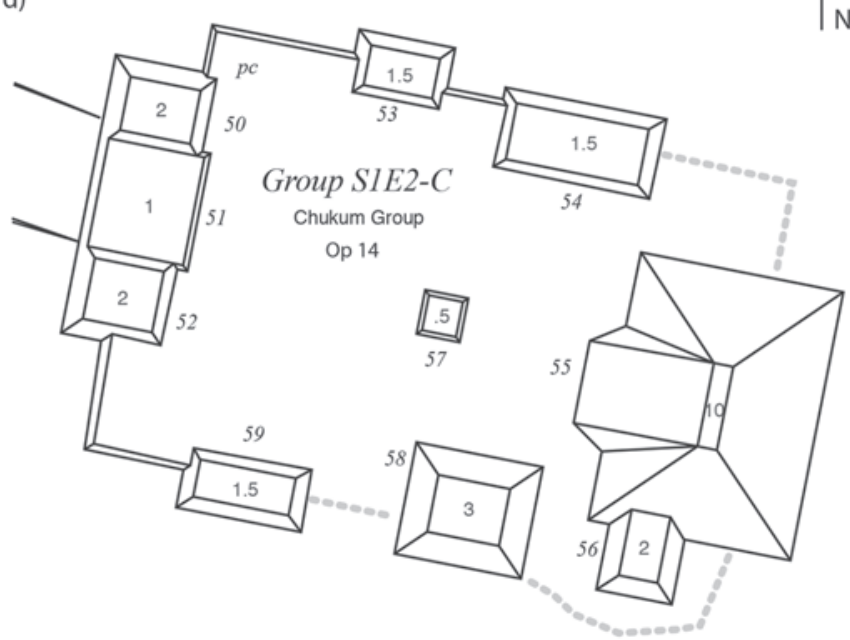

FIGURE I 2.5. Templo-Patio-Adoratorio (TPA) complexes from Oaxaca juxtaposed with a type I quadrangle from Chunchucmil: (a) System M, Monte Albán; (b) Terrace I449, Monte Albán; (c) Terrace I455, Cerro de la Cruz; (d) Group SiE2-C from Chunchucmil. (a, b, and c adapted from Winter 1986: figures 3 and 5.) 
Maya. Chapter 3 lists examples of quadrangles from the Puuc area and southern Quintana Roo. More broadly, the basic plan-a four-sided plaza with a temple pyramid on one side and low platforms on the others-is found widely in the Maya area. George Andrews (1975:II) argues that this plan is the prototype for the basic ceremonial group across the lowlands (see also Kubler 196I). Such a plan manifests itself in contexts ranging from the first ceremonial plazas at Preclassic Cuello, Belize (Hammond 1999:50), to Plaza Plan 2 identified in the Classic-period Petén (Becker 199I). In closer resemblance to Plaza Plan 2, the temples in I2 of the Is type I and 2 quadrangles at Chunchucmil are on the east side of the patio (see also chapter 3), a pattern not seen in Oaxaca. Of course, the phenomenon of a temple facing a quadrilateral courtyard is in fact general enough to include examples from well beyond the Maya area. Though it would be more parsimonious to suggest that the people from Chunchucmil followed local cultural traditions, we cannot refute the notion that their embrace of this general form might also reflect cosmopolitan ambitions.

\section{THE LOOL RESIDENTIAL GROUP}

Horizontal excavations at the Lool houselot (group $\mathrm{N}_{2} \mathrm{E}_{2}-\mathrm{N}$, Op. 13) uncovered three structures situated around the northern, eastern, and southern sides of a small central patio (figure 12.6). The Lool group is labeled in figure 5.I directly northeast of the Pich group near the northeast edge of the site center (see also figure 12.4). The remains of a quadrangular structure can be found on the west side of the patio and a chich pile is in the center. The northern structure, Structure 74 , is a very low platform with the remains of a small circular enclosure on its western edge. The eastern structure, Structure 75 , is an approximately 3 -m-tall platform built in the talud-tablero style (figure I2.6) with associated artifacts that likewise demonstrate a strong connection to traditions best known from outside the Maya area. The southern structure, Structure 76 , consists of a low platform that supported an elaborate residence with four rooms, a bench, and two columns facing the patio. The Lool group is disturbed by a gravel road that cuts through the group immediately to the east of Structure 75. Based on ceramic evidence and a single radiocarbon date, the three main structures of this group were all built during the late facet of the Early Classic period and retained little evidence of later modifications. Structure 75 , the platform, had a smaller interior substructure, only a few meters square, that was likely the original houselot shrine. Structure 76 , the residential area, had a few minor additions, such as the bench. Phosphorus sampling confirmed the location of an outdoor kitchen area immediately adjacent to Structure 76 .

The stone walls that enclose the Lool houselot circumscribe an area of approximately $3,400 \mathrm{~m}^{2}$, which is below the mean $\left(4,197 \mathrm{~m}^{2}\right)$ but close to the median $(3,575$ 


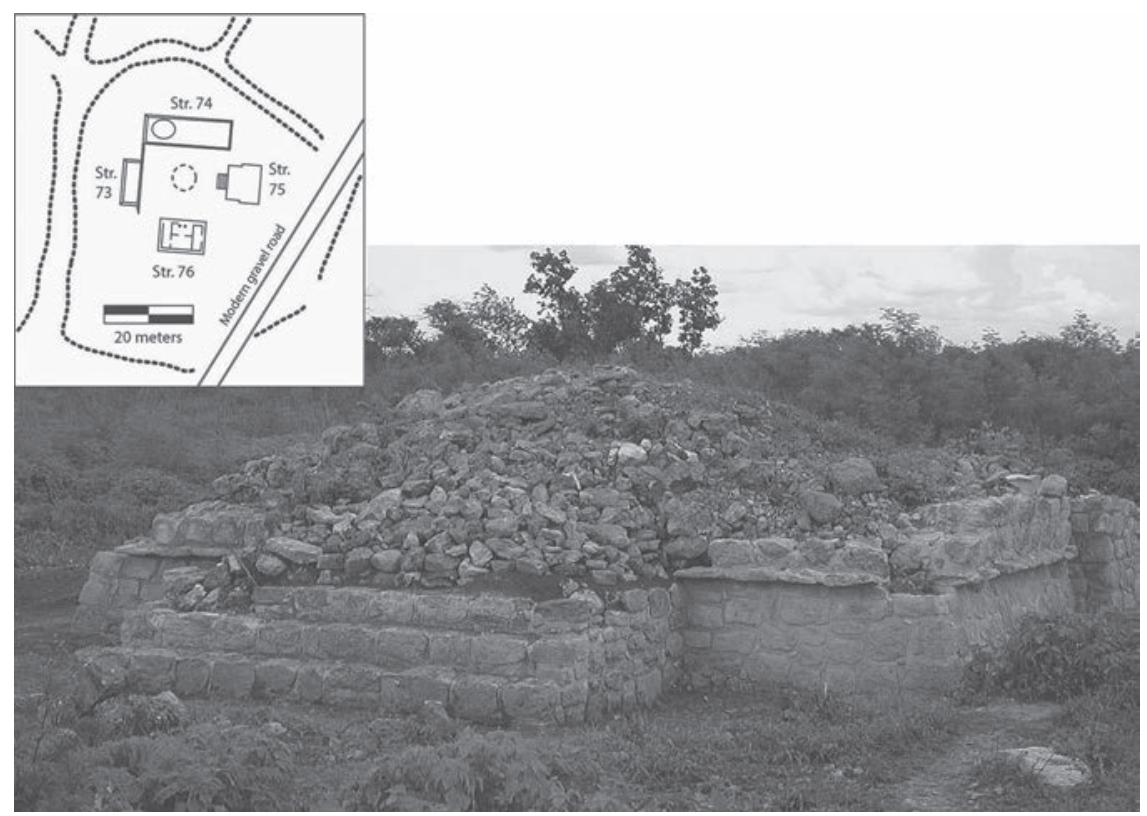

FIGURE 12.6. Photo of Structure $\mathrm{N}_{2} \mathrm{E}_{2}-75$, showing talud-tablero façade. The map at upper left shows the location of this structure within Group N2E2-N/Lool.

$\mathrm{m}^{2}$ ) for a sample of 392 architectural groups that are mostly enclosed by albarrada walls (Magnoni et al. 2012). The volume of architecture is $440 \mathrm{~m}^{3}$, which is right at the median but predictably below the mean $\left(770 \mathrm{~m}^{3}\right)$, given that the site's monumental quadrangles skew the large end of the distribution. Structure 75 , on the east side of the group, is a platform whose base measures approximately $7 \mathrm{~m}$ east/west by $8 \mathrm{~m}$ north/south. It has a single staircase on the western or patio side that leads half way up the structure. There are no other points of access into the building and like eastern structures at other residential houselots at Chunchucmil, this platform was likely a focus for ancestral activities. The front and side walls of Structure 75 were made of evenly cut, worked stone set in thick mortar. The back of the structure, however, was made of very irregular stones set with larger amounts of stucco and plaster. The structure displays the distinctive talud-tablero design of outward sloping walls topped with slab stones, and was covered originally with simple modeled stucco. The basal portions of the northern, southern, and eastern walls were battered at a slope of 70 degrees. Along the northern and southern walls (but not the east), at approximately $80 \mathrm{~cm}$ above ground surface, was a single horizontal line of rough-hewn slab stones (lajas) that projected from the platform. The lajas 
supported a row of larger cut stones, ranging between 30 and $40 \mathrm{~cm}$ in length and 20 and $30 \mathrm{~cm}$ in height that projected farther out than either the lower wall or the slightly inset upper wall. The configuration of a vertical face on top of a battered foundation, separated by a line of lajas, is an example of the talud-tablero architectural style associated with the Central Mexican site of Teotihuacan but found throughout Mesoamerica from the Late Preclassic through Postclassic periods (Gendrop 1984; Giddens 1995; Heyden and Gendrop 1980; Marquina 1964). A limited number of sites in the region surrounding Chunchucmil also contain talud-tablero architecture, at both elite and houselot settings, and these particular sites were likely also engaged in heightened commercial activity in the Early Classic period (E. W. Andrews IV and E. W. Andrews V 1980; Ardren and Lowry 20Irb; Rodríguez Pérez et al. 20II; Stanton 2005).

Limited excavation into the area behind the stairs on the western (patio) side of Structure 75 revealed a very small substructure $(80-\mathrm{cm}-\mathrm{X}-\mathrm{I} .2-\mathrm{m})$ with a cache completely encased by the construction of the stairs and talud-tablero walls of the platform. Just below the surface of the Structure 75 stairway and in front of the substructure, an unusual cache vessel and burial had been placed into the construction fill. The cache consisted of a 15 -cm-tall cylindrical tripod vase with a small inverted bowl for a lid, set into loose reddish soil stained with hematite. The Teotihuacan-style vase contained the same reddish brown soil and a large quantity of small bone fragments. The bones have been identified as the remains of a human cremation (Vera Tiesler, personal communication 2002). At Teotihuacan, cremated burials are relatively more common than they are in the Maya area, and both Manzanilla and Rattray assert that the most important individuals from each compound at Teotihuacan were cremated (Manzanilla 2002; Rattray 1992). Within Teotihuacan's Merchants' Barrio, which has cultural affinities with what is now coastal Veracruz, burials are often placed inside altars or ancestral shrines, and tripod cylinder vessels are a common burial offering (Manzanilla 2002; Rattray and Civera Cerecedo 1999).

Conservation revealed polychrome hieroglyphic painting on the exterior of the cylinder vase. While small glyphic elements are recognizably Maya, others are not identifiable and the inscription overall is both very early and very poorly preserved. Analysis of the text indicates it is Early Classic but largely undecipherable (Alfonso Lacadena, David Stuart, and John Justeson, personal communication 2004, 2012). Given the rarity of finding such an intact vessel in the northern lowlands, it is difficult to assign the cache vessel to existing ceramic types. The red slip and black line drawing over a buff paste is consistent with northern lowland ceramic technology and practice during the Early Classic period, and it is unlikely the vessel is a true import but is rather a local copy, or homology, of a form known best from Central Mexico (Ball 1983; Stanton 2005). The open-work supports do not match the most 
common form of such supports found in the Maya area, but rather a style (Type D in the Ortíz and Santley schema) found most often at Teotihuacan (Hutson 2or2b; Ortíz Ceballos and Santley 1998).

Ceramics from Structure 75 fall within the Oxkintok Regional complex, and both local and imported wares were recovered. Local types include those from the Hunabchen and Kochol groups, and imported types include wares from the Balanza group that show connections with the central Maya lowlands as well as Dos Arroyos from the southern lowlands (Varela Torrecilla and Braswell 2003:26I). Varela Torrecilla and others have described the Oxkintok Regional complex as exhibiting an "inter-regionalism" of ideas and materials from throughout Mesoamerica, in stark contrast to the regionally specific traditions of the beginning of the Early Classic period (Varela Torrecilla and Braswell 2003; Rodríguez Pérez et al. 20II).

The deliberate use of non-local stylistic elements in the architecture, artifacts, and burial patterns of the Lool houselot group signals an effort by residents of this modest household near the center of the site to express ideological connections with pan-Mesoamerican traditions also known as Early Classic internationalism. While the architecture and ceramics of the Lool group are not true imports from outside the northern lowlands, they nonetheless fall outside local (and highly conservative) traditions. Data from the Lool group reflects the intense hybridization that occurred at Chunchucmil during this time, likely as a result of the active Gulf Coast trading systems. The talud-tablero ancestral shrine, cylinder vase, and cremation burial practice can also be seen as material elements that reinforced an identity based on commercial (rather than primarily agricultural) economic activity (Ardren 2015; Magnoni et al. 2014).

\section{THE AAK RESIDENTIAL GROUP}

Horizontal excavations in the Aak houselot (group $S_{2} E_{2}-F$, Op. 9c/3g) uncovered a surprising amount of foreign goods. This houselot, located approximately 600 $\mathrm{m}$ southeast of the site center, consists of five stone structures, four of which were built on an artificially and naturally raised patio platform (figure 12.7). It is labeled to the southeast of the site center in figure 5.I, south of Area F (see also figure I2.4). A total of $336 \mathrm{~m}^{2}$ was excavated in the Aak houselot, including three completely cleared structures $\left(\mathrm{S}_{2} \mathrm{E}_{2}-22,23\right.$, and 24). Three of the four structures on the patio platform are residences. The structure on the east side of the patio $\left(\mathrm{S}_{2} \mathrm{E}_{2}-23\right)$ is an ancestor shrine. Before the shrine was built, a house with a plaster floor (23-subI) occupied the location. At a point early in the history of the group, the floor was broken, a stone-lined cist with two burials was prepared, and the cist and burials were covered by a square platform. At this same time, the patio platform and the 


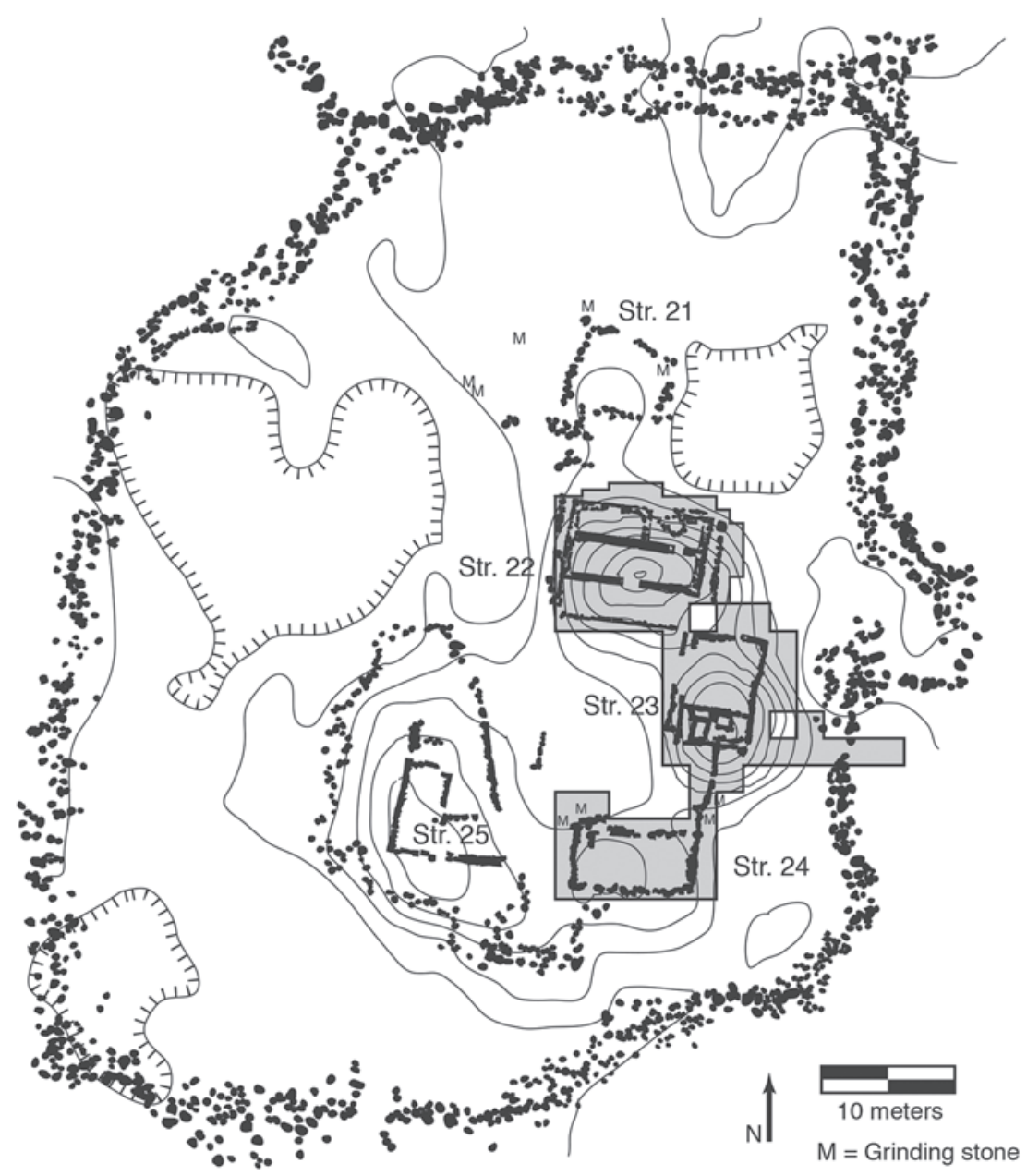

FIGURE 12.7. Map of Group S2E2-F/Aak. Contour lines are $25 \mathrm{~cm}$.

house on the north side of the patio $\left(\mathrm{S}_{2} \mathrm{E}_{2}-22\right)$ were built. This house had masonry walls extending to the roof, which was built of wood beams and mortar. The other two houses ( $\mathrm{S}_{2} \mathrm{E}_{2}-24$ and 25$)$ were built later. They had stone walls rising perhaps halfway to their roofs, which were perishable. Of the three houses, $\mathrm{S}_{2} \mathrm{E}_{2}-22$ was clearly the most elaborate and required the most effort to build. Presuming that there were three nuclear families living in the Aak houselot in its final stages, the head family of the group probably lived in $\mathrm{S}_{2} \mathrm{E}_{2}-22$. The building located off the patio $\left(\mathrm{S}_{2} \mathrm{E}_{2}-2 \mathrm{I}\right)$ was an auxiliary structure, probably a kitchen, given the presence 
of metates nearby. It sat on its own stone platform but was smaller than the houses on the patio and lacked stone walls.

Architectural modifications allow the chronology of the houselot to be divided into five stages. The first stage is not well known and corresponds to 23 -subi, prior to the construction of the patio platform and the shrine. The next stage is marked by the construction of the shrine, patio platform, and $\mathrm{S}_{2} \mathrm{E}_{2}-22$. The final three stages correspond to modifications to the temple as well as other changes. For example, at the beginning of the fourth stage, the construction of Structure $\mathrm{S}_{2} \mathrm{E}_{2}-24$ demolished and covered an earlier kitchen located to the southwest of the shrine, presumably triggering the construction of the $\mathrm{S}_{2} \mathrm{E}_{2}-2 \mathrm{I}$ kitchen off the patio. Elsewhere we have suggested that the latter four stages pertain to four human generations (Hutson et al. 2004).

The albarrada that encircles the Aak houselot encloses an area of 3,910 $\mathrm{m}^{2}$, which is close to both the median and mean area $\left(3,597 \mathrm{~m}^{2}\right.$ and 4,197 $\mathrm{m}^{2}$, respectively) of the 392 architectural groups that were sufficiently well enclosed to permit an area measurement (Magnoni et al. 2012; see also Hutson et al. 2006). The total volume of the structures and platforms in the Aak houselot is $370 \mathrm{~m}^{3}$, which is below the mean and median volumes $\left(443 \mathrm{~m}^{3}\right.$ and $740 \mathrm{~m}^{3}$, respectively) for that same sample of 392 groups. Thus, to the extent that household wealth can be assessed by the volume of architecture (Abrams 1994; M. E. Smith 1987) and the amount of terrain for gardening associated with the houselot (Hutson et al. 2006:87; Smyth, Dore, and Dunning 1995; Tourtellot and Sabloff 1994), the Aak group would be considered average or below average.

The Aak group's average/below-average rank among other houselots at Chunchucmil is what makes the quantity of foreign goods a surprise. These goods include 670 obsidian artifacts, 58 jade ornaments, is Spondylus-shell ornaments, is Spondylusshell fragments, and sherds from a Teotihuacan-style cylinder tripod vessel. All of the Spondylus-shell and all but one of the jade ornaments came from the two burials placed in the cist in the center of the shrine. The other jade ornament was encountered on the plaster floor of one of three stone compartments built immediately south of the shrine in the second and third stages. These compartments were filled in and incorporated by the shrine during the fourth stage. The obsidian, consisting almost entirely of prismatic blade fragments, was found throughout the group, although a bit more than half of the artifacts came from a midden off the northeast corner of the patio. Microscopic use-wear analysis suggests that the occupants used much of the obsidian to process fibers (Hutson et al. 2007). The Teotihuacan-style sherds consist of open-work rectangular supports from two separate vessels. One vessel is a cylinder tripod pertaining to the Chencoh ceramic group, a thin pottery with red slip common at nearby Oxkintok at the end of the Early Classic. The other 
vessel cannot be described because the support to which the vessel was attached was broken off the vessel in such a way that it does not contain diagnostic information on vessel form or finish. Open-work supports are common on vases with planorelief incision at both Teotihuacan (Rattray 200I) and Veracruz (Ortíz Ceballos and Santley 1998). Ortíz Ceballos and Santley present six types of open-work supports, distinguished by their decorations. The two examples from the Aak group are different from each other and pertain to none of Ortíz Ceballos and Santley's six types (Hutson 2012b). Approximately 2 percent of Aak obsidian came from the Pachuca source in Central Mexico, which was controlled by Teotihuacan.

Based on their familiarity with cosmopolitan styles and access to exotic foreign goods (jade, Pachuca obsidian), the occupants of the rather modest Aak houselot (and probably others not yet explored intensively) appear to have been involved in Chunchucmil's long-distance commerce. This differs from a pattern proposed earlier in which elites monopolized long-distance trade in the Classic period (McAnany 1993). At Chunchucmil, it appears that elites (presumed to reside in the quadrangles) cooperated with lower-status households at the site.

\section{CONCLUSION}

Chapters io and is established the presence of marketplace exchange at Chunchucmil and the role of a variety of commodities from within the Chunchucmil economic region; this chapter establishes the role that Chunchucmil played in economic processes that extended well beyond Chunchucmil. Caracol stands as an analogy to Chunchucmil when considering the role it played in long-distance trade. According to Chase and Chase (2014:246) Caracol managed "the flow of metamorphic and other resources out of the Maya Mountains into the Peten, thus impacting trade throughout central Belize and the southeast Peten." LiDAR imagery supports this claim insofar as it shows that Caracol's causeway system extended nearly all the way east to the source of metamorphic rock and west at least to the border of Guatemala (Chase et al. 2014:215). We have argued that Chunchucmil's role in Gulf Coast trade, which minimally involved obsidian, made it a key node-a gateway center-in a much larger economic system: a macroeconomy.

Not surprisingly, Chunchucmil's status as a gateway center exposed it to nonlocal practices and material culture. Some households, like the one that occupied Group $\mathrm{N}_{2} \mathrm{E}_{2}-\mathrm{N} /$ Lool embraced such non-local traits, expressing ideological connections with pan-Mesoamerican traditions also known as Early Classic internationalism. People in the Aak houselot (Group S2E2-F) also embraced internationalism, though in different ways. The other five extensively excavated contexts show less evidence for non-local influence. Nevertheless, the Oxkintok Regional ceramic 
assemblages from these residential groups exhibit an interregional flavor that contrasts with the starkly local and conservative Early Classic ceramic traditions from elsewhere in the northern lowlands. A variety of hypotheses could account for variation in the degree to which households embraced material culture that broadcasts long-distance ties: differences in occupation, differences in the intensity of ties to quadrangles and other leadership institutions, different consumer preferences, and more. We lack the data to test these hypotheses.

The next chapter presses further into Chunchucmil's macroeconomy with a consideration of trade in foodstuffs beyond Chunchucmil's hinterlands to the east. 



\title{
Conclusions
}

\author{
SCOTt R. Hutson
}

Thus far in this book, we have established a number of points about ancient Chunchucmil and its economy. We showed that the city's population was between 31,000 and 48,000 at the end of the Early Classic period (chapters 4 and 5). At this time, the number of people living in Chunchucmil's hinterland was at least as large as the number of people within the site itself (chapter 8). Extensive soil studies showed that the land around Chunchucmil could not have provided enough food to support all of these people (chapter 9). At the same time, Chunchucmil and its hinterland sites to the west were located in a way that enabled them to take advantage of a variety of environmental niches and non-food resources, such as salt, cordage, roofing thatch, and more (chapters 6 and ro). These contextual lines of evidence (see also chapter II) strongly suggest that Chunchucmil engaged in commerce, exchanging non-food resources to ameliorate the shortfall in food production from local land. The identification of a central marketplace and evenly distributed commodities throughout the site further strengthens the argument for the importance of commerce (chapter II). Chunchucmil's central marketplace offered both food and non-food items. The preceding chapter (I2) presented lines of evidence that meet other expectations derived from the hypothesis that commerce was central to Chunchucmil's economy. For example, a Gulf Coast-based trade route extending into the highlands to the south was viable when Chunchucmil was booming, Chunchucmil had a port on the Gulf Coast, there were features that facilitated travel between the port and Chunchucmil, and there is evidence 
within Chunchucmil of material culture resembling that of faraway places. In sum, Chunchucmil was a gateway center.

The picture, however, is incomplete in a variety of ways. Among other things, the authors in this book have not discussed who managed trade, where food came from and how it got to Chunchucmil, nor the political and social consequences of an economy that was based heavily on commerce. The present chapter aspires to tie up these loose ends. I have saved much of this discussion for the final chapter because some of these themes involve a greater degree of speculation. I begin by discussing some of the mechanics of trade (leadership behind long-distance ventures, transport of bulk goods, currencies) and then move to the consequences.

\section{HOW DID TRADE WORK AT CHUNCHUCMIL?}

Discussing the mechanics of trade involves a series of interlocking factors, some of which have been discussed already. For example, we know where Chunchucmil's main market was, we know that this market supplied food (as seen in the high phosphate signatures), pottery, and obsidian (as seen in distributional data), we know the trade routes upon which obsidian traveled from the highlands to Chunchucmil, and we suspect that these distant suppliers got salt in return for obsidian. But precisely who managed this long-distance trade?

To begin the discussion of who managed long-distance trade and how, I focus on trade to the south of Chunchucmil, along the Gulf Coast and then inland to the Petén and beyond. I highlight two goods, salt (because it is an excellent candidate for export from Chunchucmil) and obsidian (because of the ease of tracking trade routes to El Chayal, the main source for Chunchucmil obsidian), while also recognizing first that a broad variety of other goods (greenstone, cacao, feathers, pelts, slaves, dyes, etc.) would also have been on the move and second that trade could have been much more complex than simply salt for obsidian, perhaps involving currencies (see below) and other items. Later in this section I discuss the movement of bulk goods like staple foods.

Revisions of our understanding of the extent of Teotihuacan's obsidian business (Clark 1986) and reconsiderations of the evidence of Teotihuacan influence at Kaminaljuyú (Braswell 2003) make it difficult to claim that Teotihuacan merchants managed the trade of El Chayal obsidian across the Maya area (cf. Brown 1977). Though it may still be safe to assume that elites at Kaminaljuyú controlled access to the El Chayal source (Dreiss and Brown 1989; Nelson 1985), there is room to speculate on who managed the circulation of El Chayal obsidian (and other goods) to and through the lowlands. Given Tikal's presence along the Pasión River in the Early Classic (see chapter 12), the notion that Tikaleños engaged directly in trade 
with the highlands or served as an intermediary marketing hub (Dreiss and Brown 1989:85) is likely.

Even if Tikaleños moved obsidian and other goods not just along the Pasión but also down the Usumacinta and along the Gulf Coast, there is a compelling reason to speculate that people from Chunchucmil also got involved in Gulf Coast/Usumacinta trade. While Mayanists now recognize that more and more Classic-period cities depended for their livelihoods on trade (Freidel and Shaw 2000; King 2015; Masson and Freidel 2012), we have argued in this book that Chunchucmil was in a particularly tight spot in terms of getting a very basic thing: food. Chunchucmileños might have waited for other merchants to bring them what they needed. For example, in the contact period there is documentation of Zoque towns bringing food to towns in the Chontalpa (the area of the Gulf Coast that is now part of the modern Mexican state of Tabasco) that specialized in cacao and salt production but were not agriculturally self-sufficient. Yet to my mind, the people of Chunchucmil, facing food shortages, would have been especially motivated not just to wait for trade but to initiate it on their own. This does not mean that Chunchucmil "controlled" Gulf Coast commerce, nor does it mean that other merchants didn't use Chunchucmil as a port of trade. Chunchucmil may not have gotten much staple food in their trade down the Gulf Coast and into the southern lowlands; I argue below that much of the food trade to Chunchucmil came from people to the east. Even so, trade for non-food goods down the Gulf Coast and into the southern lowlands would still have been linked to basic subsistence at Chunchucmil if we presume, as we did in chapter 12 (see also Hutson et al. 2010), that merchants from Chunchucmil passed on these goods (obsidian, for example) to inland sites. Thus, I speculate that Chunchucmileños organized long-distance trade ventures to the south.

The logistics of these ventures imply coordination and cooperation of many actors (Rathje 1971; Clark 1987:273; Rice 1987:80). These logistics include stimulating the production of surplus goods (such as salt) to exchange for obsidian, outfitting trading expeditions with canoes and other equipment to make the journey, gaining knowledge of and access to provisions and freshwater sources along the route, negotiating safe passage through foreign territory, maintaining trade relationships with producers/suppliers of polyhedral cores far to the south, and conducting the exchange itself, possibly in different languages.

Thus, getting obsidian (and other goods) was a collective enterprise requiring leadership above the level of the household, but probably not so complex an enterprise as to require a centralized state (Chase 1992; Clark 1986). Though the amount of obsidian coming into Chunchucmil and passing through it on the way to other inland sites was not enormous (see Hutson et al. 2010), obsidian was probably not 
the only good coming north to Chunchucmil on canoes. Greenstone (see chapter II, this volume; Woodfill and Andrieu 20I2), feathers, and cacao are also candidates. The volume of trade once again suggests a collective enterprise requiring the guidance of large, resourceful corporate groups. Dahlin (Dahlin and Ardren 2002:269; Hutson et al. 2010) suspected that each quadrangle may have been the headquarters of such a group, serving to store goods, receive visiting merchants, and more. Excavations at the Pich quadrangle (Group $\mathrm{NIEI}_{\mathrm{I}} \mathrm{C}$, chapter s) indicate that it served as a ceremonial space as well as a high-status residence and had the capacity to store goods and receive merchants. The quantities of labor required to construct the pyramids within the quadrangles suggest that the leaders who lived there had the skill, managerial experience, and clout to be able to coordinate local surplus production and long-distance exchange. The labor invested in the pyramids also suggests that these leaders could count on the willing cooperation of some sector of the site's population. Feasts that took place inside the quadrangles (Dahlin et al. 2010:2II-2I2) may have been a reward for followers. An independent line of evidence supports the notion that quadrangles were affiliated with constituencies of supporters. Most quadrangles at Chunchucmil have callejuelas that connect them to a wedge-shaped conglomeration of houselots (Hutson 2016). These conglomerations hold anywhere from 100 to 2000 people and the ceremonial patios of each quadrangle are large enough to accommodate these numbers of people.

The role of leaders in the quadrangles probably extended beyond sponsorship of long-distance trade expeditions. They probably organized the salt harvest, oversaw the central market, and perhaps negotiated trade for foodstuffs. Salt, because it is extremely patchy, occurring only in the salt flats, is a commodity subject to control by a limited number of actors. I imagine that the occupants of quadrangles may have been some of the first settlers at Chunchucmil and claimed ownership over the most productive salt flats (i.e., the principle of first occupancy: McAnany 1995:II2; Webster 1992). It makes sense for leaders to covet salt because it was a strategic trade good in high demand across the lowlands. In the Terminal Classic period, Chichén Itzá controlled salt works located over $100 \mathrm{~km}$ away (Kepecs 2003). Following a well-documented contact-era pattern of followers working the estates of leaders (Foias 2002:227), the laborers who actually worked a particular quadrangle's salt flats were most likely people from the houselots affiliated with that quadrangle, though they could also have been drawn from the small sites to the west of Chunchucmil (see chapter 8). I assume that these saltworkers benefited from their loyalty to the leaders of the quadrangles: they probably received, via redistribution, some of the other exotic goods that came from the trade expeditions organized by quadrangles, such as jade. Excavations in Chunchucmil houselots show access to jade (chapter I2, this volume; Dahlin 2009; Hutson et 
al. 2010:90-91). Households working the salt flats may also have been allowed to pocket their own salt. Perhaps they worked as tenant harvesters. Less-productive salt flats may not have been under the control of quadrangles.

Chunchucmil's central marketplace was probably sponsored and regulated by a coalition of quadrangles because it is located right at the crux of the sacbe system that links the quadrangles. The leaders in the quadrangles had much to gain from a smoothly running market. By selling obsidian and perhaps other long-distance goods at the central market, leaders could get access to goods whose production, unlike salt, they most likely could not control, such as pottery, fibers, cordage, thatch, honey, fish, lumber, and so on (West 2002). By sponsoring marketplaces, they could perhaps levy a charge on vendors who wanted to use a booth at the marketplace (Shaw 20I2). Even if leaders could not benefit economically from marketplaces, they could gain a degree of prestige or symbolic capital from hosting them (Hirth 2010) and could gain an outlet for exchanging goods they collected as tribute (Garraty 2010:20-2I).

Thus far, I have considered (I) exchange between Chunchucmil and people far to the south and (2) exchange within Chunchucmil. A third kind of exchange involves that between people from Chunchucmil and those producing food surpluses beyond Chunchucmil. This is the least-understood aspect of Chunchucmil's economy. To restate the theme of chapter 9, the people of Chunchucmil grew corn in low-yield outfields beyond the site and in small houselot gardens (see Groups $\mathrm{S}_{2} \mathrm{EI}_{\mathrm{I}} \mathrm{G} / \mathrm{Kaab}$ ' and $\mathrm{S}_{4} \mathrm{~W} 8-\mathrm{F} /$ Balam, chapter 5 ) and likely hunted and fished to the west, but they probably needed additional sources of food to feed the minimum number of people $(60,000)$ in the area. Dahlin often noted that some of the best land for farming in Yucatán is located between 50 and $100 \mathrm{~km}$ to the east, just north of the Sierrita de Ticul between the modern towns of Muna and Oxkutzcab. This area was a major granary of Yucatán during the colonial period (Patch 1977; Kurjack et al. 1979; Kurjack and Garza Tarazona de González 1981; Robles Castellanos and Andrews 1986). Compared to the Chunchucmil region, this area was relatively underpopulated when Chunchucmil reached its peak (Garza Tarazona de González and Kurjack 1980), suggesting that it could have been a breadbasket during the Classic period as well. Roman Piña Chan's (1978) survey of the 1549 Lista de Tributos showed that people from this exact area, the Maní province, produced major surpluses in corn. The people from the Ah Canul province, located in between Chunchucmil and the Maní territory, also produced surplus corn.

A number of studies show that in Mesoamerica, distances of between 50 and $100 \mathrm{~km}$ are entirely feasible in terms of costs and benefits for humans transporting bulk foods like corn by foot. Drennan (1984a, 1984b) estimated that costs outweigh benefits once the travel distance reaches $137.5 \mathrm{~km}$, or $275 \mathrm{~km}$ round trip (see also 
Cowgill 1993; Sluyter 1993). According to Sahagún, maize came to the Tlatelolco market from as far as $200 \mathrm{~km}$ away (Hirth 2013:93). Elsewhere in Central Mexico during the contact period, the Relaciones Geográficas document families traveling between 50 and $160 \mathrm{~km}$ to get maize, and people regularly moving crops $100 \mathrm{~km}$ in times of local shortfalls (Hirth 2013:93). Using tumplines or backracks, porters could carry loads of $40 \mathrm{~kg}$ (McAnany 2010:254) and perhaps up to $90 \mathrm{~kg}$ (Hirth 2013:92). As Masson and Freidel note (2012:477; 2013:219), food interdependency among regions separated by such distances was probably very common among the ancient Maya. Culbert (1988) argued that Tikal imported food from up to $100 \mathrm{~km}$ away in the Late Classic period. Average annual rainfall may vary up to $50 \mathrm{~cm}$ per year in adjacent areas and it is also the case that within a single area that receives similar average rainfall per year, some places by mere chance alone get more or less rain in any given year. Thus, localized droughts and fluctuations in agricultural productivity drove a need for bulk food exchange (Freidel and Shaw 2000; Masson and Peraza Lope 2014:274). We have argued in this book that bulk food exchange at Chunchucmil occurred steadily, as opposed to merely on the occasion of drought. Corn could be stored for up to three years and leaders amassed currencies such as shell beads to trade for corn (Freidel and Shaw 2000). Marketplaces in Mesoamerica played a key role here because they "had an enormous effect in mobilizing bulk resources over short to intermediate distances of 30 to $150 \mathrm{~km}$ " (Hirth and Pillsbury 2013a:15; see also Hirth 2013; Tokovinine and Beliaev 2013:170).

The difficulty resides in specifying the details of exchange with food producers $50-100 \mathrm{~km}$ to the east. Such producers would not have been part of Chunchucmil's polity. If they were part of some other polity, we need to consider how goods moved from one polity to another. Carol Smith (1976) provided several models for this sort of movement (see also chapter iI). In the solar marketing model, each polity would have a major market in the polity capital and producers in the hinterlands were only able to use markets at their capital. If a solar market model was in operation, a limited amount of goods crossed polity boundaries and they did so as part of official diplomatic missions. Alternatively, in an interlocking market system, political boundaries did not heavily affect economic boundaries. Unlike a solar marketing system, there would have been several secondary markets and producers could choose which market to use. Evidence can be found for both solar market systems and interlocking market systems. At Tikal and Palenque, common utilitarian pottery appears to have circulated within polity bounds, as part of a solar marketing system (West 2002). Sheets (2000) argues that villagers at Cerén in El Salvador had a choice of which markets to use, thus implying an interlinked market system. The presence of markets not just at large cities but also at smaller Classicperiod centers like Motul de San José, Buenavista, and Trinidad de Nosotros leads 
Masson and Freidel (2012:478, 2013:220) to argue for interlinked market systems in the southern lowlands. Tokovinine and Beliaev (2013:170-172) review contactera ethnohistorical sources from highland Chiapas that indicate voluminous trade across political boundaries, falling in line with a broader argument about moreintensive commercialism in the Postclassic (Masson 2002b; Sabloff and Rathje 1975). Braswell (2010) has argued that the degree of boundedness in market systems correlates with the degree of political centralization: areas or eras of decentralization feature less-bounded market systems. Competing political alliances affected the flow of goods during the highly centralized Late Postclassic in Central Mexico (Minc 2006) and during Classic-period antagonisms between Tikal and Calakmul (see below).

At present, we do not understand the archaeology between Chunchucmil and the potential breadbasket to the east during the middle of the Classic period well enough to specify precisely how exchange across this distance occurred. In a solar market system, high-level leaders would be more heavily involved. Yet the lack of massive Early Classic sites in the area between Muna and Oxkutzcab suggests that there may not have been strong leaders involved. In a less bounded system, a variety of types of actors and groups could get involved. Quadrangle leaders could have commissioned porters to take salt or long-distance goods such as obsidian to the east in exchange for food. Alternatively, smaller social units, such as large households, could have amassed a surplus of coastal, estuarine, and savanna resources and sent a few people eastward to exchange them for food. They could consume that food themselves or sell it at Chunchucmil's market in exchange for obsidian or perhaps more fungible equivalencies. The chemical data presented in chapter to and elsewhere (Dahlin et al. 2007, 2010) certainly point to sales of food at Chunchucmil, as do the murals at Calakmul, though a case can be made that this kind of food selling is more like a restaurant and less like a grocery (Speal 2014).

Speaking of equivalencies, did any of this trade involve currency? Freidel and Shaw (2000) argue that currencies would have been particularly useful in non-local trade for maize. Currencies used widely in Postclassic Mesoamerica include cacao beans, metal bells, salt, and cotton mantles (Berdan 2003). In the Maya area, jade and Spondylus beads could also have been used as currency (Freidel et al. 2002). The use of beads and cacao beans as currency in Classic-period Maya markets would blur the distinction between what Hirth (2010:233) calls staple goods markets and prestige goods markets. Indeed, Masson and Freidel (2013:20I) call for precisely the kinds of economic models that reconnect staple and wealth finance. Very few commercial items have an exchange equivalence of precisely the same value; one usually costs more than the other. Here, a currency such as salt, which is infinitely partible and divisible, could have served as a third item, added to the value of the 
less-expensive item, to establish the equivalency of a transaction. Such currencies may also have been used to pay for services along trade routes. Finally, traders who had established mutual trust though multiple successful exchanges may have used credit in some transactions.

\section{HOW DID CHUNCHUCMIL'S ECONOMY DEVELOP?}

Given the scarcity of pure Late Preclassic contexts at Chunchucmil (chapter 4 ), we have difficulty understanding precisely how Chunchucmil grew from a modest settlement to a large city engrossed in commerce. Based on a survey of premodern societies across the world, Blanton and Fargher (2010) note that highly commercialized economies develop in contexts where there is collective political organization, large population, and potential for agricultural surplus (see also Sanders and Webster 1988; Trigger 1972:582-584). Chunchucmil never had much potential for agricultural surplus. In place of agricultural surplus, Chunchucmil could have maximized several other resources such as salt. When Chunchucmil was booming, it appears to have had collective political organization (see below) and a large population, yet large population could have been a result of commercialization as opposed to a cause of it (Ardren 2015). Marketplaces attract people because they make exchange more efficient. They provide a space where buyers can find a variety of sellers and goods, and where sellers can find a critical mass of buyers. This spares buyers and sellers from having to travel very far to complete their transactions. Marketplaces also help households provision themselves. Furthermore, as an outlet for exchanging surpluses, marketplaces provide an incentive for households to specialize in crafts and increase surplus production (Hirth and Pillsbury 2013a:16).

Whereas these attractions of marketplaces tend toward the economic, marketplaces also provided other kinds of attractions. The best information for this comes from ethnohistorical sources on Central Mexican markets in the sixteenth century (Hutson 2000). The variety of goods for sale at the Tlatelolco marketplace, adjacent to the Aztec capital of Tenochtitlán, astounded the first Spaniards who saw it. Many people went to the market just to see what was sold. Others came to gossip, socialize, and stroll. Clendinnen (1991:147-148) drew explicit attention to the possibility that the social excitement of the market was its main draw: like any other "large, promiscuous social gathering," the Aztec market "exercised a powerful attraction over its habitués." Natives found great pleasure in visiting the market (Durán 1951:2:216-217; Torquemada 1943:556). A variety of spectacles occurred at the marketplace: slaves performing, slaves attempting to escape, executions of thieves, foreigners with distinctive clothing, and occasional carnival-style buffoonery with bodily humor. Young men and women caroused and flirted (Durán 1951:1:256). I 
have argued before that Mesoamerican marketplaces were liminal spaces where social-status hierarchies were suspended, encouraging not only unpredictable interactions but also commerce between people who might not interact with each other in other contexts (Blanton 2013; Hutson 2000).

In any event, once a properly run market gets going, it can bring fame to a settlement and attract more people to it (Hirth 2010; Hutson 2016). In both the Maya area and Central Mexico, authorities boosted the attractiveness of markets by enforcing honesty and order (Hirth 2010:238; Masson and Freidel 2013:208). Not all markets have such oversight features. The fact that Chunchucmil boomed as a market city suggests early elite oversight of its market. Yet we do not really know which came first at Chunchucmil, the market or the masses of people. Chunchucmil had Late Preclassic settlement and the fact that Canbalam had Late Preclassic pottery implies that Chunchucmil's Late Preclassic population was active on the Gulf Coast. If Late Preclassic Chunchucmil were a port of trade active in obsidian, as was Classic-period Chunchucmil, we might expect some blades from the San Martín Jilotepeque/Río Pixcaya source, which boomed in the Late Preclassic (Braswell 2002). Yet such blades are absent at Chunchucmil. Thus, we simply do not know whether Chunchucmil had a deep history as a port of trade (cf. Caracol, which played a major role in long-distance exchange well before its period of peak occupation; Chase and Chase 2014:246).

Though we are uncertain about precisely how commercialism developed at Chunchucmil, Dahlin believed that the timing of this development fits well in a sequence proposed by Blanton and colleagues (2005:273-275). This sequence consists of three empirically derived if loosely defined and overlapping stages. The sequence begins in the Preclassic period with the production of prestige goods, items that conferred "symbolic and processual significance in the political realm" (2005:274). They included, for example, cacao, jaguar skins, fine ceramics, jade adornments, and iron pyrite mirrors. They entailed, among other things, changes in pottery-making methods and lapidary methods in semiprecious stone as chiefdoms and early states emerged from purely egalitarian societies. The transformation from this exclusively prestige economy to a "regional goods" economy began somewhat later in the Preclassic. The regional goods economy characterized some parts of prehistoric Mesoamerica throughout the Classic and Postclassic periods and persists in the market economies of the region to this day. "Regional goods developed primarily in the context of regional-scale systems of tribute flows and periodic markets" (Blanton et al. 2005:274). In addition to prestige goods, a regional goods economy included the production and exchange of utilitarian items on a broad and intensified scale as responses to production problems attendant upon (I) regional population pressures and urbanization, (2) new demands imposed by state formation, 
and (3) the innovation of new, more-intensive production technologies. Blanton et al. list utilitarian pottery, cotton, salt and obsidian as examples. Chunchucmil's exchange system fits the regional goods stage. Finally, Blanton et al., following Kepecs $(2003,2005)$, postulate an era of trade in "bulk luxury goods" that is characteristic of greater Mesoamerica’s Postclassic period.

Though Chunchucmil stands as an example of a regional goods economy, the traditional point of view is that most Maya sites were regal-ritual cities with little commerce prior to the Postclassic period (Sanders and Webster 1988). Within this context, Dahlin (2009) referred to Chunchucmil as being "ahead of its time." Dahlin's claim that Chunchucmil was ahead of its time implies that most other Classic-period Maya economies were indeed relatively un-commercialized. If this were the case, then Chunchucmil would be a mere outlier among Maya cities and therefore inconsequential to a general understanding of the ancient Maya. In the following section, I argue that this is not the case; that the narrative presented in this book brings about several important consequences regarding our understanding of Maya life.

\section{CONSEQUENCES OF THE IMPORTANCE OF MARKETING}

What makes this book's full findings about Chunchucmil and its hinterland more important is the fact that they do not stand alone. Since Dahlin and Ardren's 2002 hypothesis that there was a high degree of commercialism at Chunchucmil, convincing data on marketplaces have come from several major cities, such as Caracol (Chase and Chase 2014), Tikal (Masson and Freidel 2012; Jones 2015), Calakmul (Martin 20I2) and Cobá (Coronel et al. 2015). For example, in showing that the distribution of artifacts at Tikal nearly matches that of Postclassic Mayapán, Masson and Freidel (2012) demonstrate that Chunchucmil was only slightly ahead of its time.

Unquestionably, marketing occurred alongside other forms of exchange, such as redistribution (LeCount 1999; 200I), but archaeologists can no longer claim that redistribution anchored Maya political economies (Aoyama 200ra, 200rb; Webster 1998). Managing urban economies with redistribution would have been too large an undertaking for Maya leaders (Dahlin et al. 2010; McAnany 2010:263; Shaw 2012). Close studies of historical records from many eras and many parts of the world suggest that redistribution as a kind of economy (see Polanyi 1944; Sahlins 1963) never really existed (Earle 1977; Feinman and Garraty 2010). Finally, marketplace exchange can explain distributions of objects said to be produced by redistribution (Hirth 2010; Hutson et al. 2010).

Were Maya cities as commercialized as Tlatelolco/Tenochtitlán or Teotihuacan? No, but it should be noted that such Central Mexican behemoths were outliers 
(Manzanilla 2012:55): the more common, smaller Central Mexican cities were also not as commercialized as Tenochtitlán (M. E. Smith 2008). Furthermore, similarities between contact-period markets in the Maya area and Central Mexico are extensive (Masson and Freidel 2013:table 8.I). Were all Maya economies as highly commercialized as Chunchucmil? No. Maya settlements can be arranged on a continuum from less commercial to more commercial (Garraty 2010:18; Masson and Freidel 2013:221; M. E. Smith 2004). One might be tempted to say that the high degree of commercialism at places like Caracol, Tikal, and Chunchucmil was unique to large cities. However, research in the countryside shows that marketing played an important role in rural economies as well. For example, Scarborough and Valdez (2009) argue that resource-specialized communities in northwest Belize were economically interdependent and exchanged surpluses with each other in rural markets. Sheets (2000) finds that within the small community of Cerén, different households specialized in specific crafts and bartered surpluses with each other but also brought surpluses to regional market centers to exchange for goods like Copador polychrome offered by elites.

The topic of interaction between farmers and elites (or lack thereof, as Scarborough and Valdez [2009] maintain) brings forward the notion of a dual economy, consisting of an elite sphere involving production and exchange of very prestigious goods (exquisite polychrome pottery, jade adornments) that exhibits little or no overlap with the production and exchange, by non-elites, of mundane goods such as utilitarian pottery. The cooperation between quadrangle leaders and affiliated houselots at Chunchucmil, as put forward above, challenges the separations inherent in the dual-economy model (see also Hutson et al. 20ro). This challenge becomes more consequential when paired with studies like that of Kovacevich (2007, 2013), which show that the production of jade ornaments at Cancuén involved both noble and humble households (see also McAnany 2010:267 on interdependency).

What we have found at Chunchucmil also has consequences for broader debates about the kinds of cities one finds in the Maya area. Chunchucmil lacks the massive monumental architecture normally found in cities of similar size and, with the exception of the marketplace, has no broad, central plaza/performance space. Instead, the biggest architecture (temples ranging from 8 to $17 \mathrm{~m} \mathrm{high}$ ) and the clearest formal ceremonial spaces are found inside the quadrangles. The largest quadrangle-NIEI-G/Chakah-is not drastically larger than the others, though it is the only architectural compound at Chunchucmil with a ballcourt. If NIEI-G were the seat of authority at Chunchucmil (Dahlin and Ardren 2002:269 refer to it as the first among equals), it was not a major regal-ritual focus, because it lacked a large performance space. The size of patios in quadrangles ranges from 0.I to 0.6 ha, with a mean of 0.25 ha (Hutson 2016:table 4.I). Though the entire city could 
fit in the patios of the site's quadrangles, no single patio could hold more than a small fraction of the site's population. This stands in contrast to other lowland Maya cities in which a single massive monumental architectural complex towered over others and served as a stage for public civic/religious (Inomata 2006). Thus, there is reason to think that Chunchucmil's growth and urban development were not driven by a desire to provide a public ritual venue for a divine king and his retinue. Instead, Chunchucmil's urban form reflects a concern for trade. If each of the is quadrangles in the site core represents a faction, or competing trade cartel, the fact that they are all linked to each other by a network of causeways (see figure 2.5) suggests they had a stake not just in competition but also cooperation (Hutson et al. 2010). Maya cities were central places for more than just the leadership of the polity (Chase et al. 1990; Masson and Freidel 2012:476; M. E. Smith 1989; Trigger 2003:I21; cf. Sanders and Webster 1988; Webster and Sanders 200I). Chunchucmil was a central place for commerce.

The finding that Chunchucmil was not a regal-ritual center leads to one of the most commonly posed questions: how did economy and authority intersect? In the context of markets, Hirth (2010:234-235; see also Garraty 2010) frames this as a question of top-down or bottom-up. Did the development of marketplaces require elite management, as Polanyi argued, or did marketplaces grow organically from reciprocal exchanges between households? Hirth prefers the bottom-up approach, not merely because there is documentation of markets that flourished without strong government involvement (Blanton and Fargher 2010), but because households are generally not self-sufficient. All over the world households therefore seek an efficient exchange mechanism for provisioning themselves. Graeber (20II) arrives at a very different conclusion by approaching the topic from the question of the origins of currency and debt. According to Graeber, nearly all economists agree (alongside Hirth and others) that households produce only a portion of their needs and therefore must enter into exchange with other households. Since barter is too inefficient, markets and currency appear. In arguing for an essentially governmentfree origin for markets, contemporary economists retain a cornerstone of Adam Smith's Wealth of Nations - that money, property, and exchange predate political institutions-while also justifying once again the existence of economics as a field of human inquiry distinct from (not embedded in) politics or ethics (Graeber 20II:24-25). Yet Graeber points out that barter as the primeval form of exchange never existed. Other kinds of exchange, often involving gifting, delayed returns, and extended-kin networks, precede markets. When they make their first appearance in places like Sumeria, markets do so as an adjunct to temple and palace institutions.

What can Chunchucmil contribute to this top-down/bottom-up debate? On the one hand, markets at Chunchucmil existed independently of the kind of 
ruling institution found at other large Maya cities if only because such an institution does not appear to have existed at Chunchucmil. On the other hand, I argue above that suprahousehold institution anchored in Chunchucmil's quadrangles organized local surplus production and long-distance trade ventures. This activity kept Chunchucmil viable in a land of low agricultural returns. Though no particular quadrangle controlled Chunchucmil's marketplace, each of the quadrangles as trade factions benefited from and depended on the marketplace and likely worked together to ensure its continued existence.

As a final consequence, this study shines a light on gender in Maya cities. Royal and noble men and women are often displayed in Maya art (Joyce 1996), but depictions of non-noble men and women are less common. Figurines and decorated pottery show women weaving, preparing food, and rearing children, while men hunt and wage war (Hendon 1997; Joyce 1993). It is difficult to state who did other things, such as tending bees, gathering materials as diverse as water, herbal medicine, and firewood, and making everything from baskets to stone tools to pots to plaster. For example, essentially no art depicts the practice of farming. Robin (2006) shows the risks in using ethnohistorical and ethnographic evidence to infer men's or women's participation in farming (Robin 2006). It is even more difficult to assess how particular activities might have empowered ancient actors. Getting at the gender of commerce is no easier, but there are some very promising leads. Commerce was a public domain in which Mesoamerican women played extensive roles. In Aztec marketplaces, women worked as both vendors and administrators. Though some women who worked in markets may have been poor (Brumfiel i991), they could both gain prosperity in the market (Sahagún 1950-1982:4:2) and, as administrators, control some aspects of its development. In other words, marketplaces appear to be a realm in which women could excel (Blanton 2013; Hutson 2000) and contest unequal gender ideologies (Brumfiel 1996).

Ethnohistorical evidence from the Maya area implies strong participation of women not only as buyers and sellers in the marketplace (King 2015; Wurtzburg 2015) but as participants in long-distance trade voyages: Christopher Columbus found women on a seagoing merchant's canoe off the coast of Honduras (Colón 1959:232). The murals in the Calakmul marketplace confirm what ethnohistorical sources suggest: they depict both women and men selling various goods, implying that the marketplace featured as much social diversity as could be seen at Tlatelolco. Houston (2014) infers female prostitution at Classic-period Maya marketplaces, something also found at Tlatelolco. If we take the leap of engendering the faces found in a trade center like Chunchucmil, we would see many active and empowered men and women (Tringham 199I). I don't think Chunchucmil was alone in this regard. 


\section{THE END}

Taken together, the chapters in this book suggest that Chunchucmil's growth and urban development were driven by long-distance trade, that the success of this trade attracted a population that eventually exceeded local carrying capacity, and that a burgeoning market economy in staple supplies compensated for food deficits. But by $700 \mathrm{CE}$, the city had shrunk to less than a tenth of its peak size (Magnoni 2008). How did Chunchucmil's success come to an end? Chunchucmil was unquestionably linked to a Mesoamerica-wide sphere of exchange. The collapse of Teotihuacan in the seventh century upset some aspects of this sphere, but more compelling causes for Chunchucmil's decline can be found within the Maya area.

For example, the Pasión River portion of the trade route that brought obsidian to Chunchucmil was heavily influenced by Tikal in the Early Classic but came under Calakmul's control in the seventh century (Freidel et al. 2007; Martin and Grube 2008). Unlike many sites in the northern lowlands during the Early Classic (see, for example, Puuc sites like Chac II [Smyth and Rogart 2004:figure 2] or sites in the Ucí/Izamal/Aké area [Hutson and Welch 20I4]), Chunchucmil's domestic architecture conforms closely to Petén-like plazuela groups (see chapter 3 ). This suggests that Chunchucmil had close ties to the southern lowlands and may have been affected by Calakmul's ascendancy, unquestionably the largest transformation in southern lowlands politics at the time. We do not think that southern lowland kings intervened directly in Chunchucmil's affairs (cf. Suhler and Freidel 1998), but we do believe that political upheaval in the south could have disrupted Chunchucmil's commercial system. Furthermore, competition from Salinas de los Nueve Cerros, a major salt producer in the southern lowlands, might have reduced the southern lowland demand for Chunchucmil's salt in the Late classic, precisely when Chunchucmil declines. Only 6 percent of the pottery at Salinas de Los Nueve Cerros dates to the Early Classic, but 56 percent dates to the Late Classic (Woodfill et al. 2015: table 2), suggesting that Salinas de los Nueve Cerros's salt production was not substantial in the Early Classic but boomed in the Late Classic, potentially elbowing out Chunchucmil.

Even closer to home, the leaders of Oxkintok, located $27 \mathrm{~km}$ to the east of Chunchucmil, constructed monumental architecture and erected carvings with long-count dates during the exact time when Chunchucmil experienced its major periods of growth, the fifth and sixth centuries CE. As noted in chapter 4, these two sites used nearly identical pottery at the time. Though settlement survey at Oxkintok shows that the site was much smaller than Chunchucmil when Chunchucmil reached its apogee, Oxkintok began a growth spurt toward the end of the seventh century (Velázquez Morlet and López de la Rosa 1995). Oxkintok stands directly in between Chunchucmil and the area $50-100 \mathrm{~km}$ to the east from which we believe 
Chunchucmil acquired some of its food. The fact that Chunchucmil declined as Oxkintok grew may not be a coincidence. The rise of Oxkintok as a regional power may have enabled it to limit Chunchucmil's access to nearby foodstuffs.

Disruption of trade routes near and far serve merely as a trigger (cf. Willey 1974) that upset what was at root a precarious subsistence strategy. In other words, once Chunchucmil had grown to the point that it needed overland food imports from 50 to $100 \mathrm{~km}$ away, a series of variables not fully under Chunchucmil's control had to realign continually in order to keep the city afloat. If one of those variables changed-if diplomacy between Chunchucmil and its suppliers went awry, if the suppliers encountered unexpected difficulties in producing surpluses (due, for example, to fluctuations in rainfall), or if the suppliers were forced to deliver their surplus elsewhere (to Oxkintok, to Calakmul)-Chunchucmil could go belly up. In a manner perhaps analogous to the boom-and-bust cycles that propelled spectacular but short-lived Terminal Classic cities in the nearby Puuc hills (Carmean et al. 2004; Isendahl et al. 2014), Chunchucmil's prosperity simply could not be sustained.

The fact that Chunchucmil collapsed does not mean, however, that Chunchucmil was a hopeless experiment and that, by extension, commercial development in the Maya area was doomed to fail. Data from many other sites, gathered partly in response to Dahlin's stimulating ideas, join data from Chunchucmil demonstrating that marketplaces were a key component of Classic-period Maya economies. To the extent that economic systems are the foundation of complex societies, the archaeological debate over the relative importance of markets and other forms of exchange can only grow. Like a venerated ancestor continuing to bear witness to the goingson of kith and kin, Dahlin will be pleased to see this. 



\section{References}

Abrams, Elliott. 1994. How the Maya Built Their World. Austin: University of Texas Press.

Adams, Richard E. W. 1978. "Routes of Communication in Mesoamerica: The Northern Guatemalan Highlands and the Peten". In Mesoamerican Communication Routes and Cultural Contacts, ed. Thomas A. Lee and Carlos Navarrete, 27-36. Papers of the New World Archaeological Foundation No. 40. Provo, UT: Brigham Young University Press.

Adams, Richard E. W., and Richard C. Jones. 1981. "Spatial Patterns and Regional Growth among Maya Cities." American Anthropologist 46:301-322.

Aldama-Aguilera, Cristóbal, Celina Llanderal-Cázares, Marcos Soto-Hernández, and Luis E. Castillo-Márquez. 2005. "Producción de Grana-Cochinilla (Dactylopius coccus Costa) en plantas de nopal a la intemperie y en microtúneles” "“Cochineal [Dactylopius coccus Costa] Production in Prickly Pear Plants in the Open and in Microtunnel Greenhouses"). Agrociencia 39:16I-171.

Alston, Richard. 1998. "Trade and the City in Roman Egypt." In Trade, Traders and the Ancient City, ed. H. M. Parkins and C. Smith, 168-202. London: Routledge.

Anawalt, Patricia. 1981. Indian Clothing Before Cortes. Norman: University of Oklahoma Press. Ancona Aragón, Iliana. 2014. "Residencias habitacionales de élite en la periferia de Oxkintok: La evidencia cerámica." Los Investigadores de la Cultura Maya 22(II):I53-178. Campeche: Universidad Autónoma de Campeche.

Ancona Aragón, Iliana, and Socorro del Pilar Jiménez Álvarez. 2005. "Las cerámicas Gris y Negra Fina como marcadores de interacción en el litoral Campechano." Los Investigadores de la Cultura Maya I3(I):209-218. Campeche: Universidad Autónoma de Campeche. 
Anderson, David S., Daniel A. Bair, and Richard E. Terry. 2012. "Soil Geochemical Analyses at the Preclassic Site of Xtobo, Yucatan, Mexico." Ancient Mesoamerica 23(2):365-377. http://dx.doi.org/10.1017/S0956536112000247.

Andrews, Anthony P. 1983. Maya Salt Production and Trade. Tucson: University of Arizona Press. Andrews, Anthony P. 1984. "Long-Distance Exchange among the Maya: A Comment on Marcus." American Antiquity 49(4):826-828. http://dx.doi.org/10.2307/279749.

Andrews, Anthony P. 1990. "The Role of Trading Ports in Maya Civilization." In Vision and Revision in Maya Studies, ed. F. S. Clancy and P. D. Harrison, 159-168. Albuquerque: University of New Mexico Press.

Andrews, Anthony P. 1998. "El Comercio Maritimo de los Mayas del Posclasico." Arqueología Mexicana 6(33):16-23.

Andrews, Anthony P. 200I. "Notes on the History of Chunchucmil, Yucatan, and Venezia, Campeche." Unpublished Manuscript in possession of authors.

Andrews, Anthony P. 2008. "Facilidades Portuarias Mayas." In El Territorio Maya: Memoria de la Quinta Mesa de Palenque, ed. Rodrigo Liendo Stuardo, I4-40. Mexico City: Instituto Nacional de Antropología e Historia.

Andrews, Anthony P., and Tomás Gallareta Negrón. 1986. “The Isla Cerritos Archaeological Project, Yucatan, Mexico." Mexicon 8(3):44-48.

Andrews, Anthony P., Tomás Gallareta Negrón, and R. Cobos Palma. 1989. "Preliminary Report of the Cupul Survey Project." Mexicon II (5):9I-95.

Andrews, Anthony P., and Shirley B. Mock. 2002. "New Perspectives on the Prehispanic Salt Trade." In Ancient Maya Political Economies, ed. M. A. Masson and D. A. Freidel, 307-334. Walnut Creek, CA: Altamira.

Andrews, Anthony P., and Fernando Robles Castellanos. 2004. "An Archaeological Survey of Northwest Yucatan, Mexico." Mexicon 25:7-14.

Andrews, Anthony P., and Fernando Robles Castellanos. 2014. "Los primeros pobladores." In Historia General de Yucatán, Volume i: La Civilización Maya Yucateca, ed. Sergio Quezada, Fernando Robles, and Anthony P. Andrews, 44-6r. Yucatán, México: Mérida.

Andrews, E. Wyllys, IV. 1969. The Archaeological Use and Distribution of Mollusca in the Maya Lowlands. Middle American Research Institute Publication 34. New Orleans: Middle American Research Institute, Tulane University.

Andrews, E. Wyllys, IV, and E. Wyllys Andrews, V. 1980. Excavations at Dzibilchaltun, Yucatan, Mexico. Middle American Research Institute Publication 48. New Orleans: Middle American Research Institute, Tulane University.

Andrews, E. Wyllys, V. 1989. The Ceramics of Komchen, Yucatán. New Orleans: Middle American Research Institute, Tulane University.

Andrews, E. Wyllys, V, and Georgy J. Bey III. 20II. The Earliest Ceramics of the Northern Maya Lowlands. New Orleans: 8th Tulane Maya Symposium.

Andrews, George F. 1975. Maya Cities: Placemaking and Urbanization. Norman: University of Oklahoma Press.

Andrews, George F. 1984. Edzna, Campeche, Mexico: Settlement Patterns and Monumental Architecture. Culver City: Foundation for Latin American Anthropological Research. 
Andrews, George F. 1985. "Chenes-Puuc Architecture: Chronology and Cultural Interaction.” In Arquitectura y Arqueologia: Metodologias en la Cronologia de Yucatan, II-40. Etudes Mesoamericaines, serie II-8. Mexico City: Centre D'etudes Mexicaines et Centramericaines.

Andrews, George F. 1995. Architecture of the Puuc Region and the Northern Plains Areas. vol. I. Pyramids and Palaces, Monsters and Masks: The Golden Age of Maya Architecture. Lancaster, CA: Labyrinthos.

Aoyama, Kazuo. 1995. "Microwear Analysis in the Southeast Maya Lowlands: Two Case Studies at Copan Honduras." Latin American Antiquity 6(2):I29-144. http://dx.doi.org/10.2307 1972148 .

Aoyama, Kazuo. 2001a. Ancient Maya State, Urbanism, Exchange, and Craft Specialization: Chipped Stone Evidence of the Copan Valley and the La Entrada Region, Honduras. Memoirs in Latin American Archaeology, no. 12. Pittsburgh: University of Pittsburgh.

Aoyama, Kazuo. 20orb. "Classic Maya State, Urbanism, and Exchange: Chipped Stone Evidence from the Copan Valley and its Hinterland." American Anthropologist 103(2):346-360. http://dx.doi.org/10.1525/aa.2001.103.2.346.

Appleby, Gordon. 1976. "The Role of Food Needs in Regional Development: Puno, Peru." In Regional Analysis, vol. I. ed. C. Smith, 147-178. New York: Academic Press. http://dx.doi.org/10.1016/B978-0-12-652101-6.50013-9.

Ardren, Traci. 2003. "Excavations at the Lool Group." In Pakbeh Regional Economy Program: Report of the 2002 Field Season, ed. Bruce H. Dahlin and Daniel E. Mazeau, 42-47. Washington, DC: Department of Sociology/Anthropology, Howard University.

Ardren, Traci. 2015. Social Identities in the Classic Maya Northern Lowlands: Gender, Age, Memory, and Place. Austin: University of Texas Press.

Ardren, Traci. In press. "Savanna Products and Resources Abundance: Asking the Right Questions about Ancient Maya Trade and Urbanism." In Abundance: The Archaeology of Plenitude, ed. Monica Smith. Boulder: University Press of Colorado.

Ardren, Traci, and Justin Lowry. 20rra. "The Travels of Maya Merchants in the Ninth and Tenth Centuries AD : Investigations at Xuenkal and the Greater Cupul Province, Yucatan, Mexico.” World Archaeology 43(3):428-443. http://dx.doi.org/10.1080/00438243.2011.607613.

Ardren, Traci, and Justin Lowry. 20Irb. "Intercambio a largas distancias y mantenimiento identitario en Chunchucmil durante el Clásico Temprano." Paper presented at the Tercer Congreso Internacional de la Cultura Maya, Mérida, Yucatán, México.

Ardren, Traci, T. Kam Manahan, Julie K. Wesp, and Alejandra Alonso Olvera. 2010. "Cloth Production and Economic Intensification in the Area Surrounding Chichen Itza." Latin American Antiquity 2I(3):274-289. http://dx.doi.org/10.7183/1045-6635.21.3.274.

Arnold, Jeanne, and Anabel Ford. 1980. "A Statistical Examination of Settlement Patterns at Tikal, Guatemala." American Antiquity 45(4):713-726.

Arnold, Phillip. 1990. "The Organization of Refuse Disposal and Ceramic Production within Contemporary Mexican Houselots." American Anthropologist 92(4):915-932. http://dx.doi .org/10.1525/aa.1990.92.4.02a00040. 
Ashmore, Wendy. 198I. "Some Issues of Method and Theory in Lowland Maya Settlement Archaeology." In Lowland Maya Settlement Patterns, ed. W. Ashmore, 37-70. Albuquerque: University of New Mexico Press.

Ashmore, Wendy, and Richard Wilk. 1988. "Household and Community in the Mesoamerican Past." In Household and Community in the Mesoamerican Past, ed. R. Wilk and W. Ashmore, I-27. Albuquerque: University of New Mexico Press.

Ashmore, Wendy, and Gordon R. Willey. 1981. "A Historical Introduction to the Study of Lowland Maya Settlement Patterns." In Lowland Maya Settlement Patterns, ed. W. Ashmore, 3-18. Albuquerque: University of New Mexico Press.

Back, William, and Bruce B. Hanshaw. 1970. "Comparison of Chemical Hydrogeology of the Carbonate Peninsulas of Florida and Yucatan." Journal of Hydrology (Amsterdam) Io(4):330368. http://dx.doi.org/10.1016/0022-1694(70)90222-2.

Brinkhoff, Thomas. 2015. City Population. Accessed I March 2015. http://www.citypopulation .de/php/mexico-yucatan.php?cityid=31052000I.

Baer, Donald Franklin. 1976. "Systematics of the Genus Bix and Geography of the Cultivated Annotta Tree." PhD dissertation, University of California, Los Angeles.

Bair, Daniel A. 2010. The Dirt on the Ancient Maya: Soil Chemical Investigations of Ancient Maya Marketplaces. Provo, UT: Department of Plant and Wildlife Sciences, Brigham Young University.

Bair, Daniel A., and R. E. Terry. 2012. "In Search of Markets and Fields: Soil Chemical Investigations at Motul de San Jose." In Motul de San Jose: Politics, History and Economy in a Maya Polity, ed. A. E. Foias and K. F. Emery, 357-385. Gainesville: University Press of Florida. http://dx.doi.org/10.5744/florida/9780813041902.003.0013.

Ball, Joseph W. 1983. "Teotihuacan, the Maya, and Ceramic Interchange: A Contextual Perspective." In Highland Lowland Interaction in Mesoamerica: Interdisciplinary Approaches, ed. A. Miller, 126-146. Washington, DC: Dumbarton Oaks.

Bandelier, Adolph F. 1884. Report of an Archaeological Tour in Mexico in I881. Papers of the Archaeological Institute of America, American Series 2. Boston: Archaeological Institute of America.

Barba, Luis. 1986. "La química en el estudio de áreas de actividad." In Unidades habitacionales mesoamericanas y sus áreas de actividad. Arqueología, ed, L. Manzanilla, 2I-39. Serie Antropología, Vol. 76. Mexico City: Instituto de Investigaciones Antropológicas, Universidad Nacional Autónoma de México.

Barba, Luis, and Agustín Ortíz. 1992. "Análisis químico de pisos de ocupación: un caso etnográfico en Tlaxcala, Mexico." Latin American Antiquity 3(I):63-82. http://dx.doi.org/10.2307 /971930.

Barnhart, Edward L. 2007. “Indicators of Urbanism at Palenque." In Palenque: Recent Investigations at the Classic Maya Center, ed. D. B. Marken, 107-I21. Lanham, MD: AltaMira Press.

Barrera Vásquez, Alfredo. 1980. Diccionario Maya Cordemex. Merida, Yucatan, Mexico: Ediciones Cordemex.

Barrera Marín, Alfredo, Alfredo Barrera Vásquez, and Rosa M. López Franco. 1976. Nomenclatura Etnobotánica Maya: Una Interpretación Taxonómica. Centro Regional del Sureste del 
Instituto Nacional de Antropología e Historia. vol. 36. Mexico City: Colección Científica, Etnología.

Baskes, Jeremy. 2000. Indians, Merchants and Markets: A Reinterpretation of the Repartimiento and Spanish-Indian Economic Relations in Colonial Oaxaca, 1750-182I. Stanford: Stanford University Press.

Batun Alpuche, Ivan. 2004. "Maya Settlement Patterns and Land Use in Buena Vista, Cozumel, México." Research Report submitted to the Foundation for the Advancement of Mesoamerican Studies, Inc. (FAMSI). http://www.famsi.org/reports/o2016/.

Bautista, Francisco, David Palma, and M. Wendy Huchin. 2005. "Actualización de la clasificación de los suelos del estado de Yucatán." In Caracterización y Manejo de los Suelos de la Peninsula de Yucatán: Implicaciones Agropecuarias, Forestales y Ambientales, Universidad Autónoma de Campeche. Universidad Autónoma de Yucatán, ed. F. Bautista and G. Palacio, I05-22. México: Instituto Nacional de Ecología.

Beach, Timothy. 1998a. "Soil Constraints on Northwest Yucatan, Mexico: Pedoarchaeology and Maya Subsistence at Chunchucmil." Geoarchaeology: An International Journal ${ }_{13}$ (8) 759-791. http://dx.doi.org/10.1002/(SICI)I520-6548(199812)13:8<759::AID-GEAI>3.0.CO;2-B.

Beach, Timothy. 1998b. "Soil Catenas, Tropical Deforestation, and Ancient and Contemporary Soil Erosion in the Petén, Guatemala." Physical Geography 19(5):378-405.

Beach, Tim, Nicholas P. Dunning, Sheryl Luzzader-Beach, Duncan E. Cook, and Jon Lohse. 2006. "Impacts of Ancient Maya on Soil and Soil Erosion in the Central Maya Lowlands." Catena 66(2):166-178.

Beach, Timothy, Sheryl Luzzadder-Beach, Duncan Cook, Nicholas Dunning, Douglas Kennett, Samantha Krause, Richard Terry, Deborah Trein, and Fred Valdez. 2015. "Ancient Maya Impacts on the Earth's Surface: An Early Anthropocene Analog?” Quaternary Science Reviews 124:1-30. http://dx.doi.org/10.1016/j.quascirev.2015.05.028.

Beach, Timothy, Sheryl Luzzadder-Beach, Richard Terry, Nicholas Dunning, Stephen D. Houston, and Thomas Garrison. 2011. "Carbon Isotopic Ratios of Wetland and Terrace Soil Sequences in the Maya Lowlands of Belize and Guatemala." Catena 85(2):109-118. http://dx .doi.org/10.1016/j.catena.2010.08.014.

Beach, Timothy, Sheryl Luzzadder-Beach, Thomas Guderjan, and Samantha Krause. 2015.

"The Floating Gardens of Chan Cahal: Soils, Water, and Human Interactions." Catena I32:15I-I64.

Becker, Marshall J. 1991. "Plaza Plans at Tikal, Guatemala and at Other Lowland Maya Sites: Evidence for Patterns of Culture Change." Cuadernos de Arquitectura Mesoamericana I4:1I-26.

Becker, Marshall J. 2003. "A Classic-Period Barrio Producing Fine Polychrome Ceramics at Tikal Guatemala." Ancient Mesoamerica I4:95-112. http://dx.doi.org/10.1017/S0956536 103141053 .

Becker, Marshall J. 2015. "Ancient Maya Markets: Using the Architecture of the Market at Tikal (Plaza Plan 9) to Identify Other Possible Examples in Lowland Classic Period Cities." In Ancient Maya Marketplaces: The Archaeology of Transient Space, ed. Eleanor M. King, 90-IIo. Tucson: University of Arizona Press. 
Benavides Castillo, Antonio. 1981. "Coba y Tulum: Adaptacion al medio ambiente y control del medio social." Estudios de Cultura Maya 13:205-222.

Benavides Castillo, Antonio, and Linda Manzanilla. 1987. "Introducción: Estudio de Centros Urbanos.” In Coba, Quintana Roo: Análisis de Dos Unidades Habitacionales Mayas, ed. L. Manzanilla, II-24. Mexico City: Universidad Nacional Autonoma de Mexico.

Berdan, Frances F. 1983. "The Reconstruction of Ancient Economies: Perspectives from Archaeology and Ethnohistory." In Economic Anthropology: Topics and Theories, Monograph in Economic Anthropology No. I, ed. S. Ortíz, 83-95. Lanham, MD: University Press of America.

Berdan, Frances F. 1987. "Cotton in Aztec Mexico: Production, Distribution and Uses." Mexican Studies / Estudios Mexicanos 3(2):235-262. http://dx.doi.org/10.2307/1051808.

Berdan, Frances F. 2003. “The Economy of Postclassic Mesoamerica." In The Postclassic Mesoamerican World, ed. M. E. Smith and F. F. Berdan, 93-95. Salt Lake City: University of Utah Press.

Bey, George J., III. 2006. "Changing Archaeological Perspective on the Northern Maya Lowlands." In Lifeways in the Northern Maya Lowlands: New Approaches to Archaeology in the Yucatan Peninsula, ed. Jennifer Mathews and Bethany Morrison. Tucson: University of Arizona Press.

Bezanilla, Clara I. 1995. "Salt-Making in Celestun, Yucatan, Mexico: Contemporary Evidence and Archaeological Problems.” BA thesis, Institute of Archaeology, University College London, London.

Blanton, Richard E. 1983. "Factors Underlying the Origin and Evolution of Market Systems." In Economic Anthropology: Topics and Theories, Monograph in Economic Anthropology No. I, ed. S. Ortíz, 5I-66. Lanham, MD: University Press of America.

Blanton, Richard E. 1985. "A Comparison of Early Market Systems." In Markets and Marketing, ed. S. Plattner, 399-416. Lanham, MD: University Press of America.

Blanton, Richard E. 1996. "The Basin of Mexico Market System and the Growth of the Aztec Empire.” In Aztec Imperial Strategies, ed. F. F. Berdan, R. E. Blanton, E. H. Boone, M. G. Hodge, M. E. Smith, and E. Umberger, 47-84. Washington, DC: Dumbarton Oaks.

Blanton, Richard E. 2013. "Cooperation and the Moral Economy of the Marketplace." In Merchants, Markets and Exchange in the Pre-Colombian World, ed. K. G. Hirth and J. Pillsbury, 23-48. Washington, DC: Dumbarton Oaks Research Library and Collections.

Blanton, Richard E., and Lane F. Fargher. 2010. "Evaluating Causal Factors in Market Development in Premodern States: A Comparative Study, with Critical Comments on the History of Ideas about Markets." In Archaeological Approaches to Market Exchange in Ancient Societies, ed. C. P. Garraty and B. L. Stark, 207-227. Boulder: University Press of Colorado.

Blanton, Richard E., Lane F. Fargher, and Verenice Y. Heredia Espinoza. 2005. "The Mesoamerican World of Goods and its Transformations." In Settlement, Subsistence, and Social Complexity: Essays Honoring the Legacy of Jeffrey R. Parsons, ed. R. E. Blanton, 260-294. Los Angeles: Cotsen Institute, University of California.

Blanton, Richard, Stephen Kowalewski, Gary Feinman, and Jill Appel. 1982. Monte Alban's Hinterland, Part I: The Prehispanic Settlement Patterns of the Central and Southern Parts of the Valley of Oaxaca, Mexico. Memoirs of the Museum of Anthropology, University of Michigan, I5. Ann Arbor: Museum of Anthropology, University of Michigan. 
Bohannan, Paul, and George Dalton. 1962. "Introduction." In Markets in Africa, ed. P. Bohannan and G. Dalton, I-26. Evanston: Northwestern University Press.

Bond-Freeman, Tara, and Eugenia Mansell. 2006. "Análisis cerámico preliminary del proyecto Pakbeh, Programa de la Economía Regional de Chunchucmil." In Los Mayas de Ayer y Hoy, ed. A. Barrera Rubio and R. Gubler, 62-72. Merida: Gobierno del Estado de Yucatan.

Borges, Jorge L. 1975. “On Exactitude in Science.” In A Universal History of Infamy, trans. N. T. D. Giovanni. London: Penguin Books.

Brady, James E., Joseph W. Ball, Ronald L. Bishop, Duncan C. Pring, Norman Hammond, and Rupert A. Housley. 1998. “The Lowland Maya Protoclassic: A Reconsideration of its Nature and Significance." Ancient Mesoamerica 9(OI):17-38. http://dx.doi.org/10.1017/S0956536I 00001826.

Brandenburger, Adam, and Barry Nalebuff. 1996. Co-opetition. New York: Currency/Doubleday. Braswell, Geoffrey E. 2002. "Praise the Gods and Pass the Obsidian? The Organization of Ancient Economy in San Martín Jilotepeque, Guatemala." In Ancient Maya Political Economies, ed. M. A. Masson and D. A. Freidel, 285-306. Walnut Creek, MD: Altamira.

Braswell, Geoffrey E. 2003. "Introduction: Reinterpreting Early Classic Interaction." In The Maya and Teotihuacan: Reinterpreting Early Classic Interaction, ed. G. E. Braswell, I-43. Austin: University of Texas Press.

Braswell, Geoffrey E. 2010. “The Rise and Fall of Market Exchange: A Dynamic Approach to Ancient Maya Economy." In Archaeological Approaches to Market Exchange in Ancient Societies, ed. C. P. Garraty and B. L. Stark, 3-32. Boulder: University Press of Colorado.

Braswell, Geoffrey E., and Michael D. Glascock. 2002. "The Emergence of Market Economies in the Ancient Maya World: Obsidian Exchange in Terminal Classic Yucatan, Mexico." In Geochemical Evidence for Long-Distance Exchange, ed. M. D. Glascock, 308-334. Westport, CT: Bergin and Garvey.

Bricker, Victoria, Eleuterio Po'ot Yah, and Ofelia Dzul de Po'ot. 1998. A Dictionary of the Maya Language as Spoken in Hocabá, Yucatán. Salt Lake City: University of Utah Press.

Brodowski, S., A. Rodionov, Lludwig Haumaier, Bruno Glaser, and Wulf Amelung. 2005.

"Revised Black Carbon Assessment Using Benzene Polycarboxylic Acids." Organic Geochemis$\operatorname{try}$ 36(9):1299-1310. http://dx.doi.org/10.1016/j.orggeochem.2005.03.011.

Brown, Kenneth L. 1977. “The Valley of Guatemala: A Highland Port of Trade.” In Teotibuacan and Kaminaljuyu: A Study in Prehistoric Culture Contact, ed. W. T. Sanders and J. W. Michaels, 205-396. Pennsylvania State University Press Monograph Series on Kaminaljuyu. State College: Pennsylvania State University Press.

Brumfiel, Elizabeth M. 1980. "Specialization, Market Exchange and the Aztec State: A View from Huexotla." Current Anthropology 2I (4):459-478. http://dx.doi.org/10.1086/202494.

Brumfiel, Elizabeth M. 1991. "Weaving and Cooking: Women's Production in Aztec Mexico." In Engendering Archaeology: Women in Prehistory, ed. J. M. Gero, and Margaret Conkey, 224-25I. Oxford: Blackwell.

Brumfiel, Elizabeth M. 1996. "Figurines and the Aztec State: Testing the Effectiveness of Ideological Domination.” In Gender and Archaeology, ed. R. P. Wright, I43-166. Philadelphia: University of Pennsylvania. 
Bull, Ian D., Ian A. Simpson, Pim F. Van Bergen, and Richard P. Evershed. 1999. "Muck 'n' Molecules: Organic Geochemical Methods for Detecting Ancient Manuring.” Antiquity 73:86-96.

Bullard, William R., Jr. 1960. "Maya Settlement Pattern in Northeastern Peten, Guatemala." American Antiquity 25: 355-372.

Burgess, Ernest. 1925. “The Growth of the City: An Introduction to a Research Project." In The City, ed. R. E. Park, E. W. Burgess, and R. D. McKenzie, 47-62. Chicago: University of Chicago Press.

Burgos Villanueva, Rafael, Miguel Covarrubias Reyna, and Jose Estrada Faisal. 2004. "Estudios Sobre la Periferia de Izamal, Yucatan.” Los Investigadores de la Cultura Maya I2(I):249-256. Campeche: Universidad Autónoma de Campeche.

Burnett, Richard L., Richard E. Terry, Marco Alvarez, Christopher Balzotti, Timothy Murtha, David Webster, and Jay Silverstein. 20I2a. "The Ancient Agricultural Landscape of the Satellite Settlement of Ramonal near Tikal, Guatemala." Quaternary International 265:IOI-II5.

Burnett, Richard L., Richard E. Terry, Ryan Sweetwood, Timothy Murtha, David Webster, and Jay Silverstein. 20I2b. "Upland and Lowland Soil Resources of the Ancient Maya at Tikal, Guatemala.” Soil Science Society of America Journal 76:2083-2096.

Cabadas Báez, Héctor, Elizabeth Solleiro Rebolledo, Sergei Sedov, Teresa Pi Puig, and Jorge Gama Castro. 2010. "Pedosediments of Karstic Sinkholes in the Eolianites of NE Yucatán: A Record of Late Quaternary Soil Development, Geomorphic Processes and Landscape Stability." Geomorphology 122(3-4):323-337. http://dx.doi.org/10.1016/j.geomorph.2010.03.002.

Cap, Bernadette. 2015. "How to Know It When We See It: Marketplace Identification at the Classic Maya Site of Buenavista del Cayo, Belize." In Ancient Maya Marketplaces: The Archaeology of Transient Space, ed. Eleanor M. King, III-137. Tucson: University of Arizona Press.

Carmean, Kelli, Nicholas P. Dunning, and Jeff K. Kowalski. 2004. "High Times in the Hill Country: A Perspective from the Terminal Classic Puuc Region." In The Terminal Classic in the Maya Lowlands: Collapse, Transformation and Transition, ed. A. A. Demarest, P. M. Rice, and D. S. Rice, 424-449. Boulder: University Press of Colorado.

Carr, H. S. 1989. "Patterns of Exploitation and Exchange of Subsistence Goods in the Late Classic-Early Postclassic Yucatan: A Zooarchaeological Perspective.” Paper presented at the Annual Meeting of the Society for American Archaeology, Atlanta.

Carr, Robert F., and John E. Hazard. 196r. Map of the Ruins of Tikal, El Peten, Guatemala. Tikal Reports No. Ir. Philadelphia: The University Museum, University of Pennsylvania.

Carrasco, Pedro. 1978. "La Economía del México Prehispánico." In La Economía Política y la Ideología en el México Prehispánico, ed. P. Carrasco and J. Broda, I5-74. Mexico City: Instituto Nacional de Antropología e Historia.

Carrasco Vargas, Ramón, Verónica A. Vásquez López, and Simon Martin. 2009. "Daily Life of the Ancient Maya Recorded in Murals." Proceedings of the National Academy of Science Io6(46):19,245-19,249.

Carrasco Vargas, Ramón, and María Cordeiro Baqueiro. 2012. "The Murals of Chiik Nahb Structure Sub i-4, Calakmul, Mexico.” In Maya Archaeology 2, ed. C. Golden, S. D. Houston and J. Skidmore, 8-50. San Francisco: Precolumbia Mesoweb Press. 
Ceballos Gallareta, Teresa, and Fernando Robles Castellanos. 2012. "Las Etapas más Tempranas de la Alfarería Maya en el Noroeste de la Península de Yucatán." Ancient Mesoamerica $23(02): 403-419$. http://dx.doi.org/10.1017/S0956536112000260.

Chase, Arlen F. 1992. "Elites and the Changing Organization of Classic Maya Society." In Mesoamerican Elites, ed. D. Z. Chase and A. F. Chase, 30-49. Norman: University of Oklahoma Press.

Chase, Arlen F., and Diane Z. Chase. 1998. "Scale and Intensity in Classic Period Maya Agriculture: Terracing and Settlement at the "Garden City" of Caracol, Belize." Culture \& Agriculture 20(2-3):60-77. http://dx.doi.org/10.1525/cag.1998.20.2-3.60.

Chase, Arlen F., and Diane Z. Chase. 200I. "Ancient Maya Causeways and Site Organization at Caracol, Belize." Ancient Mesoamerica I2(2):273-281. http://dx.doi.org/10.1017/S0956536I 01121097.

Chase, Arlen F., Diane Z. Chase, Jaime Awe, John F. Weishampel, Gyles Iannone, Holly Moyes, Jason Yaeger, and M. Kathryn Brown. 2014. "The Use of LiDAR in Understanding the Ancient Maya Landscape: Caracol and Western Belize." Advances in Archaeological Practice 2(3):208-221. http://dx.doi.org/10.7183/2326-3768.2.3.208.

Chase, Arlen F., Diane Z. Chase, and William A. Haviland. 1990. "The Classic Maya City: Reconsidering the Mesoamerican Urban Tradition." American Anthropologist 92(2):499-506. http://dx.doi.org/10.1525/aa.1990.92.2.02a00210.

Chase, Arlen F., Diane Z. Chase, Richard E. Terry, Jacob M. Horlacher, and Adrian S. Z. Chase. 2015. "Markets among the Ancient Maya: The Case of Caracol, Belize." In Ancient Maya Marketplaces: The Archaeology of Transient Space, ed. Eleanor M. King, 226-250. Tucson: University of Arizona Press.

Chase, Arlen F., Diane Z. Chase, John F. Weishampel, Jason B. Drake, Ramesh L. Shrestha, K. Clint Slatton, Jaime Awe, and William E. Carter. 20Ir. "Airborne LiDAR, Archaeology, and the Ancient Maya Landscape at Caracol, Belize." Journal of Archaeological Science 38(2):387-398. http://dx.doi.org/10.1016/j.jas.2010.09.018.

Chase, Arlen F., Diane Z. Chase, Elayne Zorn, and Wendy G. Teeter. 2008. "Textiles and the Maya Archaeological Record: Gender, Power and Status in Classic Period Caracol, Belize.” Ancient Mesoamerica 19(1):127-142. http://dx.doi.org/10.1017/S095653610700003X.

Chase, Diane Z. 1986. "Social and Political Organization in the Land of Cacao and Honey: Correlating the Archaeology and Ethnohistory of the Postclassic Lowland Maya." In Late Lowland Maya Civilization, ed. J. Sabloff and E. W. Andrews V, 347-377. Albuquerque: University of New Mexico Press.

Chase, Diane Z. 1990. "The Invisible Maya: Population History and Archaeology at Santa Rita Corozal." In Precolumbian Population History in the Maya Lowlands, ed. T. P. Culbert and D. S. Rice, 199-214. Albuquerque: University of New Mexico Press.

Chase, Diane Z., and Arlen F. Chase. 2004. "Archaeological Perspectives on Classic Maya Social Organization from Caracol, Belize." Ancient Mesoamerica I5(OI):139-I47. http://dx.doi.org /10.1017/S0956536104151080.

Chase, Diane Z., and Arlen F. Chase. 2014. "Ancient Markets and the Economic Integration of Caracol, Belize." Ancient Mesoamerica 25(I):239-250. http://dx.doi.org/10.1017/S0956536 II 4000145 . 
Chen, J. H., H. A. Curran, B. White, and G. J. Wasserburg. 1991. "Precise Chronology of the Last Interglacial Period: ${ }^{234} \mathrm{U}-{ }^{230}$ Th Data from Fossil Coral Reefs in the Bahamas." Geological Society of America Bulletin 103(I):82-97. http://dx.doi.org/10.1130/0016-7606(1991)103 $<0082$ :PCOTLI>2.3.CO;2.

Chisholm, Michael. 1979. Rural Settlement and Land Use: An Essay in Location. 3 rd ed. London: Hutchinson University Library.

Clark, John E. 1986. "From Mountains to Molehills: A Critical Review of Teotihuacan's Obsidian Industry." In Economic Aspects of Prehispanic Highland Mexico, ed. B. Isaac, 23-74. Economic Anthropology, Supplement 2. Greenwich, CT: JAI Press.

Clark, John E. 1987. "Politics, Prismatic Blades, and Mesoamerican Civilization." In The Organization of Core Technology, ed. J. K. Johnson and C. A. Morrow, 259-284. Economic Anthropology, Supplement 2. Boulder, CO: Westview Press.

Clark, John E. 1995. "Craft Specialization as an Archaeological Category." Research in Economic Anthropology 16:267-294.

Clark, John E. 2003. "A Review of 2oth Century Obsidian Studies." In Mesoamerican Lithic Technology: Experimentation and Interpretation, ed. K. G. Hirth, 15-54. Salt Lake City: University of Utah Press.

Clark, John E., and Stephen D. Houston. 1998. "Craft Specialization, Gender, and Personhood among the Post-conquest Maya of Yucatan, Mexico.” In Craft and Social Identity, ed. C. L. Costin, and Rita P. Wright. Archaeological Papers of the American Anthropological Association, number 8, vol. 8. Arlington, VA: American Anthropological Association.

Clendinnen, Inga. 1991. The Aztecs. Cambridge: Cambridge University Press.

Cobos, Rafael, and Terance L. Winemiller. 200I. "The Late and Terminal Classic Period Causeway Systems of Chichen Itza, Yucatan, Mexico." Ancient Mesoamerica I2(02):283-291. http://dx.doi.org/10.1017/S0956536101122066.

Coe, Sophie D. 1994. America's First Cuisines. Austin: University of Texas Press.

Colón, Ferdinand. 1959 [1502]. The Life of the Admiral Christopher Columbus by His Son, Ferdinand. Trans. B. Keen. New Brunswick, NJ: Rutgers University Press.

Conklin, H. C. 1957. "Population-Land Balance under Systems of Tropical Forest Agriculture." Proceedings of the Ninth Pacific Science Congress, Pacific Science Association 7:63.

Conservation Foundation. 1954. "Soil Erosion Survey of Latin America." Reprinted in the Journal of Soil and Water Conservation, 9.

Contreras Sánchez, Alicia del Carmen. 1991. "Los Circuitos Comerciales del Palo de Tinte (1750-1807)." In España y Nueva España: Sus Acciones Transmaritimas, Memorias del I Simposio Internacional (Mexico 1990), 171-200. Mexico: Universidad Iberoamericana.

Contreras Sánchez, Alicia del Carmen. 1996. Capital Comercial y Colorantes en la Nueva España: Segunda Mitad del Siglo XVIII.Zamora: El Colegio de Michoacán/Universidad Autónoma de Yucatán.

Coronel, Eric G., Daniel A. Bair, C. T. Brown, and Richard E. Terry. 2014. “The Utility and Limitations of Portable X-ray Fluorescence and Field Laboratory Conditions on the Geochemical Analysis of Soils and Floors at Areas of Known Human Activities." Soil Science 179(5):258-27I. http://dx.doi.org/10.1097/SS.0000000000000067. 
Coronel, Eric G., Scott R. Hutson, Aline M. Magnoni, Chris Balzotti, Austin Ulmer, and Richard E. Terry. 2015. "Geochemical Analysis of Late Classic and Post Classic Maya Marketplace Activities at the Plazas of Cobá, Mexico." Journal of Field Archaeology 40(I):89-109. http://dx.doi.org/10.1179/0093469014Z.000000000107.

Costa, M. L., D. C. Kern, A. H. E. Pinto, and J. R. T. Souza. 2004. "The Ceramic Artifacts in Archaeological Black Earth (terra preta) from Lower Amazon Region, Brazil: Chemistry and Geochemical Evolution." Acta Amazonica 34(3):375-386. http://dx.doi.org/10.1590/So0 44 -59672004000300004 .

Covarrubias Reyna, Miguel, Rafael Burgos Villanueva, and Yoly Palomo Carrillo. 2012. "Desarrollo Costero Estrategioc en la Region Ah Kin Chel." Los Investigadores de la Cultura Maya 20(I):163-174. Campeche: Universidad Autónoma de Campeche.

Cowgill, George L. 1990. “Toward Refining Concepts of Full-Coverage Survey." In The Archaeology of Regions: A Case for Full-Coverage Survey, 249-259. Washington, DC: Smithsonian Institution.

Cowgill, George L. 1993. "Comments on Andrew Sluyter: Long-distance Staple Transport in Western Mesoamerica: Insights through Quantitative Modeling." Ancient Mesoamerica $4(2): 201-203$. http://dx.doi.org/10.1017/S0956536100000894.

Cowgill, George L. 2007. “The Urban Organization of Teotihuacan, Mexico." In Settlement and Society: Essays Dedicated to Robert Mc Cormick Adams, ed. E. C. Stone, 261-295. Los Angeles: Cotsen Institute of Archaeology, UCLA.

Cowgill, Ursula M. 1960. "Soil Fertility, Population, and the Ancient Maya." National Academy of Sciences 46:1,009-I,oIr. http://dx.doi.org/ro.1073/pnas.46.8.1009.

Craddock, P. T., D. Gurney, F. Pryor, and M. Hughes. 1985. "The Application of Phosphate Analysis to the Location and Interpretation of Archaeological Sites." Archaeological Journal I42(I):36I-376. http://dx.doi.org/10.1080/00665983.1985.11021068.

Culbert, T. Patrick. 1988. “The Collapse of Classic Maya Civilization." In The Collapse of Ancient States and Civilizations, ed. N. Yoffee and G. L. Cowgill, 69-10I. Tucson: University of Arizona Press.

Culbert, T. Patrick, Lisa J. Kosakowsky, Robert E. Fry, and William A. Haviland. 1990. "The Population of Tikal, Guatemala." In Precolumbian Population History in the Maya Lowlands, ed. T. P. Culbert and D. S. Rice, I03-21. Albuquerque: University of New Mexico Press.

Curtis, Jason H., David A. Hodell, and Mark Brenner. 1996. “Climate Variability on the Yucatan Peninsula (Mexico) during the Past 3500 Years, and Implications for Maya Cultural Evolution." Quaternary Research 46(I):37-47. http://dx.doi.org/10.1006/qres .1996 .0042 .

Dahlin, Bruce H. 1984. "A Colossus in Guatemala: The Preclassic Maya City of El Mirador." Archaeology 37(3):18-25.

Dahlin, Bruce H., ed. 1997. The Chunchucmil Regional Economy Program: A Summary Report of 1997 Archaeological Field Research at the Site Center and Residential Districts of Chunchucmil, Yucatan, Mexico. Washington, DC: Sociology and Anthropology Department, Howard University. 
Dahlin, Bruce H. 2000. "The Barricade and Abandonment of Chunchucmil: Implications for Northern Maya Warfare." Latin American Antiquity II(3):283-298. http://dx.doi.org/10.2307 /972179.

Dahlin, Bruce H. 2002. "Climate Change and the End of the Classic Period in Yucatan: Resolving a Paradox." Ancient Mesoamerica 13(2):327-340. http://dx.doi.org/10.1017/S095653610 2132135 .

Dahlin, Bruce H. 2003. "Chunchucmil: A Complex Economy in NW Yucatan." Mexicon 25:129-138.

Dahlin, Bruce H. 2009. "Ahead of Its Time? The Remarkable Early Classic Maya Economy of Chunchucmil." Journal of Social Archaeology 9(3):34I-367. http://dx.doi.org/10.1177/146960 5309338424 .

Dahlin, Bruce H., Anthony Andrews, Tim Beach, Clara Bezanilla, Patrice Farrell, Sheryl Luzzadder-Beach, and Valerie McCormick. 1998. "Punta Canbalam in Context: A Peripatetic Coastal Site in Northwest Campeche, Mexico." Ancient Mesoamerica 9(I):I-I5. http://dx .doi.org/10.1017/S0956536100001814.

Dahlin, Bruce H., and Traci Ardren. 2002. "Modes of Exchange and Regional Patterns: Chunchucmil, Yucatan, Mexico." In Ancient Maya Political Economies, ed. M. Masson, and David Freidel, 249-284. Walnut Creek, CA: Altamira.

Dahlin, Bruce H., Daniel A. Bair, Timohty Beach, Mathew Moriarty, and Richard Terry. 2010. "The Dirt on Food: Ancient Feasts and Markets among the Lowland Maya." In Pre-Columbian Foodways: Interdisciplinary Approaches to Food, Culture, and Markets in Ancient Mesoamerica, ed. J. E. Staller and M. Carrasco, I9I-232. New York: Springer. http://dx.doi.org /10.1007/978-I-4419-047I-3_8.

Dahlin, Bruce H., Marjukka Bastamow, Timothy Beach, Zachary X. Hruby, Scott R. Hutson, and Daniel E. Mazeau. 20Ir. "Phantom Lithics at Chunchucmil, Yucatan, Mexico." In The Technology of Maya Civilization: Political Economy and Beyond in Lithic Studies, ed. Z. X. Hruby, G. E. Braswell, and O. Chinchilla Mazariegos, 76-87. Oakville, CT: Equinox.

Dahlin, Bruce H., Timothy Beach, Sheryl Luzzadder-Beach, David Hixson, Scott R. Hutson, Aline Magnoni, Eugenia B. Mansell, and Daniel E. Mazeau. 2005. "Reconstructing Agricultural Self-Sufficiency at Chunchucmil, Yucatan, Mexico." Ancient Mesoamerica I6(2):229247. http://dx.doi.org/10.1017/S0956536105050212.

Dahlin, Bruce H., Christopher T. Jensen, Richard E. Terry, David R. Wright, and Timothy Beach. 2007. "In Search of an Ancient Maya Market." Latin American Antiquity I8(4):363384. http://dx.doi.org/10.2307/25478193.

Dai, X., Thomas W. Boutton, Bruno Glaser, R. James Ansley, and Wolfgang Zech. 2005. "Black Carbon in a Temperate Mixed-grass Savanna.” Soil Biology \& Biochemistry 37:1,879-1,88I.

Dalle, Sarah Paule, and Sylvie de Blois. 2006. "Shorter Fallow Cycles Affect the Availability of Noncrop Plant Resources in a Shifting Cultivation System.” Ecology and Society II (2):2 [online]. http://www.ecologyandsociety.org/volir/iss2/art2

Davis, Loren G., Shane J. Macfarlan, and Celeste N. Henrickson. 2012. "A PXRF-based Chemostratigraphy and Provenience System for the Cooper's Ferry Site, Idaho." Journal of Archaeological Science 39(3):663-671. http://dx.doi.org/10.1016/j.jas.2011.10.029. 
Deal, Michael. 1985. "Household Pottery Disposal in the Maya Highlands: An Ethnoarchaeological Interpretation." Journal of Anthropological Archaeology 4(4):243-291. http://dx.doi .org/10.1016/0278-4165(85)90008-X.

Dekker, L. W., S. H. Doerr, K. Oostindie, A. K. Ziogas, and C. J. Ritsema. 200I. "Water Repellency and Critical Soil Water Content in a Dune Sand." Soil Science Society of America Journal 65(6):1,667-1,674. http://dx.doi.org/10.2136/sssaj2001.1667.

Delgado, Gabriela, Rosario Morales, Jose L. Mendez, and Aalejandro Cravioto. 20II. "The Reemergence of Cholera in the Americas." In Epidemiological and Molecular Aspects on Cholera, ed. T. Ramamurthy and S. K. Bhattacharya, 79-95. New York: Springer. http://dx.doi.org/ıo .1007/978-I-60327-265-0_5.

Demarest, Arthur A., Chloé Andrieu, Paola Torres, Mélanie Forné, Tomas Barrientos, and Marc Wolf. 20I4. "Economy, Exchange, and Power: New Evidence from the Late Classic Maya Port City of Cancuen." Ancient Mesoamerica 25(I):187-219. http://dx.doi.org/10.1017/So95 6536114000121 .

Demarest, Arthur A., and Federico Fahsen. 2002. "Nuevos Datos e Interpretaciones de los Reinos Occidentals del Clásico Tardío: Hacia Una Visión Sintética de la Historia PasiónUsumacinta." In XVI Simposio de Investigaciones Arqueológicas en Guatemala, ed. J. P. Laporte, B. Arroyo, H. Escobedo, and H. Mejía, 160-176. Guatemala: Museo Nacional de Arqueología y Etnología.

Dia, A., C. Chauvel, M. Boulorde, and M. Girard. 2005. "Eolian Contribution to Soils on Mount Cameroon: Isotopic and Trace Element Records." Chemical Geology 226:232-252.

Domínguez Carrasco, María del Rosario, William J. Folan, and Joel D. Gunn. 1996. "Calakmul, Campeche: Sus Áreas de Actividades Ceremoniales, Cívicas y Domésticas, Derivadas de sus Materiales Líticos y Cerámicos." Investigadores de la Cultura Maya 4:80-106. Campeche: Universidad Autónoma de Campeche.

Dreiss, Meredith L., and David O. Brown. 1989. “Obsidian Exchange Patterns in Belize.” In Prehistoric Maya Economies of Belize, ed. Patricia A. McAnany and Barry L. Isaac. Research in Economic Anthropology Supplement 4: 57-90.

Drennan, Robert D. 1984a. "Long-Distance Transport Costs in Pre-Hispanic Mesoamerica." American Anthropologist 86(I):105-II2. http://dx.doi.org/I0.1525/aa.1984.86.1.02a00100.

Drennan, Robert D. 1984b. "Long-distance Movement of Goods in the Mesoamerican Formative and Classic." American Antiquity 49(I):27-43. http://dx.doi.org/10.2307/280510.

Dunning, Nicholas P. 1992. Lords of the Hills: Ancient Maya Settlement in the Puuc Region, Yucatan, Mexico. Monographs in World Archaeology I5. Madison, WI: Prehistory Press.

Dunning, Nicholas P, and Timothy Beach. 1994. "Soil Erosion, Slope Management, and Ancient Terracing in the Maya Lowlands." Latin American Antiquity 5(I):51-69. http://dx .doi.org/10.2307/971902.

Dunning, Nicholas P., and Timothy Beach. 2000. "Stability and Instability in Pre-Hispanic Maya Landscapes." In Imperfect Balance: Landscape Transformations in the Precolumbian Americas, ed. D. Lentz, 179-202. New York: Columbia University Press.

Dunning, Nicholas P, and Timothy Beach. 2004. "Fruit of the Lu'um: Lowland Maya Soil Knowledge and Agricultural Practices." Mono y Conejo 2(2):I-25. 
Dunning, Nicholas P, and Timothy Beach. 2010. "Farms and Forests: Spatial and Temporal Perspectives on Ancient Maya Landscapes." In Landscapes and Societies, ed. I. P. Martini and Ward Chesworth, 369-389. Berlin: Springer-Verlag. http://dx.doi.org/10.1007/978-90 -48I-94I3-I_23.

Dunning, Nicholas, Timothy Beach, Patrice Farrell, and Sheryl Luzzadder-Beach. 1998. "Prehispanic Agrosystems and Adaptive Regions in the Maya Lowlands." Culture \& Agriculture 20(2-3):87-IOI. http://dx.doi.org/I0.1525/cag.1998.20.2-3.87.

Dunning, Nicholas, John Jones, Timothy Beach, and Sheryl Luzzadder-Beach. 2003. "Physiography, Habitats, and Landscapes of the Three Rivers Region.” In Heterarchy, Political Economy, and the Ancient Maya, ed. V. Scarborough, F. J. Valdez, and N. Dunning, I4-24. Tucson: University of Arizona Press.

Dunning, Nicholas, Carmen McCane, Tyler Swinney, Matthew Purtill, Jani Sparks, Ashley Mann, Jon-Paul McCool, and Chantal Ivenso. 2015. "Geoarchaeological Investigations in Mesoamerica Move into the 21st Century: A Review.” Geoarchaeology: An International Journal 30 (3): 167-99. http://dx.doi.org/10.1002/gea.21507.

Durán, Fray Diego. 1951. Historia de las Indias de Nueva España y Islas de Tierra Firme. 2 vols. Mexico City: Editora Nacional.

Durán, Rafael. 1987. “Lista Florística de la Región de los Petenes, Campeche, México." Biótica I2:199-208.

Earle, Timothy K. 1977. “A Reappraisal of Redistribution: Complex Hawaiian Chiefdoms.” In Exchange Systems in Prehistory, ed. T. K. Earle and J. E. Ericson, 213-229. New York: Academic Press. http://dx.doi.org/10.1016/B978-0-12-227650-7.50018-3.

Eaton, Jack. 1978. "Archaeological Survey of the Yucatan-Campeche Coast." In Studies in the Archaeology of Coastal Yucatan and Campeche, Mexico. Publication 46. New Orleans: Middle American Research Institute, Tulane University.

Eidt, Robert C. 1977. "Detection and Examination of Anthrosols by Phosphate Analysis." Science 197 (4,31I): 1,327-1,333. http://dx.doi.org/10.1126/science.197.4311.1327.

Emerson, Rollins A. 1953. "A Preliminary Survey of the Milpa System of Maize Culture as Practiced by the Maya Indians of the Northern Part of the Yucatan Peninsula." Annals of the Missouri Botanical Garden 40(I):5I-62. http://dx.doi.org/10.2307/2398974.

Eppich, Keith, and David A. Freidel. 2015. "Markets and Marketing in the Classic Maya Lowlands: A Case Study from El Perú-Waka." In Ancient Maya Marketplaces: The Archaeology of Transient Space, ed. Eleanor M. King, 195-225. Tucson: University of Arizona Press.

Eswaran, Hari, Russell Almaraz, E. van den Berg, and P. Reich. 1997. "An Assessment of the Soil Resources of Africa in Relation to Productivity." Geoderma 77(I):I-I8. http://dx.doi.org/Io .ror6/Soor6-706I(97)00007-4.

Escamilla Ojeda, Barbara. 2004. Los Artefactos de Obsidiana de Mayapan. Mérida: Tesis de Licenciatura, Universidad Autónoma de Yucatán, Mérida, Yucatan.

Evensky, Jerry. 2005. Adam Smith's Moral Philosophy: A Historical and Contemporary Perspective on Markets, Law, Ethics, and Culture. Cambridge: Cambridge University Press. http://dx .doi.org/10.1017/CBO9780511610646. 
Farrell, Patrice, Timothy Beach, and Bruce Dahlin. 1996. "Beneath the Roots of the Chukum Tree: A Preliminary Soil Analysis of the Chunchucmil Region.” Yearbook - Conference of Latin Americanist Geographers 22:41-50.

Farriss, Nancy M. 1984. Maya Society under Colonial Rule: The Collective Enterprise of Survival. Princeton: Princeton University Press.

Fedick, Scott L. 1995. "Land Evaluation and Ancient Maya Land Use in the Upper Belize River Area, Belize, Central America." Latin American Antiquity 6(I):16-34. http://dx.doi.org $/ 10.2307 / 971598$.

Fedick, Scott L., ed. 1996. The Managed Mosaic: Ancient Maya Agriculture and Resource Use. Salt Lake City: University of Utah Press.

Fedick, Scott L. 2014. "A Reassessment of Water and Soil Resources in the Flatlands of the Northern Maya Lowlands." In The Resilience, and Vulnerability of Ancient Landscapes: Transforming Maya Archaeology through IHOPE, ed. A. F. Chase and V. L. Scarborough, 72-83. Washington, DC: Archaeological Papers of the American Anthropological Association. http://dx.doi.org/ı.ı1II/apaa.I2030.

Fedick, Scott L., Bethany A. Morrison, Bente J. Anderson, Sylviane Boucher, Jorge C. Acosta, and Jennifer P. Mathews. 2000. "Wetland Manipulation in the Yalahau Region of the Northern Maya Lowlands." Journal of Field Archaeology 27(2):131-152.

Feinman, Gary M., Richard E. Blanton, and Stephen A. Kowalewski. 1984. "Market System Development in the Prehispanic Valley of Oaxaca, Mexico." In Trade and Exchange in Early Mesoamerica, ed. K. G. Hirth, I57-178. Albuquerque: University of New Mexico.

Feinman, Gary M., and Christopher P. Garraty. 2010. "Preindustrial Markets and Marketing: Archaeological Perspectives." Annual Review of Anthropology 39(I):167-191. http://dx.doi.org/10.1146/annurev.anthro.012809.105118.

Feldman, L. 1994. “The Maize Root." In The Maize Handbook, ed. Michael Freeling and Virginia Walbot, 29-37. New York: Springer.

Fernández, Fabian G., Kristofer D. Johnson, Richard E. Terry, Sheldon Nelson, and David Webster. 2005. "Soil Resources of the Ancient Maya at Piedras Negras, Guatemala." Soil Science Society of America Journal 69(6):2,020-2,032. http://dx.doi.org/10.2136/sssaj2004.0306.

Fernández, Fabian G., Richard E. Terry, Takeshi Inomata, and Marcus Eberl. 2002. "An Ethnoarchaeological Study of Chemical Residues in the Floors and Soil of Q'eqchi' Maya Houses at Las Pozas, Guatemala." Geoarchaeology: An International Journal 17(6):487-519. http://dx .doi.org/10.1002/gea.10026.

Fischer, Edward. 2001. Cultural Logics and Global Economics: Maya Identity in Thought and Practice. Austin: University of Texas Press.

Fletcher, Larraine A. 1983. "Coba and Mayapan: A Comparison of Solares, Household Variation, Sociopolitical Organization and Land Tenure.” In Coba: A Classic Maya Metropolis, ed. W. Folan, Ellen Kintz, and Larraine Fletcher, I21-13r. New York: Academic Press. http://dx .doi.org/10.1016/B978-0-12-261880-2.50016-3.

Fletcher, Larraine A., and Ellen R. Kintz. 1983. "Solares, Kitchen Gardens and Status at Coba." In Coba: A Classic Maya Metropolis, ed.W. Folan, Ellen Kintz, and Larraine Fletcher, I03-II9. New York: Academic Press. http://dx.doi.org/10.1016/B978-0-12-261880-2.50015-I. 
Flores-Flores, V., and A. Tekelenburg. 1995. "Dacty (Dactylopius coccus Costa) Dye Production." In Agro-ecology, Cultivation and Uses of Cactus Pear. FAO Plant Production and Protection Paper 132. Rome, Italy.

Foias, Antonia E. 2002. "At the Crossroads: The Economic Basis of Political Power in the Petexbatun Region." In Ancient Maya Political Economies, ed. M. A. Masson and D. A. Freidel, 223-247. Walnut Creek, CA: Altamira.

Folan, William. 1983. "Archaeological Investigations of Coba: A Summary." In Coba: A Classic Maya Metropolis, ed.W. Folan, Ellen Kintz, and Larraine Fletcher, I-IO. New York: Academic Press. http://dx.doi.org/10.1016/B978-0-12-261880-2.50009-6.

Folan, William, Armando Anaya Hernandez, Ellen R. Kintz, Laraine A. Fletcher, Raymundo González Heredia, Jacinto May Hau, and Nicolas Caamal Canche. 2009. "Coba, Quintana Roo, Mexico: A Recent Analysis of the Social, Economic and Political Organization of a Major Maya Urban Center." Ancient Mesoamerica 20 (OI): 59-70. http://dx.doi.org /10.1017/S0956536109000054.

Folan, William J., Larraine A. Fletcher, Jacinto May Hau, A. Morales L., María del Rosario Dominguez Carrasco, Raymundo González Heredia, Joel D. Gunn and Vera Tiesler. 2008. "Calakmul, Campeche, Mexico: Patterns Representative of its Urban Capital and its Regional State." In Urbanism in Mesoamerica, Vol. 2, ed. A. G. Mastache, R. H. Cobean, A. G. Cook and K. G. Hirth, 349-376. College Station, PA: Pennsylvania State University Press.

Folan, William, Larraine Fletcher, Jacinto May Hau, and Linda Florey Folan. 200r. Las Ruinas de Calakmul, Campeche, México: Un Lugar Central y su Paisaje Cultural. Campeche: Universidad Autonoma de Campeche.

Folan, William J., Joel D. Gunn, and María del Rosario Dominguez Carrasco. 200r. Triadic Temples, Central Places and Dynastic Palaces. In Royal Courts of the Ancient Maya, Volume 2: Case Studies, ed. T. Inomata and S. D. Houston, 223-265. Westview Press, Boulder, CO.

Folan, William J., Ellen R. Kintz, and Larraine A. Fletcher. 1983. Coba: A Classic Maya Metropolis. New York: Academic Press.

Folan, William J., Ellen R. Kintz, Larraine Fletcher, and Burma H. Hyde. 1982. "An Examination of Settlement Patterns at Coba, Quintana Roo, Mexico, and Tikal, Guatemala: A Reply to Arnold and Ford." American Antiquity 47(2):430-436. http://dx.doi.org/10.2307/279915.

Fox, John. 1996. "Playing with Power: Ballcourts and Political Ritual in Southern Mesoamerica." Current Anthropology 37(3):483-509. http://dx.doi.org/10.1086/204507.

Fox, Richard. 1977. Urban Anthropology: Cities in Their Cultural Setting. Englewood Cliffs, NJ: Prentice Hall.

Freidel, David A. 1981. “The Political Economies of Residential Dispersion among the Lowland Maya." In Lowland Maya Settlement Patterns, ed. W. Ashmore, 371-382. Albuquerque: University of New Mexico Press.

Freidel, David A. 2002. "Preface." In Ancient Maya Political Economies, ed. M. A. Masson and D. A. Freidel, vii-xi. Walnut Creek, CA: Altamira.

Freidel, David A., Hector Escobedo, and Stanley F. Guenter. 2007. "A Crossroads of Conquerors: Waka and Gordon Willey's "Rehearsal for the Collapse" Hypothesis." In Gordon R. 
Willey and American Archaeology: Contemporary Perspectives, ed. J. Sabloff and W. L. Fash, 187-208. Norman: University of Oklahoma Press.

Freidel, David A., Kathryn Reese-Taylor, and David Mora-Marin. 2002. "The Origins of Maya Civilization: The Old Shell Game, Commodity, Treasure and Kingship." In Ancient Maya Political Economies, ed. M. A. Masson and D. A. Freidel, 4I-86. Walnut Creek, CA: Altamira.

Freidel, David A., and Jeremy A. Sabloff. 1984. Cozumel: Late Maya Settlement Patterns. Academic Press, New York.

Freidel, David A., and Justine M. Shaw. 2000. "The Lowland Maya Civilization: Historical Consciousness and Environment." In The Way the Wind Blows: Climate, History, and Human Action, ed. R. J. McIntosh, J. A. Tainter, and S. K. McIntosh, 271-300. New York: Columbia University Press.

Fry, Robert. 1979. "The Economics of Pottery at Tikal, Guatemala: Models of Exchange for Serving Vessels." American Antiquity 44(3):494-512. http://dx.doi.org/10.2307/279547.

Fry, Robert E. 1980. "Models of Exchange for Major Shape Classes of Lowland Maya Pottery." In Models and Methods in Regional Exchange, ed. R. E. Fry, 3-18. Washington, DC: Society for American Archaeology.

Gallareta Negrón, Tomás, and William Ringle. 2004. "The Earliest Occupation of the Puuc Region, Yucatan, Mexico: New Perspectives from Xocnaceh and Paso de Macho.” Paper Presented at the rozrd Annual Meeting of the American Anthropological Association, Atlanta.

García Campillo, José M., and Yolanda Fernández. 1995. “Articulación Espacial y Organización Política en Oxkintok, Yucatán.” In Religión y Sociedad en el Área Maya, ed. Carmen Varela, J. Bonor, and Yolanda Fernández, 135-157. Sociedad Española de Estudios Mayas. Número 3. Madrid, España.

Garduño Argueta, Jaime. 1979. Proyecto Coba: Investigaction "Patron de Asentamiento de Coba." Mexico City: Instituto Nacional de Antropologia e Historia.

Garraty, Christopher P. 2009. "Evaluating the Distributional Approach to Inferring Marketplace Exchange: A Test Case from the Mexican Gulf Lowlands.” Latin American Antiquity 20:157-174.

Garraty, Christopher P. 2010. "Investigating Market Exchange in Ancient Societies: A Theoretical Review." In Archaeological Approaches to Market Exchange in Ancient Societies, ed. C. P. Garraty and B. L. Stark, 3-32. Boulder: University Press of Colorado.

Garraty, Christopher P., and Barbara L. Stark, eds. 2010. Archaeological Approaches to Market Exchange in Ancient Societies. Boulder: University Press of Colorado.

Garza Tarazona de González, Silvia, and Edward B. Kurjack. 1980. Atlas Arqueológico del Estado de Yucatán. Mexico City: Instituto Nacional de Antropología e Historia.

Garza Tarazona de González, Silvia, and Edward B. Kurjack. 1981. "El Medio Ambiente y los Asentamientos Mayas en Epoca Prehispanica." 17-28. In Memoria del Congreso Interno 1979, Merida, Mexico: Centro Regional del Sureste, Instituto Nacional de Antropologia e Historia.

Gendrop, Paul. 1984. "El Talud-tablero y Otras Perfiles Arquitectónicos en Meso-America." Cuadernos de Arquitectura Mesoamericana 2:5-28. 
Giddens, Wendy L. 1995. “Talud-Tablero Architecture as a Symbol of Mesoamerican Affiliation and Power." MA thesis, UCLA, Los Angeles.

Gill, Richardson. 2000. The Great Maya Droughts. Albuquerque: University of New Mexico.

Gillespie, Susan D. 2000. "Rethinking Ancient Maya Social Organization: Replacing 'Lineage' with 'House." American Anthropologist IO2(3):467-484. http://dx.doi.org/10.1525/aa .2000 .102 .3 .467 .

Glaser, Bruno, and Wulf Amelung. 2003. "Pyrogenic Carbon in Native Grassland Soils along a Climosequence in North America." Global Biogeochemical Cycles 17 (2): 1064-1072. http://dx.doi.org/10.1029/2002GBo02019.

Glaser, Bruno, Georg Guggenberger, and Wolfgang Zech. 200ra. "Black Carbon in Sustainable Soils of the Brazilian Amazon Region," In Understanding and Managing Organic Matter in Soils, Sediments, and Waters, ed. R. S. Swift and K. M. Spark, 359-364. International Humic Substances Society.

Glaser, Bruno, Ludwig Haumaier, Georg Guggenberger, and Wolfgang Zech. 200rb. “The 'Terra Preta' Phenomenon: A Model for Sustainable Agriculture in the Humid Tropics." Naturwissenschaften 88(I):37-4I. http://dx.doi.org/10.1007/s001140000193.

Golden, Charles W., Andrew K. Scherer, A. René Muñoz, and Rosaura Vasquez. 2008. "Piedras Negras and Yaxchilan: Divergent Political Trajectories in Adjacent Maya Polities." Latin American Antiquity 19(3):249-274.

Gomez-Pompa, Arturo, Michael F. Allen, Scott L. Fedick, and Juan J. Jimenez-Osornio, eds. 2003. The Lowland Maya Area: Three Millennia at the Human-Wildland Interface. New York: Haworth Press.

Goodwin, Charles. 1994. "Professional Vision.” American Anthropologist 96(3):606-633. http://dx.doi.org/10.1525/aa.1994.96.3.02a00100.

Götz, Christopher. 2012. "Caza y Pesca Prehispanicas en la Costa Norte Peninsular Yucateca." Ancient Mesoamerica 23(2):421-439. http://dx.doi.org/10.1017/S0956536112000272.

Graeber, David. 20Ir. Debt: The First sooo Years. New York: Melville House.

Granovetter, Mark. 1985. "Economic Action and Social Structure: The Problem of Embeddedness." American Journal of Sociology 91(3):481-510. http://dx.doi.org/10.1086/22831I.

Griffith, M. Patrick. 2004. "The Origins of an Important Cactus Crop, Opuntia ficus-indica (Cactaceae): New Molecular Evidence." American Journal of Botany $9 \mathrm{I}(\mathrm{II}): 1,915-\mathrm{I}, 92 \mathrm{I}$. http://dx.doi.org/10.3732/ajb.91.II.1915.

Hageman, Jon B. 2004. "The Lineage Model and Archaeological Data in Late Classic Northwestern Belize.” Ancient Mesoamerica I5(OI):63-74. http://dx.doi.org/10.1017/So956536I 04151043.

Halperin, Christina T. 2008. "Classic Maya Textile Production: Insights from Motul de San José, Peten, Guatemala.” Ancient Mesoamerica 19(I):I1I-I25. http://dx.doi.org/10.1017/So95653 6108000230.

Halperin, Christina T., Ronald L. Bishop, Ellen Spensley, and M. James Blackman. 2009. "Late Classic (A.D. 600-900) Maya Market Exchange: Analysis of Figurines from the Motul de San José Region, Guatemala." Journal of Field Archaeology 34(4):457-480. http://dx.doi.org /10.1179/009346909791070745. 
Halperin, Rhonda H. 1994. Cultural Economies: Past and Present. Austin: University of Texas Press.

Hamman, Cherry. 1998. Mayan Cooking: Recipes from the Sun Kingdoms of Mexico. New York: Hippocrene Books.

Hammond, Norman. 1972a. "Obsidian Trade Routes in the Mayan Area." Science I78(4065):1,092-1,093. http://dx.doi.org/10.1126/science.178.4065.1092.

Hammond, Norman. 1972b. "The Planning of a Maya Ceremonial Center." Scientific American 226(5):82-91. http://dx.doi.org/10.1038/scientificamericano572-82.

Hammond, Norman. 1975. "Maya Settlement Hierarchy in Northern Belize." Contributions to the University of California Archaeological Research Facility 27:40-55.

Hammond, Norman. 1999. "The Genesis of Hierarchy: Mortuary and Offertory Ritual in the Pre-Classic at Cuello, Belize." In Social Patterns in Pre-Classic Mesoamerica, ed. D. C. Grove and R. A. Joyce, 49-66. Washington, DC: Dumbarton Oaks.

Hamnett, Brian. 1971. Politics and Trade in Southern Mexico, 1750-1821. Cambridge: Cambridge University Press. http://dx.doi.org/10.1017/CBO9780511759581.

Hansen, Richard D., and Stanley P. Guenter. 2005. "Early Social Complexity and Kingship in the Mirador Basin." In Lords of Creation: The Origins of Sacred Maya Kingship, ed. V. Fields, 60-6r. Los Angeles: Los Angeles County Museum of Art.

Harrison, Peter D. 1981. "Some Aspects of Preconquest Settlement in Southern Quintana Roo, Mexico." In Lowland Maya Settlement Patterns, ed. W. Ashmore, 259-386. Albuquerque: University of New Mexico Press.

Harrison, Peter D. 1996. "Settlement and Land Use in the Pulltrouser Swamp Archaeological Zone, Northern Belize." In The Managed Mosaic: Ancient Maya Agriculture and Resource Use, ed. S. Fedick, 177-190. Salt Lake City: University of Utah Press.

Haviland, William A. 1965. "Prehistoric Settlement at Tikal, Guatemala." Expedition 7(3):14-23.

Haviland, William. 1966. "Maya Settlement Patterns: A Critical Review." In Middle American Research Institute Publication 26, 21-47. New Orleans: Middle American Research Institute.

Haviland, William. 1970. “Tikal, Guatemala, and Mesoamerican Urbanism.” World Archaeology 2(2):186-198. http://dx.doi.org/10.1080/00438243.1970.9979473.

Haviland, William. 1972. "Family Size, Prehistoric Population Estimates, and the Ancient Maya." American Antiquity 37(I):135-139. http://dx.doi.org/10.2307/278895.

Haviland, William A. 1982. "Where the Rich Folks Lived: Deranging Factors in the Statistical Analysis of Tikal Settlement." American Antiquity 47(2):427-429.

Haviland, William. 1988. "Musical Hammocks at Tikal: Problems with Reconstructing Household Composition." In Household and Community in the Mesoamerican Past, ed. R. Wilk and Wendy Ashmore, I2I-I34. Albuquerque: University of New Mexico Press.

Havlin, John, James D. Beaton, Samuel L. Tisdale, and Werner L. Nelson. 2005. Soil Fertility and Fertilizers: An Introduction to Nutrient Management. 7 th ed. New Jersey: Pearson Education, Inc.

Hayden, Brian D., and Aubrey Cannon. 1983. "Where the Garbage Goes: Refuse Disposal in the Maya Highlands." Journal of Anthropological Archaeology 2(2):117-163. http://dx.doi.org /10.1016/0278-4165(83)90010-7. 
Hayes, Kat. 2013. "Parameters in the Use of pXRF for Archaeological Site Prospection: A Case Study at the Reaume Fort Site, Central Minnesota." Journal of Archaeological Science 40(8):3,193-3,211. http://dx.doi.org/10.1016/j.jas.2013.04.008.

Heinerman, John. 1996. Heinerman's Encyclopedia of Healing Herbs and Spices. West Nyack, NY: Parker.

Henderson, John S. 1981. The World of the Ancient Maya. Ithaca: Cornell University Press.

Hendon, Julia A. 1991. "Status and Power in Classic Maya Society: An Archaeological Study." American Anthropologist 93(4):894-918. http://dx.doi.org/10.1525/aa.1991.93.4.02a00070.

Hendon, Julia A. 1997. “Women's Work, Women's Space, and Women's Status among the Classic Period Maya Elite of the Copan Valley, Honduras." In Women in Prehistory: North America and Mesoamerica, ed. C. Claassen, and Rosemary Joyce, 33-46. Philadelphia: University of Pennsylvania Press.

Hendon, Julia A. 2002. "Social Relations and Collective Identities: Household and Community in Ancient Mesoamerica." In The Dynamics of Power, ed. M. O’Donovan, 273-300. Carbondale: Center for Archaeological Investigations Southern Illinois University.

Hernández Alvarez, Hector, and Nancy Peniche May. 2008. "Malacates Arqueológicos de la Península de Yucatán. Una Propuesta de Análisis." Los Investigadores de la Cultura Maya I6(II):195-213. Campeche: Universidad Autónoma de Campech.

Hester, Joseph A. 1953. "Agriculture, Economy, and Population Densities of the Maya." Carnegie Institution of Washington Year Book 52:288-292.

Heyden, Doris, and Paul Gendrop. 1980. Pre-Columbian Architecture of Mesoamerica. New York: Electa/Rizzoli.

Hirth, Kenneth G. 1978. "Interregional Trade and the Formation of Prehistoric Gateway Cities." American Antiquity 43(I):35-45. http://dx.doi.org/10.2307/279629.

Hirth, Kenneth G. 1998. “The Distributional Approach: A New Way to Identify Marketplace Exchange in the Archaeological Record." Current Anthropology 39(4):45I-476. http://dx .doi.org/10.1086/204759.

Hirth, Kenneth G. 2009a. "Craft Production, Household Diversification, and Domestic Economy in Prehispanic Mesoamerica." In Housework: Craft Production and Domestic Economy in Ancient Mesoamerica, ed. K. Hirth, 13-32. Archeological Papers of the American Anthropological Association No. 19. Alexandria, VA: American Anthropological Association. http://dx.doi.org/10.11II/j.155I-8248.2009.01010.x.

Hirth, Kenneth G. 2009b. "Craft Production in a Central Mexican Marketplace." Ancient Mesoamerica 2(I):89-102. http://dx.doi.org/10.1017/S0956536109990034.

Hirth, Kenneth G. 2010. "Finding the Mark in the Marketplace: The Organization, Development, and Archaeological Identification of Market Systems." In Archaeological Approaches to Market Exchange in Ancient Societies, ed. C. P. Garraty and B. L. Stark, 227-247. Boulder: University Press of Colorado.

Hirth, Kenneth G. 2013. “The Merchant's World: Commercial Diversity and the Economics of Interregional Exchange in Highland Mesoamerica." In Merchants, Markets and Exchange in the Pre-Colombian World, ed. K. G. Hirth and J. Pillsbury, 169-200. Washington, DC: Dumbarton Oaks Research Library and Collections. 
Hirth, Kenneth G., and Joanne Pillsbury. 2013a. "Merchants, Markets and Exchange in the Pre-Colombian World." In Merchants, Markets and Exchange in the Pre-Colombian World, ed. K. G. Hirth and J. Pillsbury, I-22. Washington, DC: Dumbarton Oaks Research Library and Collections.

Hirth, Kenneth G., and Joanne Pillsbury, eds. 2013b. Merchants, Markets and Exchange in the Pre-Colombian World. Washington, DC: Dumbarton Oaks Research Library and Collections.

Hixson, David. 20II. "Settlement Patterns and Communication Routes of the Western Maya Wetlands: An Archaeological and Remote Sensing Survey." PhD thesis, Department of Anthropology, Tulane University, New Orleans.

Hodell, David A., Mark Brenner, and Jason H. Curtis. 2005. “Terminal Classic Drought in the Northern Maya Lowlands Inferred from Multiple Sediment Cores in Lake Chichancanab (Mexico)." Quaternary Science Reviews 24:I4I3-I427.

Hodell, David A., Jason H. Curtis, and Mark Brenner. 1995. "Possible Role of Climate in the Collapse of Classic Maya Civilization.” Science 375:391-394.

Hodge, Mary G., and Leah Minc. 1990. “The Spatial Patterning of Aztec Ceramics: Implications for Prehispanic Exchange Systems in the Valley of Mexico." Journal of Field Archaeology 17:415-437.

Holliday, Vance T., and William G. Gartner. 2007. "Methods of Soil P Analysis in Archaeology." Journal of Archaeological Science 34(2):301-333. http://dx.doi.org/10.1016/j.jas.2006.05.004.

Horlacher, Jacob M. 2013. Geochemical Evidence of Ancient Maya Marketplace Activities in the Puuc Hill of Mexico and at Caracol, Belize. Provo, UT: Plant and Wildlife Sciences, Brigham Young University.

Horsfall, Gail A. 1987. "Design Theory and Grinding Stones." In Lithic Studies among the Contemporary Highland Maya, ed. Brian Hayden, 332-377. Tucson: University of Arizona Press.

Houck, Charles W. J. 2006. "Cenotes, Wetlands, and Hinterland Settlement." In Lifeways in the Northern Lowlands: New Approaches to Maya Archaeology, ed. J. P. Mathews and B. A. Morrison, 56-76. Tucson: University of Arizona Press.

Houston, Stephen D. 2013. The Life Within: Classic Maya and the Matter of Permanence. New Haven: Yale University Press.

Houston, Stephen D. 2014. "Courtesans and Carnal Commerce." In Maya Decipherment: Ideas on Ancient Maya Writing and Iconography. https://decipherment.wordpress.com/20I4 /06/08/courtesans-and-carnal-commerce/.

Hughes, William. 1672. The American Physician or a Treatise of the Roots, Plants, Trees, Shrubs, Fruit, Herbs, etc., Growing in the English Plantations in America. London: Green Dragon.

Humphrey, Caroline. 1985. "Barter and Economic Disintegration.” Man 20(I):48-72. http://dx .doi.org/10.2307/280222I.

Hutson, Scott R. 2000. "Carnival and Contestation in the Aztec Marketplace." Dialectical Anthropology 25(2):123-149. http://dx.doi.org/10.1023/A:1011058318062.

Hutson, Scott R. 2004. "Dwelling and Subjectification at the Ancient Urban Center of Chunchucmil, Yucatan, Mexico.” Doctoral Thesis, Department of Anthropology, University of California, Berkeley, Berkeley. 
Hutson, Scott R. 2010. Dwelling, Identity and the Maya: Relational Archaeology at Chunchucmil. Lanham, MD: Altamira.

Hutson, Scott R. 2012a. “Unavoidable Imperfections': Historical Contexts for Representing Ruined Maya Buildings." In The Past Presented: Archaeological Illustration in the Americas, ed. J. Pillsbury, 282-316. Washington DC and Cambridge MA: Dumbarton Oaks and Harvard University Press.

Hutson, Scott R. 2012b. "Urbanism, Architecture, and Internationalism in the Northern Lowlands during the Early Classic." In The Ancient Maya of Mexico: Reinterpreting the Past of the Northern Maya Lowlands, ed. G. Braswell, I19-142. Bristol, CT: Equinox Press.

Hutson, Scott R. 2016. Ancient Urban Maya: Neighborhoods, Inequality and Built Form. Gainesville: University Press of Florida.

Hutson, Scott R., Iliana Ancona Aragón, Miguel Covarrubias Reyna, Zachary Larsen, Katie Lukach, Shannon E. Plank, Richard E. Terry, and Willem Vanessendelft. 2015. "A Historical Processual Approach to Continuity and Change in Classic and Postclassic Yucatan." In Beyond Collapse: Archaeological Perspectives in Resilience, Revitalization and Reorganization in Complex Societies, ed. R. Falseit, I24-146. Carbondale: Southern Illinois University Press.

Hutson, Scott R., Bruce H. Dahlin, and Daniel E. Mazeau. 2010. "Commerce and Cooperation among the Classic Maya: The Chunchucmil Case." In Cooperation in Economy and Society, ed. R. Marshall, 8I-103. Lanham, MD: Altamira Press.

Hutson, Scott R., David Hixson, Aline Magnoni, Daniel E. Mazeau, and Bruce H. Dahlin. 2008. "Site and Community at Chunchucmil and Ancient Maya Urban Centers." Journal of Field Archaeology 33(I):19-40. http://dx.doi.org/10.1179/009346908791071439.

Hutson, Scott R., and Aline Magnoni. 20Ir. "Identidad Social en el Mosáico Urbano de Chunchucmil, Yucatán, México." In Localidad y Globalidad en el Mundo Maya Prehispánico e Indígena Contemporáneo: Estudios de Espacio y Género, ed. M. J. Gallegos Gómora, 65-78. Mexico City: Instituto Nacional de Antropología e Historia.

Hutson, Scott R., Aline Magnoni, Timothy Beach, Richard E. Terry, Bruce H. Dahlin, and Mary J. Schabel. 2009. "Phosphate Fractionation and Spatial Patterning in Ancient Ruins: A Case Study from Yucatan.” Catena 78(3):260-269. http://dx.doi.org/10.1016/j.catena.2009 .02 .005 .

Hutson, Scott R., Aline Magnoni, Daniel E. Mazeau, and Travis W. Stanton. 2006. “The Archaeology of Urban Houselots at Chunchucmil, Yucatan, Mexico." In Lifeways in the Northern Lowlands: New Approaches to Maya Archaeology, ed. J. P. Mathews and B. A. Morrison, 77-92. Tucson: University of Arizona Press.

Hutson, Scott R., Aline Magnoni, and Travis Stanton. 2004. "House Rules?: The Practice of Social Organization in Classic Period Chunchucmil, Yucatan, Mexico." Ancient Mesoamerica I5(OI):75-92. http://dx.doi.org/10.1017/So956536104151055.

Hutson, Scott R., Travis W. Stanton, Aline Magnoni, Richard E. Terry, and Jason Craner. 2007. "Beyond the Buildings: Formation Processes of Ancient Maya Houselots and Methods for the Study of Non-architectural Space." Journal of Anthropological Archaeology 26(3):442-473. http://dx.doi.org/10.1016/j.jaa.2006.12.00I. 
Hutson, Scott R., and Richard E. Terry. 2006. "Recovering Social and Cultural Dynamics from Plaster Floors: Chemical Analyses at Ancient Chunchucmil, Yucatan, Mexico.” Journal of Archaeological Science 33(3):391-404. http://dx.doi.org/10.1016/j.jas.2005.08.004.

Hutson, Scott R., and Jacob A. Welch. 20I4. "Sacred Landscapes and Building Practices at Uci and Kancab Yucatan, Mexico." Ancient Mesoamerica 25 (2):421-439. http://dx.doi.org/ı .1017/S0956536114000285.

Inomata, Takeshi. 2006. "Plazas, Performers and Spectators: Political Theaters of the Classic Maya." Current Anthropology 47:805-842.

Inomata, Takeshi, and Daniela Triadan. 2000. "Craft Production by Classic Maya Elites in Domestic Settings: Data from Rapidly Abandoned Structures at Aguateca, Guatemala." Mayab I3:57-66.

Inurreta Díaz, Armando F. 2004. Uaymil: Un Puerto de Transbordo en la Costa Norte de Campeche. Campeche, Mexico: Conaculta/Instituto Nacional de Antropología e Historia.

Isaac, Barry L. 1996. "Approaches to Classic Maya Economies." Research in Economic Anthropology 17:297-334.

Isendahl, Christian, Nicholas P. Dunning, and Jeremy A. Sabloff. 2014. "Growth and Decline in the Classic Maya Puuc Economies." In The Resilience, and Vulnerability of Ancient Landscapes: Transforming Maya Archaeology through IHOPE, ed. A. F. Chase and V. L. Scarborough, I-IO. Washington, DC: Archaeological Papers of the American Anthropological Association.

Isendahl, Christian, and Michael E. Smith. 2013. "Sustainable Agrarian Urbanism: The LowDensity Cities of the Mayas and Aztecs." Cities (London, England) 31:132-143. http://dx.doi .org/10.1016/j.cities.2012.07.012.

Isphording, Wayne C., and Eugene M. Wilson. 1973. "Weathering Processes and Physical Subdivisions of Northern Yucatán." Proceedings of the Association of American Geographers 5:117-I2I.

Jiménez, Socorro. 2007. "Sihó: Una Unidad Política del Occidente de Yucatán." Masters Thesis, Facultad de Ciencias Antropológicas. Mérida, México: Universidad Autónoma de Yucatán. Jiménez, Socorro, and Teresa Ceballos. 2000. Informe de las Cerámicas Recuperadas Durante los Trabajos de Salvamento Arqueologico del Centro Historico de la Ciudad de Merida, La Catedral. Mecanuscrito Depositado en el Archivo Técnico del INAH.

Jiménez Álvarez, Socorro del Pilar, Rafael Cobos Palma, Heajoo Chung, and Roberto Belmar Caso. 2006. "El Despertar de la Complejidad Sociocultural Visto Desde el Estudio Tecnológico de la Cerámica: Explicando las Transformaciones Sociopolíticas en el Occidente de Yucatán”. En XIX Simposio de Investigaciones arqueológicas en Guatemala 2005, ed. Juan Pedro Laporte, Bárbara Arroyo Héctor Mejía, 483-492. Guatemala City: Museo Nacional de Arqueología y Etnología, Ministerio de Cultura y Deportes, Instituto de Antropología e Historia, Asociación Tikal y Fundación Arqueológica del Nuevo Mundo.

Johnson, Kristofer D., David R. Wright, and Richard E. Terry. 2007. "Application of Carbon Isotope Analysis to Ancient Maize Agriculture in the Petén Region of Guatemala." Geoarchaeology: An International Journal 22(3):313-336. http://dx.doi.org/10.1002/gea.20155.

Johnston, Kevin J. 2004. “The Invisible Maya: Minimally Mounded Residential Settlement at Itzán, Petén, Guatemala." Latin American Antiquity 15(2):145-175. http://dx.doi.org/10 .2307/4141552. 
Jones, Christopher. 1991. "Patterns of Growth at Tikal." In Classic Maya Political History: Archaeological and Hieroglyphic Evidence, ed. T. P. Culbert, 102-I27. Cambridge: Cambridge University Press.

Jones, Christopher. 1996. Excavations in the East Plaza of Tikal. Tikal Report Number 16. Philadelphia: The University Museum, University of Pennsylvania.

Jones, Christopher. 2015. “The Marketplace at Tikal.” In Ancient Maya Marketplaces: The Archaeology of Transient Space, ed. Eleanor M. King, 67-89. Tucson: University of Arizona Press.

Jones, Christopher, and Robert J. Sharer. 1986. "Archaeological Investigations in the Site Core of Quirigua, Guatemala." In The Southeast Maya Periphery, ed. P. A. Urban and E. M. Schortman, 27-49. Austin: University of Texas Press.

Joyce, Rosemary A. 1993. "Women's Work: Images of Production and Reproduction in Prehispanic Southern Central America." Current Anthropology 34(3):255-274. http://dx.doi.org /10.1086/204167.

Joyce, Rosemary A. 1996. “The Construction of Gender in Classic Maya Monuments." In Gender and Archaeology, ed. R. P. Wright, 167-195. Philadelphia: University of Pennsylvania.

Keeley, Lawrence H. 1980. Experimental Determination of Stone Tool Uses: A Micro-wear Analysis. Chicago: University of Chicago Press.

Keller, Angela. 2006. "Roads to the Center: The Design, Use, and Meaning of the Roads of Xunantunich, Belize." PhD thesis, Department of Anthropology. Philadelphia: University of Pennsylvania.

Keller, Angela. 2010. "The Social Construction of Roads at Xunantunich, from Design to Abandonment." In Classic Maya Provincial Politics: Xunantunich and Its Hinterlands, ed. L. J. Lecount and J. Yaeger, 184-208. Tucson: University of Arizona Press.

Kellman, Martin, and Rosanne Tackaberry. 1997. Tropical Environments: The Functioning and Management of Tropical Ecosystems. New York: Routledge. http://dx.doi.org/10.4324 19780203392843 .

Kennett, Douglas, and Timothy Beach. 2013. "Archaeological and Environmental Lessons for the Anthropocene from the Classic Maya Collapse." The Anthropocene 4:88-100.

Kepecs, Susan. 1998. "Diachronic Ceramic Evidence and Its Social Implications in the Chikinchel Region, Northeast Yucatan.” Ancient Mesoamerica 9(OI):I21-I35. http://dx.doi.org /10.1017/S0956536100001899.

Kepecs, Susan. 2003. "Chikinchel." In The Postclassic Mesoamerican World, ed. M. E. Smith and F. F. Berdan, 259-268. Salt Lake City: University of Utah Press.

Kepecs, Susan. 2005. “Spaniards, Maya, and Salt." In The Post-Classic to Spanish Era Transition in Mesoamerica: Archaeological Perspectives, ed. S. Kepecs and R. Alexander, I18-137. Albuquerque: University of New Mexico Press.

Kepecs, Susan, and Sylviane Boucher. 1996. "The Pre-Hispanic Cultivation of Rejolladas and Stone-Lands: New Evidence from Northeast Yucatan." In The Managed Mosaic, ed. S. L. Fedick, 69-91. Salt Lake City: University of Utah Press.

Killion, Thomas W. 1992. "Residential Ethnoarchaeology and Ancient Site Structure: Contemporary Farming and Prehistoric Settlement Agriculture at Matacapan, Veracruz, Mexico.” In 
Gardens of Prehistory: The Archaeology of Settlement Agriculture in Greater Mesoamerica, ed. T. W. Killion, I19-I49. Tuscaloosa: University of Alabama Press.

King, Eleanor M. 2015. “The Ethnohistoric Evidence for Maya Markets.” In Ancient Maya Marketplaces: The Archaeology of Transient Space, ed. Eleanor M. King, 33-66. Tucson: University of Arizona Press.

King, Eleanor M., and Leslie C. Shaw. 2015. “Introduction.” In Ancient Maya Marketplaces: The Archaeology of Transient Space, ed. Eleanor M. King, 3-32. Tucson: University of Arizona Press.

King, M. E. 1979. “The Prehistoric Textile Industry of Mesoamerica." In The Junius B. Bird PreColumbian Textile Conference, 265-278. Washington, DC: Textile Museum and Dumbarton Oaks.

King, P. M. 1981. "Comparison of Methods for Measuring Severity of Water Repellence of Sandy Soils and Assessment of Some Factors that Affect Its Measurement." Australian Journal of Soil Research 19(3):275-285. http://dx.doi.org/10.1071/SR9810275.

Klingebiel, A. A., and P. H. Montgomery. 1961. Land Capability Classification. Agriculture Handbook 210. Washington, DC: U.S. Government Printing Office.

Kolb, Charles. 1985. "Demographic Estimates in Archaeology: Contributions from Ethnoarchaeology on Mesoamerican Peasants." Current Anthropology 26(5):58I-599. http://dx.doi.org/10.1086/203348.

Kovacevich, Brigitte. 2007. "Ritual, Crafting and Agency at the Classic Maya Kingdom of Cancuen.” In Mesoamerican Ritual Economy, ed. E. C. Wells and K. L. Davis-Salazar, 67-II9. Boulder: University Press of Colorado.

Kovacevich, Brigitte A. 2013. "Craft Production and Distribution in the Maya Lowlands: A Jade Case Study." In Merchants, Markets and Exchange in the Pre-Colombian World, ed. K. G. Hirth and J. Pillsbury, 255-282. Washington, DC: Dumbarton Oaks Research Library and Collections.

Kubler, George. 196r. “The Design of Space in Maya Architecture." In Miscellanea Paul Rivet: Octogenario Dicata, 515-531. México, DF: Universidad Nacional Autónoma de México.

Kunen, Julie. 2004. Ancient Maya Life in the Far West Bajo: Social and Environmental Change in the Wetlands of Belize. Anthropological Papers of the University of Arizona, no. 69. Tucson, AZ: University of Arizona Press.

Kunen, Julie, and Paul Hughbanks. 2003. "Bajo Communities as Resource Specialists: A Heterarchical Approach to Maya Socioeconomic Organization.” In Heterarchy, Political Economy and the Ancient Maya: The Three Rivers Region of East Central Yucatan, ed. Vernon L. Scarborough, Fred Valdez, Jr., and Nicholas Dunning, 92-108. Tucson: University of Arizona Press.

Kurjack, Edward B. 1974. Prehistoric Lowland Maya Community and Social Organization: A Case Study at Dzibilchaltun, Yucatan, Mexico. Middle American Research Institute 38. New Orleans: Middle American Research Institute.

Kurjack, Edward B., and E. Wyllys Andrews V. 1976. "Early Boundary Maintenance in Northwest Yucatan, Mexico." American Antiquity 4I(3):318-325. http://dx.doi.org/10.2307 /279520. 
Kurjack, Edward B., and Silvia Garza Tarazona de González. 1981. "Pre-Colombian Community Form and Distribution in the Northern Maya Area." In Lowland Maya Settlement Patterns, ed. W. Ashmore, 287-309. Albuquerque: University of New Mexico Press.

Kurjack, Edward B., Silvia Garza Tarazona de González, and Jerry Lucas. 1979. "Archaeological Settlement Patterns and Modern Geography in the Hill Region of Yucatan." In The Puuc: New Perspectives, ed. L Mills, 36-45. Pella, IA: Central College.

Landa, Diego de. 1978. Yucatan before and after the Conquest. Trans. William Gates. New York: Dover.

Lane, Chad S., C. I. Mora, Sally P. Horn, and Kenneth H. Orvis. 2008. "Sensitivity of Bulk Sedimentary Stable Carbon Isotopes to Prehistoric Forest Clearance and Maize Agriculture.” Journal of Archaeological Science 35(8):2,119-2,132. http://dx.doi.org/10.1016/j.jas.2008.01.019.

LeCount, Lisa. 1999. "Polychrome Pottery and Political Strategies in Late and Terminal Classic Lowland Maya Society." Latin American Antiquity 10(3):239-258. http://dx.doi.org/10.2307 1972029.

LeCount, Lisa. 200I. "Like Water for Chocolate: Feasting and Political Ritual among the Late Classic Maya at Xunantunich, Belize." American Anthropologist I034):935-953. http://dx.doi .org/10.1525/aa.2001.103.4.935.

Leventhal, Richard M. 1981. "Settlement Patterns in the Southeast Maya Area." In Lowland Maya Settlement Patterns, ed. W. Ashmore, 187-210. Albuquerque: University of New Mexico Press.

Leventhal, Richard M. 1983. "Household Groups and Classic Maya Religion." In Prehistoric Settlement Patterns: Essays in Honor of Gordon R. Willey, ed. E. Z. Vogt and R. M. Leventhal, 55-76. Cambridge, MA: Peabody Museum of Archaeology and Ethnology, Harvard University.

Lewenstein, Suzanne M. 1981. "Mesoamerican Obsidian Blades: An Experimental Approach to Function.” Journal of Field Archaeology 8(2):175-188.

Lewenstein, Suzanne M. 1987. Stone Tool Use at Cerros: The Ethnoarchaeological and Use-wear Evidence. Austin: University of Texas Press.

Leyden, Barbara, Mark Brenner, Jason H. Curtis, Dolores Piperno, Tom Whitmore, and Bruce Dahlin. 1996. "A Record of Long- and Short-term Paleoclimatic Variation from Northwest Yucatan: Cenote San José Chulchaca." In The Managed Mosaic: Ancient Maya Agriculture and Resource Use, ed. S. L. Fedick, 30-52. Salt Lake City: University of Utah Press.

Leyden, Barbara W., Mark Brenner, and Bruce H. Dahlin. 1998. "Cultural and Climatic History of Coba, a Lowland Maya City in Quintana Roo, Mexico.” 2uaternary Research 49(I):IIII22. http://dx.doi.org/10.1006/qres.1997.194I.

Lillios, Katina T. 1992. "Phosphate Fractionation of Soils at Agroal, Portugal." American Antiquity $57(3): 495-506$. http://dx.doi.org/10.2307/280937.

Linderholm, Johan, and Erik Lundberg. 1994. "Chemical Characterization of Various Archaeological Soil Samples Using Main and Trace Elements Determined by Inductively Coupled Plasma Atomic Emission Spectrometry." Journal of Archaeological Science 2I(3):303-314. http://dx.doi.org/10.1006/jasc.1994.1030.

Littmann, Edwin R. 1958. "Ancient Mesoamerican Mortars, Plasters, and Stuccos: The Composition and Origins of Sascab." American Antiquity 24(2):172-176. http://dx.doi.org/1o $.2307 / 277478$. 
Lohse, Jon C., Kerry L. Sagebiel, and Joanne P. Baron. 2013. “The Ball Game, Community Ceremony, and Political Development in Northwestern Belize." In Classic Maya Political Ecology: Resource Management, Class Histories, and Political Change in Northwestern Belize, ed. J. C. Lohse, 99-127. Los Angeles: Cotsen Institute for Archaeology, University of California, Los Angeles.

Lohse, Jon C., and Fred Jr. Valdez. 2004. “Examining Ancient Maya Commoners Anew.” In Ancient Maya Commoners, ed. J. C. Lohse and F. J. Valdez, I-2I. Austin: University of Texas Press.

Loya González, Tatiana, and Travis Stanton. 2013. "Impact of Politics on Material Culture: Evaluating the Yaxuna-Coba Sacbe." Ancient Mesoamerica 24(or):25-42. http://dx.doi.org/ro $.1017 /$ So956536113000023.

Lucero, Lisa J. 2003. "The Politics of Ritual: The Emergence of Classic Maya Kings." Current Anthropology 44(4):523-558. http://dx.doi.org/10.1086/375870.

Luzzadder-Beach, Sheryl. 2000. "Water Resources of the Chunchucmil Maya." Geographical Review 90(4):493-510. http://dx.doi.org/10.2307/325078I.

Luzzadder-Beach, Sheryl. 2015a. "Groundwater/water Table." In The Encyclopedia of the Ancient Maya, ed. Walter Witschey, 85-86. Walnut Creek, CA: AltaMira Press.

Luzzadder-Beach, Sheryl. 2015b. "Chicxulub Crater (and the Cenote Zone)." In The Encyclopedia of the Ancient Maya, ed. Walter Witschey, 164-165. Walnut Creek, CA: AltaMira Press.

Luzzadder-Beach, Sheryl, and Timothy Beach. 2008. "Water Chemistry Constraints and Possibilities for the Ancient and Contemporary Maya Wetlands.” Journal of Ethnobiology 28(2):21I-230. http://dx.doi.org/10.2993/0278-077I-28.2.21I.

Luzzadder-Beach, Sheryl, and Timothy Beach. 2009. "Arising from the Wetlands: Mechanisms and Chronology of Landscape Aggradation in the Northern Coastal Plain of Belize." Annals of the Association of American Geographers 99(I):I-26. http://dx.doi.org/10.1080/000456 00802458830 .

Luzzadder-Beach, Sheryl, Timothy Beach, Jonathan Flood, and Scott Hutson. 20r2. "Living on the Edge of the World: Hydrogeoarchaeology of the Chunchucmil and Ucí-Cansahcab Maya Sites." Paper in Symposium 167, Bruce H. Dahlin Memorial Session, Part 2, Adaptations and Maladaptations to Environmental Change, Society for American Archaeology 77 th Annual Meetings, Memphis TN 4/20/12.

Luzzadder-Beach, Sheryl, Timothy Beach, Richard E. Terry, and K. Z. Doctor. 20rI. "Elemental Prospecting and Geoarchaeology in Turkey and Mexico." Catena 85(2):I19-I29. http://dx .doi.org/10.1016/j.catena.2010.09.001.

Maca, Allen. 2002. "Socio-Spatial Boundaries in Classic Maya Settlement Systems: Copan's Urban Foothills and the Excavations at Group 9J-5." Ph.D dissertation, Department of Anthropology, Harvard University, Cambridge, MA.

MacKinnon, J. Jefferson, and Susan M. Kepecs. 1989. "Prehispanic Saltmaking in Belize: New Evidence.” American Antiquity 54(3):522-533. http://dx.doi.org/10.2307/280780.

Magnoni, Aline. 2007. "Population Estimates at the Ancient Maya City of Chunchucmil, Yucatán, Mexico." In Digital Discovery: Exploring New Frontiers in Human Heritage. Computer Applications and Quantitative Methods in Archaeology, CAA 2006, Proceedings of the 34 th 
Conference, Fargo, United States, April 20o6, ed. J. T. Clark and E. M. Hagemesiter, 175-182. Budapest: Archaeolingua.

Magnoni, Aline. 2008. From City To Village: Landscape And Household Transformations at Classic Period Chunchucmil, Yucatán, Mexico. New Orleans: Department of Anthropology, Tulane. Magnoni, Aline. 2015. 2015. Proyecto Sacbé Yaxuná-Cobá: Primera Temporada de Campo. DF, México: Informe Técnico al Consejo de Arqueología del INHA.

Magnoni, Aline, Traci Ardren, Scott R. Hutson, and Bruce H. Dahlin. 2014. "Urban Identities: Social and Spatial Production at Classic Period Chunchucmil, Yucatan, Mexico." In Making Ancient Cities, ed. A. T. Creekmore and K. D. Fisher, 145-180. Cambridge: Cambridge University Press. http://dx.doi.org/10.1017/CBO9781107110274.006.

Magnoni, Aline, and David Hixson. 2010. "From Pencil to Pentium: Digitizing the Classic Period Maya City of Chunchucmil, Yucatán, Mexico." In CAA 2009 Proceedings, 217-227.

Magnoni, Aline, Scott R. Hutson, and Bruce H. Dahlin. 2012. "Living in the City: Settlement Patterns and the Urban Experience at Classic Period Chunchucmil, Yucatan, Mexico.” Ancient Mesoamerica 23(02):313-343. http://dx.doi.org/10.1017/S0956536112000223.

Magnoni, A., and Scott R. Hutson, Eugenia B. Mansell, and Travis W. Stanton. 2004. "La Vida Domestica Durante el Periodo Clasico en Chunchucmil, Yucatan.” In XVII Simpósio de Investigaciones Arqueológicas en Guatemala, 2003, ed. J. P. Laporte, H. Escobedo and B. Arroyo, 991-1,006. Guatemala: Museo Nacional de Arqueología y Etnología.

Magnoni, Aline, Scott R. Hutson, and Travis W. Stanton. 2008. "Urban Landscape Transformations and Changing Perceptions at Chunchucmil, Yucatán." In Ruins of the Past: The Use and Perception of Abandoned Structures in the Maya Lowlands, ed. T. W. Stanton and A. Magnoni, 193-222. Boulder: University Press of Colorado.

Mansell, Eugenia Brown, Robert H. Tykot, David A. Freidel, Traci Ardren, and Bruce Dahlin. 2006. "Early to Late Terminal Classic Maya Diet in the Northern Lowlands of the Yucatán (Mexico)." In Histories of Maize: Multidisciplinary Approaches to the Prehistory, Linguistics, Biogeography, Domestication, and Evolution of Maize, ed. J. Staller, R. H. Tykot, and B. Benz, 173-185. New York: Academic Press.

Manzanilla, Linda. 2002. "Houses and Ancestors, Altars and Relics: Mortuary Patterns at Teotihuacan, Central Mexico." In The Space and Place of Death, vol. ir. ed. H. Silverman and D. B. Small, 55-65. Archaeological Papers of the American Anthropological Association. http://dx .doi.org/10.1525/ap3a.2002.II.I.55.

Manzanilla, Linda. 2012. "Neighborhoods and Elite "Houses" at Teotihuacan, Central Mexico." In The Neighborhood as a Social and Spatial Unit in Mesoamerican Cities, ed. M. C. Arnauld, L. Manzanilla, and M. E. Smith, 55-73. Tucson: University of Arizona Press.

Marcus, Joyce. 1983. "Lowland Maya Archaeology at the Crossroads." American Antiquity 48(3):454-488. http://dx.doi.org/10.2307/280556.

Marcus, Joyce. 2000. “Toward an Archaeology of Communities.” In The Archaeology of Communities: A New World Perspective, ed. M. A. Canuto and J. Yaeger, I23-I4I. London: Routledge.

Marcus, Joyce, and Jeremy A. Sabloff. 2008. "Introduction." In The Ancient City: New Perspectives on Urbanism in the Old and New Worlds, ed. J. Marcus and J. A. Sabloff, 3-28. Washington, DC, and Santa Fe, NM: National Academy of Sciences and the School of American Research. 
Marquina, Ignacio. 1964. Arquitectura Prehispanica. 2nd ed. Mexico City: INHA.

Marshall, Robert C. 2010. "Introduction." In Cooperation in Economy and Society, ed. R. C. Marshall, vii-xxi. Lanham, MD: Altamira.

Martin, Simon. 2003. "In the Line of the Founder: Dynastic Politics at Tikal." In Tikal: Dynasties, Foreigners and Affairs of State Advancing Maya Archaeology, ed. J. A. Sabloff, 3-46. Santa Fe: SAR Press.

Martin, Simon. 2012. "Hieroglyphs from the Painted Pyramid: The Epigraphy of Chiik Nahb Structure Sub I-4, Calakmul, Mexico." In Maya Archaeology 2, ed. C. Golden, S. D. Houston and J. Skidmore, 60-80. San Francisco: PreColumbian Mesoweb Press.

Martin, Simon, and Nikolai Grube. 1995. "Maya Superstates." Archaeology 48(6):4I-46.

Martin, Simon, and Nikolai Grube. 2008. Chronicles of the Maya Kings and Queens. 2nd ed. London: Thames and Hudson.

Martínez-Ballesté, Andrea, Carlos Martorell, and Javier Caballero. 2008. “The Effect of Maya Traditional Harvesting on the Leaf Production, and Demographic Parameters of Sabal Palm in the Yucatán Peninsula, Mexico." Forest Ecology and Management 256(6):1,320-1,324. http://dx.doi.org/10.1016/j.forec0.2008.06.029.

Masson, Marilyn A. 200I. "Changing Patterns of Ceramic Stylistic Diversity among the Maya Lowlands." Acta Archaeologica 73:1-30.

Masson, Marilyn A. 2002a. "Introduction." In Ancient Maya Political Economies, ed. M. A. Masson, I-30. Walnut Creek: Altamira.

Masson, Marilyn A. 2002b. "Community Economy and Mercantile Transformation in Postclassic Northeastern Belize.” In Ancient Maya Political Economies, ed. M. A. Masson and D. A. Freidel, 335-364. Walnut Creek: Altamira.

Masson, Marilyn. 2004. "Fauna Exploitation from the Preclassic to the Postclassic Periods at Four Maya Settlements in Northern Belize." In Maya Zooarchaeology: New Directions in Methods and Theory, ed. Kitty F. Emery: 97-124. Cotsen Institute of Archaeology, Monograph 51, University of California, Los Angeles.

Masson, Marilyn A., and H. Chaya. 2000. "Obsidian Trade Connections at the Postclassic Maya Site of Laguna de On, Belize." Lithic Technology 25(2):135-I44. http://dx.doi.org/I0.1080/or 977261.2000.11720969.

Masson, Marilyn A., and David A. Freidel. 2012. "An Argument for Classic-era Maya Market Exchange." Journal of Anthropological Archaeology $3 \mathrm{I}(4): 455-484$. http://dx.doi.org/10.1016 /j.jaa.2012.03.007.

Masson, Marilyn A., and David A. Freidel. 2013. "Wide Open Spaces: A Long View of the Importance of Maya Market Exchange." In Merchants, Markets and Exchange in the PreColombian World, ed. K. G. Hirth and J. Pillsbury, 20I-228. Washington, DC: Dumbarton Oaks Research Library and Collections.

Masson, Marilyn A., and Carlos Peraza Lope. 2014. Kukulcan's Realm: Urban Life at Ancient Mayapan. Boulder: University Press of Colorado.

Matallo, Heitor, Jr., Fernando Casas-Castañeda, and Elizabeth Migongo-Bake. 2002. "Use of Live Fences of Nopal (Opuntia) and Associated Crops to Rehabilitate and Protect Sloping 
Land in Loja, Ecuador." Mountain Research and Development 22(I):22-25. http://dx.doi.org /10.1659/0276-474I(2002)022[0022:UOLFON]2.0.CO;2.

Matheny, Ray T., Deanne Gurr, Don W. Forsyth, and Forest R. Hauck. 1983. Investigations at Edzna, Campeche, Mexico, Vol. I, Part I: The Hydraulic System. Papers of the New World Archaeological Foundation, No. 46. Provo, UT: Brigham Young University.

Mathews, Jennifer P., and Rubén Maldonado C. 2006. "Late Formative and Early Classic Interaction Spheres Reflected in the Megalithic Style." In Lifeways in the Northern Lowlands: New Approaches to Maya Archaeology, ed. J. P. Mathews and B. A. Morrison, 95-118. Tucson: University of Arizona Press.

Matsushi, Y., K. Sasa, T. Takahashi, K. Sueki, Y. Nagashima, and Y. Matsukura. 2010. "Denudation Rates of Carbonate Pinnacles in Japanese Karst Areas: Estimates from Cosmogenic $36 \mathrm{Cl}$ in Calcite." Nuclear Instruments \& Methods in Physics Research. Section B, Beam Interactions with Materials and Atoms 268(7-8):1,205-1,208. http://dx.doi.org/10.1016/j.nimb.2009.10.134.

Maudslay, Alfred P. 1889-1902. Biologia Centrali-Americana: Archaeology, 6 vols. London: R. H. Porter and Dulau.

Mazeau, Daniel E., and Jamie Forde. 2004. "Continued Analysis of Lithic Materials at Chunchucmil." In The Pakbeh Regional Economy Program: Report of the 2002 Field Season, ed. Bruce H. Dahlin and Daniel E. Mazeau, 133-138. Washington, DC: Howard University Sociology/Anthropology Department.

McAnany, Patricia A. 1992. "Resources, Specialization and Exchange in the Maya Lowlands." In The American Southwest and Mesoamerica, ed. J. Ericson and T. G. Baugh, 213-245. New York: Plenum Press.

McAnany, Patricia A. 1993. "The Economics of Social Power and Wealth among Eighth Century Maya Households." In Lowland Maya Civilization in the Eighth Century AD, ed. J. A. Sabloff and J. S. Henderson, 65-90. Washington, DC: Dumbarton Oaks.

McAnany, Patricia A. 1995. Living with the Ancestors: Kinship and Kingship in Ancient Maya Society. Austin: University of Texas Press.

McAnany, Patricia A. 2004. "Appropriative Economies: Labor Obligations and Luxury Goods in Ancient Maya Societies.” In Archaeological Perspectives on Political Economy, ed. G. M. Feinman and L. Nicholas, 145-165. Salt Lake City: University of Utah Press.

McAnany, Patricia A. 2010. Ancestral Maya Economies in Archaeological Perspective. Cambridge: Cambridge University Press. http://dx.doi.org/ı.1017/CBO9781139195867.

McAnany, Patricia A., and Shannon E. Plank. 200I. "Perspectives on Actors, Gender Roles, and Architecture at Classic Maya Courts and Households." In Royal Courts of the Ancient Maya, Volume I: Theory, Comparison and Synthesis, ed. T. Inomata and S. D. Houston, 84-129. Boulder: Westview Press.

McAnany, Patricia A., Ben S. Thomas, Steven Morandi, Polly A. Peterson, and Eleanor Harrison. 2002. "Praise the Ajaw and Pass the Kakaw: Xibun Maya and the Political Economy of Cacao." In Ancient Maya Political Economies, ed. M. A. Masson and D. A. Freidel, I23-139. Walnut Creek, CA: AltaMira Press.

McCafferty, Sharisse D., and Geoffrey G. McCafferty. 1988. "Powerful Women and the Myth of Male Dominance in Aztec Society." Archaeological Review from Cambridge 7(I):45-59. 
McKillop, Heather. 1996. "Ancient Maya Trading Ports and the Integration of Long-Distance and Regional Economies: Wild Cane Cay in South-Coastal Belize." Ancient Mesoamerica 7(OI):49-62. http://dx.doi.org/10.1017/S0956536100001280.

McKillop, Heather. 2002. Salt: White Gold of the Ancient Maya. Gainesville: University Press of Florida. http://dx.doi.org/10.5744/florida/9780813025117.001.0001.

McKillop, Heather. 2005. In Search of Maya Sea Traders. College Station: Texas A\&M Press.

Me-Bar, Yoav, and Fred Valdez, Jr. 2003. "Droughts as Random Events in the Maya Lowlands." Journal of Archaeological Science 30(12):1,599-1,606. http://dx.doi.org/10.1016/S0305-4403 (03)00057-8.

Medina-Elizalde, Martín, Stephen J. Burns, David W. Lea, Yemane Asmerom, Lucien von Gunten, Victor Polyak, Mathias Vuille, and Ambarish Karmalkar. 20ı。. "High Resolution Stalagmite Climate Record from the Yucatán Peninsula Spanning the Maya Terminal Classic Period." Earth and Planetary Science Letters 298(I-2):255-262. http://dx.doi.org/10.1016/j .epsl.2010.08.016.

Medina-Elizalde, Martin, Stephen J. Burns, Josue M. Polanco-Martinez, Timothy Beach, Fernanda Lases-Hernández, Chuan-Chou Shen, and Hao-Cheng Wang. October 2015.

"“'High-resolution Speleothem Record of Precipitation from the Yucatan Peninsula Spanning the Maya Preclassic Period." Global and Planetary Change." Online (Bergheim) 19. http://dx .doi.org/10.1016/j.gloplacha.2015.10.003.

Medina-Elizalde, Martín, and Eelco J. Rohling. 2012. "Collapse of Classic Maya Civilization Related to Modest Reduction in Precipitation.” Science 335(607I):956-959. http://dx.doi.org /10.1126/science.1216629.

Mefford, Jill J. 1992. "Basketry, Twined Sandal Soles, and Cordage." In Artifacts from the Cenote of Sacrifice, Chichen Itza, Yucatan, ed. C. C. Coggins, 91-97. Memoirs of the Peabody Museum of Archaeology and Ethnology io:3. Cambridge, MA: Harvard University.

Merino, Martín. 1997. "Upwelling on the Yucatan Shelf: Hydrographic Evidence." Journal of Marine Systems 13(I-4):I0I-I21. http://dx.doi.org/10.1016/So924-7963(96)00123-6.

Middleton, William D. 1998. Craft Specialization at Ejutla, Oaxaca, Mexico: An Archaeometric Study of the Organization of Household Craft Production. Madison: University of Wisconsin.

Middleton, William D., and T. Douglas Price. 1996. "Identification of Activity Areas by MultiElement Characterization of Sediments from Modern and Archaeological House Floors using Inductively Coupled Plasma-atomic Emission Spectroscopy." Journal of Archaeological Science 23(5):673-687. http://dx.doi.org/10.1006/jasc.1996.0064.

Miller, Naomi, and Kathleen L. Gleason. 1994. "Fertilizer in the Identification and Analysis of Cultivated Soil." In The Archaeology of Garden and Field, ed. N. F. Miller, and Kathryn L. Gleason, 25-43. Philadelphia: University of Pennsylvania Press.

Millet Cámara, Luis. 1984. "Logwood and Archaeology in Campeche." Journal of Anthropological Research 40(2):324-328. http://dx.doi.org/10.1086/jar.40.2.3629579.

Millet Cámara, Luis. 1994. “La Costa de Barlovento de Campeche.” In Mirador Campechano, ed. L. Millet, 64-94. Campeche: Universidad Autonoma de Campeche.

Millon, René, Bruce Drewitt, and George Cowgill. 1973. The Teotihuacán Map, Part 2: Maps. vol. I. Urbanization at Teotihuacán, Mexico. Austin: University of Texas Press. 
Minc, Leah. 2006. "Monitoring Regional Market Systems in Prehistory: Models, Methods, and Metrics." Journal of Anthropological Archaeology 25(I):82-116. http://dx.doi.org/10.1016/j.jaa .2005 .09 .003 .

Moholy-Nagy, Hattula. 1989. “Who Used Obsidian at Tikal?” In La Obsidiana en Mesoamerica, ed. M. Gaxiola G. and J. E. Clark, 379-390. Mexico City: Instituto Nacional de Antropología e Historia.

Moholy-Nagy, Hattula. 1997. "Middens, Construction Fill, and Offerings: Evidence for the Organization of Classic Period Craft Production at Tikal, Guatemala." Journal of Field Archaeology 24(3):293-313.

Moholy-Nagy, Hattula. 2003. "Source Attribution and the Utilization of Obsidian in the Maya Area." Latin American Antiquity I4(3):301-310. http://dx.doi.org/10.2307/3557561.

Monmonier, Mark. 1991. How to Lie with Maps. Chicago: University of Chicago Press.

Morrison, Beth A., and Roberto Cozatl-Manzano. 2003. "Initial Evidence for Use of Periphyton as an Agricultural Fertilizer by the Ancient Maya Associated with the El EdenWetland, Northern Quintana Roo, Mexico." In The Lowland Maya Area: Three Millennia at the Human-Wildland Interface, ed. Arturo Gomez-Pompa, Michael F. Allen, Scott L. Fedick, and Juan J. Jimenez-Osornio, 4OI-4I4. New York: Food Products Press.

Morton, Julia. 1960. "Can Annatto (Bixa orellana L.), an Old Source of Food Color, Meet New Needs for Safe Dye?” Florida State Horticultural Society (73):301-309.

Muhs, Daniel R., James R. Budahn, Joseph M. Prospero, and Steven N. Carey. 2007. “Geochemical Evidence for African Dust Inputs to Soils of Western Atlantic Islands: Barbados, the Bahamas, and Florida." Journal of Geophysical Research II2(2):Fo2009.

Munro-Stasiuk, Mandy, and T. Kam Manahan. 2010. "Investigating Ancient Maya Agricultural Adaptation through Ground Penetrating Radar (GPR) Analysis of Karst Terrain, Northern Yucatán, Mexico." Acta Carsologica 39(I):85-97. http://dx.doi.org/10.3986/ac.v39ir.II8.

Muñoz, Arturo René. 2006. Power, Production and Prestige: Technological Change in the Late Classic Ceramics of Piedras Negras, Guatemala. Unpublished Dissertation. University of Arizona.

Nelson, Fred W. 1973. Archaeological Investigations at Dzibilnocac. Campeche, Mexico. Papers of the New World Archaeological Foundation, no. 33. New World Archaeological Foundation. Provo, UT: Brigham Young University.

Nelson, Fred. 1985. "Summary of the Results of Analysis of Obsidian Artifacts from the Maya Lowlands." Scanning Electron Microscopy II:631-649.

Nelson, Fred W. 1989. "Rutas de Intercambio de Obsidiana en el Norte de la Peninsula de Yucatan." In La Obsidiana en Mesoamerica, ed. M. Gaxiola and J. E. Clark, 363-368. Mexico City: Instituto Nacional de Antropología e Historia.

Nelson, Fred W., Kirk K. Nielsen, Nolan F. Mangelson, Max W. Hill, and Ray T. Matheny. 1977. "Preliminary Studies of the Trace Element Composition of Obsidian Artifacts from Northern Campeche Mexico." American Antiquity 42(2):209-225. http://dx.doi.org/10.2307/278982.

Nelson, Fred W., D. A. Phillips, and Alfredo Barrera Rubio. 1983. "Trace Element Analysis of Obsidian Artifacts from the Northern Maya Lowlands." In Investigations at Edzna, Campeche, Mexico: Volume I, Part I: The Hydraulic System, ed. R. Matheny, D. Gurr, D. Forsyth, and F. Hauck, 204-219. Provo: New World Archaeological Foundation. 
Nelson, F. W., Raymond Sidrys and R. D. Holmes. 1978. “Trace Element Analysis by X-Ray Fluorescence of Obsidian Artifacts from Guatemala and Belize." In Excavations at Seibal, Department of Peten, Guatemala, Artifacts, ed. R. Matheny, Memoirs Number I4. Cambridge, MA: Peabody Museum.

Netting, Robert McC. 1982. "Some Home Truths on Household Size and Wealth." American Behavioral Scientist 25(6):641-662. http://dx.doi.org/10.1177/000276482025006004.

Nigh, Ronald, and Stewart A. W. Diemont. 2013. "The Maya Milpa: Fire and the Legacy of the Living Soul." Frontiers in Ecology and the Environment. II(sI):e45-54. http://dx.doi.org/ı $.1890 / 120344$.

Novelo, Eberto, and Rosaluz Tavera. 2003. "The Role of Periphyton in the Regulation and Supply of Nutrients in a Wetland at El Eden, Quintana Roo." In The Lowland Maya: Three Millennia at the Human-Wildland Interface, ed. A. Gomez-Pompa, M. Allen, S. Fedick, and J. J. Jimenez-Osorio, 217-239. New York: Haworth Press.

Oades, J. M. 1988. “The Retention of Organic Matter in Soils.” Biogeochemistry 5(I):35-70. http://dx.doi.org/10.1007/BFo2180317.

Oonk, Stijn, C. P. Slomp, and Dirk J. Huisman. 2009. "Geochemistry as an Aid in Archaeological Prospection and Site Interpretation: Current Issues and Research Directions." Archaeological Prospection I6(I):35-5I. http://dx.doi.org/10.1002/arp.344.

Ortíz Ceballos, Ponciano and Robert S. Santley. 1998. "Matacapan, un Ejemplo de Enclave Teotihuacano en la Costa del Golfo." In Los Ritmos de Cambio en Teotihuacan: Reflexiones y Discusiones de su Cronología, ed. R. Brambila Paz and R. Cabrera Castro, 377-46o. Mexico City: Instituto Nacional de Antropología e Historia.

Osborne, Lilly de Jongh. 1965. Indian Crafts of Guatemala and El Salvador. Norman: University of Oklahoma Press.

Ostrom, Elinor. 1992. Crafting Institutions for Self-Governing Irrigation Systems. San Francisco: Institute for Contemporary Studies.

Pacheco A., Julia, Armando Cabrera S., and Luis E. Marín. 2000. "Bacteriological Contamination in the Karstic Aquifer of Yucatán, Mexico." Geofisica Internacional-Mexico 39(3):285-29I.

Parnell, J. Jacob, Richard E. Terry, and Charles Golden. 200I. "Using In-Field Phosphate Testing to Rapidly Identify Middens at Piedras Negras, Guatemala." Geoarchaeology: An International Journal $16(8): 855-873$. http://dx.doi.org/10.1002/gea.1024.

Parnell, J. Jacob, Richard E. Terry, and Zach Nelson. 2002. "Soil Chemical Analysis Applied as an Interpretive Tool for Ancient Human Activities at Piedras Negras, Guatemala." Journal of Archaeological Science 29(4):379-404. http://dx.doi.org/10.1006/jasc.2002.0735.

Parnell, J. Jacob, Richard E. Terry, and Payson D. Sheets. 2002. "Soil Chemical Analysis of Ancient Activities in Cerén, El Salvador: A Case Study of a Rapidly Abandoned Site." Latin American Antiquity 13(3):331-342. http://dx.doi.org/10.2307/972114.

Parsons, Jeffrey. 2006. The Last Pescadores of Chimalhuacan, Mexico, An Archaeological Ethnography. Anthropological Papers No. 96. Ann Arbor: University of Michigan Museum of Anthropology.

Patch, Robert. 1977. "El mercado urbano y la economía campesina en el siglo XVIII." Boletín de la Escuela de Ciencias Antropológicas 5(27):52-66. 
Patch, Robert W. 2003. "The (Almost) Forgotten Plants of Yucatan." In The Lowland Maya Area: Three Millennia at the Human-Wildland Interface, ed. A. Gomez-Pompa, M. Allen, S. Fedick, and J. Jimenez-Osorio, 56I-570. Boca Raton: CRC Press.

Perry, Eugene, Luis Marin, Jana McClain, and Guadalupe Velazquez. 1995. "Ring of Cenotes (Sinkholes), Northwest Yucatan, Mexico: Its Hydrogeologic Characteristics and Possible Association with the Chicxulub Impact Crater." Geology 23(I):17-20. http://dx.doi.org/ı $.1130 / 0091-7613(1995) 023<0017$ :ROCSNY>2.3.CO;2.

Perry, Eugene, Jennifer Swift, Jose Gamboa, Andrew Reeve, Robert Sanborn, Luis Marin, and Miguel Villasuso. 1989. "Geologic and Environmental Aspects of Surface Cementation, North Coast, Yucatan, Mexico." Geology 17(9):818-821. http://dx.doi.org/10.1130/0091-7613 (1989)017<0818:GAEAOS>2.3.CO;2.

Perry, Eugene, Guadalupe Velazquez-Oliman, and Richard A. Socki. 2003. "Hydrogeology of the Yucatan Peninsula." In The Lowland Maya Area: Three Millennia at the HumanWildland Interface, ed. Arturo Gomez-Pompa, Michael F. Allen, Scott L. Fedick, and Juan J. Jimenez-Osornio, II5-I38. New York: Food Products Press.

Peuramaki-Brown, Meaghan. 2013. "Identifying Integrative Built Environments in the Archaeological Record: An Application of New Urban Design Theory to Ancient Urban Spaces." Journal of Anthropological Archaeology 32(4):577-594. http://dx.doi.org/10.1016/j.jaa.2013 .09 .006 .

Phillips, David. 1979. "Material Culture and Trade of Postclassic Maya." PhD dissertation, Department of Anthropology, University of Arizona, Tucson.

Piña Chan, Román. 1978. "Commerce in the Yucatan Peninsula: The Conquest and the Colonial Period." In Mesoamerican Communication Routes and Cultural Contacts, ed. T. A. Lee and C. Navarrete, 37-48. Provo, Utah: New World Archaeological Foundation.

Pohl, John M. D., John Monaghan, and Laura Stiver. 1997. "Religion, Economy, and Factionalism in Mixtec Boundary Zones." In Codices y Documentos Sobre Mexico, ed. S. Rueda Smithers, C. Vega Sosa, and R. Martinez Baracas, 205-232. Mexico City: Instituto Nacional de Antropología e Historia.

Polanyi, Karl. 1944. The Great Transformation: The Economic and Political Origins of Our Time. New York: Rinehart.

Polanyi, Karl. 1957. “The Economy as Instituted Process." In Trade and Market in the Early Empires, ed. K. Polanyi, C. M. Arensberg, and H. W. Pearson, 243-270. New York: Academic Press.

Pollock, Harry E. D. 1980. The Puuc: An Architectural Survey of the Hill Country of Yucatan and Northern Campeche. Cambridge, MA: Peabody Museum of Archaeology and Ethnology, Harvard University.

Pollock, Harry E. D., Ralph Roys, Tatiana Proskouriakoff, and A. Ledyard Smith. 1962. Mayapan, Yucatan, Mexico. Carnegie Institution Publication 619. Washington, DC: Carnegie Institution of Washington.

Pope, Kevin O., and Bruce H. Dahlin. 1989. "Ancient Maya Wetland Agriculture: New Insights from Ecological and Remote Sensing Research.” Journal of Field Archaeology 16:87-106. 
Pope, Kevin O., Adriana C. Ocampo, Gary L. Kinsland, and Randy Smith. 1996. "Surface Expression of the Chicxulub Crater." Geology 24(6):527-530. http://dx.doi.org/10.1130 /0091-7613(1996)024<0527:SEOTCC>2.3.CO;2.

Pope, Kevin O., Eliska Rejmankova, Jack R. Paris, and Robert Woodruff. 1996. "Monitoring Seasonal Flooding Cycles in Marshes of the Yucatan Peninsula with SIR-C polarimetric Radar Imagery." Remote Sensing of Environment 59(2):157-166.

Pope, Kevin O., Adriana C. Ocampo, Alfred G. Fischer, Walter Alvarez, Bruce W. Fouke, Clyde L. Webster, Franciso J. Vega, Jan Smit, A. Eugene Fritsche, and Philippe Claeys. 1999. "Chicxulub Impact Ejecta from Albion Island, Belize." Earth and Planetary Science Letters I70(4):351-364. http://dx.doi.org/10.1016/So012-821X(99)00123-5.

Pope, Kevin O., Mary D. Pohl, and John S. Jacob. 1996. "Formation of Ancient Maya Wetland Fields: Natural and Anthropogenic Processes." In The Managed Mosaic: Ancient Maya Agriculture and Resource Use, ed. S. Fedick, 165-176. Salt Lake City: University of Utah Press.

Pope, Kevin O., Eliska Rejmankova, and Jack F. Paris. 200I. "Spaceborne Imaging Radar-C (SIR-C) Observations of Groundwater Discharge and Wetlands Associated with the Chicxulub Impact Crater, Northwestern Yucatan Peninsula, Mexico." Geological Society of America Bulletin $\mathrm{II}_{3}(3): 403-416$. http://dx.doi.org/10.1130/0016-7606(200I) II3 $_{3}<0403$ :SIR CSC>2.0.CO;2.

Potter, Daniel. 1993. "Analytical Approaches to Late Classic Maya Lithic Industries." In Lowland Maya Civilization in the Eighth Century A.D, ed. J. Sabloff and J. Henderson, 273-298. Washington, DC: Dumbarton Oaks.

Potter, Daniel R., and Eleanor M. King. 1995. "A Heterarchical Approach to Lowland Maya Socioeconomies." In Heterarchy and the Analysis of Complex Societies, ed. R. M. Ehrenreich, C. L. Crumley, and J. E. Levy, 17-32. Arlington, VA: American Anthropological Association. http://dx.doi.org/10.1525/ap3a.1995.6.1.17.

Pritchard-Parker, Mari A. 1994. "Milling Implements as Indicators of Household Economics and Social Differentiation among the Rural Ancient Maya: An Analysis of Data from the BRASS Archaeological Survey." Unpublished Masters Thesis, Department of Anthropology, University of California, Riverside.

Prufer, Keith M., Amy E. Thompson, and Douglas J. Kennett. 2015. "Evaluating Airborne LiDAR for Detecting Settlements and Modified Landscapes in Disturbed Tropical Environments at Uxbenka, Belize." Journal of Archaeological Science 57:I-13. http://dx.doi.org/10.1016/j.jas.2015.02.013.

Pryor, Frederic L. 1977. The Origins of the Economy: A Comparative Study of Distribution in Primitive and Peasant Economies. New York: Academic Press.

Puleston, Dennis. 1983. The Settlement Survey of Tikal. The Tikal Reports 13. University of Pennsylvania. Philadelphia: The University Museum.

Pulido, Maria T., and Javier Caballero. 2006. "The Impact of Shifting Agriculture on the Availability of Non-timber Forest Products: The Example of Sabal yapa in the Maya Lowlands of Mexico." Forest Ecology and Management 222(I-3):399-409. http://dx.doi.org/10.1016/j.for ec0.2005.10.043.

Purseglove, John W. 1968. Tropical Crops: Dicotyledons 2. London: Longmans, Green. 
Pyburn, K. Anne. 1989. Prehistoric Maya Community and Settlement at Nohmul, Belize. Oxford: B.A.R. International Series.

Pyburn, K. Anne. 2008. "Pomp and Circumstance before Belize: Ancient Maya Commerce and the New River Conurbation." In The Ancient City: Perspectives from the Old and New World, ed. J. Marcus and J. Sabloff, 247-272. Washington, DC, and Santa Fe, NM: National Academy of Sciences and School of American Research.

Pyburn, K. Anne, Boyd Dixon, Patricia Cook, and Anna McNair. 1998. "The Albion Island Settlement Pattern Project: Domination and Resistance in Early Classic Northern Belize.” Journal of Field Archaeology 25:37-62.

Querejeta, José Ignacio, Héctor Estrada-Medina, Michael F. Allen, and Juan José JiménezOsornio. 2007. "Water Source Partitioning among Trees Growing on Shallow Karst Soils in a Seasonally Dry Tropical Climate.” Oecologia I52(I):26-36. http://dx.doi.org/10.1007/soo 442-006-0629-3.

Quyum, Abdul. 2000. “Water Management through Hydrophobic Soils.” MA Thesis, University of Calgary, Calgary, Alberta.

Rajagopal, Ram, and Graham Tobin. 1989. "Expert Opinion and Ground-Water Quality Protection: The Case of Nitrate in Drinking Water." Ground Water $27(6): 835-847$. http://dx.doi .org/10.1111/j.1745-6584.1989.tboro47.x.

Rands, Robert L., and Ronald L. Bishop. 1980. "Resource Procurement Zones and Patterns of Ceramic Exchange in the Palenque Region, Mexico." In Models and Methods in Regional Exchange, ed. R. Fry, 19-46. SAA Papers. Washington, DC: Society for American Archaeology.

Rands, Robert L., Ronald L. Bishop, and Jeremy A. Sabloff. 1982. "Maya Fine Paste Ceramics: An Archaeological Perspective." In Excavations at Seibal, Department of Peten, Guatemala, ed. Jeremy A. Sabloff, 315-337. Memoirs of the Peabody Museum of Archaeology and Ethnology, vol. 15. Cambridge, MA: Harvard University.

Rathje, William L. 1971. “The Origin and Development of Lowland Classic Maya Civilization.” American Antiquity 36(3):275-285. http://dx.doi.org/10.2307/277715.

Rathje, William L. 1975. "The Last Tango in Mayapan: A Tentative Trajectory of ProductionDistribution Systems." In Ancient Civilization and Trade, ed. J. A. Sabloff and C. C. Lamberg-Karlovsky, 409-448. Albuquerque: University of New Mexico Press.

Rattray, Evelyn. 1992. The Teotihuacan Burials and Offerings: A Commentary and Inventory. Nashville: Vanderbilt University Press.

Rattray, Evelyn Childs. 200I. Teotihuacan: Ceramics, Chronology and Cultural Trends. Mexico City: Instituto Nacional de Antropología e Historia/University of Pittsburgh.

Rattray, Evelyn, and M. Civera Cerecedo. 1999. "Los Entierros del Barrio de Comerciantes." In Practicas Funerarias en la Ciudad de los Dioses: Los Enterramientos Humanos de la Antigua Teotihuacan, ed. L. Manzanilla and C. Serrano, 149-172. Mexico: Instituto Nacional de Antropologia e Historia.

Redfield, Robert, and Alfonso Villa Rojas. 1934. Chan Kom: A Maya Village. Carnegie Institute of Washington Publication No. 448. Washington, DC: Carnegie Institute of Washington. 
Rees, Abraham. 1819. "Annatto." In The Cyclopaedia, or, Universal Dictionary of Arts, Sciences and Literature, vol. II. Philadelphia: S. F. Bradford.

Reina, Ruben E. 1967. "Milpas and Milperos: Implications for Prehistoric Times." American Anthropologist 69(I):I-20. http://dx.doi.org/10.1525/aa.1967.69.1.02a00020.

Reina, Ruben E., and Robert M. Hill. 1980. "Lowland Maya Subsistence: Notes from Ethnohistory and Ethnography." American Antiquity 45(I):74-79. http://dx.doi.org/10.2307 /279660.

Renfrew, Colin. 1977. “Alternative Models for Exchange and Spatial Distribution.” In Exchange Systems in Prehistory, ed. T. K. Earle and J. E. Ericson, 71-90. New York: Academic Press. http://dx.doi.org/10.1016/B978-0-12-227650-7.50010-9.

Restall, Matthew. 1997. The Maya World: Yucatec Culture and Society, I550-1850. Palo Alto: Stanford University Press.

Rice, Don S., and T. Patrick Culbert. 1990. "Historical Contexts for Population Reconstruction in the Maya Lowlands." In Precolumbian Population History in the Maya Lowlands, ed. T. P. Culbert and D. S. Rice, I-36. Albuquerque: University of New Mexico Press.

Rice, Don S., and Prudence M. Rice. 1990. "Population Size and Population Change in the Central Peten Lakes Region, Guatemala." In Pre-Colombian Population History in the Maya Lowlands, ed. T. Patrick Culbert, and Don S. Rice, I23-148. Albuquerque: University of New Mexico Press.

Rice, Prudence M. 1984. "Obsidian Procurement in the Central Peten Lakes Region, Guatemala." Journal of Field Archaeology in:I8 I-194.

Rice, Prudence M. 1986. “The Peten Postclassic: Perspectives from the Central Peten Lakes.” In Late Lowland Maya Civilization: Classic to Postclassic, ed. E. W. Andrews V and J. A. Sabloff, 25I-299. Albuquerque: University of New Mexico Press.

Rice, Prudence M. 1987. “Economic Change in the Lowland Maya Late Classic Period.” In Specialization, Exchange and Complex Societies, ed. E. M. Brumfiel and T. K. Earle, 76-85. Cambridge: Cambridge University Press.

Rico-Gray, Victor. 1982. "Estudio de la Vegetacion de la Zona Costera Inundable del Noroeste del Estado de Campeche, Mexico: Los Petenes." Biotica 7:171-190.

Rico-Gray, Víctor, Jose G. García Franco, A. Puch and P. Sima. 1988. "Composition, Structure of a Tropical Dry Forest, Yucatan, Mexico." International Journal of Ecology and Environmental Sciences 14:2I-29.

Ringle, William M. 20I4. “Organización Política Maya del Norte.” In Historia General de Yucatán, Volume r: La Civilización Maya Yucateca, ed. Sergio Quezada, Fernando Robles, and Anthony P. Andrews, 44-6r. Mérida: Universidad Autónoma de Yucatán.

Ringle, William M., and E. Wyllys Andrews V. 1988. "Formative Residences at Komchen, Yucatan, Mexico." In Household and Community in the Mesoamerican Past, ed. R. Wilk, and W. Ashmore. , 190-197. Albuquerque: University of New Mexico Press.

Ringle, William M., and E. Wyllys Andrews V. 1990. “The Demography of Komchen, An Early Maya Town in Northern Yucatan." In Precolumbian Population History in the Maya Lowlands, ed. T. P. Culbert, and Don S. Rice. Albuquerque: University of New Mexico Press. 
Ringle, William, and George J. Bey III. 200I. "Post-Classic and Terminal Classic Courts of the Northern Maya Lowlands." In Royal Courts of the Ancient Maya, Vol. 2: Data and Case Studies, ed. T. Inomata and S. D. Houston, 266-307. Boulder: Westview Press.

Rissolo, D. 2007. "La Costa Escondida: An Archaeological Investigation of the Ancient Maya Port of Vista Alegre, Quintana Roo, México.” Research Report submitted to the Foundation for the Advancement of Mesoamerican Studies, Inc. (FAMSI). http://www.famsi.org /reports/03043/03043Rissoloor.pdf

Rivera Dorado, Miguel. 1992. "Introducción.” Oxkintok 4, ed. Miguel Rivera Dorado, 7-20. Madrid: Misión Arqueológica de España y Ministerio de Cultura.

Rivera Dorado, Miguel. 1996. Los Mayas de Oxkintok. Ministerio de Educación y Cultura de Madrid.

Robin, Cynthia. 2004. "Social Diversity and Everyday Life within Classic Maya Settlements." In Mesoamerican Archaeology: Theory and Practice, ed. J. A. Hendon and R. A. Joyce, 148-168. Malden, MA: Blackwell.

Robin, Cynthia. 2006. "Gender, Farming and Long-Term Change." Current Anthropology 47(3):409-433. http://dx.doi.org/10.1086/503060.

Robin, Cynthia, ed. 2012. Chan, an Ancient Maya Farming Community. Gainesville: University Press of Florida. http://dx.doi.org/10.5744/florida/9780813039831.001.0001.

Robles Castellanos, Fernando, and Anthony P. Andrews. 1986. "A Review and Synthesis of Recent Postclassic Archaeology in Northern Yucatan." In The Late Lowland Maya Civilization: Classic to Postclassic, ed. J. A. Sabloff and E. W. Andrews V, 53-98. Albuquerque: University of New Mexico Press.

Robles Castellanos, Fernando, and Anthony P. Andrews. 2000. Proyecto Arqueológico Costa de Yucatán, Informe para el Consejo Nacional de Arqueológica. Mérida: Centro Instituto Nacional de Antropología e Historia Yucatán.

Robles Castellanos, Fernando. In press. "El Nuevo Paradigma de la Cronología e índole de la genesis de la civilización Maya en el Norte de Yucatán.” In Origins of Maya Civilization, ed. W. Saturno and D. Stuart. Boundary End, NC: Center for Maya Research.

Robles Ramos, R. 1950. “Apuntes Sobre la Morfologia de Yucatán." Boletín de la Sociedad Mexicana de Geografía y Estadistica 69:27-106.

Rodríguez Lazcano, Catalina, and Sergio Torres Quintero. 1992. La Cesteria Maya de Tierras Bajas. Mexico: Instituto Nacional de Antropologia e Historia.

Rodríguez Pérez, Monica, Teresa Ceballos Gallareta, and Rubén Chuc Aguilar. 20rI. “Un Enclave de Oxkintok en el Norte de Caucel a Inicios del Clasico Tardio: El Desarrollo de la Estructura BU 17/26 oII-006." Paper presented at the Tercer Congreso Internacional de la Cultura Maya, Mérida, Yucatán, México.

Rohling, E. J., K. Grant, C. Hemleben, M. Siddall, B. A. A. Hoogakker, M. Bolshaw, and M. Kucera. 2008. "High Rates of Sea-level Rise during the Last Interglacial Period.” Nature Geoscience I(I):38-42. http://dx.doi.org/10.1038/ngeo.2007.28.

Rovner, Irwin. 1976. "A Method for Determining Obsidian Trade Patterns in the Maya Lowlands." Katunob g(I):43-5I. 
Rovner, Irwin. 1989. "Theories and Methods in Obsidian Analysis: Methodological Problems at Trade Recipient Sites." In La Obsidiana en Mesoamerica, ed. M. Gaxiola and J. E. Clark, 427-431. Mexico City: Instituto Nacional de Antropología e Historia.

Rovner, Irwin, and Suzanne M. Lewenstein. 1997. Maya Stone Tools of Dzibilchaltún, Yucatán, and Becán and Chicanná, Campeche. Middle American Research Institute Publication No. 65. New Orleans: Tulane University.

Roys, Ralph L. 1943. The Indian Background of Colonial Yucatan. Washington, DC: Carnegie Institution of Washington.

Roys, Ralph L. 1957. The Political Geography of the Yucatan Maya. Carnegie Institute of Washington Publication 613. Washington, DC: Carnegie Institution.

Roys, Ralph L. 1962. "Literary Sources for the History of Mayapan.” In Mayapan, Yucatan, Mexico, ed. H. E. D. Pollock, Ralph L. Roys, T. Proskouriakoff, and A. Ledyard Smith, 25-86. Carnegie Institution of Washington Publication. vol. 619. Washington DC: Carnegie Institution.

Roys, Ralph L., France V. Scholes, and Eleanor B. Adams. 1940. Report and Census of the Indians of Cozumel, 1570. Contributions to American Anthropology and History, No. 30, Publication 523. Washington, DC: Carnegie Institution of Washington.

Russell, Bradley. 2008. "Postclassic Maya Settlement on the Rural-Urban Fringe of Mayapan, Yucatan, Mexico.” PhD dissertation, Department of Anthropology, State University of New York at Albany.

Sabloff, Jeremy A., and William Rathje. 1975. "The Rise of a Maya Merchant Class." Scientific American 233(4):72-82. http://dx.doi.org/I0.1038/scientificamericanI075-72.

Sahagún, Bernardino de. 1950-1982. The Florentine Codex, volume 4. Santa Fe: Monographs of the School of American Research.

Sahlins, Marshal. 1963. "Poor Man, Rich Man, Big Man, Chief: Political Types in Melanesia and Polynesia." Comparative Studies in Society and History 5(3):285-305. http://dx.doi.org/ı .1017/So010417500001729.

Sahlins, Marshall. 1972. Stone Age Economics. New York: Aldine de Gruyter.

Sanders, William T. 1977. "Environmental Heterogeneity and the Evoluton of Lowland Maya Civilization.” In The Origins of Maya Civilization, ed. R. E. W. Adams, 287-297. Santa Fe: School of American Research.

Sanders, William T. 198r. "Classic Maya Settlement Patterns and Ethnographic Analogy." In Lowland Maya Settlement Patterns, ed. W. Ashmore, 351-369. Albuquerque: University of New Mexico Press.

Sanders, William T., and Barbara J. Price. 1968. Mesoamerica: The Evolution of a Civilization. New York: Random House.

Sanders, William T., and David L. Webster. 1988. “The Mesoamerican Urban Tradition.” American Anthropologist 90(3):521-546. http://dx.doi.org/10.1525/aa.1988.90.3.02a00010.

Scarborough, Vernon L., and Fred Valdez. 2009. "An Alternative Order: The Dualistic Economies of the Ancient Maya." Latin American Antiquity 20:207-227.

Schaefer, C. E. G. R., H. N. Lima, R. J. Gilkes, and J. W. V. Mello. 2004. "Micromorphology and Electron Microprobe Analysis of Phosphorus and Potassium Forms of an Indian 
Black Earth (IBE) Anthrosol from Western Amazonia." Australian Journal of Soil Research 42(4):40I-409. http://dx.doi.org/I0.I07I/SR03106.

Schevill, Margot B., Janet C. Berlo, and Edward B. Dwyer. 1991. Textile Traditions of Mesoamerican and the Andes: An Anthropology. Austin: University of Texas Press.

Schmidt, Michael W. I., and Angela G. Noack. 2000. "Black Carbon in Soils and Sediments: Analysis, Distribution, Implications, and Current Challenges." Global Biogeochemical Cycles I4(3):777-793. http://dx.doi.org/10.1029/1999GBoor208.

Scholes, France V., and Ralph L. Roys. 1948. The Maya Chontal Indians of Acalan-Tixchel. 2nd ed. Norman: University of Oklahoma Press.

Schuldenrein, Joseph. 1995. "Geochemistry, Phosphate Fractionation, and the Detection of Activity Areas at Prehistoric North American Sites." In Pedological Perspectives in Archaeological Research, ed.M. E. Collins, B. J. Carter, B. G. Gladfelter and R. G. Southard, 107-132. SSSA Special Publication Number 44. Madison, WI: Social Science Society of America.

Sedov, Sergei, E. Solleiro-Rebolledo, Scott L. Fedick, J. Gama-Castro, A. Palacios-Mayorga and E. Vallejo Gómez. 2007. "Soil Genesis in Relation to Landscape Evolution and Ancient Sustainable Land Use in the Northeastern Yucatan Peninsula, Mexico." Atti. Soc. tosc. Sci. nat. Mem. Serie A 112:115-126.

Semenov, Sergei A. 1964. Prehistoric Technology. Trans. M. Thompson. London: Adams and Dart.

Shafer, Harry J., and Thomas R. Hester. 1983. "Ancient Maya Chert Workshops in Northern Belize, Central America." American Antiquity 48(3):519-543. http://dx.doi.org/10.2307/280559.

Shaw, Justine. 2008. White Roads of the Yucatan: Changing Social Landscapes of the Yucatec Maya. Tucson: University of Arizona Press.

Shaw, Leslie C. 2012. "The Elusive Maya Marketplace: An Archaeological Consideration of the Evidence." Journal of Archaeological Research 2 (2):117-155. http://dx.doi.org/10.1007/s10814 -OII-9055-0.

Shaw, Leslie C., and Eleanor M. King. 2015. “The Maya Marketplace at Maax Na, Belize.” In Ancient Maya Marketplaces: The Archaeology of Transient Space, ed. E. M. King and L. C. Shaw, 168-194. Tucson: University of Arizona Press.

Sheets, Payson. 1976. "Islands of Lithic Knowledge among Seas of Ignorance in the Maya Area." In Maya Lithic Studies: Papers from the 1976 Belize Field Symposium, ed. T. R. Hester and N. Hammond, I-9. San Antonio: The University of Texas at San Antonio Center for Archeaological Research.

Sheets, Payson. 2000. "Provisioning the Ceren Household." Ancient Mesoamerica II(02):217230. http://dx.doi.org/10.1017/S0956536100112039.

Short, Nicholas M., and Robert W. Blair. 1986. Geomorphology from Space: A Global Overview of Regional Landforms. Washington, DC: National Aeronautics and Space Administration.

Shuman, Malcom K. 1974. The Town Where Luck Fell: The Economics of Life in a Henequen Zone Pueblo. New Orleans: Anthropology Department, Tulane University.

Sidrys, Raymond V. 1977. "Mass-Distance Measures for the Maya Obsidian Trade." In Exchange Systems in Prehistory, ed. T. K. Earle and J. E. Ericson, 91-107. New York: Academic Press. http://dx.doi.org/10.1016/B978-0-12-227650-7.50011-0. 
Siemens, Alfred H. 1996. "Benign Flooding on Tropical Lowland Floodplains.” In The Managed Mosaic: Ancient Maya Agriculture and Resource Use, ed. S. Fedick, 132-144. Salt Lake City: University of Utah Press.

Sierra Sosa, Thelma N. 1999. “Xcambó: Codiciado Enclave Econóomico del Clásico Maya." Arqueología Mexicana $7(37): 40-47$.

Sierra Sosa, Thelma, Andrea Cucina, T. Douglas Price, James H. Burton, and Vera Tiesler. 2014. "Maya Coastal Production, Exchange, Life Style, and Population Mobility: A View from the Port of Xcambo, Yucatan, Mexico." Ancient Mesoamerica 25(I):221-238.

Skinner, G. William. 1964. "Marketing and Social Structure in Rural China, Part I." Journal of Asian Studies 24 (I):3-43. http://dx.doi.org/10.2307/2050412.

Sluyter, Andrew. 1993. "Long-Distance Staple Transport in Western Mesoamerica: Insights through Quantitative Modeling." Ancient Mesoamerica 4(02):193-199. http://dx.doi.org/ı .1017/S0956536100000882.

Smith, A. Ledyard. 1962. "Residential and Associated Structures at Mayapan." In Mayapán, Yucatán, Mexico, ed. H. E. D. Pollock, Ralph L. Roys, T. Proskouriakoff, and A. Ledyard Smith, 165-320. vol. Publication number 619. Washington DC: Carnegie Institution of Washington.

Smith, Carol A. 1976. "Exchange Systems and the Spatial Distribution of Elites: The Organization of Stratification in Agrarian Societies." In Regional Analysis, vol. 2. ed. C. A. Smith, 309374. New York: Academic Press. http://dx.doi.org/10.1016/B978-0-12-652102-3.50022-0.

Smith, J. Gregory. 2000. "The Chichen Itza-Ek Balam Transect Project: An Intersite Perspective on the Political Organization of the Ancient Maya." PhD thesis, Department of Anthropology, University of Pittsburgh.

Smith, Michael E. 1987. "Household Possessions and Wealth in Agrarian States: Implications for Archaeology." Journal of Anthropological Archaeology 6(4):297-335. http://dx.doi.org/10.1016 /0278-4165(87)90004-3.

Smith, Michael E. 1989. "Cities, Towns, and Urbanism: Comment on Sanders and Webster." American Anthropologist 91 (2):454-460. http://dx.doi.org/10.1525/aa.1989.91.2.02a00180.

Smith, Michael E. 1999. "On Hirth’s 'Distributional Approach.” Current Anthropology 40:528-530.

Smith, Michael E. 2003. "Information Networks in Postclassic Mesoamerica." In The Postclassic Mesoamerican World, ed. M. E. Smith and F. F. Berdan, I8I-I85. Salt Lake City: University of Utah Press.

Smith, Michael E. 2004. "The Archaeology of Ancient State Economies." Annual Review of Anthropology 33(1):73-102. http://dx.doi.org/10.1146/annurev.anthro.33.070203.144016.

Smith, Michael E. 2008. Aztec City State Capitals. Gainesville: University of Florida Press.

Smith, Robert E. 1971. The Pottery of Mayapan. Papers of the Peabody Museum of Archaeology and Ethnology. vol. 66. Cambridge, MA: Harvard University.

Smith, Robert E., Gordon R. Willey, and James C. Gifford. 1960. "The Type-Variety Concept as a Basis for the Analysis of Maya Pottery." American Antiquity 25(3):330-340. http://dx.doi .org/10.2307/277516.

Smyth, Michael P. 2006. "Architecture, Caching and Foreign Contacts at Chac (II), Yucatan, Mexico." Latin American Antiquity 17(2):123-150. http://dx.doi.org/10.2307/25063044. 
Smyth, Michael P., Christopher C. Dore, and Nicholas P. Dunning. 1995. "Interpreting Prehistoric Settlement Patterns: Lessons from the Maya Center of Sayil, Yucatan." Journal of Field Archaeology 22:321-347.

Smyth, Michael P., Christopher C. Dore, Hector Neff, and Michael D. Glascock. 1995. "The Origin of Puuc Slate Ware: New Data from Sayil, Yucatan, Mexico." Ancient Mesoamerica 6:119-134. http://dx.doi.org/10.1017/S0956536100002133.

Smyth, Michael P., and David Ortegón Zapata. 2006. "Foreign Lords and Early Classic Interaction at Chac II, Yucatan." In Lifeways in the Northern Lowlands: New Approaches to Maya Archaeology, ed. J. P. Mathews and B. A. Morrison, II9-I4I. Tucson: University of Arizona Press.

Smyth, Michael P., and Daniel Rogart. 2004. "A Teotihuacan Presence at Chac II, Yucatan, Mexico: Implications for Early Political Economy of the Puuc Region.” Ancient Mesoamerica I5(I):17-47. http://dx.doi.org/10.1017/S095653610415102X.

Soil Survey Staff. 2003. Keys to Soil Taxonomy. 9th ed. Blacksburg, VA: Pocahontas Press Inc.

Speal, Scott. 2014. "The Evolution of Ancient Maya Exchange Systems: An Etymological Study of Economic Vocabulary in the Mayan Language Family." Ancient Mesoamerica 25(I):69-II3. http://dx.doi.org/10.1017/S0956536114000078.

Standley, Paul C. 1920. Trees and Shrubs of Mexico. Contributions from the United States National Herbarium. vol. 23, Part I. Washington, DC: Smithsonian Institution, United States National Museum.

Stanish, Charles, and Lawrence S. Coben. 2013. "Barter Markets in the Pre-Hispanic Andes." In Merchants, Markets and Exchange in the Pre-Colombian World, ed. K. G. Hirth and J. Pillsbury, 42I-436. Washington, DC: Dumbarton Oaks Research Library and Collections.

Stanton, Travis W. 2005. "Taluds, Tripods, and Teotihuacanos: A Critique of Central Mexican Influence in Classic Period Yucatan." Mayab i8:17-35.

Stanton, Travis W., and David A. Freidel. 2005. "Placing the Centre, Centreing the Place: The Influence of Formative Sacbeob in Classic Site Design at Yaxuna, Yucatan." Cambridge Archaeological Journal 16 (2): 225-249.

Stanton, Travis W., David A. Freidel, Charles K. Suhler, Traci Ardren, James N. Ambrosino, Justine M. Shaw, and Sharon Bennett. 2010. Archaeological Investigations at Yaxuná, 1986-1996: Results of the Selz Foundation Yaxuna Project. Oxford: BAR.

Stanton, Travis W., and Scott R. Hutson. 2012. "Patrones de Crecimiento Urbano: Albarradas y Grupos Domésticos en el Clásico Temprano en Chunchucmil, Yucatán.” In VII Coloquio Pedro Bosch Gimpera, ed. Guillermo Acosta Ochoa, 299-316. Mexico City: UNAM.

Stanton, Travis W., and Socorro Jiménez. 2007. "La Cerámica de Santa Barbára Dentro del Contexto Socio-político del Occidente de Yucatán." Los Investigadores de la Cultura Maya I5(II):347-58. Ciudad de Campeche: Universidad Autónoma de Campeche.

Stanton, Travis W., and Aline Magnoni. 2014. "Proyecto De Interacción Política del Centro de Yucatán (PIPCY), Sexta Temporada de Campo.” Informe Técnico Anual al Consejo de Arqueología del INHA. University of California, Riverside.

Stanton, Travis W., and Aline Magnoni. 2015. "Proyecto de Interacción Política del Centro de Yucatán (PIPCY), Séptima Temporada de Campo.” Informe Global al Consejo de Arqueología del INHA. University of California, Riverside. 
Stark, Barbara L., and Christopher P. Garraty. 2008. "Parallel Archaeological and Visibility Survey in the Western Lower Papaloapan Basin, Veracruz, Mexico." Journal of Field Archaeology 33(2):177-196. http://dx.doi.org/10.1179/009346908791071286.

Stark, Barbara L., and Christopher P. Garraty. 2010. "Detecting Marketplace Exchange in Archaeology: A Methodological Review." In Archaeological Approaches to Market Exchange in Ancient Societies, ed. C. P. Garraty and B. L. Stark, 3-32. Boulder: University Press of Colorado.

Stark, Barbara L., Lynnette Heller, and Mark Ohnersorgen. 1998. "People with Cloth: Mesoamerican Economic Change from the Perspective of Cotton in South-central Veracruz." Latin American Antiquity 9(1):7-36. http://dx.doi.org/10.2307/972126.

Steggerda, Morris. 1941. Maya Indians of Yucatan. Publication 531. Washington, DC: Carnegie Institution.

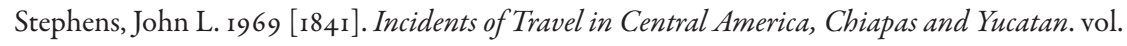
II. New York: Dover.

Stephens, John L. 1843. Incidents of Travel in Yucatan. vol. r. London: John Murray.

Stoltman, James B. 1978. Lithic Artifacts from a Complex Society: The Chipped Stone Tools from Becán, Campeche, Mexico. Middle American Research Institute, Occasional Paper No. 2. New Orleans: Middle American Research Institute.

Stuart, George, John C. Scheffler, Edward B. Kurjack, and John W. Cottier. 1979. Map of the Ruins of Dzibilchaltun, Yucatan, Mexico. Middle American Research Institute Publication Number 47. New Orleans: Middle American Research Institute.

Stone, Glenn D. 1991. "Agricultural Territories in a Dispersed Settlement System." Current Anthropology 32(3):343-353. http://dx.doi.org/10.1086/203967.

Suhler, Charles, and David A. Freidel. 1998. "Life and Death in a Maya Warzone." Archaeology $5 \mathrm{I}(3): 28-34$.

Sweetwood, Ryan. 2008. "Searching for the Maya Footprint: A Description of Soil Physical and Chemical Properties across the Landscape of Chunchucmil, Mexico, Yucatan.” M.A. Thesis, Brigham Young University, Salt Lake City, Utah.

Sweetwood, Ryan, Richard Terry, Timothy Beach, Bruce H. Dahlin, and David Hixson. 2009.

"The Maya Footprint: Soil Resources of Chunchucmil, Yucatán, Mexico." Soil Science Society of America Journal 73(4):1,209-1,219. http://dx.doi.org/10.2136/sssaj2008.0262.

Taschek, Jennifer. 1994. The Artifacts of Dzibilchaltun, Yucatan, Mexico: Shell, Polished Stone, Bone, Wood, and Ceramics. Middle American Research Institute Publication 50. New Orleans: Middle American Research Institute, Tulane University.

Taylor, Christopher C. 1974. Fieldwork in Medieval Archaeology. London Batsford.

Taylor, G. H., M. Teichmuller, A. Davis, C. F. K. Diessel, R. Littke, and P. Robert. 1998. Organic Petrology. Stuttgart, Germany: Gebruder.

Terry, Richard E., Sheldon D. Nelson, Jared Carr, Jacob Parnell, Perry J. Hardin, Mark W. Jackson, and Stephen D. Houston. 2000. "Quantitative Phosphorous Measurement: A Field Test Procedure for Archaeological Site Analysis at Piedras Negras, Guatemala." Geoarchaeology: An International Journal I5(2):15I-166. http://dx.doi.org/10.1002/(SICI)1520-6548(200002) 15:2<151::AID-GEA3>3.0.CO;2-T. 
Terry, Richard E., Daniel A. Bair, and Eric G. Coronel. 2015. "Soil Chemistry in the Search for Ancient Maya Marketplaces." In Ancient Maya Marketplaces: The Archaeology of Transient Space, ed. Eleanor M. King, 138-167. Tucson: University of Arizona Press.

Thomas, Prentice. 1981. Prehistoric Maya Settlement Patterns at Becan, Campeche, Mexico. MARI Publication 45. New Orleans: Middle American Research Institute.

Thompson, J. E. S. 1931. Archaeological Investigations in the Southern Cayo District, British Honduras. Field Museum of Natural History Publication 301, Anthropological Series, Volume 17, number 3. Chicago: Field Museum of Natural History.

Thompson, J. Eric S. 1966. The Rise and Fall of Maya Civilization. 2nd ed. Norman: University of Oklahoma Press.

Thompson, J. Eric S. 1970. Maya History and Religion. Norman: University of Oklahoma Press.

Tokovinine, Alexandre, and Dmitri Beliaev. 2013. "People of the Road: Trade and Travelers in Ancient Maya Words and Images." In Merchants, Markets and Exchange in the Pre-Colombian World, ed. K. G. Hirth and J. Pillsbury, 169-200. Washington, DC: Dumbarton Oaks Research Library and Collections.

Torquemada, Fray Juan de. 1943. Monarquia Indiana, Vol. 2. Mexico City: Salvador Chavez Hayhoe.

Tourtellot, Gair. 1983. "An Assessment of Classic Maya Household Composition.” In Prehispanic Settlement Patterns: Essays in Honor of Gordon R. Willey, ed. E. Vogt, and Richard Leventhal, 35-54. Cambridge, MA: Peabody Museum of Archaeology and Ethnology, Harvard University. Tourtellot, Gair. 1988. Excavations at Seibal, Department of Peten, Guatemala: Peripheral Survey and Excavation: Settlement and Community Patterns. Memoirs of the Peabody Museum of Archaeology and Ethnology, Harvard University 16. Cambridge, MA: Peabody Museum of Archaeology and Ethnology, Harvard University.

Tourtellot, Gair. 1990. "Population Estimates for Preclassic and Classic Seibal, Peten." In Precolumbian Population History in the Maya Lowlands, 83-102. Albuquerque: University of New Mexico Press.

Tourtellot, Gair. 1993. "A View of Ancient Maya Settlements in the Eighth Century." In Lowland Maya Civilization in the Eighth Century A.D, ed. Jeremy A. Sabloff and John S. Henderson, 219-24I. Washington, DC: Dumbarton Oaks.

Tourtellot, Gair, and Jeremy A. Sabloff. 1994. "Community Structure at Sayil: A Case Study of Puuc Settlement.” In Hidden among the Hills, ed. H. J. Prem, 71-90. Mockmuhl: Verlag Von Fleming.

Tourtellot, Gair, Michael P. Smyth, and Jeremy A. Sabloff. 1990. "Room Counts and Population Estimation for Terminal Classic Sayil in the Puuc Region, Yucatan, Mexico." In Precolumbian Population History in the Maya Lowlands, 245-261. Albuquerque: University of New Mexico Press.

Tozzer, Alfred M. 1907. A Comparative Study of the Mayas and the Lacandones. London: Archaeological Institute of America.

Tozzer, Alfred M. 1941. Landa's "Relacion de las Cosas de Yucatan": A Translation. Papers of the Peabody Museum of American Archaeology and Ethnology, Harvard University. vol. XVII. Cambridge, MA: Peabody Museum of American Archaeology and Ethnology. 
Trigger, Bruce. 1972. "Determinants of Urban Growth in Pre-Industrial Societies." In Man, Settlement, and Urbanism, ed. P. J. Ucko, R. Tringham, and G. W. Dimbleby, 575-599. London: Duckworth.

Trigger, Bruce. 2003. Understanding Early Civlization: A Comparative Study. New York: Cambridge University Press. http://dx.doi.org/10.1017/CBO9780511840630.

Tringham, Ruth. 1991. "Households with Faces: The Challenge of Gender in Prehistoric Architectural Remains." In Engendering Prehistory, ed. J. M. Gero and M. W. Conkey, 93-13I. Oxford: Blackwell.

Turner, Billie L., II. 1974. "Prehistoric Intensive Agriculture in the Mayan Lowlands." Science I85(4146):II8-124. http://dx.doi.org/10.1126/science.185.4146.118.

Turner, Billie L. I. 1983. Once beneath the Forest: Prehistoric Terracing in the Rio Bec Region of the Maya Lowlands. Latin American Studies 13. Boulder: Westview Press.

Turner, Billie L., and P. D. Harrison, eds. 1983. Pulltrouser Swamp: Ancient Maya Habitat, Agriculture, and Settlement in Northern Belize. Austin: University of Texas Press.

Turner, Billie L., and Jeremy A. Sabloff. 20r2. "Classic Period Collapse of the Central Maya Lowlands: Insights about Human-environment Relationships for Sustainability." Proceedings of the National Academy of Science [online]. http://dx.doi.org/10.1073/pnas.1210106109.

United States Environmental Protection Agency (USEPA). 2006. “Chapter I4: Salinity." In Voluntary Estuary Monitoring Manual: A Methods Manual, 2nd Edition, EPA-842-B-06-003, I4-I.

USDA. 2015. "World Agricultural Production. Foreign Agricultural Service." Circular Series WAP $3-15$.

Vail, Gabrielle, and Andrea Stone. 2002. "Representations of Women in Postclassic and Colonial Maya Literature and Art.” In Ancient Maya Women, ed. T. Ardren, 203-228. Walnut Creek: Altamira.

Van Wambeke, Armand. 1987. Soil Moisture and Temperature Regimes of Central America, Carribean, and Mexico. Soil Management Support Services Technical Monograph No. 16. Washington, DC: US Department of Agriculture, Natural Resources Conservation Service.

Varela Torrecilla, Carmen. 1993. "El Complejo Cerámico Motul en el Occidente de Yucatán y la Transición a la Cerámica Pizarra." In Perspectivas Antropológicas en el Mundo Maya, ed. M. Josefa Iglesias Ponce de Léon and Francese Ligorred Perramón. 253-268, Madrid, España: Sociedad Española de Estudios Mayas.

Varela Torrecilla, Carmen. 1996. "La Secuencia Histórica de Oxkintok: Problemas Cronológicos y Metodológicos Desde el Punto de Vista de la Cerámica.” Revista Espanola de Antropologia Americana 26:29-55.

Varela Torrecilla, Carmen. 1998. El Clásico Medio en el Noroccidente de Yucatan. Paris Monographs in American Archaeology 2 (BAR International Series 739).

Varela Torrecilla, Carmen, and Geoffrey E. Braswell. 2003. "Teotihuacan and Oxkintok: New Perspectives from Northern Yucatan." In The Maya and Teotihuacan: Rerinterpreting Early Classic Interaction, ed. G. E. Braswell, 249-271. Austin: University of Texas Press.

Vargas Pacheco, Ernesto, Patricia Santillan, and Marta Vilalta. 1985. "Apuntes para el Análisis del Patrón de Asentamiento de Tulum.” Estudios de Cultura Maya 16:55-83. 
Velázquez Morlet, Adriana and E. López de la Rosa. 1995. "La Región y la Ciudad [Oxkintok]: Dinámica de los Patrones de Asentamiento en el Occidente de Yucatán." In Seis Ensayos Sobre Antiguos Patrones de Asentamiento en el Area Maya, ed. E. Vargas Pacheco, 93-I22. Mexico City: UNAM, Instituto de Investigaciones Antropologicas.

Vlcek, David. 1978. "Muros de Delimitación Residencial en Chunchucmil." Mérida. Boletín de la Escuela de Ciencias Antropológicas de la Universidad de Yucatán 5(28):55-64.

Vlcek, David, Silvia Garza Tarazona de González, and Edward B. Kurjack. 1978. "Contemporary Maya Farming and Ancient Settlements: Some Disconcerting Evidence." In Prehispanic Maya Agriculture, ed. P. D. Harrison and B. L. I. Turner, 21I-223. Albuquerque: University of New Mexico Press.

Watanabe, Takeshi. 2000. "Form and Function of Metates in Chunchucmil, Yucatan, Mexico." Master's Thesis, Anthropology Department, Florida State University, Tallahassee.

Webb, Elizabeth A., Henry P. Schwarcz, and Paul F. Healy. 2004. "Detection of Ancient Maize in Lowland Maya Soils Using Stable Carbon Isotopes: Evidence from Caracol, Belize.” Journal of Archaeological Science 31 (8):I,039-1,052. http://dx.doi.org/10.1016/j.jas.2004.01.00I.

Webb, Elizabeth A., Henry P. Schwarcz, Christopher T. Jensen, Richard E. Terry, Mathew D. Moriarty, and Kitty F. Emery. 2007. "Stable Carbon Isotope Signature of Ancient Maize Agriculture in the Soils of Motul de San José, Guatemala." Geoarchaeology: An International Journal 22(3):291-312. http://dx.doi.org/10.1002/gea.20154.

Webster, David L. 1992. "Maya Elites: The Perspective from Copan." In Mesoamerican Elites, ed. D. Z. Chase and A. F. Chase, 135-156. Norman: University of Oklahoma.

Webster, David L. 1998. "Warfare and Status Rivalry: Lowland Maya and Polynesian Comparisons." In Archaic States, ed. G. M. Feinman and J. Marcus, 3II-35I. Santa Fe, NM: School of American Research Press.

Webster, David L., and Stephen Houston. 2003. "Piedras Negras: The Growth and Decline of a Classic Maya Center." In El Urbanismo en Mesoamerica, ed. W. T. Sanders, A. G. Mastache, and R. H. Cobean, 427-449. Mexico City: Instituto Nacional de Antropología e Historia.

Webster, David L., and William Sanders. 200ı. "La Antigua Ciudad Mesoaméricana: Teoría y Concepto." In Reconstruyendo la Ciudad Maya: El Urbanismo en las Sociedades Antiguas, ed. A. Ciudad Ruiz, M. J. Iglesia Ponce de Léon and M. d. C. Martínez, 43-64. Madrid: Sociedad Española de Estudios Mayas.

Webster, James W., George A. Brook, L. Bruce Railsback, Hai Cheng, R. Lawrence Edwards, Clark Alexander, and Philip P. Reeder. 2007. "Stalagmite Evidence from Belize Indicating Significant Droughts at the Time of Preclassic Abandonment, the Maya Hiatus, and the Classic Maya Collapse." Palaeogeography, Palaeoclimatology, Palaeoecology 250(I-4):I-17. http://dx.doi.org/10.1016/j.palaeo.2007.02.022.

Weisbach, C., H. Tiessen, and Juan J. Jimenez-Osornio. 2002. "Soil Fertility during Shifting Cultivation in the Tropical Karst Soils of Yucatan.” Agronomie 22(3):253-263. http://dx.doi .org/10.1051/agro:2001008.

Wellhausen, E. J., Alejandro Fuentes, and Antonio Hernández. 1957. Races of Maize in Central America. National Research Council, Publication No. 51I. Washington DC: National Academy of Sciences. 
Wells, E. Christian. 2006. "Recent Trends in Theorizing Mesoamerican Economies." Journal of Archaeological Research I4(4):265-312.

Wells, E. Christian, Richard E. Terry, Jacob J. Parnell, Perry J. Hardin, M. W. Jackson, and Stephen D. Houston. 2000. "Chemical Analyses of Ancient Anthrosols in Residential Areas at Piedras Negras, Guatemala.” Journal of Archaeological Science 27(5):449-462. http://dx .doi.org/10.1006/jasc.1999.0490.

West, Georgia. 2002. "Ceramic Exchange in the Late Classic and Postclassic Maya Lowlands: A Diachronic Approach." In Ancient Maya Political Economies, ed. M. A. Masson and D. A. Freidel, 140-196. Walnut Creek, CA: Altamira.

Wilk, Richard. 1998. "Comment on Hirth." Current Anthropology 39(4):469.

Willey, Gordon R. 1978. Excavations at Seibal, Department of Peten, Guatemala: Artifacts. Memoirs of the Peabody Museum of Archaeology and Ethnology, Harvard University, vol. I 4, no. I. Cambridge, MA: Peabody Museum of Archaeology and Ethnology, Harvard University.

Willey, Gordon R. 1974. “The Classic Maya Hiatus: A Rehearsal for the Collapse?” In Mesoamerican Archaeology: New Approaches, ed. N. Hammond, 417-430. Albuquerque: University of New Mexico Press.

Willey, Gordon, and William Bullard. 1965. "Prehispanic Settlement Patterns in the Maya Lowlands." In Archaeology of Southern Mesoamerica, Part I, ed. G. Willey, $360-377$. Handbook of Middle American Indians. vol. 2, R. Wauchope, general editor. Austin: University of Texas Press.

Willey, Gordon, William Bullard, J. B. Glass and James C. Gifford. 1965. Prehistoric Maya Settlement in the Belize Valley. Paper of the Peabody Museum of Archaeology and Ethnology, Harvard University 54. Cambridge, MA: Peabody Museum of Archaeology and Ethnology, Harvard University.

Willey, Gordon, and Richard M. Leventhal. 1979. "Prehistoric Settlement at Copan.” In Maya Archaeology and Ethnohistory, ed. N. Hammond and G. Willey, 75-102. Austin: University of Texas Press.

Williamson, Oliver E. 1985. The Economic Institutions of Capitalism. New York: Free Press. Wilson, Eugene M. 1980. "The Physical Geography of the Yucatan Peninsula." In Yucatan: A World Apart, ed. E. Mosely and E. Terry, 5-40. Tuscaloosa: University of Alabama Press.

Winter, Marcus C. 1986. “Templo-Patio-Adoratorio: Un Conjunto Arquitectonico Noresidencial en el Oaxca Preshipanico." Cuadernos de Arquitectura Mesoamericana 7:51-59.

Wisdom, Charles. 1940. The Chorti Indians of Guatemala. Chicago: University of Chicago Press. Wolf, Marc. 1997. “A History of Maya Archaeological Mapping." Unpublished Master's thesis, Department of Archaeology, Boston University, Boston.

Woodfill, Brent, and Chloe Andrieu. 2012. "Tikal's Early Classic Domination of the Great Western Trade Route: Ceramic, Lithic, and Iconographic Evidence." Ancient Mesoamerica 2 (02):189-209. http://dx.doi.org/10.1017/S0956536112000156.

Woodfill, Brent K., Brian Dervin Dillon, Marc Wolf, Carlos Avendaño, and Ronald Canter. 2015. "Salinas de los Nueve Cerros, Guatemala: A Major Economic Center in the Southern Maya Lowlands." Latin American Antiquity 26 (2):162-179. 
Woods, William I., Wenceslau G. Teixeira, Johannes Lehmann, and Christoph Steiner. Antoinette M. G. A. WinklerPrins, and Lilian Rebellato, eds. 2009. Amazonian Dark Earths: Wim Sombroek's Vision. Berlin: Springer. http://dx.doi.org/10.1007/978-I-4020-9031-8.

Wright, David R., Richard E. Terry, and Markus Eberl. 2009. "Soil Properties and Stable Carbon Isotope Analysis of Landscape Features in the Petexbatún Region of Guatemala." Geoarchaeology: An International Journal 24(4):466-491. http://dx.doi.org/10.1002/gea.20275.

Wright, Lori E. 2005. "Identifying Immigrants to Tikal, Guatemala: Defining Local Variability in Strontium Isotope Ratios of Human Tooth Enamel." Journal of Archaeological Science 32(4):555-566. http://dx.doi.org/10.1016/j.jas.2004.I1.orI.

Wurtzburg, Susan. 1991. Sayil: Investigations of Urbanism and Economic Organization at an Ancient Maya City. Albany: Department of Anthropology, State University of New York.

Wurtzburg, Susan. 2015. "Contemporary Maya Marketplaces: Gender, Social Change, and Implications for the Past." In Ancient Maya Marketplaces: The Archaeology of Transient Space, ed. Eleanor M. King, 251-272. Tucson: Arizona University Press.

Yaeger, Jason. 2000. "The Social Construction of Communities in the Classic Maya Countryside: Strategies of Affiliation in Western Belize." In The Archaeology of Communities: A New World Perspective, ed. M. A. Canuto and J. Yaeger, I23-I4I. London: Routledge.

Źrałka, Jarosław, Wiesław Koszkul, Katarzyna Radnicka, Laura Elena Sotelo Santos, and Bernard Hermes. 2014. "Excavations in Nakum Structure 99: New Data on Protoclassic Rituals and Precolumbian Maya Beekeeping." Estudios de Cultura Maya 44:85-117. http://dx .doi.org/10.1016/So185-2574(I4)71396-6. 


\section{Contributors}

Anthony P. Andrews is Professor of Anthropology, New College of Florida. He received his BA from Harvard University and his $\mathrm{MA}$ and $\mathrm{PhD}$ from the University of Arizona. His main research area is the archaeology and history of Yucatán, Mexico.

Traci Ardren is Professor and Chair in the Department of Anthropology at the University of Miami. She co-directs the Political Interaction in Central Yucatan Project at the ancient Maya site of Yaxuna and directs the Matecumbe Chiefdom Project in the Florida Keys.

Tiмотну BEACH, Centennial Chair in Geography, University of Texas at Austin, directs its Soils and Geoarchaeology Laboratory. He has more than roo publications on soils, geomorphology, and geoarchaeology of Central America and worldwide.

Chelsea Blackmore is Assistant Professor of Anthropology at the University of California, Santa Cruz. Her work examines gender, class, and everyday life among ancient and colonial period Maya.

TARA Bond-Freeman received her PhD from Southern Methodist University. Her research focuses on the archaeology of Mesoamerica and the northern Maya lowlands with an interest in ceramic analysis. 
Bruce H. Dahlin (deceased) initiated major multidisciplinary projects at El Mirador, Guatemala, and Chunchucmil, Mexico. After retiring from Howard University, he devoted himself to rebuilding log houses and documenting ancient climate change with stalagmites.

Patrice Farrell is Associate Professor in the Department of Geography, Urban Environment and Sustainability Studies, at the University of Minnesota at Duluth.

David R. Hixs on received his PhD from Tulane University with a specialization in archaeological remote sensing. He is currently an adjunct professor of archaeology, anthropology, and geography at Hood College, Maryland, and Shepherd University, West Virginia.

Scot T R. Huts ON is Professor of Anthropology at the University of Kentucky. He received his $\mathrm{PhD}$ from the University of California at Berkeley and currently directs the Ucí-Cansahcab Regional Integration Project in Yucatan, Mexico.

SOCORRO JIMÉNEZ received her doctorate in anthropology from the Universidad Nacional Autónoma de México. She currently works as a research professor in the Facultad de Ciencias Antropológicas at the Universidad Autónoma de Yucatán.

JUSTIN LOWRY is a specialist in spatial analysis of social phenomenon. His research takes the anthropological perspective, using cross-cultural understandings, to shed new light on the studies of migration and immigration in the ancient and modern world.

SHERYL LUZZAD DER-BEACH (PhD, Minnesota) is Professor and Chair of the Department of Geography and the Environment at the University of Texas at Austin, specializing in hydrology, geomorphology, geoarchaeology, geostatistics, and human rights.

Aline Magnoni is a Science and Technology Policy Fellow at the American Association for the Advancement of Sciences. She is an anthropological archaeologist with a $\mathrm{PhD}$ from Tulane and more than twenty years of research experience in the Maya region.

EUGENiA MANSELL has directed ceramic analysis and managed archaeological labs in Mexico and Belize. In addition to pottery, she has published on stable isotopes and ancient Maya diet. 
Daniel E. Mazeau is a Principal Investigator with the Cultural Resources Survey Program at the New York State Museum. His research interests include precontact archaeology of the Northeast United States, socioeconomic systems and structure, and the organization of lithic technology.

Travis W. Stanton is an associate professor and chair in the Department of Anthropology at the University of California, Riverside. He currently co-directs the PIPCY Project in Yucatan and has published and edited several books.

RYAN V. SWEETWOOD is an Environmental Scientist in the state of Arizona. He received his BS and MS at Brigham Young University.

Richard E. Terry is retired Professor of Soil Science at Brigham Young University. His research is focused on the soil resources and geochemistry of Maya fields, plazas, and households. 



\section{Index}

Page numbers in italics indicate illustrations.

Aak phase, ceramics, 85-93

Aak residential group, 89, I21, I26-27; foreign material culture in, 288, 293, 295-96

Acanceh Appliqué-Impressed, 94

achiote (Bixa orellana), 226-27

Acú Group ceramics, 89, 259

agave, processing of, 234, 248

agriculture, 7, I6, I51, 278, 303, 304; carrying capacity, 139-40, 197; disturbance from, 48-49; groundwater quality, I6I, I63, I64; isotopic signatures of, 209-II; modern, 198-200; soil qualities and, 206-9, 216-I8

Aguateca, 116, 206

Aguila Group ceramics, 89

Ah Canul province, I42, I50, 222, 237, 303

albarradas, 28, 29, 36, 38, 39-40, 93, I17, 133, 188, 189, I91, 193, 295; architectural groups and, 52-53; at Pich Group, II2, II 4

alleyways, Postclassic, 28

aloe (Aloe vera), 198

Alta Verapaz region, 276

amate, 230

ancestor veneration, in houselot shrines, II9, I27

andadores, 40, I80, 194-95; networks of, 279-82

animals, 150,238

annatto (Bixa orellana), 226-27

anona, 236 anteater, 238

anthrosols, Celestún Peninsula, 202

apiaries, apiculture, I5O, I78, 237-38

aquifers, Yucatán, $145-46$

arboriculture, 126, 137

Archaeological Atlas of Yucatán, 139, 173

architectural groups, sampling and classifying, $5 \mathrm{I}-53$

architecture: symbolic features, 174-75; Kaab' Group, I2I-27; naming conventions for, 36-39; types of, 33-36; Xnokol phase, 97-99, roo-ror (table)

Area C (Chunchucmil), geochemistry of, 254-55

Area D (Chunchucmil), 19; accessibility of, 252-53, 255; as marketplace, 255-56

Arena, Isla, I42, 279

Aztecs, 23I; market economy, II-I2. See also Tlatelolco

Balam Group, I29; phosphate analysis, I29-32

Balanza Black, 88

Balanza Group ceramics, 293

balche, 237

ballcourts, 51, 108, 174, 175, 309

barricade wall, Xnokol phase, Ios

barrios, II 8-19

Barton Ramie, spinning implements, 228 
basket production, $116,233,248$

bathroom/toilet area, in Balam Group, 132

Batres Red, 89

beach ridges: fossilized, I $48-49$; soils, 202-3

Becán, 277, 284; albarradas at, 28, 39

Bec region, Río, albarradas in, 39

beekeeping, I5O, 178, 237-38

bees (Melipona beecheii), 237

beeswax, 222, 237, 238

bejuco vine, 233

Belize: logwood from, 232; salt production, 23, 224

bells, as currency, 305

birds, I 44, I5O, 238

Bixa orellana, 226-27

Blanco, lower Río, access to obsidian in, 268-69

bohóm, 236

Bon, 173,210

boundaries, of Chunchucmil, $133-34$

boundary walls, 28, 40, 178. See also albarradas; chichbes

boxlu'um, 204, 216; agriculture and, 210, 217; characteristics of, 205-6, 207, 208-9, 213

Brosimium alicastrum, $\mathrm{I} 49$

Buenavista, 8; marketplace at, 249, 304

Buena Vista (Cozumel Island), 178

Buenavista del Cayo, I9

buildings, 32 ; naming conventions for, $36-39$; types of, $33-36$

burials, 94, 221, 246, 288, 292, 293; Kaab' Group, I22, $125-26$

Busycon sp., 243, 246

Caan polity, 284

cacao, 302,305

caches, Lool Group platform, 292

Calakmul, 8, 19, 34, 39, 116, 276, 284, 312, 313; marketplaces at, 18, 249, 250, 308, 31I

Calkini, 116

callejones, 39, 40; in residential peripheries, I30-3I

callejuelas, 39, 40, 43, 182, I89, 252, 287, 302; in residential core, $117-18$

Campeche, 21, I45

camps, in perennially inundated zones, 172

canals, 172 , 232; and ports of trade, $280-8 \mathrm{I}$; in wetlands, I46, I47

Canbalam, Punta, I40, 145, 170, 286, 307; andadores connecting, 279, 282; as port of trade, I44, I7I-72, 277-78; soils, 2OI-2
Cansahcab, groundwater for, $157,158,162$

Caracol, 8, 18, 20, 269, 296, 309; marketplaces at, $249,252,256,267,308$

carbon, black (BC), 212-13

carbon isotopes, 22I; and agriculture, 209-II, 218

Carica papaya, 198, 236

catfish, preparation of, $236-37$

Catoche, Cabo, logwood from, 232

Caucel, IO3

causeways. See sacbes

cazuelas, Maxcanú, 96

ceba (Ceiba pentandra), 230

cedar, 236

Ceibal, 8, 228, 276; marketplace at, 249, 256

Celestún, 21, 274, 279

Celestún, Río, and Punta Canbalam, 170-71

Celestún Biosphere Reserve, I44

Celestún Peninsula, I42, 170-71; salt beds on, I40, I43, I44, I54; salt production, 223-24; soils, $201-3$

cenotes, I9I; around Chixculub crater, $157-58$

CER. See Chunchucmil Economic Region ceramics, 5, 175; Chunchucmil, 73-77; Early

Classic phase, 85-93; intrasite distribution, 258-60, 26I-66, 292-93, 295-96;

Late Classic, 94-99; Late Preclassic, 8I-85; long-distance trade of, 2I, 288; manufacturing, 19-20; marketplace trade in, 250, 304;

Middle Preclassic, 78-8I

ceremonies, 5; and patio size, 117

Cerén, 19, 309; market system in, 268, 305

Cerros de Caracoles, 274

Chac, 60; obsidian at, 284, 28 s

Chac II, 247, 312

chachalaca, I5O

Chakah quadrangle, III, 309

Chak Luuk, 173

Chancenote Striated, 88

Chan Kom, 134

charcas, Celestún Peninsula, 143

charcoal, as soil amendment, 2I2-13, 218

Chencoh Group ceramics, 89, 259, 295

Chencoh Thin Orange, $g I$, I22

Chen Huech, 174; andadores near, 279, 28I, 282

Chen Yokop, 182

chert, 247; production debris, 25I-52

Chiapas, trade systems, 305

chichbes, 39, 40, 42, 182, 182, 231; around houselots, 129 
Chichén Itzá, 8, 19, 21, 236, 268, 274, 302; spindle whorls from, 228-29

chich mounds, 35, 37, I28; population estimates and, I37; settlement density and, II9-2I

Chicxulub crater, groundwater and, 157-58, 160

Chiik Nahb complex (Calakmul), ı 8,250

Ch'ikam Composite, go, $9 I$

Ch'ikam Group ceramics, 89

chili (Capsicum spp.), 198

Chinaja trail, 276

Chiwol Group (houselot), I22

Chixoy drainage, trade routes, 276, 277

Chochola, 236

Chontal Maya, 227

Chontalpa, 301

chronology, 74; Punta Canbalam, I7 I-72

Chuburna Brown, $9 I$

Chuburna Group, 87, 89

chukum, 236

chultunes, 158. See also wells

Chum Group ceramics, 97

Chun Chen, I84-85, 187, 194

Chunchintok Striated, 99

Chunchucmil, 3, 7, 8, 22, 159; architectural types at, 53-62; disturbances to, 48-49; excavations at, $5 \mathrm{I}-53$; historic period at, $\mathrm{IO}_{3}-5$; mapping of, 27-36, 46-48; sampling strategy at, 62-72

Chunchucmil Economic Region (CER), I39, 242; coastal zone settlements, I70-72; environmental zones in, I40-153; perennially inundated zone settlements, $172-73$; settlement patterns, 169-70, 194-96

Chunhinta Group ceramics, 78

cities, Maya centers as, I5-16

citrus (Citrus spp.), 198

Classic period, 4, 5, 8, 17, 28, 229; environment, 153-54. See also by subdivision

Classic Puuc architecture, 98-99

climate, I54

coastal zone, I4O; resources in, $142-44$; settlement patterns, $170-72$; soils, $20 \mathrm{I}-2$

coatimundi, I5O, 238

Cobá, 5, 8, 28, 39, 55; mapping, 34, 47; marketplace at, 249, 256, 308

cochineal (Dactylopus coccus), 230-3I

Cochuah horizon, 89

Cocom family, 4

cocoyol, 236

Codakia sp., 246
Códice de Calkini, 222

Colha, chert workshops at, 247

Columbus, Christopher, 4 ; in Honduras, 274, 3 II

commercialism, 4, 305, 306, 307-8, 309, 310

commodities, control of, 142

communities, II, I5; non-stratified, I86, I88-90; stratified, I40, I87-88, 190-94

compounds, multi-family, ing

Contact period, I03, II 6 ; food trade, 301, 304

Copán, 38, 6I, 260, 268

cordage, products and materials used in, 233-34

corporate groups, II8-19; residential houselots, I27

Costa Maya project, 103

CostaYuc Project, 174, 274

cotton (Gossypium hirsutum), production and trade in, 222, 227-30

cotton mantles, as currency, 305

Cozumel, 39, 229, 237

craft specialization, 19-20, 116, 309; production evidence, $25 \mathrm{I}-52$

cremation burials, 292

Crescentia cujete, 147

crocodile, I50, 238

C-shaped structure, 122

Cuca, 39

currencies, trade and, 305-6

Dactylopus coccus, 230-3I

deer, I5O, 238

depopulation, Postclassic, $\mathrm{IO}_{2}-3$

depressions, 32, 43-44

Díaz del Castillo, Bernal, 231

diseases, microbial, I63-64

dolphins, 237

Dos Arroyos Group ceramics, 293

Dos Arroyos Orange Polychrome, 88

drainages, natural, $15 \mathrm{I}-52$

droughts, Late Preclassic, I54

dyes: achiote, 226-27; cochineal, 230-31; palo de tinto, 232-33

dyewoods, I46, 232-33

Dzehkabtun, 60

Dzibanche, 284

Dzibical Black on Orange, $9 I, 94$

Dzibilchaltún, 15, 39, 236; mapping of, 28, 29, 34,47 ; population estimates, $137-38$; spindle whorls from, 228, 243

Dzibilinocac, 277, 284 
Dzitas Slateware, IOI

Dzudzuquil group ceramics, 78

Dzununcan Striated, go

Early Aak phase, 73, 85; ceramics, 86, 87-89, 95

Early Classic period, 73, 11I, 276, 293, 305; apiculture, 237-38; ceramics, 81, 84, 85-93; Chunchucmil city structure, I07-8; Kaab' Group, I22; obsidian trade, 160, 284-85

Early Nabanche ceramics, 78

Early Oxkintok/Proto Puuc A architectural style, 87

Early Puuc architecture, 98-99

East Plaza (Tikal), as marketplace, 249, 250

economies, 3, 5; Chunchucmil, 299-300; market, II-I2; Postclassic, II6-I7, 305

Edzná, obsidian trade, 284-85

El Cerrito, 274

El Chayal, obsidian from, 260-61, 268, 273-74, $276,277,300$

elites, 20, II 6, I28, 228, 229, 260-6I

El Muc, 28I

Elote Striated-Impressed, 79, 96

El Perú/Waka', 8, i9

El Sauce, as market center, 269

Emal, 2I

Emal district, 182

English, logwood harvesting, 232

environment: changes in, $153-54$; and resource access, I4-I5

environmental zones, in Chunchucmil

Economic Region, $140-42$

erosion, I53; soil depth and, 204-5

excavations: mapping, 32, 46; sampling strategy, 62-72

exchange, $3,7,8,14$

eyeglass structures, at Pochol Ch'en, 176

fallowing, soil nutrients, 200

families, 134 ; in residential core, $126-27$

farming, modern, $48-49$

faunal remains, 221, 236-38

feasting, in quadrangle patios, 115,302

feathers, trade in, 302

fertilizer, 214

fiber production/processing, $233-34,248$

Ficus glabrata, 230

fieldhouses, 35 ; in savanna/tzekel zone, 173-74

field walls, 39 fig (Ficus glabrata), paper made from, 230

fish, 236-37

fishing, 144

flamingo, pink (Phoenicopterus ruber), 238

flooding, seasonal, I8I-82

food, I5, 16; chemical signatures of, 253, 255; importation of, 22I-22, 301, 312-13; longdistance trade in, 303-6; preparation/processing of, $108,116,131$

forest products, 236. See also by type

foundation braces, 34

fox, 238

fruit trees, 149,236

gardens, houselot, I26, I30-3I

gates, at Pochol Ch'en, 178,179

gateway center, Chunchucmil as, 273, 282-87, 296-97

gender, and commerce, 3 II

geochemistry, public and household spaces, $253-57$

goods, I5; production and consumption of, 4 , 20

Gossypium hirsutum, production and trade in, 222, 227-30

gourds (Crescentia cujete), I47

Greater Chunchucmil, I34

Great Western Trade Route, 276, 283

greenstone, trade in, 276, 302

grinding stones, 45

groundwater, 158; access to, 154, 157; and maize agriculture, 199-200; quality of, $160-67$

Group $4 \mathrm{~h}-\mathrm{I}$ (Tikal), pottery making, 19-20

groups: building, 35-36; naming conventions for, $36-37$

Grupo Abalá, 174

guano (Sabal spp.), 235

Guatemala, trade routes from, 274-76

guaya, 236

guiro (Crescentia cujete), 147

Gulf Coast, trade networks, 274-75, 30 I

habin, 236

Haematoxylum campechianum, 146, 232-33

hardwoods, I46, I49, 236

henequen, 198,233

hinterland, 133 ; settlement patterns in, $169-70$

historic features, 32, 45

Honduras, 4; trade expeditions, 274, 3 II 
honey, 237; as tribute, 116, 222

households, 8, 153, 186; access to goods, 257-58, 268, 288; archaeology of non-noble, 16-17; craft specialization, 19-20; and marketplaces, 4-5, 269-70; metate use, 224-25; soil chemistry, 253-56

houselots, 40, 4I, 117, II9, I84, 231, 235; Aak group, 293-96; Kaab' Group, I24-27; Lool Group, 290-93; obsidian and pottery in, 262-64; population estimates and, I35; and pyramids, 6I-62; in residential core, I2I-22; in residential periphery, $127-32$

Hunabchen Group ceramics, 85, 87, 89, 96, 293

Hunabchen Orange, 90, 91, 93, 94

hunting, campsites, 172

Hunucmá, 103, 236

hydrology, Ucí-Chunchucmil transect, 160-63

hydrophobicity, soil, 206-7

Ichpá ceramic complex, 85

Ichpá I phase, 86

Ichpá II phase, 86

identity, 9; household, I27

iguana, 150,238

Ikmil, 174, 175, 212, 215

INAA analysis, 77

insects, as resource, $150,230-31$

institutions, 10 ; markets and, $12-13$

Isla Cerritos, 237; trade routes, 274, 28I

Isla Providencia, 28I

isotopic signatures; of agriculture, 209-II, 218; in skeletal remains, 221

Izamal, 274

Izamal/Ucí/Aké area, 54-55, 312

jade, 276, 305; access to, 302-3

jaguar, 150,238

jipijapa, 233

Josco, 173

Joventud Group ceramics, 78

Joventud Red, 79, 175

Kaab', 93

Kaab' Group: Early Classic, 122; gardens in, 126; Late Classic, 124-25; social organization in, I26-27

Kaab' phase, 73; ceramics, 94-97

Kabah, 60

Kaminaljuyú, obsidian trade, 300
Kanachen Brown-Black, $g I$

Kanachen Group ceramics, 89

Kanan, as non-stratified community, I88-90, IgI

kancab flats, 149

kancab, 204, 216; agricultural production, 206, 2IO, 2II, 2I7-I8; characteristics of, 207-8, 213

karstic plains: environmental conditions on, I50-5I; geomorphology of, I5I-53; settlements on, $185-94$

Katil Unslipped, 94

Kinich Group ceramics, 94

Kinchil, 103

kitchens, I25, I3I, 290

Kiuic, 256

Kochol, IO5

Kochol Black, $9 I$

Kochol Group ceramics, 89, 259, 293

Kocholito, 132-33, 195, 196

Komchen, 84

Kukulá Group, 102

Kum, I84, I85, 194

lajas, in Lool Group, 291-92

Lakandon Maya, 200

Landa, Diego de, on perishable goods, 222, 233

large domestic groups, 59

Las Coloradas, salt production, 223

Late Aak phase, 73, 94, 137; ceramics, 86-87, 89, 93, 95

Late Classic period, 5, 21, 73, 93, 176, 278; ceramics, 94-99; Kaab' Group, I24-25

Late Preclassic period, 154; Chunchucmil, 73, $8 \mathrm{I}-85,307$

Late/Terminal Classic period, 73, 137, 172; ceramics and architecture, 97-102

leadership, 302-3, 305

leather tanning, 236

LIDAR, 27

limestone, 44, I47; karstic, 150-51, 205. See also sascaberas

linear features, 32; mapping of, 39-43

linguistics, market exchange, 17

Lista de Tributos, 303

lithics: at Chunchucmil, 246-47; production debris, $25 \mathrm{I}-52$

logwood, 232-33

Lool Group, I2I; ceramics from, 292-93; features in, 290-92; foreign material culture in, 288, 296; residential compound, 86-87 
Lost Plaza (Xunantunich), 251-52

Lubaantun, 8

Lucha Incised, 88

Maax Na, 8, 249

mahogany, 236

maize agriculture, 198, 211, 304; groundwater and, $199-200$

Mama Group, 102

mamey, 236

mammals, 237,238

manatees, 237

mangrove estuaries, 144, 202; resources in, 216, 236; settlements and, $170-71$, 172

Maní province, 303

mapping, of Chunchucmil, 27-36

margay, 238

marine fauna, 236-37

marketplace(s), 242, 256; accessibility of, 252-53; areas serviced by, 268-69; artifact distribution and, 257-66; at Chunchucmil, 2I-23, 108, II2, 214, 24I, 266-67, 310-II; competitive and administrative, 267-68; dependence on, 269-70; functions of, 306-7; identifying, 5, 248-57; origins of, IO-II

markets, market systems, 3, 4-5, 7-8, IO, II, I4, I5, 304-5; archaeological identification of, I7-I8; modern, I2-I3

market stalls, identifying, I8-19

Maxcanú Buff, go, g2, 94

Maxcanú Group ceramics, 85, 87, 89, 93; Kaab' phase, 96-97; Xnokol phase, 99-100, I0I, 102

Maya lowlands, resources, I4-15

Maya Mountains, 296

Mayapán, 8, 15, 20, 116, 134, 178, 236, 243, 247; marketplace at, 249, 256,308

mecates, 29-30

Melipona beecheii, 237

Melongena sp., 246

Merchants' Barrio (Teotihuacan), 292; cotton textile production, 229-30

Mérida, 88

metallurgy, lost-wax, 23

metates, 45, 99, I21, 189, 191, 21I, 238; and architectural groups, 52, 53; salt grinding, 224-26; in site center, $108, \mathrm{II} 4, \mathrm{II} 6$

Mexico, Basin of, Postclassic markets, 12 middens, 2I4

Middle Classic Oxkintok Regional Complex, 85,86

Middle Classic period, obsidian trade, 284

Middle Preclassic period, 229; architecture, 174-75; Chunchucmil, 73, 78-8I

milpa agriculture, 198, 200, 206, 278; soils and, 216-17

minimal residential units (MRUs), 56

mollusks, I5O

Monachus tropicalis, 237

Monte Alban, 288, 289

Montejo, Francisco, II 6

monumental architecture, 52. See also platforms; pyramids

Motul de San José, 8, 19; groundwater use, I57, 164; marketplace at, 249, 256, 304

Motul Striated, 94

mounds, 34

mud flats, I 45

Muluchtzekel, 60

Muna Group, 97

Muna Slateware, 99, IO2

murals, 3II; marketplace, I8-I9

mussels, 150

Muuch Group, I2I

Múuli Mis, 173, 174-75, 196(n2)

Nah Caña, 173, 206, 212

Nah Kax, 173-74

Nakum, apiculture at, $237-38$

nance, 236

Naranjo, 173

Navulá Group, IO2

neighborhoods, II 8-19

night soil, use of, 214, 218

nitrates, in groundwater, $163-64$

Noheb Complex, 94

Noheb I Complex, 85

Noheb II Complex, 85

non-stratified communities, I86; Kanan as,

I88-90, IgI

nopal (Opuntia sp.), cochineal production, 230, 231

Northern River Lagoon, catfish preparation,

$$
\text { 236-37 }
$$

nuts, $\mathrm{I} 49$

Oaxaca, 288 
obsidian, 234; access to, $133,268-69$; at

Chunchucmil, 222, 246-47, 250, 285, 295;

long-distance distribution of, 282, 283; intrasite distribution 258-66; production debris, 25I-52; sources of, 267-68; trade routes, $273-74,275-76,277,300,301-2,303$

ocelot, 238

ojos de agua, I58, 172

open space, in site center, 108

opossum, 238

Opuntia sp., cochineal production, 230, 23I

organic materials, evidence of, I25, 130-3I

Oxcúm, 236

Oxil Group ceramics, 85, 87, 88-89

Oxil Unslipped, 79, 94, 96

Oxkintok, 169, 247, 312, 313; ceramics from, 77, $78,94,96$, IOI

Oxkintok Regional Complex, 85-86, 288, 293, 295-96, 297

paca, 150,238

Pacel, 173

Pachuca obsidian, 268

Pakbeh Regional Economy Program (PREP), 7, 9, 23, $25(\mathrm{nI})$, 197; goals of, 139-40; hinterlands survey, $169-70$

Palenque, 8, 19, 304

paleoenvironment, changes in, $153-54$

paleoethnobotanical analyses, 22I-22

paleosols, Celestún Peninsula, 202-3

palms, 233; thatch, 149, 234-36

palo de tinte (Haematoxylum campechianum), I46, 232-33

papaya (Carica papaya), 198, 236

Paradero ceramics, 88

Pasión River, trade routes, 276, 277

pathways, 174

patio groups, 36, 87, 99, II2; at Chunchucmil, $53-60$

patios, II5, II7, I22, I24-25; Aak group, 294-95;

Balam Group, I29; in quadrangles, 309-10

peccary, I5O, 238

Peón, Simon, 105, 278

Peon Losa, Rafael, ros

perennially inundated zone: resources in,

I44-46; sites in, $172-73$

performance spaces, III

perishable goods, II6; trade in, 222-23, 239. See also by type
Petén district, 21, 23, 195, 274, 312

petenes, I46, I72-73, 202, 233

Petenes de Xlabarco, 274

Petén Xnuc, 28I

Petjal Red on Black and Cream to Buff, 79

Phoenicopterus ruber, 238

phosphate analysis, 214, 290; Balam Group,

130-32; garden areas, I26; public spaces,

253-55

phytolith analysis, 22I

Pich Group, 262, 288, 302; activities in, II5-16; architecture of, II3-I5; excavations at, II2-I4

Pich phase, 73; ceramics and architecture, 8I-85

Piedras Negras, 277

pigments, geochemical evidence of, 253

pilgrimage-fair model, 19

Pital Incised, 88

pitaya, 236

pizote, $\mathrm{I} 5 \mathrm{O}$

platforms, 35, 51, II5, I22, I36-37, 176, 190, 193, 262; Aak Group, 293-95; Balam houselot, I29; Middle Preclassic, 78, 80; naming conventions for, 37, 38-39; in site center, I08, II3-I4; talud-tablero style, 290-9I; Xnokol phase (Late/Terminal Classic), 97-99, roo-ror (table)

planteles, 29-30

Plaza Plan 2 (PP2), 6I

plazas, 256, 290; as marketplaces, 5, I 8, 249-50

plazuela groups, $60,87,312$

Plumbate ware, 278

Poc Che Manuel Juárez, I74, 179-8I

Pochol Ch'en, 173, 194, 212, 282; architecture at, 176-79; baxlu'um-o formation at, 205-6, 209

Polvero Group ceramics, $8 \mathrm{I}$

Polyani, Karl, on markets and market economies, II-I2

population, I95; estimating, I34-37

population density, I5, II9-2I, I95

ports of trade, 274, 307; andadores in, 280-8I; on Celestún Peninsula, I44, I7 I-72

Postclassic period, 4, 5, 12, 21, 28, 229, 305; apiculture, 237-38; depopulation during, $102-3$; economics, I16-17; market system, 267, 268 pottery. See ceramics

Poxilá, 84

PREP. See Pakbeh Regional Economy Program prismatic blades, 246, 248 prisms, in mapping representations, $38-39$ 


\section{Progreso, 274}

PR I-3-I, I74

Proto-Puuc A architectural style, 85, 87, 88

Proto-Puuc B architectural style, 94 public spaces, IIO; soil chemistry of, 253-57 puma, 238

Putún Maya, achiote trade, 227

Puuc, quadrangles, 60, 290

Puuc hills, I5I, 222, 247; trade routes, 277, 278, 312

Puuc stones, 45

Puuc-style architecture, 98-99

Puuc wares, 77

Puut, as stratified community, 190-92

pyramid-plaza, at Kum, 184

pyramids, 60, 6I-62, IIO, 302

quadrangles, 60, 1II, 302; at Chunchucmil, 288-30, 303; functions of, 115-16; Pich Group, II $2-14$

quarries, $43,44,108,191$

querns, 45, 225-26

Quintana Roo, logwood from, 232

Quiriguá, 8, 264

rabbit, 238

raccoon, 238

radiocarbon dates, 94; from Lool residential compound, 86-87

rainfall, 199,228

ramón (Brosimium alicastrum), I49

Real de Salinas, Hacienda, paleosols in, 202-3

regal-ritual centers, I6, I09-10

rejolladas, 43, I51, I52, 153, I82

Relaciones Geográficas, 304

residences, 34, 35; comparisons of, 53-56; compounds, 28, 8I, 87, I2I-25; patio groups, 56-57 residential core, 136 ; callejuelas, $117-18$; Kaab'

Group in, I2I-27; neighborhoods and districts in, II8-19; settlement density, II9-2I; social organization in, $126-27$

residential periphery, I21, 127-28, 136-37; Balam houselot in, $129-32$

resources, II 6, I57; access to, I4-I5; coastal zone, I4I-44; faunal, 236-38; floral, 226-36; logwood, 232-33; mineral, 223-26; perennially inundated zone, I44-46; seasonal wetlands, I 47, I $49-50$

Ring of Cenotes, 157, 160, 164, 166 rodents, 238
Sabal spp., 235, 235

Saban Group ceramics, 8I

Saban Unslipped, 79

Sabero Thin Preslate, 94

Sacalum Black on Slate, ro I

sacbes, 39, 40-43, 108, 184, 252, 296; geochemical analyses of, 253, 255, 256; with Middle and Late Preclassic ceramics, 81, 83-84

saklu'um, 203-4, 216; agriculture and, 210, 217; characteristics of, 207, 208, 213

Salama Valley, 276

Salinas de los Nueve Cerros, 23

salinity, groundwater, $160-61,163$

salt: as currency, 305-6; as export, 222, 236, 237; harvesting, 302, 303; importance of, 22-23; metates and, 224-26; trade in, 2I, $142-43$, $223-24,239,300$

salt beds, on Celestún Peninsula, I40, 143, I44, I54

San Clemente Gouged/Incised, 88

San José Chulchaca, Cenote, 153, 205

San Mateo, 173

San Simón, Rancho, logwood canal, 278

Santa Bárbara, ceramics at, 99

Santa Clara, 192

saramuyo, 236

sascaberas, 43, 44-45, 52, I3I-32, I5I, I52-53, I9I, 199

Sat Preslate, 94

Satunsat, 94

savannas, 199; resources on, I49-50, 233; seasonally inundated, $146-48$, I8I-85; settlements in, $173-8 \mathrm{I}, 194-95$

Sayil, 5, 77, 137

seaborne trade, 2I

sea level, I54

seals, tropical (Monachus tropicalis), 237

seasonal transhumance, I44, I80

sedimentation, rates of, 205

Seibal, 5, I35

settlement density, in Chunchucmil Economic

Region, II9, I28, I32-33, 133-34, I86, I94-96 settlement patterns, I33, I40; coastal zone, I7072; hinterlands, 169-70; soils and, 216-17

Shangurro Group, 84, 87

shell, marine, 243-46, 295

shrines, 190; ancestral, 119, 292, 293; household/

domestic, I22, I26-27, I35

Sierra Group, 8I, 84 
Sierra Red, 79,88

Sihó, 78, 99, 139, 172

site center, I08; monumental compounds in, IIO-II; Pich Group, II2-I6, I17; streets, III-I2

sitios de paso, 172, 173

skeletal remains, carbon isotope analysis, 221

slateware, 94, IOI-2

slaves, as export, 222

snail, apple, 150

snakes, 150,238

social organization, Kaab' Group, I26-27

society, disruption of, I3-I4

soil chemistry, public and household spaces and, 253-57

soils, 197, 199; agriculture and, 217-18; black carbon, 212-I3; carbon isotopes and, 219-II; at Chunchucmil, 214-16; depth of, 204-6; in environmental zones, 200-203; fertility of, 207-9; formation rates of, 205-6; moisture retention, 206-7; and settlement patterns, 216-17; Yucatec Maya classification of, 203-4 solares, I84, 231, 236

solar marketing system, 304-5

Sotuta Complex ceramics, $\mathrm{IO}_{2}$

Spanish Archaeological Mission, in Oxkintok, 85

special stones, 32, 45

spindle whorls, 228-29; at Chunchucmil, 242-43

Spondylus sp., 246, 295, 305

stingray spines, 237

stone tools, fiber production, 234

storehouses, 5, II6, II7, I22

stratified communities, I40, I87-88; Puut as,

190-93; Yaxkakap as, 193-94

streets, III, 252. See also callejuelas

Strombus sp., 243, 246

structures, 34, 94, I13-15; and inhabited residences, 136; Kaab' Group, I21-27; naming conventions for, $38-39$

subsistence, 7, 197-98, 218-19

subsurface features, 43

sulfates, in groundwater, 164

survey, Chunchucmil Economic Region, 169-70

swales, soils in, 202

swamps. See mangrove estuaries

swidden agriculture, 198, 200, 206, 278; soils and, 216-17
Tabasco, 2I

Tacopate Trickle, IoI

talud-tablero platform, in Lool Group, 290-92

Tankuche, 232

Teabo Group ceramics, 89, 97

Tec Composite, go

Telchaquillo, 256

Templo-Patio-Adoratorio (TPA) complex, 288, 289

Teotihuacan, 292, 300, 312; ceramic influence from, 86, 293, 295-96; cotton imports, 229-30

tepezcuintle (paca), 150, 238

Terminal Classic period, 21, 93, 103, 154, 229, 260, 274, 278; ceramics, 97-99; competitive markets during, $267-68$

Términos, Laguna de, 232

terra preta, $212-13$

Tetíz, 103, 236, 279

textiles, II 6; production of, 228-30, 242-43

thatch, palm, I49, 234-36

thin slate complex, 94

Thrinax radiata (chit), 235

Ticul, Sierra de, 2 II

tigrillo, 150

Tikal, 5, 8, 34, 224, 304, 309; craft specialization, 19-20, II6; marketplace at, 249, 250, 308; obsidian at, 264, 269, 283-84; population estimates, 134, 135, 138; trade networks, 300-30I; trade routes, 276,277 ; as urban center, I5, I8

timber, wetland, $146,232-33$

Timucuy Group ceramics, 89

Timucuy Polychrome, 87-88, 259

Tipikal Group, 8I

Tituc Polychrome, 259

Tixcacal Polychrome, 84

Tiznuk Composite, 90

Tiznuk Striated, 96

Tlatelolco, 304; marketplace at, 250, 306, 31I

Tomb 7, 94

trade, 4, $117,140,221,311$; in cotton, 227-30; in fish, 236-37; in food, 303-6; gateway cities and, 282-87; long-distance, 273-82, 312-13; obsidian, 283-85; in perishable materials, 222-23, 237-39; Punta Canbalam, 171-72; seaborne, 2I, I44

trade routes/networks, 140, 296; Chunchucmil, 300-306; gateway centers and, $282-87$; sites on, I72, 173; through Yucatán, 274-82 
transitional slate complex, 94

transportation, I5; waterborne, I45, 146

tranvias, 278,279

Trapiche, 173

trees: fruit- and nut-bearing, I49; timber, 146 , $232-33$

Tres Iglesias, 173

tribute, 222, 231, 236; goods storage, II6, II7

Trinidad de Nosotros, 8, 249, 304

Tulum, 39

Turbinella sp., 246

turkey, oscillated, I50

turtles, sea, 237

Tzakol 3 ceramics, 86, 88

tzekeles, I46, I48, 286; resources on, $149-50,216$; settlements on, $173-8 \mathrm{I}$

Tzemé, 236

Tzikul, 274

Uaymil, I39, I72, 274

Ucí, I59, 195; groundwater at, I57, 158, 160-67

Ucú, I03

Ukmul I Complex, 94

Unto Group, 8I

Usil Ware, 87

Usumacinta River, trade routes, 276, 277, 301

Uxmal, 60, 268

vault stones, 45

Venezia, 278

visitors, treatment of, II $6-17$

Vista Alegre, 28I

walkways, 40

walls, 36, 39; at Pochol Ch'en, 176, 178-79. See also albarradas

warehouses, 116

watercraft, 145,146

water repellance, $206-7$

water table, 157-158, 209; Ucí-Chunchucmil transect, $160-63$

waterways, I45; canalized, I46, 147

wealth, and artifact distribution, 258-66

wells, 43, 44, 158, 159, I82, 199, 238; freshwater, I5I, I53, I84; water quality in, $160-6 \mathrm{I}$, 163-67 wetlands, 279; palo de tinte from, 232-33; perennial, I45-46, I72-73; seasonal, I46-50, I73-8I, 194, 238

women, commercial roles of, 9, 3II

Xanaba Group ceramics, 8I, 84, 87

Xcambo, 2I, 268, 274, 28I, 288

Xcaret, 39

Xcopte, 274

Xiu family, 4

Xkichmook, chert at, 247

Xnokol phase, 73, I05; ceramics and architecture, 95, 97-102

Xochicalco, 259-60, 288

Xocnaceh, 84

Xpim phase, 73, 78-81

Xpim quadrangle, 8I

$\mathrm{X}$-ray fluorescence (XRF), 256

Xtobó, 84

Xuenkal, 229

Xunantunich, 8; marketplace at, 249, 25I-52

Yảab K'i'ix, 188,189

Yakal Chuc, 60

Yalahau, 202

Yaxchilán, 277

Yaxhá, 268

Yaxkakap, 193-94, 195

Yaxuná, 84, 235, 285

Yaxuná Pre-pizarra, 92

Yaxuná Preslate, 96, 99

Yaxuná/Yaxcabá area, 55

Yokat Striated, IoI

Yokop, I53, 194, 196; architecture at, 183-84; plaza at, $181-82$

Yucatán, 39, 199, 303; apiculture on, 237-38; salt trade, 142-43; seaborne trade, 2I, 274-75; social disruption in, $13-14$; trade routes through, 275-82

Yucatán aquifer, $145-46$

Yucatán Glossware, 94

Yucatán Glossy Ware, 96

zapote, 236

zona de cenotes, 158,160

Zoque towns, $30 \mathrm{I}$ 